\title{
Assessing coastal vulnerability: development of a combined physical and economic index
}

\section{Komali Kantamaneni (B.Sc., M.Sc., M.B.A.)}

Director of Studies: Professor Mike Phillips Second Supervisor: Professor Rhian Jenkins

Submitted to the University of Wales Trinity Saint David in partial fulfilment for the Degree of Doctor of Philosophy

University of Wales Trinity Saint David

Faculty of Architecture, Computing and Engineering

April 2017

Volume 1 


\section{Acknowledgements}

This Ph.D. thesis is a pinnacle of a perfect functioning association with my supervisors who are also my gurus and research role models-Professor Mike Phillips and Professor Rhian Jenkins, to whom I am enduringly thankful. Professor Phillips, Professor Jenkins, and Dr. Tony Thomas provided unreserved sustenance during my Ph.D. and openhandedly paved the way for my academic growth as a research scientist. Perhaps most significantly, I thank Professor Phillips for being my research companion on our mission to determine what lies in the shadow of the statue.

I am also deeply obliged to the several academicians who in some way contributed to the development and publication of the work comprised here. First and foremost, I acknowledge my co-authors: Dr. Xiaoping Du (Chinese Academy of Sciences), Dr. Ibrahim Alrashed (Director General of KSA Government Construction and Management Department), Dr. Omar Alharbi (Umm Al-Qura University), Professor Andy Penaluna (UWTSD), and Kelechi and Judith (UWTSD). I also appreciate the help offered by Professor Nagesh (Indian Institute of Science), Dr. Brian Bulla (Purdue University), Dr. Andrew Morgan (UWTSD), Dr. Talib Butt (UWTSD), Trevor Francis (UWTSD), Mrs. Kath Penaluna (UWTSD), and many other anonymous reviewers and online technical specialists.

Writing this $\mathrm{Ph} . \mathrm{D}$. thesis was not the solitary involvement it could have been because of esteemed friends who offered interest and compassion in just the right doses. The amazing comradeship of Mrs. Linda Rudd, Dr. Arzu Taylan, Dr. Michael Barclay, and many others certifies that I can only think back upon the last few years with feelings of fondness and affection. The unreserved love, inspiration, and stimulating environment that were given to me by my family assured me a steady anchor during the difficult and easy times; thank you. 


\section{Table of Contents}

DECLARATION

ACKNOWLEDGEMENTS 3

LIST OF FIGURES 8

LIST OF TABLES 11

LIST OF ACRONYMS 12

ABSTRACT 14

1. INTRODUCTION 16

1.1 PREFACE 16

1.2 IDENTIFIED RESEARCH GAPS

1.2.1 COASTAL VULNERABILITY

1.3 AIMS AND OBJECTIVES

1.4 SCIENTIFIC RIGOUR AND CHALLENGES

1.5 SUMMARY

2. LITERATURE REVIEW 21

2.1 INTRODUCTION

2.2 TOPIC REVIEW

2.2.1 GLOBAL WARMING

2.2.2 GREENHOUSE GASES

2.2.3 SEA LEVEL RISE (SLR)

2.2.4. STORMS - OVERVIEW

2.2.5 COASTAL ZONES AND FLOOD RISK

2.2.6 FLOODS AND DAMAGE COSTS

2.2.7 ECONOMIC LOSS

2.2.8 GEOLOGY, GEOGRAPHY AND CLIMATE CHANGE

2.2.9 COASTLINES

2.3 Methodological REVIEW

2.3.1. COASTAL VULNERABILITY

2.3.2 ASPECTS OF VULNERABILITY

2.3.3 COASTAL VULNERABILITY INDEX AND PROCEDURES 34

2.3.4 INDEX-BASED METHODS

2.3.5 INDICATOR-BASED INDICES

2.3.6 GIS-BASED DECISION SUPPORT SYSTEMS 38

2.3.7 METHODS BASED ON DYNAMIC COMPUTER MODELS $\quad 40$

2.3.8. COASTAL VULNERABILITY FRAMEWORKS 41

2.3.9 SOCIAL VULNERABILITY INDEX $\quad 42$

2.3.10 ECONOMIC VULNERABILITY INDEX

2.3.11 FLOOD VULNERABILITY INDEX

2.3.12 LIVELIHOOD VULNERABILITY INDEX

2.3.13 CLIMATE VULNERABILITY INDEX

2.3.14 ENVIRONMENTAL VULNERABILITY INDEX 44

2.3.15 MULTI-SCALE COASTAL VULNERABILITY INDEX 44 
2.4. AdVANTAGES AND DISADVANTAGES OF THE COASTAL VULNERABILITY METHODOLOGIES

2.5. DAMAGE COSTS IMPACT ON THE ECONOMY

48

2.6. SUMMARY

3. PHYSICAL AND ECONOMIC GEOGRAPHY 52

$\begin{array}{ll}3.1 \text { INTRODUCTION } & 52\end{array}$

$\begin{array}{ll}3.2 \text { GEOGRAPHY } & 52\end{array}$

$\begin{array}{ll}\text { 3.3 SEA LEVEL RISE } & 53\end{array}$

$\begin{array}{lr}3.4 \text { STORMS } & 55\end{array}$

$\begin{array}{lr}3.5 \text { WINDS } & 56\end{array}$

$\begin{array}{lr}3.6 \text { TEMPERATURE } & 57\end{array}$

3.7 DEVELOPED COASTLINES AND COASTAL VULNERABILITY INDICES 5

3.7.1. COASTAL VULNERABILITY INDICES $\quad 60$

$\begin{array}{lr}3.8 \text { HISTORY OF FLOODS IN THE UK } & 60\end{array}$

$\begin{array}{lr}3.9 \text { COASTAL EROSION } & 62\end{array}$

$\begin{array}{ll}3.10 \text { ECONOMIC LOSS } & 64\end{array}$

3.11 NATIONAL (UK) GDP AND IMPACT OF DESTRUCTION COSTS ON GDP 65

3.12 SUMMARY

4. METHODOLOGY $\quad 68$

$\begin{array}{lr}\text { 4.1 INTRODUCTION } & 68\end{array}$

\begin{tabular}{ll}
4.2 & DESK STUDY \\
\hline
\end{tabular}

4.2.1 PARAMETRIC TESTS ASSOCIATED WITH THE DESK STUDY 69

4.3. METHODOLOGICAL APPROACHES FOR COASTAL VULNERABILITY INDICES 70

$\begin{array}{ll}4.4 \text { SITE SELECTION } & 71\end{array}$

4.4.1 DESCRIPTION OF SELECTED SITES $\quad 73$

$\begin{array}{ll}4.5 \text { PCVI DATA } & 86\end{array}$

4.5.1 PHYSICAL PARAMETERS AND MEASUREMENT 86

4.6 ECONOMIC COASTAL VULNERABILITY 88

4.6.1 INDICATOR BASED APPROACH -1 88

4.6.2 INDICATOR BASED APPROACH -2 89

\begin{tabular}{l} 
4.6.3 GIS APPROACH \\
\hline G.7
\end{tabular}

\begin{tabular}{l} 
4.7 ECVI DATA \\
\hline
\end{tabular}

4.7.1. SELECTION OF ECONOMIC PARAMETERS 90

$\begin{array}{lr}\text { 4.7.2 ECVI TECHNICAL DESCRIPTION } & 90\end{array}$

4.7.3 ECONOMIC PARAMETERS THRESHOLD 92

4.8 COMPARISON OF PCVI AND ECVI 94

$\begin{array}{ll}\text { 4.9 SUMMARY } & 96\end{array}$

5. DATA EVALUATION AND PARAMETER SELECTION

$\begin{array}{lr}\text { 5.1 INTRODUCTION } & 98\end{array}$

$\begin{array}{lr}5.2 \text { PRECIPITATION } & 98\end{array}$

$\begin{array}{lr}5.3 \text { POPULATION } & 99\end{array}$

$\begin{array}{lr}\text { 5.4 SEA LEVEL CHANGE } & 100\end{array}$

$\begin{array}{lr}\text { 5.5. SELECTION OF PARAMETERS } & 101\end{array}$

$\begin{array}{ll}\text { 5.6 ECONOMIC PARAMETERS DESCRIPTION } & 104\end{array}$

$\begin{array}{lr}\text { 5.7 PHYSICAL VULNERABILITY INDEX (PCVI) } & 108\end{array}$

$\begin{array}{lr}\text { 5.7.1 PHYSICAL PARAMETERS } & 108\end{array}$

5.8. ACCURACY OF NASA- GOOGLE EARTH MAPS AND DATA 114

5.9 SUMMARY 116 
6. PHYSICAL COASTAL VULNERABILITY INDEX (PCVI)

6.1 INTRODUCTION

6.2 SPURN HEAD

6.3 HALLSANDS

120

6.4. LYNMOUTH

6.5 HAPPISBURGH

122

6.6 DAWLISH

6.7 GREAT YARMOUTH

6.8 SKEGNESS

6.9 BENBECULA

6.10 ABERYSTWYTH

6.11. PORT TALBOT

6.12 LLANELLI

6.13. OVERALL CVI MEASUREMENT

6.14. SUMMARY

7. PHYSICAL COASTAL VULNERABILITY INDEX (PCVI) ANALYSIS

7.1 INTRODUCTION

7.2 SPURN HEAD

7.3 HALLSANDS

7.4. LYNMOUTH

7.5 HAPPISBURGH

7.6 DAWLISH

7.7 GREAT YARMOUTH

7.8 SKEGNESS

7.9 BENBECULA

7.10 ABERYSTWYTH 150

7.11. PORT TALBOT 153

$\begin{array}{ll}7.12 \text { LLANELLI } & 153\end{array}$

7.13. OVERALL DESCRIPTIVE ANALYSIS

7.14 CVI ANALYSIS FOR INDIVIDUAL PARAMETERS 156

7.15 OVERALL CVI SCORES $\quad 158$

7.16 CUMULATIVE PHYSICAL VULNERABILITY 160

7.17. SUMMARY

8. ECONOMIC COASTAL VULNERABILITY INDEX (ECVI)

8.1 INTRODUCTION

8.2. POPULATION AND PROPERTIES

8.3 ECONOMIC ANALYSIS

8.3.1 COMMERCIAL PROPERTIES

8.3.2 RESIDENTIAL PROPERTIES

8.3.3 ECONOMIC VALUE OF SITE

8.3.4 POPULATION

8.3.5 COASTAL EROSION

8.3.6 FLOOD IMPACT

8.4 ECVI VALUES

8.4.1COMMERCIAL PROPERTIES 
8.4.5 COASTAL EROSION

9.1 INTRODUCTION

9.2 PCVI

$9.3 \mathrm{ECVI}$

9.4 COMPARISON OF ECVI AND PCVI

9.5 COMBINED COASTAL VULNERABILITY INDEX (CCVI)

9.6 SUMMARY

10. CONCLUSIONS

10.1 INTRODUCTION 227

$\begin{array}{ll}10.2 \text { PCVI } & 227\end{array}$

10.3 ECVI 228

10.4 COMPARISON OF PCVI AND ECVI/ COMBINED COASTAL VULNERABILITY, CCVI 228

10.5 JUSTIFICATION OF AIMS AND OBJECTIVES $\quad 229$

10.6 LIMITATIONS OF RESEARCH 229

10.7 DATA COLLECTION AND CHALLENGES $\quad 229$

$\begin{array}{ll}10.8 \text { SUMMARY } & 231\end{array}$

REFERENCES $\quad 232$

\begin{tabular}{lr} 
APPENDICES & 260 \\
\hline
\end{tabular} 


\section{List of Figures}

Figure 2.1: Literature review process

Figure 2.2: Global greenhouse gas emissions (\%) 23

Figure 2.3: Greenhouse gas emissions (1990-2010)__ 24

Figure 2.4: SLR trends since $1880 \ldots 25$

Figure 2.5: Storm classification 26

Figure 2.6: Storm damage in Aberystwyth - $2014 \_26$

Figure 2.7: Southern England floods in 2013

Figure 2.8 Coastal population and shoreline degrading trends across the globe __ 31

Figure 2.9 Shoreline degradation across the globe___ 31

Figure 2.10 Coastal vulnerability framework __ 34

Figure 2.11: Diverse formulations of CVI 36

Figure 2.12 Structure o Structure of ECVI

Figure. 2.13: Variables of CVI _ 45

Figure 3.1: The UK with Sea Boundaries _ 53

Figure 3.2: Map of UK sea level rise (2000-2080)_ 55

Figure 3.3: a) Wind speed at 25 stations and b) Average wind speed as per month (2000-2014) _ 57

Figure 3.4: a) Average sea surface temperature trends for the period of 2000-2014 at 25 locations

around the UK and b) Annual average sea level temperatures ___ 59

Figure 3.5: Developed Coastline (Aberystwyth) _ 60

Figure. 3.6: Flood risk map -Wales __ 61

Figure 3.7: Lynmouth Floods in 1952

Figure 3.8: Map of coastal erosion in the UK__ 63

Figure 4.1: Map of coastal vulnerability sites__ 73

Figure 4.2: Spurn Head coastline and measuring points___ 74

Figure 4.3: Hallsands coastline and measuring points ___ 75

Figure 4.4:- Lynmouth coastline and measuring points ___ 77

Figure 4.5: Happisburgh coastline and measuring points___ 78

Figure 4.6: Dawlish coastline and measuring points __ 79

Figure 4.7: Great Yarmouth coastline and measuring points ___ 80

Figure 4.8: Skegness coastline and measuring points___ 81

Figure 4.9: Benbecula coastline and measuring points___ 82

Figure 4.10: Aberystwyth coastline and measuring points____ 83

Figure 4.11: Port Talbot coastline and measuring points ___ 84

Figure 4.12: Llanelli coastline and measuring points___ 85

Figure 4.13: Transect line and $0.5 \mathrm{~km}$ coastal cell __ 87

Figure 4.14: $1 \mathrm{~km}$ coastal cells on Transect line ___ 91

Figure 5.1: Annual average precipitation rates for the UK in-between 1910-2016 a) Spring and

Autumn values, b) Summer and winter values and c) overall average values. __ 99

Figure 5.2: Temporal Changes in the UK population from $1972-2014 \_100$

Figure 5.3: Sea level changes between 1920 and 2014, a) time series showing sea level variation at

four UK ports and $b$ ) time series showing overall average change __ 101

Figure 5.4: Process model showing the reduction of economic coastal vulnerability parameters 103

Figure 5.5: Commercial property distance measurement from coast__ 104

Figure 5.6: Residential properties distance measurement from the coast at Dawlish __ 105

Figure 5.7: Assessment of economic value of site 106

Figure 5.8: High and low density of population in different coastal areas of the UK __ 107

Figure 5.9: Coastal properties in Dawlish after math of 2014 flood incident___ 108

Figure 5.10: An Ordnance Survey Map showing the measurement of beach width from back beach

to MLW. 109 
Figure 5.11: An Ordnance Survey Map showing the measurement of dune width 110

Figure 5.12: an aerial photograph and section through (inset) showing coastal slope measurement from the back-beach elevation and highest and lowest elevation points are depicted in red. 110 Figure 5.13: An aerial photograph showing the measurement of back beach vegetation to $500 \mathrm{~m}$ inland distance line

Figure 5.14: An aerial photograph showing the measurement of built structures behind the back beach

Figure 5.15: Rocky outcrop __ 113

Figure 5.16: Sea defence structures 114

Figure 6.1: Graphical representations of Spurn Head___ 120

Figure 6.2: Graphical representations of Hallsands 121

Figure 6.3: Graphical representations of Lynmouth__ 122

Figure 6.4: Graphical representations of Happisburgh__ 124

Figure 6.5: Graphical representations of Dawlish _ 125

Figure 6.6: Graphical representations of Great Yarmouth __ 126

Figure 6.7: Graphical representations of Skegness _ 128

Figure 6.8: Graphical representations of Benbecula___ 129

Figure 6.9: Graphical representations of Aberystwyth__ 130

Figure 6.10: Graphical representations of Port Talbot 132

Figure 6.11: Graphical representations of Llanelli 133

Figure 6.12: Graphical representations of overall CVI scores __ 136

Figure 7.1: Distribution of CVI scores for Spurn Head ___ 140

Figure 7.2: Distribution of CVI scores for Hallsands __ 142

Figure 7.3: Distribution of CVI scores for Lynmouth 143

Figure 7.4: Distribution of CVI scores for Happisburgh __ 145

Figure 7.5: Distribution of CVI scores for Dawlish __ 146

Figure 7.6: Distribution of CVI scores for Great Yarmouth___ 148

Figure 7.7: Distribution of CVI scores for Skegness ___ 149

Figure 7.8 Distribution of CVI scores for Benbecula 151

Figure 7.9: Distribution of CVI scores for Aberystwyth _ 152

Figure 7.10 Distribution of CVI scores for Port Talbot _ 154

Figure 7.11: Distribution of CVI scores for Llanelli _ 155

Figure 7.12: Distribution of overall CVI scores _ 157

Figure 7.13: Distribution of overall CVI scores 158

Figure 7.14: Cumulative CVI scores __ 159

Figure 7.15: Distribution of aggregated CVI scores and ranking__ 159

Figure 7.16: PCVI map ___ 161

Figure 8.1: Transect line showing $1 \mathrm{~km}$ coastal cells: Spurn Head ___ 166

Figure 8.2: Transect Line showing $1 \mathrm{~km}$ coastal cells: Hallsands ___ 166

Figure 8.3: Transect line showing $1 \mathrm{~km}$ coastal cells: Lynmouth ___ 167

Figure 8.4: Transect line showing $1 \mathrm{~km}$ coastal cells: Happisburgh __ 167

Figure 8.5: Transect line showing $1 \mathrm{~km}$ coastal cells: Dawlish ___ 168

Figure 8.6: Transect line showing $1 \mathrm{~km}$ coastal cells: Great Yarmouth 169

Figure 8.7: Transect line showing $1 \mathrm{~km}$ coastal cells: Skegness __ 169

Figure 8.8: Transect line showing $1 \mathrm{~km}$ coastal cells: Benbecula $\_170$

Figure 8.9: Transect line showing $1 \mathrm{~km}$ coastal cells: Aberystwyth 171

Figure 8.10: Transect line showing $1 \mathrm{~km}$ coastal cells: Port Talbot__ 171

Figure 8.11: Transect line showing $1 \mathrm{~km}$ coastal cells: Llanelli___ 172

Figure 8.12: Commercial properties $(£ \mathrm{M}-£ \mathrm{~B}) \ldots 173$

Figure 8.13: Residential properties (£M-£B)—_ 175

Figure 8.14: Economic value of site (£M-£B)__ 177 
Figure 8.15: Population per coastal cell 179

Figure 8.16: Coastal erosion (£M)

Figure 8.17: Flood Impact (£M- £B)

Figure 8.18: ECVI scores for commercial properties

Figure 8.19: ECVI scores for residential properties 187

Figure 8.20: ECVI scores for economic value of site 189

Figure 8.21: ECVI scores for population 191

Figure 8.22: ECVI scores for coastal erosion___ 193

Figure 8.23: ECVI scores for flood impact__ 195

Figure 8.24: Percentage distribution of ECVI categories___ 199

Figure 8.25: Coastal Cells and Cumulative ECVI _ 200

Figure 8.26: Average economic vulnerability according to ECVI__ 206

Figure 8.27: Aberystwyth: Coastal damage and consequent defence improvements___ 207

Figure 8.28: Infrastructure damage and flooding at Dawlish (2014)__ 208

Figure 8.29: Coastal vulnerability: Lynmouth __ 210

Figure 8.30: Coastal risk at Hallsands 211

Figure 9.1: Interlinking physical and economic impacts _ 219

Figure 9.2: Variation of PCVI and ECVI __ 221

Figure 9.3: Graphical Representation of sites by PCVI and ECVI___ 222

Figure 9.4: Representation of vulnerability indexes ___ 224

Figure 9.5: Coastal vulnerability maps showing a) ECVI and PCVI average values and b) combined values (Key: red ECVI; amber PCVI; blue CCVI). 


\section{List of Tables}

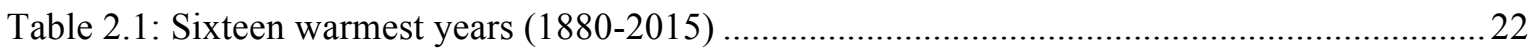

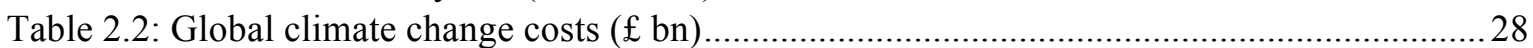

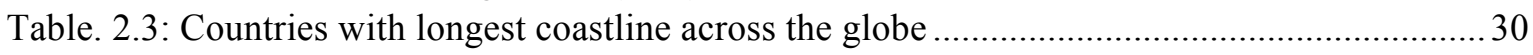

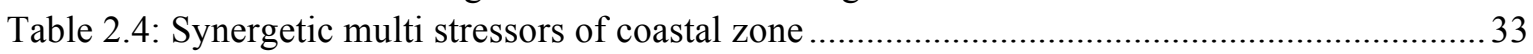

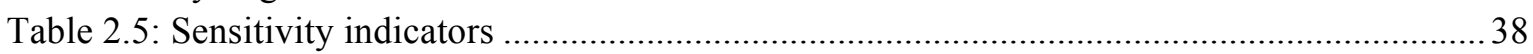

Table. 2.6 Matrix for the Variable Ranking and Calculation of 3 Sub-Indexes for the Northern

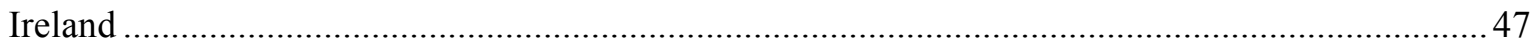

Table. 3.1: Current and predicted SLR at various locations around the UK ...................................54

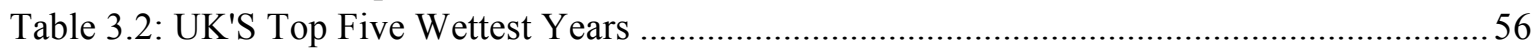

Table 3.3: Top ten Natural Disasters and Damage Costs in the UK (1990 - 2014).........................64

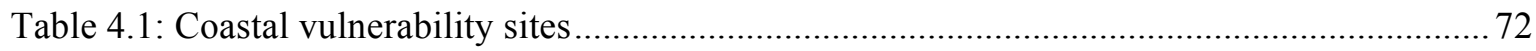

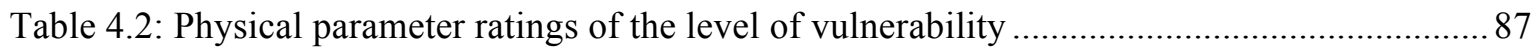

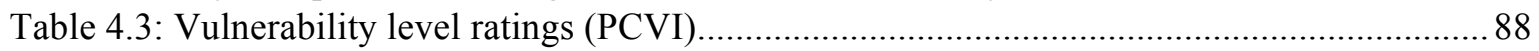

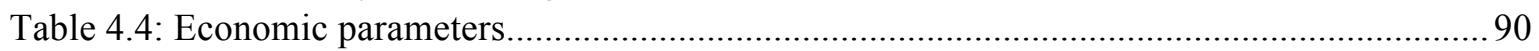

Table 4.5: Rating economic coastal vulnerability parameters (m- millions; bn- billions) ............... 92

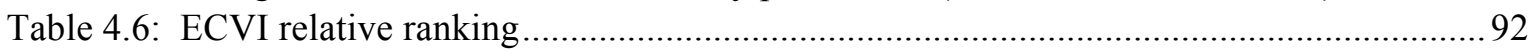

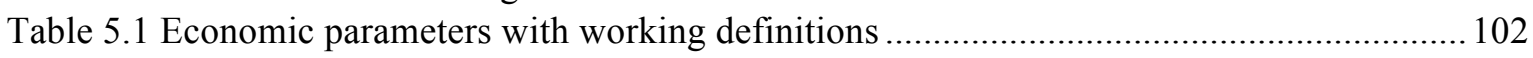

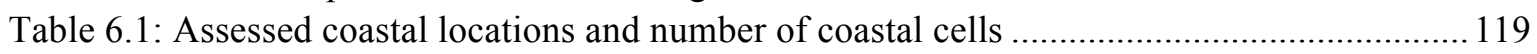

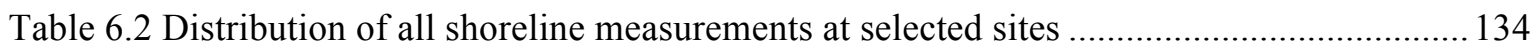

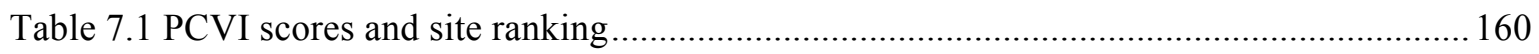

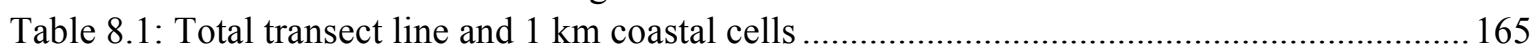

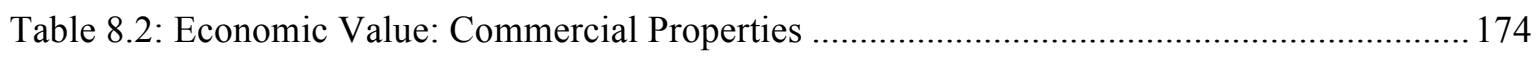

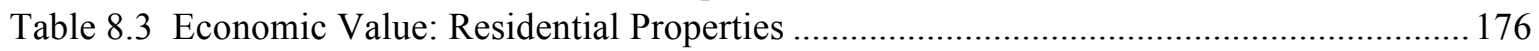

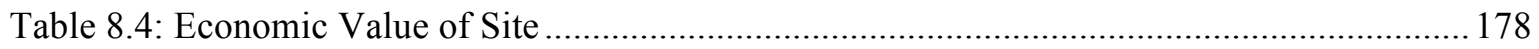

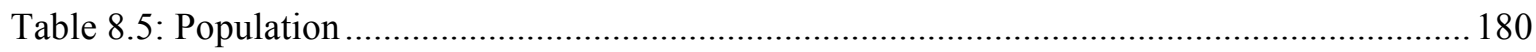

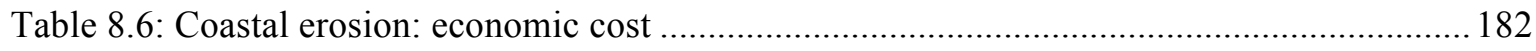

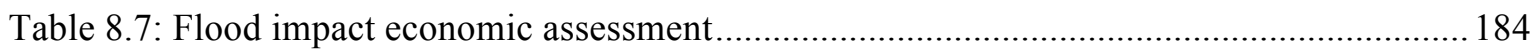

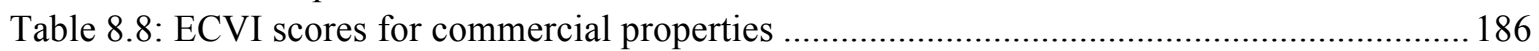

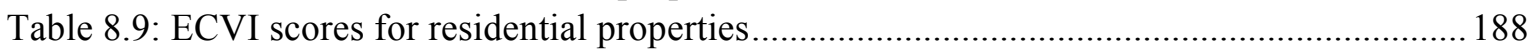

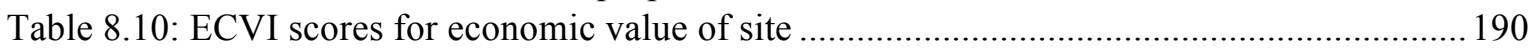

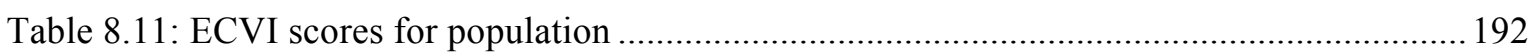

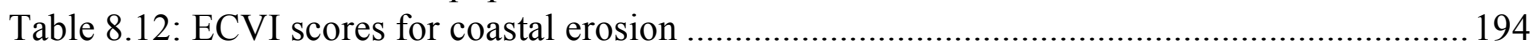

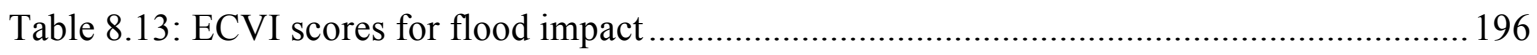

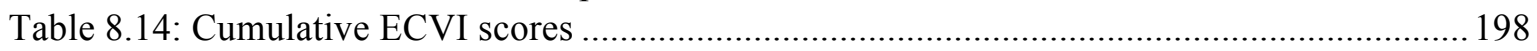

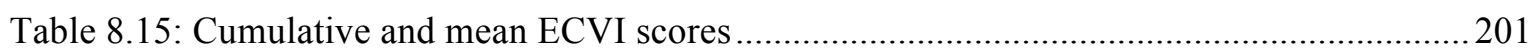

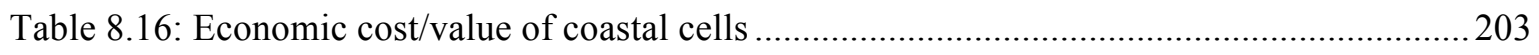

Table 8.17: Site Ranking according to ECVI, including cost/value and population data ..............205

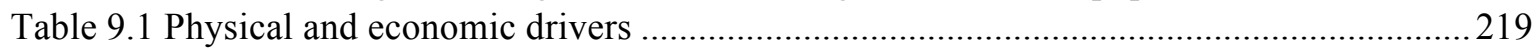

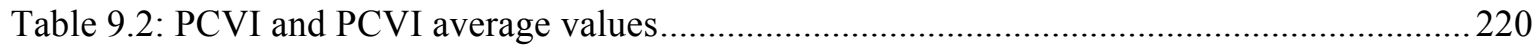

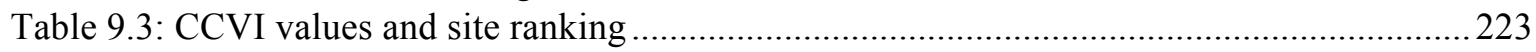




\section{List of Acronyms}

\begin{tabular}{|c|c|}
\hline $\mathbf{A B I}$ & Association of British Insurers \\
\hline $\mathbf{A M C}$ & Agricultural Mortgage Corporation \\
\hline BBC & British Broadcasting Corporation \\
\hline BGS & British Geological Survey \\
\hline CIA & Central Intelligence Agency \\
\hline CVI & Coastal Vulnerability Index \\
\hline CVI & Climate Vulnerability Index \\
\hline CCVI & Combined Coastal Vulnerability Index \\
\hline DARA & No Abbreviation Meaning \\
\hline & An independent, international organisation based in Madrid, Spain \\
\hline DEFRA & Department for Environment, Food and Rural Affairs \\
\hline DESYCO & $\begin{array}{l}\text { DESYCO is a GIS-based Decision support System for Coastal } \\
\text { climate change impact assessment }\end{array}$ \\
\hline DITTY & $\begin{array}{l}\text { Development of an Information Technology Tool for the } \\
\text { management of southern European lagoons under the influence of } \\
\text { river-basin runoff }\end{array}$ \\
\hline $\mathbf{E F}$ & Enhanced Fujita \\
\hline EM-DAT & The International Emergency Disasters Database \\
\hline EVI & Economic Vulnerability Index \\
\hline EVI & Environment Vulnerability Index \\
\hline ECVI & Economic Coastal Vulnerability Index \\
\hline FVI & Flood Vulnerability Index \\
\hline EUROSION & A European Initiative for Sustainable Coastal Erosion Management \\
\hline EPA & Environmental Protection Agency \\
\hline EA & Environment Agency \\
\hline GDP & Gross Domestic Product \\
\hline IPCC & Intergovernmental Panel on Climate Change \\
\hline LVI & Livelihood Vulnerability Index \\
\hline MLW & Mean Low Water Level \\
\hline NOAA & National Hurricane Centre \\
\hline NASA & National Aeronautics and Space Administration \\
\hline
\end{tabular}




$\begin{array}{ll}\text { ONS } & \text { Office of National Statistics } \\ \text { PCVI } & \text { Physical Coastal Vulnerability Index } \\ \text { RRA } & \text { Regional Risk Assessment } \\ \text { RSMA } & \text { Regional Specialised Meteorological Center } \\ \text { SLR } & \text { Sea Level Rise } \\ \text { UKCIP } & \text { United Kingdom Climate Impact Programme } \\ \text { SOVI } & \text { Social Vulnerability Index } \\ \text { SPSS } & \text { Statistical Package for Social Sciences } \\ \text { UK } & \text { United Kingdom } \\ \text { UNEP } & \text { United Nations Environment Programme } \\ \text { US } & \text { United States } \\ \text { USA } & \text { United States of America }\end{array}$




\section{Abstract}

As a consequence of climate change, global coastal communities are increasingly at risk from sea level rise and increased storm intensities. Therefore, to inform coastal zone management coastal vulnerability assessments with respect to present and predicted climate change scenarios is important. Most of the literature concentrates on physical, and to a lesser extent socio-economic aspects but no comparable studies detailing coastal vulnerability from both physical and economic vulnerability were found. To fill this important research gap, the current study developed a combined coastal vulnerability (physical + economic) index by integrating both a Physical Coastal Vulnerability Index (PCVI) and an Economic Coastal Vulnerability Index (ECVI). All indices were applied to eleven case study sites across the country and based on assessments, the Combined Coastal Vulnerability Index (CCVI) was validated. Subsequently, coastal areas were ranked according to their PCVI, ECVI and CCVI values.

PCVI results showed that Great Yarmouth and Happisburgh have high vulnerability, contrasted against an Aberystwyth frontage that was least vulnerable. ECVI assessments showed that both Great Yarmouth and Skegness have high economic vulnerability while Spurn Head had low economic vulnerability. In total, the economic costs related to case study site vulnerability was assessed at $£ 22.36$ billion. Combined coastal vulnerability results showed that Great Yarmouth is highly vulnerable with the highest aggregated score (25) followed by Aberystwyth (21). Llanelli (16) and Lynmouth (16) were least vulnerable with respect to site CCVI.

This research makes a contribution to knowledge, not just for the UK but on a global level. Each location has a unique set of conditions and economic needs, and was found to be functions of physical and economic pressures, e.g. number of properties, coastal erosion and population. Finding the most effective and sustainable solution is important and one that includes knowledge of environmental impact and socio-economic consequences. The three indices (PCVI, ECVI and CCVI) are justified as tools for planners and policy makers for developing management strategies to improve coastal resilience under scenarios of sea-level rise and climate change. 


\section{CHAPTER 1 - INTRODUCTION}




\section{Introduction}

\subsection{Preface}

Coastal regions are vulnerable to extreme weather, such as storms, which incur significant costs to coastal societies. Historically, there are fundamental associations between coastal regions and anthropological settlements (Smit and Pilifosova, 2003; Sing, 2006; Haslett, 2008; Smith, 2013). Coastal populations and infrastructure have increased dramatically resulting in additional stresses due to land use and hydrological changes within low-level catchments (Nicholls et al., 2007; Baker, 2012). More than 40\% of the world's population lives within 150 kilometres of the coast, and 8 of the 10 largest cities in the world are near the shoreline (Atlas, 2013). Globally, several recent worldwide extreme storm events have caused major human and economic losses in coastal zones, for example, Storm Xynthia (Kolen et al., 2010), Hurricane Sandy (Kantamaneni and Phillips, 2013), Typhoon Haiyan (Lagmay et al., 2015), and Cyclone Hudhud (Chejarla et al., 2016). While in the UK, the 2013-14 storm events caused extensive damage to coastal infrastructure (Huntingford et al., 2014; Dawson, 2016; Rangel-Buitrago et al., 2016).

According to Nicholls et al. (2007), in excess of 120 million people are exposed to cyclone hazards every year, and 250,000 fatalities were caused by flooding between 1980 and 2000 . Globally, floods affect 46 million people every year, and may rise to as many as 60 million a year by 2100 as a consequence of predicted sea level rise (Hoozemans et al., 1993). Increased flood events greatly affect socio-economic costs, particularly in populated estuaries, low-lying coastal urban areas, and islands, and these are important communal hotspots of vulnerability (Hinkel et al., 2010). The impacts of regional and global climate change, sea level rise, and weather fluctuations, alongside terrestrial processes, are serious threats to all coastal communities (Oliver-Smith, 2009; Zsamboky et al., 2011). Therefore, coastal vulnerability assessments are very important when consideration is given to the management and future development of coastal regions not only in the UK but elsewhere across the globe.

\subsection{Identified research gaps}

Research suggests there is much worldwide physical (Chapter 2) and to a lesser extent, socioeconomic coastal vulnerability studies. Despite the socio-economic work of McLaughlin et al. (2002) and McLaughlin and Cooper (2010) on the Irish coast, and Denner et al.'s (2015) physical vulnerability work on the Welsh coast, very few UK studies have been undertaken. 
This includes economic consequences and this was repeated globally because very few studies could be found which detailed both physical and economic vulnerability.

\subsubsection{Coastal vulnerability}

The UK coastline varies significantly in terms of morphology and human use, the coast being renowned for its distinctive natural beauty and diverse ecosystems. In some areas, there has been intensive tourism growth while, in others, intense industrial expansion. Suffolk and North Norfolk face extensive coastal erosion, with property, and vital natural areas under threat (Cooper and McKenna, 2008). Therefore, the vulnerability of coastal regions, around the United Kingdom with current predictions of sea level rise and climate change is an important factor. England and Wales were profoundly affected by severe storms in 2007, 2012, 2013, and 2014, all of which exacerbated vulnerability in many coastal regions (Slingo et al., 2014). Several worldwide studies evaluated coastal vulnerability based on geomorphological and physical perspectives but not from an economic viewpoint (Pethick and Crooks, 2000; Garthe and Hüppop, 2004; Martinez et al., 2006; Vittal Hegde and Radhakrishnan Reju, 2007; Abuodha and Woodroffe, 2010; Palmer et al., 2011; Balica et al., 2012; Gorokhovich et al., 2013; Kunte et al., 2014). Limited global research has been performed taking into account some socio-economic variables; see for example, Cutter et al. (2003), Vincent (2004), Schröter et al. (2005), Rygel et al. (2006), Hahn et al. (2009).

\subsection{Aims and objectives}

The main aim of this research is the development of a Combined Physical and Economic

\section{Coastal Vulnerability Index}

To achieve this research aim, the following objectives have been outlined:

To identify vulnerable coastal locations across the UK based on review of literature and multiple site visits;

To assess physical vulnerability by developing and applying a site specific Physical Coastal Vulnerability Index (PCVI) modified from Palmer et al.'s (2011) and Denner et al. 's (2015) work;

$>$ To estimate economic costs of UK coastal vulnerability at the selected sites by developing and applying an Economic Coastal Vulnerability Index (ECVI);

$>$ To establish a combined Coastal Vulnerability Index (CCVI) from evaluation of site specific PCVI and ECVI indices. 
Assessments will provide a useful, easy to use model that can be utilised by coastal managers, policy and decision makers for coastal zone management.

\subsection{Scientific rigour and challenges}

In developing countries, climate change influences can be catastrophic in terms of human cost but with developed nations, it is more of an economic challenge. However, there are conflicting views on climate change research worldwide. Consequently, this research concentrated on the nexus of climate change, storms, and coastal vulnerability of chosen sites in the UK. Economic data collection and analysis of coastal vulnerability is truly challenging and generally is compiled scientifically. In this respect this study differs in its approach by developing simple models, reducing data input and thereby having a wider appeal. 


\subsection{Summary}

In order to assess current research findings and identify research gaps, literature searches

(Chapter 2) began by examining the factors that contribute to coastal vulnerability, followed by an evaluation of current methodological approaches. 


\section{CHAPTER 2 - LITERATURE REVIEW}




\section{Literature Review}

\subsection{Introduction}

A literature review is an objective, via summary and critical scrutiny of relevant, accessible research and non-research literature on the particular topic being studied/investigated (Hart, 1998). There are two main types of literature review; traditional and systematic or methodological. The methodological approach is a rigorous and well-defined method of reviewing the literature regarding particular frameworks in a precise subject area (Parahoo, 2006). Accordingly, the current study divided the literature review into two significant parts as follows (Figure 2.1):

- $\quad 2.2$ - Topic review

- $\quad 2.3$ - Methodological review

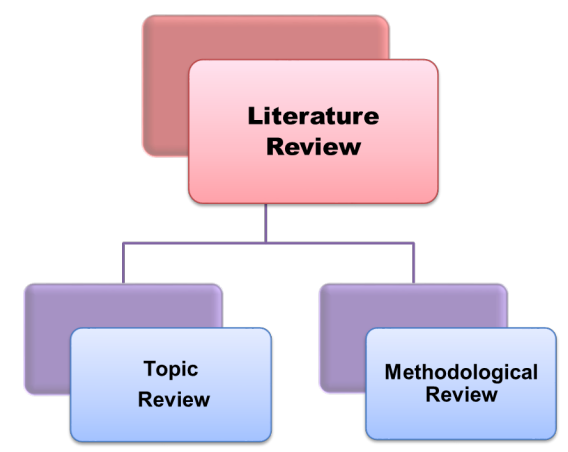

Figure 2.1: Literature review process

\subsection{Topic review}

Climatologists accept that climate change is an issue that must be addressed, and current climatic scenarios are undoubtedly linked to population growth, global warming, sea level rise, and industrialisation (Hitz and Smith, 2004; Schellnhuber, 2006; Weisse et al., 2014). Human-induced or natural climate change can create variations in the occurrence of moderate to severe weather patterns (Meehl et al., 2007). Human-induced global warming has significantly contributed to several climatic events that have been observed in the last two centuries (Pachauri et al., 2014). Coastal environments are severely affected by these climatic fluctuations (Sutton-Grier et al., 2015), and coastal flooding is a growing global concern (McGranahan et al., 2007; Kirshen et al., 2008). Therefore, this chapter deals with the importance of climate change, global warming, greenhouse gases, sea level rise, and temperature trends related to coastal environmental vulnerability. 


\subsubsection{Global warming}

Global warming is augmented by anthropogenic influence, such as, $\mathrm{CO}_{2}$ and other emissions alongside weak climate policies and procedures (Cox et al., 2000; Walther et al., 2002; Lal, 2004; Shine et al., 2005; Stern and Treasury, 2006; Leiserowitz, 2006; Houghton, 2009). This has led to increasing climatic change and the formation of unprecedented weather events such as flooding, coastal erosion and storm surges (Adger et al., 2005; Bouwer, 2011) evident from recent global storm disasters such as cyclone Hduhud (2014 - India) and hurricane Matthew (2016- US, Canada, Cuba, Jamaica, Colombia) (Chejarla et al., 2016; Camacho et al., 2016).

Increasing worldwide temperatures have been the cause of glacial melt across the world (Hansen et al., 2005; Hanna et al., 2008), and due to these consequences, storminess has amplified in both frequency and severity (Hanna et al., 2008). The warmest year since records began in 1880 was 2015 (NOAA, 2016) and 15 of the 16 warmest years, in the 134year record, occurred during the 21 st century (Table 2.1). Global annual temperature has increased at an average rate of $0.07^{\circ} \mathrm{C}$ per decade since 1880 and at an average rate of $0.17^{\circ} \mathrm{C}$ per decade since 1970 (NOAA, 2016). Several factors contribute to global warming, but the main one is an upsurge in greenhouse emissions (Meinshausen et al., 2009).

Table 2.1: Sixteen warmest years (1880-2015) Reproduced from NOAA, 2016

\begin{tabular}{ccc}
\hline Rank & Year & Anomaly $^{\circ} \mathbf{C}$ \\
\hline 1 & 2015 & 0.9 \\
2 & 2014 & 0.74 \\
3 & 2010 & 0.7 \\
4 & 2013 & 0.66 \\
5 & 2005 & 0.65 \\
6 & 1998 & 0.63 \\
6 & 2009 & 0.63 \\
8 & 2012 & 0.62 \\
9 & 2003 & 0.61 \\
9 & 2006 & 0.61 \\
9 & 2007 & 0.61 \\
12 & 2002 & 0.6 \\
13 & 2004 & 0.57 \\
13 & 2011 & 0.57 \\
15 & 2001 & 0.54 \\
15 & 2008 & 0.54 \\
\hline
\end{tabular}




\subsubsection{Greenhouse gases}

Since the start of the industrial age there has been significant increases in greenhouse gas emissions $\left(\mathrm{CO}_{2}, \mathrm{CH}_{4}, \mathrm{~N}_{2} \mathrm{O}\right.$, fluorinated gasses, hydro fluorocarbons, and sulphur hexafluoride), which entrap the temperature in the atmosphere (Dalal and Allen, 2008; Wiedmann and Minx, 2008) and also generate negative ripples in climate change patterns (Overpeck et al., 1997). The rapid increase in $\mathrm{CO}_{2}$ concentrations across the globe is mainly due to the combustion of fossil fuels, land use change (Wuebbles and Jain, 2001) and agricultural processes. These actions also cause the high accumulation of $\mathrm{CH}_{4}$ and $\mathrm{N}_{2} \mathrm{O}$ (Motha and Baier, 2005; Conrad, 1996; Wood and Cowie, 2004) gases. However, the impact of rising greenhouse-gas emissions on climate is not evenly felt across the world (Meinshausen et al., 2009) (Figure 2.2).

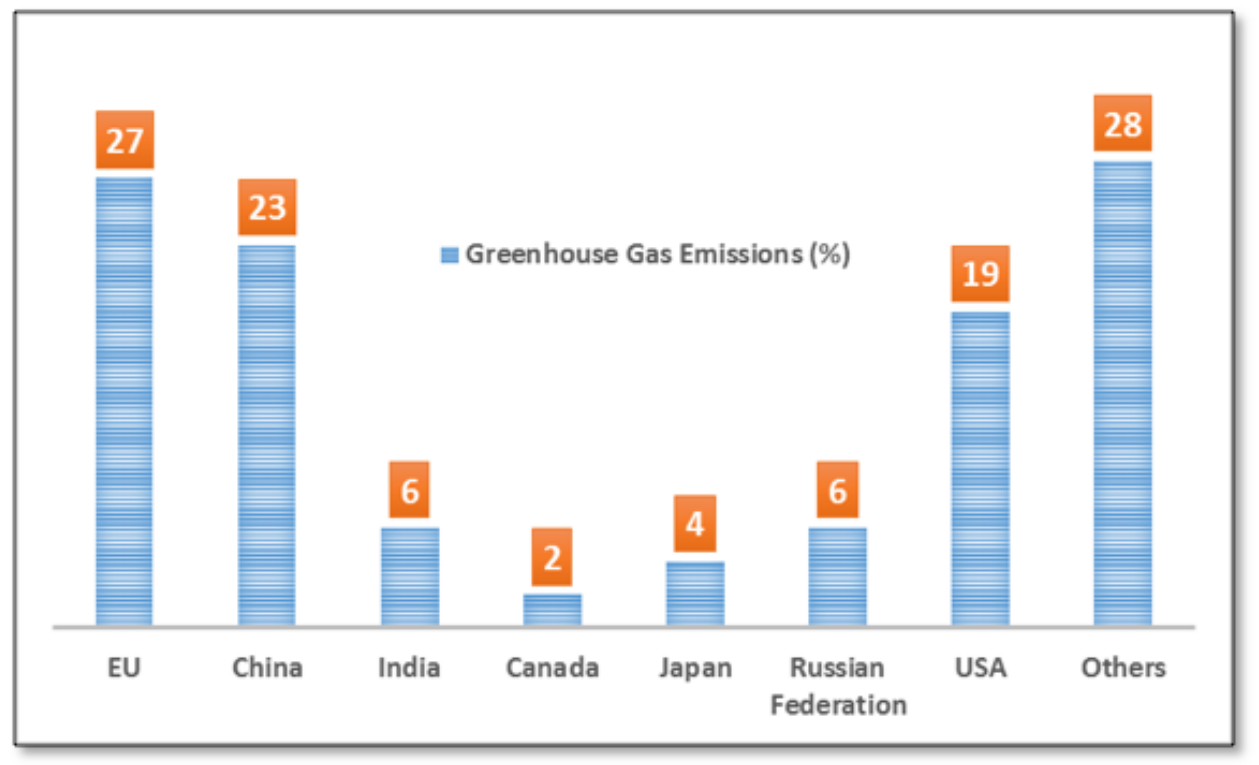

Figure 2.2: Global greenhouse gas emissions (\%)

(EU- Excludes Estonia, Latvia and Lithuania)

Reproduced from EPA, 2015

Anthropogenic activities produced 46 billion tonnes of greenhouse gases in 2010, an increase by 35\% since 1990 (EPA, 2015; Figure 2.3). Indeed, global emissions of all major greenhouse gases for the period 1990-2010 increased significantly (Figure 2.3) and, $\mathrm{CO}_{2}$ net emissions rose by $42 \%$, which is important because $\mathrm{CO}_{2}$ accounts for approximately threequarters of total global emissions (EPA, 2015). In addition, $\mathrm{N}_{2} \mathrm{O}$ and $\mathrm{CH}_{4}$ emissions increased by $9 \%$ and $15 \%$ respectively, while fluorinated gases emissions more than doubled (Loáiciga, 2011). 


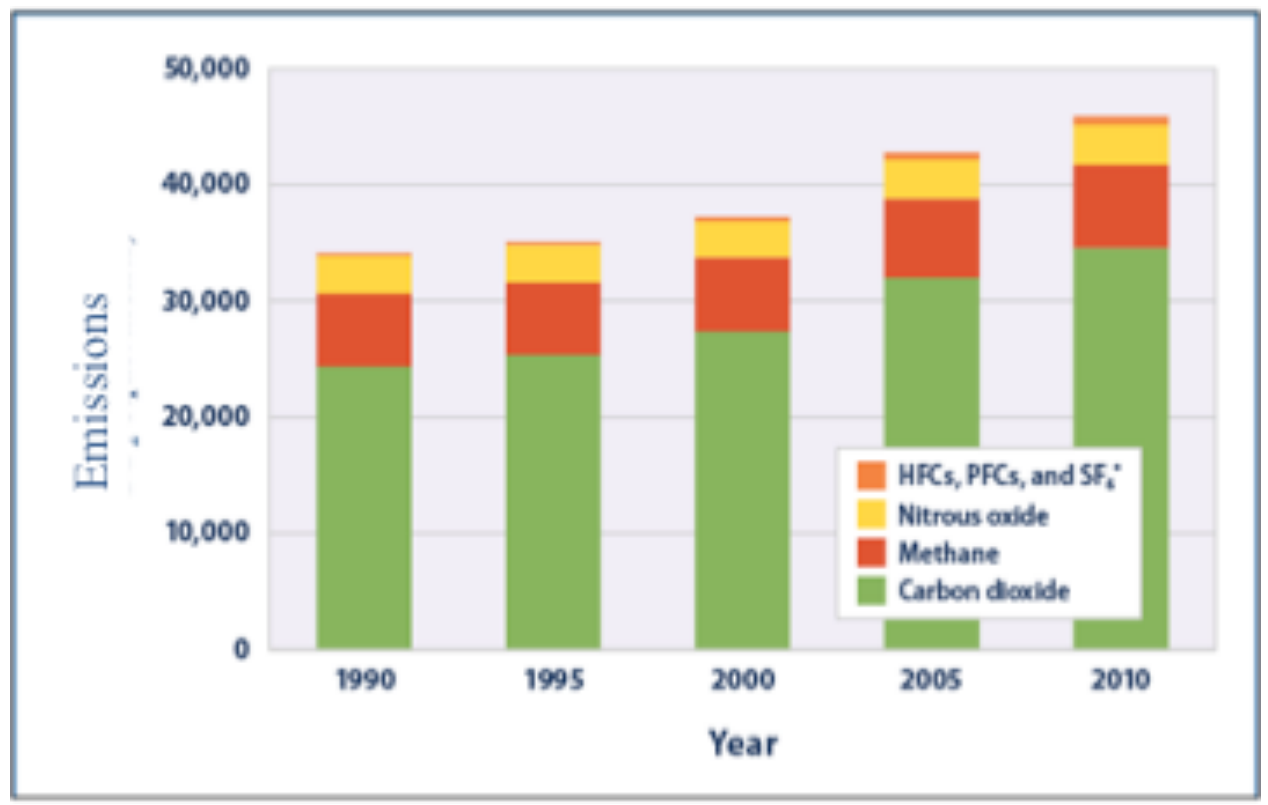

Figure 2.3: Greenhouse gas emissions (1990-2010)

Source: EPA, 2015

\subsubsection{Sea level rise (SLR)}

In the coming decades SLR is arguably the most harmful effect of increasing global temperatures (El Raey, 2011). The long-term view of increasing sea levels has consequences for both policy and adaptation approaches. Damage costs due to coastal land loss and involuntary migration will be significant as nearly 150 million people living in locations within $1 \mathrm{~m}$ of high tides have to move (Anthoff et al., 2010; Anthoff and Tol, 2010). Another main consequence of climate change is increased storm incidence and intensity resulting in coastal flooding (Tol, 2002).

Current and predicted future SLR has social and economic implications for those living in low-lying coastal regions (Parmesan and Yohe, 2003; Jevrejeva et al., 2008; Nicholls and Cazenave, 2010; Church and White, 2011). There are conflicting estimates of previous SLR for example, Kemp et al. (2013) argued that in the last 2000 years sea levels rose by a maximum of $0.6 \mathrm{~mm} \mathrm{yr}^{-1}$ and Church and White (2011) debated that global sea level had risen by about $1.6 \mathrm{~mm} \mathrm{yr}^{-1}$ from late $19^{\text {th }}$ century. However, IPCC (2007) suggest that global SLR rates have increased from a relatively constant equilibrium to $>3.1 \mathrm{~mm} \mathrm{yr}^{-1}$ in the last 135 years (Figure 2.4) this is largely due to anthropogenic activities and predictions suggest increases of between 3 and 5 times as much by the end of $21^{\text {st }}$ century. Rahmstorf et al. (2007) and Horton et al. (2008) suggested that global SLR of between $0.18 \mathrm{~m}$ and $0.59 \mathrm{~m}$ 
and Jevrejeva (2012) estimated upper and lower extremes of between $0.57 \mathrm{~m}$ and $1.10 \mathrm{~m}$ by 2100 , would be observed.

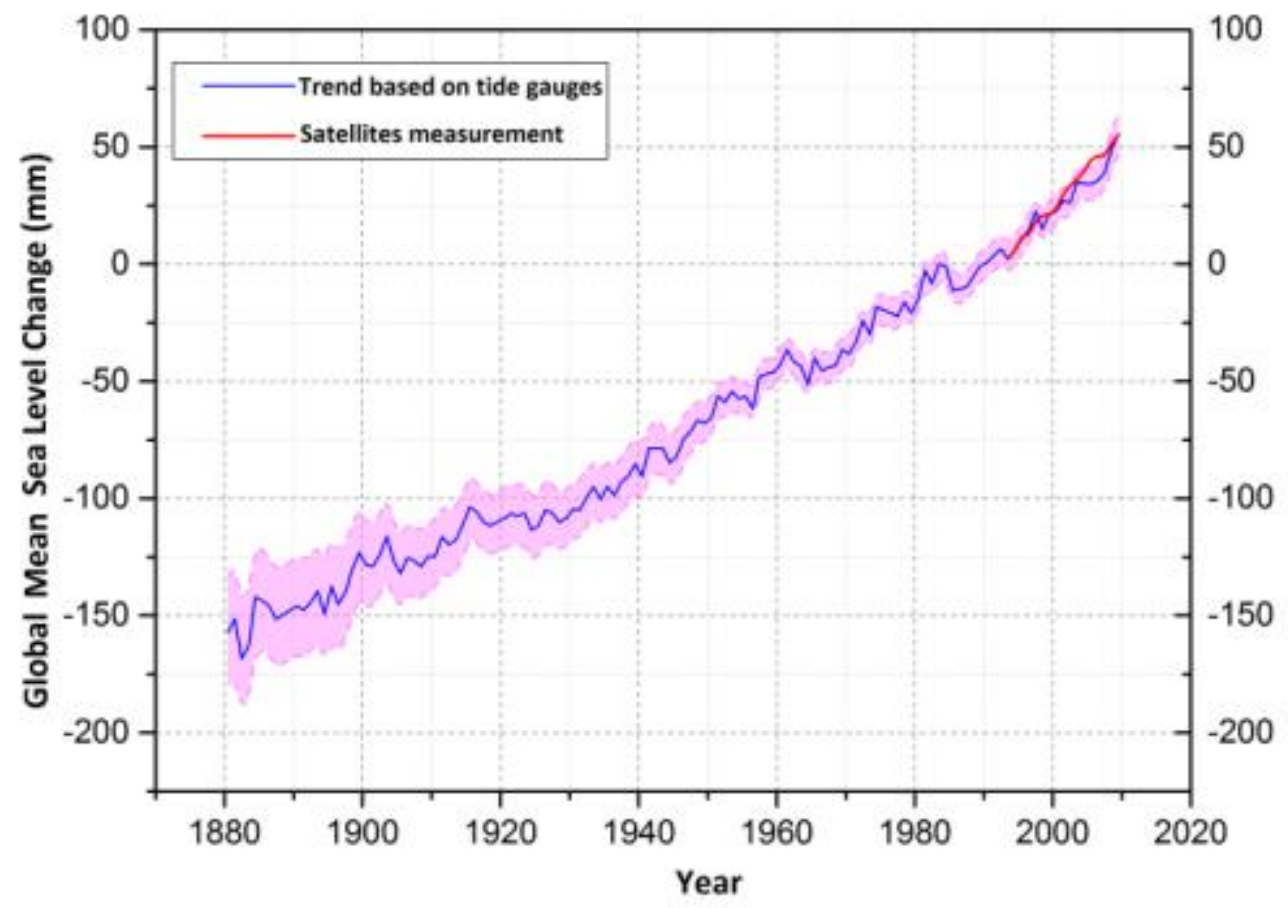

Figure 2.4: SLR trends since 1880

(Produced based on the data of Commonwealth Scientific and Industrial Research Organisation (CSIRO)

\subsubsection{Storms - overview}

Discussions related to global climate change and the potential of more extreme weather events that may impact on both the coastal population and infrastructure involve both politics and science (O'riordan, 1996). Storms are defined by strong winds, moderate to heavy rain with thunder (Donat et al., 2010), differing in origin depending on region and environment from which they originate and are often designated as tropical cyclones, hurricanes, tornadoes, thunderstorms and typhoons (NASA, 2014) (Figure 2.5).

Globally, more than 40,000 thunderstorms occur each day, most occur in the USA, where they can generate tornadoes, severe floods, lightning, cyclones and high winds, etc. (NASA 2014). In November 2013, super typhoon Haiyan, one of the strongest recorded storms struck the Philippines, causing in excess of 5000 fatalities and more than $£ 1$ billion damage costs (Lin et al., 2014; Lum and Margesson, 2014). 


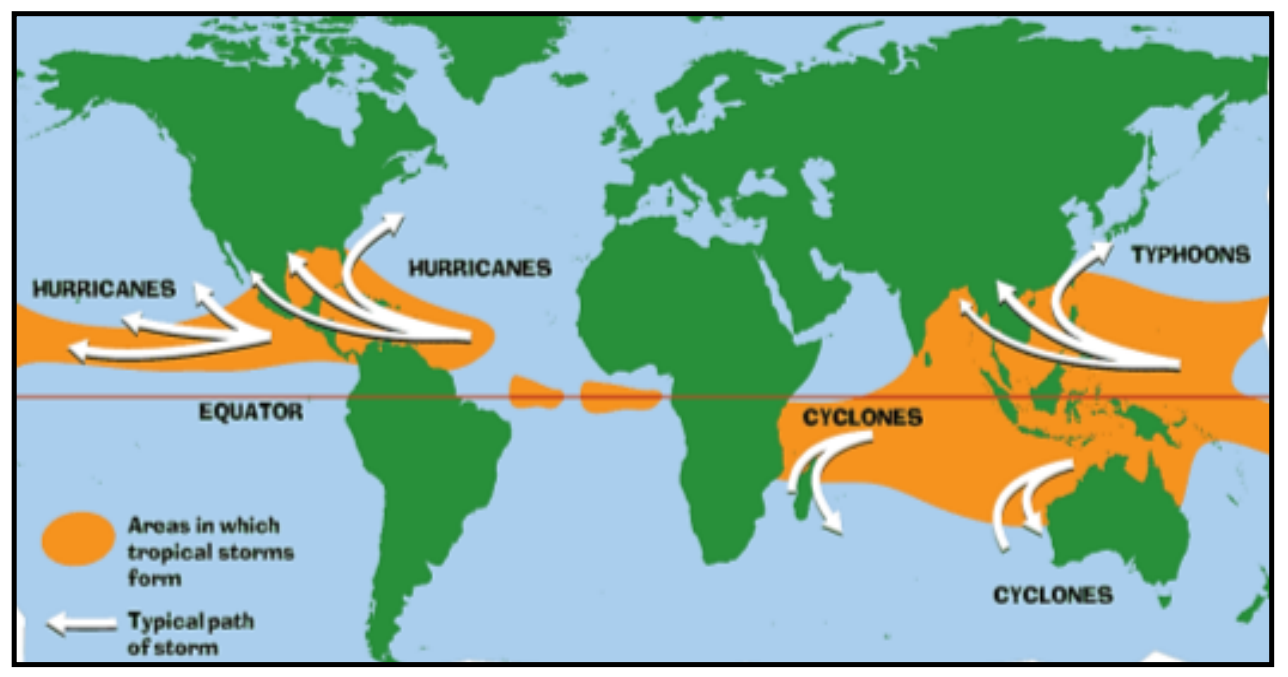

Figure 2.5: Storm classification

\section{Source:NASA, 2014}

High intensity hurricanes are more likely to occur in the USA than any other country (Strobl, 2011). However, severe storm events with hurricane force winds are regularly experienced in the UK (Pitt, 2008; Sibley, 2010). For example, a series of powerful winter storms with hurricane force winds occurred between mid-December 2013 and early January 2014 (Slingo et al., 2014; Kendon and McCarthy, 2015). Many coastal regions in England and Wales were severely affected by these extreme weather conditions, resulting in several fatalities, approximately 1,700 commercial and residential properties flooded and 160,000 homes suffering power cuts (Huntingford et al., 2014; Lewis et al., 2015) (Figure 2.6).

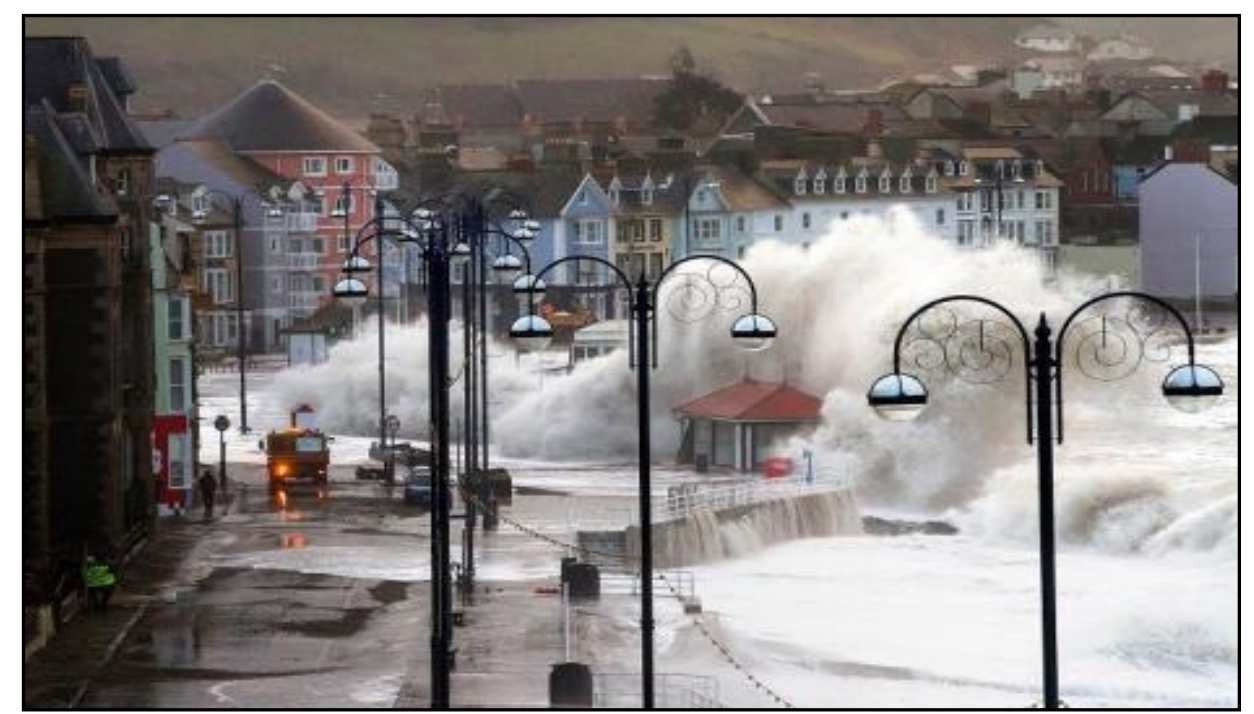

Figure 2.6: Storm damage in Aberystwyth - 2014

Source: The Times, 2015 


\subsubsection{Coastal zones and flood risk}

Flooding is a significant natural hazard in many regions across the world. Floods increase the erosion risk and cause concern for the stability of infrastructure and water quality (Dutta et al., 2003). Historical records highlight that the frequency and intensity of flooding have increased year by year (Easterling et. al., 2000; Knutson et al., 2010). While, predictions highlight that $>80 \%$ of the global population over the next 50 years will reside in coastal flood risk zones (McGranahan et al., 2007; Huq et al., 2007; Grimm et al., 2008). McGranahan et al. (2007) also suggest that many urbanised coastal zones will require improved drainage, flood risk management and flood protection arrangements in many areas. Several factors influence flood occurrence, such as rainfall trends, land and water usage, the characteristics of the drainage basin and most importantly, coastal, estuarine and river management. Flooding has been linked with population increases, urbanisation, and the increase of activities in coastal areas (Meyer and Turner, 1992; Re, 1997; Douben, 2006). Coastal flooding mainly occurs when a storm corresponds with high tides breaching natural and manmade beach protection (Re, 2007). Hurricane-scale weather patterns can occur in the UK, which generate heavy rain and cause coastal flooding (Weisse et al., 2014).

\subsubsection{Floods and damage costs}

Coastal floods are mainly triggered by high water levels due to an amalgamation of tide and storm surges and wave incidents on the coast caused by the effects of wave setup and runup (Wadey, 2013). Globally between 1994 and 2013, flood events were responsible for 43\% of all recorded disasters and affected almost 2.5 bn people, who were living in low-lying coastal areas (Hyndman and Hyndman, 2016; Figure 2.7). In the last two decades, research has shown that storm events are the most expensive in terms of both monetary terms and human loss (EM-DAT, 2014). Between 1980 and 2012, annual global flood losses were > $£ 16$ bn, with an average of 5,900 lives lost each year; without resilience procedures, these costs are expected to increase by $430 \%$ by 2080 , and possibly by as much as $2,000 \%$ (Jongman et al., 2015). If no adaptation measures are implemented to control global warming, Hinkel et al. (2014) estimates that the annual global coastal flooding cost may reach $£ 59$ billion by 2100 . Global coastal flooding events indicate a substantial humanitarian and socioeconomic hazard with more than 20 million people living at or below high tide levels, and 200 million live under storm tide levels (Nicholls and Cazenave, 2010). 


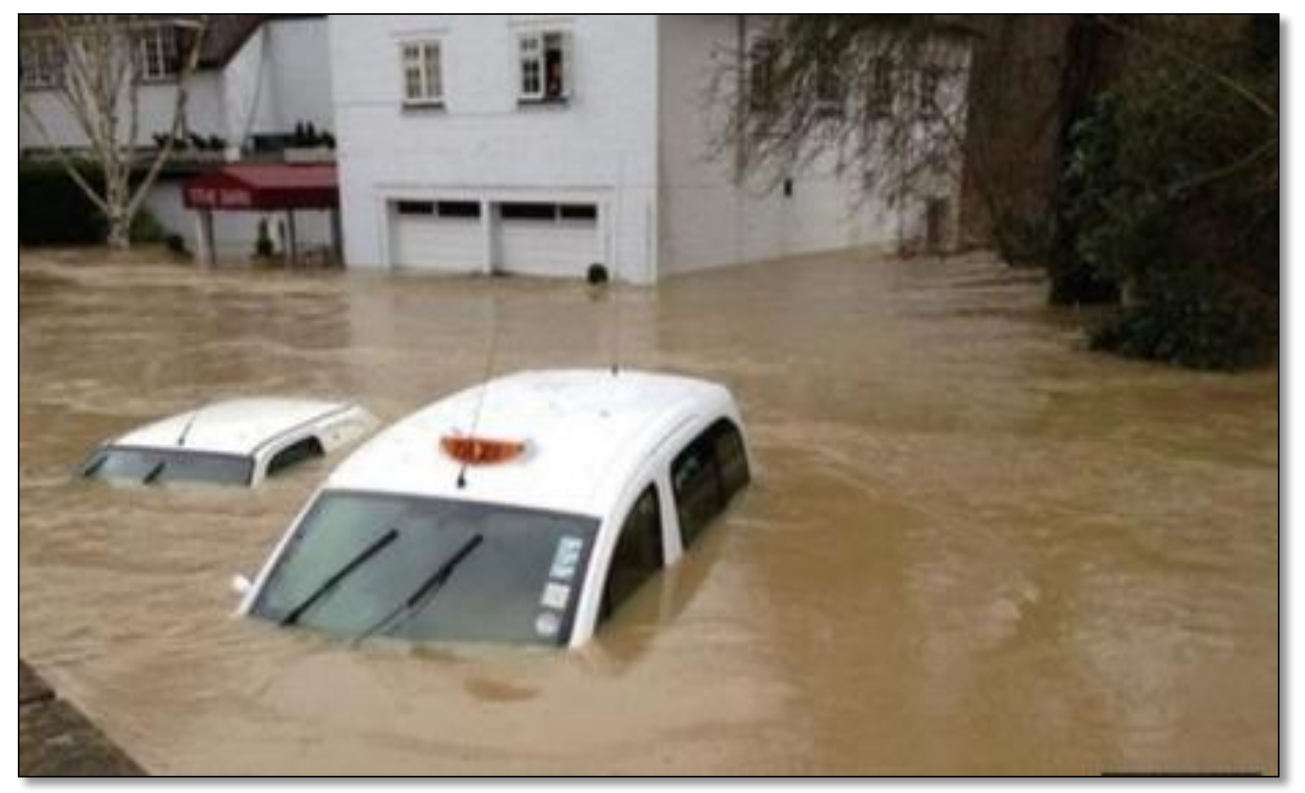

Figure 2.7: Southern England floods in 2013

Source: BBC, 2013

\subsubsection{Economic loss}

Human-induced climate change, though unclear in its particulars, may have adverse effects on the ecology and the economies of the world (Mahlman, 1997). Estimations of annual economic losses caused by climate change are $>£ 490$ billion, representing only $1 \%$ of the (global domestic product) GDP, while the costs of carbon emissions are $>0.7 \%$ (DARA, 2012; Table 2.2). According to Stern (2007), the majority of climate change costs comes from global warming and emissions.

Table 2.2: Global climate change costs ( $£$ bn) Reproduced from DARA, 2012

\begin{tabular}{cc}
\hline Sector & Costs in billions 2010 (£) \\
\hline Climate & 454 \\
Carbon & 353 \\
World & 807 \\
\hline
\end{tabular}

\subsubsection{Geology, geography and climate change}

The geological record comprises enough evidence highlighting climate fluctuations over millions of years, conserving this evidence in the fossil and sedimentary record (Seinfeld 
and Pandis, 2012; Crutzen, 2006). Recent technological advances have enabled geologists and geo-researchers to demonstrate how and why climate has transformed in the past, highlighting the importance of separating out natural climatic changes from those influenced by anthropogenic activity. Geography and climate change are heavily interlinked, as geography will determine the variations in climate patterns. To map out the changes, many researchers used the climate classification map, also known as the Wladimir Köppen climate classification map, originally developed by Rudolf Geiger (Rubel and Kottek, 2010; Kottek et al., 2006). Climate classification has been extensively used in a wide range of subjects particularly in climate study and in physical geography, agriculture, biology, hydrology, and environmental areas of study.

Furthermore, the nexus of geography and climate change in the UK will be explained in detail in the chapter on physical geography.

\subsubsection{Coastlines}

Across the globe, there is a relationship between coastal zones and anthropological settlements (Smit and Pilifosova, 2003; Smith, 2013). Coasts have diverse geographical characteristics that influence the generation of trade and other coastal activities, which contributing significantly to the economies of countries. Coastline length also plays an important role in nations' economies. Various countries with the longest coastline are as follows: (Table 2.3). 
Table. 2.3: Countries with longest coastline across the globe Reproduced from CIA, 2012.

*Taken from Masselink and Russell, 2013.

\begin{tabular}{|l|l|l|}
\hline Rank & Country & $\begin{array}{l}\text { Coastline } \\
(\mathbf{k m})\end{array}$ \\
\hline 1 & Canada & 202,080 \\
\hline 2 & Indonesia & 54,716 \\
\hline 3 & Greenland (Denmark) & 44,087 \\
\hline 4 & Russia & 37,653 \\
\hline 5 & Philippines & 36,289 \\
\hline 6 & Japan & 29,751 \\
\hline 7 & Australia & 25,760 \\
\hline 8 & Norway & 25,148 \\
\hline 9 & United States & 19,924 \\
\hline 10 & United Kingdom & $17,381 *$ \\
\hline 10 & New Zealand & 15,134 \\
\hline
\end{tabular}

The average population density in coastal areas is more than 80 persons per square kilometre, which is double the global average population density (Creel, 2003;). Due to high anthropogenic use, particularly in recent times, coastlines were adversely affected in the Europe (Carter, 2013). According to UNEP (2013a \& b), coastal populations living near to the shoreline around the world suffer from the highest coastal erosion especially in the Europe (Figures 2.8 and 2.9). Figure 2. 8 highlights that the UK coast has mostly altered and it is a one of the shoreline degrading countries in the world. Collectively, rapid population growth and economic and technological development are having a significant effect on coastlines and surrounding areas. However, not all human activities will cause environmental damage, but they are main factors. The physical background chapter explores the coastlines of the UK in-depth and with various examples. 


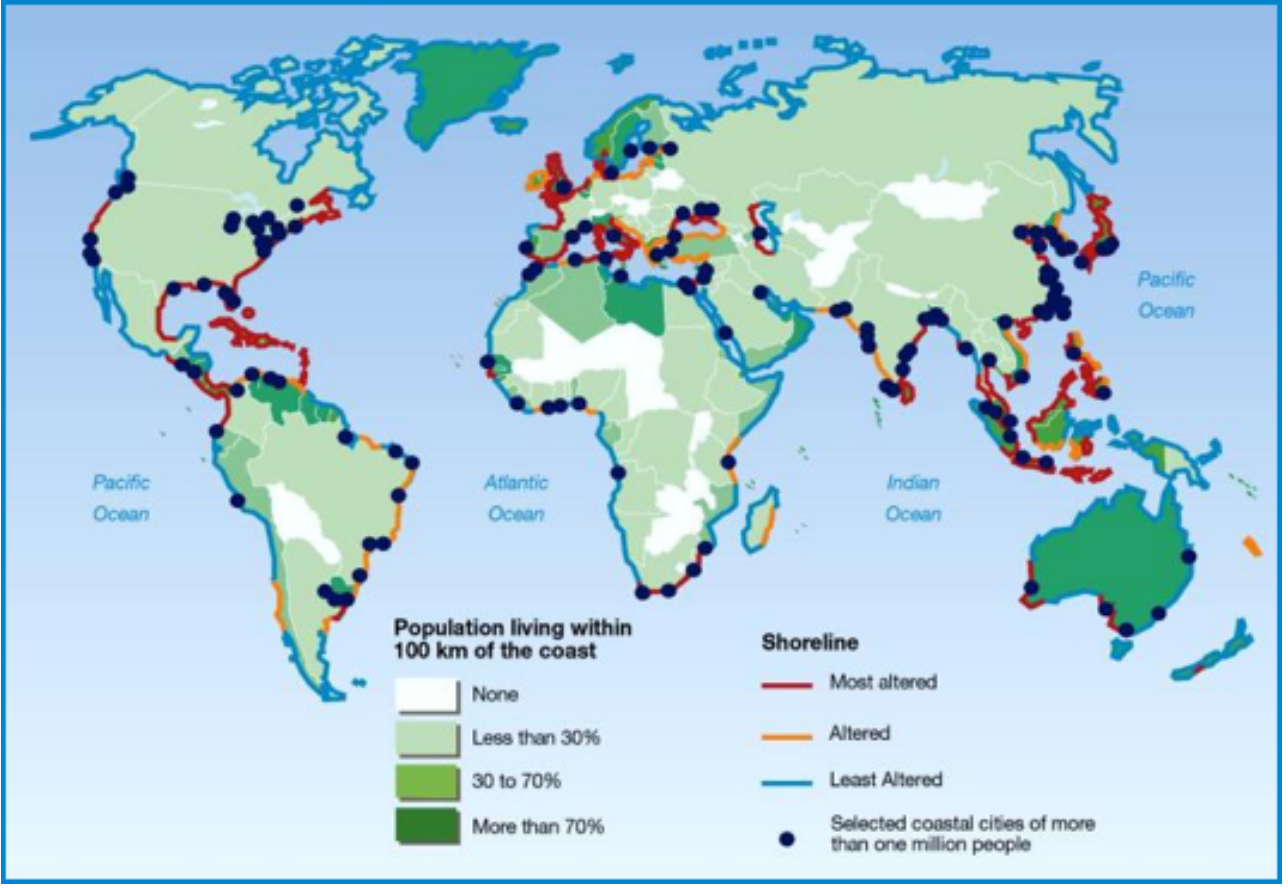

Figure 2.8: Coastal population and shoreline degrading trends across the globe

Source: UNEP, $2013 a$

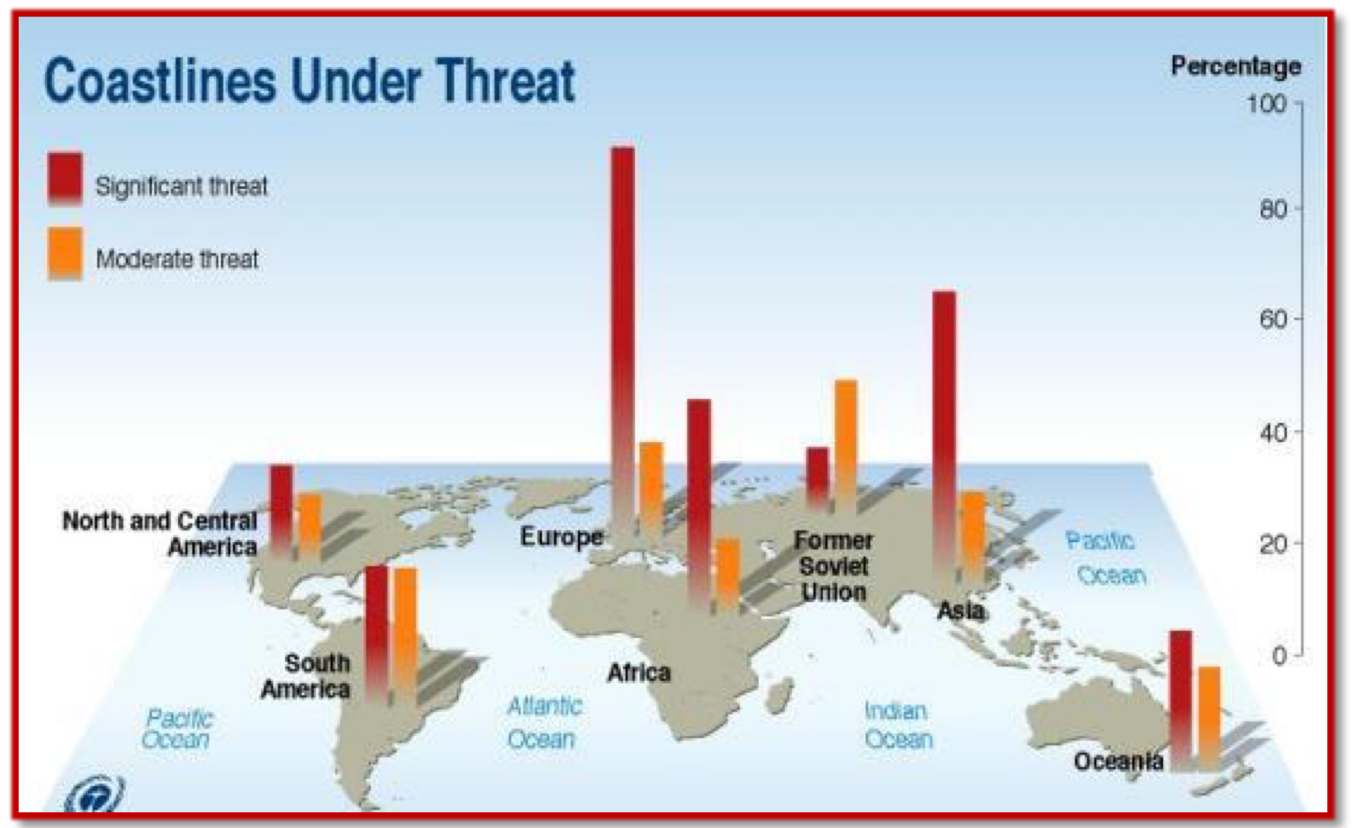

Figure 2.9: Shoreline degradation across the globe

Source: UNEP, $2013 b$ 


\subsection{Methodological review 2.3.1. Coastal vulnerability}

The term vulnerability originated in the field of geography to determine potential risk from naturally occurring hazards. Vulnerability assessments have now become commonplace in the fields of physical and economic geography, environmental science and in related research areas, such as, climate change impacts, sustainability, ecology, public health, livelihood, food security and land usage, and the respective fields define vulnerability in diverse terms (Adger, 2006). The third assessment report of the IPCC (McCarthy, 2001) defined vulnerability as "the degree to which a system is susceptible to, or unable to cope with, the adverse effects of climate change". Historically, much of literature on the topic of human and geographical vulnerability exists but relatively few detail coastal vulnerability; and studies that detail coastal vulnerability in terms of economic cost are extremely sparse (Kantamaneni and Phillips, 2016). The threat to the coastlines occurs where comprehensive growth on the land near the sea is affected by shape and biophysical features (Carter, 2013). Newton et al. (2012) introduced a syndrome method of coastal vulnerability assessment that emerged from concerns related to the impacts of climate variations on coastal zones, suggesting that multi-stressors impact the global coastal systems in several ways (Table 2.4). Overall, the concept of vulnerability is multidimensional and it depends on the area and source of hazards (Kantamaneni, 2016a \& Kantamaneni2016b). 
Table 2.4: Synergetic multi stressors of coastal zone Reproduced from Newton et al., 2012

Sediment

Water

Eutrophication

Coastal land-

Coastal urbanisation

Biodiversity
From sediment trapping by damming of rivers and the physical disruption of the coastal dynamics by coastal engineering, as well as subsidence

Such as the over-extraction of water from coastal aquifers, decreased river-flow and ageing of water at the river-mouth from damming

From agriculture, animal rearing, processing of organic matter and sewage

Such as the destruction of coastal forest, mangroves, salt marshes and wetlands

In a flood, prone, low-lying coastal zone, on marginal land, as well as coastal megacities

From stressing or over exploitation of biotic resources, introduction of invasive species, changes in the food web and regime change

\subsubsection{Aspects of vulnerability}

The concept of coastal vulnerability varies depending on the researcher and environment each defining vulnerability in different ways. Some researchers related vulnerability to natural hazards and the environment (Blaikie et al., 2014); others define vulnerability in relation to climate change as well as coastal susceptibility (Adger, 1999; Kelly and Adger, 2000). Klein and Nicholls (1999) developed a framework, which included both natural and socio-economic structures commonly found in coastal environments (Figure 2.10). The main fundamentals of this agenda include the variation between autonomous adaptation and planned adaptation, as well as the substantial effect of the socio-economic system on the natural system. There are diverse opinions on the definition of vulnerability across the globe, as it has a multi-dimensional aspect. However vulnerability related with coasts is simply a measure of the intensity to which anthropological or natural system is unable to cope with adverse effects. Vulnerability can be related with natural hazards, anthropogenic hazards, 
social hazards or a combination of all three. In this context, a working definition (for the current study) for the vulnerability is as follows:

"Identification of intensity of risk from various hazards, in this case, from coastal impacts, such as, flooding, erosion, storm surge etc. in both physical and economic perspectives.

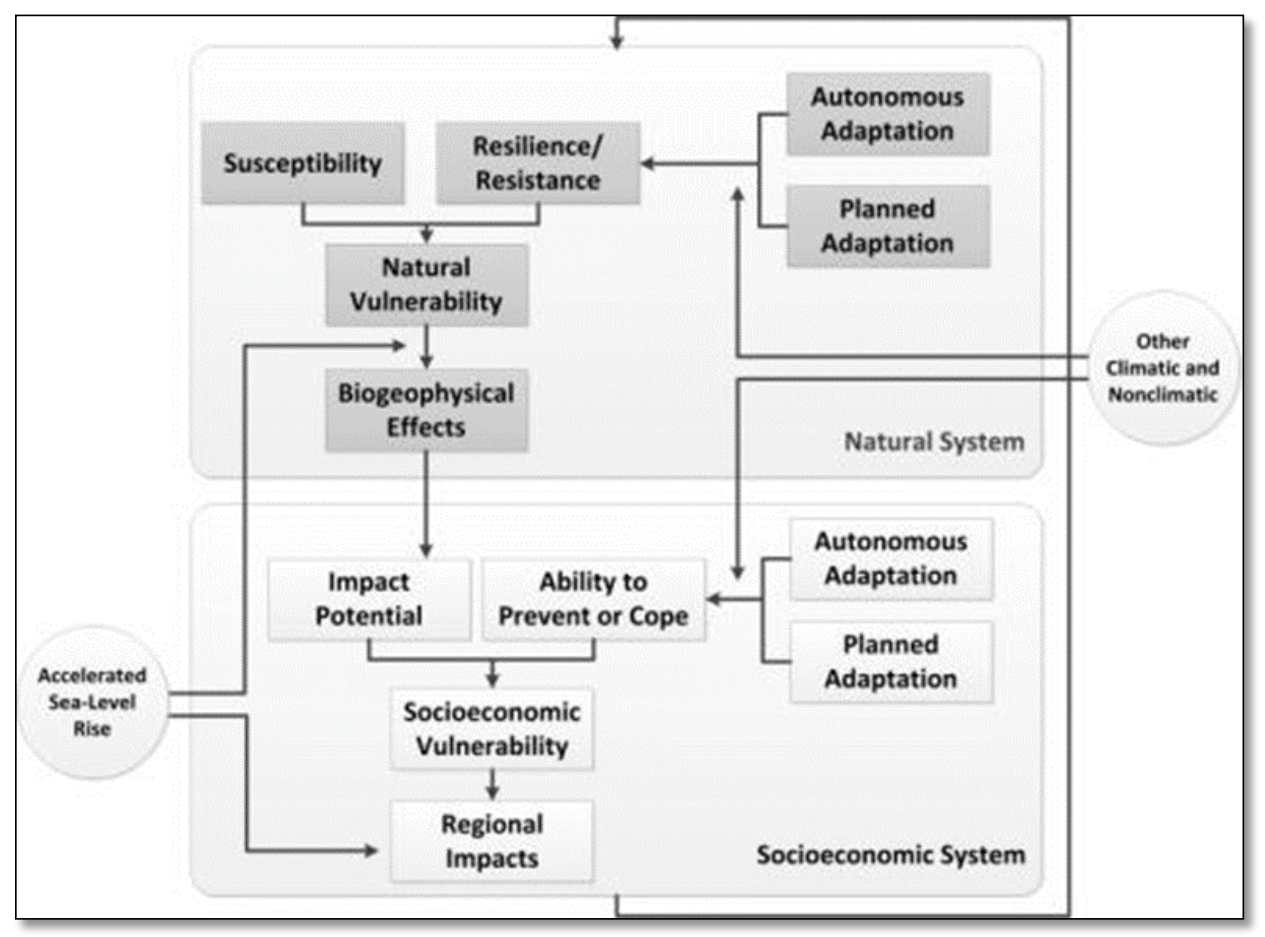

Figure 2.10: Coastal vulnerability framework

Reproduced from Klein and Nicholls, 1999

Based on this working definition, the current study evaluates combined coastal vulnerability of the UK at selected sites, which will be explained in detail in forthcoming chapters.

\subsubsection{Coastal vulnerability index and procedures}

Even though several methodologies have been used to estimate coastal vulnerability, most are categorised by four basic approaches as described by Ramieri et al. (2011), which are explained in detail in following sections.

1 Index-based methods

2 Indicator-based approaches

3 GIS-based decision support systems

4 Dynamic computer models 
The Cabinet Office-UK (2012) evaluated risk assessment under the NRA (National Risk Assessment) programme in three categories such as natural events (disasters), major accidents and malicious attacks. This report (4th Chapter) explored that risk assessments for both hazards and threats have been assessed by the public participation surveys. The definition given in section 2.3.3 suggests that the both physical and economic components need to be assessed and this forms the main aim of the current research project. To achieve the aim physical vulnerability will be assessed using an indicator methodology originally developed by Palmer et al. (2011) refined for Welsh coast by Denner et al. (2015). They now follows a detailed review of the most current methodological approaches used in worldwide coastal vulnerability assessments.

\subsubsection{Index-based methods}

Index-based methods evaluate coastal vulnerability using a unit-less single-magnitude index scale, measured by quantitative or semi-quantitative assessments and an amalgamation of diverse variables (Pethick and Crooks, 2000). With these methods, the final results dictate the overall vulnerability score based on a combination of all values but they do not provide any indication of how each index value contributes to the overall score (Balica et al., 2012). A clear description of accepted procedures is therefore vital to reinforce appropriate usage of index-based methods. A drawback when used on coastal systems is an inability to evaluate socio-economic features such as the number of people affected, quantification of infrastructure damaged, and costs (Gornitz et al., 1993; Cooper and McLaughlin, 1998; McLaughlin and Cooper, 2010). These limitations were addressed by using the original CVI's linked with other appropriate indicators, e.g. producing combined indices capable of representing coastal system complexities. However, this involves a large increase in the numbers of indices and complicate the methodology. Alternatively, it is possible to transform the original method of CVI by, for example, taking erosion into account separately and then integrating it with another CVI, for example storms, and then considering socio-economic structures within each of the considered CVIs.

CVI has been used to evaluate coastal vulnerability at European levels, but these tend to be more challenging to apply to the various complex geographical zones (see, for example, Capobianco et al., 1999; Sullivan and Meigh, 2005; Garthe and Hüppop, 2004). At regional levels Mendoza and Jimènez (2008) established an approach to evaluate coastal vulnerability at regional scales, which included the effects of storms alongside socio-economic factors, using 42 Catalan coast beaches as a case study. 
The initial or first stage deals with the identification of primary variables demonstrating important procedures inducing the coastal vulnerability and the coastal evolution in general aspects (Gornitz, 1991). The number of main variables can be altered slightly depending on geographical and environmental settings but generally a CVI will contain 6 or 7 variables. A second stage then deals with the quantification of relevant variables. Even though several methods may be accessible for this step, quantification is normally grounded on the description of semi-quantitative scores according to a 1-5 scale (Gornitz, 1990). Where 1 specifies a low influence and 5 designates high. Finally, primary variables are combined into a single index. Gornitz et al. (1997) offered and tested (in terms of sensitivity analysis) formulations that considered seven key variables for the derivation of the final CVI (Figure 2.11).

\begin{tabular}{|c|c|}
\hline Product mean: & $\mathrm{CVI}_{1}=\frac{\left(\mathrm{x}_{1} * \mathrm{x}_{2} * \mathrm{x}_{3} * \mathrm{x}_{4} * \ldots \mathrm{x}_{n}\right)}{\mathrm{n}}$ \\
\hline Modified product mean: & $\mathrm{CVI}_{2}=\frac{\left[\mathrm{x}_{1} * \mathrm{x}_{2} * 1 / 2\left(\mathrm{x}_{3}+\mathrm{x}_{4}\right) * \mathrm{x}_{5} * 1 / 2\left(\mathrm{x}_{6}+\mathrm{x}_{7}\right)\right]}{\mathrm{n}-2}$ \\
\hline Average sum of squares: & $\mathrm{CVI}_{3}=\frac{\left(\mathrm{x}_{1}{ }^{2}+\mathrm{x}_{2}{ }^{2}+\mathrm{x}_{3}{ }^{2}+\mathrm{x}_{4}{ }^{2}+\ldots \mathrm{x}_{n}^{2}\right)}{\mathrm{n}}$ \\
\hline Modified product mean (2): & $\mathrm{CVI}_{4}=\frac{\left(\mathrm{x}_{1} * \mathrm{x}_{2} * \mathrm{x}_{3} * \mathrm{x}_{4} * \ldots \mathrm{x}_{0}\right)}{5^{(\mathrm{n}-4)}}$ \\
\hline Square root of product mean: & $\mathrm{CVI}_{5}=\left[\mathrm{CVI}_{1}\right]^{1 / 2}, \quad$ and \\
\hline Sum of products: & $\mathrm{CVI}_{6}=4 \mathrm{x}_{1}+4 \mathrm{x}_{2}+2\left(\mathrm{x}_{3}+\mathrm{x}_{4}\right)+4 \mathrm{x}_{5}+2\left(\mathrm{x}_{6}+\mathrm{x}_{7}\right)$ \\
\hline Where: $\begin{aligned} & n=\text { variables present } \\
\mathrm{x}_{2} & =\text { local subsidence trend } \\
\mathrm{x}_{4} & =\text { geomorphology } \\
\mathrm{x}_{6} & =\text { maximum wave height }\end{aligned}$ & $\begin{array}{l}x_{1}=\text { mean elevation } \\
x_{3}=\text { geology } \\
x_{5}=\text { mean shoreline displacement } \\
x_{7}=\text { mean tidal range. }\end{array}$ \\
\hline
\end{tabular}

Figure 2.11: Diverse formulations of CVI

Source: Gornitz et al., 1997

\subsubsection{Indicator-based indices}

An indicator or set of indicators can be described as an intrinsic and distinctive measure that quantitatively estimates the situation of a structure. An indicator is a sign that précises the data related to a specific phenomenon (Gallopin, 1997). Indicators are simple numerals that indicate the certainty, such as the population rate and the GDP per capita. Certain indicators, such as, population are useful for growth assessment in coastal risk management studies, coastal defence procedures, and coastal risk management organisational procedures (Balica et al., 2012). Balica et al. (2012) developed a Coastal City Flood Vulnerability Index based 
upon exposure, susceptibility and resilience to coastal flooding. It is applied to nine cities (Calcutta, Casablanca, Dhaka, Manila, Buenos Aires, Osaka, Marseille, Shanghai and Rotterdam) across the world, each with diverse kinds of exposure.

Developing and using indicators is not a new concept as economic indicators were developed during the 1940s (Hartmuth, 1998). Indicators offer knowledge regarding structures' elevations, places, densities of population, usages of land, nearness to the coast, and proximity to return periods of various coastal vulnerability events, as well as the responsiveness and preparedness of communal and physical structures (Hinkel, 2011). Researchers have established several vulnerability indicators within a socialecological system (SES) context (Abson et al., 2012; Brooks et al., 2005; Mamauag et al., 2013; Eakin and Luers, 2006). However, identification of social and natural structures that are inherently attached should be considered for a more holistic method for the assessment of vulnerability (Eakin and Luers, 2006; Kasperson et al., 2005; Folke et al., 2002).

An indicator Coastal Vulnerability Index is a popular tool to measure the intensity of exposure of communities to hazards (Giljum and Polzin, 2009). The index comprises several qualitative and quantitative indicators, which are interlinked with the formula. Each indicator helps describe the vulnerability of various structures (Balica et al., 2012). In those frameworks, indicator-based methods assess the vulnerability of coastal areas based on a set of elements (indicators) that describe vital coastal factors such as coastal drivers, forces, condition, effects, reactions, sensitivity, exposure, hazard, and destruction (Carapuco et al., 2016; Tan and Chadbourne, 2015; Giljum and Polzin, 2009). These elements are in some cases pooled into a final indicator. The primary and most vital step in the indicatorbased evaluation of vulnerability is a selection of various indicators as well as the number of indicators to be used. Most researchers restrict the number of indicators to between four and ten. The Canadian Council of Ministers of the Environment (2013) considered one hundred indicators, but by a process of elimination narrowed the indicator used in the study to the 12 most important factors.

Furthermore, Houghton et al., (2001) categorised the vulnerability indicators into two types: the first type relates to the direct impact on nature and the second relates to the direct impact on people. The first type is constructed on hypothetical conceptions and the second one on numerical perceptions. When this methodology is applied to certain places or events, it is essential to consider two significant factors. The first, encompasses indicators dealing 
regional capabilities and vulnerabilities, including environmental, ecological, social, and economic procedures along with space and event time. The second one deals with monetary factors, population growth, commercial and residential properties, and climate change patterns (Houghton et al., 2001). The indicator set comprised nine sensitivity indicators (Smeets et al., 1999) that are showed in Table 2.5:

Table 2.5: Sensitivity indicators

Reproduced from Smeets et al., 1999

\begin{tabular}{cl}
\hline Number & \multicolumn{1}{c}{ Indicator } \\
\hline 1 & Relative sea level rise \\
2 & Shoreline evolution trend status \\
3 & Shoreline changes from stability to erosion or \\
& accretion \\
4 & Highest water level \\
5 & Coastal urbanisation (in the 10 km land strip) \\
6 & Reduction of river sediment supply \\
7 & Geological coastal type \\
8 & Elevation \\
9 & Engineered frontage
\end{tabular}

\subsubsection{GIS-based decision support systems}

Geographical Information System (GIS)-based methodologies are useful to evaluate the physical condition of a particular system and the development of vulnerability maps. GIS have been approved by users/researchers looking to acquire further information about the physical geography through the computers to transmute vast databases into thematic maps. With the addition of GIS-based models, decision-makers can begin employing the data in a true planning atmosphere (Faber et al., 1997). However, the coastal environment GIS-DSS (geographical information system - decision support system) contains two types: the DITTY DSS - development of information technology tool (Agnetis et al., 2006) and DESYCODSS - DEcision support SYstem for COastal climate change impact assessment (Montanari et al., 2014). While Geographical Information System (GIS) tools probably strengthen the spatial application of various CVI indices, GIS can be utilised to improve the spatial data linked to CVI variables and develop various scales of maps highlighting their spatial dissemination (De León and Carlos, 2006). GIS also allows the overlay of CVI outcomes 
with other spatial data (e.g. layers representing coastal protection procedures, density of population, urbanisation indices, and ecological values). Therefore, GIS supports the combined analysis, which is vital in the evaluation of coastal vulnerability studies, and accordingly in coastal zone assessments. GIS is most valuable for developing quality spatial resolution pictures, which are essential in describing parts of huge geographical regions that are at greater risk and need to be protected (Lillesand et al., 2014). Contemporary GIS software permits for this multi-scale and multi-criteria analysis to be carried out both interactively and programmatically in order to test a model via a scripting interface.

\subsubsection{Development of information technology tool for the management of Southern European lagoon (DITTY-DSS)}

This is one of the GIS-based methods for coastal vulnerability evaluation. Mainly it was developed to attain sustainable and rational application of resources in the southern European lagoons by taking into account main anthropogenic effects (Agnetis et al., 2006). The DITTY project was produced and tested in five sites for the supervision of coastal lagoons.

\subsubsection{Decision support system for coastal climate change adaptation (DESYCO)}

DESYCO is a GIS-based Decision Support System (DSS) intended for the integrated assessment of multiple impacts of climate change on vulnerable coastal systems (e.g. river deltas, beaches, estuaries and lagoons, wetlands, agricultural and urban areas) (Zanuttigh et al., 2014). It implements a Regional Risk Assessment (RRA) procedure, based on MultiCriteria Decision Analysis (MCDA), to recognise and rank the zones at risk in the considered area. DESYCO is an open source software that accommodates a number of data input files, such as, csv, txt, shape or raster files concerning both climate change hazard circumstances, e.g., global and regional climate projections; high resolution hydrodynamics; hydrological and biogeochemical simulations and physical circumstances related to a specific site, e.g. ecological and socio-economic features of the studied area e.g. geomorphology, coastal topography, occurrence and distribution of vegetation cover, location of synthetic defence (Zanuttigh et al., 2014). In the initial stages of development, DESYCO comprised vulnerability indicators and indices for the appraisal of impacts of climate change in coastal zones. Indeed, indicators or indices can be selected from data connected to fields such as ecology, geomorphology, and socio-economics. 


\subsubsection{Methods based on dynamic computer models}

Sector models enable detailed quantitative analyses of coastal processes or specific coastal systems. They are capable of assessing non-linear effects and consider interactions between different processes. They are most useful for addressing specific key factors of coastal vulnerability, in particular at the local and regional scale.

Integrated assessment models can evaluate the vulnerability of coastal systems to multiple climate change impacts. They can include the cross-sector analysis of interaction among different impacts and the synergetic effects of changes in climate and in other key variables affecting the coastal system (such as socio-economic development and adaptation measures). The ability of a fully integrated assessment of coastal vulnerability, also considering dynamic interactions between sectors and/or processes, makes integrated assessment models very useful in supporting policy and decision-making at various scales. However, given the complex nature of such models, their implementation can require significant expertise. In some cases (e.g. RegIS and DESYCO) further effort from the research community is still needed to up-scale the applicability of integrated assessment models to the European scale.

Computer simulations are the main tools used for analysing and mapping susceptibility and risks of coastal systems to climate change. Accessible methods for these procedures are based on dynamic computer modelling and according to Ramieri et al. (2011), these fall into two main groups' sector models and integrated assessment models.

- Sector models focus on the examination of coastal vulnerability linked to a specific coastal system. However, these do not directly deal with the appraisal of coastal vulnerability to several climate change impacts (Cicin-Sain and Belfiore, 2005).

- Integrated assessment models appraise the capabilities of coastal vulnerability systems against multiple climate change impacts, including cross-sector examinations of the collaboration among diverse effects and considering variations in other aspects disturbing the coastal system.

Examples of integrated assessment models include FUND, DIVA, SimCLIM, and RegIS (Hinkel and Klein, 2009; Nicholls and Tol, 2006; McLeod et al., 2010). The choice of an appraisal technique in a specific situation is also dependent on the accessibility of relevant data. Although several other methods have been developed for coastal vulnerability assessment, most researchers use index- and indicator-based methods and/or integrated models. 


\subsubsection{Coastal vulnerability frameworks}

The seminal work of Gornitz and Kanciruk (1989) created the first coastal vulnerability index, followed by several researchers who established similar methodologies but with different variables depending on physical, environmental and socio-economic circumstances (Shaw et al., 1998; Boruff et al., 2005; Doukakis, 2005; Pethick and Crooks, 2000; Vittal Hegde and Radhakrishnan Reju, 2007; and Palmer et al., 2011). Coastal vulnerability index variables generally measure vulnerability in terms of physical changes, influenced by erosion and sea level rise, the CVI highlighting areas with different levels of impact. The classification of CVI is dependent on the comparative contributions and collaboration of six variables:

$\begin{array}{ll}\text { a } & \text { Geomorphology } \\ \text { b } & \text { Shoreline erosion/accretion rate } \\ \text { c } & \text { Coastal slope } \\ \text { d } & \text { Relative sea-level rise rate } \\ \text { e } & \text { Mean wave height } \\ \mathrm{f} & \text { Mean tide range }\end{array}$

CVI values range between 0.0 and 1.00: i.e. low values 0.0 to 0.25 , and very high values $0.75-1.00$; each calculated figure falls into the relevant quartile, and each coastal region is then characterised accordingly. CVI is designated (calculated) as the square root of the product of the rank variables divided by total number of variables, as follows:

$$
C V I=\sqrt{ }(a * b * c * d * e * f) / 6
$$

This methodology has been successfully applied at many coastal locations around the world, most with differing physical parameters (Pethick and Crooks, 2000; Hegde and Radhakrishnan Reju, 2007; Garthe and Hüppop, 2004; McLaughlin and Cooper, 2010). Alternatively, some CVI evaluations can be performed to appraise the amount of loss that could result from a hazardous incident of a given severity, comprising destruction of infrastructure, disruption of monetary activities, and effects on livelihoods (Blaikie et al., 2014; Langston, 2008; Turner et al., 1996; McLaughlin and Cooper, 2010; Pendleton et.al., 2010).

In the last two decades, researchers have developed a wide range of vulnerability index parameters that vary depending on the area of research. The following an examination of the most popular indices. 


\subsubsection{Social vulnerability index}

Cutter et al. (2003) developed the Social Vulnerability Index (SoVI) by scrutinising the relationship between spatial patterns of social vulnerability and environmental hazards at the sub-local level (county) in the United States. This index identifies potential social burdens (e.g. Flanagan et al,'s (2011) social vulnerability index for disaster management) and for this reason, it was initially used by the construction industry. Firstly, the SoVI was calculated for several accumulations and with a subdivision of the distinctive variables to define the impact of scalar and variable changes in index construction; secondly, to test the sensitivity of the algorithm to changes in construction and to determine if that sensitivity was constant in different geographic circumstances or not.

\subsubsection{Economic vulnerability index}

The United Nations Development, Policy, and Analysing Division (DESA) developed the Economic Vulnerability Index (EVI). It evaluates the structural vulnerability of countries to economic and environmental risk. However, several versions of the EVI index have been produced in recent years and applied to diverse geographical zones (Briguglio, 1995; Briguglio and Galea, 2003; Guillaumont, 2009). The EVI comprises eight socio-economic indicators, which are assembled into several sub-groups (Figure 2.12). The primary aim of EVI is to be applicable at least to developed countries.

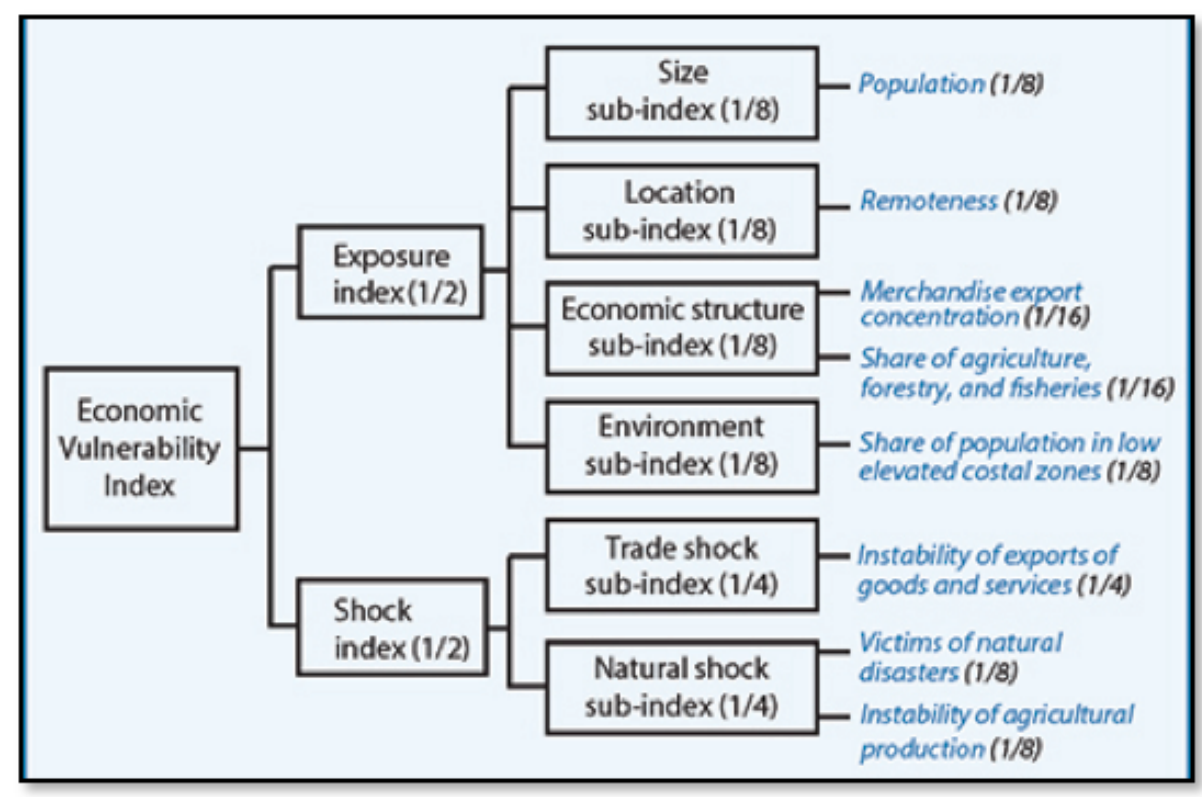

Figure 2.12: Structure o Structure of ECVI

Source: DESA, 2014 


\subsubsection{Flood vulnerability index}

Balica et al. (2012) developed Flood Vulnerability Index, which is also called as City Coastal Flood Vulnerability Index (CCFVI; equation 1). The CCFVI model was constructed based on exposure (E) susceptibility (S) and resilience (R) factors and applied to 9 cities around the world, each with different levels of exposure. The index gives a number from 0 to 1 , representing relatively low or high coastal flood vulnerability, which displays which cities are in maximum need of additional, more detailed investigation for the needs of decisionmakers. With the help of this index, it can be established which cities are greatly vulnerable to coastal flooding with regard to the system's components, i.e. socio-economic, hydrogeological, and politico-administrative. The vulnerability index gives a number from 0 to 1 , demonstrating comparatively lower or higher coastal flood vulnerability, which displays which cities are most in need of further and more comprehensive examinations for decisionmakers. Once the establishment of flood vulnerability index is finished, it is used to scrutinize the climate change impacts on the vulnerability of these cities over a longer period.

$$
F V I=\frac{E \times S}{R}
$$

\subsubsection{Livelihood vulnerability index}

Hahn et al. (2009) established the Livelihood Vulnerability Index (LVI), which is used to estimate climate change vulnerability. Primarily, this was applied to Mabote and Moma Districts of Mozambique. Accordingly, researchers surveyed 200 households in each district to collect data on livelihoods, water security, socio-demographics, social networks, health, food, natural disasters, and climate variability. Data was analysed by using a composite index and differential vulnerabilities.

\subsubsection{Climate vulnerability index}

Sullivan and Meigh (2005) developed the Climate Vulnerability Index (CVI), and it contains a descriptive range of social and physical structures. The CVI emphasises primarily waterrelated subjects, but it is also relevant to vulnerability issues. The objective of this index is to validate the possibility for construction vulnerability valuations by the CVI. It is also extendable to large areas and contains six key components, and the range is between 0 and 100. 


\subsubsection{Environmental vulnerability index}

The Environmental Vulnerability Index (EVI) is an amalgamation framework for understanding the environmental vulnerability of various countries, which was developed by Kaly and Commission (1999) with the support of the South Pacific Applied Geoscience Commission. The EVI consists of 50 indicators, which are called smart indicators and are used to assess the vulnerability of the environment. These indicators represent the degradation and risk for the environment. EVI contains 5 groups: extremely vulnerable (1), highly vulnerable (2), vulnerable (3), at risk (4) and resilient (5). However, this index is only applied to limited small-island countries.

\subsubsection{Multi-scale coastal vulnerability index}

McLaughlin and Cooper (2010) established a multi-scale CVI for assessing erosion impacts. It is also applicable to other climate change influenced impacts. The index assimilates three sub-indices:

Coastal characteristic sub-index

Coastal forcing sub-index

Socio-economic sub-index
Defining the resilience and coastal susceptibility to erosion

Describing the forcing variables subsidising to wave-induced erosion Defining targets potentially at risk

The calculation of every sub-index is constructed on the source of several variables, and its definite identification (number and typology), which depends on the measured application scale. Figure 2.13 demonstrates the variables applied to obtain the three sub-indices in Northern Ireland at the national level (McLaughlin and Cooper, 2002; McLaughlin and Cooper, 2010). The same authors applied the CVI index (and the sub-indices) at the regional and local levels also. However, for these cases, a variety of variables were used. 


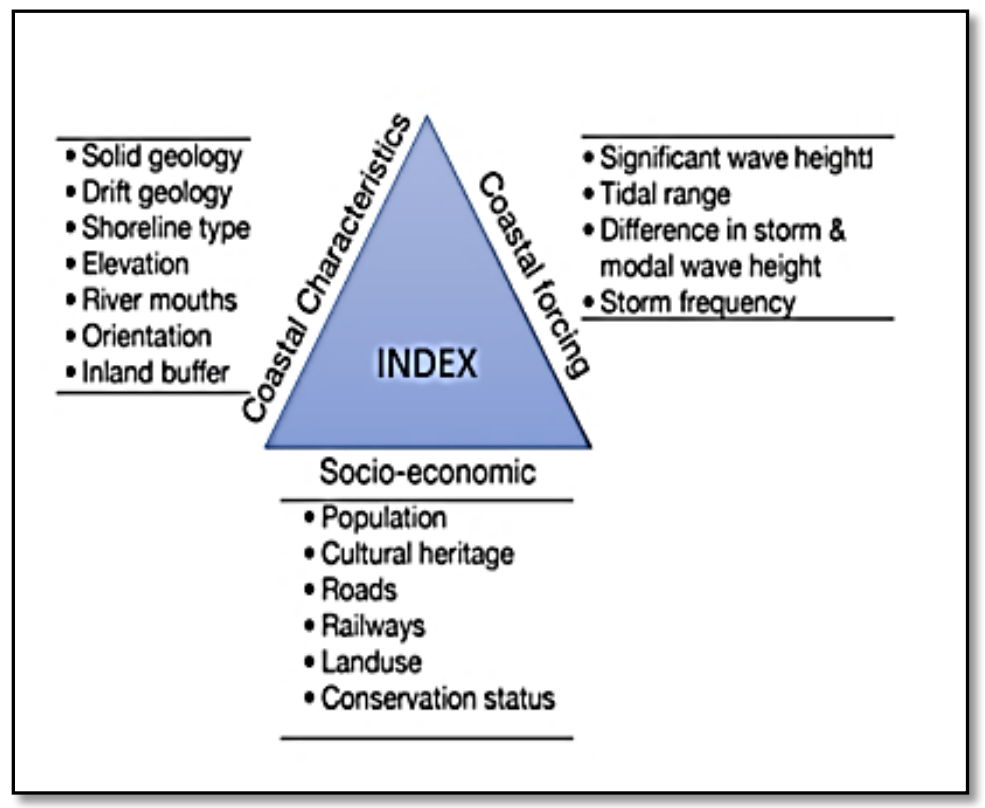

Figure. 2.13: Variables of CVI

Source: Modified from McLaughlin and Cooper, 2010

The recognised variables are further classified according to a 1-5 scale based upon Gornitz (1990) methodology in order to assess the achievements of the coastal vulnerability system, assigning it values from 1 (lowest value) to 5 (highest value).

Table 2.6 demonstrates the matrix used to categorise the three sub-indices variables in McLaughlin and Cooper (2010). The 1-5 scale permits the arithmetic amalgamation of different variables. Sub-indices are computed with the sum of the values of the relative variables; the figure obtained is further standardised to the range of 0-100.

The nationwide applications of this study, which was conducted in Northern Ireland, are measured and shown in Table 2.6

The sub-indices use the subsequent formulations:

Coastal classification $(\mathrm{CC})$ sub-index $=($ sum of CC var. $)-7] / 28\} \times 100$

Coastal forcing $(\mathrm{CF})$ sub-index $=\{[($ sum of CF var. $)-4] / 16\} \times 100$

Socio-economic $(\mathrm{SE})$ sub-index $=\{[($ sum of SE var. $)-6] / 24\} \times 100$

The final CVI index is calculated as the average of the values of the three sub-indices:

$$
\mathrm{CVI}=(\mathrm{CC} \text { sub-index }+\mathrm{CF} \text { sub-index }+\mathrm{SE} \text { sub-index }) / 3
$$

CVI values can be envisioned as a colour-coded vulnerability map. This CVI index is simple and easy to calculate and can be applied easily to several spatial scales. Consequently, 
supportive multi-scale analysis is vital for coastal planning and management (McLaughlin and Copper, 2010). In addition to the explanation of physical components, the CVI also assimilates socio-economic components. This element does not always significantly impact the whole index score. 
Table. 2.6 Matrix for the Variable Ranking and Calculation of 3 Sub-Indexes for the Northern Ireland

Reproduced from McLaughlin and Cooper, 2010

\begin{tabular}{|c|c|c|c|c|c|c|}
\hline $\begin{array}{l}\text { Sub- } \\
\text { Inde } \\
x\end{array}$ & Variable & 1 & 2 & 3 & 4 & 5 \\
\hline \multirow[t]{7}{*}{$\mathrm{CC}$} & $\begin{array}{l}\text { Shoreline } \\
\text { Type }\end{array}$ & $\begin{array}{l}\text { High } \\
(>40 \mathrm{~m})\end{array} \quad$ Cliff & $\begin{array}{l}\text { Medium Cliff } \\
(20-20 \mathrm{~m})\end{array}$ & $\begin{array}{l}\text { Low Cliff } \\
(10-20 \mathrm{~m})\end{array}$ & $\begin{array}{l}\text { Shingle } \\
\text { Ridge/Bar }\end{array}$ & Sand Beach \\
\hline & Rivers & Absent & & & & Present \\
\hline & $\begin{array}{l}\text { Solid } \\
\text { Geology }\end{array}$ & $\begin{array}{l}\text { Plutonic, } \\
\text { volcanic, } \\
\text { high-medium } \\
\text { grade } \\
\text { metamorphic } \\
\text { s }\end{array}$ & $\begin{array}{l}\text { Low-grade } \\
\text { metamorphics } \\
\text { sandstone and } \\
\text { conglomerate } \\
\text { well } \\
\text { cemented }\end{array}$ & $\begin{array}{l}\text { Most } \\
\text { sedimentary } \\
\text { rocks }\end{array}$ & $\begin{array}{l}\text { Coarse and/or } \\
\text { poorly } \\
\text { sorted } \\
\text { unconsolidate } \\
\text { d } \\
\text { sediments }\end{array}$ & $\begin{array}{l}\text { Fine } \\
\text { unconsolidate } \\
\text { d sediment, } \\
\text { volcanic ash }\end{array}$ \\
\hline & $\begin{array}{l}\text { Drift } \\
\text { Geology }\end{array}$ & $\begin{array}{l}\text { Bedrock, } \\
\text { urban }\end{array}$ & $\begin{array}{l}\text { Till/boulder, } \\
\text { clay }\end{array}$ & & $\begin{array}{l}\text { Raised beach, } \\
\text { deposits }\end{array}$ & $\begin{array}{l}\text { Alluvium, } \\
\text { blown sand, } \\
\text { peat, glacial } \\
\text { sands and } \\
\text { gravels, glacial } \\
\text { outwash } \\
\text { sands, recent } \\
\text { marine }\end{array}$ \\
\hline & Elevation & $>30$ & $20-30$ & $10-20$ & $5-10$ & $<5$ \\
\hline & Orientation & $\begin{array}{l}\text { Not relevant, } \\
\text { e.g. sea } \\
\text { Loughs }\end{array}$ & & Easterly & & Northerly \\
\hline & $\begin{array}{l}\text { Inland } \\
\text { Buffer }\end{array}$ & $\begin{array}{l}500-1000 \mathrm{~m} \\
\text { inland }\end{array}$ & & & & $0-500 \mathrm{~m}$ inland \\
\hline \multirow[t]{6}{*}{$\mathbf{C F}$} & Significant & $0-0.74 \mathrm{~N}$ & $0.74-1.49 \mathrm{~N}$ & $1.49-2.23 \mathrm{~N}$ & $2.23-2.98 \mathrm{~N}$ & $>2.98 \mathrm{~N}$ \\
\hline & Wave hieght & $0-0.24 \mathrm{E}$ & $0.24-0.48 \mathrm{E}$ & $0.48-0.72 \mathrm{E}$ & $0.72-0.96 \mathrm{E}$ & $>0.96 \mathrm{E}$ \\
\hline & Tidal range & $>5$ & $3,5-5$ & $2-3,5$ & $1-2$ & $<1$ \\
\hline & Difference in & $<0.10 \mathrm{~N}$ & $0.10-1.70 \mathrm{~N}$ & $1.70-3.30 \mathrm{~N}$ & $3.30-4.90 \mathrm{~N}$ & $>4.9 \mathrm{~N}$ \\
\hline & $\begin{array}{l}\text { model and } \\
\text { storm waves }\end{array}$ & $<0.10 \mathrm{~S}$ & $0.10-0.25 \mathrm{~S}$ & $0.25-0.40 \mathrm{~S}$ & $0.40-0.55 \mathrm{~S}$ & $>0.55 \mathrm{~S}$ \\
\hline & $\begin{array}{l}\text { Frequency of } \\
\text { onshore } \\
\text { storms }\end{array}$ & $0-2.8$ & $2.8-5.6$ & $5.6-8.4$ & $8.4-11.2$ & $>11.2$ \\
\hline \multirow[t]{5}{*}{ SE } & $\begin{array}{l}\text { Settlement } \\
\text { Cultural } \\
\text { Heritage }\end{array}$ & $\begin{array}{l}\text { No settlement } \\
\text { Absent }\end{array}$ & Village & Small town & Large town & $\begin{array}{l}\text { City } \\
\text { Present }\end{array}$ \\
\hline & Roads & Absent & & A-class & & $\begin{array}{l}\text { Motorway, } \\
\text { dual, } \\
\text { carriageway }\end{array}$ \\
\hline & Railways & Absent & & & & Present \\
\hline & Land use & $\begin{array}{l}\text { Water bodies, } \\
\text { marsh/bog } \\
\text { and moor, } \\
\text { sparsely } \\
\text { vegetated } \\
\text { areas, bare } \\
\text { rocks }\end{array}$ & $\begin{array}{l}\text { Natural } \\
\text { grasslands, } \\
\text { coastal areas }\end{array}$ & Forest & Agriculture & $\begin{array}{l}\text { Urban and } \\
\text { industrial } \\
\text { Infrastructure }\end{array}$ \\
\hline & $\begin{array}{l}\text { Conservatio } \\
\mathrm{n} \text { designation }\end{array}$ & Absent & & $\begin{array}{l}\text { Internationa } \\
1\end{array}$ & & National \\
\hline
\end{tabular}




\subsection{Advantages and disadvantages of the coastal vulnerability methodologies}

Indicators and index-based methods are simple tools to implement. However, their use and application at various capacities fundamentally depend on the availability and quality of data. Modifications of the approaches may also be required in order to address appropriate features in certain areas. Indicators or index-based methods are valuable techniques for supporting the identification of significant vulnerable coastal zones and systems but are not beneficial for a more comprehensive quantifiable appraisal of coastal vulnerability (Harrison et al., 2013). However, the simple methodological procedures make CVI index methods valuable for communication purposes. On the whole, indicator methods are quite useful to evaluate coastal vulnerability in greater scales, mostly in economic aspects (Eg: Balica et al., 2012). Index methods are useful for an assessment of vulnerability and coastal risk in both small (Eg: Kumar et al., 2010; Denner et al., 2015) and larger scales (Thieler and Klose, 1999; Romieu et al., 2010) within physical aspects.

\subsection{Damage costs impact on the economy}

Global natural disasters significantly impact coastal economies. Geographical variations can decrease the global economy at various magnitudes (Lumsdaine and Prasad, 2003). The world's economy is interlinked with climate change, extreme weather variations, and other climate-related factors (Stern, 2007). Hurricane Sandy caused $£ 57$ billion damages and reduced the GDP in the USA in 2012 by $0.2 \%$ (Kantamaneni and Phillips, 2013). Moreover, the recent flood, as well as extreme weather events in Britain, significantly affected the nation's GDP growth rate (Kantamaneni and Phillips, 2013).

Samuel Henry Prince, a father of disaster studies in the social sciences, offered a systematic description of the Canada Halifax Harbour explosion in 1917 (Prince, 1920). Since then, several scientists have focused their interest on natural disasters. However, chronological records and statistics regarding extreme weather events in the natural environment revealed that the frequency of disasters increased during the 21 st century (Seneviratne et al., 2012). However, in the late 20th century, occurrences of natural disasters doubled, and economic damage costs far exceeded estimations (Re, 2007). In welldeveloped countries, such as the US and the UK, natural disasters cause high levels of physical damage and fewer fatalities, but in the developing world, the loss of human life is greater. From 1974 to 2003, two million people died, and more than 180 million people became homeless due to natural disasters (Guha-Sapir et al., 2004). 
Accordingly, this research focuses on the evaluation of coastal vulnerability of the UK (in selected sites), which is associated with extreme weather events such as floods and coastal erosion and properties within the physical and economic perspectives. Consequently, detailed information on the aforementioned issues will be quoted in subsequent chapters with complete statistics and figures. 


\subsection{Summary}

The literature review analysed and explored existing research related to coastal vulnerability and assessment frameworks such as index and indicator methods, climate change, storms (floods and hurricanes), and their costs and economic consequences. Most research has concentrated on various geomorphological variables/parameters. However, there are no standardised, combined CVI methods to measure the physical and economic impact of coastal vulnerability at all levels. These research gaps are strongly associated with vulnerability aspects but to address these at a regional level and more precise information would need to be collected. While, this chapter reviewed current literature concentrating on coastal vulnerability aspects worldwide, Chapter 3 focuses on the physical and economic geography of the UK. 


\section{CHAPTER 3 - PHYSICAL AND ECONOMIC GEOGRAPHY}




\section{Physical and Economic Geography}

\subsection{Introduction}

The literature review (Chapter 2) dealt with various issues of climate change, coastal vulnerability and economic consequences and the current research thinking with regard to the evaluation of coastline vulnerability on a global scale. This chapter reviews current literature detailing the geography, seal level rise, winds, temperature trends, coastal erosion, floods, environmental forcing and coastal vulnerability of the UK.

\subsection{Geography}

The UK with its moderately temperate climate (Easterling et al., 2000), is an Island nation located in Western Europe and made up of four countries, Wales, England, Scotland and Northern Ireland (Figure 3.1). The total area of the UK is $243,610 \mathrm{~km}^{2}$ comprising of $241,930 \mathrm{~km}^{2}$ land and $1,680 \mathrm{~km}^{2}$ of water, with a population of circa 63 million (The World Bank, 2014). Bounded by four bodies of water, the English Channel, the North Sea, Irish Sea and Atlantic Ocean (Mackinder, 1907), UK coastline measured 17,381 km in length (Masselink and Russell, 2013). The UK coast is one of the diverse coasts in the Europe and hugely developed with massive urbanisation and industrialisation especially at Southeast (Ballinger, 2002). Most of the infrastructure located near to the coast is severely affected by coastal erosion and flooding (Phillips and Jones, 2006) in some coastal regions. Recent climate change variations increase the risk of flooding and extreme weather events (Easterling et al., 2000). 


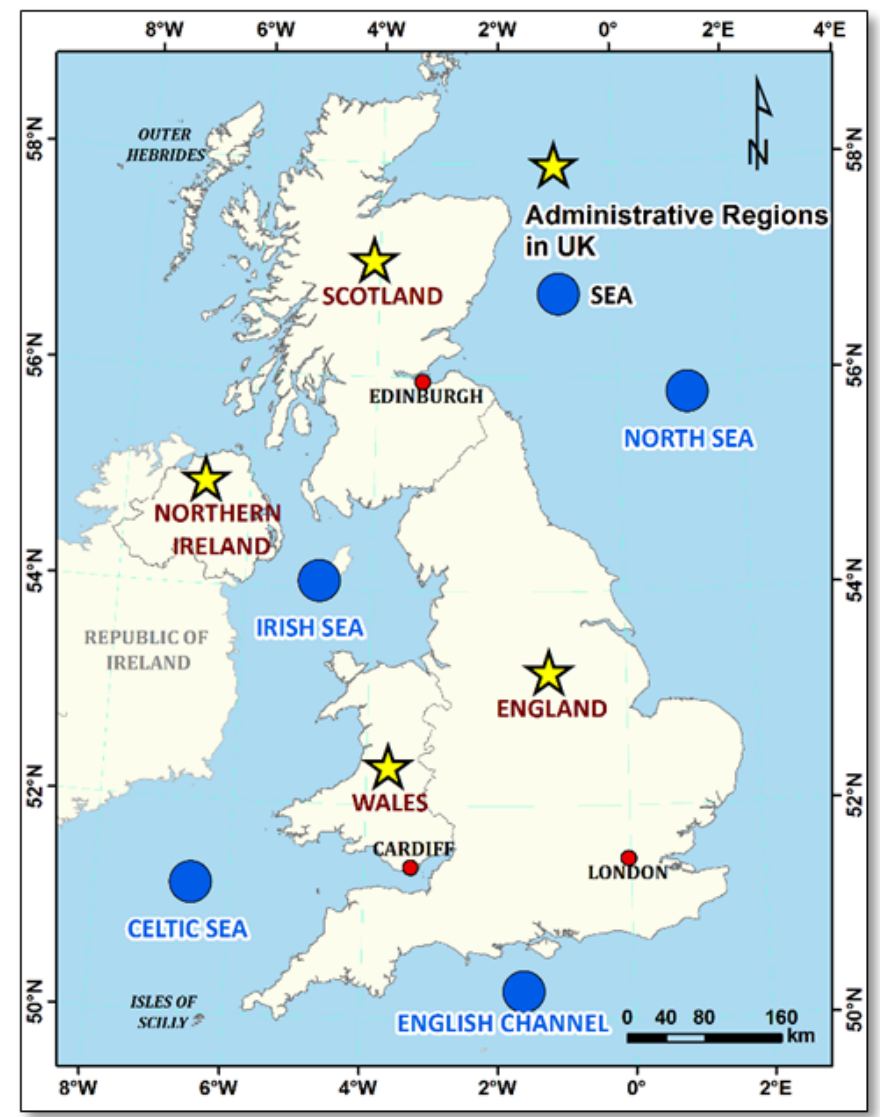

Figure 3.1: The UK with Sea Boundaries

\subsection{Sea level rise}

Global warming and rising sea levels are the strongest reasons for the local sea-level rise (LSL) (French, 1993; Gornitz et al., 1994). It creates dangerous scenarios for the population as well as properties, particularly in coastal areas in the form of coastal floods, erosion and storm surges (Nicholls, 2007). Globally, sea levels have risen almost $20 \mathrm{~cm}$ since the mid$19^{\text {th }}$ century (Douglas, 2001), these trends are in line with other research results (Antunes and Taborda (2009) and the UK climate projections (UKCP09). These global trends influence the UK especially along the Norfolk and Suffolk coastlines in southeast England, where records show a historic rising trend (Doody, 2004a; Pye and Blot, 2006; Brooks and Spencer, 2012). In recent decades, sea levels have risen by circa $2 \mathrm{~mm} \mathrm{yr}^{-1}$ at Lowestoft, circa $1.2 \mathrm{~mm}$ at Newlyn (Cannell et al., 2004) and in a recent comprehensive review of tide gauge data for the Bristol Channel and Severn Estuary by Phillips and Crisp (2010) concluded that there had been a detectible rise in mean sea levels and indicated a rise in the order of $30 \mathrm{~cm}$ by 2050 , and a rising trend of $2.4 \mathrm{~mm} / \mathrm{yr}^{-1}$. 
Meanwhile, the rise in local sea level creates increased risk at many locations around the UK (Table 3.1) and this is of concern considering that more than $40 \%$ of energy and manufacturing industries and in excess of $50 \%$ of fertile agricultural land are located close (within $10 \mathrm{~km}$ ) to the coast (Nicholls and Small, 2002).

Table. 3.1: Current and predicted SLR at various locations around the UK

Reproduced from UKCIP (December 2010)

\begin{tabular}{llllllllllllll}
\hline & \multicolumn{3}{l}{ London } & \multicolumn{3}{l}{ Cardiff } & \multicolumn{3}{c}{ Edinburgh } & \multicolumn{3}{c}{ Belfast } \\
\cline { 2 - 13 } & High & Med & Low & High & Med & Low & High & Med & Low & High & Med & Low \\
& & & & & & & & & & & & \\
$\mathbf{2 0 0 0}$ & 3.5 & 3.0 & 2.5 & 3.5 & 2.9 & 2.5 & 2.2 & 1.6 & 1.2 & 2.3 & 1.7 & 1.3 \\
$\mathbf{2 0 1 0}$ & 7.3 & 6.2 & 5.3 & 7.3 & 6.2 & 5.3 & 4.7 & 3.5 & 2.6 & 4.9 & 3.8 & 2.8 \\
$\mathbf{2 0 2 0}$ & 11.5 & 9.7 & 8.2 & 11.5 & 9.7 & 8.2 & 7.5 & 5.7 & 4.3 & 7.8 & 6.0 & 4.6 \\
$\mathbf{2 0 3 0}$ & 16.0 & 13.5 & 11.4 & 15.9 & 13.4 & 11.4 & 10.7 & 8.2 & 6.1 & 11.1 & 8.6 & 6.6 \\
$\mathbf{2 0 4 0}$ & 20.8 & 17.5 & 14.8 & 20.8 & 17.5 & 14.8 & 14.2 & 10.9 & 8.2 & 14.7 & 11.4 & 8.7 \\
$\mathbf{2 0 5 0}$ & 25.8 & 21.8 & 18.4 & 25.9 & 21.8 & 18.4 & 18.0 & 13.9 & 10.5 & 18.6 & 14.5 & 11.1 \\
$\mathbf{2 0 6 0}$ & 31.4 & 26.3 & 22.2 & 31.4 & 26.3 & 22.2 & 22.1 & 17.1 & 13.0 & 22.9 & 17.8 & 13.7 \\
$\mathbf{2 0 7 0}$ & 37.2 & 31.2 & 26.3 & 37.1 & 31.1 & 26.3 & 26.6 & 20.6 & 15.7 & 27.4 & 21.4 & 16.5 \\
$\mathbf{2 0 8 0}$ & 43.3 & 36.3 & 30.5 & 43.3 & 36.2 & 30.5 & 31.4 & 24.4 & 18.6 & 32.3 & 25.3 & 19.6 \\
$\mathbf{2 0 9 0}$ & 49.7 & 41.6 & 35.0 & 49.7 & 41.6 & 35.0 & 36.5 & 28.4 & 21.8 & 37.6 & 29.4 & 22.8 \\
$\mathbf{2 0 9 5}$ & 53.1 & 44.4 & 37.3 & 53.1 & 44.4 & 37.3 & 39.2 & 30.5 & 23.4 & 40.3 & 31.6 & 24.5 \\
\hline
\end{tabular}

The range of sea level rise around the UK (before land movements are included) is estimated to be between 12 and $76 \mathrm{~cm}$ for the period 1990-2095. Taking vertical land movement into consideration provides larger sea level rise predictions relative to the land in more southern regions of the UK, where land is collapsing, and somewhat lower upsurges in relative sea level for northern regions (Figure 3.2). 


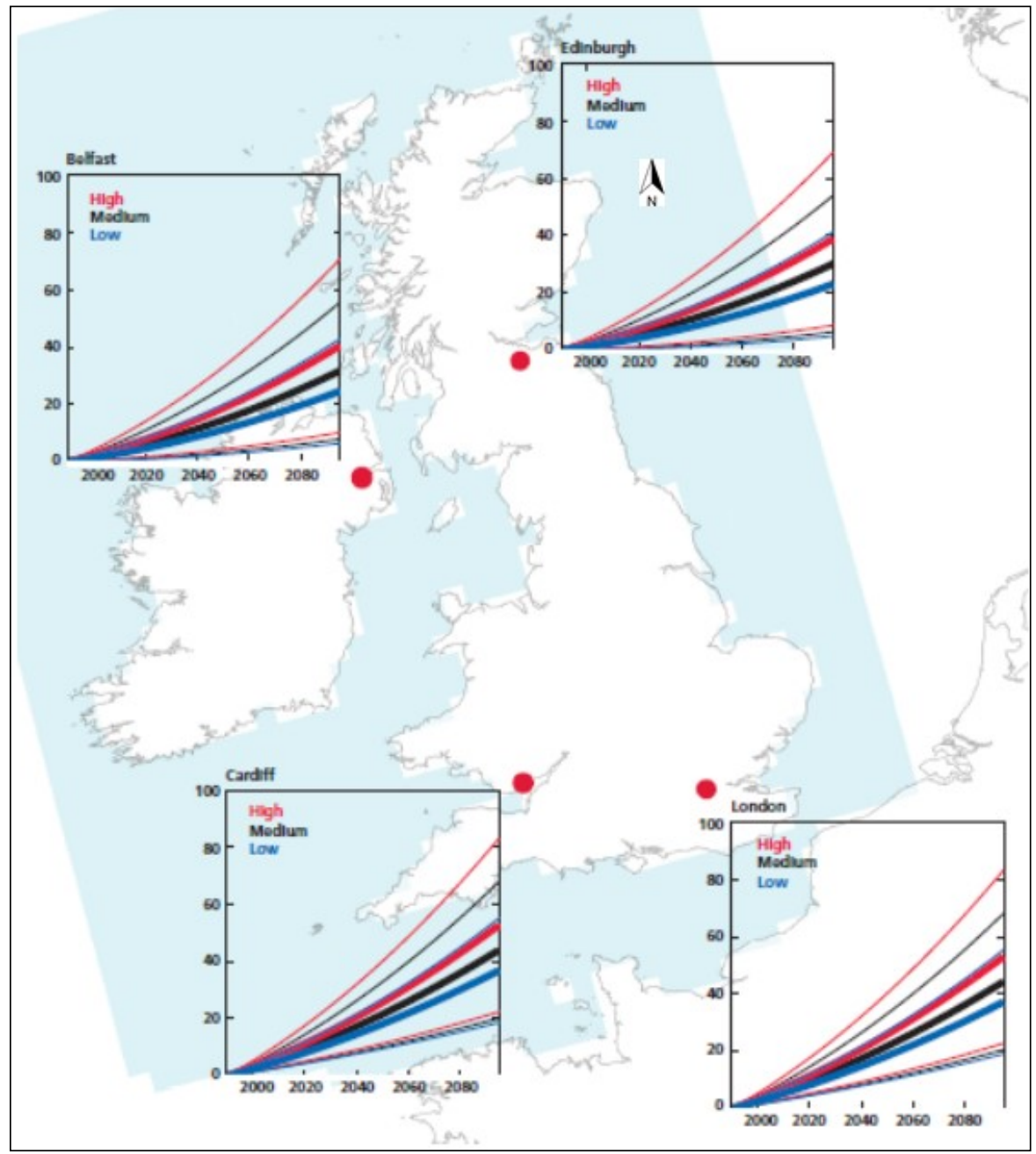

Figure 3.2: Map of UK sea level rise (2000-2080)

Source: UKCIP, 2010

\subsection{Storms}

Frequency and intensity of storms are predicted to increase with the potential to cause significant damage to coastal infrastructure and cause potential economic loss (Benson and Clay, 2004; Nicholls and Kebede, 2011; Slingo et al., 2014). Over the last 60 years, major storm events around the UK have increased (in the terms of damage and intensity) (Allan et al., 2009). However, Rangel-Buitrago et al.'s (2016) work on the Bristol Channel showed that the increasing storminess in the late $20^{\text {th }}$ Century reported by Allan et al. (2009) -(such as Port Talbot) did not as expected continue into the first decades of the $21^{\text {st }}$ century. However, Smith (2013) has predicted that storms and associated coastal and river flooding, along with hurricane winds, will be the greatest threat to the UK in the $21^{\text {st }}$ century. Indeed, December 2013 and January 2014 were the third wettest months since 1910, and December 2013 was the windiest month since 1969 with average wind speed of almost 60 knots (31 
$\mathrm{ms}^{-1}$ ) (Met Office, 2014; Huntingford et al., 2014). Table 3.2 produced from data supplied by the Meteorological Office highlights that 2000 and 2012 were amongst the wettest on record For example between 1981 and 2010 the average yearly rainfall was around 1100 $\mathrm{mm}$, in 2012 the total rainfall was $1,330.7 \mathrm{~mm}$ (Met Office, 2014).

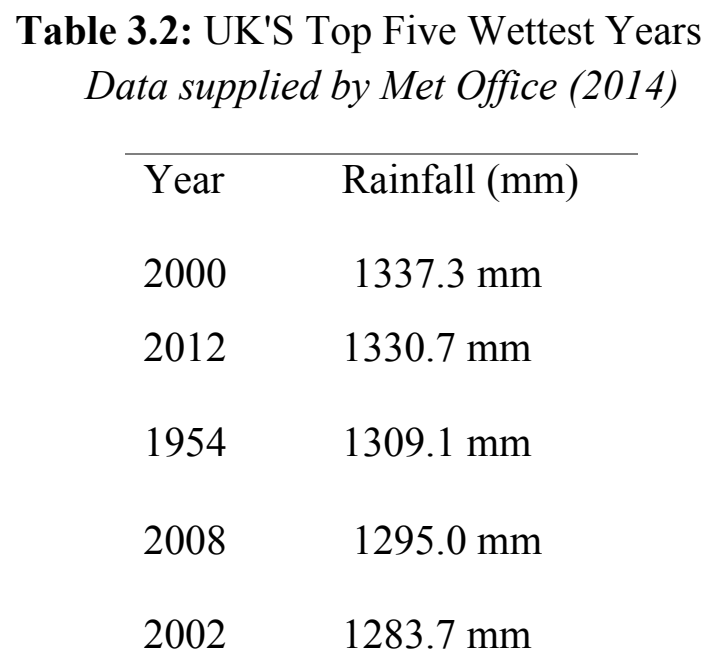

\subsection{Winds}

As previously discussed hurricane scale winds were recorded in December 2013, subjecting the country to an unusually energetic sequence of storms with the highest recorded winds between the $4^{\text {th }}$ and $5^{\text {th }}$ December. Storm surges coupled with high tides caused significant damage around the UK's coastline comparable to the 1953 flood events along the eastern English coastline (Slingo et al., 2014; Met Office, 2014). However, many weather warnings from the Environment Agency and Met Office, as well as coastal defence structures, reduce the intensity of economic damage.

Furthermore, average wind speed for the period between 2000 and 2014 for the UK (25 locations) was $4.84 \mathrm{~ms}^{-1}$, with the highest recorded at Lydd airport $\left(6.6 \mathrm{~ms}^{-1}\right)$, and lowest $>$ $3.3 \mathrm{~ms}^{-1}$ recorded at Southampton (Kantamaneni, 2015; Figures 3.3a and 3.3b). However, the highest wind speeds occur in January $\left(5.4 \mathrm{~ms}^{-1}\right)$ and the lowest in June $\left(4.1 \mathrm{~ms}^{-1}\right)$. The average wind speed is showing an increasing trend, and it rose from $0.1 \mathrm{~ms}^{-1}$ to $3.5 \mathrm{~ms}^{-}$ ${ }^{1}$ for the aforementioned period (Kantamaneni, 2015). 


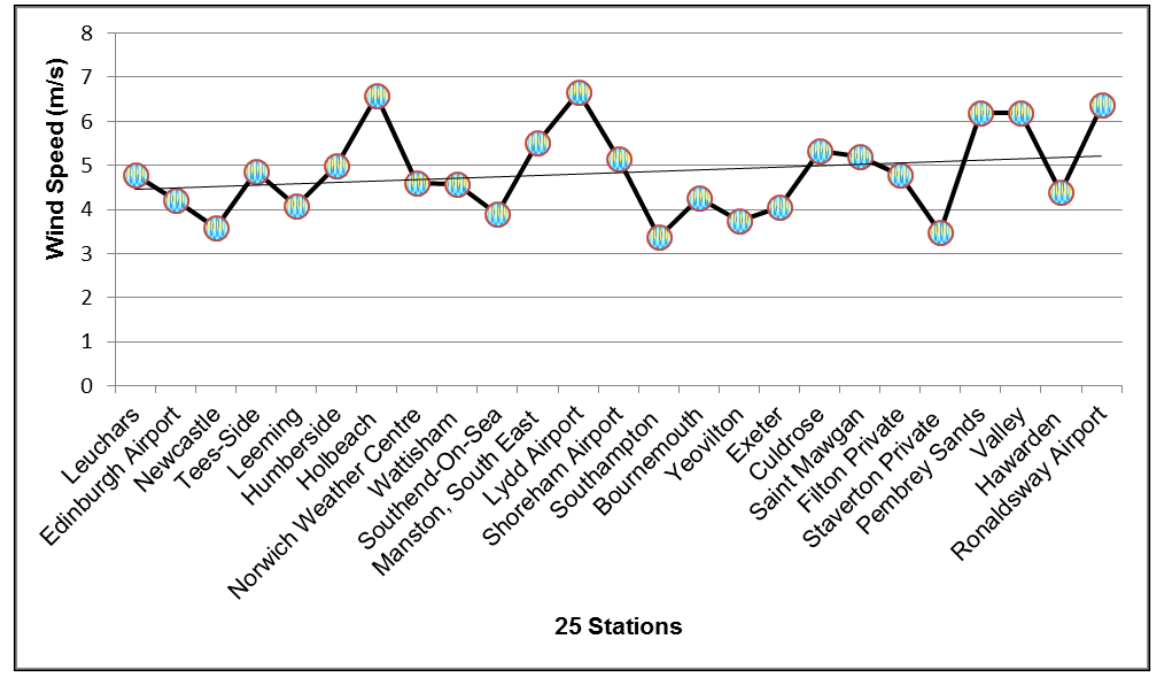

(a)

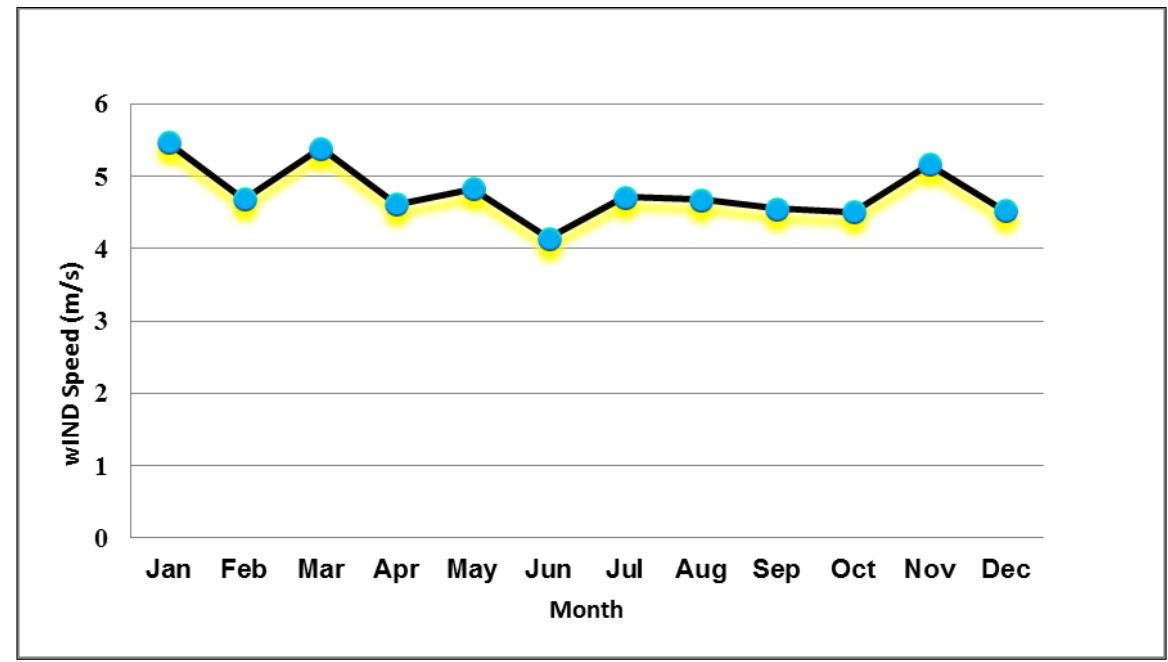

(b)

Figure 3.3: a) Wind speed at 25 stations and b) Average wind speed as per month (20002014)

As previously mentioned, much of the damage caused by the 2013/14 storms was associated to storm surges (Huntingford et al., 2014). For example, In the Bristol Channel (Avonmouth) tide heights in excess of $15 \mathrm{~m}$ were recorded (Met Office, 2014).

\subsection{Temperature}

The global climate is being affected by rising human-induced emissions of greenhouse gases into the atmosphere (Moss et al., 2010), and the United Kingdom is not exempt from those impacts. Greenhouse gases in particular, $\mathrm{CO}_{2}$ emissions, are the primary reason for rapid and recent climate change scenarios (Hulme et al., 2002; Boykoff, 2007; Johnson et al., 2009). $\mathrm{CO}_{2}$ emissions, derived mainly from fossil-fuel combustion, increased by 
more than $40 \%$ from 1990 to 2008, and since the last century, while the earth has warmed by circa $0.7^{\circ} \mathrm{C}$, average UK temperatures have increased by $1^{\circ} \mathrm{C}$ from the mid-1970s (Jenkins and Newborough, 2007). More than 2,000 deaths were recorded in England and Wales during the 2003 August heat wave (Johnson et al., 2005). Accelerated temperature change is expected to become more severe in the future due to human-induced climate forcing (Mitchell et al., 2006).

Average sea surface temperatures (SST) recorded at 25 locations between 2000 and 2014 around the $\mathrm{UK}$ is $11.8^{\circ} \mathrm{C}$; the highest temperature was $12.6^{\circ} \mathrm{C}$, which was recorded in 2007 , and the lowest was $11^{\circ} \mathrm{C}$, which was recorded in 2010 (Figure 3.4a \& b; Kantamaneni, 2015). It is quite evident that there are increasing SST trends in UK. Overall, in fifteen years, regional sea surface temperatures rose from $0.1^{0} \mathrm{C}$ to $0.7^{0} \mathrm{C}$ (Kantamaneni, 2015). However, the trends of 2013 and 2014 are unclear, currently, because of lack of an incomplete dataset. Between 2000 and 2014 SST's varied at the 25 recording locations around the UK. The highest temperature recorded was $15.3^{\circ} \mathrm{C}$ in Tilbury PS, and the lowest was $9.2^{\circ} \mathrm{C}$, recorded at Whitehaven (Figure 3.4a).

Figure $3.4 \mathrm{~b}$ shows the average annual sea level temperature recorded at the 25 locations around the UK for the period between 2000 and 2014. Despite predicted increases and in line with Rangel -Buitrago et al.'s (2016) storm work, SST's rose from the beginning of the century until 2007 and then a lowering trend was observed until the end of the assessment period.

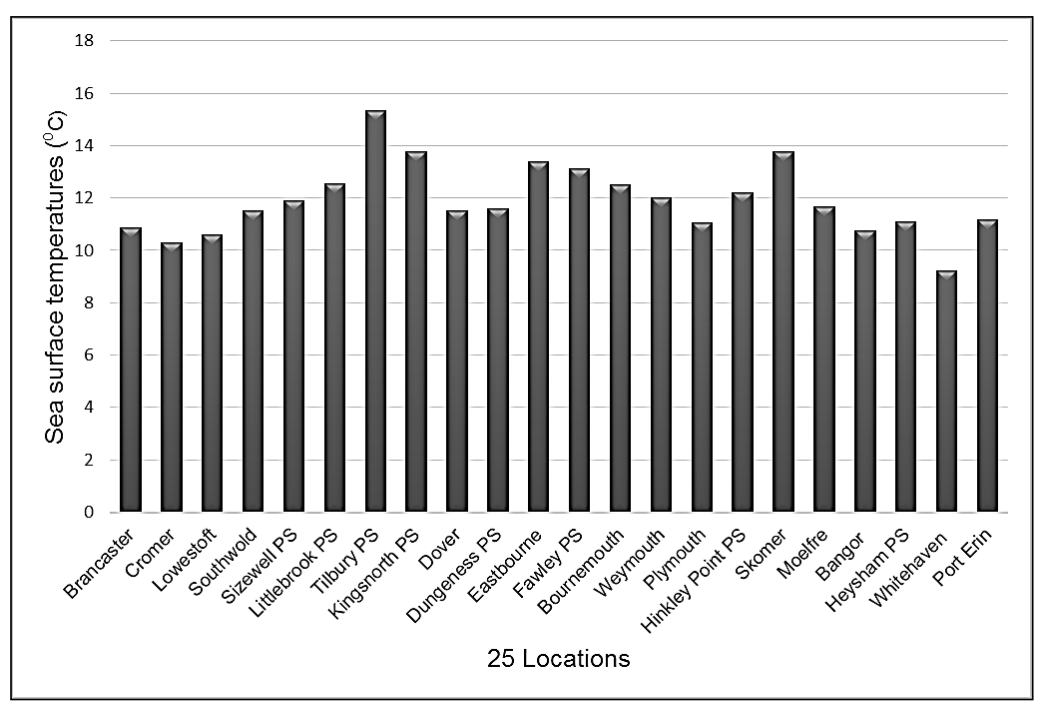

(a) 


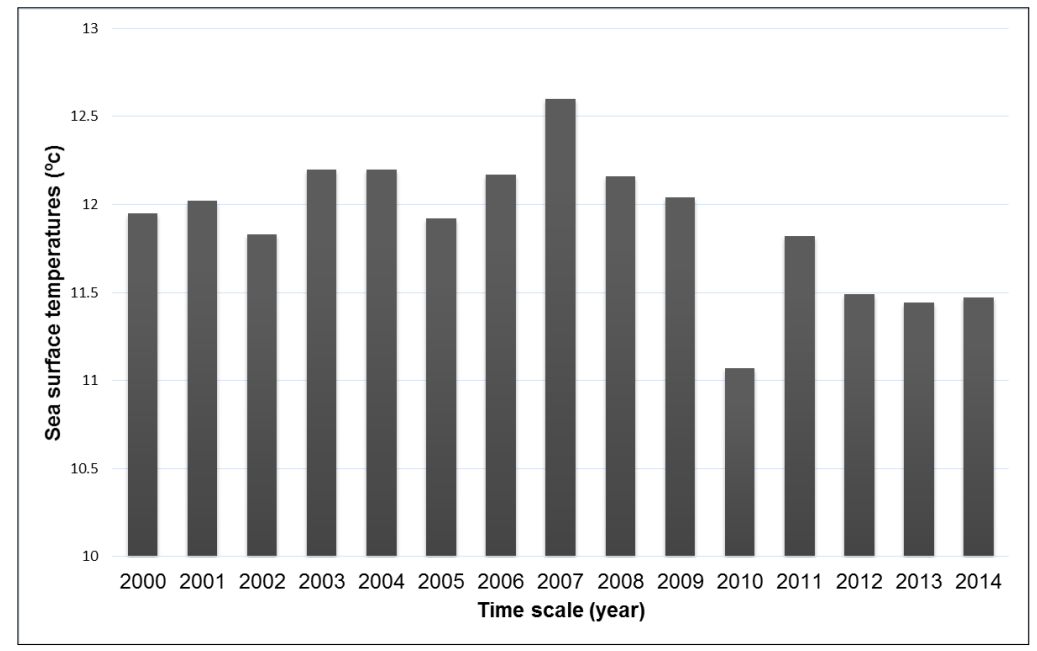

(b)

Figure 3.4: a) Average sea surface temperature trends for the period of 2000-2014 at 25 locations around the UK and b) Annual average sea level temperatures

Source: Kantamaneni, 2016

\subsection{Developed coastlines and coastal vulnerability indices}

In the UK, more than $50 \%$ of the population live and work near the coastline (Dorling and Thomas, 2004; McGranahan et al., 2007). Every year, the UK's coasts, particularly attract tourists from all over the world, crucial to many regional economies and contributing generate up the national economy (Gormsen, 1997; Davenport and Davenport, 2006). Ninety percentage of trade commutes through seaports (Warwick University, 2010), and maritime industries and service sectors contribute more than $£ 17$ billion annually to the UK's economy, with the figure expected to rise to as much as $£ 25$ billion by 2020 (Marine Industries Leadership Council, 2010). The maritime service sector contributed circa $1 \%$ to the national GDP and $£ 2.7$ billion in tax revenue in 2011 (Economics, 2013). Continuous occupation and rapid population growth within UK coastal areas have aggravated current risks of coastal flooding and erosion (Dodman, 2009; Figure 3.5). Furthermore, nearly 3008 $\mathrm{km}$ are currently undergoing erosion, (Doody, 2004b; 2013). Engineering structures protect an additional $3185 \mathrm{~km}$ of the coastline, and recent research reveals that the rate and pace of erosion across the UK are moderate (EUROSION, 2004; Masselink and Russell, 2011). 


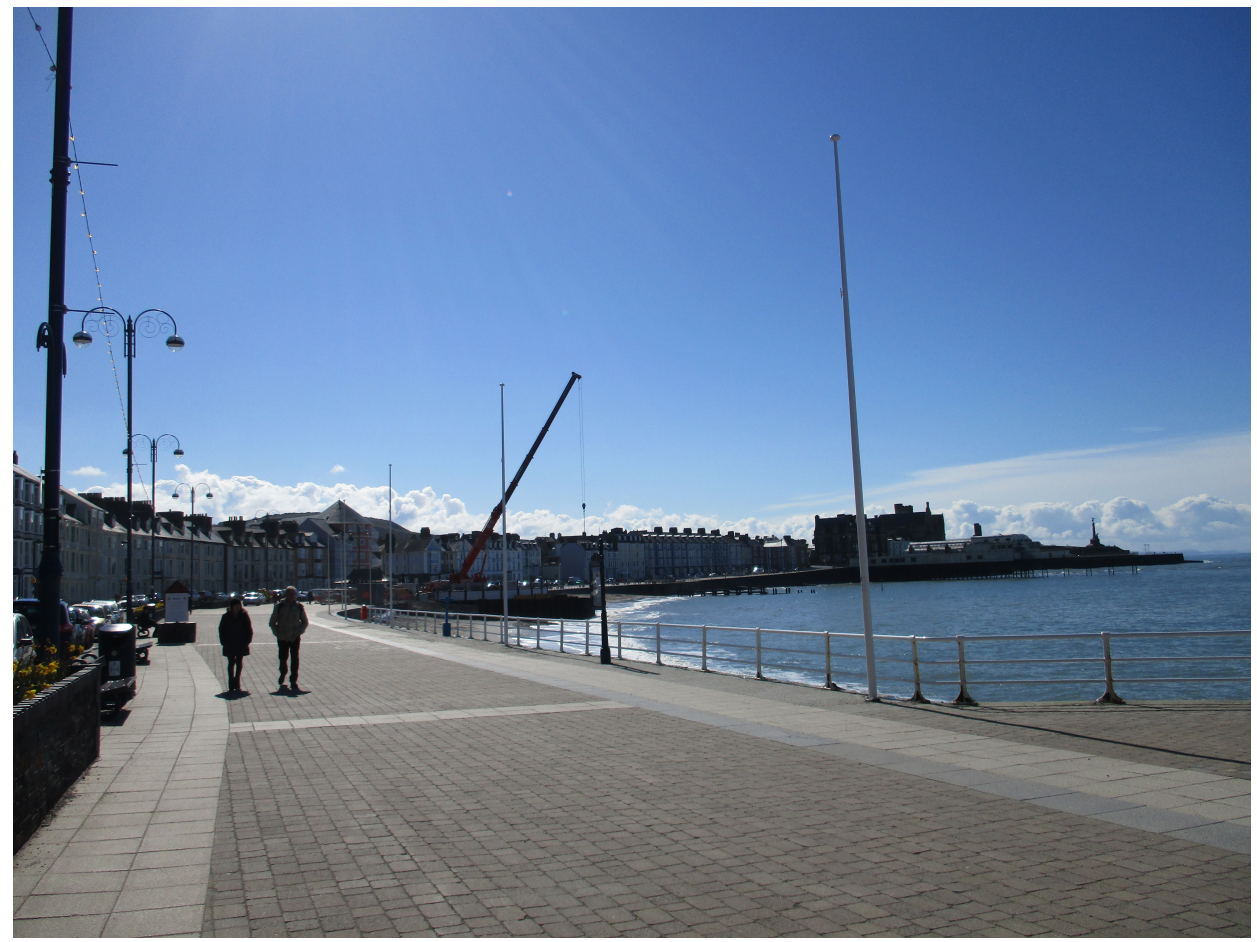

Figure 3.5: Developed Coastline (Aberystwyth)

\subsubsection{Coastal vulnerability indices}

As mentioned in Chapter 2 (Section 2.3), there are many existing methodologies across the globe to evaluate coastal vulnerability, but not in the UK. However, very few studies (McLaughlin and Cooper, 2010; Denner et al., 2015) focused on physical aspects of coastal susceptibility at regional scales (Northern Ireland and Llanelli). In those frameworks, the multi scale coastal vulnerability index was important and it was explained elaborately in Section 2.13.5.

\subsection{History of floods in the UK}

Floods are part of the UK's coastal environment, and it is accepted that it is not technically possible or economically feasible to protect all assets from flooding (Johnson et al., 2007). Prolonged time series data can play a vital role in understanding flood intensity in multiple dimensions (Kochel and Baker, 1982; Merz et al., 2010). However, the majority of universal flood records are no older than 50 years (Macklin, 2006). Human loss on a large scale is uncommon in the United Kingdom, but previously, significant events have occurred. Thousands of deaths were recorded during the Bristol Channel floods ( $30^{\text {th }}$ of January 1607) and Great storm of Britain $\left(26^{\text {th }}\right.$ November 1703$)$. These two events cumulatively accounted for $>15,000$ deaths (BBC, 2003; 2007). However, detailed recording of UK flood damage costs only commenced in 2007 and the Environment Agency now holds an extensive freely available database detailing both sustained damage and economic costs for England. 
However, Environment Agencies and other government organisations such as Natural Resource Wales, record the data regarding storms and other related events that occur across the country. They also map the flood risk areas as shown in Figure 3.6.

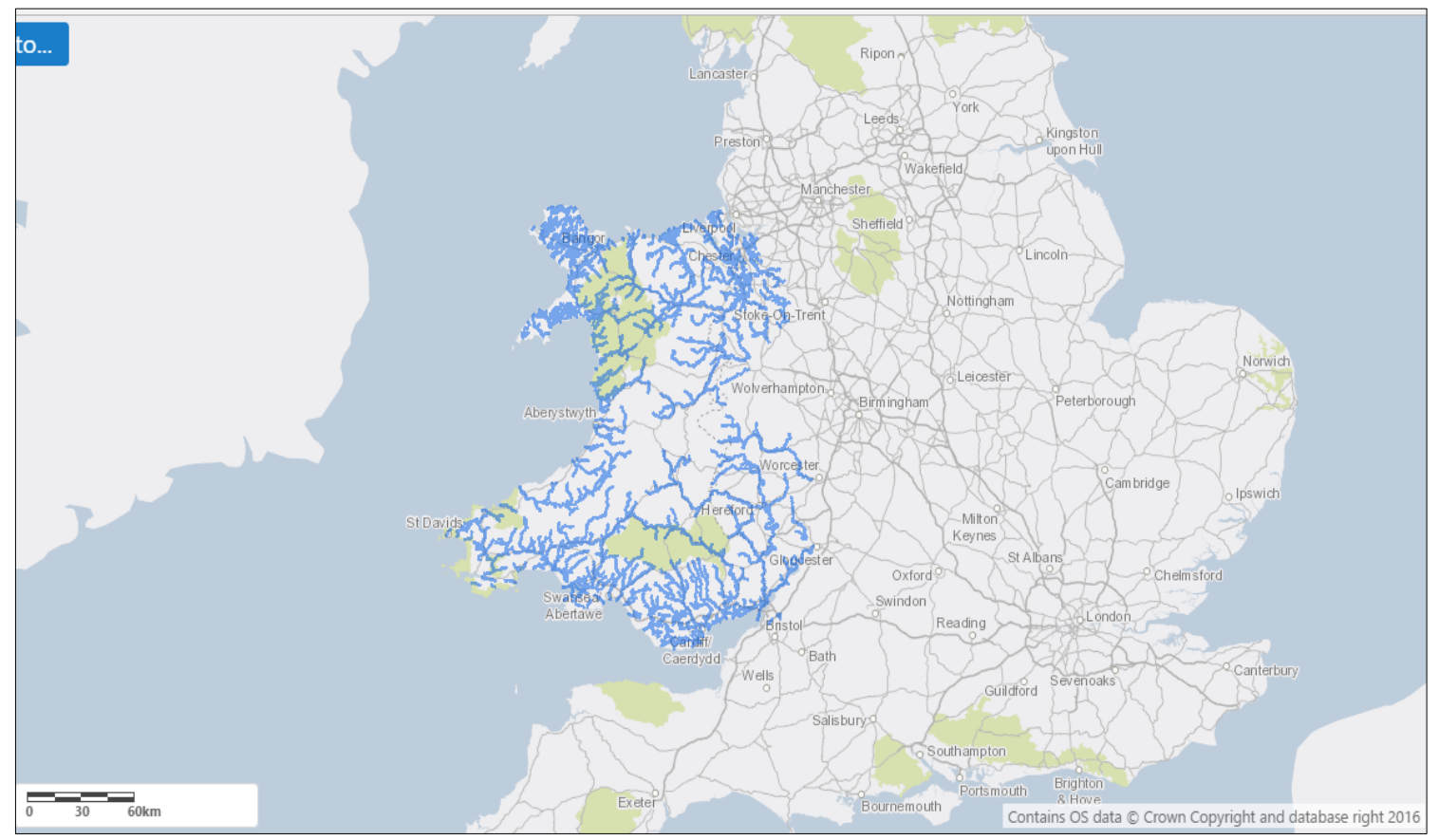

Figure. 3.6: Flood risk map -Wales

Source: Natural Resource Wales, 2016

As an example, in 1952, a natural disaster/flood struck the small coastal town of Lynmouth (Devon, England) and destroyed 100 buildings (Figure 3.7) 28 bridges, and additional commercial properties (Dobbie and Wolf, 1953). In 1953, North Sea floods struck England and Scotland and caused damage to $1,600 \mathrm{~km}$ of coastline and 24,000 residential properties (Met Office, 2015) while in April 1998, heavy rain struck the Midlands, causing heavy flooding with approximately 4,200 houses and business affected and costing $£ 350$ million (McEwen et al., 2002). Moreover, in autumn 2000, major floods affected England and Wales and caused $£ 1$ billion of damage with approximately 10,000 houses damaged, railway links washed away, and highways and power supplies cut off (Marsh and Dale, 2002; Pall et al., 2011; Alexander and Jones, 2000). In 2007, heavy summer rain caused extensive flooding in parts of England, particularly south and East Yorkshire, Worcestershire, Gloucestershire, and Oxfordshire. Significantly, there was unprecedented flooding of assets and infrastructure in some areas, and the resulting disruption, economic loss, and social anguish turned the summer 2007 floods into a nationwide catastrophe. Estimates, prepared shortly after the floods, indicated total losses at circa $£ 4$ billion, of which insured losses were thought to be 
approximately $£ 3$ billion (Environment Agency, 2010). During recent storm events, particularly during the winter of 2013 and 2014, much of the UK experienced recurrent powerful rainfall and flooding events, and this had a significant impact on property, transport and coastal protection structures in coastal regions, such as, Dawlish, Aberystwyth and Llanelli (Huntingford et al., 2015; Denner et al., 2015). Due to rapid climate changes, the UK has suffered from unprecedented flooding events, especially in recent decades (Steynor et al., 2012; Kantamaneni and Phillips, 2016).

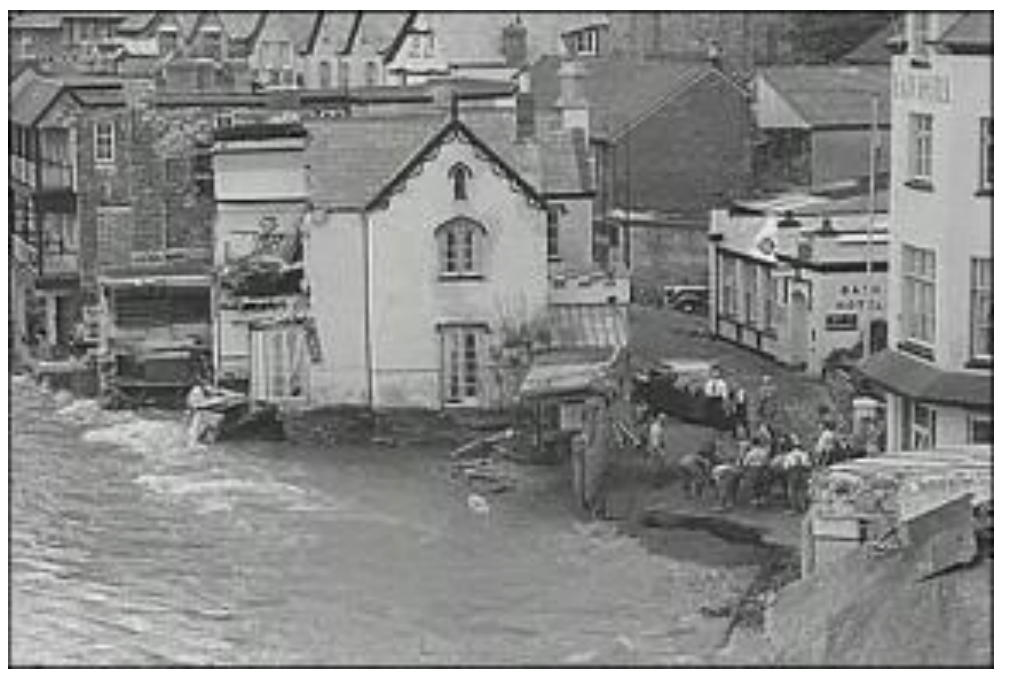

Figure 3.7: Lynmouth Floods in 1952

Source: BBC, 2010

\subsection{Coastal erosion}

Coastal erosion characteristically results in the inland retreat of the shoreline. This can increase the coastal flooding risk and result in loss of land and damage to buildings and infrastructure. Unexpected coastal erosion incidents may risk the lives of people. Rates of coastal erosion and deposition at international (Figure 2.8 and Figure 2.9), national, and regional (Figure 3.8) scales. According to BGS (2014), 113,000 residential and 9,000 commercial properties have been at risk of erosion across England and Wales. However, coastal erosion mostly occurs in coastal lowland areas and along soft sediment coastlines such as the East Anglian coast (Great Yarmouth), east Yorkshire (Spurn Head), and the Thames Estuary (French, 2004; Van der Wal, 2004). According to Muir et al. (2013) and BGS (2014), Benbecula and Happisburgh are highly vulnerable to sea level rise, coastal flooding and erosion. The magnitude of coastal erosion depends on the state of coastal defences. Though some areas have strong coastal defences (in the case of Aberystwyth), they face frequent coastal damage from the impacts of storms at sea (Kantamaneni, 2016a). Due 
to the low height of coastal defences, Dawlish is facing high erosion rates due to frequent flooding (Dawson et al., 2016; Kantamaneni and Phillips, 2016). Three major 2004 studies conducted by Foresight Future Flooding, EUROSION, and Future Coast explored flooding and erosion problems in the UK (Thorne et al., 2007).

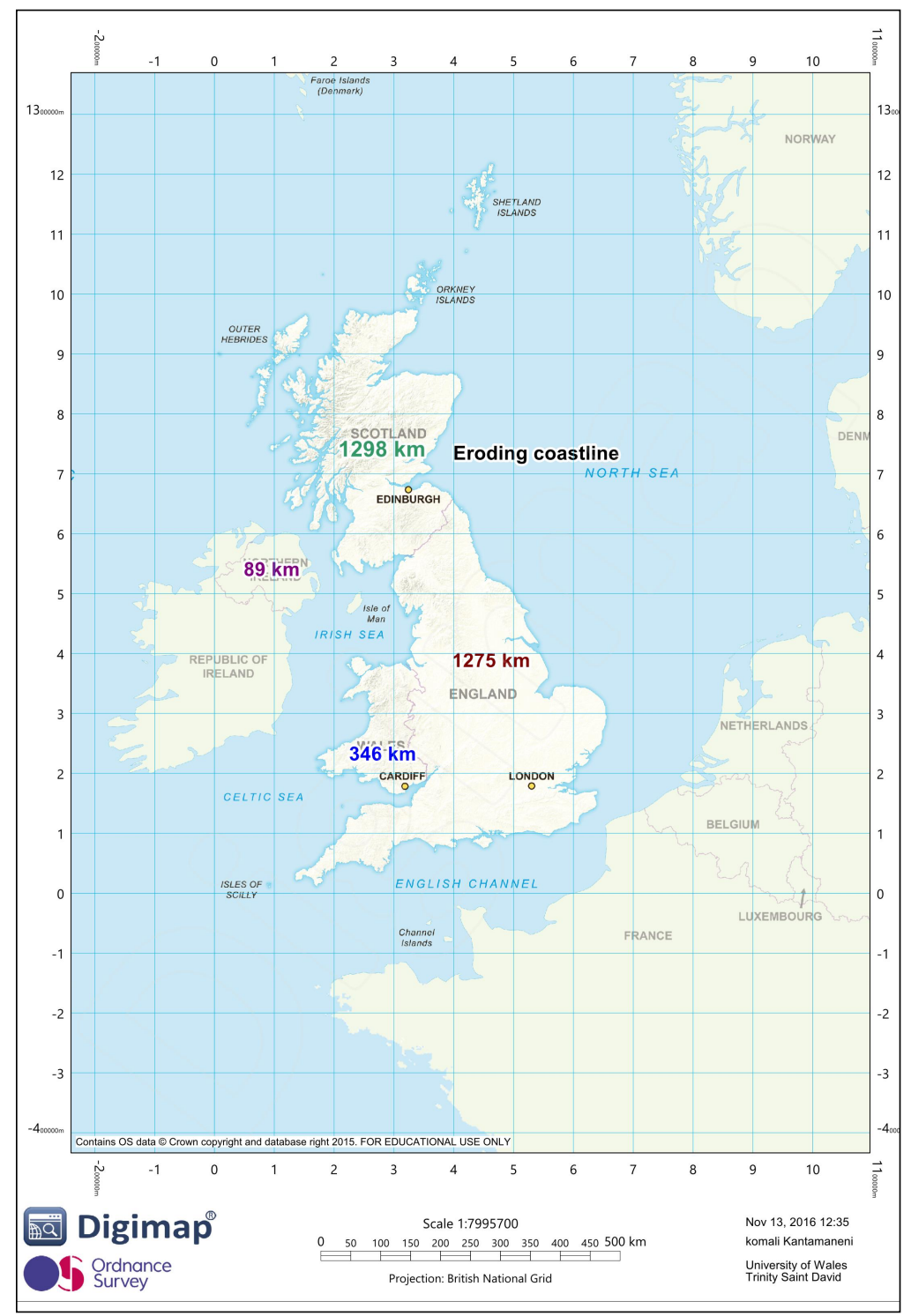

Figure 3.8: Map of coastal erosion in the UK

Source: Reproduced from Masselink and Russell, 2011

A great amount of the coastline of the UK is currently suffering from erosion (17\%), and of the 3,700-km coastline of England and Wales $28 \%$ is experiencing erosion greater than $>10$

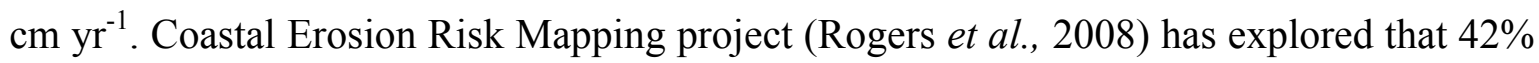
of the coast of England and Wales is at risk from erosion, of which $82 \%$ is unprotected. Coastal erosion impacts were clearly identified on tidal flats, cliffs, salt marshes, and 
beaches. The most significant risks from coastal erosion were flooding, rock falls, loss of land, and damage to commercial and residential infrastructure. Coastal properties across the country amounting to some 1,026,000 housing assets, 74,000 commercial assets, and some 432,000 hectares of farming land with a principal cost of more than $£ 132$ billion are potentially at risk from coastal flooding; altogether, this is equivalent to $£ 10.48$ billion that is converted for inflation on $£ 7.7$ billion between 2001 and 2013 (Penning-Rowsell et al., 2014). Therefore, coastal communities who are living in coastal vulnerability zones are at high risk of flooding and erosion in the UK, especially in England.

\subsection{Economic loss}

UK flood damage costs have increased significantly influenced by a series of flooding events between 2007 and 2013 and were the caused significant economic damage in England and Wales and to a lesser extent Northern Ireland and Scotland (Met Office, 2014). However, the most significant example in history is the 18th-century (1703) hurricane, which caused damage costs of more than $£ 20$ billion (calculated according to current inflation rates) and 8000 fatalities (Derham, 1704). The Lynmouth Flood (1952), which caused 34 deaths, also brought about a huge economic loss in England (Dobbie and Wolf, 1953). However, most of the economic loss came from flooding events, and, accordingly, Table 3.3 reveals monetary loss trends since 1990 .

Table 3.3: Top ten Natural Disasters and Damage Costs in the UK (1990 - 2014)

Source: Modified from - EM-DAT, 2014

\begin{tabular}{llc}
\hline Disaster & Date & Damage (£) \\
\hline Flood & 11-Oct-2000 & $3,861,471$ \\
Flood & 25-Jun-2007 & $2,814,292$ \\
Flood & 20-Jul-2007 & $2,814,292$ \\
Storm & 25-Jan-1990 & $2,225,254$ \\
Flood & 21-Nov-2012 & $1,047,178$ \\
Storm & 15-Oct-1987 & $1,024,271$ \\
Storm & 28-Oct-2000 & 981,730 \\
Storm & 18-Jan-2007 & 785,384 \\
Storm & 25-Feb-1990 & 589,038 \\
Storm & 5-Jan-1991 & 589,038 \\
\hline
\end{tabular}




\subsection{National (UK) GDP and impact of destruction costs on GDP}

The United Kingdom is the world's sixth-largest economy with a 2014 GDP of $£ 2.1$ trillion (The World Bank, 2016). It also has world-famous beaches, contributing to the national economy in the form of tourism (Vaz et al., 2009). However, the UK is increasingly vulnerable to impacts of coastal erosion, flash and surface flooding, storm surges and extremes in weather compared to recent memory (Wilby and Keenan, 2012). Severe weather conditions and adaptation costs have impacted the national GDP considerably in the $21 \mathrm{st}$ century (Turner et al., 1996; McCarthy, 2001; Kantamaneni, 2015). For example, 2007's summer floods turned into a nationwide catastrophe. The cost of this event was highlighted by a negative impact on the 2007 national GDP, significantly affecting local economies. In recent times, more weather events such as floods are creating serious destruction to infrastructure directly (Kantamaneni, 2016a) and to business indirectly causing slight albeit significant economic fluctuations (Dawson et al., 2016). 


\subsection{Summary}

This chapter concentrated on geographical and environmental drivers that influence coastal vulnerability risk issues related to the UK. Accordingly, this chapter identified that there is no combined coastal vulnerability index (CVI) for the evaluation of United Kingdom coastal vulnerability in both physical and economic terms. In order to improve expertise in this important area identified research gaps needed to be filled. Therefore, a CVI methodology has been developed that considers both physical and economic variables. This methodology will be discussed in detail in Chapter 4. 


\section{CHAPTER 4 - METHODOLOGY}




\section{Methodology \\ 4.1 Introduction}

The literature review identified that extensive research had been carried out with respect to natural disasters and coastal vulnerability procedures. The physical and economic background chapter also identified that research was needed to identify both physical and economic coastal vulnerability in the UK. Based on previous work done, there was an obvious need to better understand the available methods (indicators, index, GIS and model based methods) that can be operatively and concretely applied for assessing coastal vulnerability. Therefore, this chapter sets out methodological approaches and procedures to evaluate combined coastal vulnerability (physical and economic) of selected UK sites. Firstly, PCVI was developed and then applied to a number of case study areas and consequently an ECVI was developed and applied to the same case sites. As a result, a CCVI was developed based on PCVI and ECVI results.

Therefore, this chapter describes the development of a conceptual framework as well as the application procedures required to evaluate coastal vulnerability. Basic CVI concepts of Denner et al. (2015) and Palmer et al. (2011) have been adapted to the current study for an evaluation of PCVI. This methodology was modified based on the case study site characteristics. As a result of adding two new physical parameters (distance of built structures and coastal defences) to those defined by Palmer et al. (2011) and Denner et al. (2015) the selected areas were measured differently (Section 4.5.1). Furthermore, an Economic Coastal Vulnerability Index (ECVI) model was created by utilising newly developed economic parameters in order to appraise such vulnerability. Subsequently, the PCVI results were compared and contrasted with ECVI results and subsequently CCVI was developed. Along with these evaluations, ArcGIS vulnerability maps were also generated for an easy comparison of these indices.

\subsection{Desk study}

Before establishing the fieldwork, a desk study was undertaken to gather storm and coastal economics data for the UK. This information was obtained under special access for researchers from following organisations.

- NASA

- EEA

- NOAA 
- Met Office

- Environment Agency

- British Geological Survey

- World Disaster Data

- $\mathrm{ABI}-$ Association of British Insurers

- ONS - Office of National Statistics

- Ordnance Survey Maps

- British Museum photographs

- Devon County Council Photographs

- Act of Freedom of Information

- Local Authorities

- Insurance Companies/NGO

\subsubsection{Parametric tests associated with the desk study}

Data analysis begins with an attempt to find associations between variables and regression analysis. Regression analysis is a basic tool (Douglas and Crowell, 2000) and these type methods are useful when considering one of the variables, such as, time as a function of the other. Davis (2005) as determined from:

$$
y=(c+m x)+\varepsilon)
$$

Where $\mathrm{y}$ is the independent variable; $\mathrm{c}$ is a constant; $\mathrm{mx}$, regression coefficients; and $\mathrm{x}_{1}$, $\mathrm{x}_{2}$, and $\mathrm{x}_{\mathrm{n}}$ are dependant variables; and $\varepsilon$ is the error between model and actual results (Field, 2009). Variables $\mathrm{c}$ and $\mathrm{m}$ are calculated from the following:

$$
\begin{aligned}
& \mathrm{m}=\frac{\sum \mathrm{xy} \frac{-\sum \mathrm{x} \sum \mathrm{y}}{\mathrm{n}}}{\sum \mathrm{x}^{2} \frac{-\left(\sum \mathrm{x}\right)^{2}}{\mathrm{n}}} \\
& \mathrm{c}=\frac{\mathrm{y}}{\mathrm{n}}-\mathrm{m} \frac{\mathrm{x}}{\mathrm{n}}
\end{aligned}
$$


Proportional dataset variability is explained by the statistical model determined from the coefficient of determination, which is simply the square of the sample Pearson correlation moment coefficients. Pearson's product moment correlation coefficient (r) determined from:

$$
\begin{array}{ll}
\text { Correlation Coefficient }\left(\mathrm{r}_{\text {calc }}\right) & \mathrm{n} \sum \mathrm{xy}-\sum \mathrm{x} \sum \mathrm{y} \\
= & \frac{\sqrt{\left(\mathrm{n} \sum \mathrm{x}^{2}-\left(\sum \mathrm{x}\right)^{2}\right)\left(\mathrm{n} \sum \mathrm{y}^{2}-\left(\sum \mathrm{y}\right)^{2}\right)}}{}
\end{array}
$$

Where, $\mathrm{n}$ is the number of data pairs, $\mathrm{x}$ and $\mathrm{y}$ are data points on each axis (Wheater and Cook, 2000).

The significance of the regression line is given by the following formulae:

$$
\mathrm{SS}_{\text {total }}=\quad \sum \mathrm{y}^{2} \frac{-\left(\sum \mathrm{y}\right)^{2}}{\mathrm{n}}
$$

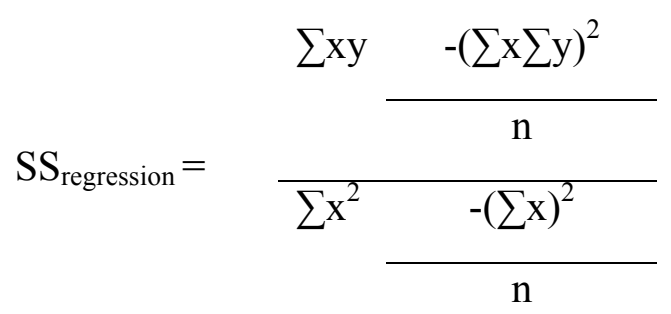

$$
\mathrm{SS}_{\text {residual }}=\mathrm{SS}_{\text {total }}-\mathrm{SS}_{\text {regression }}
$$

The statistical programme SPSS $\left(21^{\text {st }}\right.$ version) was used to analyse the gathered desktop study data and ECVI values. ArcGIS (10.3 version) was also utilised to develop coastal vulnerability maps.

\subsection{Methodological approaches for coastal vulnerability indices}

In terms of its economic value, both the literature review and physical background (Chapters 2 and 3 respectively) highlighted the need to investigate UK coastal vulnerability, mainly because of its diverse characteristics in terms of both the built and natural environments. However, Chapter 2 also identified that no single vulnerability assessment methodology existed that enabled evaluation of cost in relation to flood, storm-surge and other natural mechanisms related to climate change. Furthermore, in the UK, there is no specific government organisation that evaluates economic storm data; this leads to ambiguity in the 
study of economic coastal vulnerability. This research identified that the vulnerability effects need to be evaluated in a systematic order and that new frameworks should be developed to achieve best results.

\subsection{Site selection}

The main aim of this research is a development of combined coastal vulnerability (physical and economic) and an important objective was the identification of suitable case study sites (Section 1.3). Published work (literature), recent events and multiple site visits were used to identify the most suitable sites all with varying physical and economic characteristics. Zsamboky et al. (2011) explored that Great Yarmouth, Skegness, Llanelli and Benbecula were particularly vulnerable based on coastal erosion, SLR and frequent flooding events (section 3.9). They also identified that Lincolnshire, Yorkshire and East Anglian coastlines were highly vulnerable. Happisburgh on the East Anglian coast has been the subject of televised debate and research carried out by Poulton et al. (2006) calculated coastal erosion rates of circa $9 \mathrm{~m} \mathrm{yr}^{-1}$. However, this is partially caused by SLR and postglacial rebound as identified in Section 3.3: they suggested that tourism contributes significantly to the village economy, is being threatened by receding cliff line. The highly dynamic coastline between Holderness and Spurn head is particularly liable to erosion (BGS, 2014). The winter storms between December 2013 and January 2014 have identified both Dawlish and Aberystwyth situated close to the coastline are vulnerable see for example Dawson et al. (2015) and Kantamaneni (2016b) (section 3.9). The British Geological Survey (2014) has identified Hallsands and Happisburgh as vulnerable to rapid coastal erosion (section 3.9). While, Neath Port Talbot County Borough Council (2013) state that the steel and associated industries located in Port Talbot are vulnerable to both erosion and flood impact. Increased coastal erosion rates (Section 3.9) mainly caused by increasing environmental forcing conditions may have a catastrophic effect on heavily industrialised coastal areas, such as, Port Talbot Steelworks, may lead to economic costs that that would have an effect on National GDP (Section 3.11). Whereas the touristic Town of Aberystwyth is heavily reliant on sea defence resilience and any breakdown would lead to local economic loss (Section 3.9). Similarly, Lynmouth tourism is threatened by flood potential from two rivers (section 3.8) and coastal erosion (Environment Agency, 2012). As can be seen it is generally accepted (within the literature) factors that influence physical and economic vulnerability were explored and variables derived for eleven case study sites. Seven in England, three in Wales and one in Scotland, each with differing geographic and geological characteristics and varying 
environmental forcing exposure (Table 4.1 and Figure 4.1). Based on the analysis, there are many vulnerability hotspots across the UK, but these selected case study locations are in need of immediate consideration and accordingly those study sites were selected for an evaluation.

Table 4.1: Coastal vulnerability sites

\begin{tabular}{|c|c|c|}
\hline England & Wales & Scotland \\
\hline $\begin{array}{ll}\text { - } & \text { Spurn Head } \\
\text { - } & \text { Hallsands } \\
\text { - } & \text { Lynmouth } \\
\text { - } & \text { Happisburgh } \\
\text { - } & \text { Dawlish } \\
\text { - } & \text { Great Yarmouth } \\
\text { - } & \text { Skegness }\end{array}$ & $\begin{array}{ll}\text { - } & \text { Aberystwyth } \\
\text { - } & \text { Port Talbot } \\
\text { - } & \text { Llanelli }\end{array}$ & $\begin{array}{l}\text { - Benbecula } \\
\text { Island }\end{array}$ \\
\hline
\end{tabular}




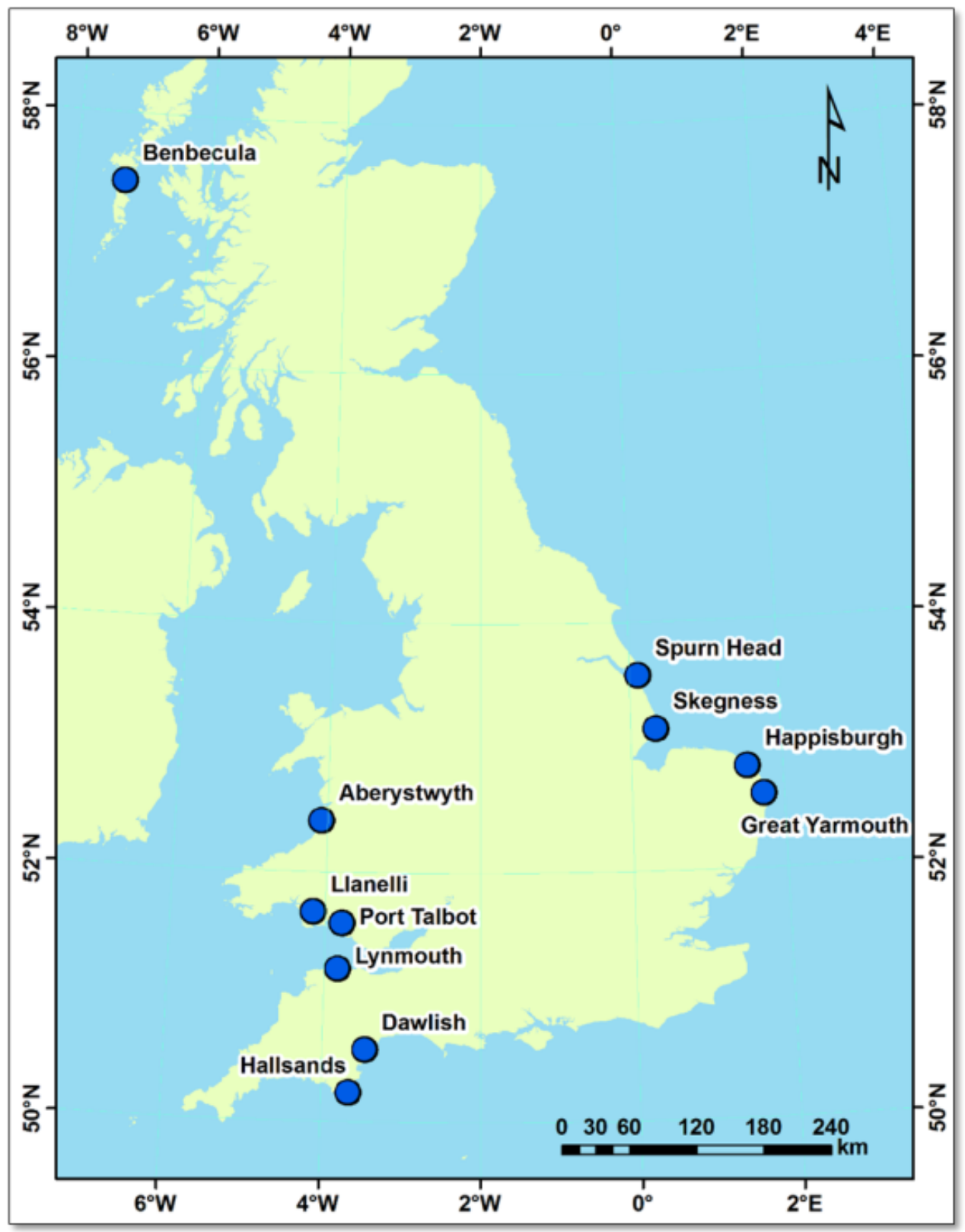

Figure 4.1: Map of coastal vulnerability sites

\subsubsection{Description of selected sites I. Spurn Head}

Spurn Head comprises (geomorphological) sand and shingle spit covered by dunes, together with an area of till and alluvium to the north (May and Hansom, 2003), which originally formed around the end of the 16th century (Sistermans and Nieuwenhuis, 2013; Figure 4.2). The spit extends 5.5.km south-westwards across the Humber estuary and rises only a few meters above sea level (May and Hansom, 2003). To the north low till cliffs are being eroded at rates (Section 3.9) in excess of $2.5 \mathrm{~m} \mathrm{yr}^{-1}$ and this in turn feeds sediment to the spit. Macro 
tidal tides with a tidal range of $6 \mathrm{~m}$ influence sediment deposition along the frontal lobe of the spit that can erode at rates of between $1 \mathrm{~m}$ and $2 \mathrm{~m} \mathrm{yr}^{-1}$ (Quinn et al., 2009). However, erosion rates have varied over time and exact estimations are difficult. The erosion occurs mostly during storm surges and there is documented evidence that the spit has been breached on several occasions (Sistermans and Nieuwenhuis, 2013). With predicted sea level rise increasing storm risk (Section 3.3) and consequential increasing flows from the Humber River, Spurn Head was identified as potentially vulnerable and in need of assessment.

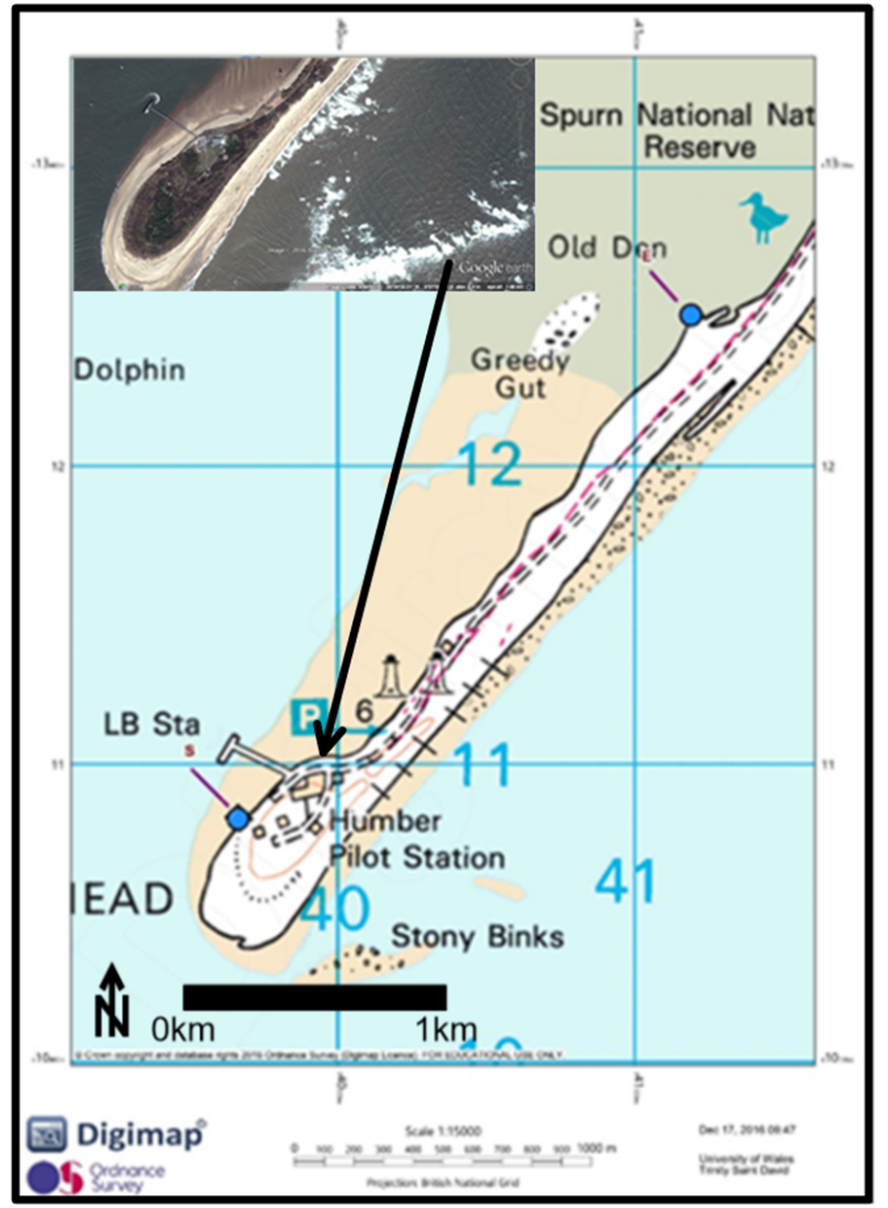

Figure 4.2: Spurn Head coastline and measuring points

\section{Hallsands}

A combination of gravel extraction, focused wave energy and high wave and tide conditions have resulted in rapid coastal erosion making this region as one of the highly-eroded sites in the UK (Section 3.9). The surrounding cliffs comprise mica-schist and quartz-schist that formed a raised platform the foundation of the hamlet of Hallsands, schists possess many structural features that weaken the cliffs, and the sea has exploited these weaknesses (May and Hansom, 2003). In February 2014, storms damaged coastal defences (Figure 4.3) by 
violent waves and high tides, which left the village nearly, vanished though shoreline management has been protecting the coastline for years. However, it is not strong enough to protect Hallsands shoreline from chronic waves and intense storm strikes. Because of these reasons Hallsands considered as one of the vulnerable sites in the UK and accordingly people are not showing interest to reside in this region. However, they want to construct only holiday homes. Surprisingly, the market for properties at this is also high given it has a significant coastal risk.

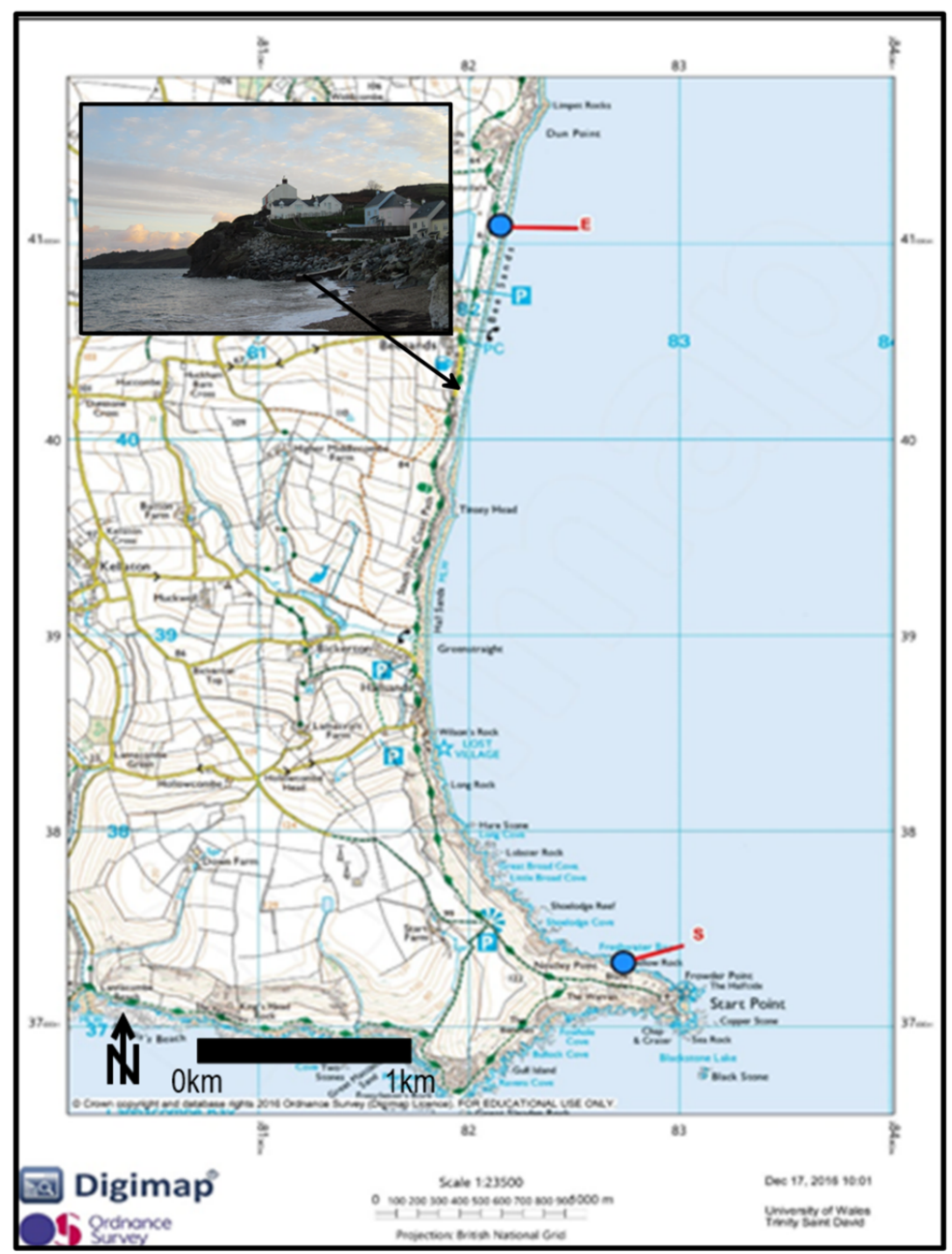

Figure 4.3: Hallsands coastline and measuring points

\section{Lynmouth}

Strong northwesterly winds coinciding with high tides can cause damage to residential and commercial properties (Figure 4.4) since 1952; severe coastal flooding events often destruct this region (Section 3.8) (Scrase and Sheate, 2005) due to exuberated climatic change scenarios (Kantamaneni and Phillips, 2016). While, floodwater also poses a significant threat to low-level properties and population; flood risk for this site comes from river, surface water 
and tidal flooding. Land use and management variations, together with urban development in the catchment, sea level rise (which will be rise $500 \mathrm{~mm}$ by 2100) will also affect the frequency and magnitude of flooding in this region (Environment Agency, 2012). Lynmouth is one of the economic zones (market town) in Devon Council area and it has relatively sluggish population growth i.e. 3.5\% since 1991 when to compare with other counties. Due to its commercial activities, Lynmouth has good fiscal value though it has a small population (Devon City Council, 2007). The south west coast of England is exposed to an energetic wave regime emanating from the Atlantic Ocean. These waves are heavily diffracted by headlands and focus the energy within in the many embayed beaches along this coastline. Between October 2013 and April 2014 the south west coast experienced 22 extreme storms (Masselink et al., 2015). Even though Lynmouth has a high coastal elevation, it was significantly vulnerable to coastal flooding and erosion as a consequence of spring tidal range storm and surge conditions, that essentially restricted river flows from entering the sea. 


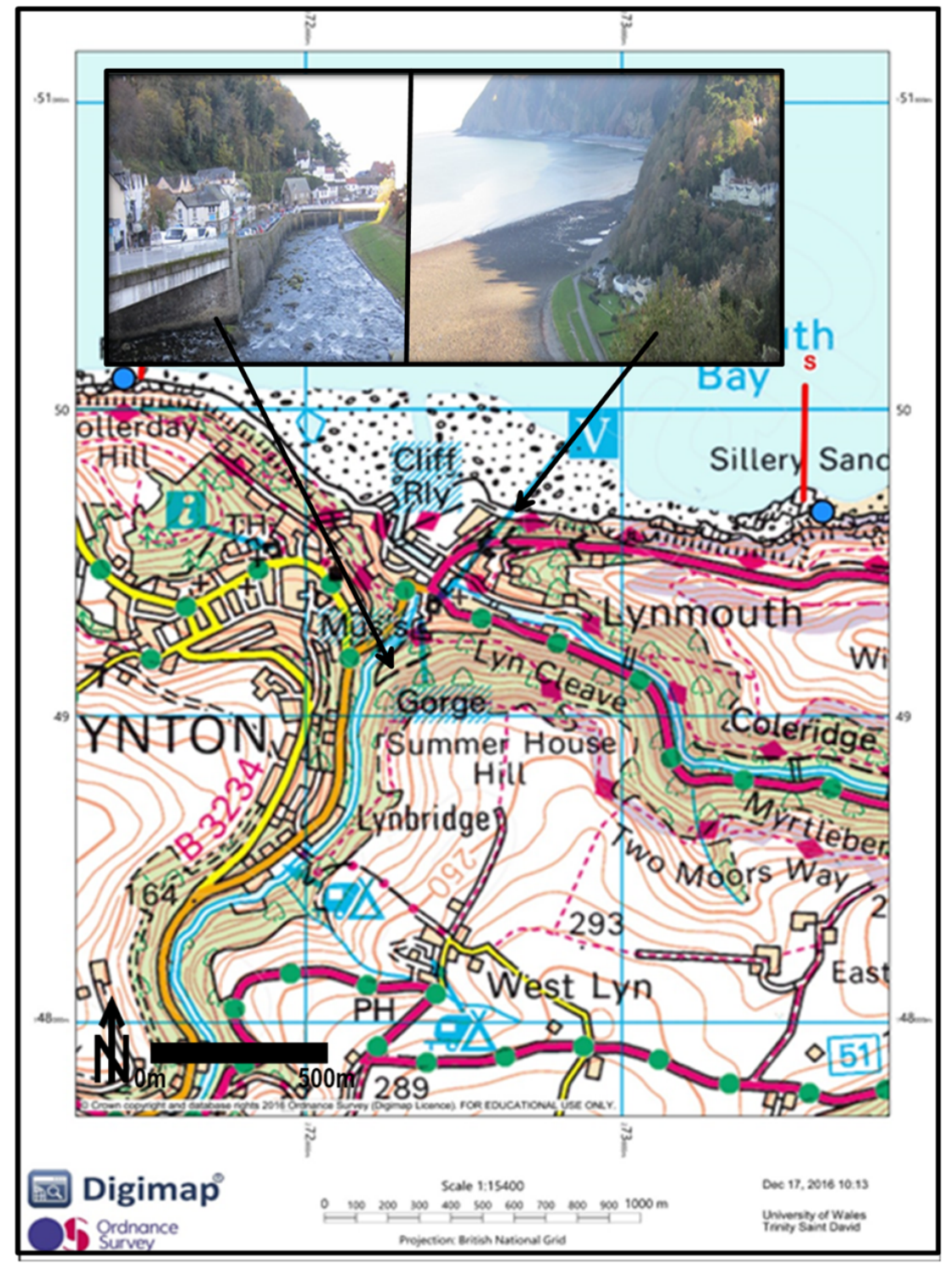

Figure 4.4:-Lynmouth coastline and measuring points

\section{Happisburgh}

Happisburgh cliffs range in height from $6 \mathrm{~m}$ to $10 \mathrm{~m}$, comprised of a sequence of several glacial tills, separated by beds of stratified silt, clay and sand, marine deposits underneath the modern beach material are periodically exposed to storms (Hart, 1999; Lee et al., 2004). Coastal flooding and erosion are significant risks at Happisburgh (Section 3.9) and in recent years the coastline has retreated by as much as 260 metres. Storm waves erode the glacial till at the base of the cliffs causing collapse and rapid erosion (BGS, 2014). Aerial photographic evidence given in Figure 4.5 shows coastal changes between 1999 (left panel) and 2014 (right panel) highlighting the previously mentioned erosion trend. While, the 2006 aerial photograph shows the coastal protection measures that reduced erosion rates. The coastline is exposed to a variety of wave directions and is especially vulnerable to storms 
generated from the north as there is no fetch limitation in this direction (Thomalla and Vincent, 2003). Because of these reasons Happisburgh is considered to be to be one of the highly vulnerable coastal sites in the UK. Even though Happisburgh is highly vulnerable to coastal erosion surprisingly property prices remain high (Kantamaneni, 2016b).

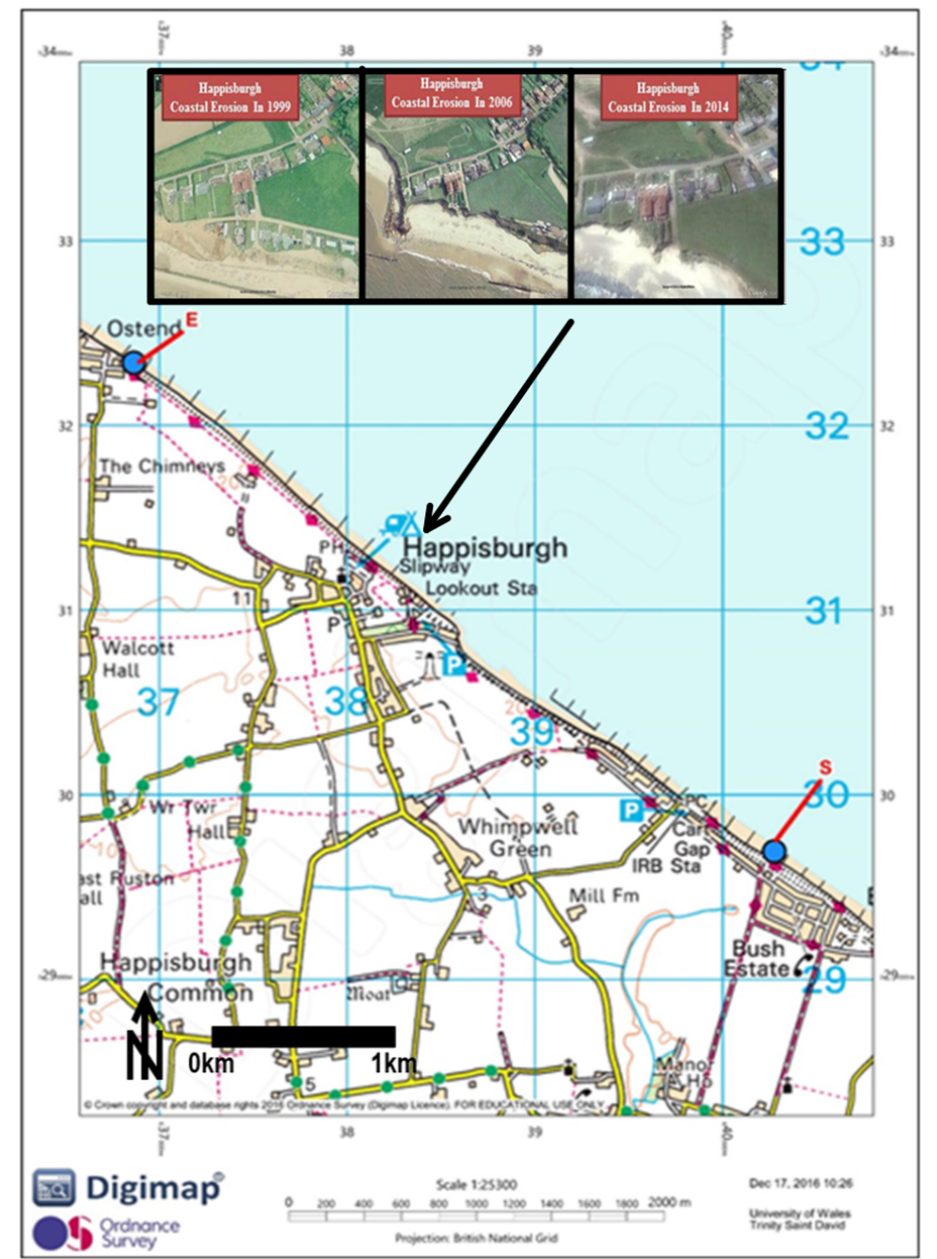

Figure 4.5: Happisburgh coastline and measuring points

\section{Dawlish}

Recent, winter storms and storm surges have caused a great deal infrastructure damage along the Dawlish coastline. This was particularly apparent during the 2013/12 winter storms, when sea was breached, properties damaged (Section 3.8) and a $6 \mathrm{~km}$ stretch of railway line was so severely damaged that train services were disrupted for more than two months (Dawson et al., 2016). However, the track between Dawlish and Teignmouth has been vulnerable to frequent closure during high waves and storm events since it was built. Dawlish is also one of the rapidly growing regions in Devon particularly along the coastline (Figure 
4.6).

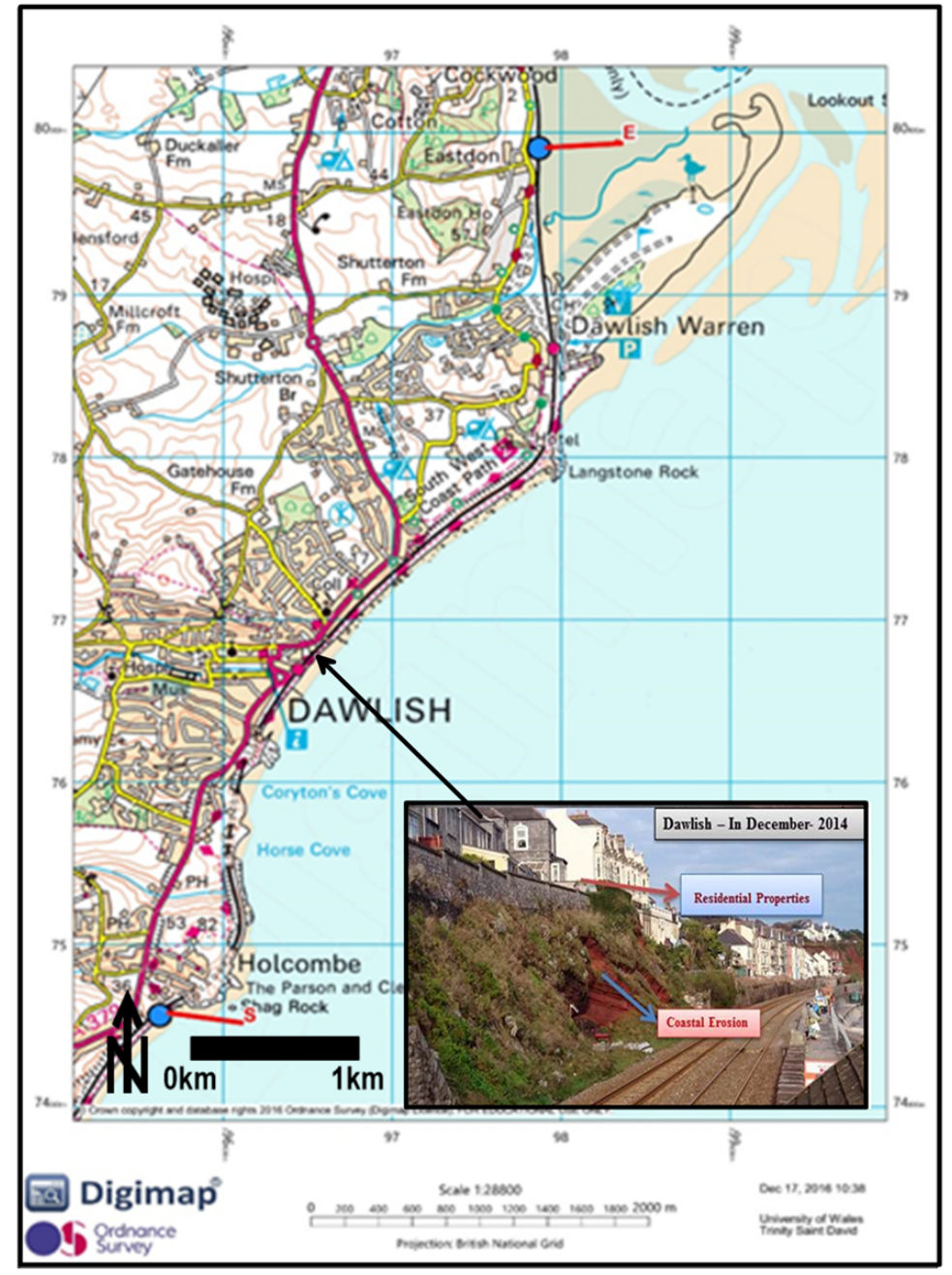

Figure 4.6: Dawlish coastline and measuring points

\section{Great Yarmouth}

Great Yarmouth is a low-lying coastal town (Figure 4.7) constructed on a spit, comprising of varying proportions of sand and gravel. The region has a history of coastal flooding, not helped by the fact that the river Yare separates the spit from the mainland at its western end (Nicholas, 2007). Great Yarmouth is one of the flood prone (coastal and fluvial) areas in the England as evidenced since 1953 (Kelman, 2003; Dawson et al., 2009). (Section 3.8 and 3.9) Three hundred million years ago, Great Yarmouth coast/beach was physically formed and widely covered with glacial drift deposits (Norfolk Heritage Explorer, 2015). Landslides and erosion are common problems in this region. Though it has coastal erosion and storm risk, population and property growth has been high over the last three decades. Economically it is one of fastest growing economies in England, consisting of several large industries such as energy, electronics and offshore gas, which contribute significantly to the GDP of national 
and local economies. This industrialisation, contributes to a high population growth in the area $7.6 \%$ since 2001, a figure that is predicted to double by 2021 (Great Yarmouth Council, 2014).

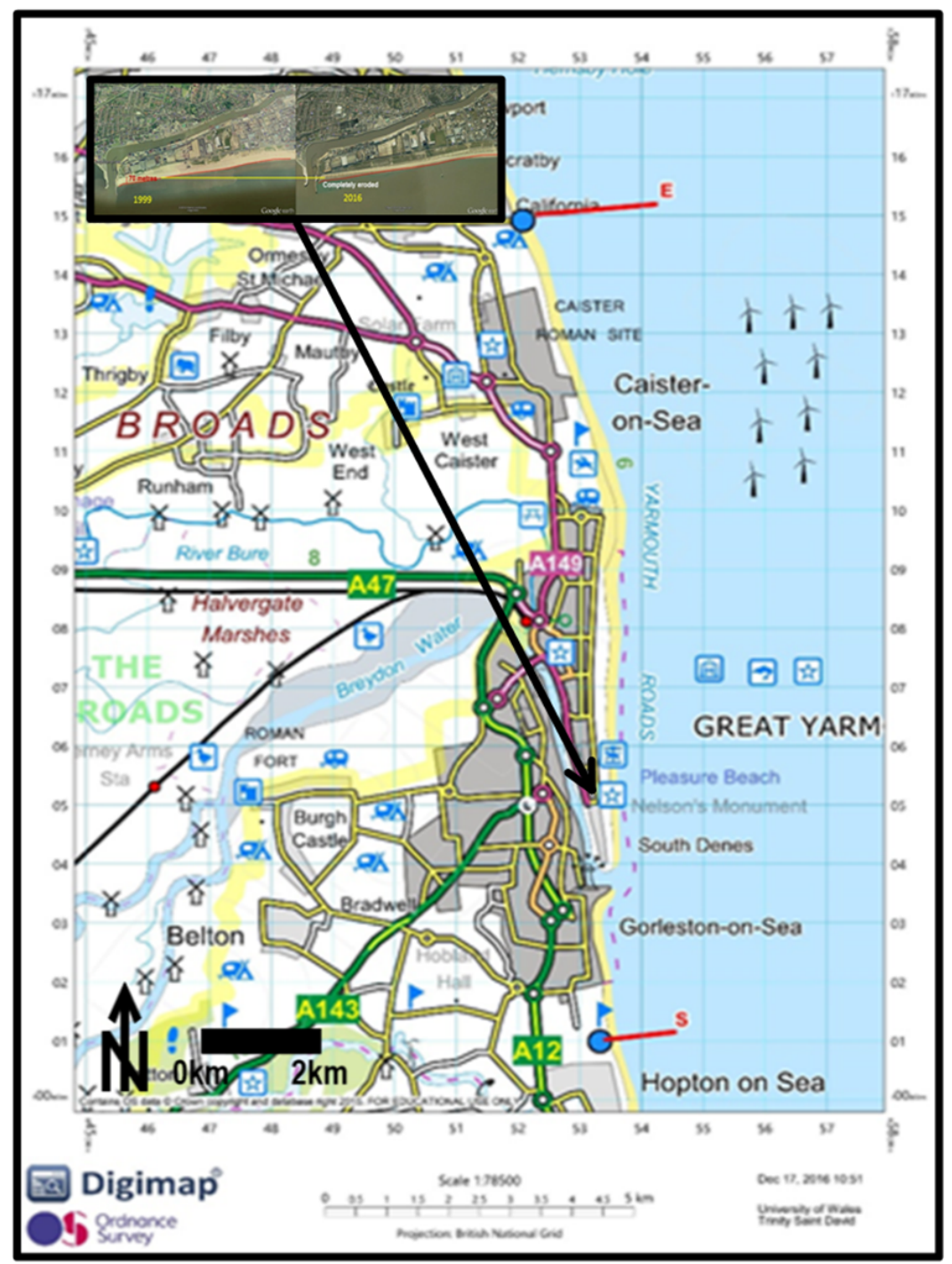

Figure 4.7: Great Yarmouth coastline and measuring points

\section{Skegness}

Skegness has been subject to erosion and general retreat for several centuries (Dugdale and Vere, 1993; Figure 4.8). The key climate risks for Skegness are frequent and unprecedented flooding events, fluctuations in weather patterns and increased occurrence of summer precipitation. In recent decades, additional sea defences were constructed to protect vital infrastructure from erosion. While, the high water table and low-lying landscape of this region, in conjunction with the increased risk associated with sea level rise, post glacial 
rebound (Subduction) and storm surges, intensify the area's physical vulnerability to the effects of climate change (Section 3.9) (Zsamboky et al., 2011).

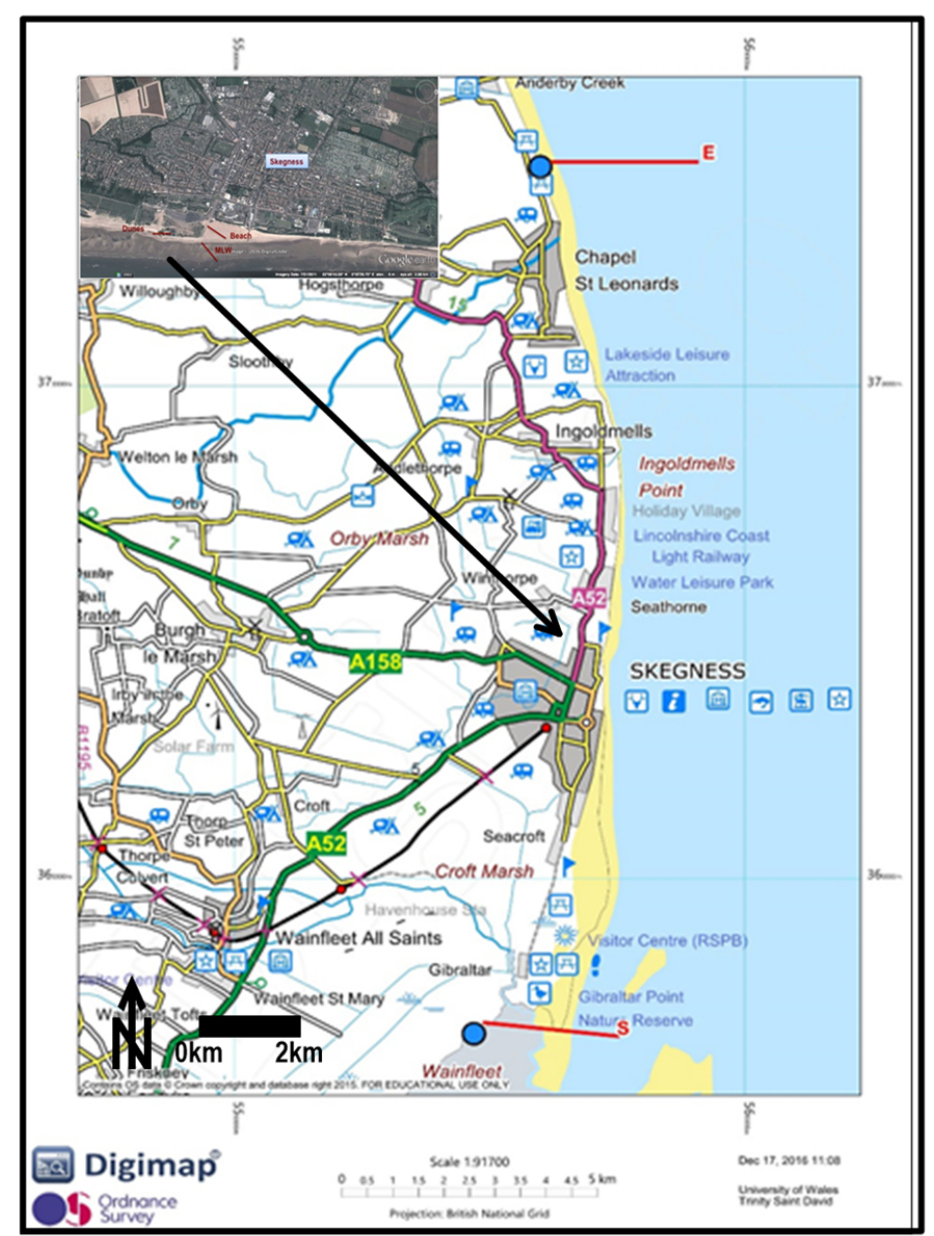

Figure 4.8: Skegness coastline and measuring points

\section{Benbecula}

Benbecula is extremely exposed to North Atlantic Ocean winter storms and waves particularly in winter months (Dawson et al., 2007; Wolf and Woolf, 2006). Accordingly, high waves and coastal erosion are the most significant problems in this region (Section 3.9), and it is a highly eroding site due to the rapid disintegration of coastline into the sea (Kantamaneni and Phillips, 2016). These situations also affect transport system (ferry service) enormously particularly in the winter period, which is the main way to reach this site. Due to these reasons, population have been in decline decrease rate is very high since 1991, i.e., 32\%. Cumulatively, these reasons make Benbecula a highly vulnerable and isolated area in the UK (Figure 4.9). 


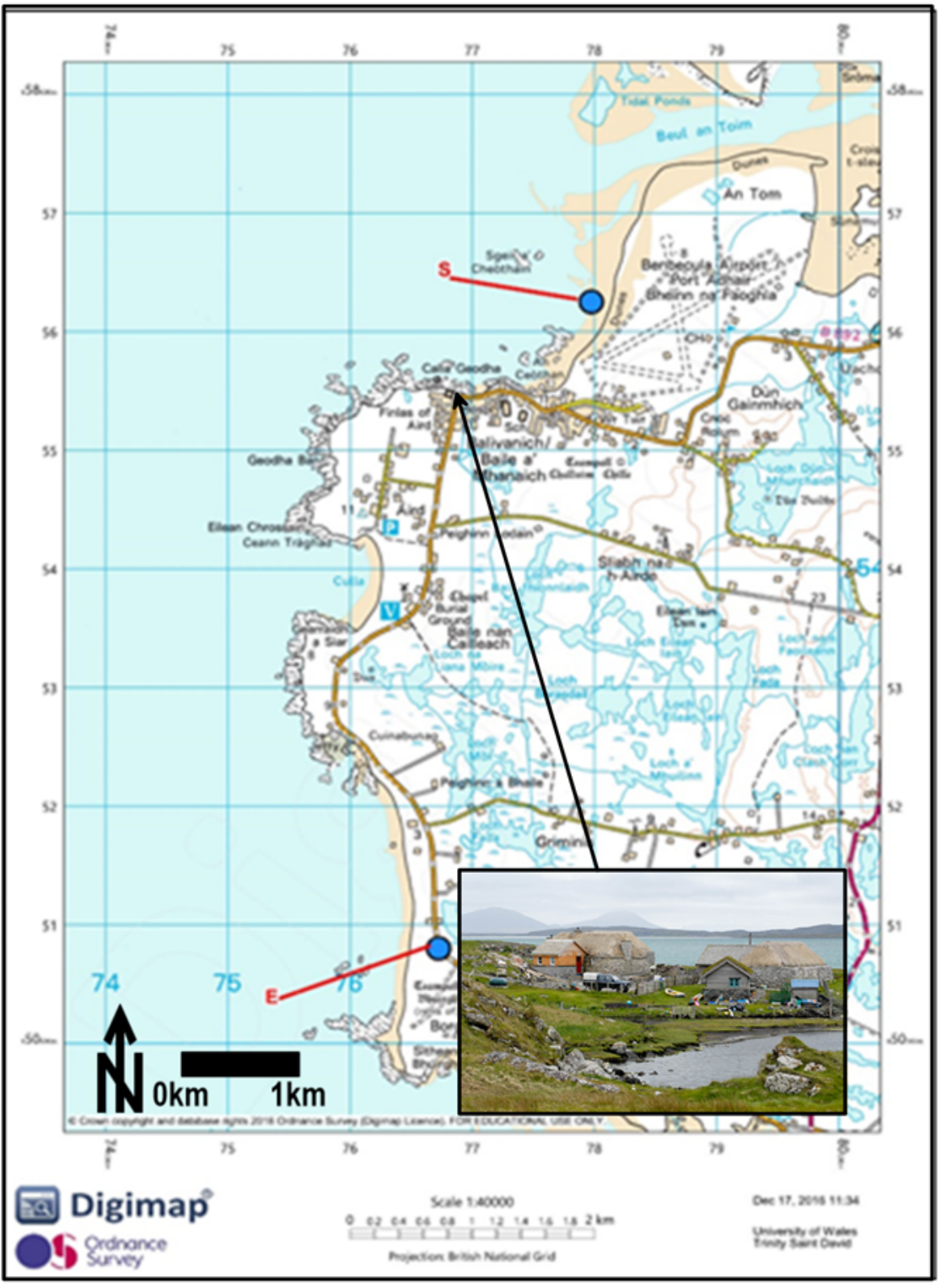

Figure 4.9: Benbecula coastline and measuring points

\section{Aberystwyth}

Aberystwyth is the main touristic spot and administrative region of the west coast of Wales; though it has a small coastline ( $>2 \mathrm{~km}$ ) (Aberystwyth Guide, 2015), it has a high socioeconomic value due to the town's tourism, education, and retail sectors. Population growth is very rapid i.e. 23\% since 1970 (Ceredigion County Council, 2006). Currently, properties in Aberystwyth have high market value (Kantamaneni, 2016b). Frequent storm strikes are not unusual phenomena in Aberystwyth; starting several decades ago, repeated storms ravaged this region and damaged infrastructure (Section 3.8 and Section 3.9) costing several million (Figure 4.10) as evidenced in 1927, 2008, 2013 and 2014 (major events). In 
particular, 2014 storms damaged circa $2 \mathrm{~km}$ of railway track between Aberystwyth and Machynlleth severely, and nearly two weeks were needed for repairs. In addition, the widespread destruction of the seawall and walking path and the flooding of more than ten houses occurred. Future climatic conditions and levels of damage due to various coastal hazards will worsen the situation if strict adaptation and coastal defence procedures are not implemented in the near future (Slingo et al. 2014).

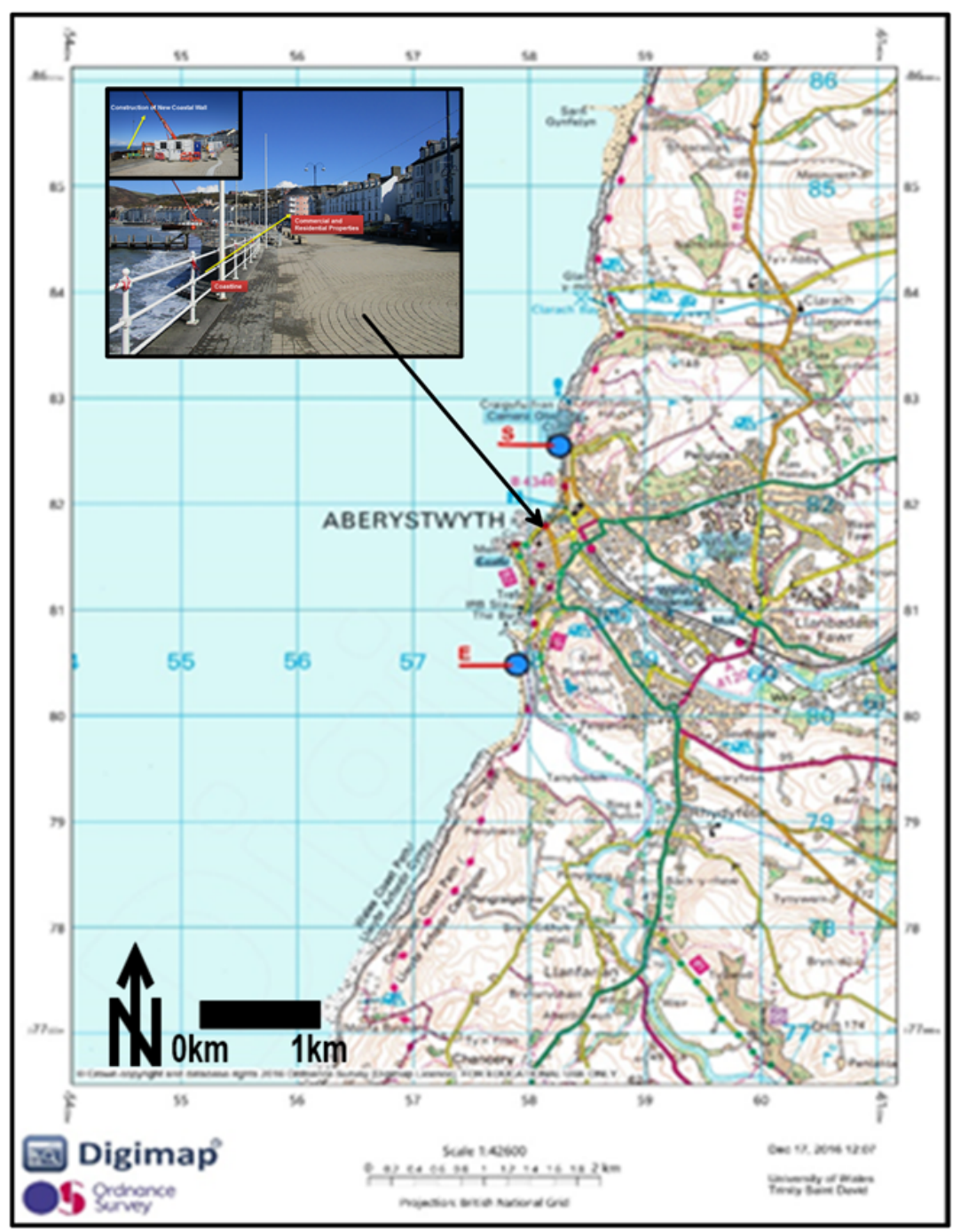

Figure 4.10: Aberystwyth coastline and measuring points

\section{Port Talbot}

The Port Talbot coastline is backed either by natural dune systems or retaining structures but many of the commercial and residential properties built in this relatively low lying area are at risk of flooding (Figure 4.11). Strong winds and tides generated in the Bristol Channel 
contribute to a high-energy wave environment (Section 3.4) (Allan et al., 2009). Prevailing winds emanate from the southwest and the macro tidal environment has a spring tidal range $7.5 \mathrm{~m}$ (Phillips and Crisp, 2010), and storm waves $>5.5 \mathrm{~m}$ with periods $>8.5 \mathrm{~s}$ are not uncommon in this region (Thomas et al., 2015). Historically linked to the coal, steel and fishing industries, the current industrial activity is centered on Port Talbot steelworks. Port Talbot Harbour promontory with associated dredged channels, interrupt longshore sediment drift, along with freshwater inputs from the rivers, Neath, Afan and Kenfig that flow into Swansea Bay (Thomas et al., 2015). While, due to the economic downturn in this region; growth rate was not positive between 2008 and 2011, but now it has constant growth from industrial side. Population growth rate has steadily increased since 2001, at 4\% (ONS, 2012). Due to the industrialisation, this area has high economic value.

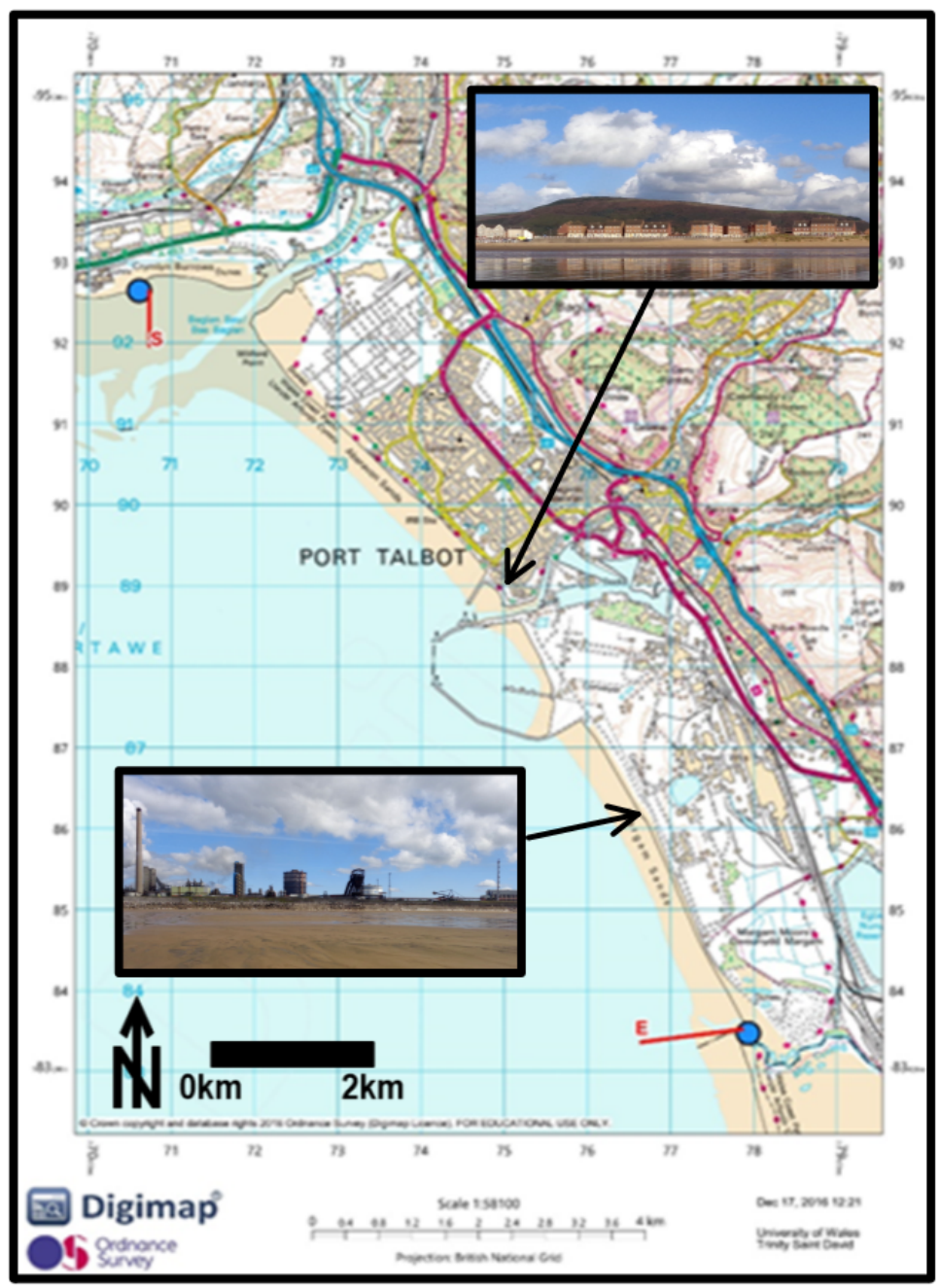

Figure 4.11: Port Talbot coastline and measuring points 


\section{Llanelli}

The decline of the coal and steel industries led to economic decline and disadvantage in the Llanelli area (Zsamboky et al., 2011). To stimulate the local economy the Local Authority in conjunction with other interested stakeholders developed a regeneration strategy focusing on the tourist sector (CCC, 2007). The transformation of the former site of the Llanelli Steel Works into Sandy Water Park was the catalyst for the Millennium Coastal Park. The park attracts a million visitors annually and was hailed as an example of successful sustainable design and construction (Figure. 4.12; Holmes, 2003; Phillips et al., 2009). However, recent storm events severely damaged the coastal path, rail infrastructure and impacted on several newly constructed dwellings (Section 3.8) (Denner et al., 2015). It is acknowledged that continuous flooding in the area resulted from an increase in impervious surfaces resulting from new developments and an increased sewage base load by housing stock expansion resulting from the coinciding of high tides with heavy rainfall (CCC, 2007).

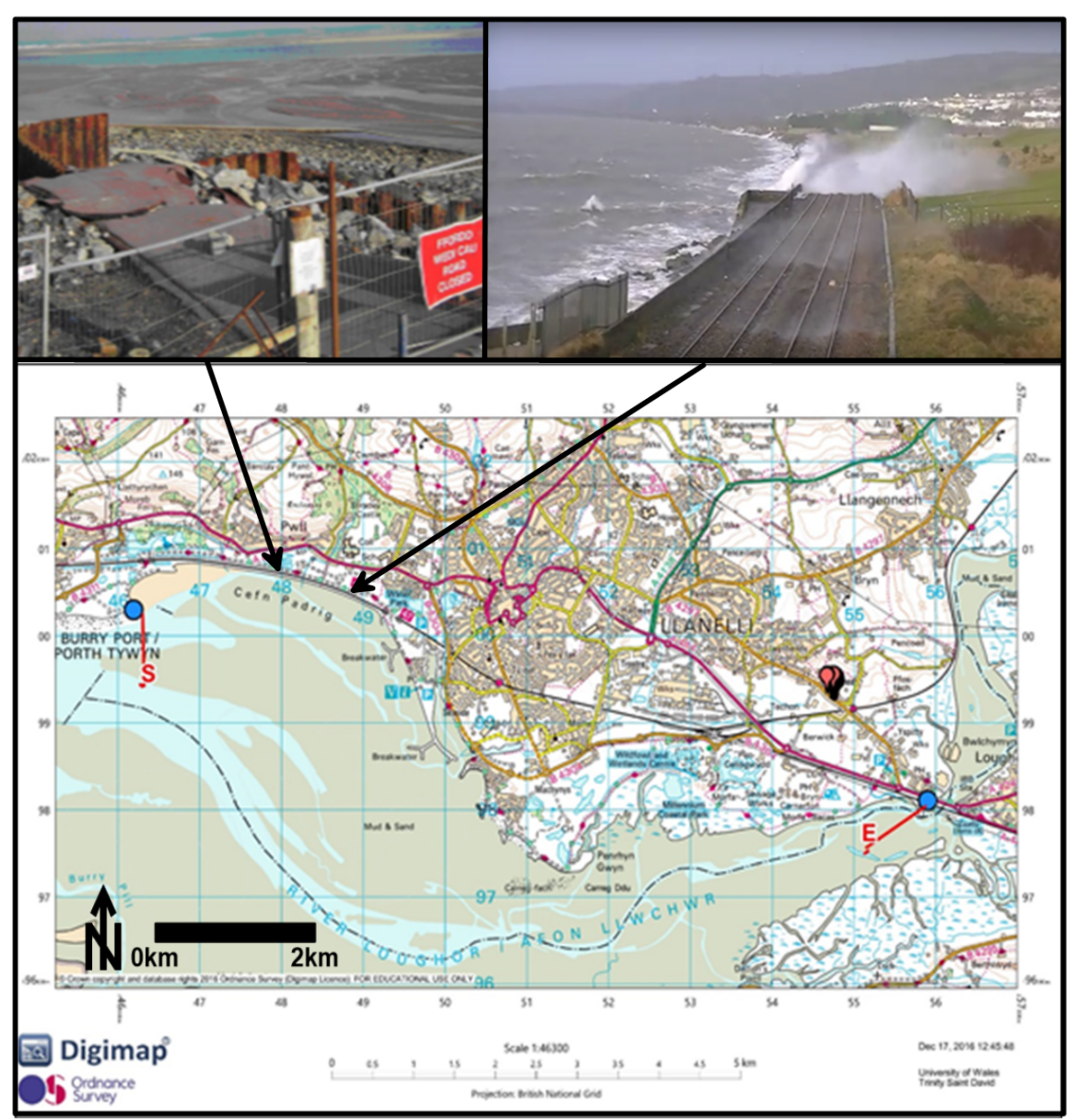

Figure 4.12: Llanelli coastline and measuring points 


\subsection{PCVI Data}

Statistical data regarding beach and dune width were obtained by direct measurement within a GIS (Mapinfo® 15) and from Ordnance survey maps obtained via Digimap ${ }^{\circledR}$. Distance of vegetation and built structures behind the back beach, coastal slope and rocky outcrop were obtained from Google Earth/NASA maps. Detailed description regarding physical parameters was given for each of the case study sites in Chapter 5.

\subsubsection{Physical parameters and measurement}

Aligning with Denner et al. 's (2015) work on the Welsh coast, seven physical parameters were used to estimate physical vulnerability (Section 4.1). These were Beach width, dune width, distance of vegetation behind the back beach, distance of built structures behind the back beach, coastal slope, rocky outcrop and coastal defences. Accordingly in this research, transect lines were drawn perpendicular to the coast at $0.5 \mathrm{~km}$ spacing. In line with Denner et al. (2015) the back beach was used as a proxy baseline, measurements extended to a line drawn $0.5 \mathrm{~km}$ inland approximately parallel to the baseline and as far as mean low water in a seaward direction (Figure 4.15). Subsequently, detailed measurements based upon each parameter were recorded along each transect.

Table 4.2 details physical thresholds for each parameter based upon the methodologies adopted by Palmer et al. (2011), and refined by Denner et al. (2015) and assigned a ranking score between 1 and 4. Individual measurements were then compared and contrasted with Table 4.3 and assigned a ranking score between extremely low (1), low (2), moderate (3) high (4) to assess vulnerability quantitatively. With rankings applied, these values were then summed for each location to provide a relative CVI score using Comparative PCVI $=P_{a}+$ $P_{b}+P c+P_{d}+P_{e}+P_{f}+P_{g}$, where " $P_{\boldsymbol{a}}$ to $\boldsymbol{P}_{\boldsymbol{g}}$ " are the respective ranking score for each parameter (equation 1; section 4.3.2). The PCVI value would range between a minimum value of 7 and a maximum of 28. These scores were compared with Table 4.3 in order to categorise the level of physical vulnerability for each location. 


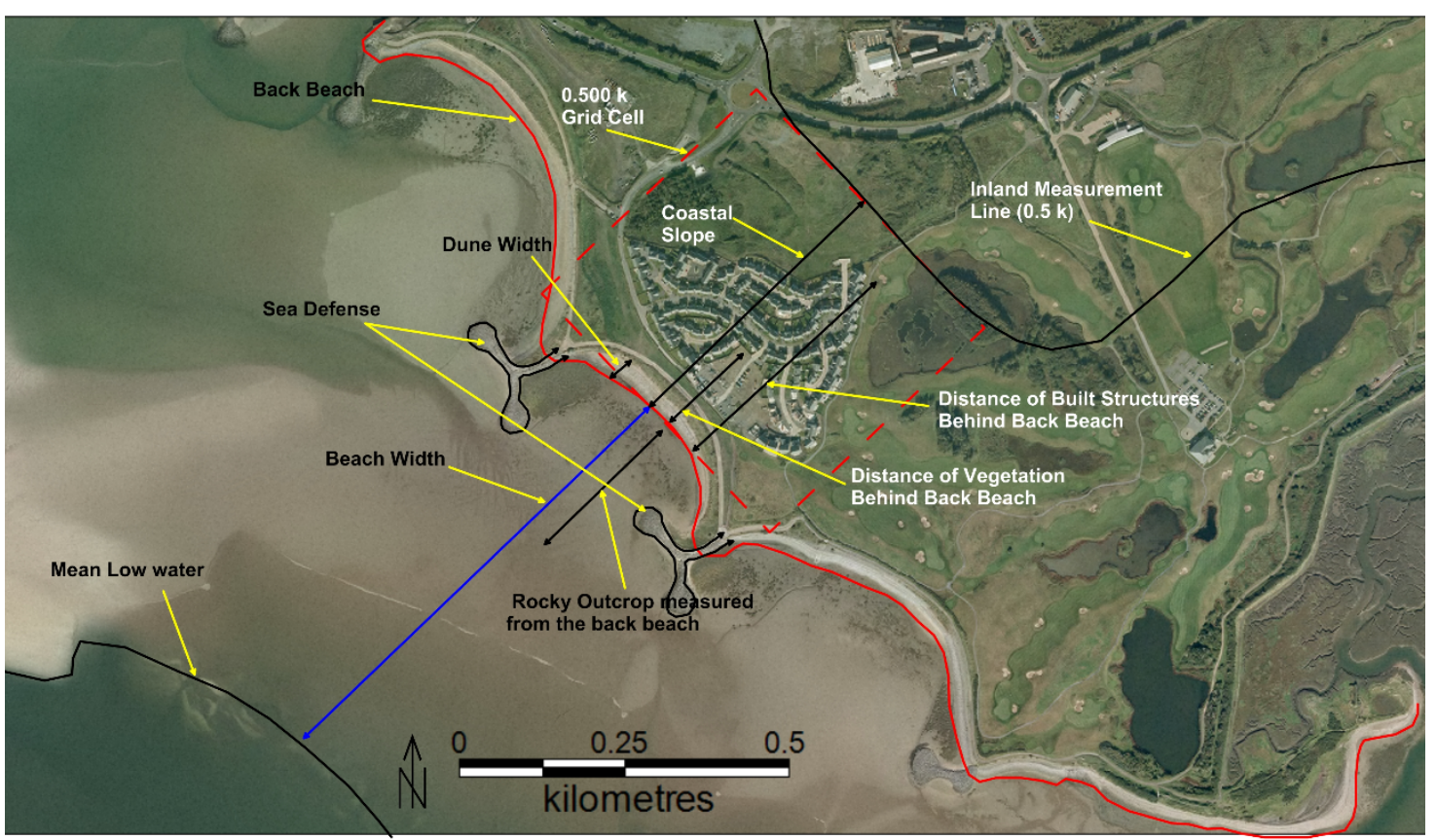

Figure 4.13: Transect line and $0.5 \mathrm{~km}$ coastal cell

Table 4.2: Physical parameter ratings of the level of vulnerability

\begin{tabular}{|c|c|c|c|c|}
\hline & \multicolumn{4}{|c|}{ Physical Vulnerability Values } \\
\hline Physical Parameter & $\begin{array}{c}\text { Extremely } \\
\text { Low (1) }\end{array}$ & Low (2) & $\begin{array}{c}\text { Moderate } \\
\text { (3) }\end{array}$ & High (4) \\
\hline Beach width $\left(P_{a}\right)$ & $>150 \mathrm{~m}$ & $100-150 \mathrm{~m}$ & $50 m-100 m$ & $<50 \mathrm{~m}$ \\
\hline Dune width $\left(P_{b}\right)$ & $>150 \mathrm{~m}$ & $50-150 m$ & $25 m-50 m$ & $<25 \mathrm{~m}$ \\
\hline Coastal slope $\left(P_{c}\right)$ & $>12 \%$ & $12 \%-8 \%$ & $8 \%--4 \%$ & $<4 \%$ \\
\hline $\begin{array}{l}\text { Distance of vegetation } \\
\text { behind the back beach } \\
\left(P_{d}\right)\end{array}$ & $>600 \mathrm{~m}$ & $200 m-600 m$ & $100 m-200 m$ & $<100 \mathrm{~m}$ \\
\hline $\begin{array}{l}\text { Distance of built } \\
\text { structures behind the } \\
\text { back beach }\left(P_{e}\right)\end{array}$ & $>600 \mathrm{~m}$ & $200 m-600 m$ & $100 m-200 m$ & $<100 \mathrm{~m}$ \\
\hline Rocky outcrop $\left(P_{f}\right)$ & $>50 \%$ & $20 \%-50 \%$ & $10 \%-20 \%$ & $<10 \%$ \\
\hline Sea defences $\left(P_{g}\right)$ & $>50 \%$ & $20 \%-50 \%$ & $10 \%-20 \%$ & $<10 \%$ \\
\hline
\end{tabular}


Table 4.3: Vulnerability level ratings (PCVI)

\begin{tabular}{|c|c|}
\hline $\begin{array}{c}\text { Total Relative } \\
\text { Vulnerability Score }\end{array}$ & Range of Vulnerability \\
\hline$<12$ & Very Low \\
\hline $12-15$ & Low \\
\hline $16-18$ & Moderate \\
\hline $19-23$ & High \\
\hline $24-28$ & Very High \\
\hline
\end{tabular}

\subsection{Economic coastal Vulnerability}

Economic coastal vulnerability was designed by the author and applied to the selected case study site locations (sections 4.1 and 4.4).

Three basic methodologies were adapted for the establishment of proposed ECVI, as follows:

I. Indicator based approach (Balica et al., 2012)

II. Indicator based approach (Palmer et al., 2011)

III. Geographical Information System

\subsubsection{Indicator based approach -1}

Balica et al. (2012) developed a flood vulnerability index based on three factors: susceptibility, exposure and resilience to coastal flooding. Originally applied to nine of the most vulnerable coastal cities, the methodology concentrated on three system components: hydro-geological, socio-economic and politico-administrative. They subsequently developed a group of indicators, interlinked with each system component. Each vulnerability factor (exposure, susceptibility and resilience) characterised a set of essential indicators based on the features of a coastal system. The dimensionless indicator index utilised a numerical system with numbers ranging from 0 to 1 to establish low or high coastal flood vulnerability. This highlighted those cities that were most at risk and suggested that further comprehensive examination would be required both for decision- and policymakers. Their indicator selection process was applied to the selection of ECVI parameters in this research. 


\subsubsection{Indicator based approach -2}

Palmer et.al. (2011) developed a coastal vulnerability index (CVI) for the KwaZulu-Natal (KZN) coast, South Africa. This approach examined the relative coastal vulnerability of the KZN coast to erosion and severe weather incidents. This CVI was established based on remote sensing data from which a set of physical parameters was developed into indicators of vulnerability. The CVI scores were used to classify the coast into five classes, based on its relative degree of vulnerability, and these values ranged from very low to very high and highlighted what proportion of coast falls within each class. The final vulnerability scores were obtained using equation 1 below. This formula concept has been taken and utilised in this research.

$$
\text { Relative CVI }=\mathrm{a}+\mathrm{b}+\mathrm{c}+\mathrm{d}+\mathrm{e}+\mathrm{f}+\mathrm{g} \quad \text { (equation } 1)
$$

\subsubsection{GIS approach}

This method is interlinked with an assessment of coastal vulnerability to estimate risk, identify vulnerable regions as well as the development of vulnerability maps for the considered coastline used in the research.

\subsection{ECVI data}

Statistical data (2013-2015) regarding population (2015), commercial and residential properties (2015) were obtained from the Office for National Statistics (ONS), together with county and District councils of England, Wales and Scotland. Property data related to the chosen case studies i.e. Llanelli, Happisburgh, Skegness and Benbecula was obtained from the UK government under the freedom of information Act. Flood data was obtained from Meteorological Office, Environment Agencies and Local Authorities (2013-2015). Coastal erosion data was collected from British Geological Survey and United Kingdom Climate Impact Predictions and Local Authorities 2013-2015). Estimated values of both commercial and residential properties and land values were obtained from Her Majesties Revenue Office for England, Wales and Scotland, Association of British Insurers (ABI) and the Agricultural Mortgage Corporation (AMC) (2013-2015).

Population data were obtained from various Local Authorities and District Councils. Aberystwyth, Port Talbot, Llanelli, Devon, Lynton, and Lynmouth, and Hallsands provided the most up-to-date and detailed information. As general overview, ONS statistics are quite useful. However, for small-scale estimations (measurements below $5 \mathrm{~km}$ ), 
Local Authorities data is very helpful and frequently up to date. In addition, this study utilised the data which obtained from multiple observations at various coastal locations across the United Kingdom between 2013 and 2015. This work used the data of rateable properties but did not take into consideration data for heritage properties such as churches and museums, or for large infrastructures such as bridges, roads, and railways. This is as a result of challenges with regard to data paucity, time limitations and requirement for selected parameters to be common to all chosen site locations. The current study already analysed several types of infrastructure such as properties, population, the economic value of the specific site, etc. While transportation and other large infrastructures are important for an economic consideration, these should be evaluated separately. If too many things are evaluated in one study, it leads to ambiguity, and the aim may not be addressed appropriately. However, this is an area that needs further investigation in the future.

\subsubsection{Selection of economic parameters}

For this study, economic parameters have been obtained using Balica et al.'s (2012) indicator-based methodology (Section 2.3.5; Section 4.1). Similar to their approach, 20 initial parameters were chosen, and after the analysis, the initial parameters were reduced to 12. Further following trend analysis, parameters were reduced to 6 of the most significant (Table 4.4). A detailed analysis of economic parameter choice is given in Chapter 5- section

Table 4.4: Economic parameters

\begin{tabular}{lll}
\hline Number & Economic Parameters & Designated Code \\
$\mathbf{1}$ & Commercial Properties & $\mathrm{a}$ \\
$\mathbf{2}$ & Residential Properties & $\mathrm{b}$ \\
$\mathbf{3}$ & Economic Value of Site & $\mathrm{c}$ \\
$\mathbf{4}$ & Population & $\mathrm{d}$ \\
$\mathbf{5}$ & Coastal Erosion & $\mathrm{e}$ \\
$\mathbf{6}$ & Flood Event Impact & $\mathrm{f}$ \\
\hline
\end{tabular}

\subsubsection{ECVI technical description}

Using the 2014 aerial photograph, a transect baseline was drawn across the frontage (i.e. parallel to the coast) on each of the identified coastal vulnerability sites and $1 \mathrm{~km}$ grid square 
(or cell) was drawn inland from the baseline (Figure 4.14). Subsequently, detailed measurements based upon each parameter were recorded within each identified cell. Detailed measures were offered in Chapter 8 in sub section 8.2.

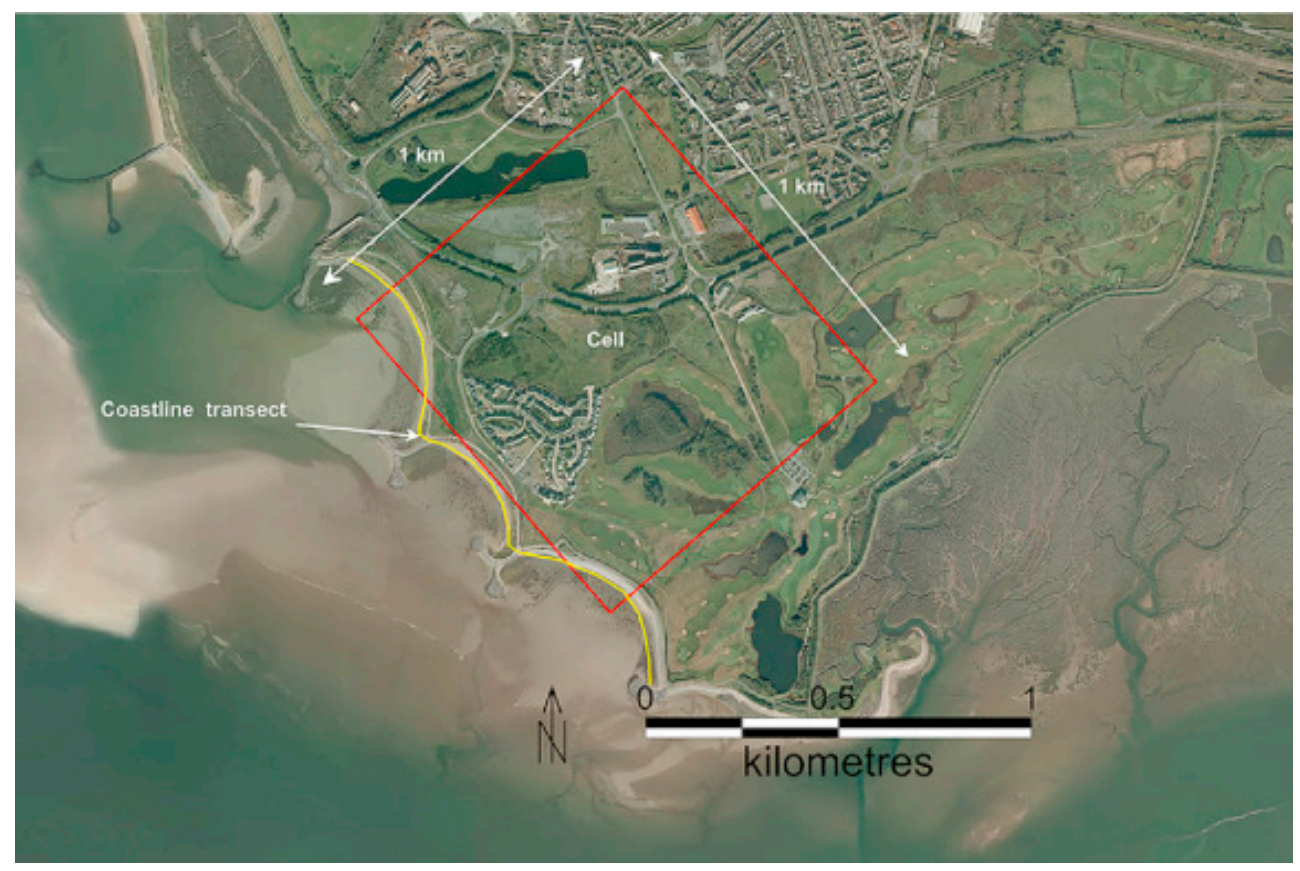

Figure 4.14: $1 \mathrm{~km}$ coastal cells on Transect line

Data was collected from various aforementioned organisations (mentioned in earlier paragraphs) regarding the number of properties (2015), cost economic value of the location and current market prices, population, and flood impact. These economic values were then used to construct Table 4.5 detailing economic thresholds for each parameter and assign a ranking score between 1 and 5. The individual cell measurements were then compared and contrasted with Table 4.6 and assigned a ranking score between extremely low (1), low (2), moderate (3) high (4) and extremely high (5) to assess vulnerability quantitatively. With rankings applied, these values were then summed for each location to provide a relative CVI score using Comparative ECVI $=\mathrm{a}+\mathrm{b}+\mathrm{c}+\mathrm{d}+\mathrm{e}+\mathrm{f}$, where " $\boldsymbol{a}$ to $\boldsymbol{f}$ " are the respective ranking score for each parameter (equation 1; section 4.3.2). The ECVI value would range between a minimum value of 6 and a maximum of 30 . These scores were utilised (Table 4.5 and Table 4.6) to categorise the level of economic vulnerability for each location. 
Table 4.5: Rating economic coastal vulnerability parameters ( $\mathrm{m}$ - millions; bn- billions) (Rates are for the period of 2013-2015)

\begin{tabular}{|c|c|c|c|c|c|}
\hline \multirow[b]{2}{*}{$\begin{array}{l}\text { Economic } \\
\text { Parameter }\end{array}$} & \multicolumn{5}{|c|}{ Economic Threshold } \\
\hline & $\begin{array}{c}1 \\
\text { Extremely Low } \\
£\end{array}$ & $\begin{array}{c}2 \\
\text { Low } \\
£\end{array}$ & $\begin{array}{c}3 \\
\text { Moderate } \\
£\end{array}$ & $\begin{array}{c}4 \\
\text { High } \\
£\end{array}$ & $\begin{array}{c}5 \\
\text { Extremely } \\
\text { High } \\
£\end{array}$ \\
\hline $\begin{array}{l}\text { Commercial } \\
\text { Properties }\end{array}$ & $<2 \mathrm{~m}$ & $2-10 m$ & $>10-30 m$ & $>30-70 m$ & $>70 \mathrm{~m}$ \\
\hline $\begin{array}{l}\text { Residential } \\
\text { Properties }\end{array}$ & $<30 \mathrm{~m}$ & $30-80 m$ & $>80-130 \mathrm{~m}$ & $>130-180 \mathrm{~m}$ & $>180 \mathrm{~m}$ \\
\hline $\begin{array}{l}\text { Economic Value } \\
\text { of Site }\end{array}$ & $<10 \mathrm{~m}$ & $10-50 m$ & $>50-100 m$ & $>100-150 \mathrm{~m}$ & $>150 \mathrm{~m}$ \\
\hline Population & $<500$ & $500-2,000$ & $>2,000-5,000$ & $>5,000-10,000$ & $>10,000$ \\
\hline Coastal Erosion & $<0.3 \mathrm{~m}$ & $0.3-2.5 \mathrm{~m}$ & $2.6-5 \mathrm{~m}$ & $>5-9 m$ & $>9 \mathrm{~m}$ \\
\hline $\begin{array}{l}\text { Flood (event) } \\
\text { Impact }\end{array}$ & $<3 \mathrm{~m}$ & $3-9 m$ & $>9-15 \mathrm{~m}$ & $>15-35 m$ & $>35 \mathrm{~m}$ \\
\hline
\end{tabular}

Table 4.6: ECVI relative ranking

\begin{tabular}{|l|l|}
\hline \multicolumn{1}{|c|}{ Total Relative Vulnerability Score } & \multicolumn{1}{|c|}{ Range of Vulnerability } \\
\hline$<\mathbf{1 2}$ & Extremely Low \\
\hline $\mathbf{1 2 - 1 5}$ & Low \\
\hline $\mathbf{1 6 - 1 8}$ & Moderate \\
\hline $\mathbf{1 9 - 2 2}$ & High \\
\hline $\mathbf{2 3 - 3 0}$ & Extremely high \\
\hline
\end{tabular}

\subsubsection{Economic parameters threshold}

Economic parameters threshold was achieved by the analysis of statistical information obtained from various government organisations such as Local Authorities, Office of National Statistics (ONS), Environment Agency, the Met Office, BGS, and others for the period 2013-2015. Each of the selected economic parameters is specific and contributes similarly (equally) towards the economic coastal vulnerability measurement. Accordingly, they are equally weighted on a measurement scale (1-5). However, the threshold for these 
parameters is allocated based on an analysis of the data, which was obtained from different organisations (above mentioned) and then compared with current international/national market rates, particularly for residential and commercial properties. Global property values reached $£ 153$ trillion in 2015 , and residential property value is $£ 113$ trillions (tn). There are 2.5 bn households in the world, and the average residential house price is $£ 35,055$. According to international trade market value, total residential housing stock in the UK has been valued at $£ 6.17 \mathrm{tn}$. However, the local organisation's value for UK properties is 6.01 tn, which is lower than the international market value (Savills World Research, 2016). In these circumstances, the research found that there was no considerable difference between international market rates and the UK organisation's data (rates) for residential and commercial properties for the 11 selected sites, but a considerable difference was identified for other UK locations such as London, Southampton, Birmingham, and Winchester. Therefore, all property rates for the 11 sites for 2013-2015 were analysed based upon data provided with thanks from the respective local authorities. This data was used to develop an economic 1-5 scale given in Table 4.5 .

Estimated commercial and residential property costs per $\mathrm{km}-2$ was calculated using equations 1 and 2. Where, the cost of commercial properties (cp) was estimated by comparing the average commercial property valuation (cpv) within each cell, with the actual number measured (mcp). Similarly, the cost of residential properties (rp) was estimated by comparing the average residential property valuation (cpv) within each cell, with the actual number measured (mrp).

$$
\begin{aligned}
& \mathrm{cp}=\mathrm{cpv} \mathrm{x} \operatorname{mcp} \ldots \ldots \ldots \ldots \ldots \ldots \ldots(\text { equation } 1) \\
& \mathrm{rp}=\operatorname{rpv} \mathrm{x} \operatorname{mrp} \ldots \ldots \ldots \ldots \ldots \ldots \ldots(\text { equation } 2)
\end{aligned}
$$

Population was the only non-economic parameter used in the analysis, with data provided by the Local Authority that consisted of overall population density (tpd), total number of residential homes (trh) and the number of unoccupied residential homes (turh). From this data, both the number of residents/residential home (nrrh) and percentage occupancy (po) was calculated using the following formulae. 


$$
\begin{gathered}
\mathrm{n}_{\mathrm{rrh}}=\frac{\mathrm{t}_{\mathrm{pd}}}{\mathrm{t}_{\mathrm{rh}-} \mathrm{t}_{\mathrm{urh}}} \cdots \\
\mathrm{P}_{\mathrm{o}}=\frac{\mathrm{t}_{\mathrm{urh}}}{\mathrm{t}_{\mathrm{rh}}} \mathrm{X} 100
\end{gathered}
$$

Google Earth and Ordnance Survey maps were used to estimate the total number of residential properties $\left(\mathrm{p}_{\mathrm{kms}}\right)$ within each $1 \mathrm{~km}$ square.

$$
\text { Population } \mathrm{km}^{-1}=\mathrm{p}_{\mathrm{kms}} \mathrm{x}(1) \mathrm{x}(2)
$$

For the remaining parameters, for example coastal erosion, flood damage impact, and economic value of each site, Local Authorities and Met Office data were analysed and compared. Literature searches (sections 3.3, 3.8, 3.9, 3.10 and 4.4) identified flood impact and coastal erosion as important factors in the analysis of coastal vulnerability. Therefore, data on flood impact and/or coastal erosion for the last decade was assessed for all selected sites.

\subsection{Comparison of PCVI and ECVI}

To assess a locations combined physical and economic vulnerability, computed scores for each location were averaged, summated and then divided by two, giving a value between 1 and 29 (equation below)

$$
C C V I=\frac{(\text { Average } P C V I+\text { Average } E C V I)}{2}
$$

For example, Spurn head combined Physical vulnerability score was 132 obtained from 6 cells, while; an overall score of 22 was obtained from 2 cells.

$$
\begin{gathered}
C C V I=\frac{(132 / 6+22 / 2)}{2} \\
C C V I=\frac{(22+11)}{2}=16
\end{gathered}
$$


Therefore, a vulnerability score of 16 would suggest that the coastal location is at moderate risk and in this case, the management response would suggest that further studies be carried out before any long-term proposals are formulated. 


\subsection{Summary}

The literature review and physical background sections identified the research gaps as well as the necessity of development of new methods to evaluate combined coastal vulnerability (physical and economic) of the UK. Accordingly, this chapter described the selection of coastal vulnerability hotspots across the UK along with the process of the methodological approaches as follows:

I. Evaluation of combined coastal vulnerability of the UK by development and application of PCVI, ECVI and then subsequently further development of CCVI based on PCVI and ECVI results.

An evaluation of recent temporal trends, which have influenced the choice of physical and economic parameters, alongside detailed descriptions of parameter selection process is given in Chapter 5. 


\section{CHAPTER 5 - DATA EVALUATION AND PARAMETER SELECTION}




\section{Data evaluation and parameter selection 5.1 Introduction}

Having dealt with the methodological frameworks for estimating physical and economic vulnerability (Chapter 4) and it is now necessary to explore the analysis of physical and economic parameters. It is also pertinent to address sea level rise, population trends, and perception, which are interlinked with the selection of economic parameters.

\subsection{Precipitation}

Temporal precipitation and time series produced from seasonal data shows a clear positive trend indicative of a temporal annual increase in rainfall during autumn, spring (Figure 5. 1a) and winter months (Figure 5. 1b). This was contrasted against a negative trend indicative of a temporal reduction in rainfall during summer months (Figure 5. 1b). A regression model was constructed using annual rainfall data for the UK, showed that positive correlation existed as given by the equation $y=0.6015 x-83.434$ (Figure 5.1c). Even though the model coefficient of determination $\left(\mathrm{R}^{2}\right)$ explained less than $1 \%$ of the data variation, it suggested that between 1910 and 2016 a statistically significant linear trend existed $(p<0.01)$, suggesting that there was an increase in UK rainfall through time of circa $1 \mathrm{~mm} \mathrm{yr}^{-1}$. 

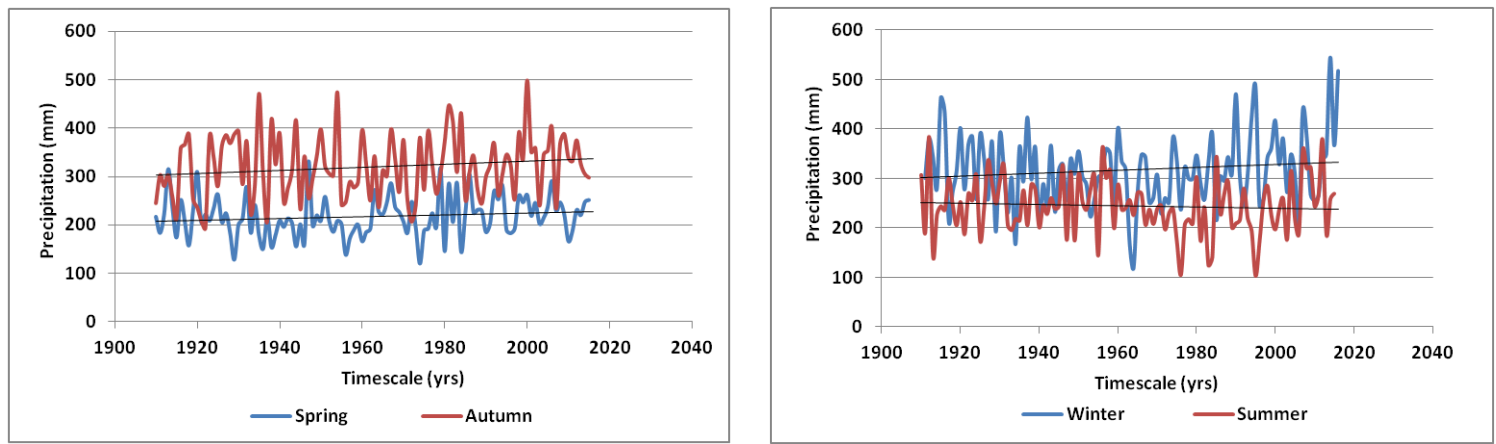

a)

b)

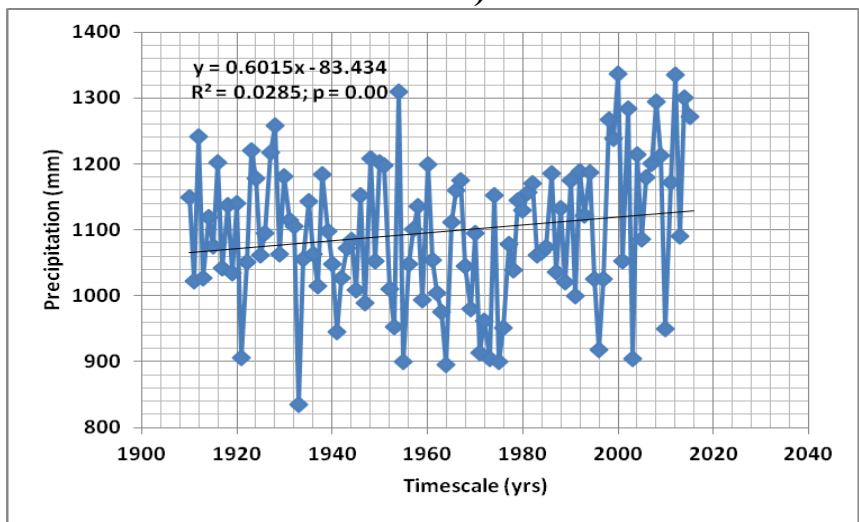

c)

Figure 5.1: Annual average precipitation rates for the UK in-between 1910-2016 a)

Spring and Autumn values, b) Summer and winter values and c) overall average values.

\subsection{Population}

Annual population data for the UK was obtained from the Office for National Statistics for the period between 1972 and 2014. A regression model constructed from temporal changes showed high positive correlation indicating a consistent increasing trend, given by the regression equation $\mathrm{y}=11707 \mathrm{x}-2 \mathrm{E}+07$. The regression model coefficient of determination $\left(\mathrm{R}^{2}=79 \%\right)$ showed that a significant percentage of data variation was explained by the passage of time $(\mathrm{p}=0.00)$ (Figure 5.2). The UK population is projected to increase by 9.7 million over the next 25 years from an estimated 64.6 million in mid-2014 to 74.3 million in mid-2039 (ONS, 2014). 


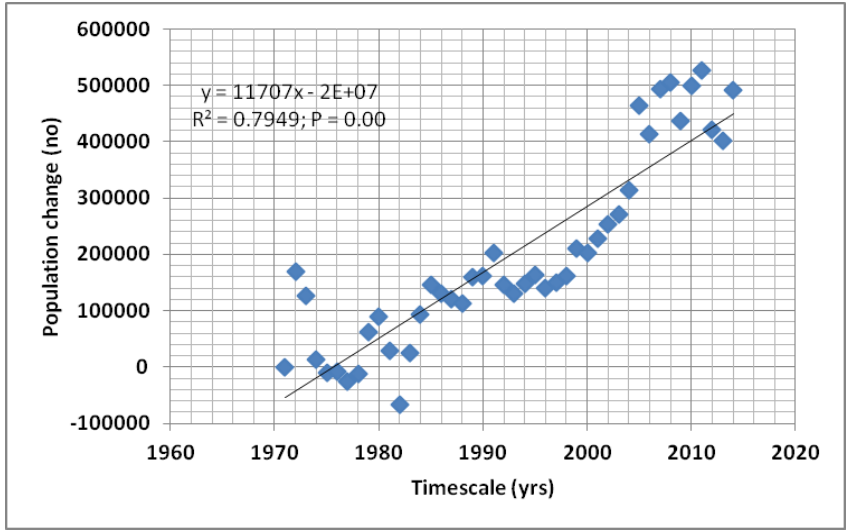

Figure 5.2: Temporal Changes in the UK population from 1972 - 2014

\subsection{Sea level change}

Sea level change data (data obtained from the National Oceanographic Centre) was analysed based upon the five longest sea level records in the UK i.e. Aberdeen (1862-2011), Liverpool (1858-2011), North Shields (1896-2011), Sheerness (1834-2006) and Newlyn (1916-2011). These data are representative of annual mean values of sea level in these areas but when overall averaged values are computed the results are representative of general sea level fluctuations experienced by the UK. Prior to 1920 data was sparse and as a consequence analysis used data from 1920 to 2014.

Figure 5.3a shows time series of sea level variation from 1920 to 2014, Recently, North Shields and Sheerness have experienced the greatest rises in sea level, compared to 1920. An increase of circa $190 \mathrm{~mm}$ compared with 1920 was seen at both these sites since 1998. Until the mid-1980s, sea levels in Aberdeen had remained relatively stable when compared to the 1920 . However, every year since 1985 , sea levels have been higher. On average, in the past two decades sea levels are more than $50 \mathrm{~mm}$ higher than the baseline (National Oceanography Centre, 2014). Sea levels have been higher than 1920 by more than $100 \mathrm{~mm}$ between 2006 and 2008, with a $55 \mathrm{~mm}$ increase from 2005 to 2006 alone.

Sea levels in Liverpool and Newlyn have also increased significantly in the past few decades. Sea levels have regularly been more than $100 \mathrm{~mm}$ higher than 1920 levels at both these sites since the 1980s. In 2011 Liverpool observed the largest rise in sea level since 1920 of all five sites i.e. $312 \mathrm{~mm}$ increase from 1920 level (National Oceanography Centre, 2014).

A regression model constructed using annual average sea level variation between the four ports, highlighted a positive correlation suggesting that sea levels had risen between 1920 and 2014 (Figure 5.3b). This was given by the regression equation $\mathrm{y}=1.8419 \mathrm{x}-3548.5$. 
The coefficient of determination showed that over three quarters of sea level variation was explained by the passage of time $(\mathrm{R} 2=83 \%)$ and was indicative of a steady sea level rise of almost $2 \mathrm{~mm} \mathrm{yr}^{-}{ }^{1}$, these results concur with Phillips et al. (2013).

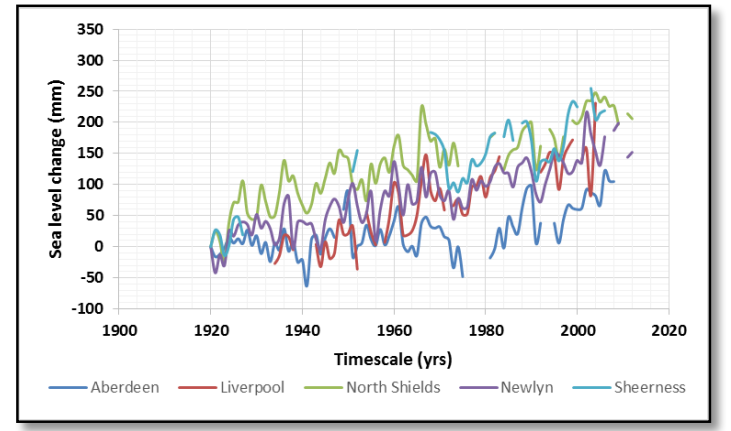

a)

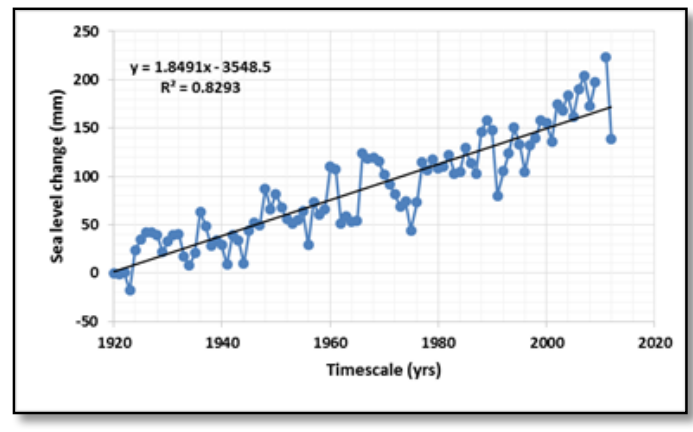

b)

Figure 5.3: Sea level changes between 1920 and 2014, a) time series showing sea level variation at four UK ports and $b$ ) time series showing overall average change

\subsection{Selection of Parameters}

For the initial analysis, this research utilised 20 economic parameters (Table 5.1; Figure 5.4), similar to Balica et al. (2012) as economic parameters. Prior to finalisation of these parameters a series of steps were involved. Initially, 20 parameters were selected based on various factors such as sea level rise, temperatures trends, and population trends.

Based on this analysis results, the parameter numbers were reduced. A reduction of the parameters for an evaluation of the economic coastal vulnerability at regional scale (UK) is necessary. Some parameters (20) are not potentially relevant in the case of the eleven identified case study areas of the UK (Example: coastal discharges and unpopulated zones), so to simplify the methodological process, they are reduced to 12 and further reduced and restricted to 6, based on the suitability and potentiality of the parameters (Figure 5.4). Parameter reduction is not a new procedure in coastal vulnerability assessment studies, and several researchers have already implemented this technique successfully. Balica et al. (2012) initially considered 71 indicators and then reduced their number to 12, and the Canadian Council of Ministries of Environment (2003) selected nearly 100 indicators, which were reduced to 12 as well. 
Table 5.1 Economic parameters with working definitions

\begin{tabular}{|c|c|c|}
\hline Number & Economic Parameter & Definition \\
\hline 1 & $\begin{array}{l}\text { Population in coastal vulnerability } \\
\text { zones }\end{array}$ & $\begin{array}{l}\text { People who are living near to coastline including } \\
\text { low-lying, and estuarine areas. }\end{array}$ \\
\hline 2 & $\begin{array}{l}\text { High growth of civilisation } \\
\text { alongside of coasts }\end{array}$ & Population growth rate alongside the coasts \\
\hline 3 & $\begin{array}{l}\text { Marine industry growth Ports } \\
\text { business, warships, sea and river } \\
\text { defences etc.) }\end{array}$ & Marine industry growth alongside the coasts \\
\hline 4 & $\begin{array}{l}\text { Infrastructure (Properties roads, } \\
\text { etc.) }\end{array}$ & $\begin{array}{l}\text { Types of infrastructure in coastal zones } \\
\text { (Did not include Transport) }\end{array}$ \\
\hline 5 & Urbanised area & $\begin{array}{l}\text { Based on population number and growth rate in } \\
\text { urbanised areas }\end{array}$ \\
\hline 6 & Urban growth & Based on urban population growth rate \\
\hline 7 & Land use & $\begin{array}{l}\text { Use of land for variety of reasons (Eg: } \\
\text { Infrastructure development) }\end{array}$ \\
\hline 8 & Economic value of site & Economic value of particular areas near to coastline \\
\hline 9 & Precipitation & Precipitation trends in various regions \\
\hline 10 & Coastal discharges & $\begin{array}{l}\text { Discharges of waste water and other materials into } \\
\text { coastal waters (excludes nuclear waste) }\end{array}$ \\
\hline 11 & Flood impact & How much of flood impact on coastal areas \\
\hline 12 & Drainage system & Quality of drainage system in coastal areas \\
\hline 13 & Frequency of floods & $\begin{array}{l}\text { Frequency period of flooding events and flood } \\
\text { strikes in coastal areas }\end{array}$ \\
\hline 14 & Storm insurance & $\begin{array}{l}\text { Claimed insurances in a particular period and in a } \\
\text { particular area especially in coastal areas }\end{array}$ \\
\hline 15 & Damage costs & Storm damage costs in coastal areas \\
\hline 16 & Coastal erosion & Coastal erosion impact in coastal areas \\
\hline 17 & Return period of storms & $\begin{array}{l}\text { Frequency period of various storms in coastal areas } \\
\text { particularly in coastal areas }\end{array}$ \\
\hline 18 & Coastal defences & $\begin{array}{l}\text { Coastal defence structures and viability of those } \\
\text { structures }\end{array}$ \\
\hline 19 & Preparedness and awareness & $\%$ of storm awareness and preparedness \\
\hline 20 & Unpopulated zones & $\begin{array}{l}\text { Coastal zones without inhabitants or very few } \\
\text { number of people }\end{array}$ \\
\hline
\end{tabular}



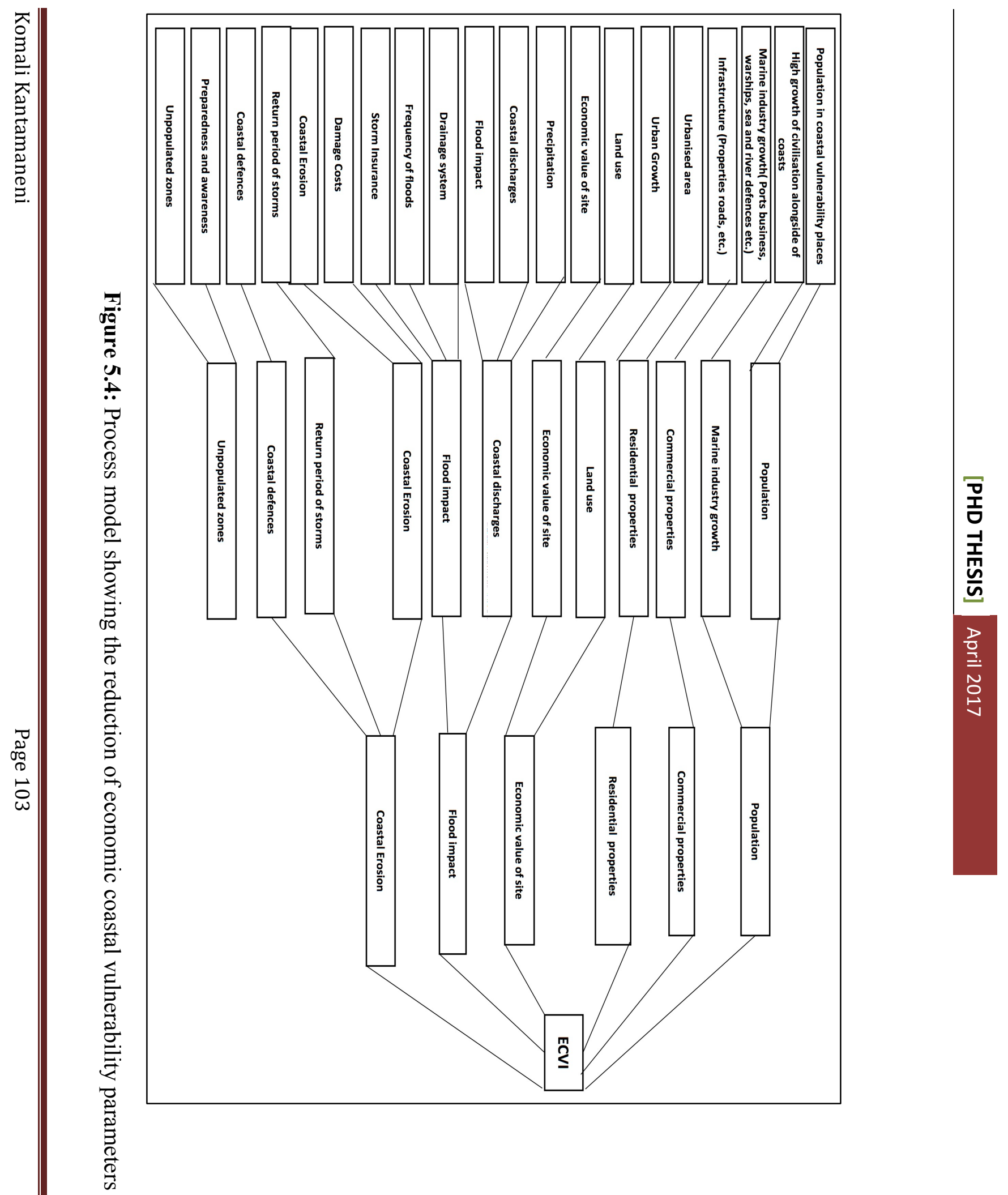


\subsection{Economic parameters description \\ a. Commercial properties}

Commercial properties are important in coastal vulnerability studies and several researchers have used this parameter in their vulnerability assessment studies in various forms (Balica et al., 2012; Gilbert and Vellinga, 1990). Meanwhile, many coastal properties are damaged by several storm events across the UK as evidenced in 2006, 2008, 2010, 2012, 2013, 2014 and 2015 (Kantamaneni and Phillips, 2016; Kantamaneni, 2016a; Kantamaneni, 2016b). This damage showed a significant impact on local economics (Kantamaneni and Phillips, 2016). Accordingly, commercial properties were selected as one of the significant parameters for this study. NASA-Google Earth Pro maps (2014 \& 2015) and Google Earth Explorer were used to identify the commercial buildings at selected sites. Economic statistics and an accurate number of commercial properties of a particular zone were obtained from UK's Office of National Statistics (ONS) and Local Authorities (2015). Figure 5.5 shows a typical measurement taken from the coast to a commercial property in Port Talbot.

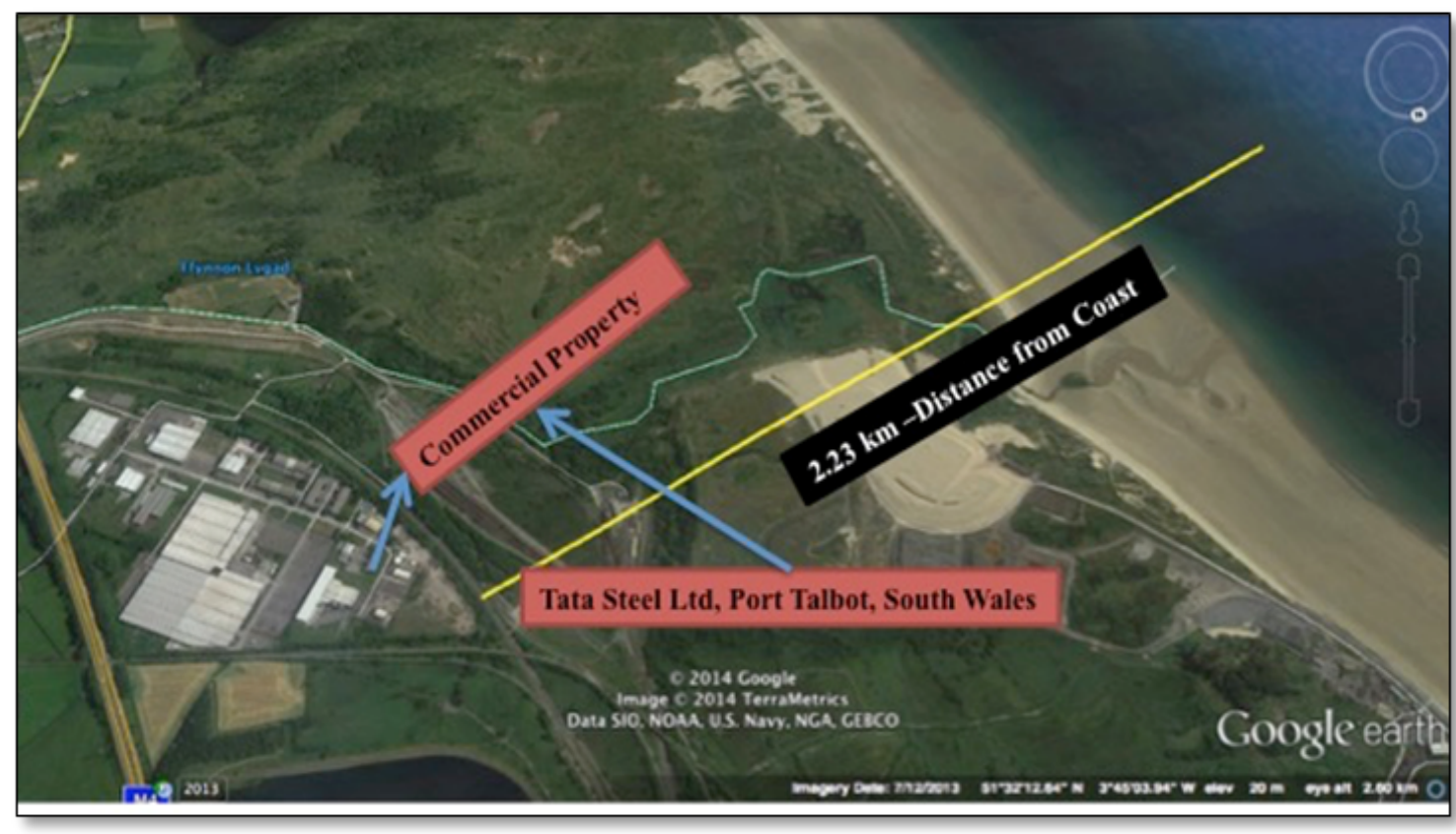

Figure 5.5: Commercial property distance measurement from coast 


\section{b. Residential properties}

Several previous studies have been highlighted that residential properties are a vital parameter in the assessment of coastal vulnerability; see, for example, Gilbert and Vellinga (1990). As a significant number of residential properties are vulnerable in some UK coastal regions, this research considered residential properties as one of the potential evaluation parameters. NASA-Google Earth Pro, Google Street maps and ordnance survey maps (2014 $\& 2015)$ were used to identify the number of properties. However, the statistics of properties, the economic value, and the numbers were obtained from insurance companies, the Office of National Statistics (ONS), and Met Office organisations. This type of measurement reflects coastal settlement vulnerability and Figure 5.6 shows typical measurements that were taken from the coast to the line of residential properties.

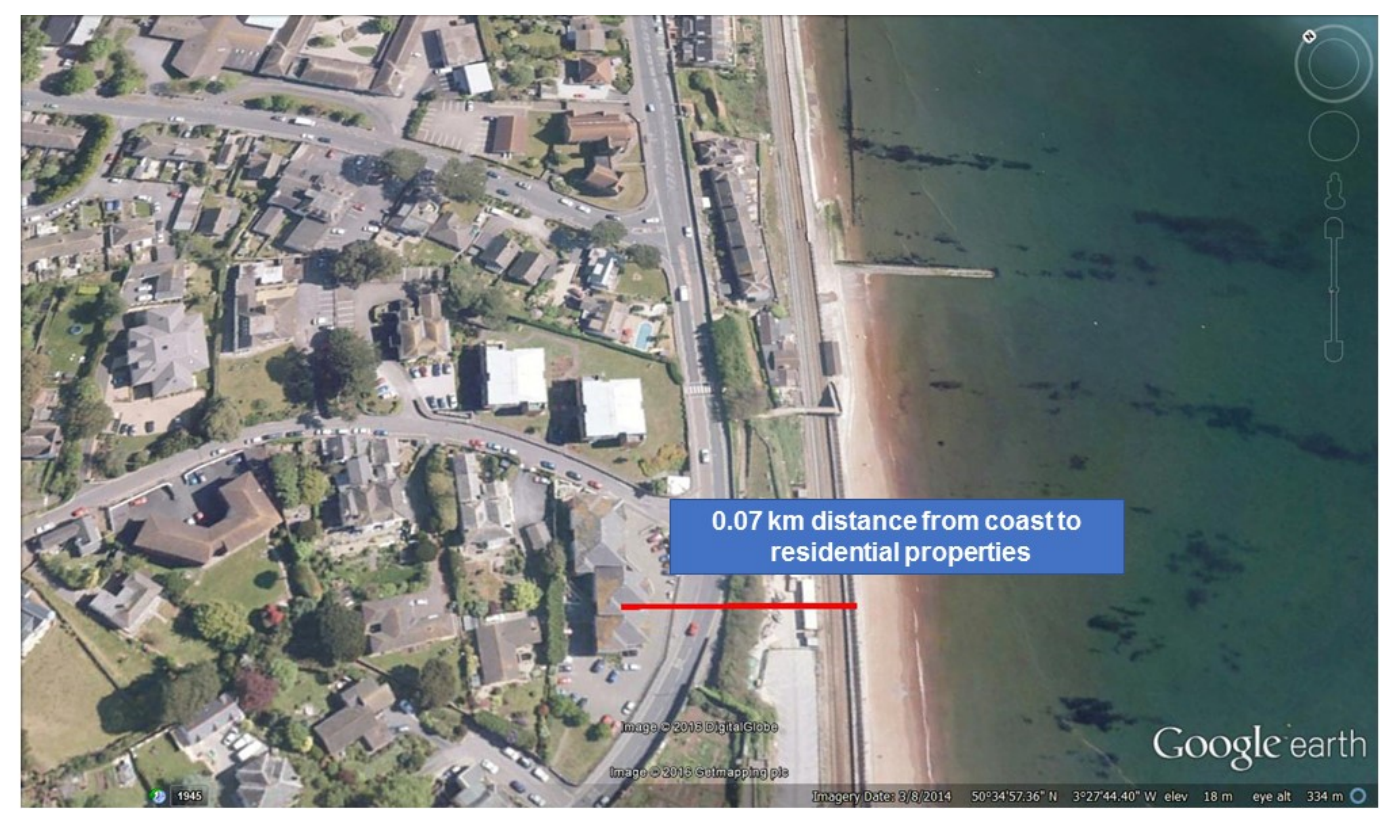

Figure 5.6: Residential properties distance measurement from the coast at Dawlish

\section{c. Economic value of site}

The economic value of sites (Figure 5.7) in particular coastal zones is used as a significant parameter in evaluating coastal vulnerability in the modern era. However, it is a challenging task to estimate land and site value based on current circumstances and market fluctuations (Fausold and Lilieholm, 1999). ONS, insurance companies, housing agencies, and Local Authorities data are utilised for the economic valuation of a particular place. Not only that but also considered various factors like intensity of exposure to flood frequency, coastal erosion, tourist zone, industrial area, and pollution. Subsequently, ECVI values are offered. 


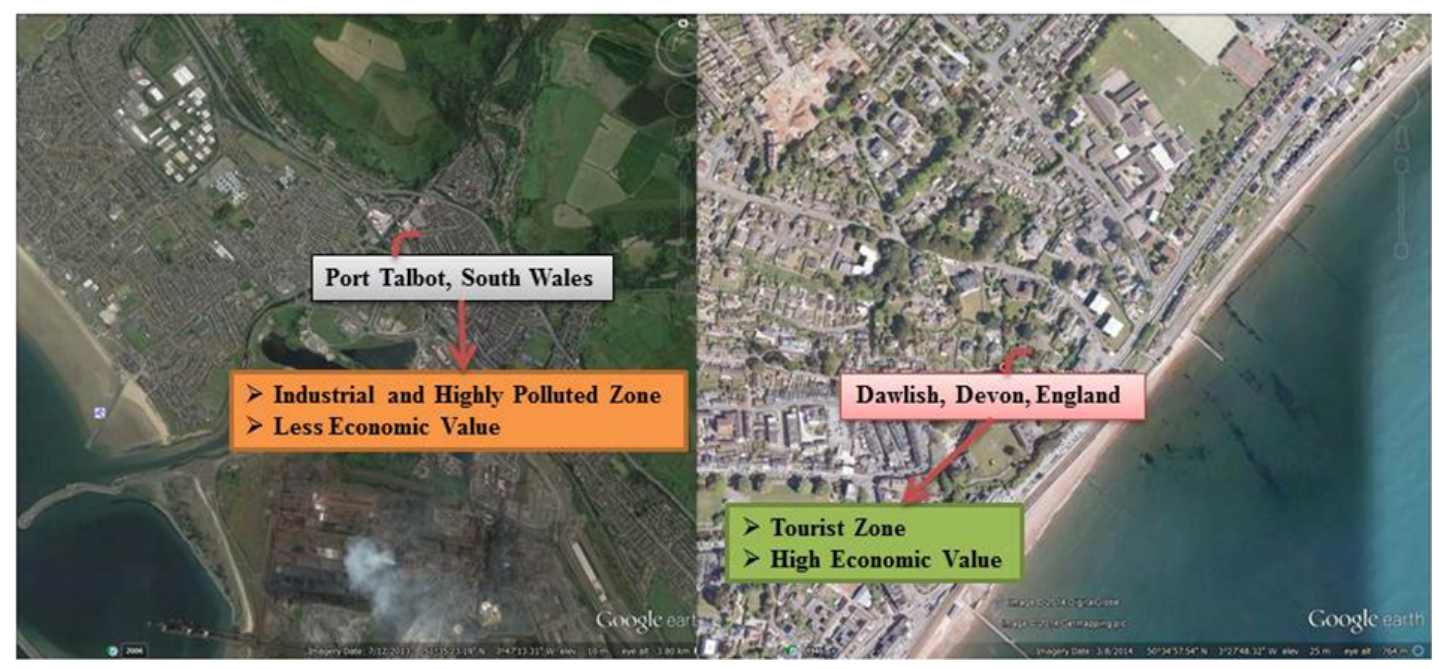

Figure 5.7: Assessment of economic value of site

\section{d. Population}

This parameter is also an important element in ECVI assessment (Figure 5.8). Several researchers have used this parameter in their coastal vulnerability studies such as Vittal Hegde and Radhakrishnan Reju (2007) and Kantamaneni (2016). Several large swathes of coastal communities are exposed to coastal hazards every year across the UK in particular at coastal regions (Kantamaneni and Phillips, 2016). Therefore, population is selected as a significant parameter. However, this study measured the population in terms of thousands (non-economic) rather than in monetary terms because it is unusual to offer economic consequences to the population $^{1}$ (with the exception of Kantamaneni, 2016a). Therefore, this type of measurement reflects the vulnerability of coastal settlements as well as coastal zones in the United Kingdom. Google Earth NASA maps are used for the estimation of populations in selected sites. However, accurate population statistics were also obtained from Local Authorities for particular areas.

${ }^{1}$ It is rather difficult to offer the same economic figure to the 11 coastal area people under the cost of life. Accordingly, I did not provide any economic consequences to the population of 11 identified (selected) areas of the UK. 


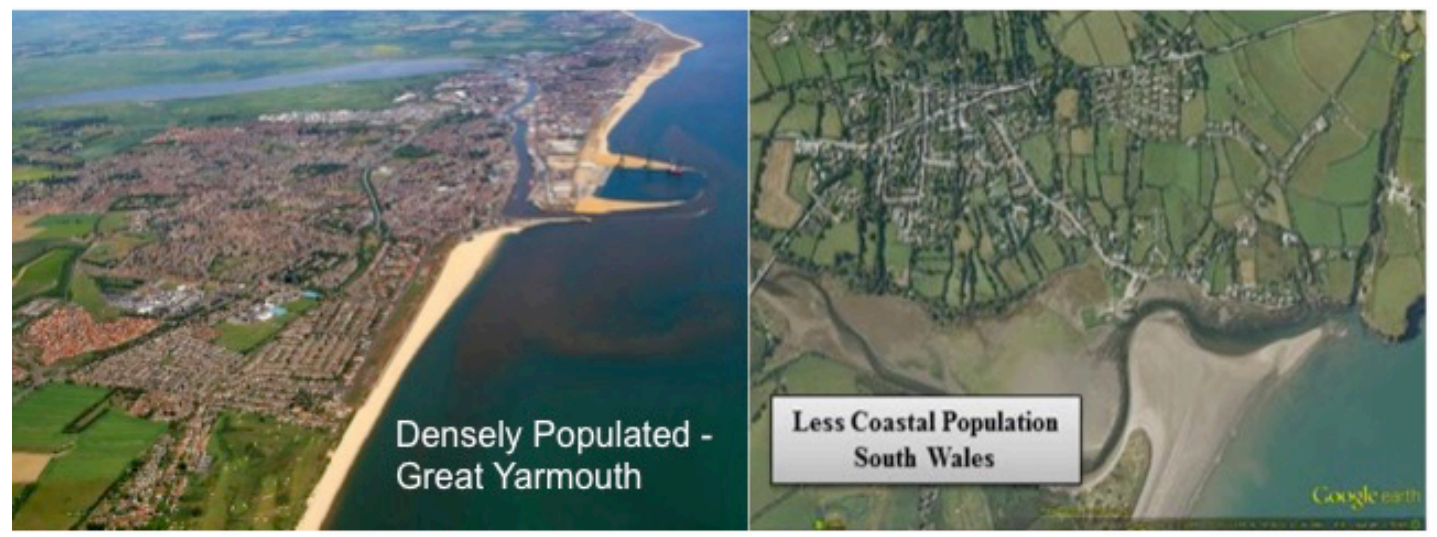

Figure 5.8: High and low density of population in different coastal areas of the UK

\section{e. Coastal erosion}

This parameter is also an impact factor in the assessment of coastal vulnerability (Boruff et al., 2005). Coastal erosion is one of the biggest problems in some coastal regions of the UK and is particularly high in England, where several kilometres of coastline have already disintegrated into the sea (Thorne et al., 2007). Accordingly, this study selected coastal erosion as a significant parameter. NASA Google Earth Pro, Ordnance Survey satellite images, and Orthophotographs are used. Infrastructure damage due to coastal erosion was also evaluated in economic terms with data of damage statistics obtained from insurance companies (private and public), the Office of National Statistics (ONS), the Met Office, and the British Geological Survey.

\section{f. Flood impact}

The literature review highlighted that flood events play a significant role in coastal change coupled with a rising global and regional sea level, they are likely to become of increasing significance in coastal erosion. Especially, coastal floods are the greatest threat to the coastal communities of the various places of England (Figure 5.9), Wales, and Scotland (Kantamaneni and Phillips, 2016). However, the geographical arrangement of coastal settlements across the United Kingdom is uneven. Besides, the heavy infrastructure established alongside the shoreline plays an important role in the building of the national economy. Therefore, additional considerations are necessary when evaluating the probability of moving settlements and infrastructure inland. For this reason, it was important to include this parameter (flood economic impact) into the index, in spite of not being a conventional economic coastal vulnerability parameter. Both the Met Office and Insurance 
companies provided these records. From historical information, it was possible to define where the most flood events had affected major coastal areas.

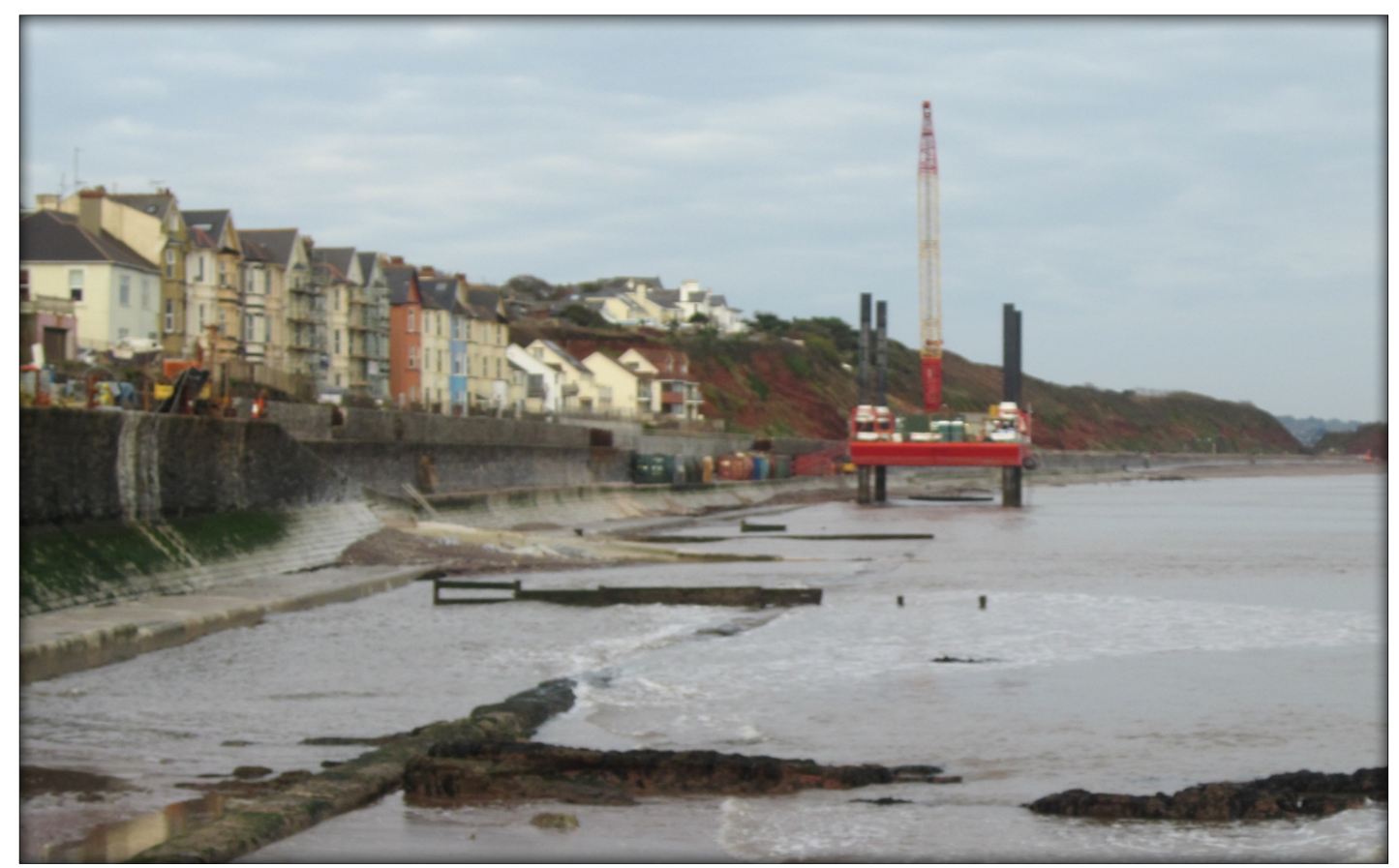

Figure 5.9: Coastal properties in Dawlish after math of 2014 flood incident

\subsection{Physical vulnerability index (PCVI) \\ 5.7.1 Physical parameters}

Denner et al.'s (2015) seminal UK work on the Welsh coast, seven physical parameters were used to estimate physical vulnerability (section 4.6.1). There follows a detailed description of the measurement principles for each parameter.

\section{a. Beach width}

Sandy beaches are extremely efficient absorbers of wave energy and, therefore, dissipate erosive energy: the wider the beach, the less vulnerable is the shoreline to the erosive power of waves (Carter and Woodroffe, 1994; Jiminez et al., 2008). Beach width was measured from the back beach (Figure 5.10) coordinates to the mean low water level MLW mark using GIS spatial datasets. Owing to variations in tidal range and the presence in some locations of deep-water channels running adjacent to the shoreline for (example Llanelli) the MLW mark differs greatly. Digimaps that comprises the Ordnance Survey maps and spatial data were used for measurement of this parameter. 


\section{b. Dune width}

Dunes are a fundamental part of the shoreline, acting as a natural barrier and the greater the width, the greater the protection Pye and Blott (2006). Dune systems are prevalent at some case study locations and therefore despite its limited usefulness across the entire study area the parameter was still considered. Dune width was measured (5.11) as the distance between a pre-determined back beach coordinate and the nearest built environment structure, or fully vegetated area, using GIS spatial databases. Digimaps that comprises the Ordnance Survey maps and spatial data were often used for measurement of this parameter.

\section{c. Coastal slope}

Determination of coastal slope provides an indication of relative vulnerability to inundation and the rapidity of shoreline retreat because low-sloping coastal regions should retreat faster than steeper regions (Pilkey, 1987). Therefore, coastal slope is very important parameter in physical vulnerability estimation studies and accordingly, for this study, a distance of $500 \mathrm{~m}$ was established to back side of beach. Google Earth's Pro (elevation profile) was used to measure this physical parameter as shown in Figure 5.12.

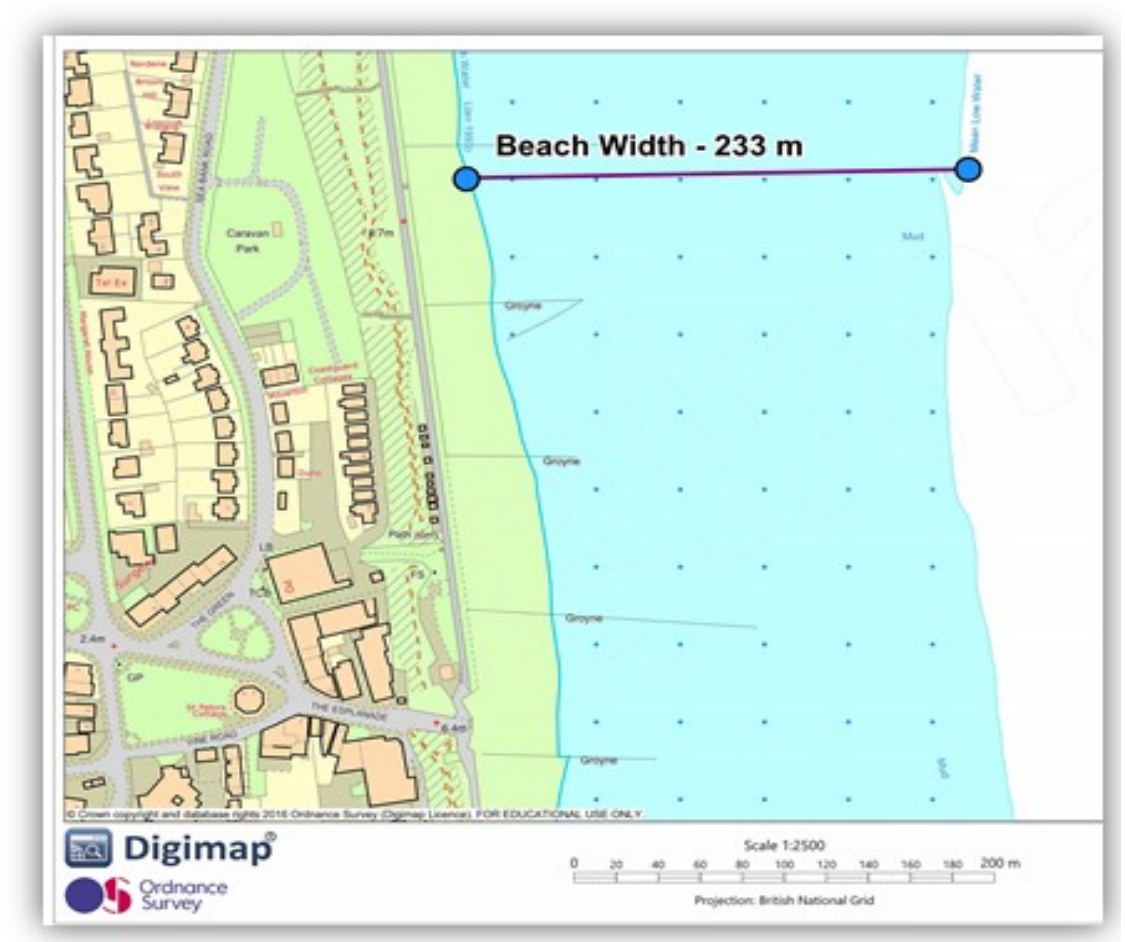

Figure 5.10: An Ordnance Survey Map showing the measurement of beach width from back beach to MLW 


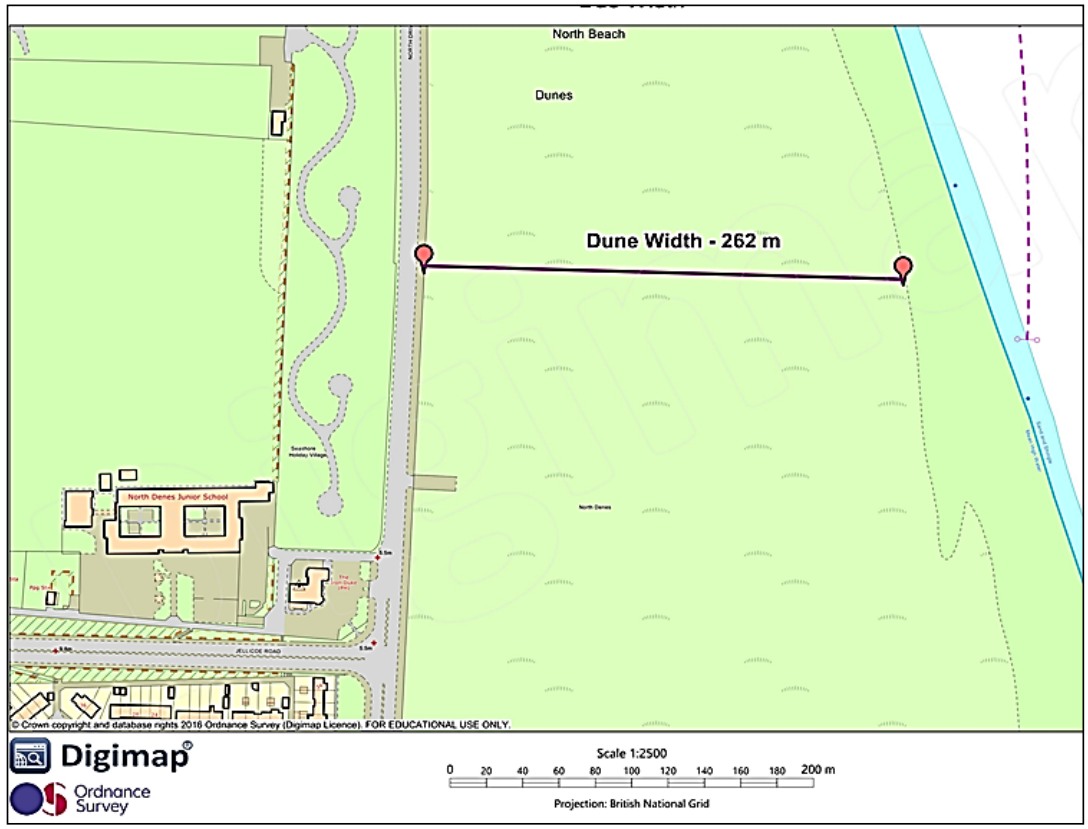

Figure 5.11: An Ordnance Survey Map showing the measurement of dune width

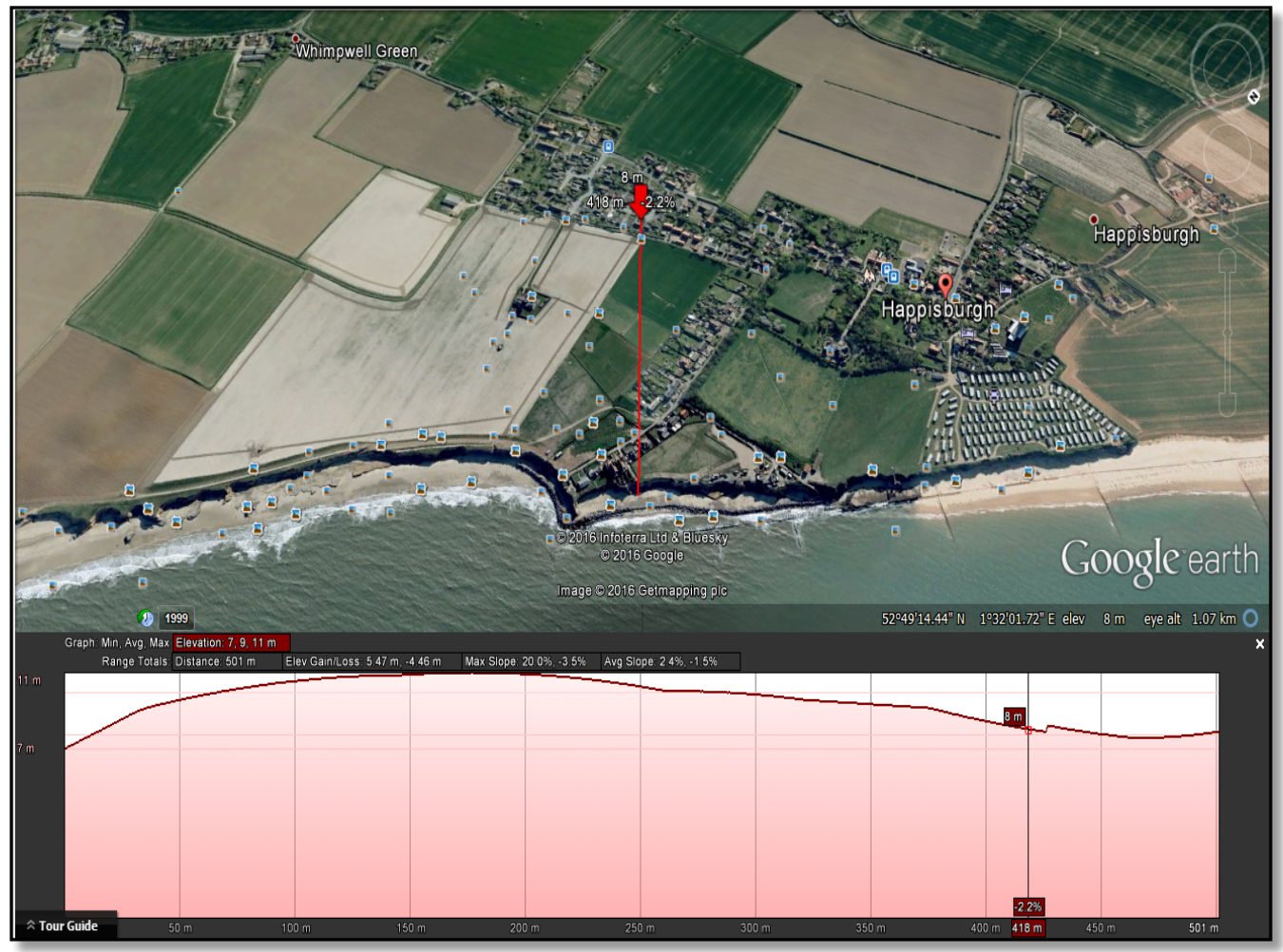

Figure 5.12: an aerial photograph and section through (inset) showing coastal slope measurement from the back-beach elevation and highest and lowest elevation points are depicted in red 


\section{d. Distance of vegetation behind the back beach}

For this study, a distance of $500 \mathrm{~m}$ was chosen to measure the distance of vegetation behind the back beach (Figure 5.13). In areas where foliage did not extend beyond built structures, vegetation was measured to that point. Built structures such as paths, roads, and railways were measured for width and deducted from the total vegetation if there was significant vegetation expanse beyond these structures. Digimaps that comprises the Ordnance Survey maps and spatial data were used for measurement of this parameter.

\section{e. Distance of built structures behind the back beach}

For this study, a distance of 500m was also chosen to measure the distance of built structures (Figure 5.14) such as paths, roads, railways, private and commercial buildings behind the back beach. In areas where foliage was encountered, the vegetation was measured and the total vegetation deducted from the built structure expanse.

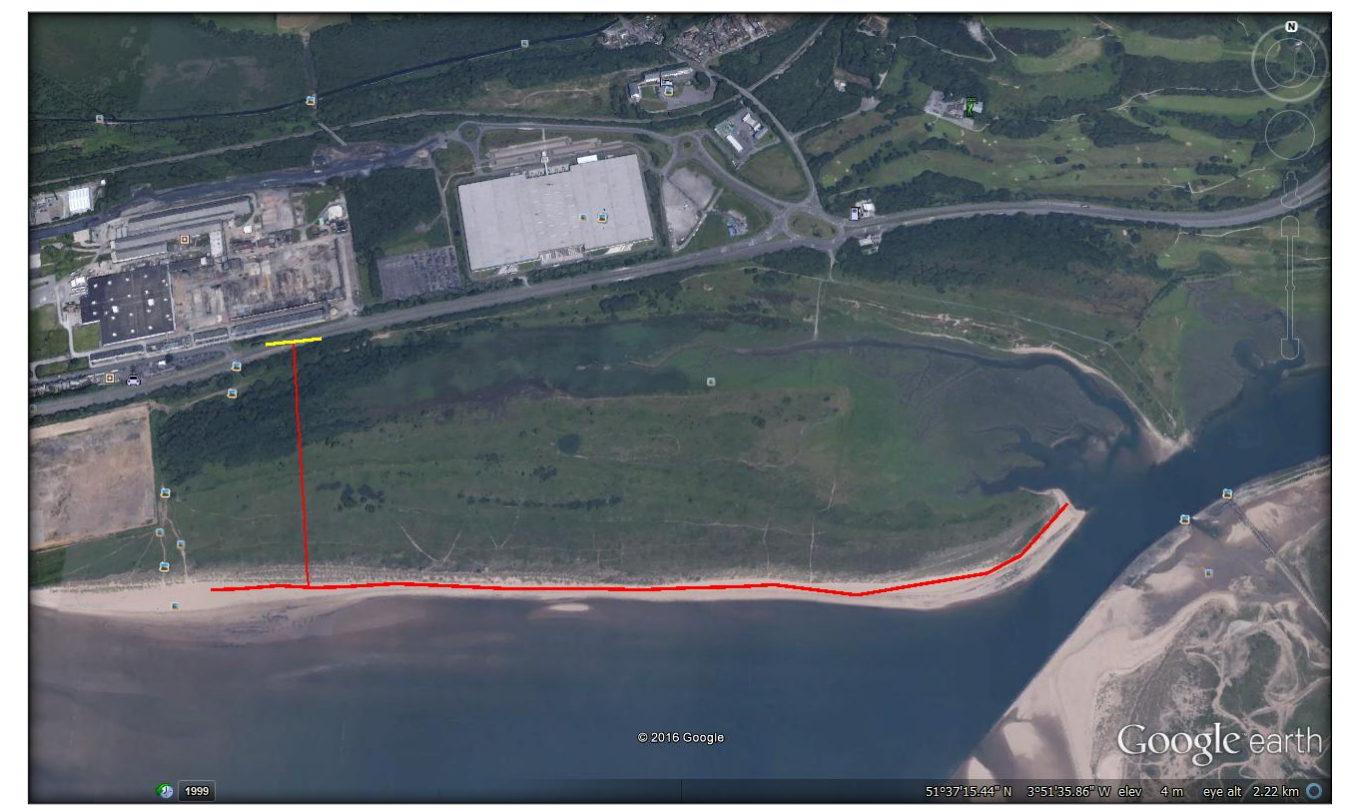

Figure 5.13: An aerial photograph showing the measurement of back beach vegetation to 500m inland distance line 


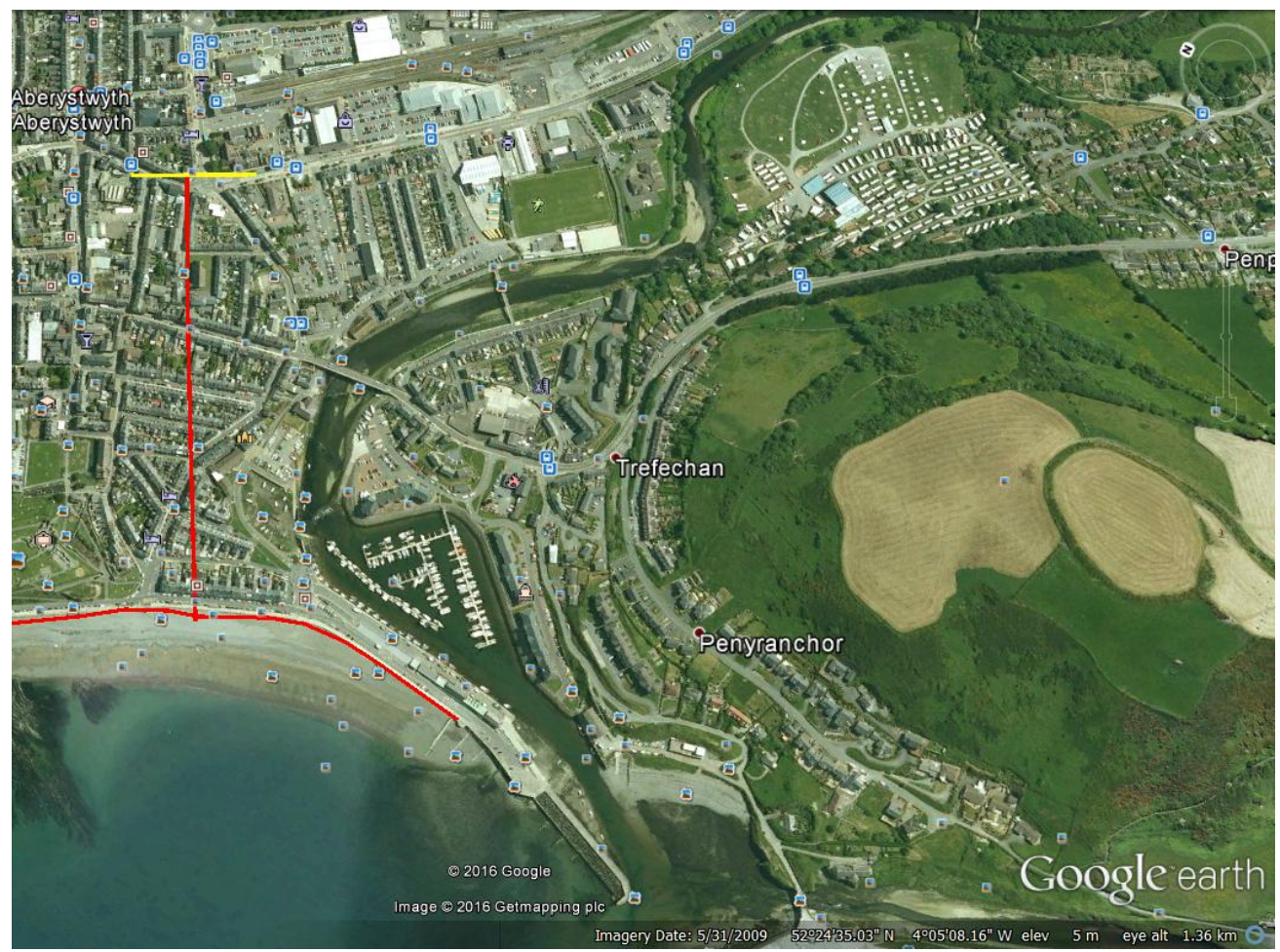

Figure 5.14: An aerial photograph showing the measurement of built structures behind the back beach

\section{f. Percentage of rocky outcrop}

The coastal landform least vulnerable to sea level rise and impacts of coastal erosion are rocky coasts (Gornitz et al., 1991). Therefore, the width of these structures within individually surveyed cells was measured and included as the percentage of rocky outcrop (Figure 5.15) along the transect line between MSL and back beach coordinates and all measurements were calculated using a combination of GIS and Orthophotographs.

\section{g. Sea defences}

Sea Defences are protection structures, which are constructed along the shoreline. These structures comprise a variety of material such as rock revetment, solid wall, timber, natural, rock. Coastal defences protect the shoreline, properties and people from coastal erosion, flooding. Therefore, sea defence was selected as one of the significant parameters for this 
study. Figure 5.16 shows typical measurements and these were based upon percentage shoreline coverage within each cell.

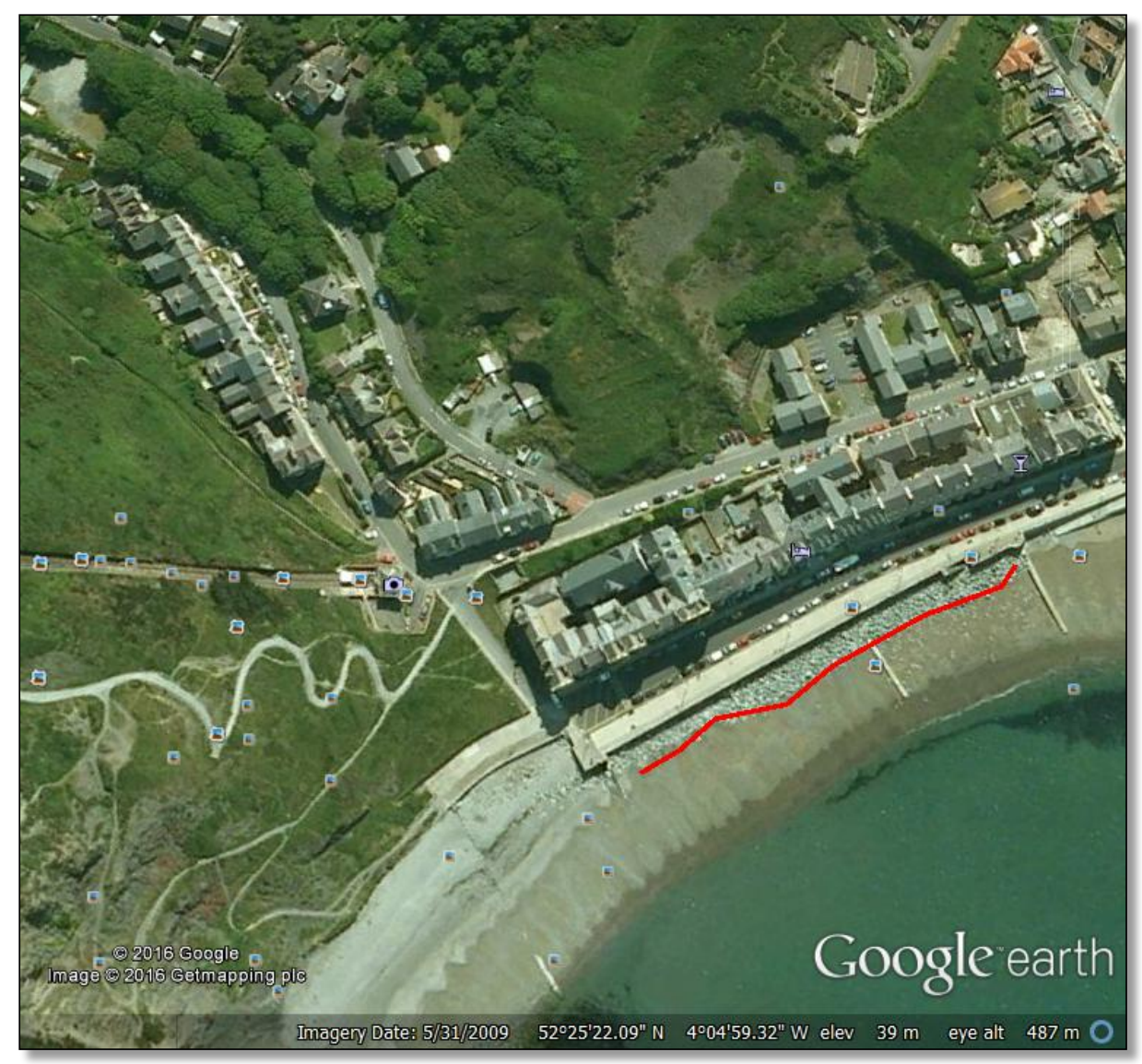

Figure 5.15: Rocky outcrop 


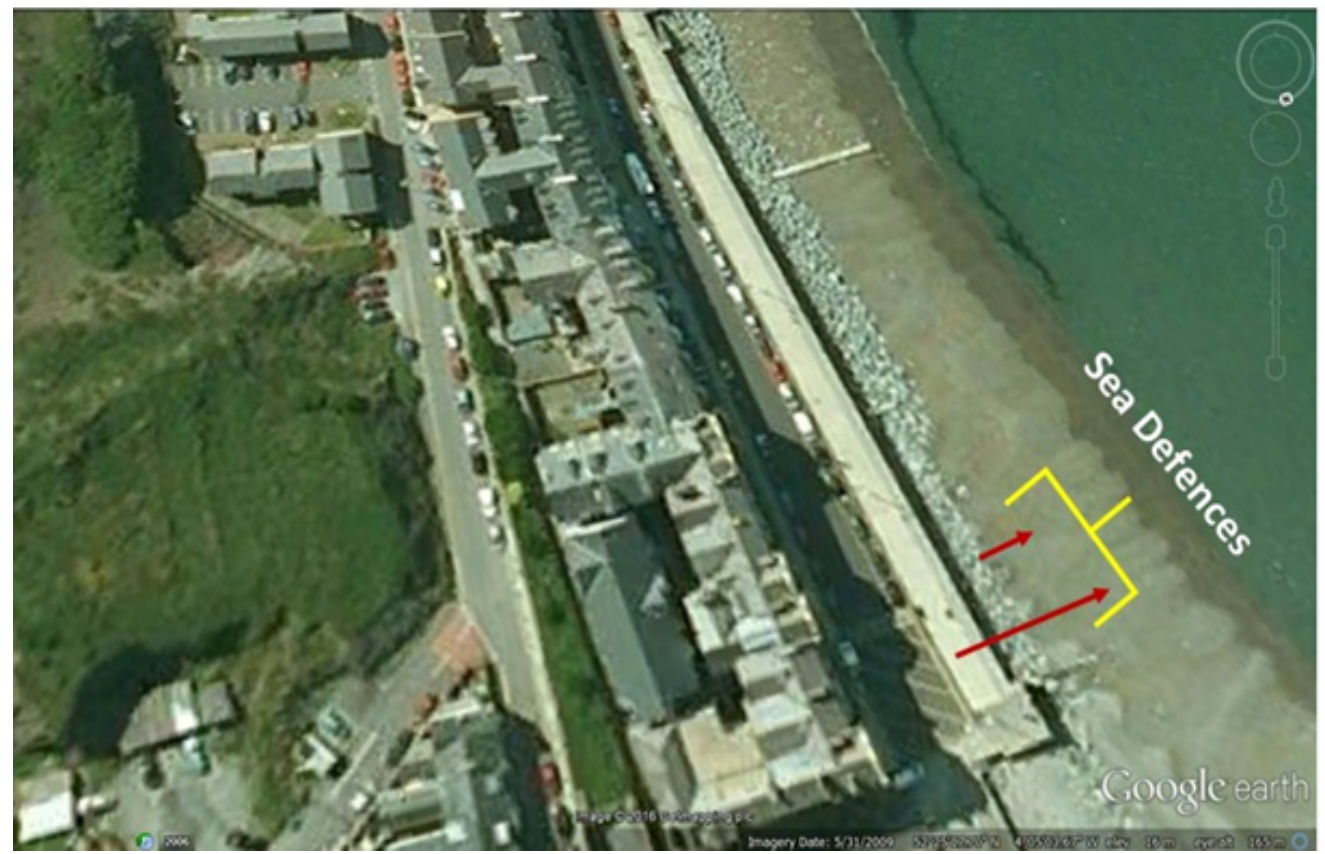

Figure 5.16: Sea defence structures

\subsection{Accuracy of NASA- Google Earth Maps and Data}

There are two kinds of accuracy regarding google maps. One is the positional accuracy and the other is image accuracy (resolution of the images).

Undoubtedly, Google Earth has become the ultimate source of spatial data and information for private and public decision-support systems for social interactions. Respect to the imagery accuracy, it is very accurate (with very high resolution). Most land areas are covered in satellite imagery with a resolution of about $15 \mathrm{~m}$ per pixel. This base imagery is $30 \mathrm{~m}$ multispectral Landsat which is pan sharpened with the $15 \mathrm{~m}$ Landsat imagery. Quality is improved in most population centers with the areas covered by aircraft imagery (orthophotography) with several pixels per meter. While oceans are generally, covered at a much lower resolution (NASA-EOSDIS, 2016). In an investigation, the researchers compared virtually traced positions against high-precision $(<1 \mathrm{~m})$ field measurements along three stratigraphic unconformity sub-sections in the Big Bend region to determine current positional accuracy for the Google Earth terrain model. A horizontal position accuracy of 2.64 m RMSE was determined for the Google Earth terrain model with mean offset distance being $6.95 \mathrm{~m}$. (Benker et al., 2011).

With more than 200 million users since its release in June 2005, Google Earth is recognised for its potential to significantly improve the visualisation and dissemination of scientific data. Some experts have recently begun using this cost-free imagery source (Potere, 2008) Komali Kantamaneni 
for their scientific research. It is common to use NASA's Google Earth maps (in various scales) and data to evaluate socioeconomic vulnerability in scientific research, evidenced by a research paper by Pulighe et al. (2016), Physical coastal vulnerability studies have also benefited from the use of google maps (see for example Palmer et al., 2011 and Denner et al., 2015).

The work of Douglas et al. (1998) demonstrated that combined errors inherent with early aerial photographs could be of the order of 7.5-8.9 m. Root Mean Square Error (RMSE), which is the most commonly used measure of accuracy. It is the squared differences between data set co-ordinate values, and co-ordinates from an independent more accurate source for identical points. Corrections should be kept as low as possible (Moore, 2000). Mohammed et al. (2013) using Google earth free source of data, evaluated both horizontal and vertical accuracy by comparing measured Google Earth coordinates with dGPS receiver coordinates. Root Mean Square Error (RMSE) was computed for horizontal coordinates and was found to be $1.59 \mathrm{~m}$. For height measurement RMSE was computed to be $1.7 \mathrm{~m}$. This compares favourably with other coastal research studies (see for example Thomas et al., 2010; Thomas et al., 2011, Thomas et al., 2014; Alharbi 2015). Even though, there was no scope to identify the error using control surveys at this stage, the work of Mohammed et al. (2013) suggests that achieved RMSE values are suitable to determine coastal change. However, it is recognised that control surveys along cell boundaries and at transect locations would enhance results and is recommended for any future work. To further enhance research accuracy, both Google imagery and Street maps were compared and to reduce the potential for human error, only one analyst was used for quantification.

However, economic parameter information (how many properties in a particular area) was gathered from Local Authorities and other reliable organisations. Based on that information, NASA's Google Earth maps were used to measure per-square-km resolution at selected sites (how many properties per square $\mathrm{km}$ at identified sites) to evaluate vulnerability for the current study. 


\subsection{Summary}

This chapter described the sea level rise, population trends, and perception, which are interlinked with the selection of economic parameters and then finalised the six economic parameters with appropriate examples. Meanwhile, this section also explored the seven physical parameters using appropriate aerial photographs and Ordnance survey maps within a GIS environment. The next chapter (chapter 6) will appraise the measurements of physical parameters applied to the 11 case studies. 


\section{CHAPTER 6 - PCVI}




\section{Physical coastal vulnerability index (PCVI) 6.1 Introduction}

Chapter 1 (section 1.1) identified that climate change and particularly SLR will have worldwide effects on low lying and heavily populated coastal areas and provided study aims and objectives. Literature searches (sections 2.3, 3 and 3.4) highlighted the severity and drivers that influence coastal change and discussed current thinking in in terms of risk evaluation and determination of coastal vulnerability extend. These underpinned the selection of case study sites and suitable methodologies (Chapters 4 and 5) to assess both the physical and economic vulnerability of each case study site. The following chapter assesses physical vulnerability aspects.

For the assessment coastal vulnerability the aim is to make use of characteristics and classify potential impacts of climate change on different coastal sections (Bagdanaviciute et al., 2015). Originally, CVI methods took into account factors related to the local hydrodynamic regime (tidal amplitude, wave climate etc.) and geomorphology (slope, sediment type etc.).

Firstly, this chapter analyses the susceptibility of each chosen coastal location and then combines results to identify overall vulnerability. Measurements were taken in accordance with the procedures described (PCVI methodology) in section 4.5.1 for each chosen case study location, by subdividing each shoreline frontage into $0.5 \mathrm{~km}$ cells. In total, 158 cells along $79 \mathrm{~km}$ of coastline were identified (Table 6.1). Three locations in Wales measured circa $27.5 \mathrm{~km}$ of coastline (55 cells), seven English locations measured 44 (88 cells) km and one Scottish region measured circa 8 (15 cells) km. Coastal cell measurements at particular specific locations have been evaluated based on council statistics (2013-2015) and 2015 NASA Google earth maps. In particular, lateral boundary information obtained from 11 Local Authorities (eg: Aberystwyth, Great Yarmouth, etc). 
Table 6.1: Assessed coastal locations and number of coastal cells

\begin{tabular}{|c|c|c|}
\hline Site Name & $\begin{array}{c}\text { Shoreline Measurement } \\
\text { Number/Cells }\end{array}$ & Area \\
\hline Spurn Head & 6 & \multirow{7}{*}{$\begin{array}{c}\text { England } \\
44 \mathrm{~km} \text { measured } \\
(0.5 \mathrm{~km} \text { cells }-88)\end{array}$} \\
\hline Hallsands & 8 & \\
\hline Lynmouth & 4 & \\
\hline Happisburgh & 8 & \\
\hline Dawlish & 11 & \\
\hline Great Yarmouth & 28 & \\
\hline Skegness & 23 & \\
\hline Benbecula & 15 & $\begin{array}{c}\text { Scotland } \\
7.5 \mathrm{~km} \text { measured } \\
(0.5 \mathrm{~km} \text { cells }-15)\end{array}$ \\
\hline Aberystwyth & 5 & \multirow{3}{*}{$\begin{array}{c}\text { Wales } \\
27.5 \mathrm{~km} \text { measured } \\
(0.5 \mathrm{~km} \text { cells }-55)\end{array}$} \\
\hline Llanelli & 26 & \\
\hline Port Talbot & 24 & \\
\hline
\end{tabular}

\subsection{Spurn Head}

The beach width showed significant variations ranging from $630 \mathrm{~m}$ within cell 1 to $109 \mathrm{~m}$ in cell 5. Sixty-six percentage recorded beach widths in excess of 250 metres, influencing an overall average beach width of 315 metres (Figure 6.1a). Dunes were recorded in five of the six identified cells and widths varied between $63 \mathrm{~m}$ (cell 6) and $13 \mathrm{~m}$ (cell 4; Figure 6.1b). The overall average dune width was 34 metres. The sand and shingle spit of Spurn Head is a narrow feature, which widens at its distal end and for this reason only one cell recorded a coastal slope in accordance with the methodology. The coastal slope close to the distal end was $2.5 \%$. Distance of vegetation behind the back beach also showed significant variation ranging from $97 \mathrm{~m}$ in cell 3 (i.e. close to the distal end) to $34 \mathrm{~m}$ in cell 4 , with an overall average width of $59 \mathrm{~m}$ (Figure 6.1c).

The distance of built structures behind the back beach is influenced by the erosive nature both the Humber Estuary flows on the western side of the spit and by a reduction in long shore sediment input on the eastern side (section 4.4.1). Only three cells recorded structures behind the back beach (cells 2, 3 and 4 respectively) all with a similar distance of around 3 $\mathrm{m}$ (Figure 6.1d). It was not surprising that rocky outcrops were absent from this spit feature and no sea defence structures had been constructed within the area of study. 

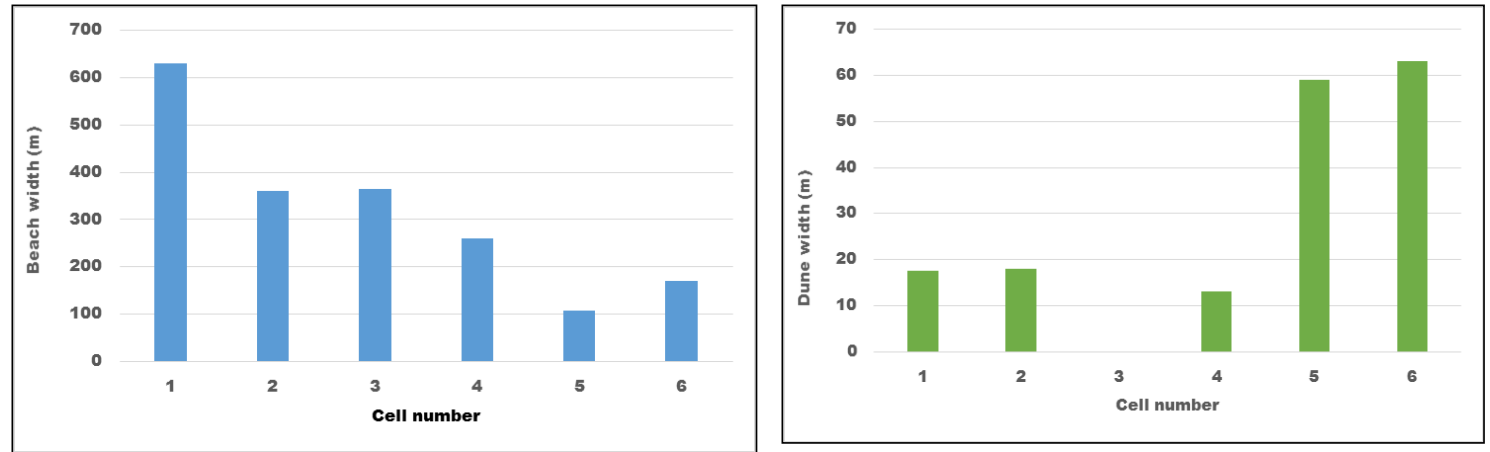

a)

b)
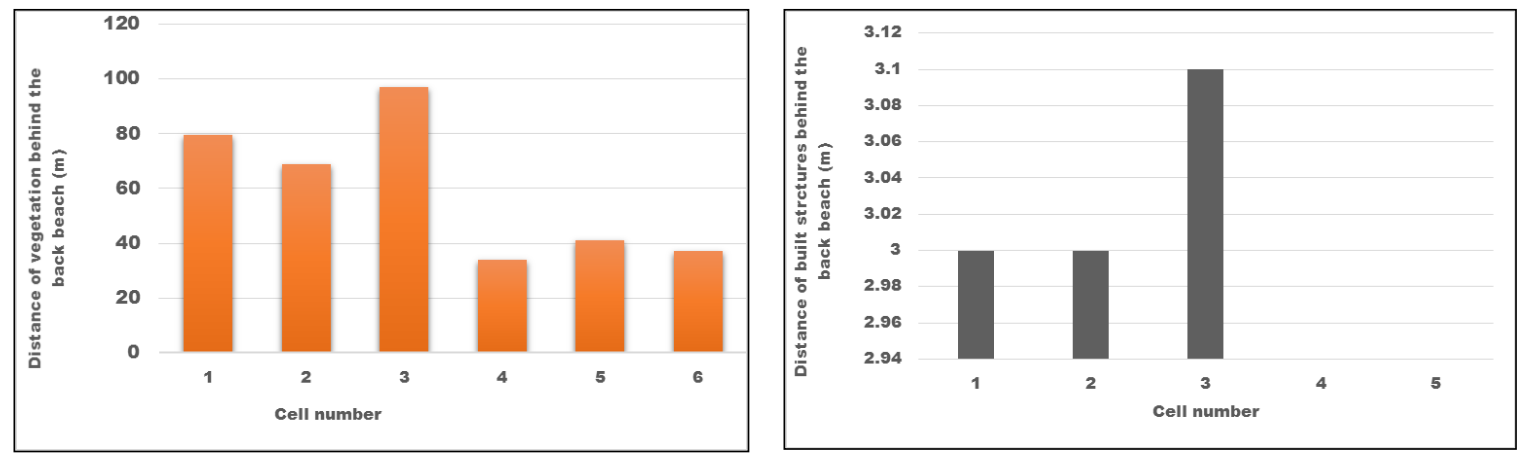

c)

d)

Figure 6.1: Graphical representations of Spurn Head

\subsection{Hallsands}

With the exception of cell $1(76 \mathrm{~m})$ beach width at Hallsands ranged between circa $20 \mathrm{~m}$ and circa $27 \mathrm{~m}$. The average overall beach width of around $30 \mathrm{~m}$ was influenced by cell 1 results and $80 \%$ of cells recorded lower than average values (Figure 6.2a). Dune width was recorded in one cell (cell $4 ; 10 \mathrm{~m})$. For coastal slope values, there is a significant difference existed between maximum (19.8\% in cell 6) and minimum (2.4\% in cell 8$)$ coastal slope values. The average coastal slope was $11.9 \%$ and similar to beach width results, $80 \%$ of cells recorded higher than the average values (Figure 6.2b). A clear difference was observed in measured distance values of vegetation behind the back beach. The average was $462 \mathrm{~m}$ between a maximum of $496 \mathrm{~m}$ recorded in 3 cells (2, 5 and 6 respectively) and minimum of $340 \mathrm{~m}$, recorded in the eighth cell. More than $60 \%$ of cells recorded higher than average values (Figure 6.2c).

When measurements taken of built structures located behind the back beach, the maximum distance was recorded in the eighth cell $(160 \mathrm{~m})$, with a minimum recorded of $4 \mathrm{~m}$ in 3 cells ( 2, 5 and 6 respectively). The overall average was $42 \mathrm{~m}$ and $25 \%$ of cells recorded higher 
than average values (Figure 6.2d). Rocky outcrops were only recorded in 2 cells, cell 7 (26\%) and cell $8(13 \%)$, rocky outcrops were not detected in $75 \%$ of the cells (Figure $6.2 \mathrm{e}$ ). Three cells comprise sea defence structures (4, 7 and 8 respectively) and of these, the average shoreline protection was 59\% (Figure 6.2f).

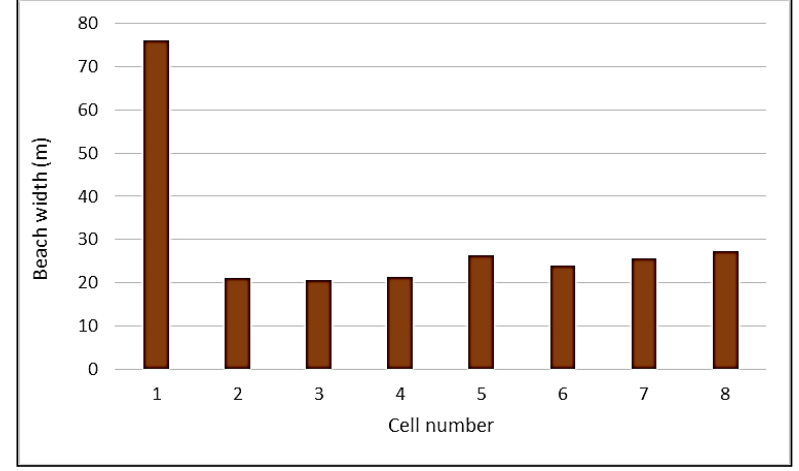

a)

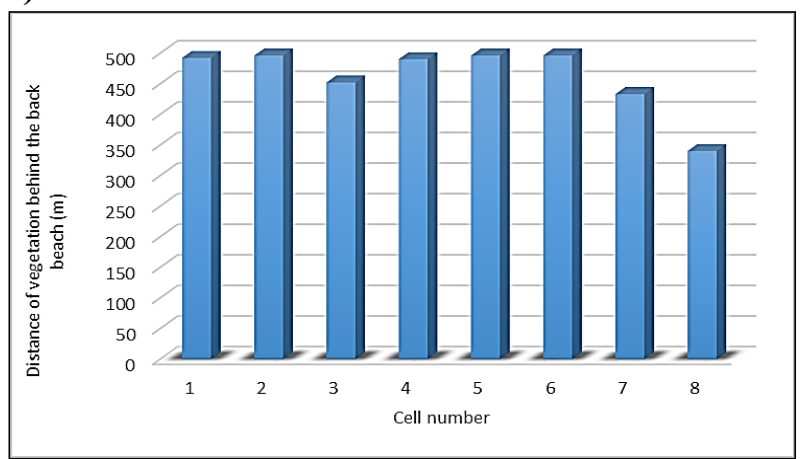

c)

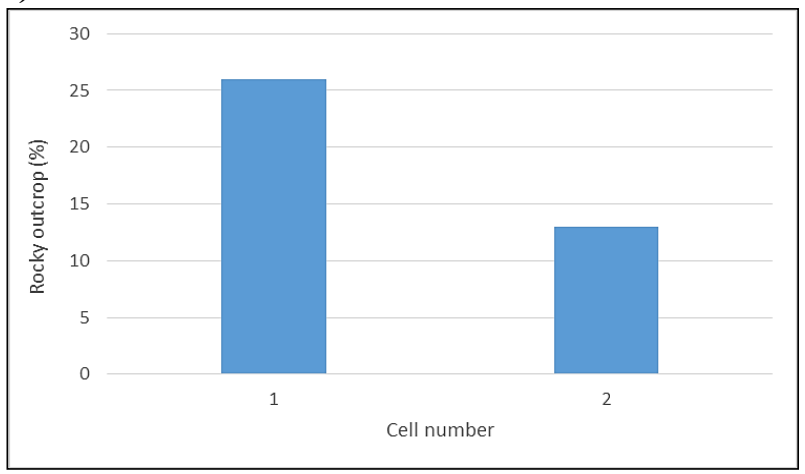

e)

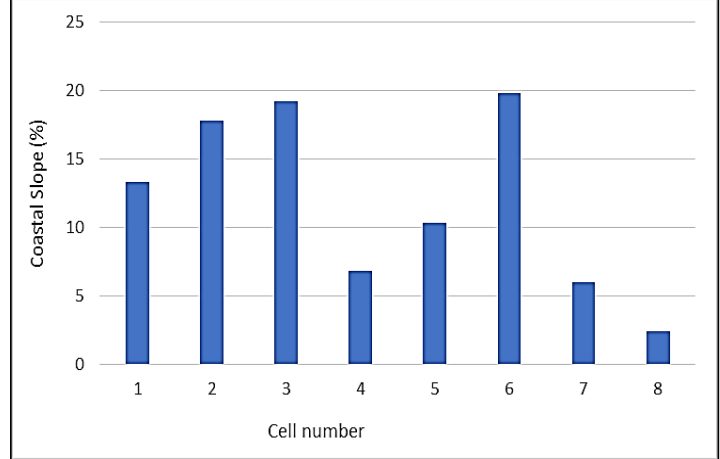

b)

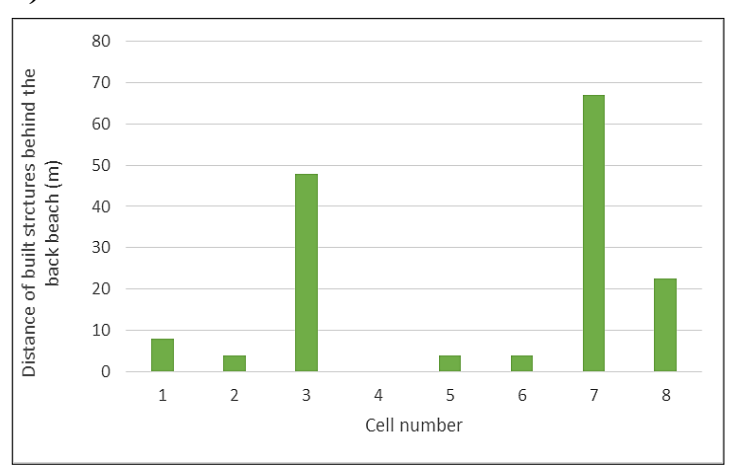

d)

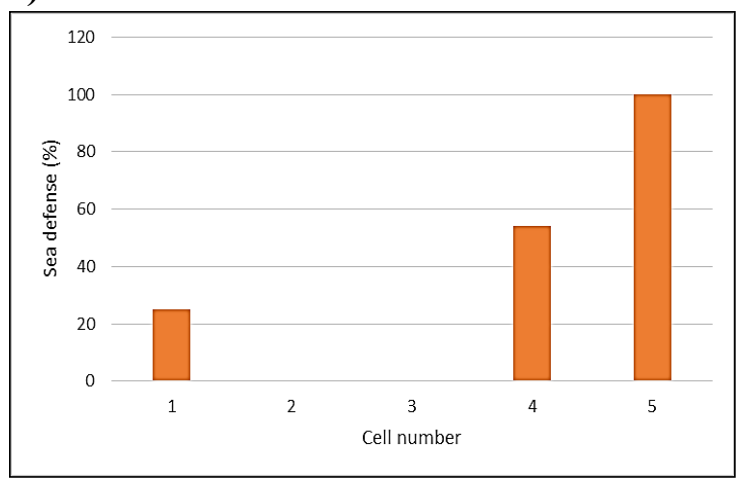

f)

Figure 6.2: Graphical representations of Hallsands

\subsection{Lynmouth}

The beach width varies significantly between a maximum of $378 \mathrm{~m}$ (cell 3) and minimum of $121 \mathrm{~m}$ in the fourth cell. The overall average beach width was $209 \mathrm{~m}$ and $50 \%$ of cells recorded more than average beach width values (Figure 6.3a). The maximum coastal slope recorded was $48 \%$ (cell 4 ) and minimum $21.3 \%$ (cell 2), with an overall average of $33.7 \%$ 
and $50 \%$ of cells recorded higher than the average measurements (Figure 6.3b). The maximum recorded distance of vegetation behind the back beach was $500 \mathrm{~m}$ (cell 4) and minimum $105 \mathrm{~m}$ (Cell 3), 50\% of cells recorded more than average value of $331 \mathrm{~m}$ (Figure $6.3 \mathrm{c}$ ). The maximum and minimum recorded for the distance of built structures behind the back beach was $295 \mathrm{~m}$ (cell 1) and $39 \mathrm{~m}$ (cell 3) respectively (Figure 6.3d) and 50\% of cells recorded more than the average of $143 \mathrm{~m}$. There were no dunes, rocky outcrops or sea defence structures.

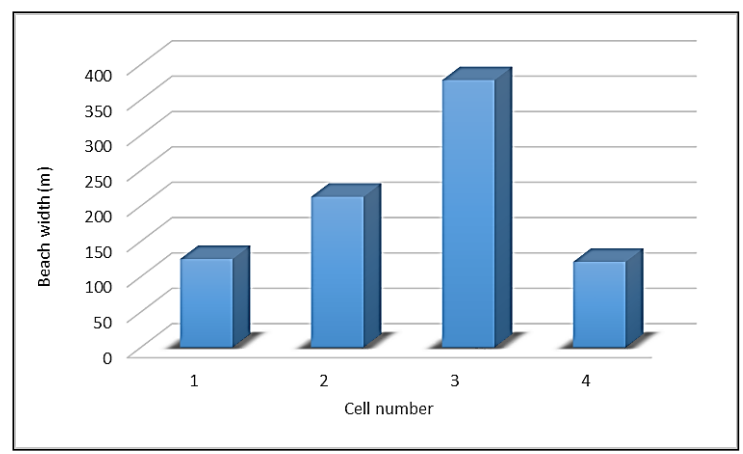

a)

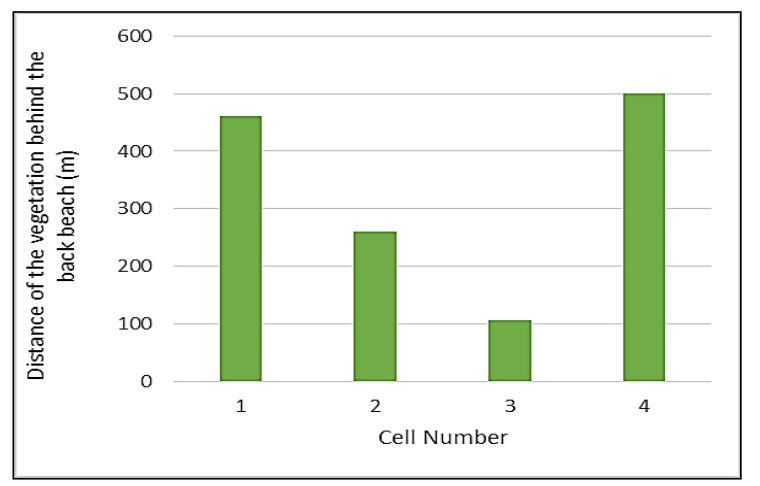

c)

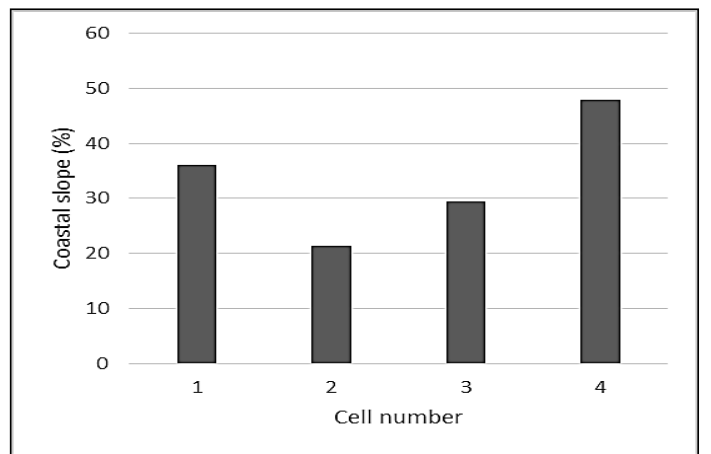

b)

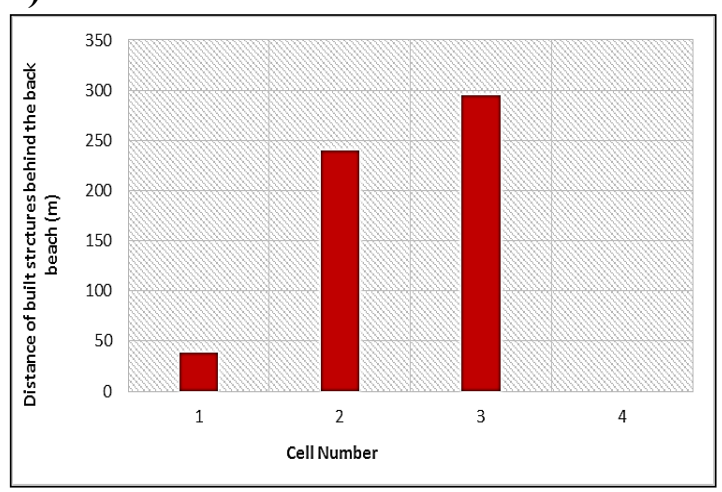

d)

Figure 6.3: Graphical representations of Lynmouth

\subsection{Happisburgh}

The average beach width between a maximum of $49 \mathrm{~m}$ (cell 5) and minimum of $11.3 \mathrm{~m}$ (cell 1) measured $36 \mathrm{~m}$ with $62 \%$ of cells recording higher than average values (Figure 6.4a). Dunes were only recorded in the first and second cells and measurements of $21 \mathrm{~m}$ and $33 \mathrm{~m}$ recorded. The average coastal slope between the maximum of 3.9\% (cell 6) and minimum of $0.6 \%$ (cell 1 ) was $1.8 \%$, and $62 \%$ of cells recorded lower than average values (Figure $6.4 \mathrm{~b}$ ). The overall average distance of vegetation behind the back beach was $281 \mathrm{~m}$ between maximum and minimum recorded distances of $477 \mathrm{~m}$ and $4 \mathrm{~m}$ respectively and $50 \%$ of the recorded values were greater than the average (Figure 6.4c). The overall average distance 
of built structures behind the back beach between the maximum of $477 \mathrm{~m}$ recorded in the fifth cell and minimum of $56 \mathrm{~m}$ (cell 1) was $166 \mathrm{~m}$ and $62 \%$ of the distances measured were lower than the average (Figure 6.4d). Only 3 cells contained rocky outcrops recording 79\% coverage in the first cell and $11.4 \%$ in the sixth cell, giving an overall average of $15.7 \%$ (Figure 6.4e). Less than half of the studied cells exhibited any form of sea defence. The overall average of those measured cells was $65 \%$, with a maximum of $100 \%$ recorded in the first cell, and minimum in the sixth cell 24\% (Figure 6.4f).

\subsection{Dawlish}

The average beach width was $67.5 \mathrm{~m}$ between the maximum of $139 \mathrm{~m}$ recorded in the eighth cell and minimum of $21.2 \mathrm{~m}$ recorded in the fourth cell. Forty five percent of cells recorded higher than average values (Figure 6.5a). Dune width was only recorded in the last 3 cells and ranged between a maximum of $107 \mathrm{~m}$ to a minimum of $79 \mathrm{~m}$ (Figure $6.5 \mathrm{~b}$ ). The average coastal slope was $4.2 \%$ between a maximum of $11.2 \%$ recorded in the second cell and minimum of $1.1 \%$ recorded in the eleventh cell and $45 \%$ of cells recorded higher than average values (Figure 6.5c). The average distance of vegetation behind the back beach between a maximum of $464 \mathrm{~m}$ in the fifth cell and minimum of $60 \mathrm{~m}$ (cell 1) was $232 \mathrm{~m}$, $27 \%$ of cells recorded more than average value (Figure $6.5 \mathrm{~d}$ ). The average distance of built structures behind the back beach was $356 \mathrm{~m}$, between the maximum distance of $500 \mathrm{~m}$, recorded in cells 2, 3 and 7, with the minimum recorded in cell 5 was $35 \mathrm{~m}$, recorded at the fifth cell and $36 \%$ of cells recorded higher than average values (Figure 6.5e). Rocky outcrops were only recorded in cell 7 (55\%), and sea defence structures were recorded in $81 \%$ of the cells, all providing 100\% coverage (Figure 6.5f). 


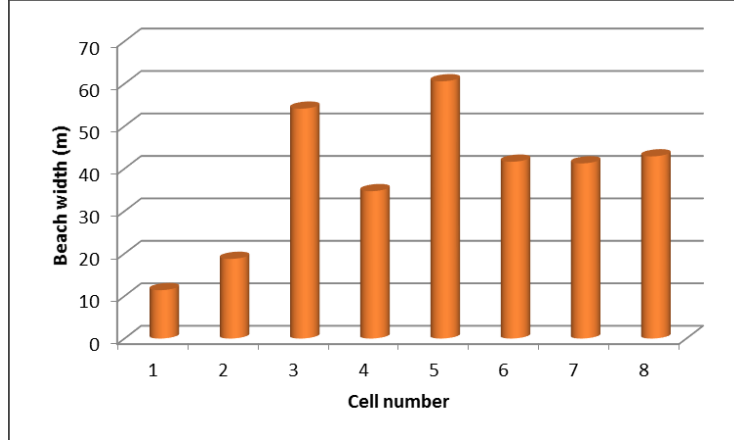

a)

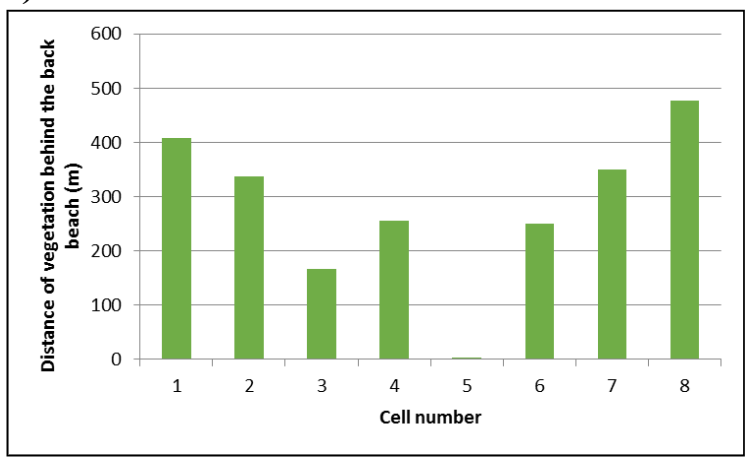

c)

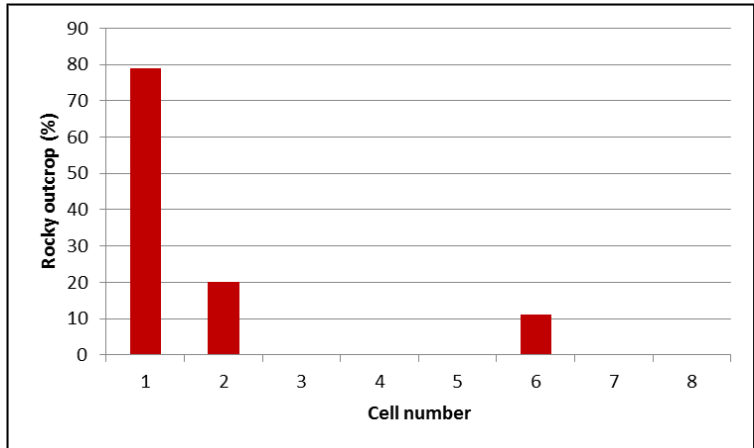

e)

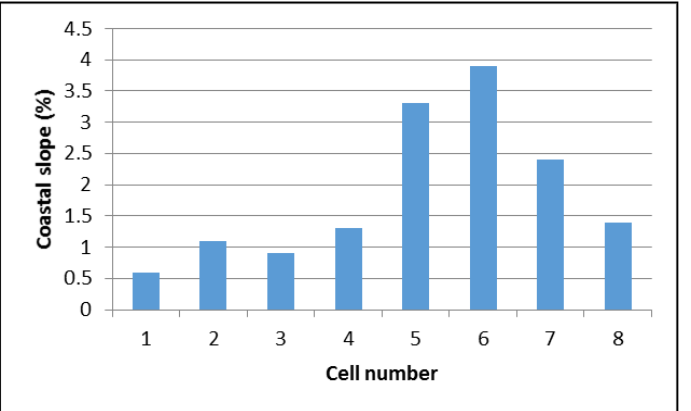

b)

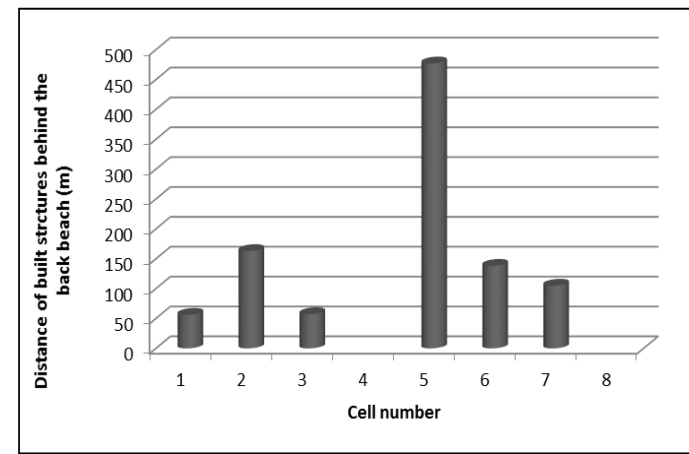

d)

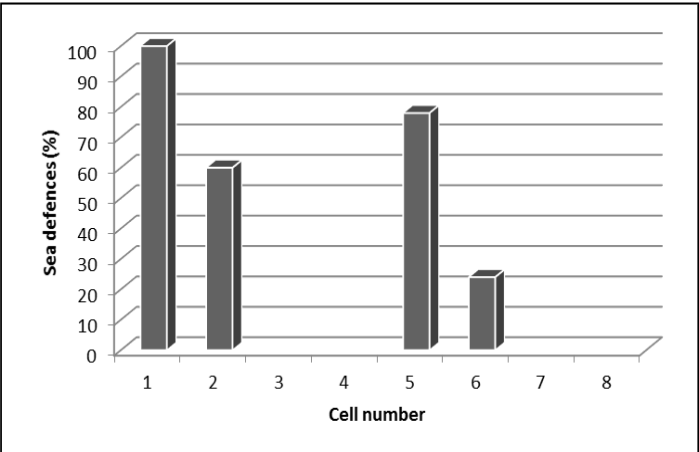

f)

Figure 6.4: Graphical representations of Happisburgh 


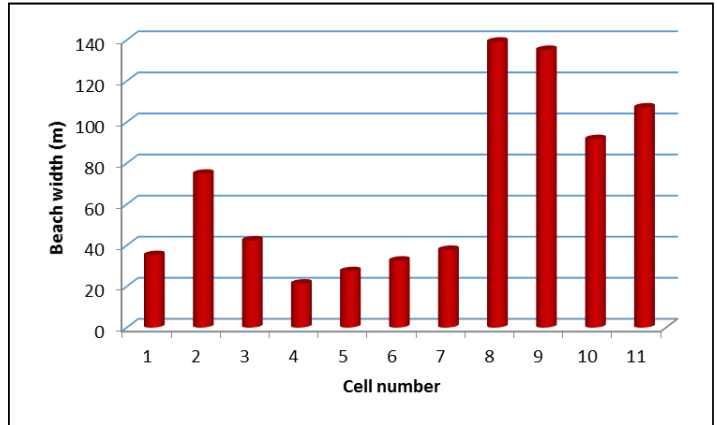

a)

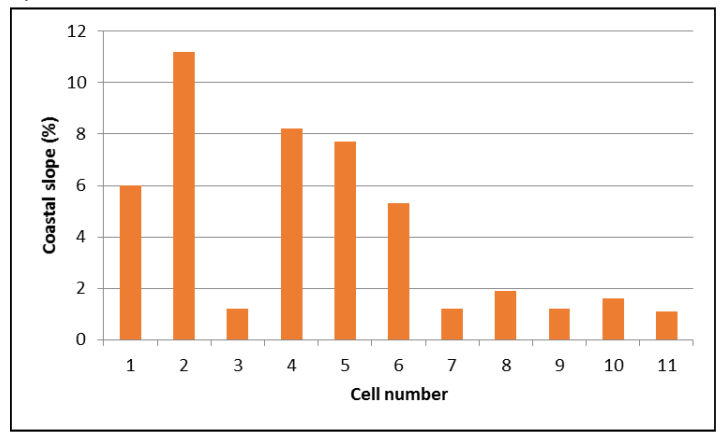

c)

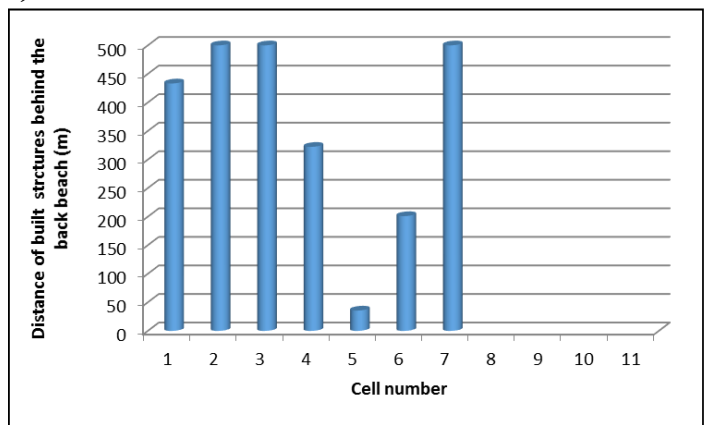

e)

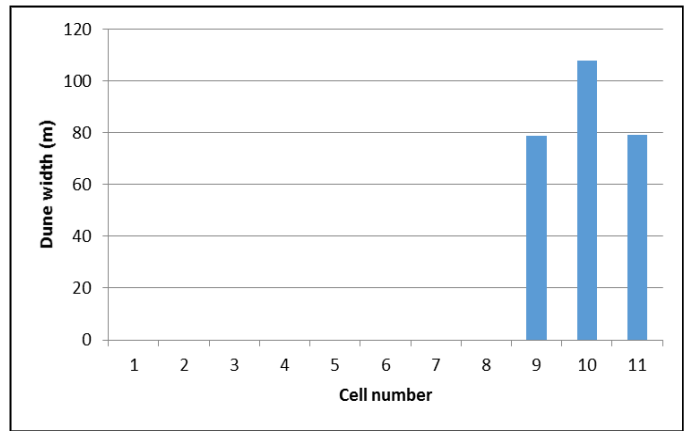

b)

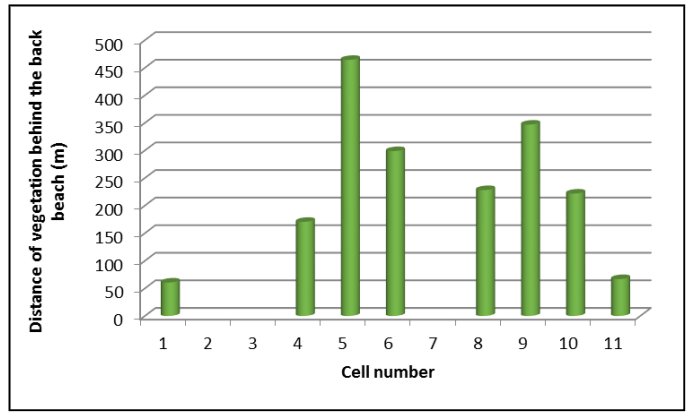

d)

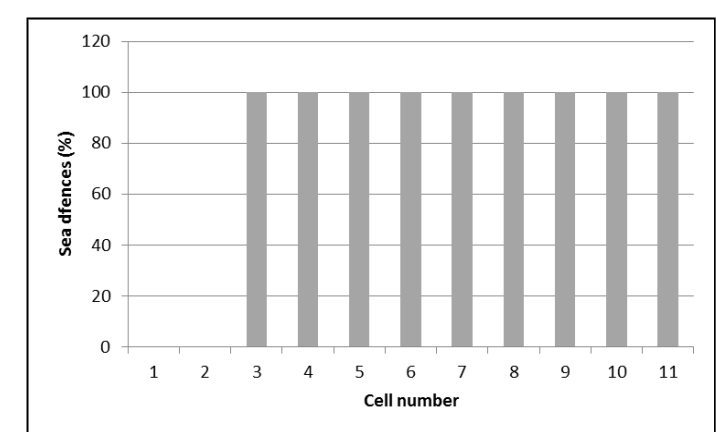

f)

Figure 6.5: Graphical representations of Dawlish

\subsection{Great Yarmouth}

The average beach width between a maximum of $590 \mathrm{~m}$ recorded in the ninth cell and minimum of $1.4 \mathrm{~m}$ in the seventh cell was 56 metres and $89 \%$ of cells recorded lower than average values (Figure 6.6a). Less than half of the assessed shoreline showed dune morphology and the average of those cells that recorded dune width was 112 metres between the maximum $336 \mathrm{~m}$; cell 12) and minimum (16 m; cell 10) recorded values (Figure 6.6b). The average recorded coastal slope was $1.8 \%$, between a maximum of $4.1 \%$ recorded in the fourth cell and minimum of $0.5 \%$ recorded in the fourteenth and eighteenth cells. Fiftyseven percent of cells recorded lower than the average value (Figure 6.6c).

The average distance of vegetation behind the back beach was 141.6 metres, with the maximum distance of $500 \mathrm{~m}$ recorded in the fourth cell and minimum in the second cell (10 
m) and 39\% of cells recorded more than the average distance (Figure 6.6d). The average distance of built structures behind the back beach was $277 \mathrm{~m}$ between the maximum (500 $\mathrm{m}$; cell 9) and minimum (5 m; cell 28) recorded distances and 53\% of cells recorded higher than average values (Figure 6.6e). There was no rocky outcrops or sea defences recorded.
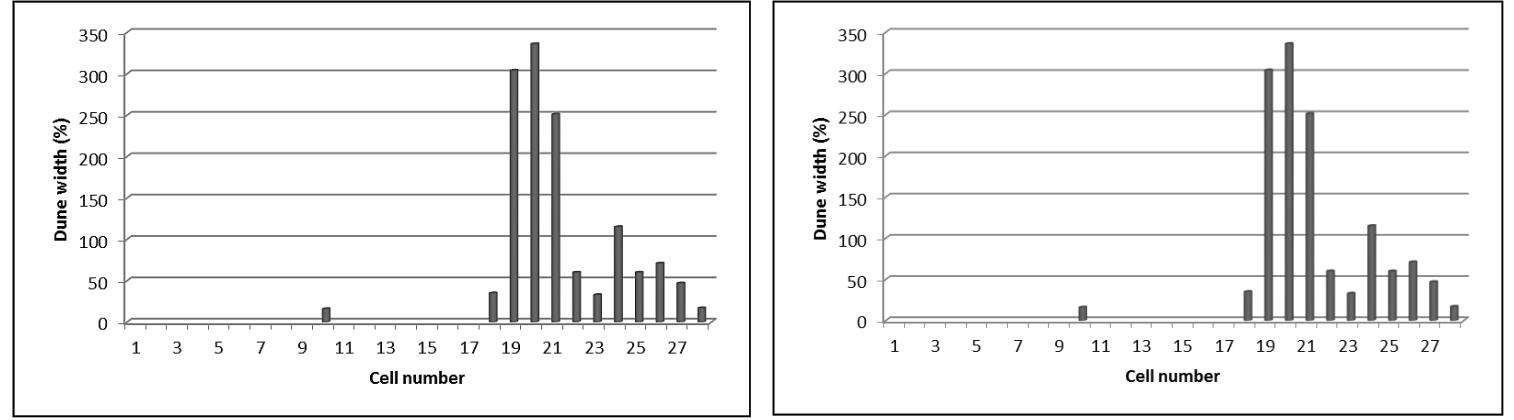

a)

b)
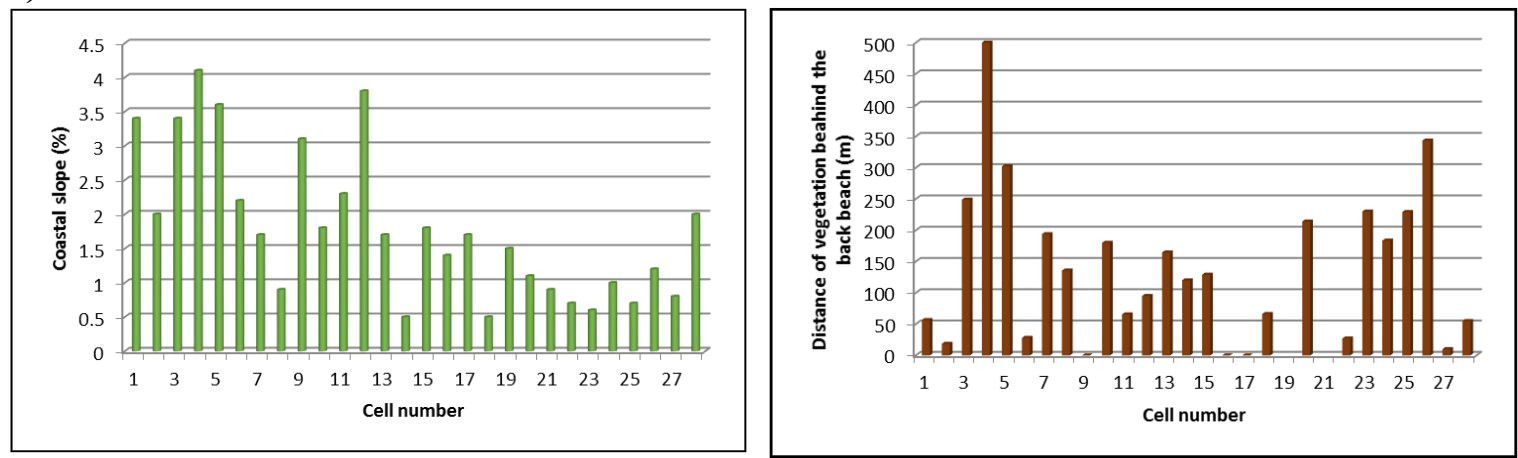

c)

d)

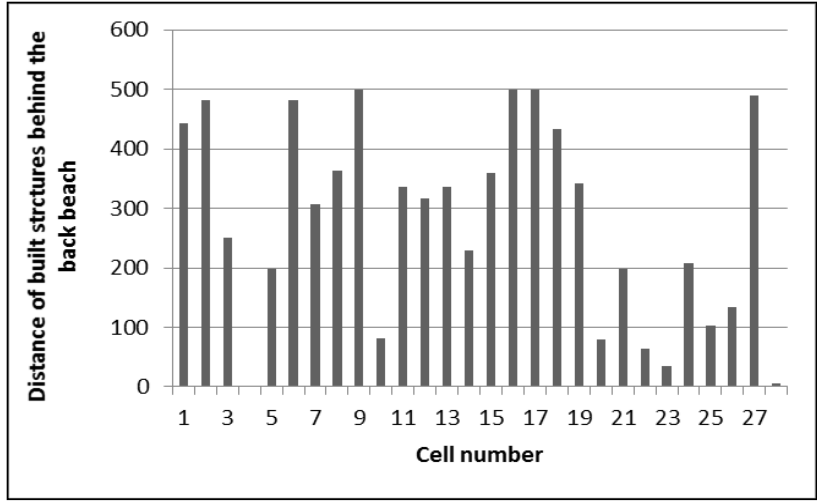

e)

Figure 6.6: Graphical representations of Great Yarmouth

\subsection{Skegness}

The average beach width between the maximum of $326 \mathrm{~m}$ recorded in the ninth cell and minimum of $128 \mathrm{~m}$ in the seventeenth cell, was $206 \mathrm{~m}$, with $56 \%$ of the cells recording higher than average values (Figure 6.7a). Less than half of the cells contained dune morphology and the average those measured between the maximum (91 m; cell 3) and 
minimum (9 m; cell 9) was $58.8 \mathrm{~m}$ (Figure 6.7b). The average coastal slope was 1.3\%, between the maximum of $3.9 \%$ recorded in the twenty first cell and minimum of $0.4 \%$ recorded in the first cell. Sixty percent of cells recorded lower than the average value (Figure 6.7c). The maximum distance of vegetation behind the back beach was $390 \mathrm{~m}$ (cell 9) and minimum of $6 \mathrm{~m}$ (cell 4 ), with $60 \%$ of cells recording lower than the average distance of 121 m (Figure 6.7d).

The average distance of built structures behind the back beach was $329 \mathrm{~m}$, recorded between a maximum distance of $494 \mathrm{~m}$ (cell 12) and minimum of $30 \mathrm{~m}$ in the first cell and $60 \%$ of cells recorded higher than the average values (Figure 6.7e). Rocky outcrop was only recorded in the eighth cell (3.09\%) and sea defences were recorded in the seventh and eighth cells (35\% and $100 \%$ respectively).

\subsection{Benbecula}

The average beach width was $105.8 \mathrm{~m}$, between the maximum of $255 \mathrm{~m}$ recorded in the first cell and minimum of $37 \mathrm{~m}$ (cell 10) and 53\% of cells recorded higher than the average values (Figure $6.8 \mathrm{a}$ ). Dune width was only recorded in $20 \%$ of the cells and the average of those cells was $97.7 \mathrm{~m}$, with the maximum recorded in the first cell of $184 \mathrm{~m}$ and minimum 49 $\mathrm{m}$ in the twelfth cell (Figure $6.8 \mathrm{~b}$ ). The average recorded coastal slope was $1.1 \%$, between a maximum of $1.9 \%$ (cell 2) and minimum of $0.6 \%$ (cell 1) and $53 \%$ of cells recorded higher than average values (Figure 6.8c).

The average distance of vegetation behind the back beach was $348 \mathrm{~m}$ and $60 \%$ of cells recorded more than the average value. The maximum distance of $490 \mathrm{~m}$ recorded in the fifteenth cell and minimum the second cell $(137 \mathrm{~m})$ (Figure 6.8d). The average distance of built structures behind the back beach was $142 \mathrm{~m}$ between the maximum ( $363 \mathrm{~m}$; cell 2) and minimum (10 m; cell 15) recorded and 60\% of cells lower than average values (Figure 6.8e). Rocky outcrops were recorded in less than half the cells the average between the maximum $(100 \%$ coverage) recorded in six cells and minimum recorded in the third cell $(76 \%)$, was $96 \%$. There were no sea defence structures present. 


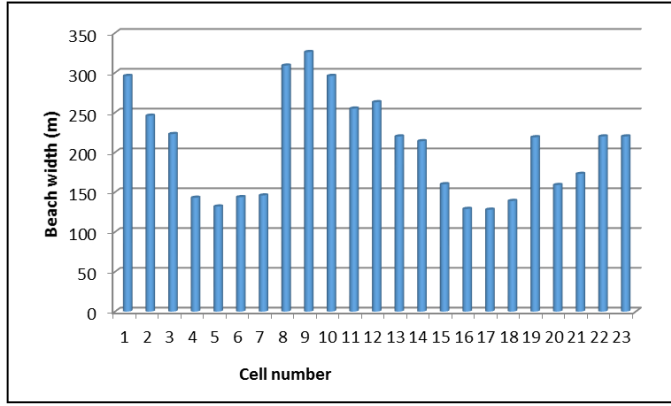

a)

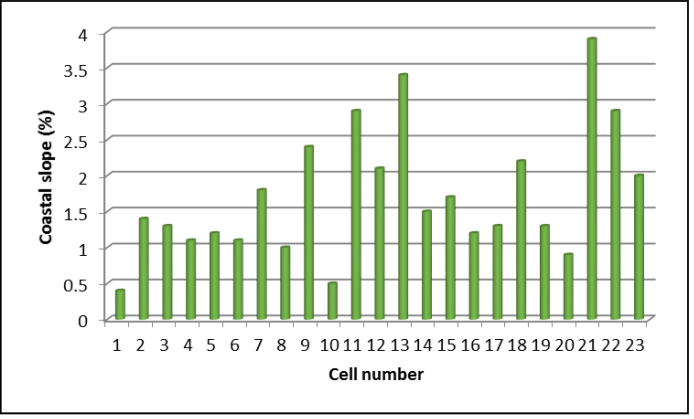

c)

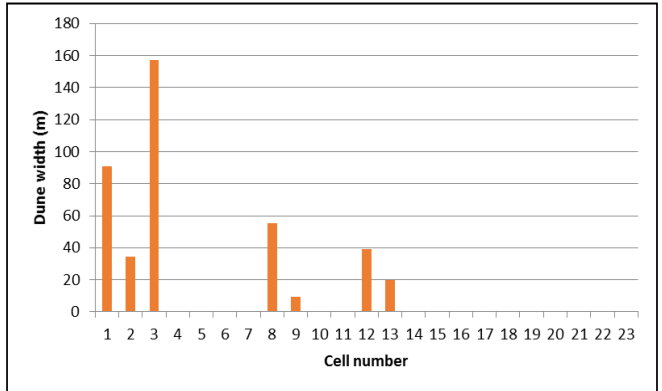

b)

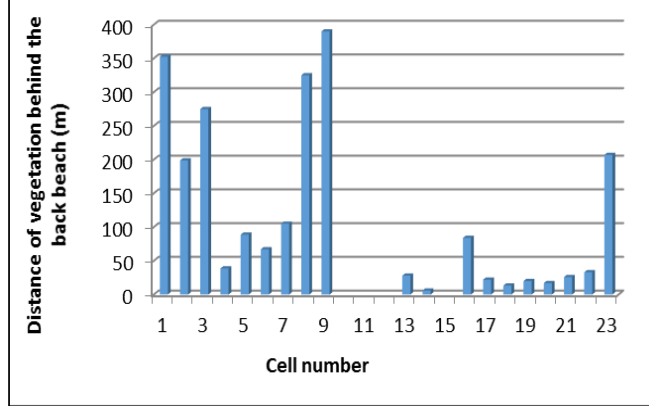

d)

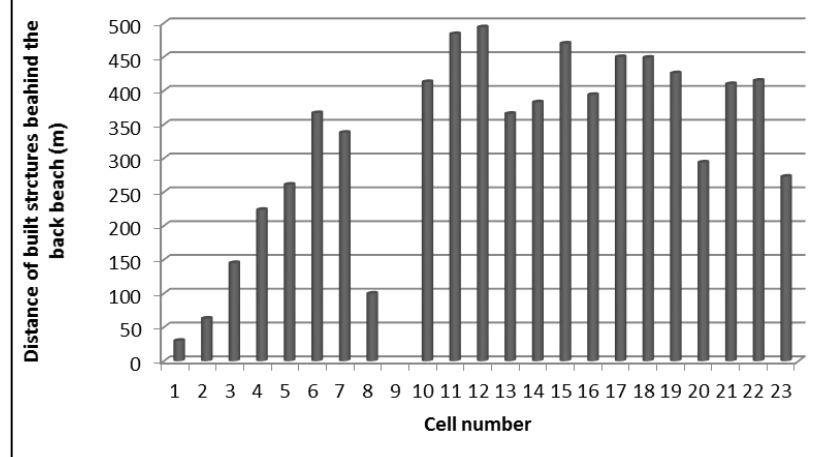

e)

Figure 6.7: Graphical representations of Skegness 


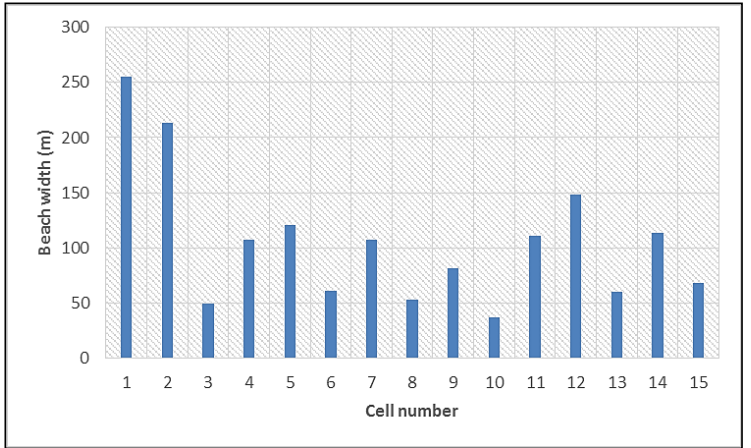

a)

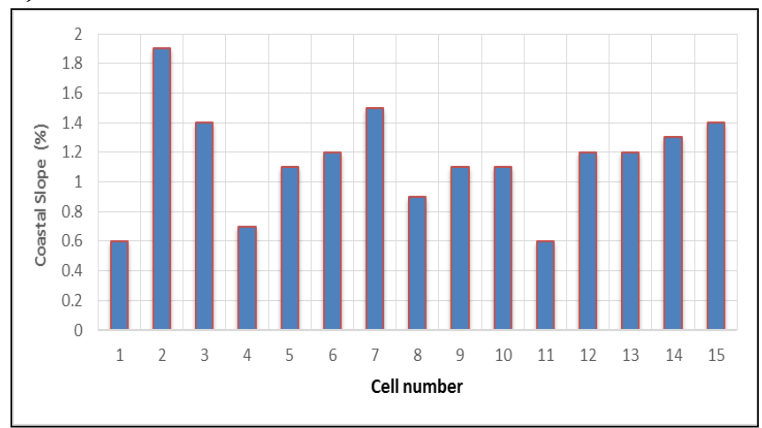

c)

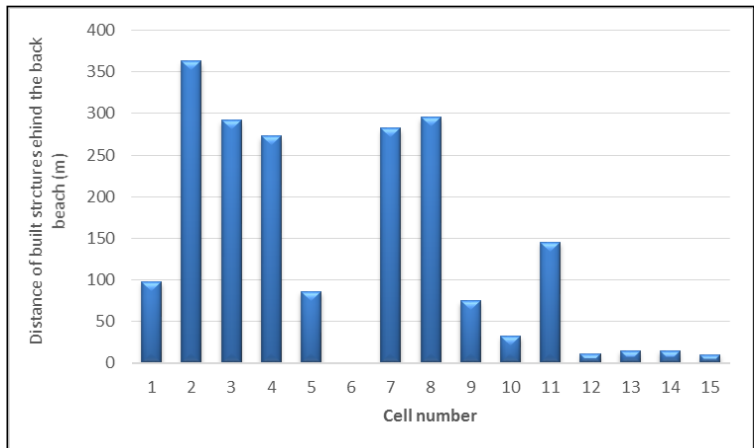

e)

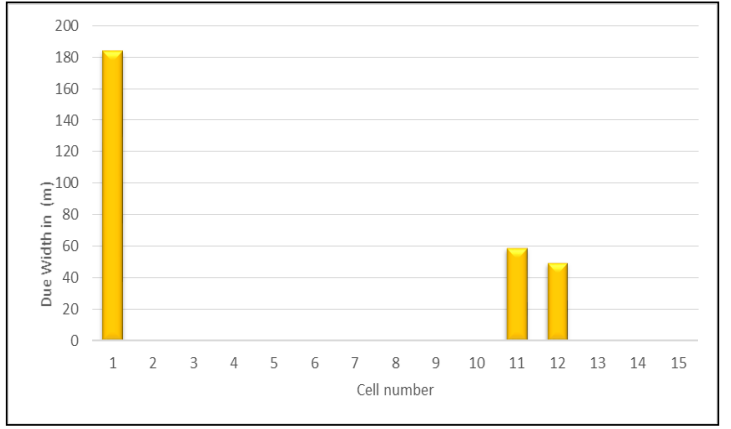

b)

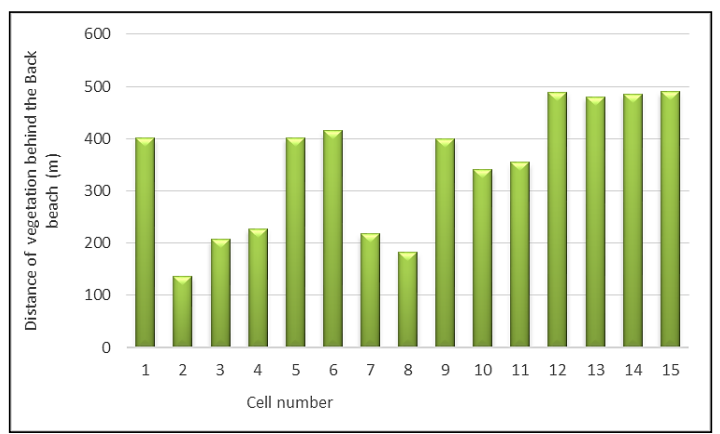

d)

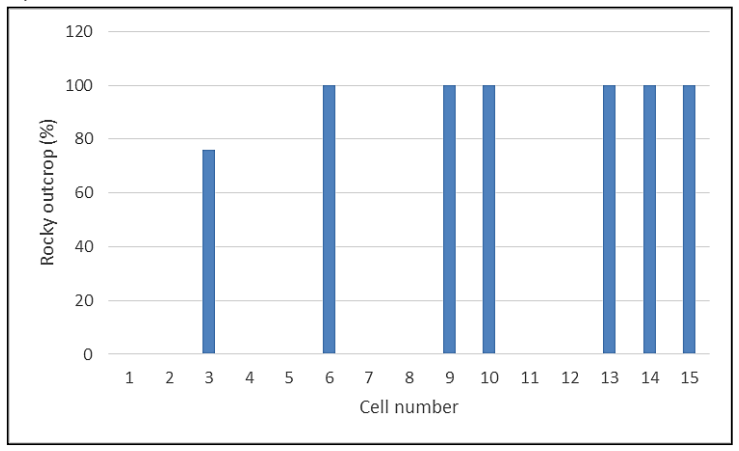

f)

Figure 6.8: Graphical representations of Benbecula

\subsection{Aberystwyth}

The average beach width was $90.6 \mathrm{~m}$ between the maximum of $168 \mathrm{~m}$ recorded in the third cell and minimum of $63 \mathrm{~m}$ in the fifth cell, and $80 \%$ of cells recorded lower than the average values (Figure 6.9a). The average recorded coastal slope was $7.6 \%$, between a maximum of $14.7 \%$ (cell 5) and minimum of $0.2 \%$ (cell 2) and $60 \%$ of cells recorded lower than average values (Figure 6.9b). The average distance of vegetation behind the back beach was $147 \mathrm{~m}$ and $60 \%$ of cells recorded lower than the average values.

The maximum recorded in the fifth cell was $306 \mathrm{~m}$ and minimum in the fourth cell $(44 \mathrm{~m})$ (Figure 6.9c). The average distance of built structures behind the back beach was $201 \mathrm{~m}$ between the maximum (455 m; cell 3) and minimum (29 m; cell 5) recorded distances and $60 \%$ of cells lower than average values (Figure 6.9d). The entire shoreline frontage was 
protected by sea defence structures (Figure 6.9e), there are no dunes recorded, and rocky outcrops were only recorded in two cells.
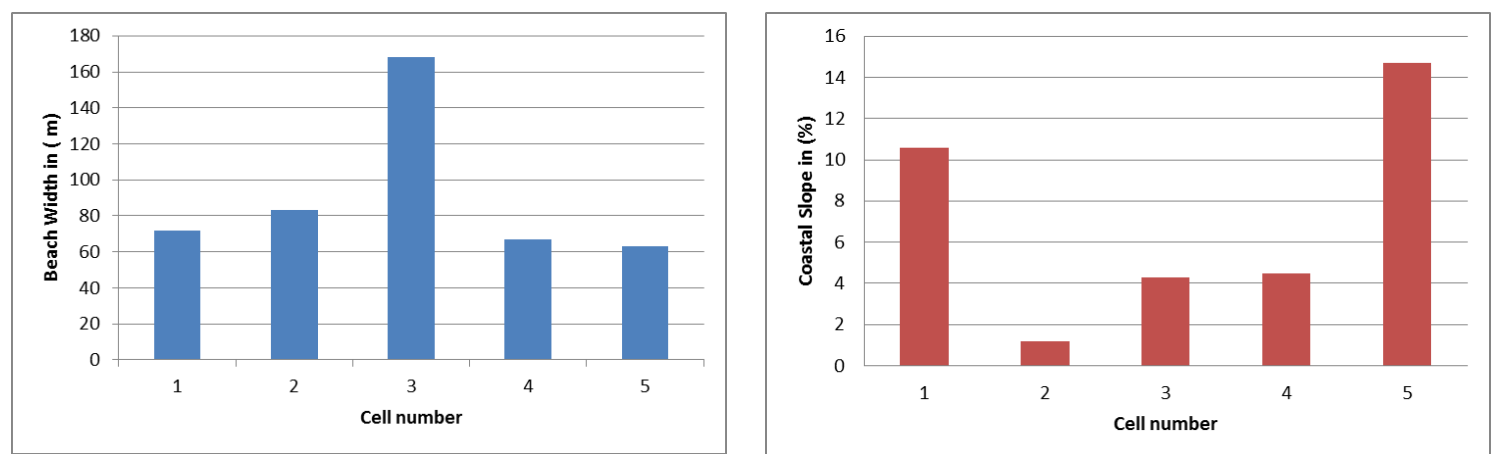

a)

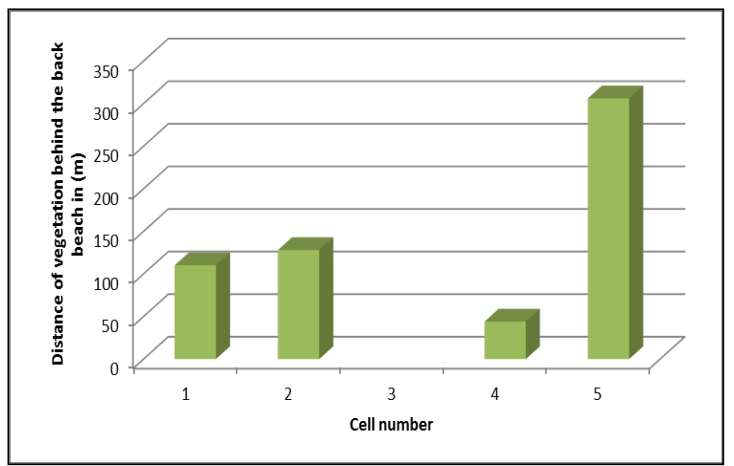

b)

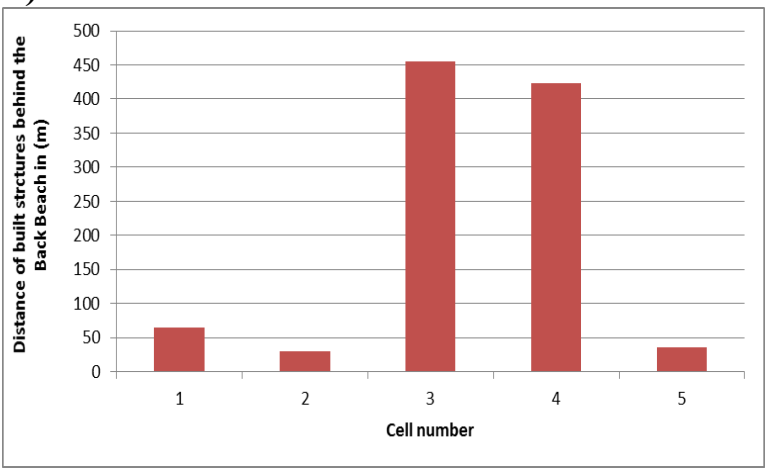

c)

d)

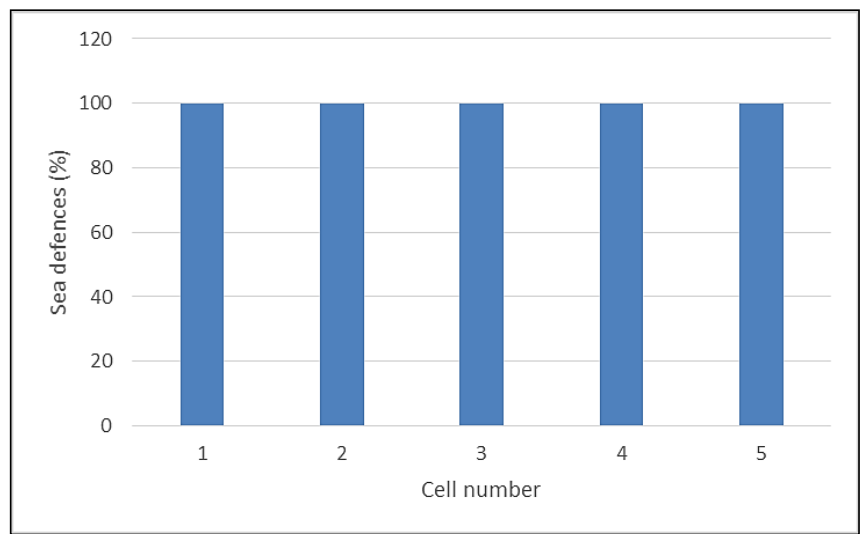

e)

Figure 6.9: Graphical representations of Aberystwyth

\subsection{Port Talbot}

The average beach width was $339 \mathrm{~m}$ and $45 \%$ of cells recorded lower than the average values. The maximum recorded in the fourth cell was $835 \mathrm{~m}$ and minimum of $100 \mathrm{~m}$ in the fifteenth (Figure 6.10a). Dunes were recorded in less than half of the cells and the average of those cells between the maximum (515 m; cell 3) and minimum ( $29 \mathrm{~m}$; cell 23) recorded values was $165 \mathrm{~m}$ and $29 \%$ of cells recorded higher than the average values (Figure 6.10b). The average recorded coastal slope was $3.3 \%$, between a maximum of $15.6 \%$ recorded in 
the sixteenth cell and minimum of $1.1 \%$ in the eleventh cell. Seventy percent of cells recorded lower than average values (Figure 6.8c).

The average distance of vegetation behind the back beach was $97 \mathrm{~m}$, with the maximum distance of $500 \mathrm{~m}$ recorded in the third cell and minimum of $40 \mathrm{~m}$ in cell nineteen (Figure $6.8 \mathrm{~d})$. The average distance of built structures behind the back beach between the maximum (500 m; cell 7) and minimum (30 m; cell 5) was 389 and 58\% of cells higher than average values (Figure 6.10e). The average rocky outcrop was $8.4 \%$ between the maximum $30 \%$, recorded at cell 13 and minimum was $1 \%$, recorded at twenty-second cell. More than $>42 \%$ of cells scored lower than average rocky outcrop (Figure 6.10f). The average sea defences was $89.6 \%$ between the maximum $100 \%$, and minimum $22 \%$, and $>50 \%$ of cells lower than average sea defence (Figure 6.10g).

\subsection{Llanelli}

The average beach width, between the maximum of $1900 \mathrm{~m}$ recorded in the eleventh and twelve cells and minimum of $37 \mathrm{~m}$ in the twenty fifth, was $668 \mathrm{~m}$ and $61 \%$ of cells recorded lower than average values (Figure 6.11a). The average recorded coastal slope was $3.3 \%$, between a maximum of $11 \%$ (cell 6) and minimum of $0.8 \%$ (cell 21) and $57 \%$ of cells recorded lower than average values (Figure 6.11b). The average distance of vegetation behind the back beach was $330 \mathrm{~m}$, with the maximum distance of $491 \mathrm{~m}$ recorded in cell 2; the minimum distance was recorded in cell $5(102 \mathrm{~m})$ and 53\% of cells recorded more than the average distance (Figure 6.11c). The average distance of built structures behind the back beach was $102 \mathrm{~m}$ between the maximum (343 m; cell 5) and minimum (2.4 m; cell 23) recorded distances and $57 \%$ of cells lower than average values (Figure $6.11 \mathrm{~d}$ ).

The average rocky outcrop was $4.3 \%$, between the maximum (117\% 8 cell) and minimum (70.8\% cell 14) and $42 \%$ of cells recorded lower than (Figure 6.11e) average values. Sea defences protected almost the entire shoreline frontage, averaging $72.4 \%$ between the maximum (100\% cells 11$)$ and minimum (11.4\% cell 10) values and $42 \%$ of cells recorded lower than average values (Figure 6.11f). 


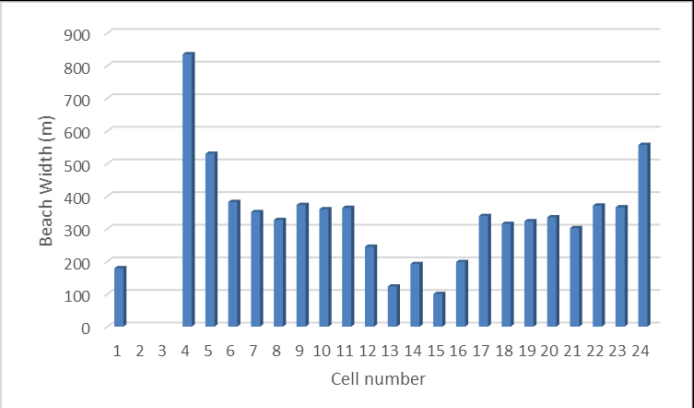

a)

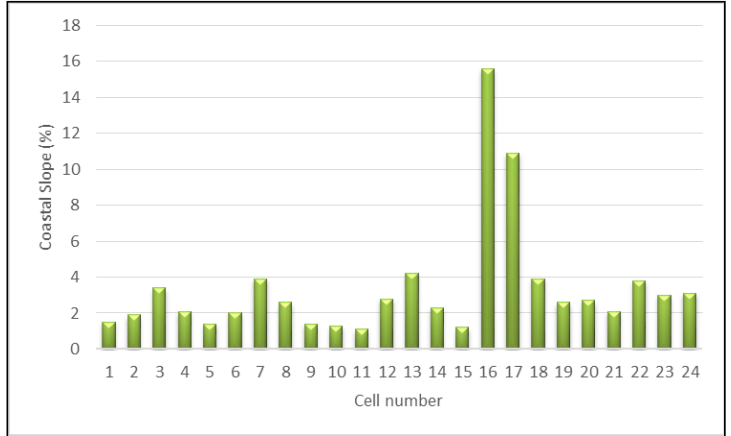

c)

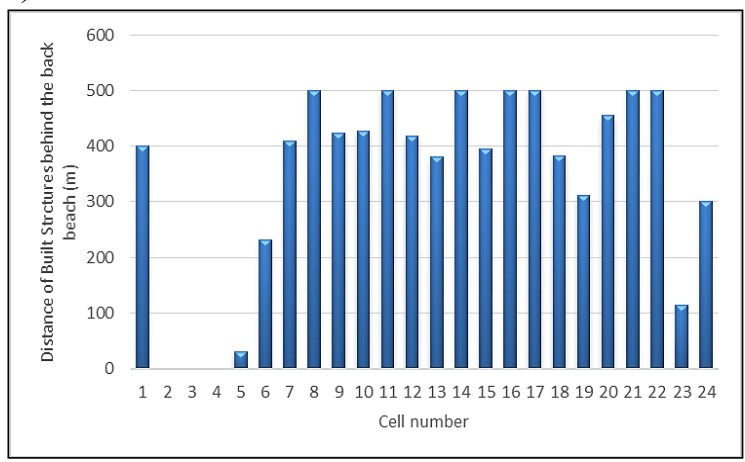

e)

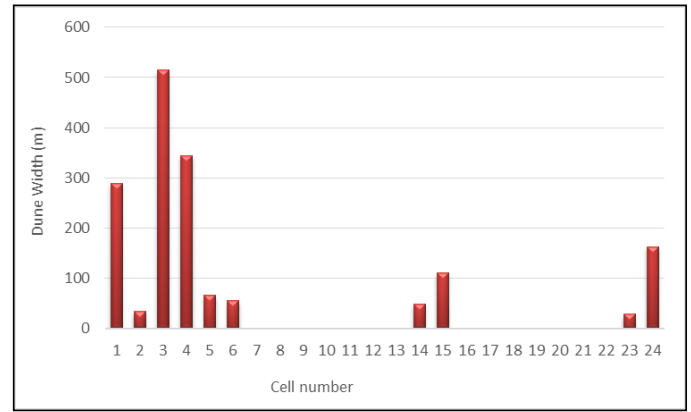

b)

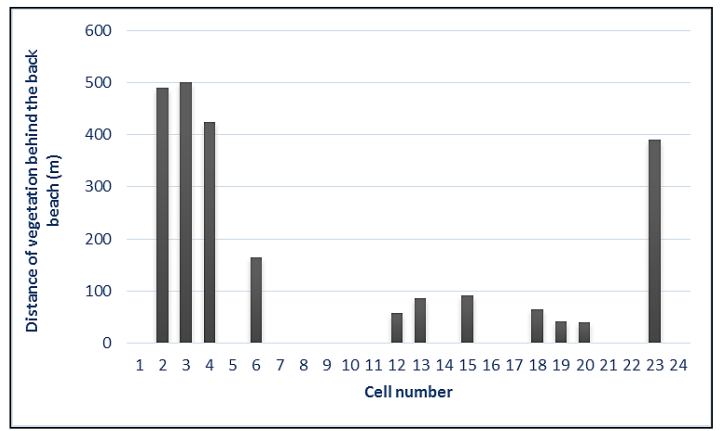

d)

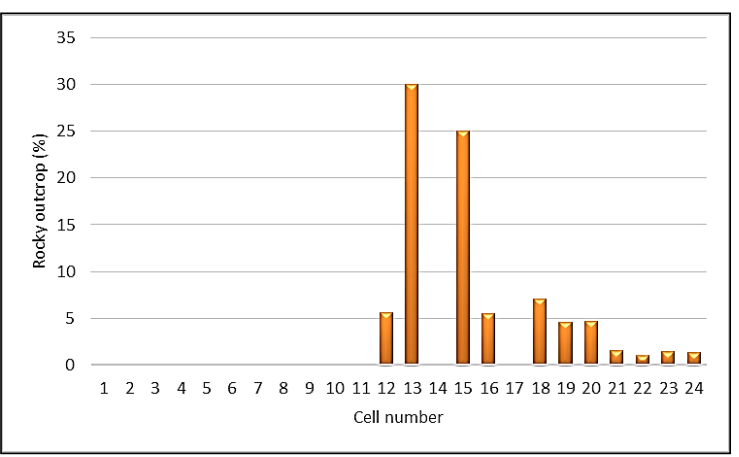

f)

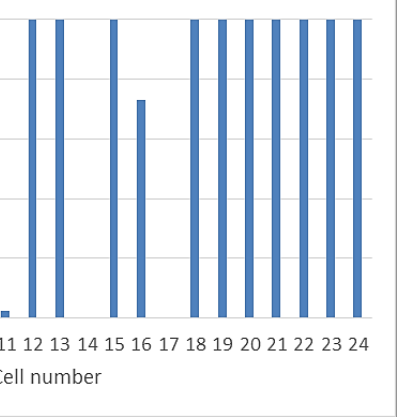

g)

Figure 6.10: Graphical representations of Port Talbot 


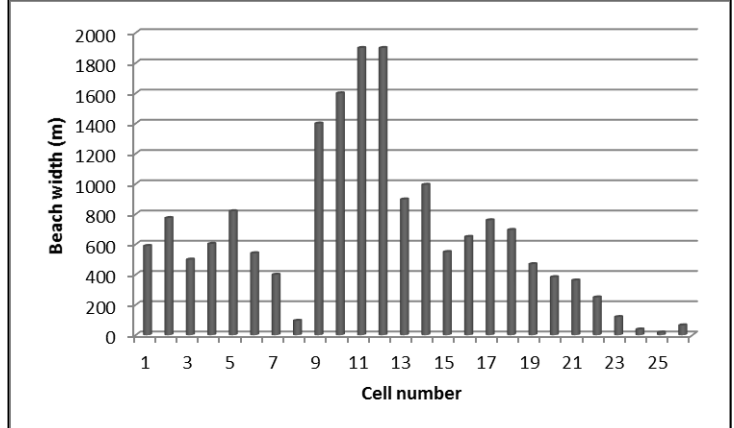

a)

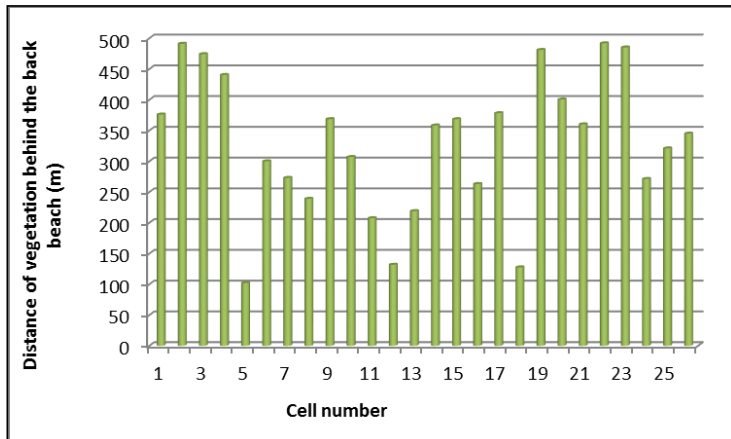

c)

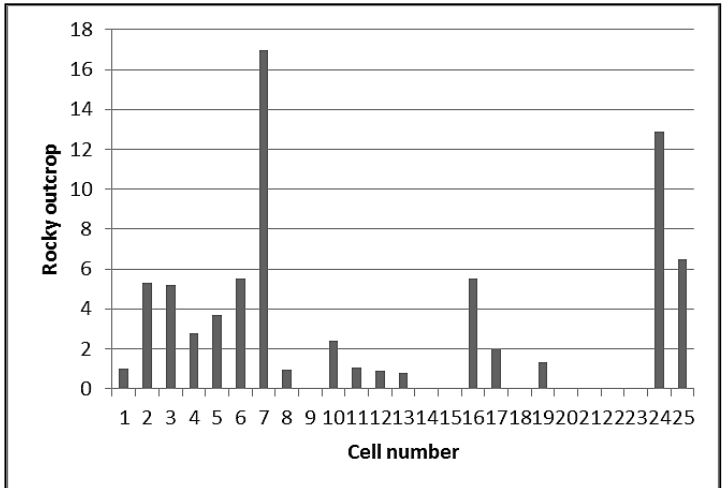

e)

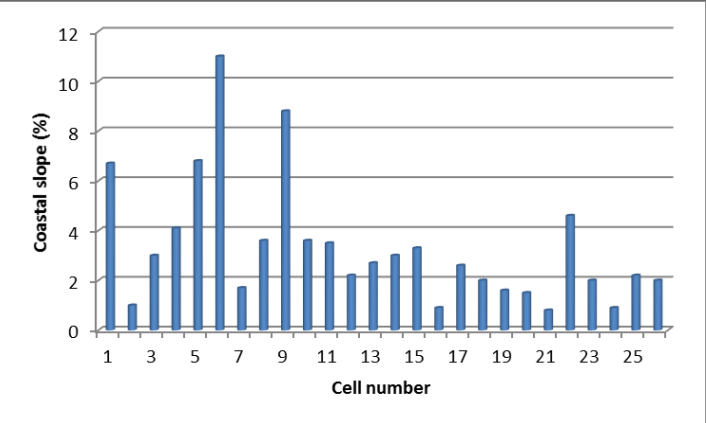

b)

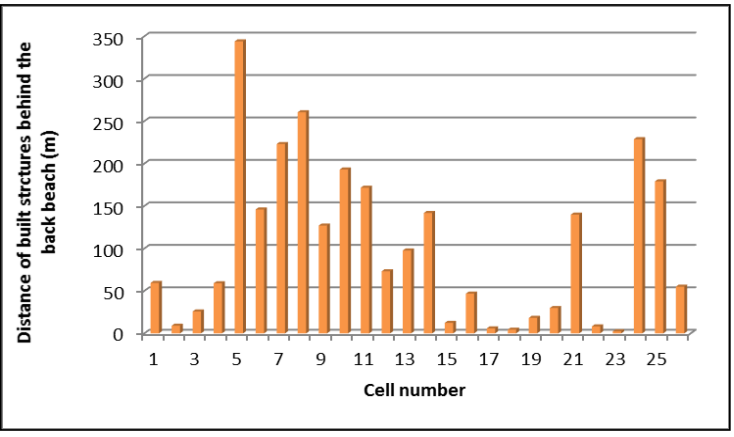

d)

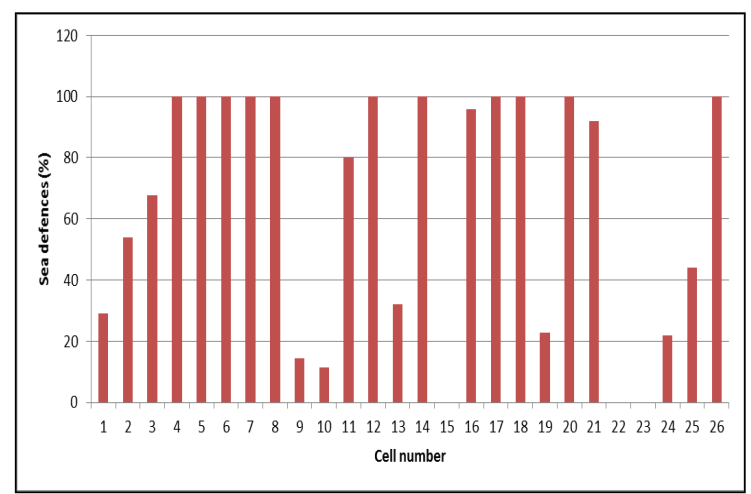

f)

Figure 6.11: Graphical representations of Llanelli

\subsection{Overall CVI measurement}

Having evaluated the measurements of the 7 physical parameters determined in sections 4.6.1 and 5.7 respectively and applying them to the 11 selected coastal areas, it is now necessary to evaluate the overall CVI measurements. Table 6.2 shows the selected coastal areas alongside allocated cell numbers. 
[PHD THESIS

April 2017

Table 6.2 Distribution of all shoreline measurements at selected sites

\begin{tabular}{|c|c|c|c|c|c|c|c|}
\hline Cell & Site Name & Cell & Site Name & Cell & Site Name & Cell & Site Name \\
\hline 1 & Spurn Head & 41 & Great Yarmouth & 81 & Skegness & 121 & Port Talbot \\
\hline 2 & Spurn Head & 42 & Great Yarmouth & 82 & Skegness & 122 & Port Talbot \\
\hline 3 & Spurn Head & 43 & Great Yarmouth & 83 & Skegness & 123 & Port Talbot \\
\hline 4 & Spurn Head & 44 & Great Yarmouth & 84 & Skegness & 124 & Port Talbot \\
\hline 5 & Spurn Head & 45 & Great Yarmouth & 85 & Skegness & 125 & Port Talbot \\
\hline 6 & Spurn Head & 46 & Great Yarmouth & 86 & Skegness & 126 & Port Talbot \\
\hline 7 & Hallsands & 47 & Great Yarmouth & 87 & Skegness & 127 & Port Talbot \\
\hline 8 & Hallsands & 48 & Great Yarmouth & 88 & Skegness & 128 & Port Talbot \\
\hline 9 & Hallsands & 49 & Great Yarmouth & 89 & Benbecula & 129 & Port Talbot \\
\hline 10 & Hallsands & 50 & Great Yarmouth & 90 & Benbecula & 130 & Port Talbot \\
\hline 11 & Hallsands & 51 & Great Yarmouth & 91 & Benbecula & 131 & Port Talbot \\
\hline 12 & Hallsands & 52 & Great Yarmouth & 92 & Benbecula & 132 & Port Talbot \\
\hline 13 & Hallsands & 53 & Great Yarmouth & 93 & Benbecula & 133 & Llanelli \\
\hline 14 & Hallsands & 54 & Great Yarmouth & 94 & Benbecula & 134 & Llanelli \\
\hline 15 & Lynmouth & 55 & Great Yarmouth & 95 & Benbecula & 135 & Llanelli \\
\hline 16 & Lynmouth & 56 & Great Yarmouth & 96 & Benbecula & 136 & Llanelli \\
\hline 17 & Lynmouth & 57 & Great Yarmouth & 97 & Benbecula & 137 & Llanelli \\
\hline 18 & Lynmouth & 58 & Great Yarmouth & 98 & Benbecula & 138 & Llanelli \\
\hline 19 & Happisburgh & 59 & Great Yarmouth & 99 & Benbecula & 139 & Llanelli \\
\hline 20 & Happisburgh & 60 & Great Yarmouth & 100 & Benbecula & 140 & Llanelli \\
\hline 21 & Happisburgh & 61 & Great Yarmouth & 101 & Benbecula & 141 & Llanelli \\
\hline 22 & Happisburgh & 62 & Great Yarmouth & 102 & Benbecula & 142 & Llanelli \\
\hline 23 & Happisburgh & 63 & Great Yarmouth & 103 & Benbecula & 143 & Llanelli \\
\hline 24 & Happisburgh & 64 & Great Yarmouth & 104 & Aberystwyth & 144 & Llanelli \\
\hline 25 & Happisburgh & 65 & Great Yarmouth & 105 & Aberystwyth & 145 & Llanelli \\
\hline 26 & Happisburgh & 66 & Skegness & 106 & Aberystwyth & 146 & Llanelli \\
\hline 27 & Dawlish & 67 & Skegness & 107 & Aberystwyth & 147 & Llanelli \\
\hline 28 & Dawlish & 68 & Skegness & 108 & Aberystwyth & 148 & Llanelli \\
\hline 29 & Dawlish & 69 & Skegness & 109 & Port Talbot & 149 & Llanelli \\
\hline 30 & Dawlish & 70 & Skegness & 110 & Port Talbot & 150 & Llanelli \\
\hline 31 & Dawlish & 71 & Skegness & 111 & Port Talbot & 151 & Llanelli \\
\hline 32 & Dawlish & 72 & Skegness & 112 & Port Talbot & 152 & Llanelli \\
\hline 33 & Dawlish & 73 & Skegness & 113 & Port Talbot & 153 & Llanelli \\
\hline 34 & Dawlish & 74 & Skegness & 114 & Port Talbot & 154 & Llanelli \\
\hline 35 & Dawlish & 75 & Skegness & 115 & Port Talbot & 155 & Llanelli \\
\hline 36 & Dawlish & 76 & Skegness & 116 & Port Talbot & 156 & Llanelli \\
\hline 37 & Dawlish & 77 & Skegness & 117 & Port Talbot & 157 & Llanelli \\
\hline 38 & Great Yarmouth & 78 & Skegness & 118 & Port Talbot & 158 & Llanelli \\
\hline 39 & Great Yarmouth & 79 & Skegness & 119 & Port Talbot & & \\
\hline 40 & Great Yarmouth & 80 & Skegness & 120 & Port Talbot & & \\
\hline
\end{tabular}


Figures 6.12(a-d) respectively show graphically the overall parameter measurements produced from the data given in Appendix 1. The average beach width was $239.1 \mathrm{~m}$, between the maximum of $1900 \mathrm{~m}$ recorded in cells 143 and 144 (Llanelli) and minimum of $1.4 \mathrm{~m}$ in cells 44 and 45 (Great Yarmouth) and 47\% of cells recorded lower than $50 \mathrm{~m}$. i.e. high vulnerability (Table 4.5; Figure 6.12a). The average dune width was $97.1 \mathrm{~m}$, between the maximum of $515 \mathrm{~m}$ recorded in cell 111 (Port Talbot) and minimum of $9.5 \mathrm{~m}$ cell 74 (Skegness) and $71 \%$ of cells did not display any dune morphology (Figure 6.12b). The average coastal slope was $3.9 \%$ between the maximum of $48 \%$ recorded in cell 18 (Lynmouth) and minimum of $0.4 \%, \mathrm{~m}$ in cell 66 (Skegness) and $70 \%$ of cells recorded lower than average values (Figure 6.12c).

The average distance of vegetation behind the back beach was $243 \mathrm{~m}$, between the maximum of $500 \mathrm{~m}$ recorded in cells 19, 41 and 112 (Happisburgh, Great Yarmouth and Port Talbot respectively) and minimum of $4 \mathrm{~m}$ in cell 23 (Happisburgh), however, vegetation cover was recorded in $85 \%$ of the cells (Figure $6.12 \mathrm{~d}$ ). The average distance of built structures behind the back beach was $235 \mathrm{~m}$, between the maximum of $500 \mathrm{~m}$ recorded in cell 13 (Hallsands) and minimum of $2.4 \mathrm{~m}$ in cell 155 (Llanelli) and only $10 \%$ of cells contained no built structures (Figure 6.12e).

The average rocky outcrop was $27 \%$ between the maximum of $100 \%$ recorded in Aberystwyth and Benbecula and minimum of $0.8 \%$ in cell 146 (Llanelli) and $72 \%$ of cells did not have rocky outcrops (Figure 6.12f). The average sea defence coverage when recorded was $81.32 \%$, between the maximum of a 100\% covering an entire cell (Dawlish, Skegness, Aberystwyth, Port Talbot, Llanelli and Benbecula) and minimum of $1 \%$ in cell 120 (Port Talbot). Importantly, no sea defence structures were recorded in $63 \%$ of the cells. (Figure 6. $12 \mathrm{~g})$. 

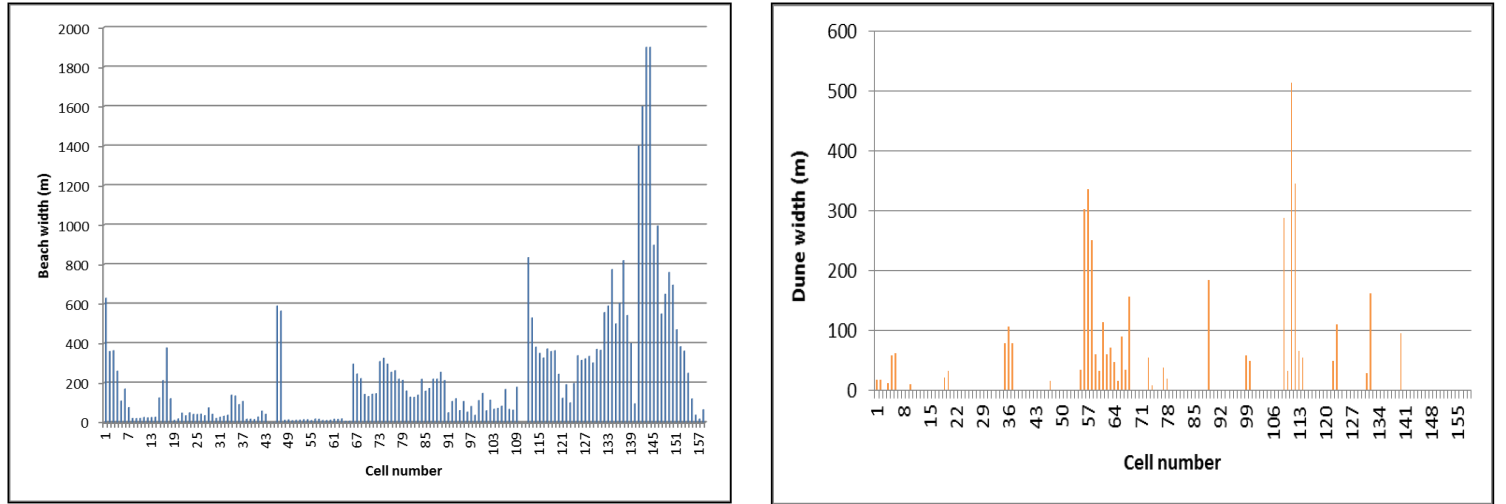

a)
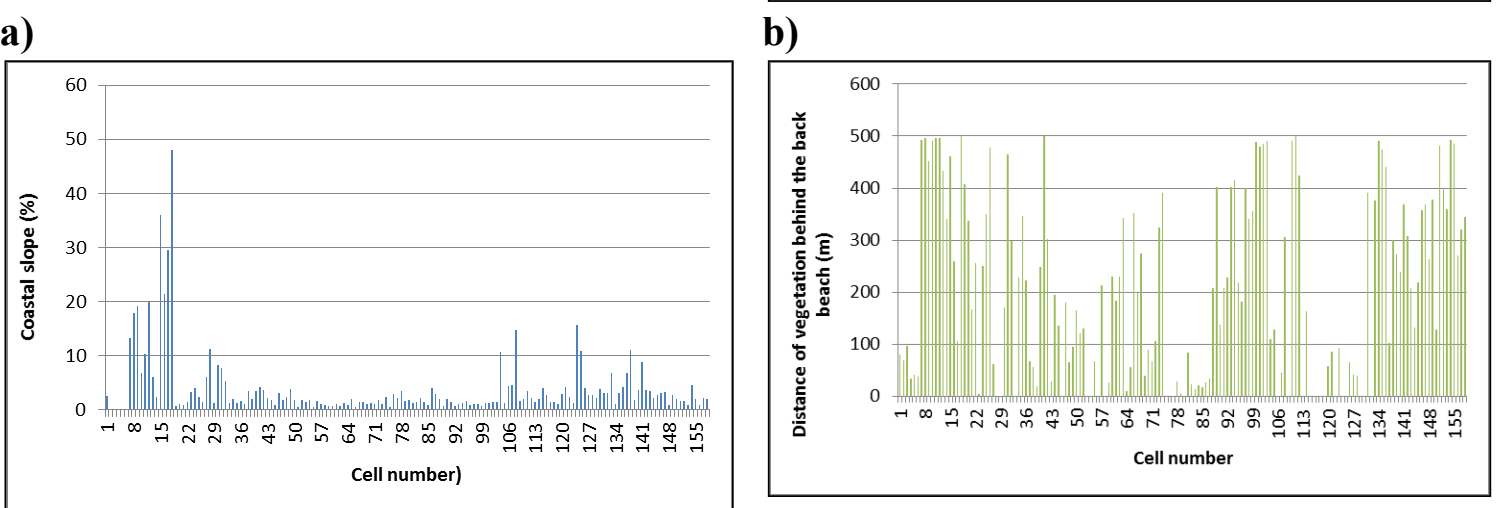

c)

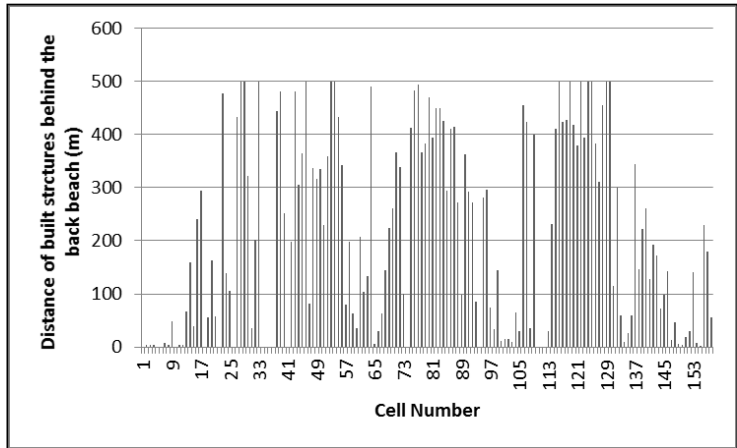

d)

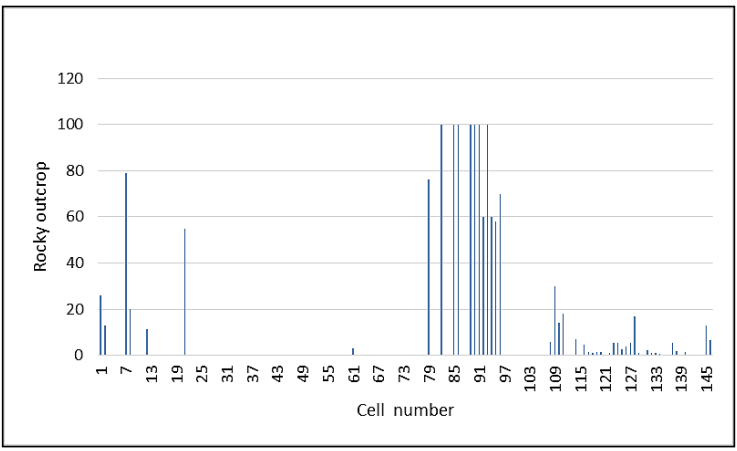

e)

f)
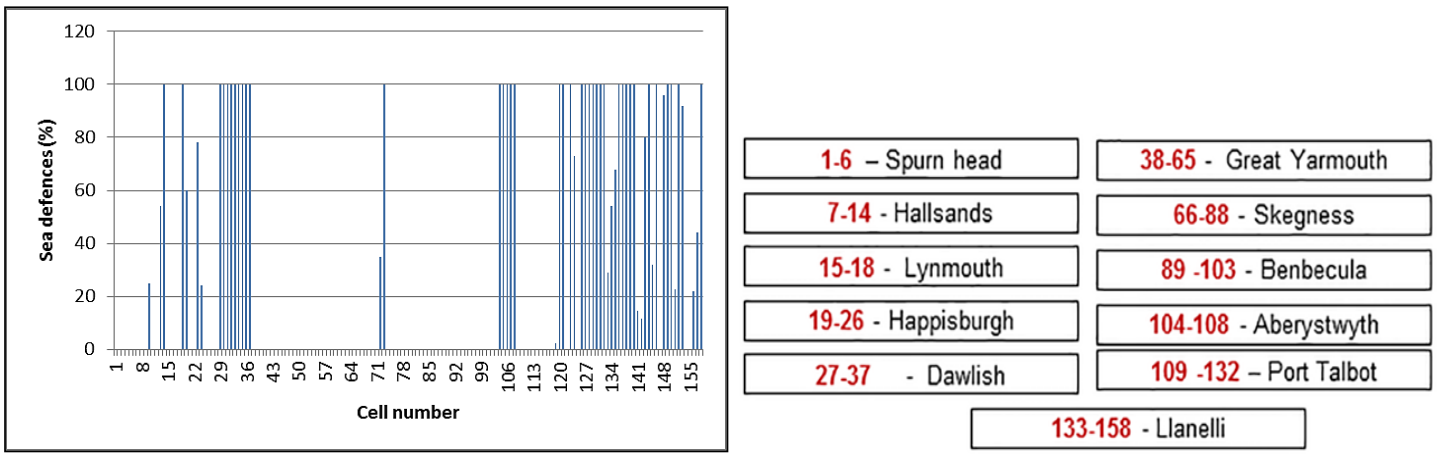

g)

Figure 6.12: Graphical representations of overall CVI scores 


\subsection{Summary}

This completes the descriptive assessment of the measurements taken for each of the physical parameters described in section 5.7, both on an individual case study and overall basis. From this point, the next Chapter will allocate CVI scores, compare in line with boundaries defined in Table 4.5. These will then be compared and from analysis a site-bysite and overall ranking according to PCVI will be determined. 


\section{CHAPTER 7 - PCVI ANALYSIS}




\section{Physical coastal vulnerability index (PCVI) Analysis}

\subsection{Introduction}

Having evaluated the seven physical parameters and applying them to the 11 selected coastal areas described in Sections 4.4. It is now necessary to apply the measurements determined in chapter 6, to allocate vulnerability scores and develop a PCVI.

\subsection{Spurn Head}

The physical parameter ratings given in Table 4.5 (Chapter 4) were used to allocate vulnerability scores and construct Figure 7.1. As beach width ranged from $630 \mathrm{~m}$ to $109 \mathrm{~m}$ (section 6.2), it stands to reason that the vulnerability scores would range between 1 (extremely low) and 2 (low). Eighty percent of cells recorded lowest value (1) and importantly the overall average beach width CVI score was 1.3 (Figure 7. 1a). Dune width values varied from $63 \mathrm{~m}$ to $13 \mathrm{~m}$ and Table 4.4 vulnerability scores ranged between 3 (moderate) and 4 (high). Over half of the cells were allocated a score of 4 , influencing the overall average of 3.2 (Figure 7.1b). When the aerial photographs were analysed within GIS only one cell could measure for coastal slope and allocated a score of 4 . This score was distributed evenly for all cells, as the topography of this coastal feature appeared consistent on the aerial photograph (7.1c).

There was a considerable variance between the lowest and highest CVI values for distance of vegetation behind the back beach. However, because the measured distances ranged between $97 \mathrm{~m}$ and $34 \mathrm{~m}$, Figure 7.1d shows that all cells were allocated a score of 4 . Only 3 cells recorded built structures behind the back beach and these were allocated a score of 4 as they were only set back $3 \mathrm{~m}$ (Figure 7.1e). Unsurprisingly, there was no rocky Outcrop or sea defences recorded at Spurn Head and because of the importance of these aspects for the dissipation of waves and shoreline protection, both parameters were allocated scores of 4 throughout (Figures 7.1f and 7.1g respectively). Figure 7.1h shows the aggregated scores in one representation, the overall average score was 22, the maximum recorded score of 25 and minimum of 20 and the cumulative score of Spurn Head was 132. 

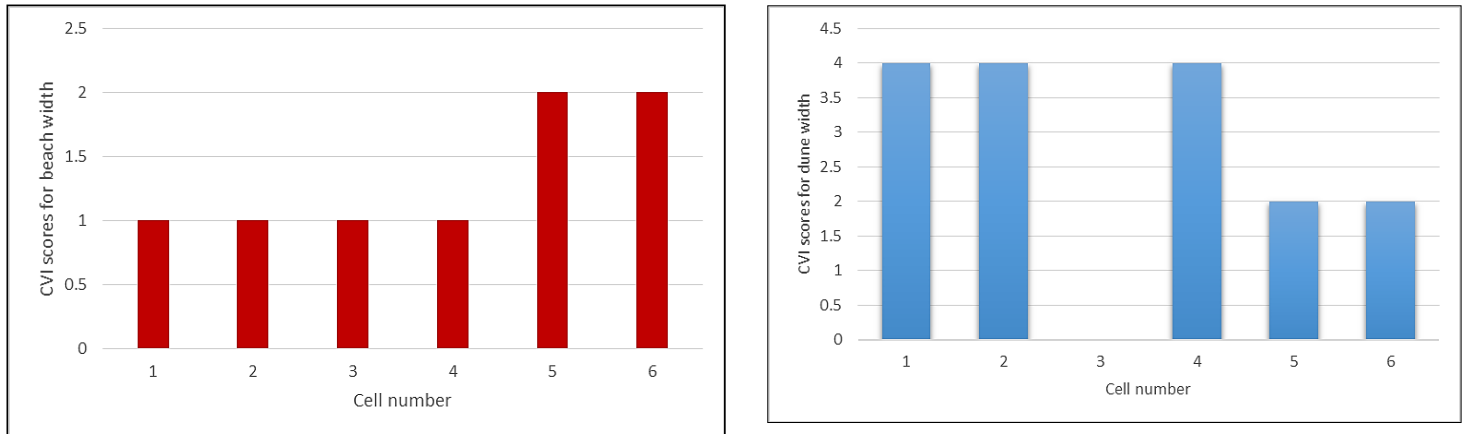

a)

b)
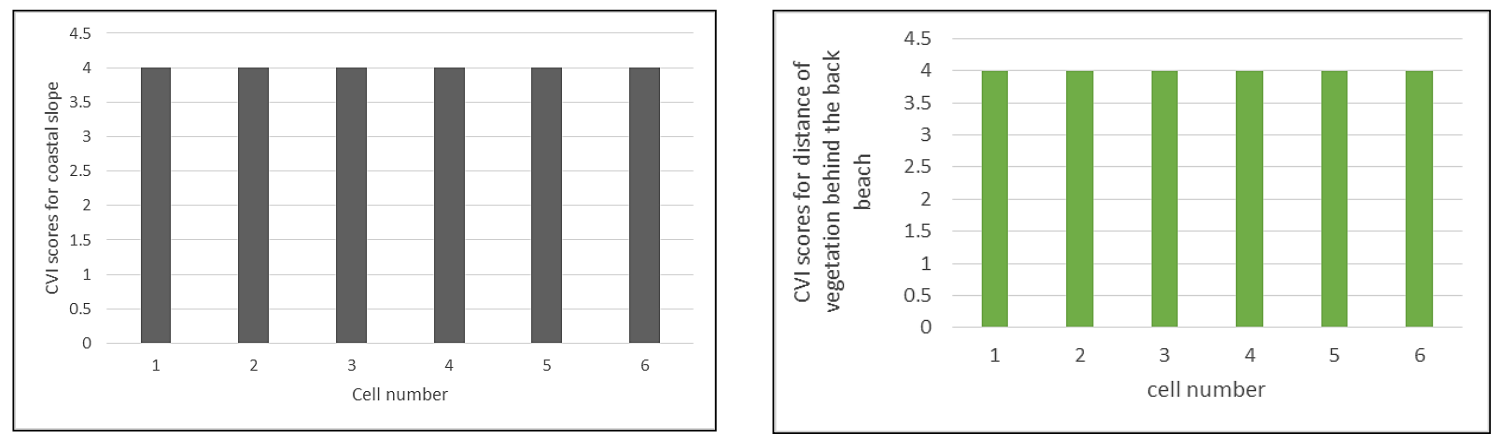

c)

d)
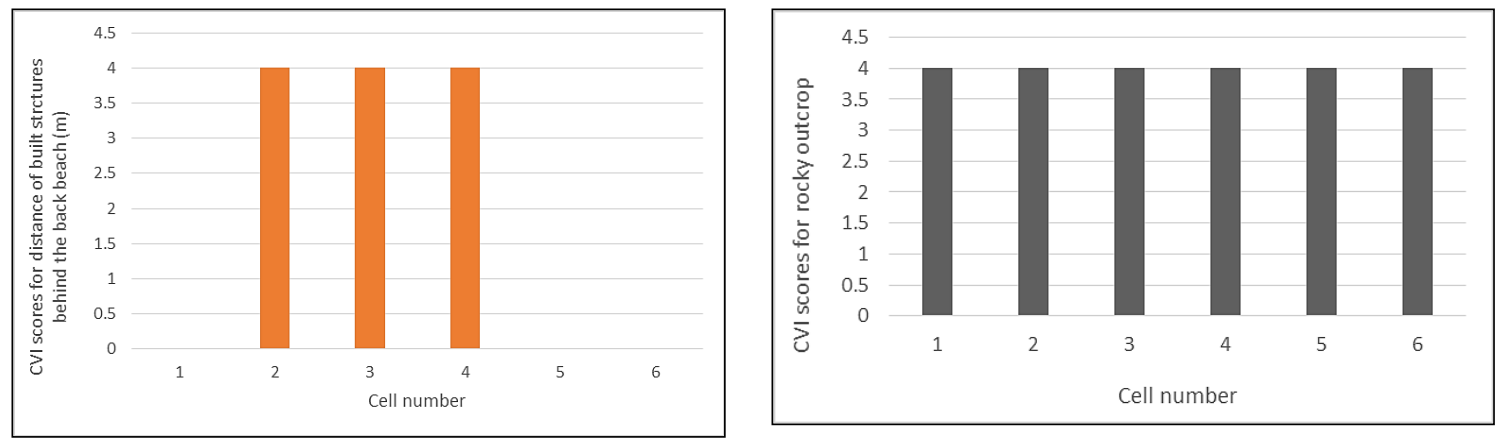

e)

f)
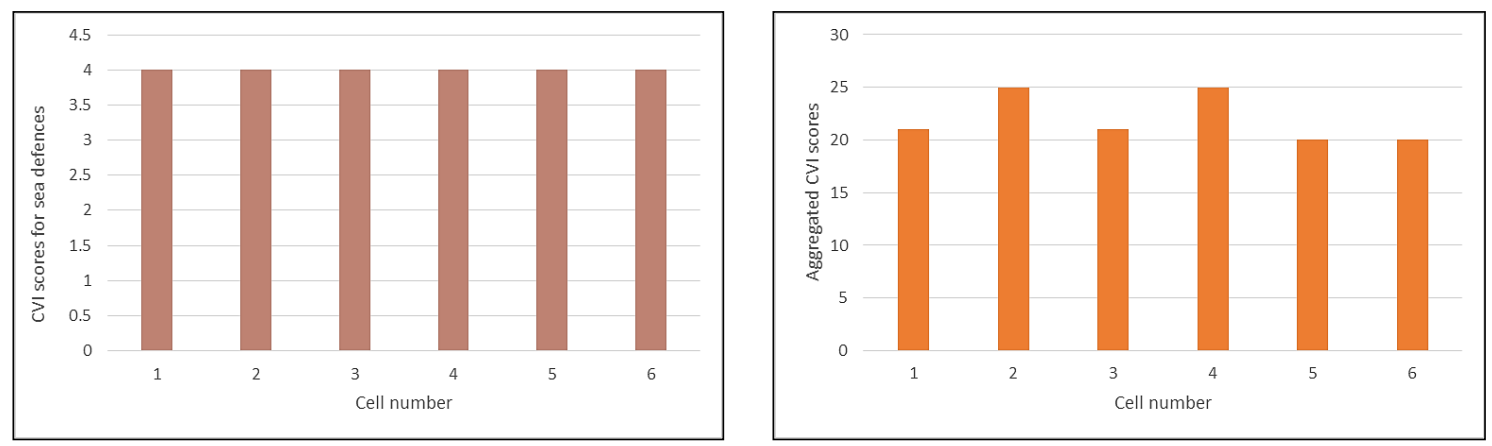

g)

h)

Figure 7.1: Distribution of CVI scores for Spurn Head 


\subsection{Hallsands}

With the exception of the first cell $(70 \mathrm{~m})$ beach width ranged from $20 \mathrm{~m}$ to $27 \mathrm{~m}$ (section 6.3 ), it stands to reason that the vulnerability scores would range between 3 and 4 . Eightyseven percentage of the cells recorded a score of 4 and the average CVI score was 3.6 (Figure 7. 2a). Dunes only present in the fourth cell; therefore, the parameter was allocated score of 4 , because no additional shoreline protection can be given (Figure 7.2b). The scores for coastal slope ranged between 1 and 4 with an average score of 1.8 (Figure 7.2c). Even though there was some variation in the measured distance of vegetation behind the back beach i.e. between $496 \mathrm{~m}$ and $340 \mathrm{~m}$ (Figure 7.2d), when compared to the respective value given in Table 4.4 all cells were allocated a score of 2. CVI scores allocated for the distance of built structures behind the back beach ranged between 3 and 4 with the average of 3.8 (Figure 7.1e). Only two cells recorded rocky outcrop and three cells sea defences but because of the importance of these natural and anthropogenic structures, for the dissipation of waves and shoreline protection. Consequently, scores of 4 were allocated and giving overall average CVI scores were 3.6 and 3 respectively (Figures $7.2 \mathrm{f}$ and $7.2 \mathrm{~g}$ respectively). The aggregated scores are graphically represented in Figure $7.2 \mathrm{~h}$, giving an overall average score was 22, maximum of 24 and minimum of 19 and a cumulative score for Hallsands of 174.

\subsection{Lynmouth}

The beach width ranged between $378 \mathrm{~m}$ and $121 \mathrm{~m}$ (section 6.4) and the cells on either end of the studied area were allocated scores of 2 and mid cells 1 (Figure 7.3a). Dunes were absent and similar to previous; all cells were allocated CVI scores of 4 (Figure 7.3b). There was very little variation when consideration was given to coastal slope and since the values calculated in section 6.4 were all $>12 \%$ (Table 4.4) all four cells were given scores of 1 (Figure 7.3c). Considering only 4 cells were located at this location, the measured distances of vegetation behind the back beach varied considerably, ranging between $500 \mathrm{~m}$ and 105 m. Table 4.4 data allocated CVI values of 2 and 3, averaging at 2.2 (Figure 7.1d). Built structures were identified in 3 of the 4 cells and a distance of $<100 \mathrm{~m}$ recorded in the first cell resulted in a score of 4 , the remaining cells recorded distances $>600 \mathrm{~m}$ and were allocated scores of 1 (Figure 7.3e). There were no rocky outcrops or sea defences and as a consequence, both were allocated scores of 4 throughout (Figures $7.3 \mathrm{f}$ and $7.3 \mathrm{~g}$ respectively). The aggregated scores represented graphically in Figure $7.1 \mathrm{~h}$, shows that the 
first cell is the most vulnerable with a score of 21 and the fourth cell the least vulnerable with a score of 17.

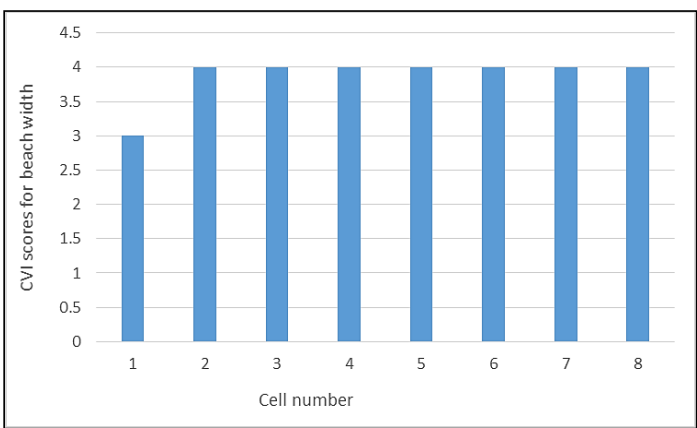

a)

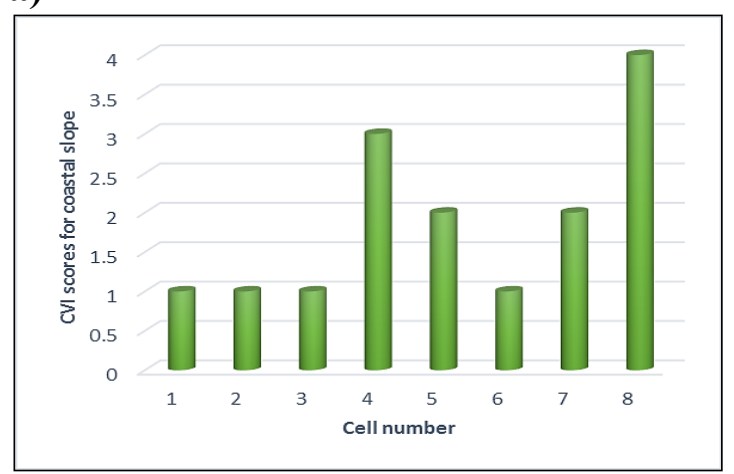

c)

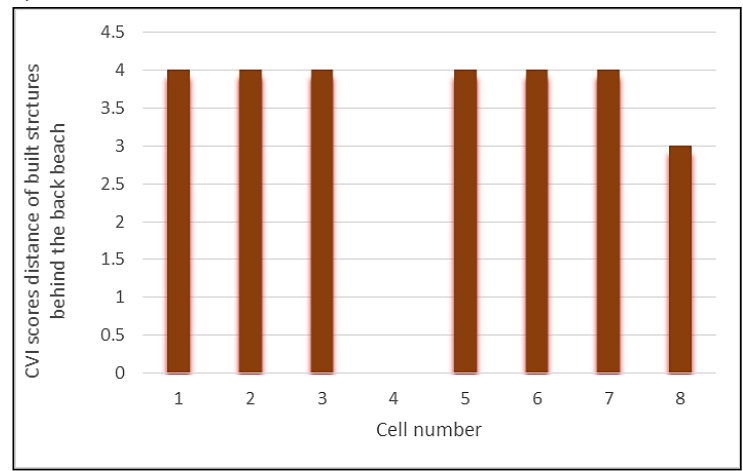

e)

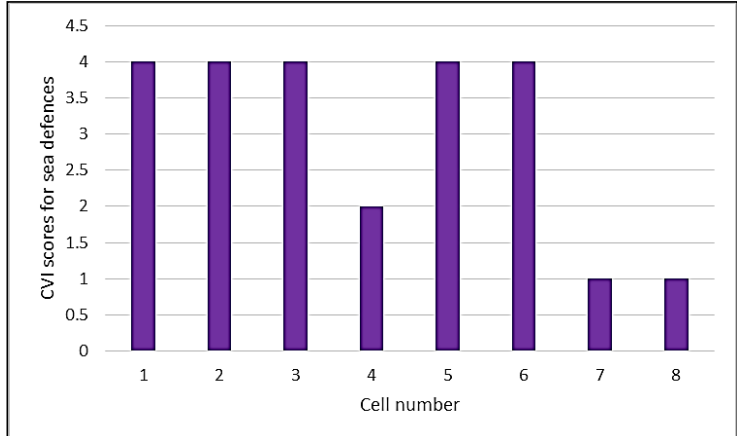

g)

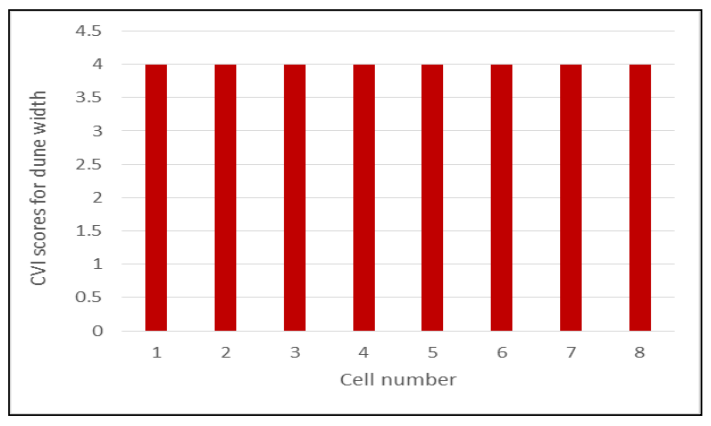

b)

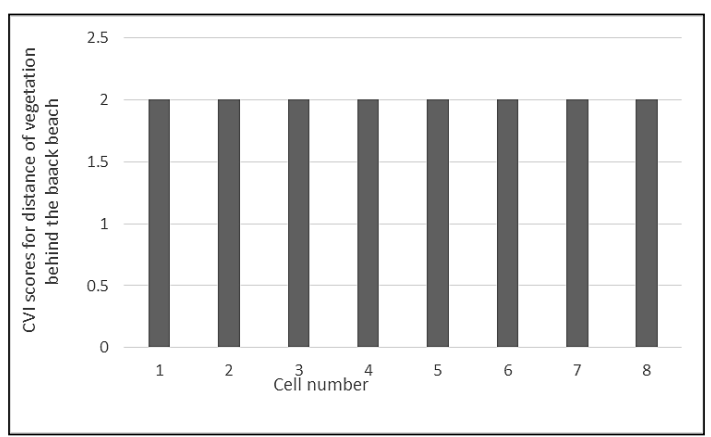

d)

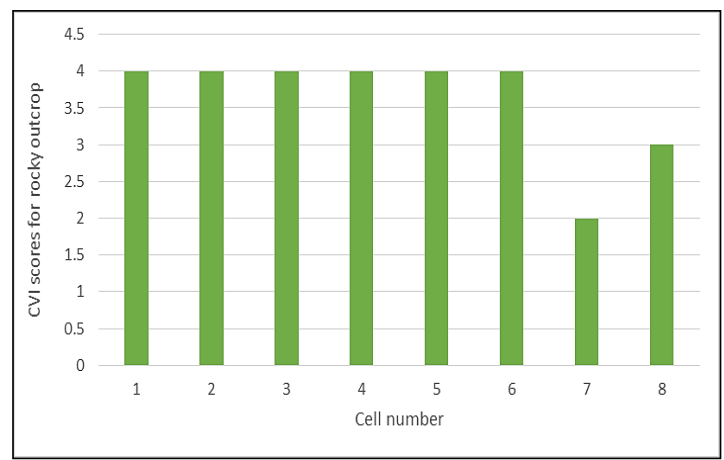

f)

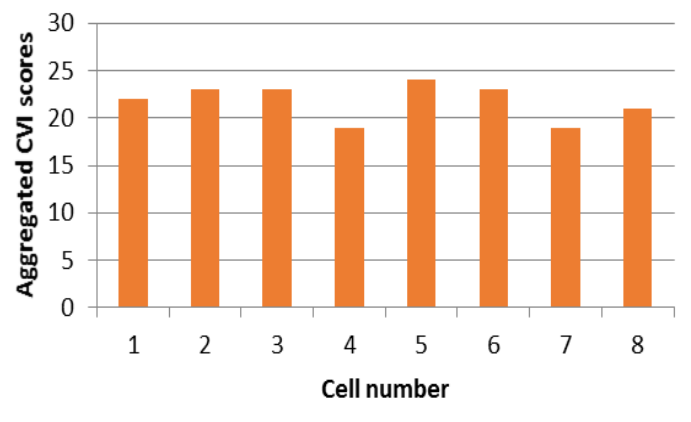

h)

Figure 7.2: Distribution of CVI scores for Hallsands 


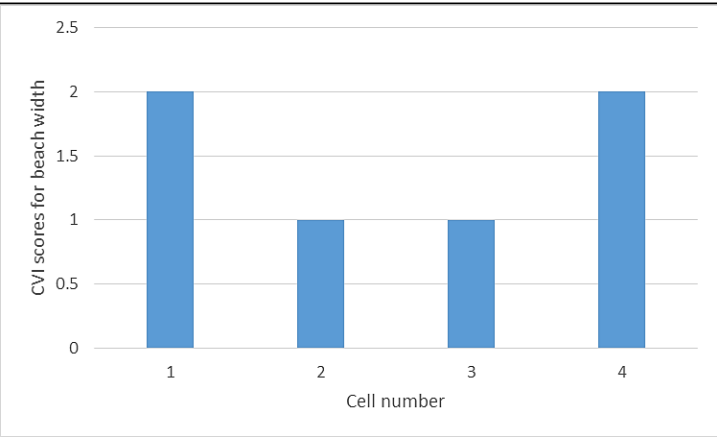

a)

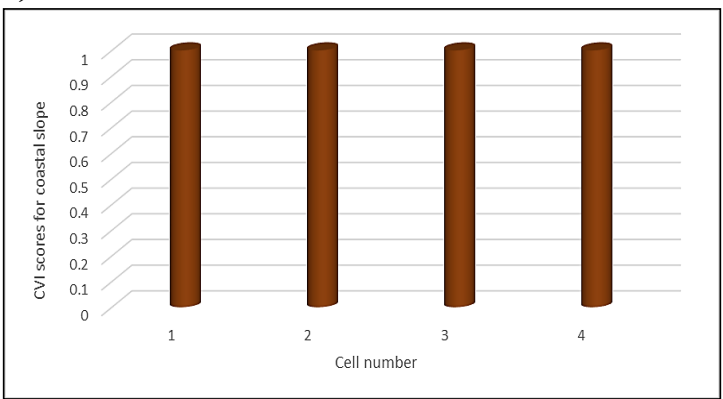

c)

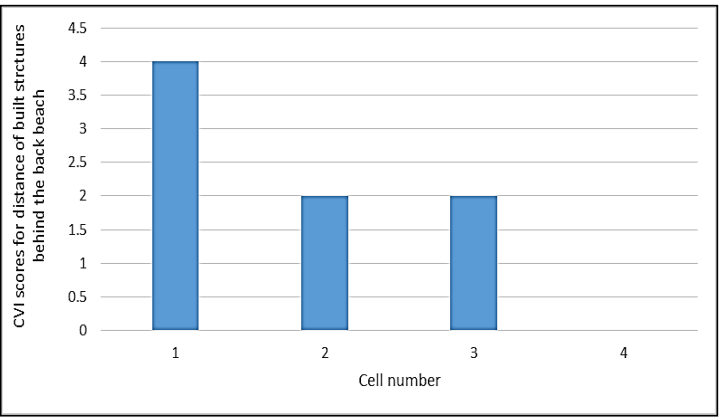

e)

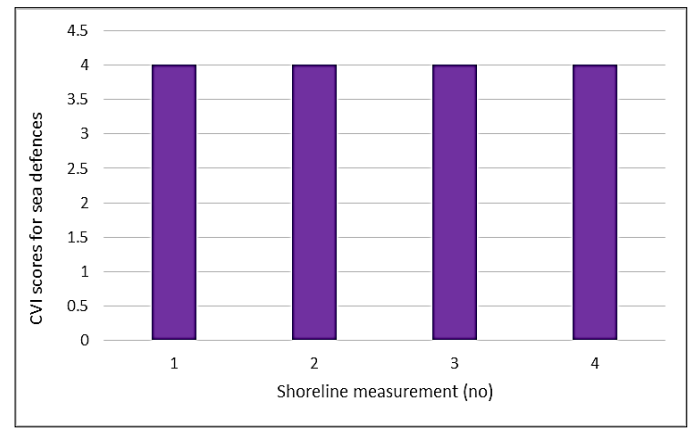

g)

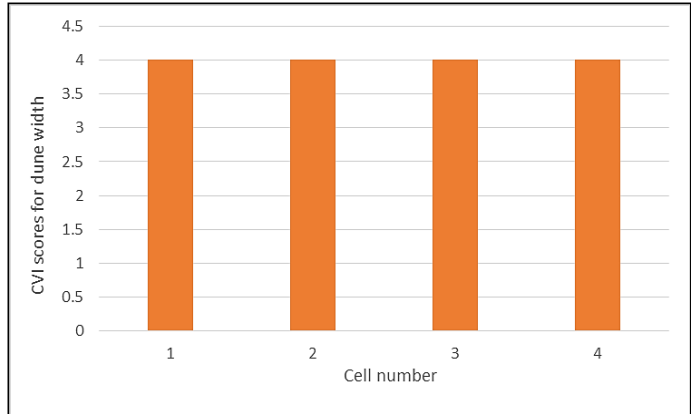

b)

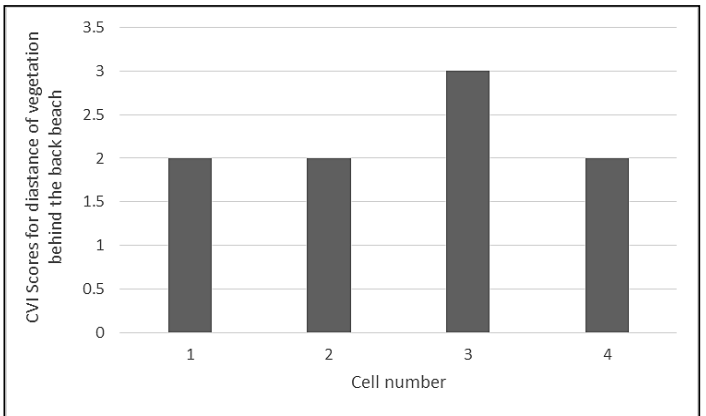

d)

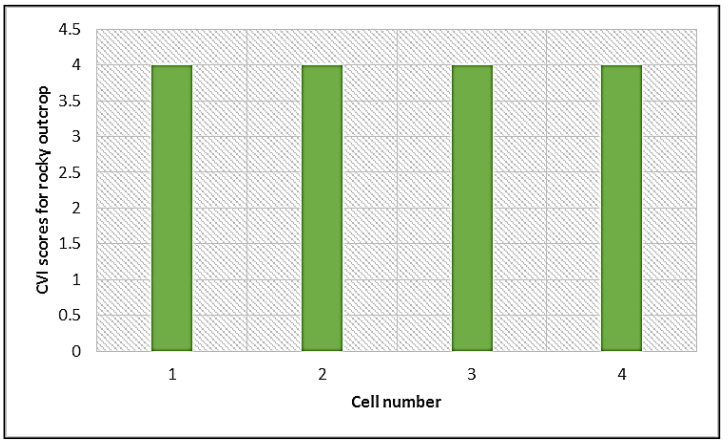

f)

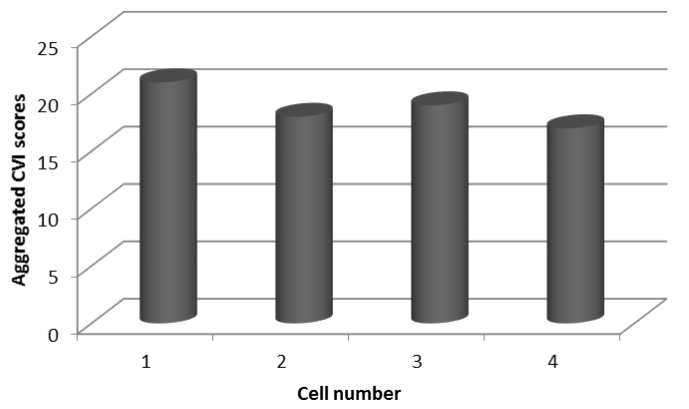

h)

Figure 7.3: Distribution of CVI scores for Lynmouth 


\subsection{Happisburgh}

The beach width ranged between $60 \mathrm{~m}$ and $11 \mathrm{~m}$ (Section 6.5) and since cells three and five exceeded $50 \mathrm{~m}$ they were allocated a CVI score of 3 , the widths of the remaining cells were $<50 \mathrm{~m}$ and therefore given a score of 4 (Figure 7.4a). Dunes were only recorded in the first and second cells and allocated scores of 3 and 4 respectively and in line with previous given scores of 4 (Figure 7.4b). The coastal slope in all cells was $<4 \%$ and accordingly all cells were allocated scores of 4 (Figure 7.4c). Measured distances of vegetation behind the back beach ranged between $408 \mathrm{~m}$, and $4 \mathrm{~m}$ with the third and fifth cell given CVI scores of 3 and 4 respectively. The distances recorded in the remaining cells ranged between $200 \mathrm{~m}$ and 600 $m$ and were allocated scores of 2 (Figure 7.1d). Two cells ( 1 and 3 ) showed structures within $100 \mathrm{~m}$ of the shoreline and where given the highest score (4) and the scores varied between 2 and 3 in the remaining cells (Figure 7.4e). Rocky outcrops were recorded in three cells with cell one scoring 1 and cells two and six 3, the remaining cells were given the highest score of 4 (Figure 7.4f). Sea defences were present in 4 cells, of those measured, three protected $>50 \%$ of the frontage and were given the lowest score (1), the remaining cell was given a score of 2 and all remaining cells 4 (Figure 7.4g). The aggregated scores are represented graphically in Figure $7.4 \mathrm{~h}$ and shows that the third cell is the most vulnerable with a score of 27 and first and second cells least vulnerable with a score of 20.

\subsection{Dawlish}

Beach width ranged from $139 \mathrm{~m}$ to $21.2 \mathrm{~m}$ (chapter 6, section 6.6), with six cells recording widths of $<50 \mathrm{~m}$ and allocated scores of 4 , the remaining cells were allocated scores between 2 and 3 (Figure 7.5a). Dunes were recorded in the last three cells and given CVI scores of 2 , and the remaining cells were allocated scores of 4 (Figure 7.5b). Over half the cells recorded coastal slopes of $<4 \%$ and allocated a score of 4 , while the remaining cell scores ranged between 2 and 3(Figure 7.5c). The distance of vegetation behind the back beach varied considerably and ranged between $464 \mathrm{~m}$ and $60 \mathrm{~m}$. The first and last cells were allocated a score of 4 and fourth cell a score of 3, all remaining cells were given score of 2 (Figure 7.5d). With the exception of cells 5 and 6 with allocated CVI scores of 4 and 3 respectively, most structures, were set back $200 \mathrm{~m}$ to $600 \mathrm{~m}$ behind the back beach and given a CVI scores of 2 (Figure 7.5e). Rocky outcrop was only recorded in seventh cell and given a score of 1 and all remaining cells were allocated a score of 4 (Figure 7.5f). The shoreline frontage is protected by extensive sea defences resulting in a low vulnerability score of 1 throughout 
(Figure $7.5 \mathrm{~g}$ ). Figure $7.5 \mathrm{~h}$ shows the aggregated scores in one representation; the overall average score was 18, the maximum-recorded score of 22 and minimum of 15.

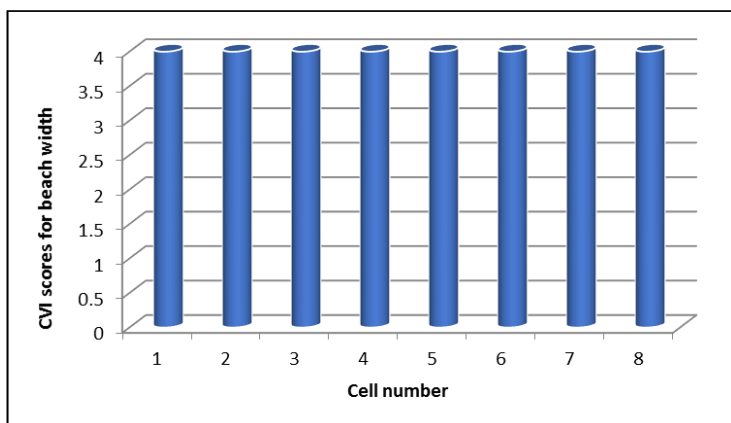

a)

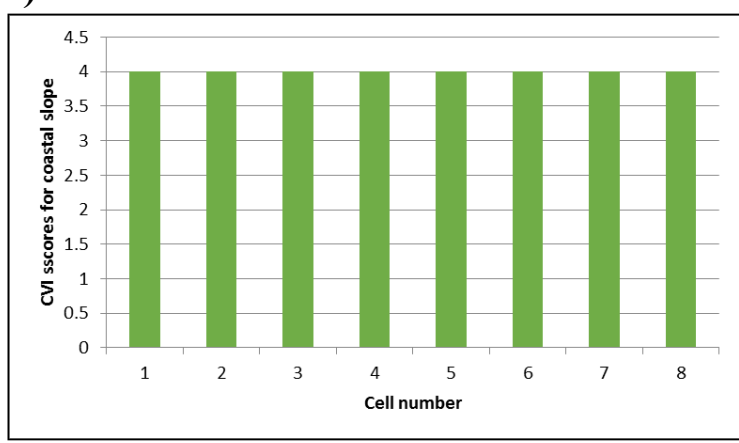

c)

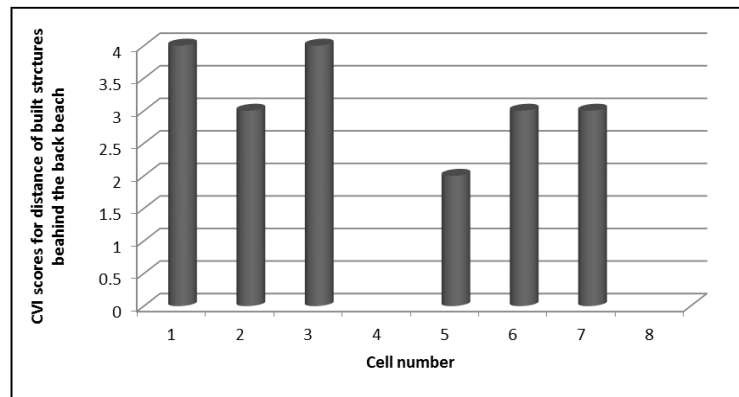

e)

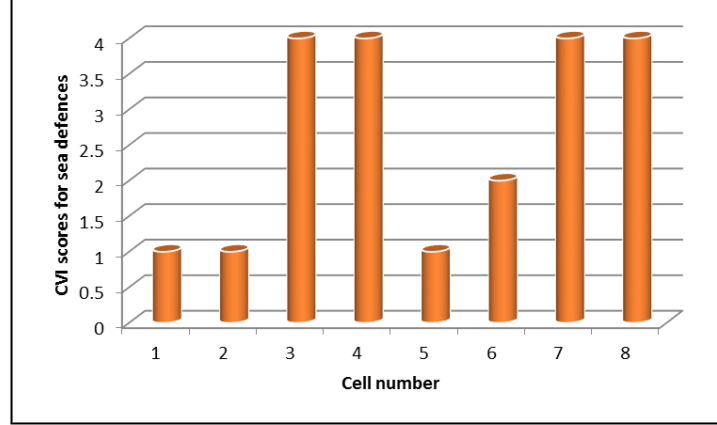

g)

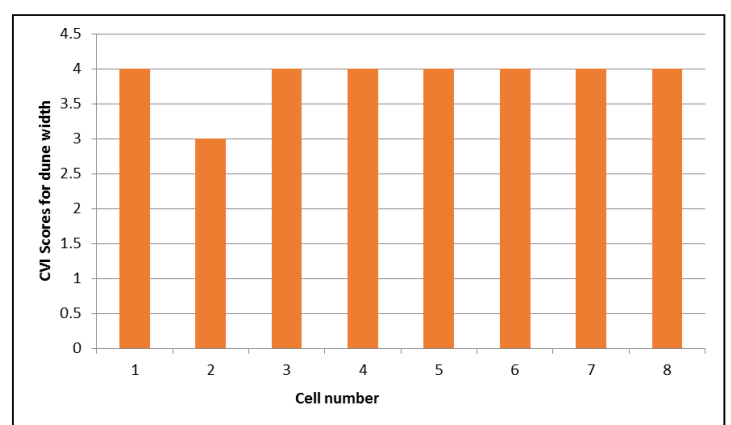

b)

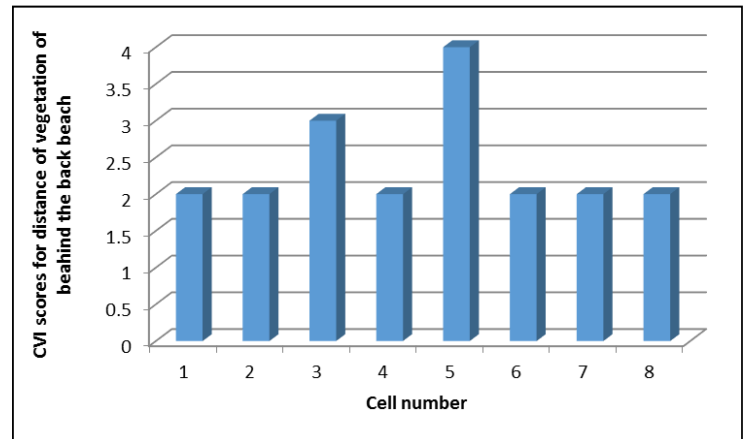

d)

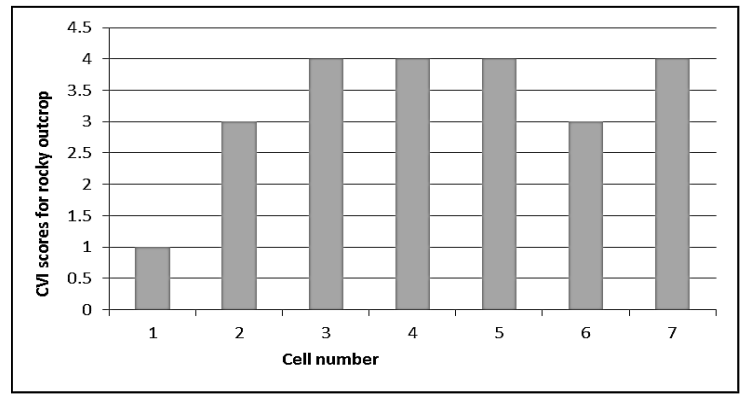

f)

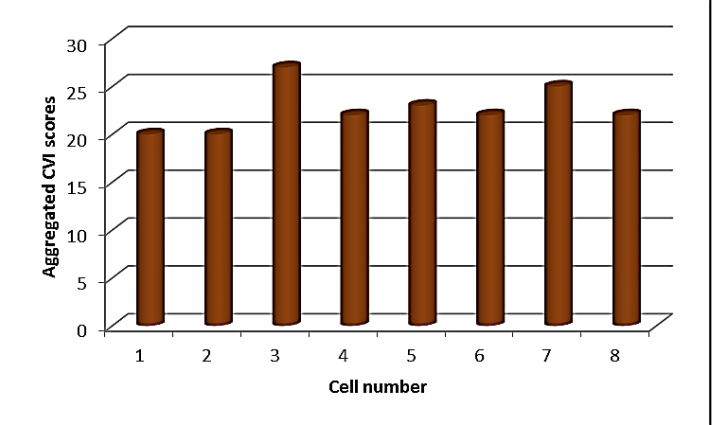

h)

Figure 7.4: Distribution of CVI scores for Happisburgh 

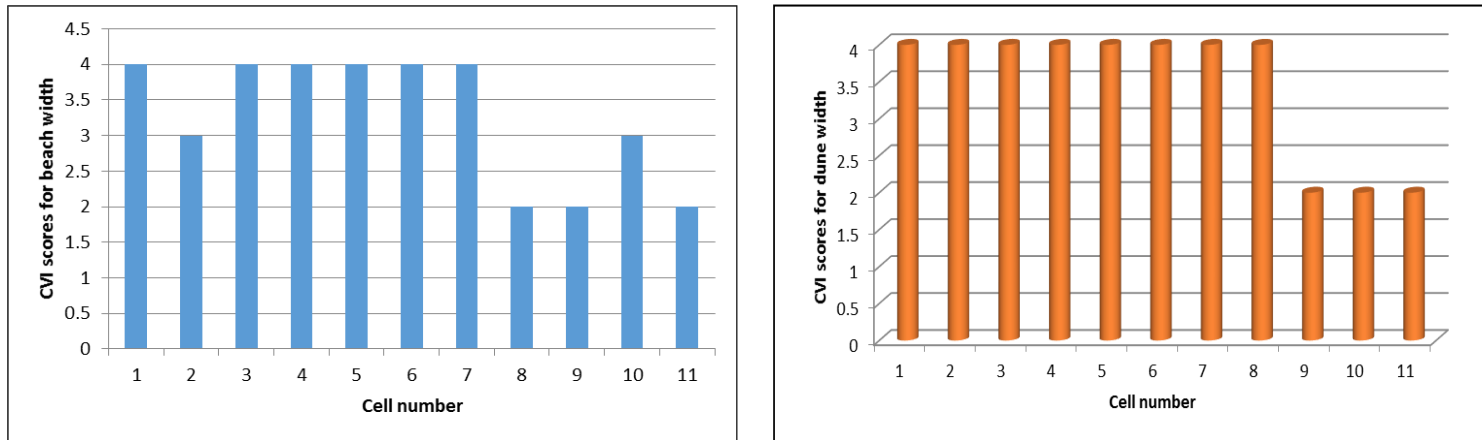

a)

b)

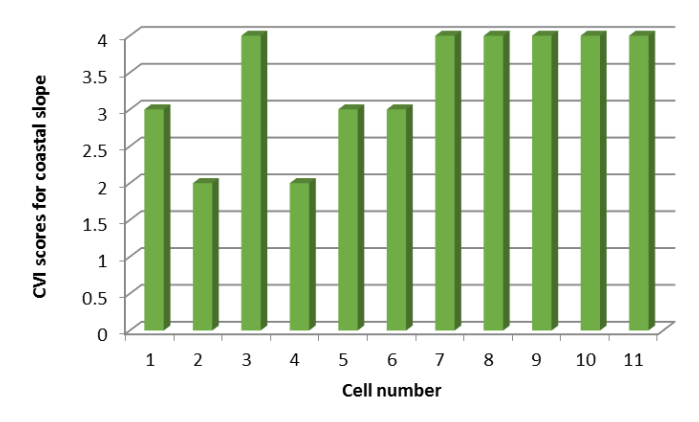

c)

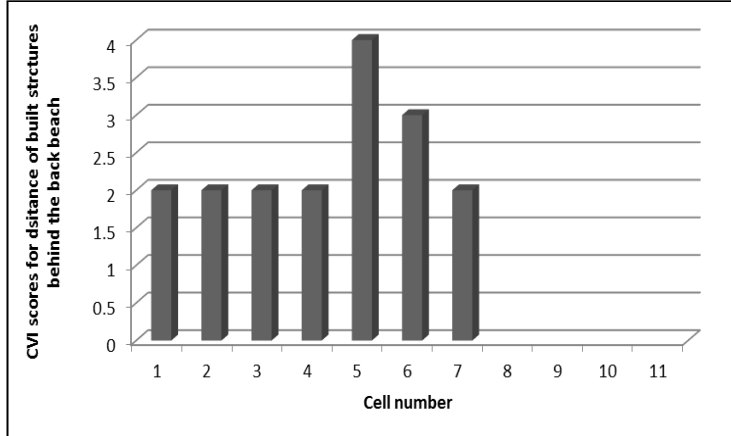

e)

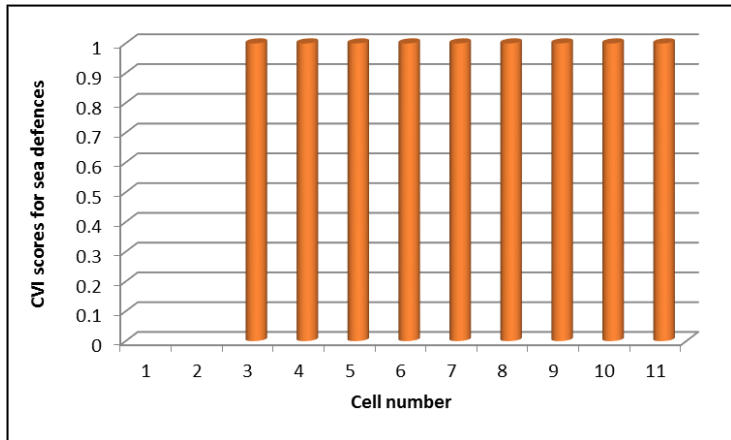

g)

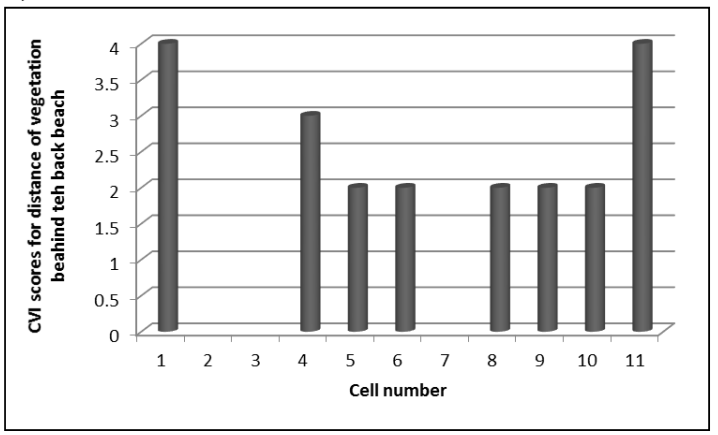

d)

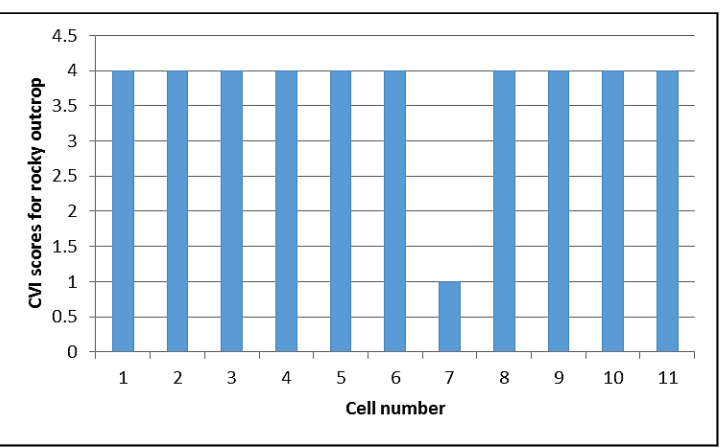

f)

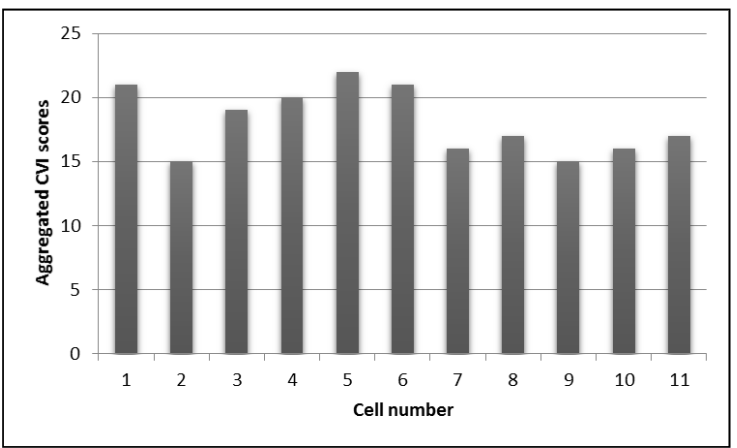

h)

Figure 7.5: Distribution of CVI scores for Dawlish 


\subsection{Great Yarmouth}

Beach width ranged from $590 \mathrm{~m}$ to $1.4 \mathrm{~m}$ (section 6.7) and 54\% of cells were allocated high scores (4) (Figure 7.6a). Dunes were only recorded in $42 \%$ of the cells, and these were allocated scores between 1 and 4, all remaining cells given a score of 4 (Figure 7.6b). With the exception of cell 4 the coastal slope was $<4 \%$ and as a consequence, almost all cells were allocated a score of 4 (Figure 7.6c). The measured distance of vegetation behind the back beach varied considerably and ranged between $500 \mathrm{~m}$ and $10 \mathrm{~m}$. Consequently, cells were allocated scores between 4 and 2 (Figure 7.6d). There was also a considerable variance in the distance of built structures behind the back beach with allocated scores ranging between 4 and 2 (Figure 7.6e). Unsurprisingly, there was no rocky outcrop and almost no sea defences and because of shoreline protection given by both parameters scores of 4 were allocated throughout (Figures 7.6f and 7.6g respectively). Figure 7.6h shows the aggregated scores in one representation, the overall average score was 24 , the maximum-recorded score of 28 and minimum of 19 .

\subsection{Skegness}

A relatively wide beach ranged from $326 \mathrm{~m}$ to $128 \mathrm{~m}$ (section 6.8) and as a consequence most cells were allocated scores of either 1 or 2 (Figure 7.7a). Dunes were only recorded in approximately $50 \%$ of the cells and allocated scores that ranged between 2 and 4 (Figure $7.7 b)$. The coastal maximum coastal slope was $<4 \%$ and all cells were allocated scores of 4 (Figure 7.7c). The distances of vegetation behind the back beach, range between $390 \mathrm{~m}$ and $6 \mathrm{~m}$. Consequently, scores were allocated between 2 and 4 (Figure 7.7d). Built structures behind the back beach also varied with allocated scores ranging between 2 and 4 (Figure 7.7e). Unsurprisingly, only one cell recorded rocky outcrop and two cells recorded sea defences because of the absence of shoreline protection, both parameters were allocated scores of 4 throughout (Figures $7.7 \mathrm{f}$ and $7.7 \mathrm{~g}$ respectively). Figure $7.7 \mathrm{~h}$ shows the aggregated scores in one representation, the overall average score was 22 , the maximumrecorded score of 24 and minimum of 13. 

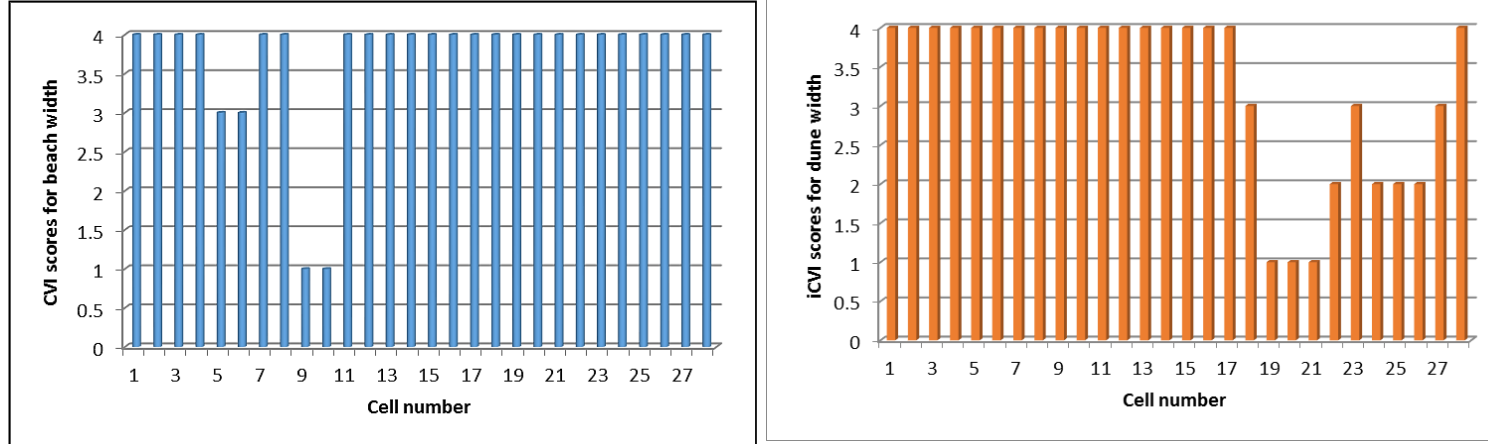

a)

b)

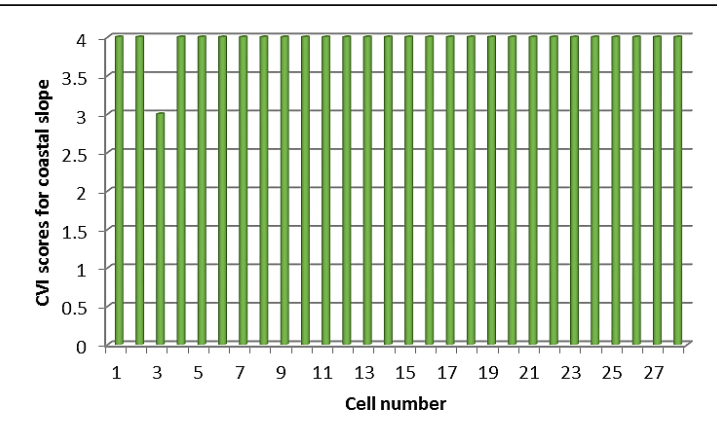

c)

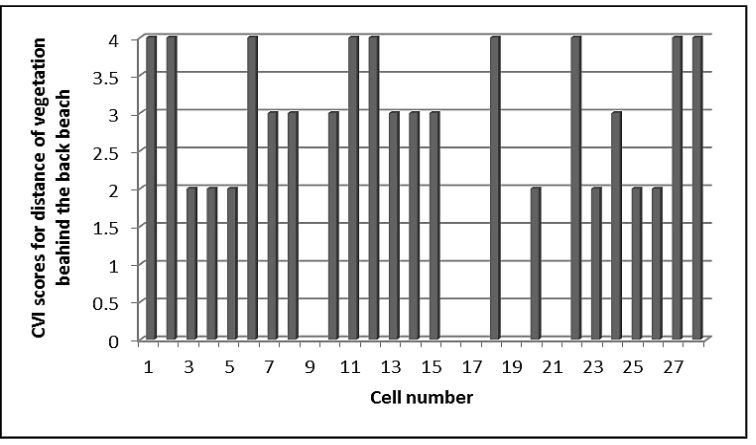

d)

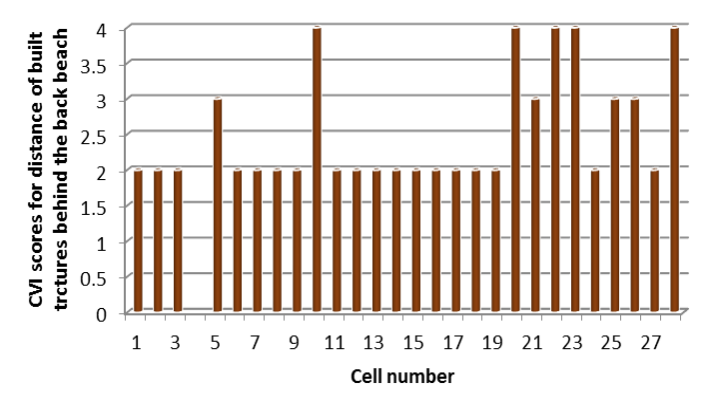

e)

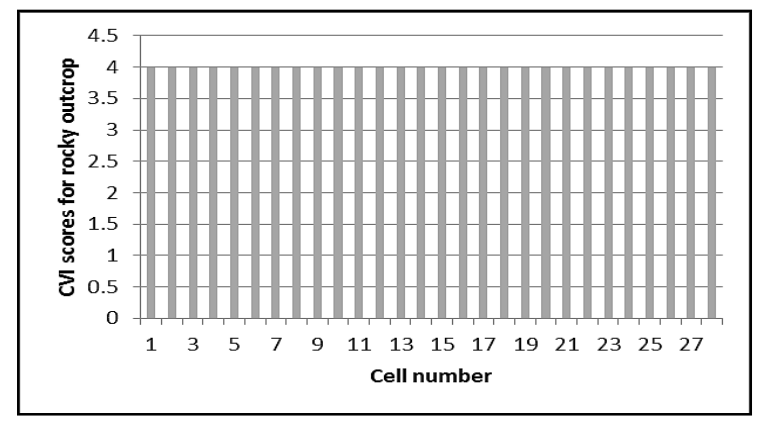

f)

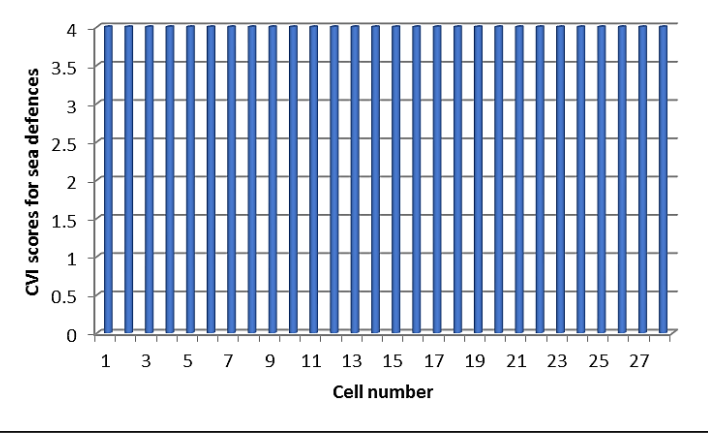

g)

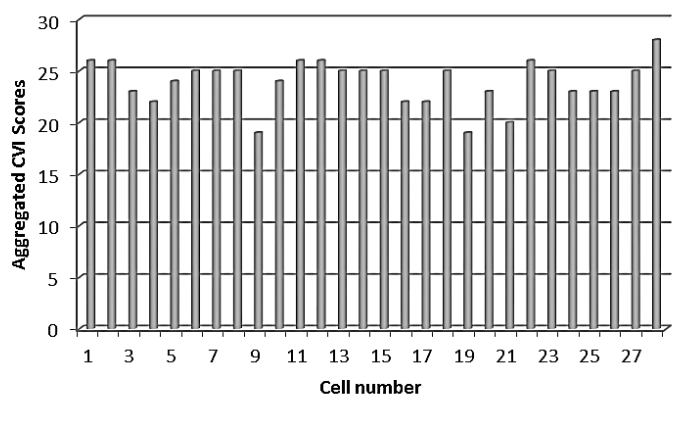

h)

Figure 7.6: Distribution of CVI scores for Great Yarmouth 


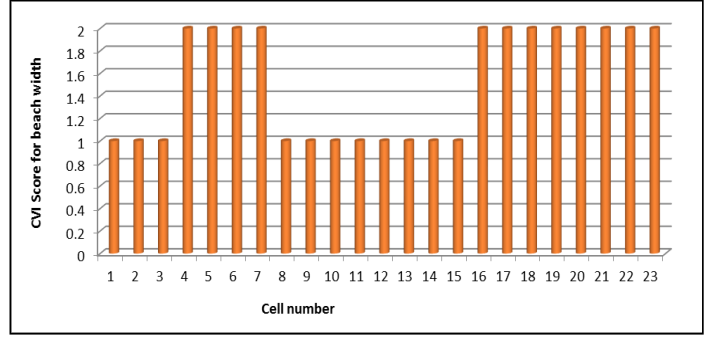

a)

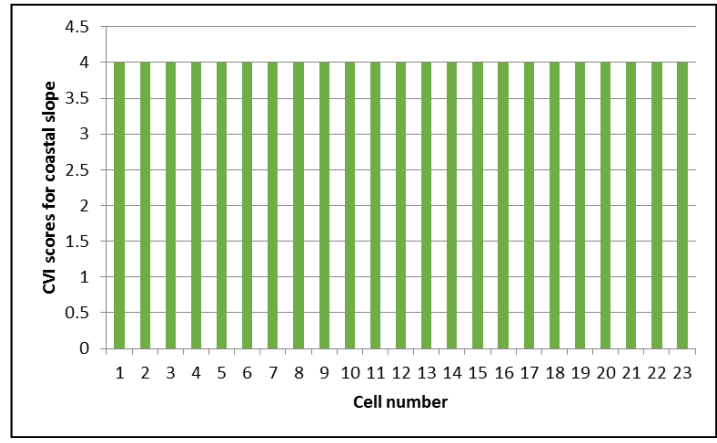

c)

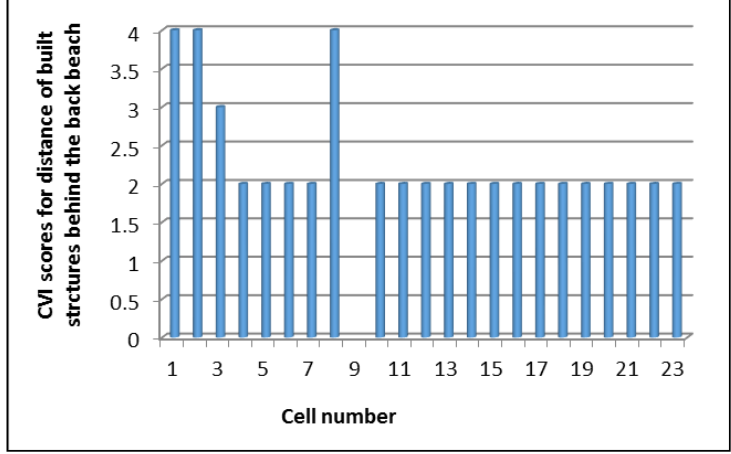

e)

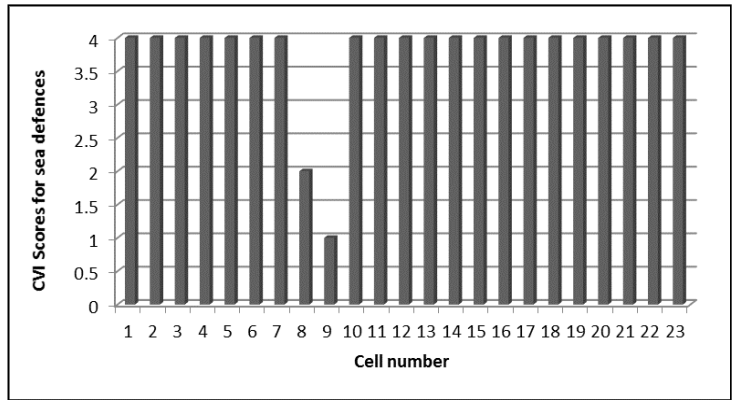

g)

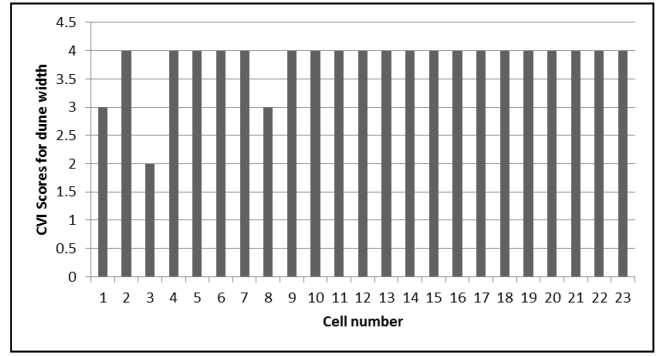

b)

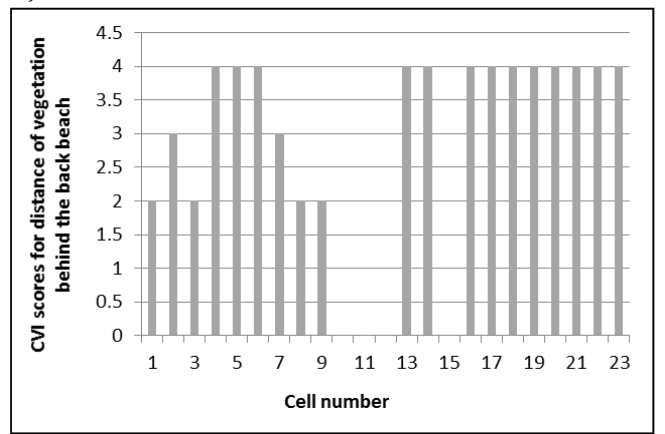

d)

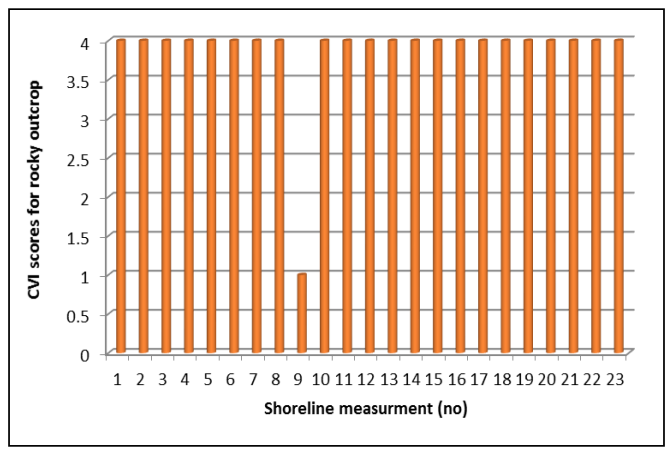

f)

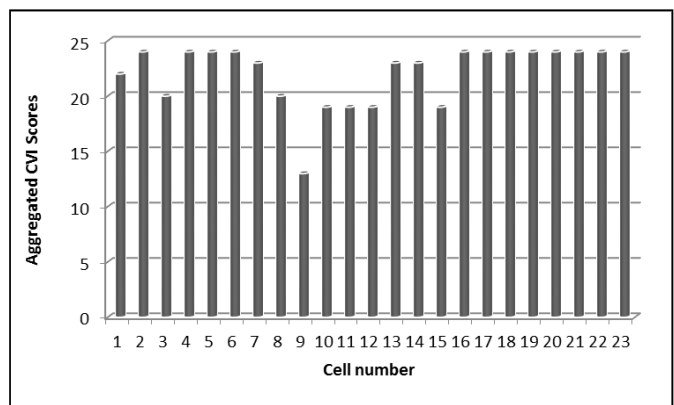

h)

Figure 7.7: Distribution of CVI scores for Skegness 


\subsection{Benbecula}

A varied beach width between $255 \mathrm{~m}$ and $37 \mathrm{~m}$, resulted in scores of 2 to 4 being allocated (Figure 7.8a). Dunes were only recorded in $20 \%$ of the cells and allocated between 1 and 3, all remaining cells were allocated scores of 4 (Figure $7.8 \mathrm{~b}$ ). The coastal slope was $<4 \%$ along the entire shoreline therefore, a score of 4 was allocated throughout (Figure 7.8c). Even though there was a considerable variation in the measured distance of vegetation behind the back beach, the allocated scores only ranged between 2 and 3 (Figure 7.8d). The measured distances of built structures behind the back beach was generally $<600 \mathrm{~m}$ and allocated scores ranged between 4 and 2, (Figure 7.8e). Rocky outcrops were recorded in less than $50 \%$ of the cells and all were given a score of 1 , the remaining cells were allocated scores of 4 throughout (Figure 7.8f). There were no sea defences recorded and similar to previous were allocated scores of 4 throughout (Figures $7.8 \mathrm{~g}$ ). Figure $7.8 \mathrm{~h}$ shows the aggregated scores in one representation, the overall average score was 22 , the maximum recorded score of 24 and minimum of 18.

\subsection{Aberystwyth}

Beach width ranged from $168 \mathrm{~m}$ to $63 \mathrm{~m}$ and $80 \%$ of cells were allocated a score of 3 (Figure 7.9a). No dunes were recorded and all cells were allocated a score of 4 (Figure 7.9b). The coastal slope values ranged between $14.7 \%$ and $0.2 \%$ and allocated scores between 1 and 4 (Figure 7.9c). The considerable variation in measured distances of vegetation behind the back beach resulted in scores that ranged between 2 and 3 (Figure 7.9d). The close proximity of built structures behind the back beach resulted in scores ranging between 2 and 4 (Figure 7.9e and Figure 7.9f). The shoreline protection given by both Rocky outcrops and sea defences, resulted in a low score being allocated throughout (Figures 7.9g). Figure 7.9h shows the aggregated scores in one representation, the overall average score was 17 , the maximum-recorded score of 22 and minimum of twelve. 


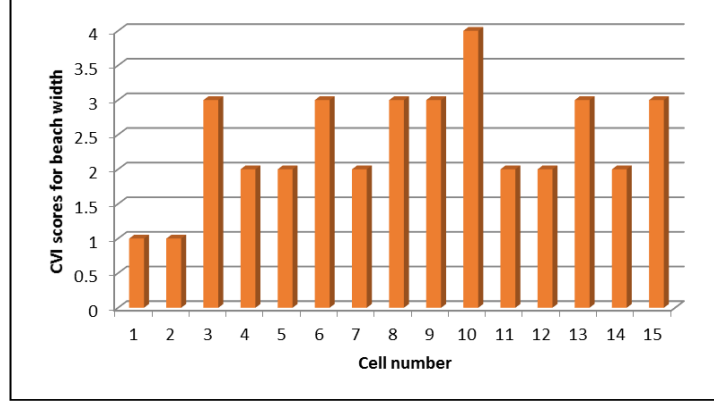

a)

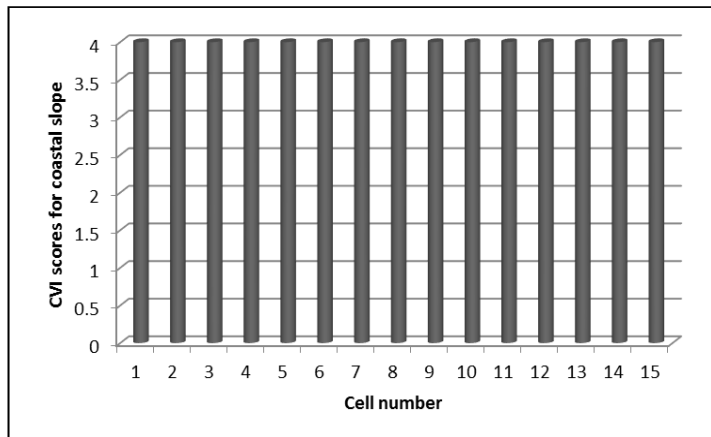

c)

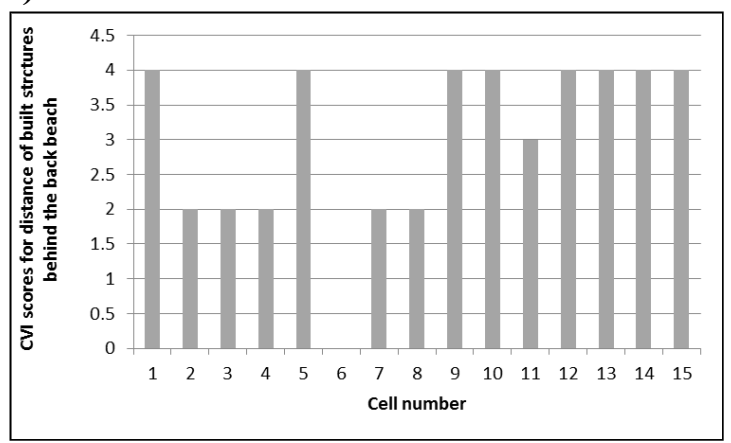

e)

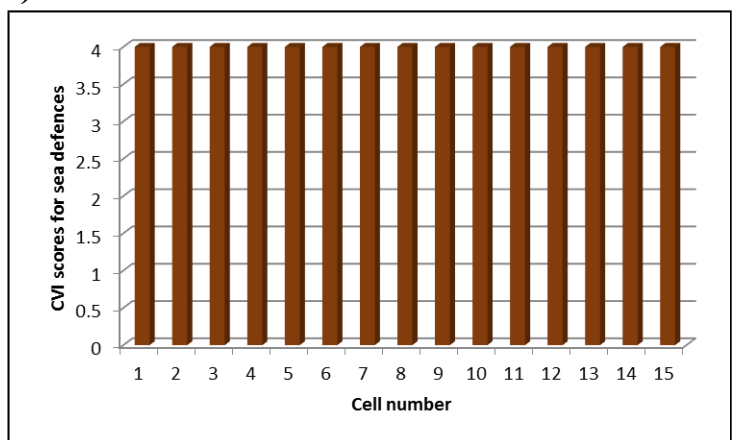

g)

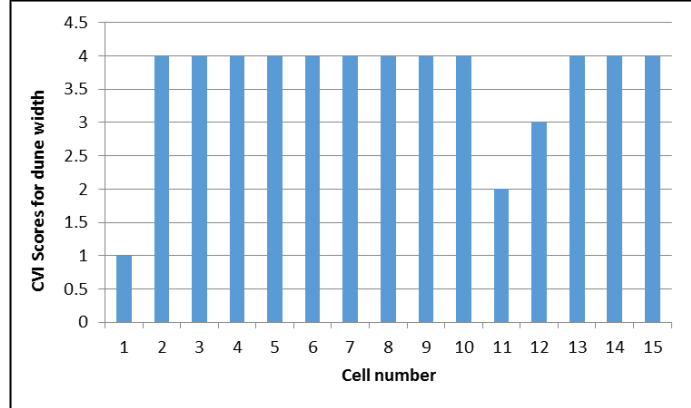

b)

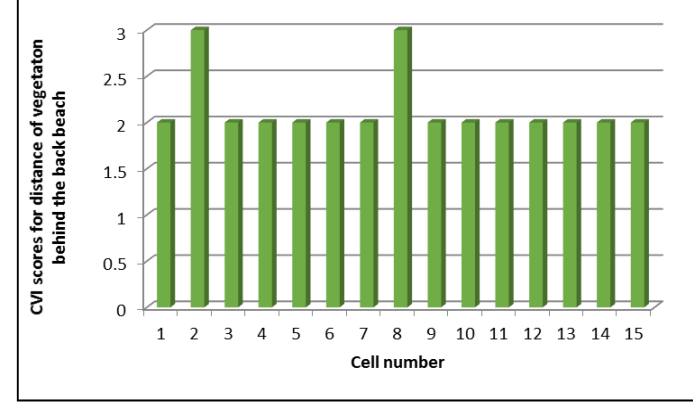

d)

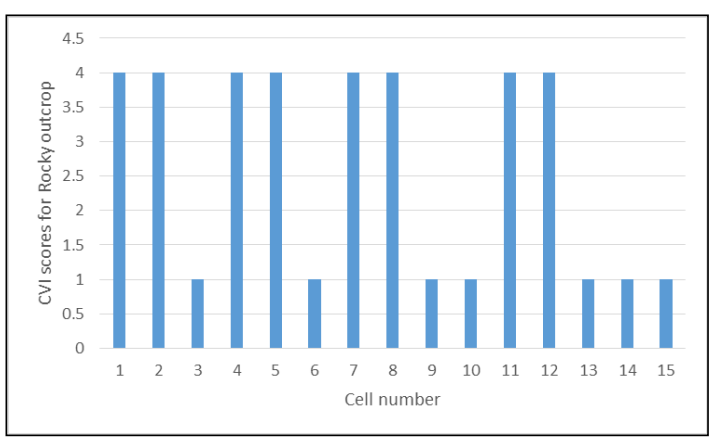

f)

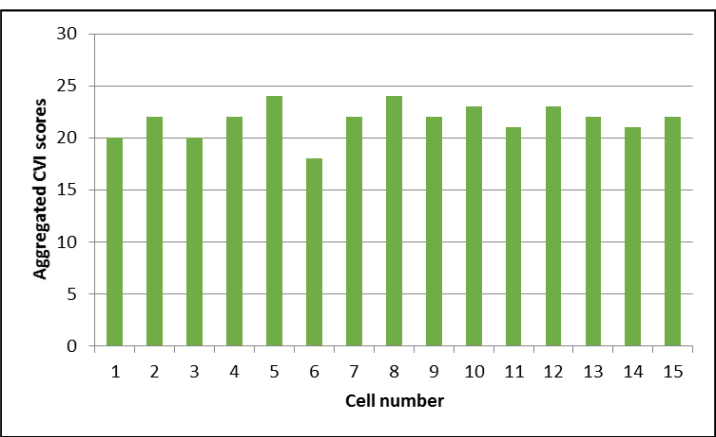

h)

Figure 7.8 Distribution of CVI scores for Benbecula 

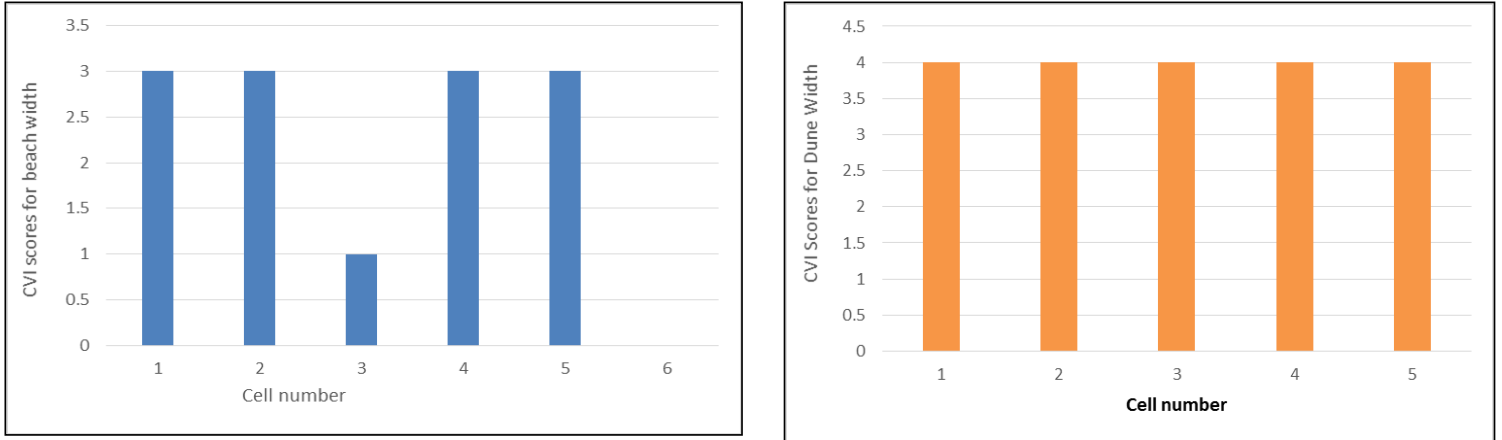

a)

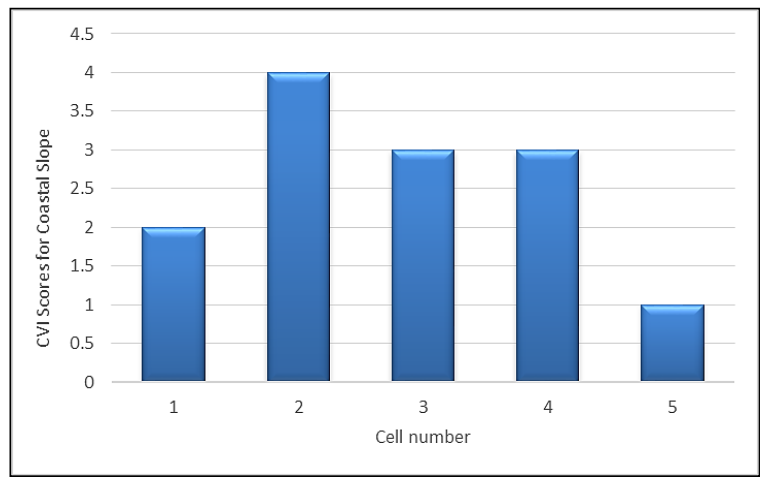

c)

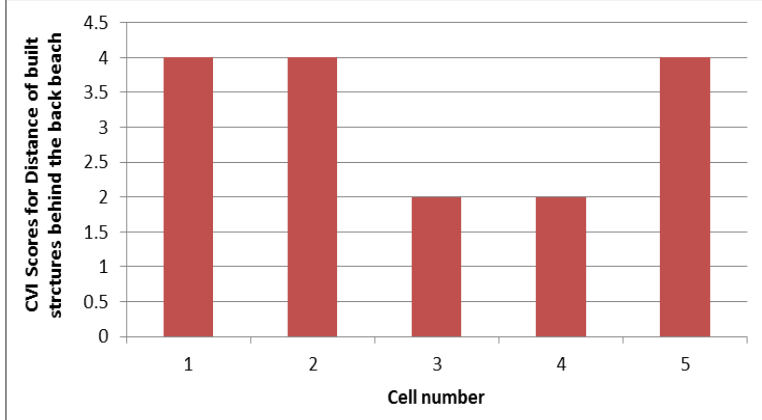

e)

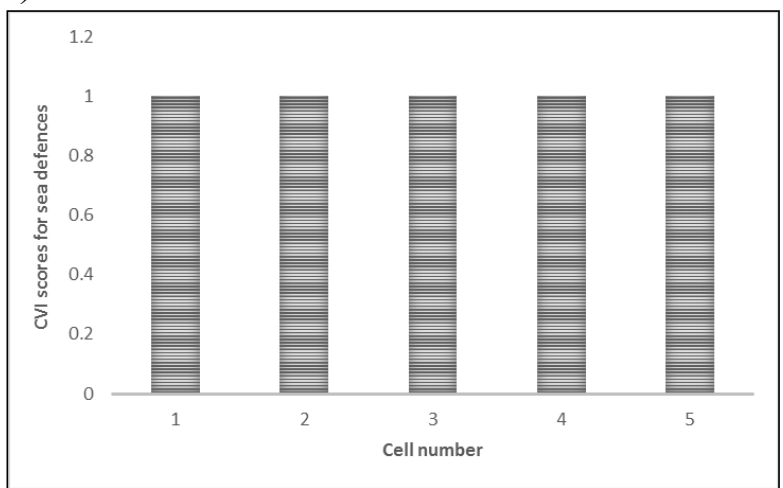

g) b)

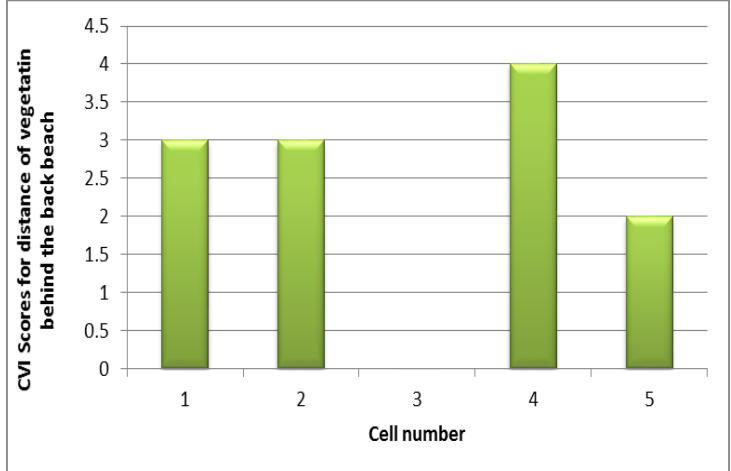

d)

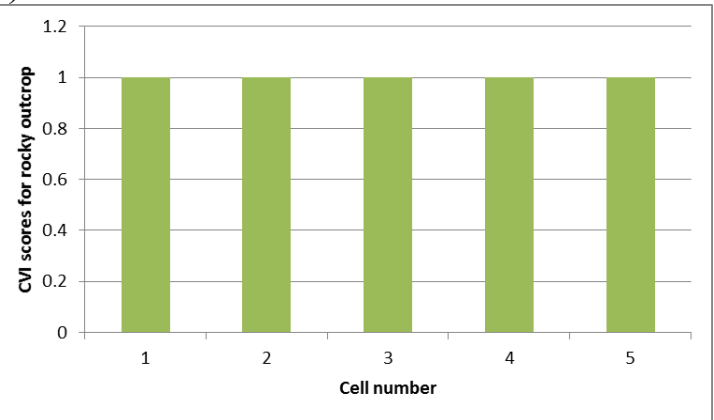

f)

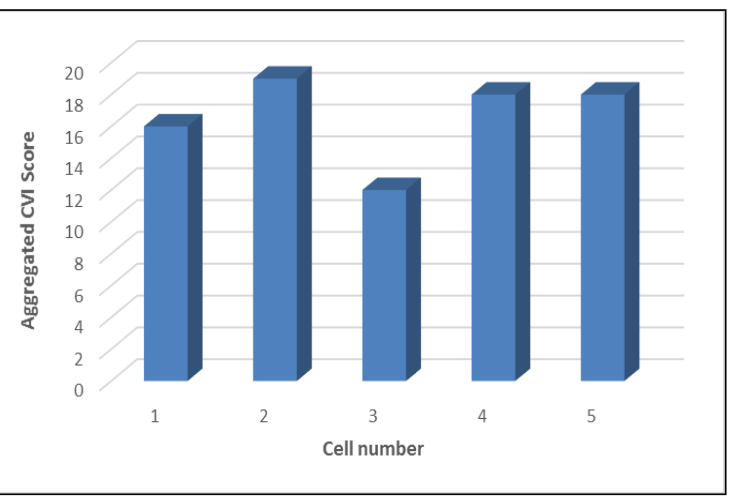

h)

Figure 7.9: Distribution of CVI scores for Aberystwyth 


\subsection{Port Talbot}

Beach width ranged from $835 \mathrm{~m}$ to $100 \mathrm{~m}$ and $91 \%$ of cells were allocated scores of 1 (Figure 7.10a). Dunes were recorded in less than half the cells, those that were measured were allocated scores between 1 and 3 and all remaining cells were given scores of 4 (Figure 7.10b). There was a considerable variation in coastal slope resulting in scores between 1 and 4 Figure 7.10c). The measured distance of vegetation behind the back beach, ranged between $500 \mathrm{~m}$ and $40 \mathrm{~m}$ and were allocated scores that ranged between 2 and 4 (Figure 7.10d). The scores allocated for built structures behind the back beach ranged between 2 and 4 (Figure 7.10e). Variable distribution of rock out crops resulted in score of between 2 and 4 being allocated throughout (Figure 7.10f). Fifty percent of the shoreline was protected by sea defence structures and allocated a low score of 1 and the remaining cells given scores of 4 (Figure $7.10 \mathrm{~g}$ ). Figure $7.10 \mathrm{~h}$ shows the aggregated scores, the overall average score was 17 , the maximum recorded score of 20 and minimum of ten.

\subsection{Llanelli}

Even though beach width ranged from $1900 \mathrm{~m}$ to $1 \mathrm{~m}$, and $80 \%$ of cells were allocated extremely low scores (Figure 7.11a). Dunes were only recorded in one cell and all remaining cells were allocated a score of 4 (Figure 7.11b). There was a considerable variation in coastal slope values resulting in score of between 1 and 4 being allocated (Figure 7.11c). The measured distance of vegetation behind the back beach, ranged between $491 \mathrm{~m}$ and $102 \mathrm{~m}$ and this resulted in scores of between 2 and 3 being allocated (Figure 7.11d). The distances of built structures behind the back beach varied and were allocated scores between 2 and 4 (Figure 7.11e). Even though 61\% of the cells recorded rocky outcrop, 90\% cells were allocated scores of 4 (Figure 7.11f). Fifty percent of shoreline was protected by sea defence structures and given a score of 1 , the remaining cells were given a score 0f 4 (Figure 7.11g). Figure $7.11 \mathrm{~h}$ shows the aggregated scores in one representation; the overall average score was 18 , the maximum-recorded score of 22 and minimum of 14.
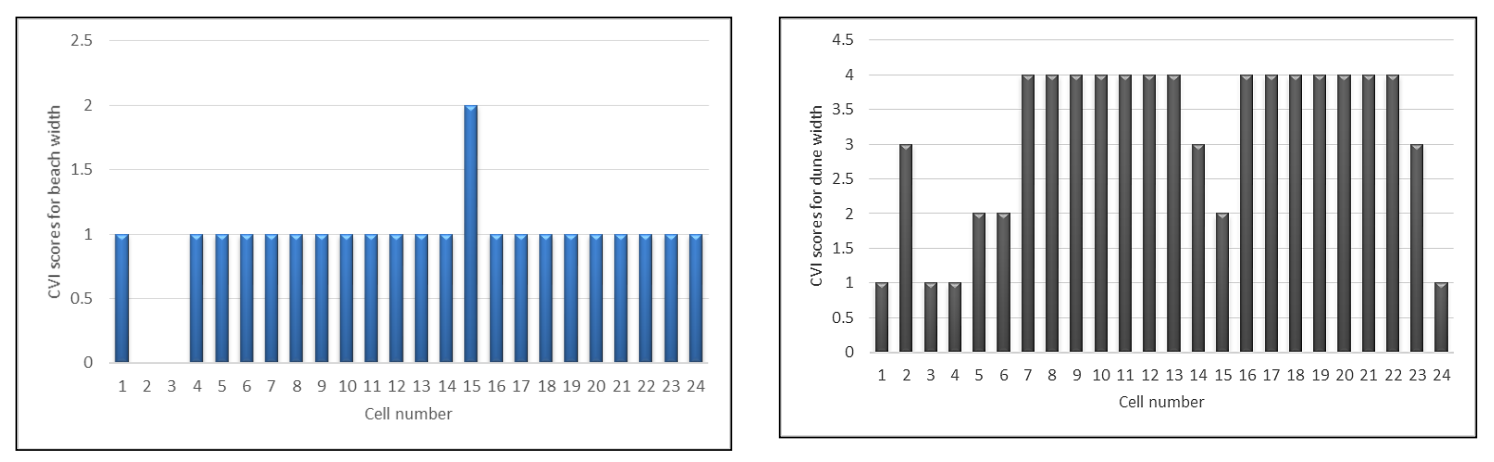
a)

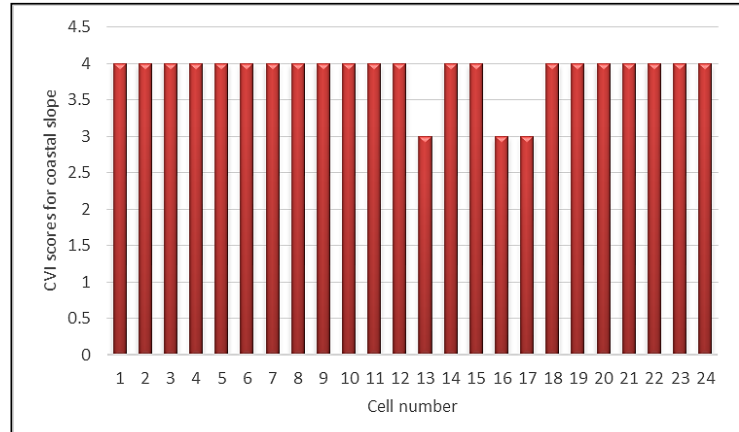

c)

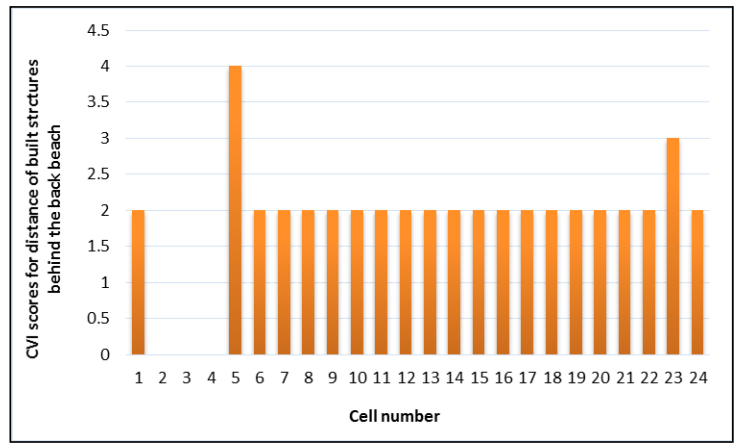

e)

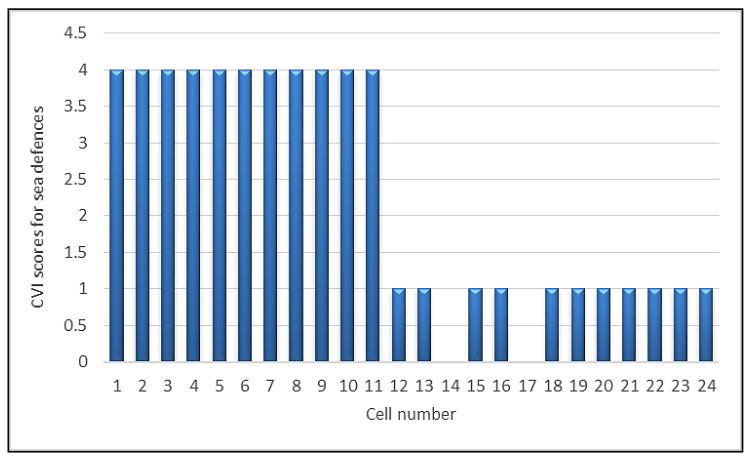

g) b)

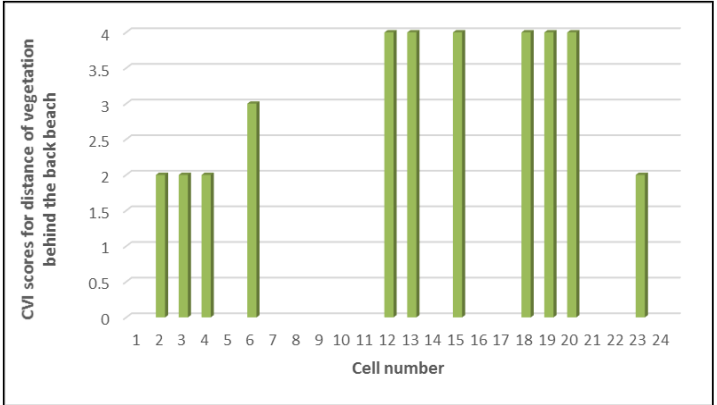

d)
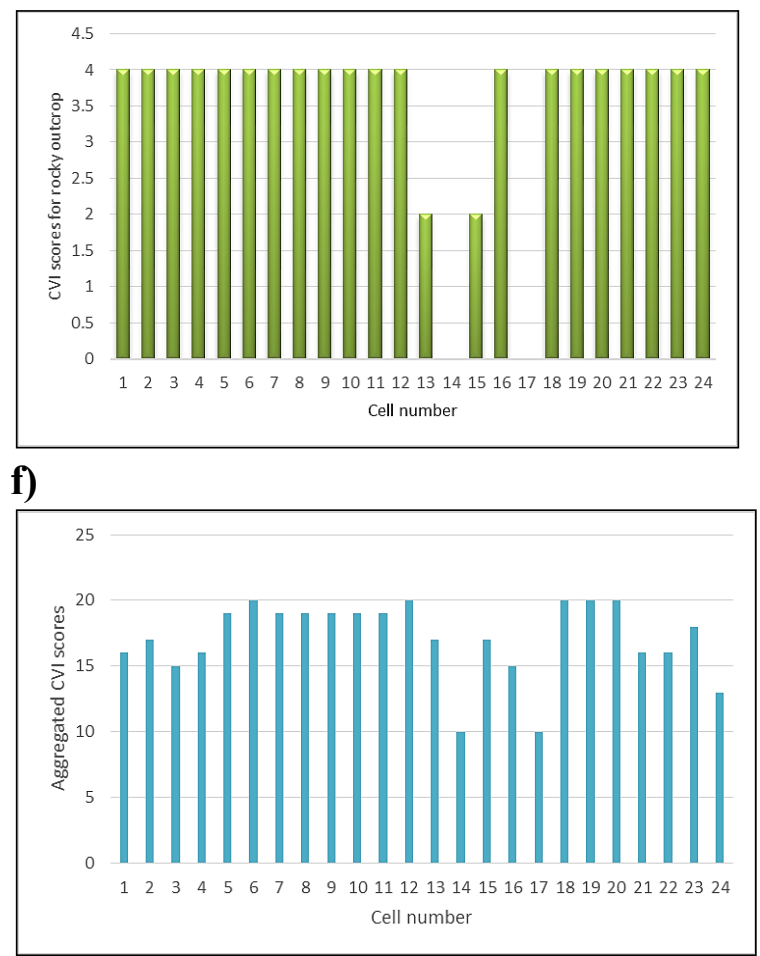

h)

Figure 7.10 Distribution of CVI scores for Port Talbot

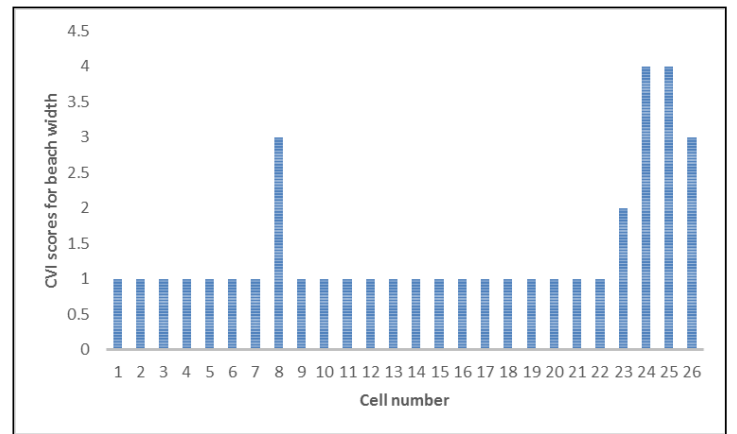

a)

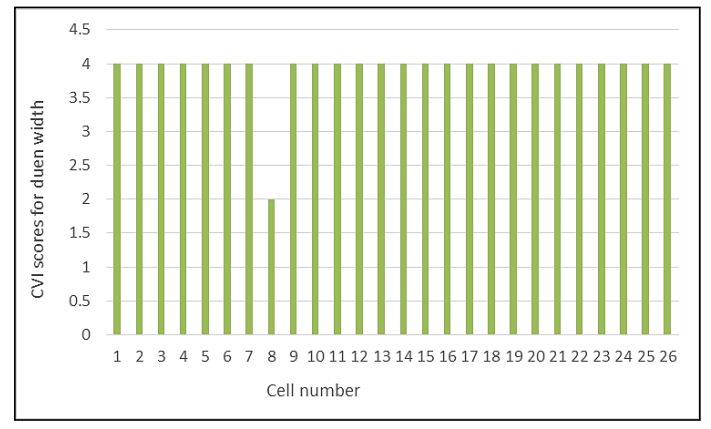

b) 


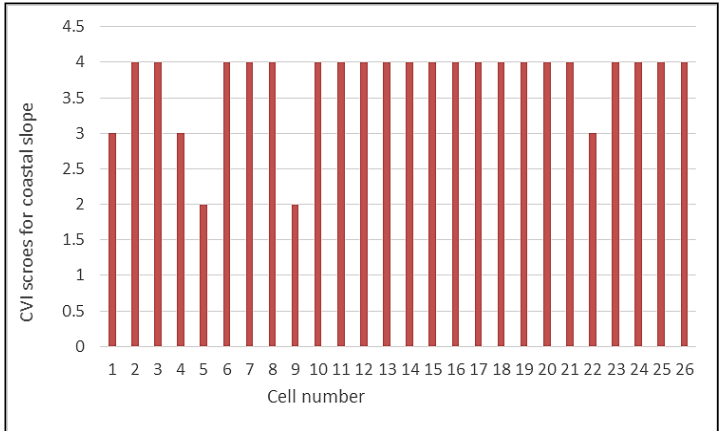

c)

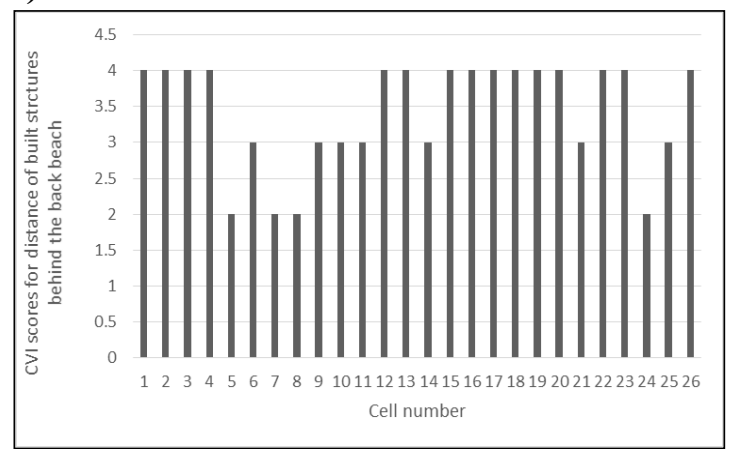

e)

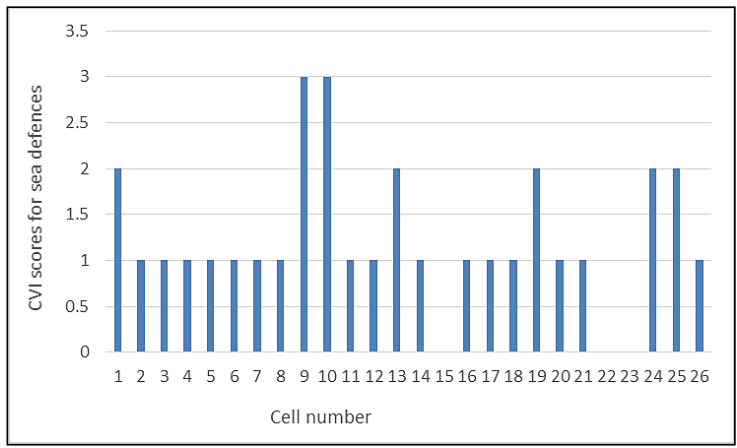

g)

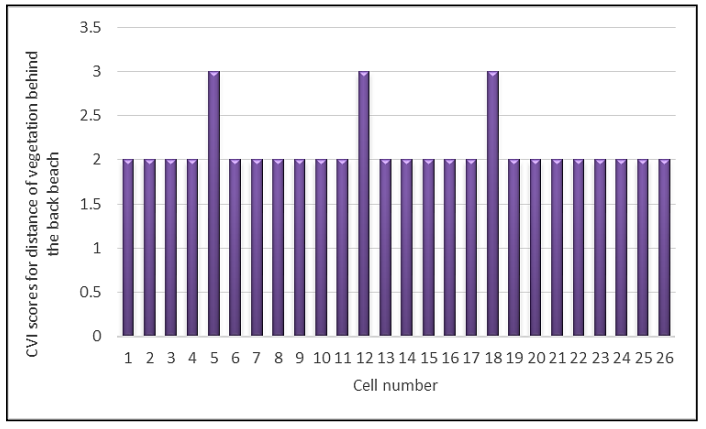

d)

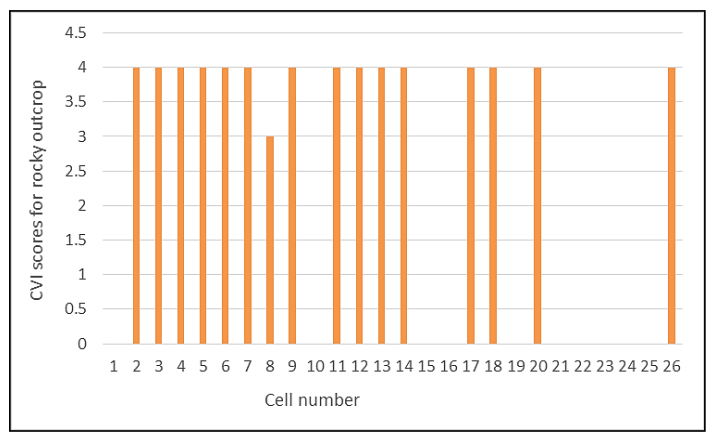

f)

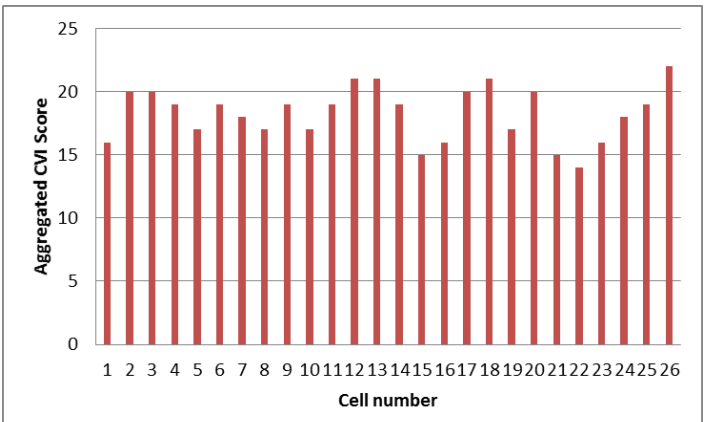

h)

Figure 7.11: Distribution of CVI scores for Llanelli

\subsection{Overall descriptive analysis}

The 11 selected coastal areas were critically analysed from a physical perspective by applying the CVI index. Results suggest that the English case study locations were more vulnerable than those in Wales and Scotland, and this is because of high industrial growth, population and the lack of natural and man-made shoreline protection measures. Some coastal cells have few or no dunes (Lynmouth, Llanelli) and others little or no rocky outcrops (Lynmouth and Spurn Head). For these reasons, most shoreline measurements were at the lower end of the scale and fell between low and moderate and relatively few cells were classified as being high in the terms of relative vulnerability. However, cumulative CVI scores of each region are relatively high. 


\subsection{Analysis for individual parameters a) Beach width}

The average CVI score for beach width was 2.3, and the highest was four recorded at 48 cells (30\%). Most of the highest values recorded at Llanelli (Wales), Hallsands Village, Happisburgh Dawlish, Great Yarmouth (England) and Benbecula (Scotland). The lowest score was one and 64 cells recorded this value. CVI scores for beach width parameter clearly indicated that England is high vulnerability than the Wales and Scotland (Figure 7.12a).

\section{b) Dune width}

A considerable variance exists between the dune width CVI values for 158 shoreline cells. The average CVI score was 3.5, and the highest score was 4 recorded at 124 cells (78\%). Those that scored highly were found at Spurn Head, Hallsands, Dawlish, Happisburgh Great Yarmouth, Skegness (England) and Benbecula. The dune width CVI scores indicated that, English sites are more physically vulnerable than those in Scotland and Wales (Figure $7.12 b)$.

\section{c) Coastal slope}

The average CVI score was 3.6 and the highest score was recorded at 129 (81\%) cells. Most of the high values were again recorded at Llanelli and Port Talbot (Wales), Happisburgh, Dawlish, Great Yarmouth and Skegness (England) and Benbecula (Scotland), while the minimum was recorded at Aberystwyth (Wales) and Hallsands and Lynmouth (England). CVI scores for coastal slope reflect high vulnerability throughout the survey area with some site-specific variations (Figure 7.12c).

\section{d) Distance of vegetation behind the back beach}

A considerable variance exists between the CVI values for distance of vegetation behind the back beach. The average CVI score was 2.7 and the highest was 4, recorded at 38 (24\%) cells. Most of the highest values recorded at Port Talbot (Wales), Great Yarmouth and Skegness (England). Lowest CVI value was one, recorded at Llanelli, Hallsands (England) and Benbecula (Scotland). Seventy-five cells (47\%) scored lowest values. CVI scores for a distance of vegetation behind the back beach explicitly specified that England and Wales have the highest vulnerability in the subject of vegetation (Figure 7.12d). 

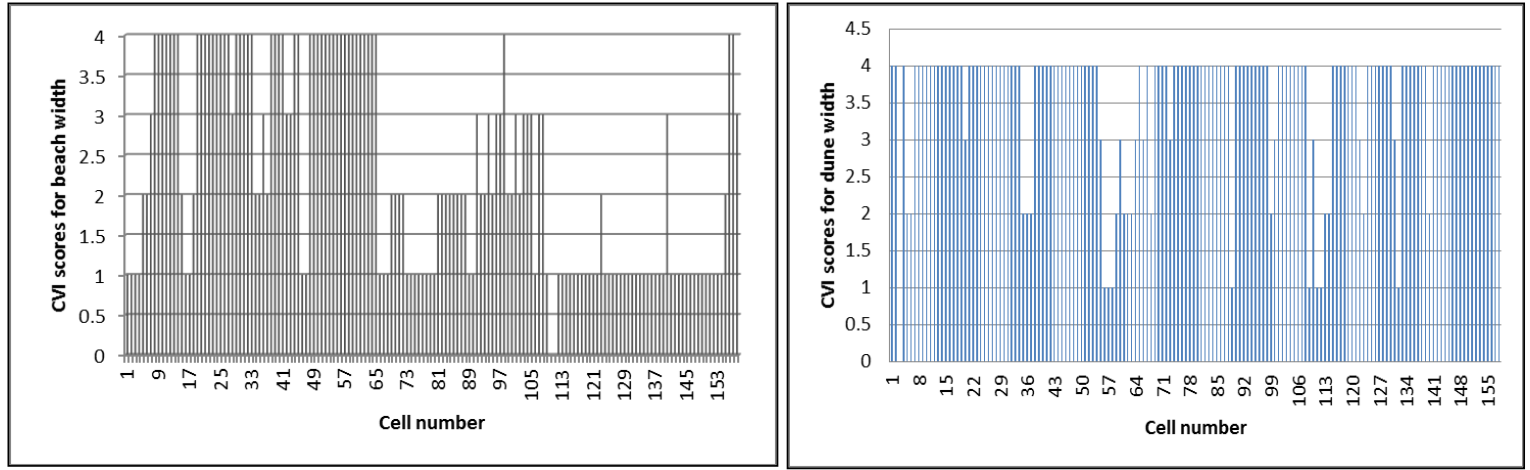

a)

b)
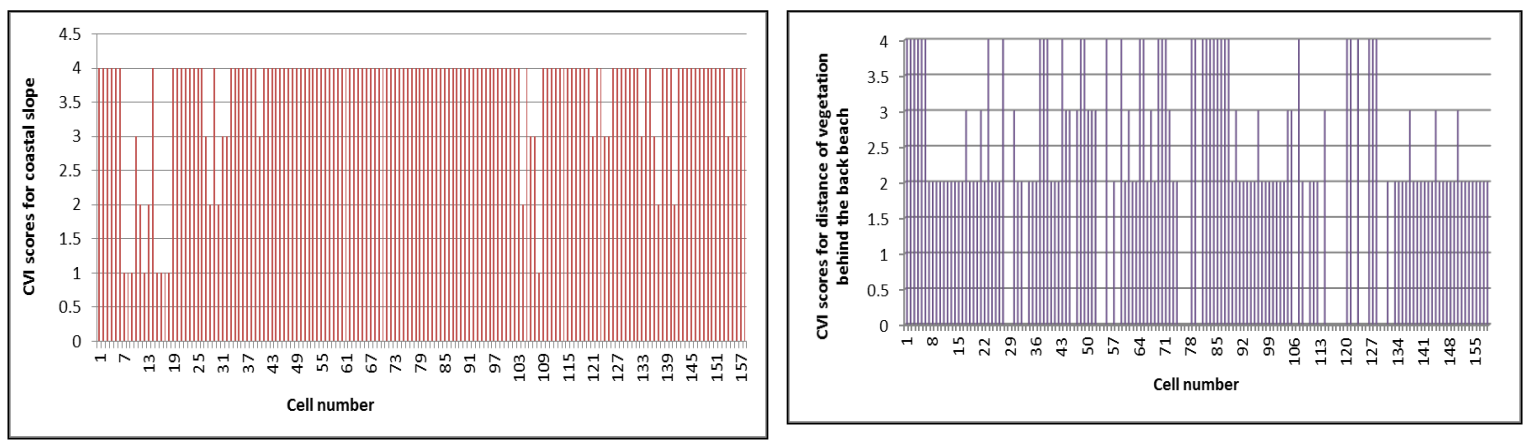

c)

d)

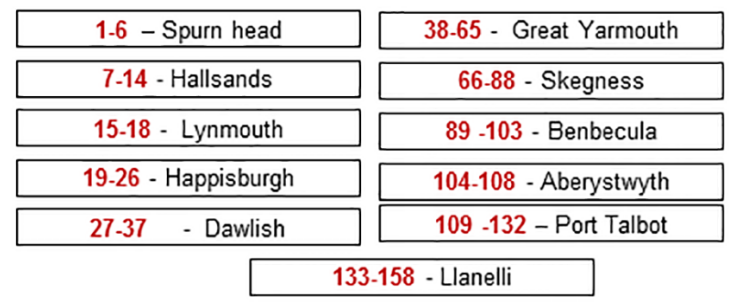

Figure 7.12: Distribution of overall CVI scores

\section{e) Distance of built structures behind the back beach}

The average CVI score for the distance of built structures behind the back beach was 2.8 and the highest CVI score was 4, recorded at $48(30 \%)$ cells. The highest values were recorded at Aberystwyth, Llanelli (Wales), Hallsands, Happisburgh (England) and Benbecula (Scotland). The lowest score was 2, recorded at 74 (46\%) (Skegness), and 15 cells did not record built structures (Figure 7.13a).

\section{f) Rocky outcrop}

A considerable variance exists between the rocky outcrop CVI values for 158 shoreline cells. The average CVI score for rocky outcrop was 3.6, and the highest CVI score was four, 
recorded at 124 (78\%) cells. Most of the highest values were recorded at Llanelli (Wales), Great Yarmouth, Skegness, Dawlish, and Benbecula. Of the sites surveyed, CVI scores for rocky outcrop suggest that English locations require more coastal protection procedures (Figure 7.13b) than Wales and Scotland.

\section{g) Sea defences}

The average CVI score for sea defences was 3.5 and highest CVI score was 4, recorded at 84 (59\%) cells. Highest values were recorded at Port Talbot (Wales), Great Yarmouth, Skegness, Dawlish, Lynmouth, Spurn Head (England) and Benbecula (Scotland). Of the sites surveyed, CVI scores for sea defences highlight that vulnerability at English sites need for more coastal protection (figure 7.13c).

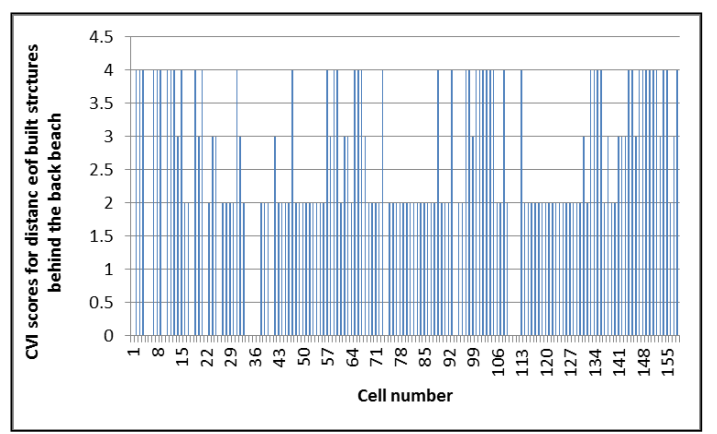

a)

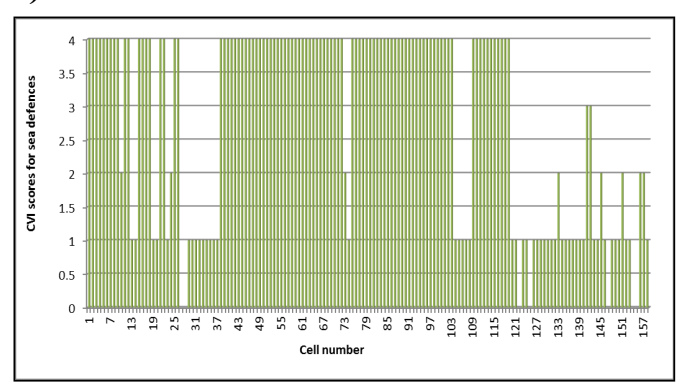

c)

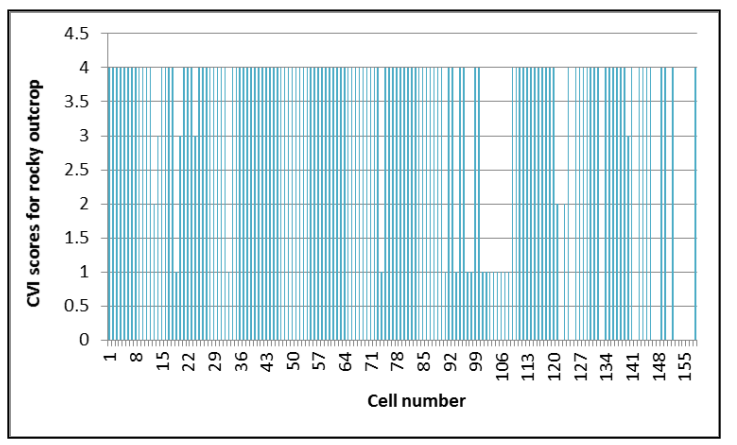

b)

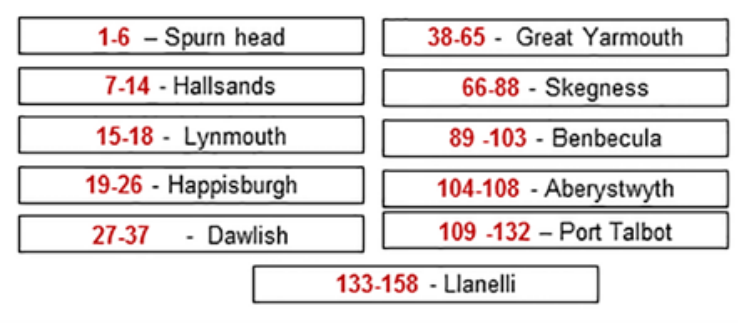

Figure 7.13: Distribution of overall CVI scores

\subsection{Overall CVI scores}

Figure 7.14 and 7.15 show a significant difference exists between the 158 cells in respect of CVI values. The average value was 20.33, a figure located in the high category. However, the maximum CVI value (28) was recorded at Great Yarmouth, while the lowest (10) was recorded at Lynmouth. More than $22 \%(n=35)$ of cells were rated with extremely high vulnerability (24-28), and 52\% of cells of high vulnerable (19-23). In addition, 17\% of cells 
were found to be moderately vulnerable (16-18), but overall CVI scores clearly indicated that physical vulnerability for selected areas in the UK have either extremely high or high vulnerability.
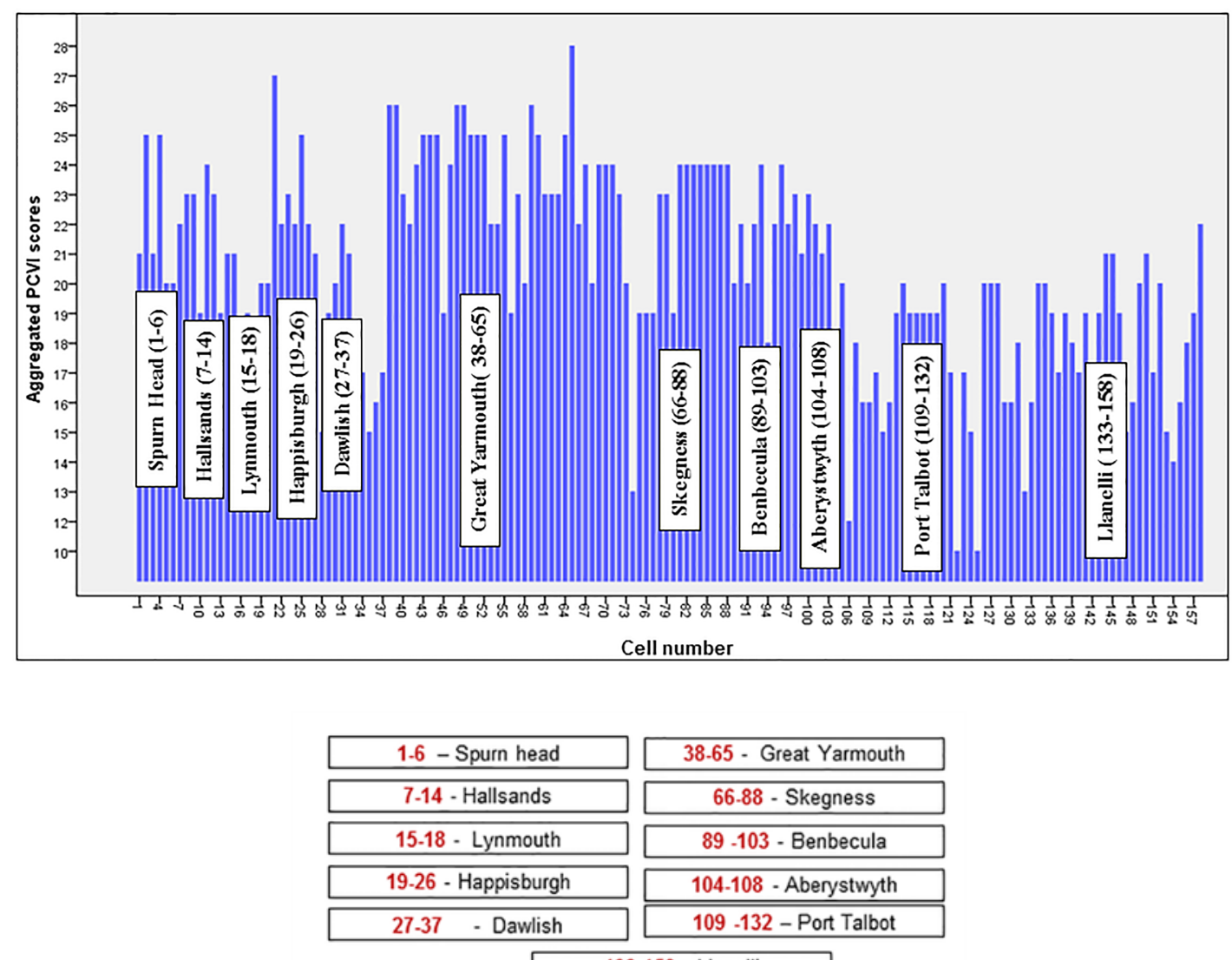

Figure 7.14: Cumulative CVI scores

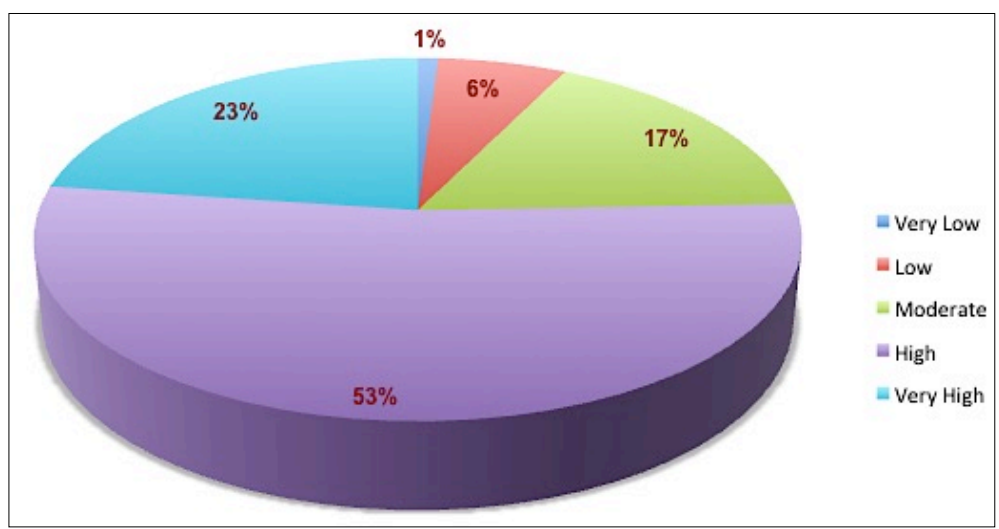

Figure 7.15: Distribution of aggregated CVI scores and ranking 


\subsection{Cumulative Physical Vulnerability}

After PCVI development, these scores were aggregated to rank the eleven coastal vulnerability zones to identify the severity of coastal vulnerability (Table 7.1) (Figure 7.16). Great Yarmouth was found to be the most vulnerable with average CVI score of 24, while, Aberystwyth and Port Talbot were found to be the least vulnerable. Crucially, these cumulative scores provide the opportunity to consider management options where physical vulnerability is highlighted. It should also focus efforts for future research on a wider scale at such sites.

Table 7.1 PCVI scores and site ranking

\begin{tabular}{lccc}
\hline Location & CVI Score & Number of Cells & Average CVI Score \\
\hline Great Yarmouth & 670 & 28 & 24 \\
Happisburgh & 181 & 8 & 23 \\
Skegness & 508 & 23 & 22 \\
Spurn Head & 132 & 6 & 22 \\
Hallsands & 174 & 8 & 22 \\
Benbecula & 326 & 15 & 22 \\
Lynmouth & 75 & 4 & 19 \\
Llanelli & 475 & 26 & 18 \\
Dawlish & 199 & 11 & 18 \\
Port Talbot & 410 & 24 & 17 \\
Aberystwyth & 84 & 5 & 17 \\
\hline
\end{tabular}




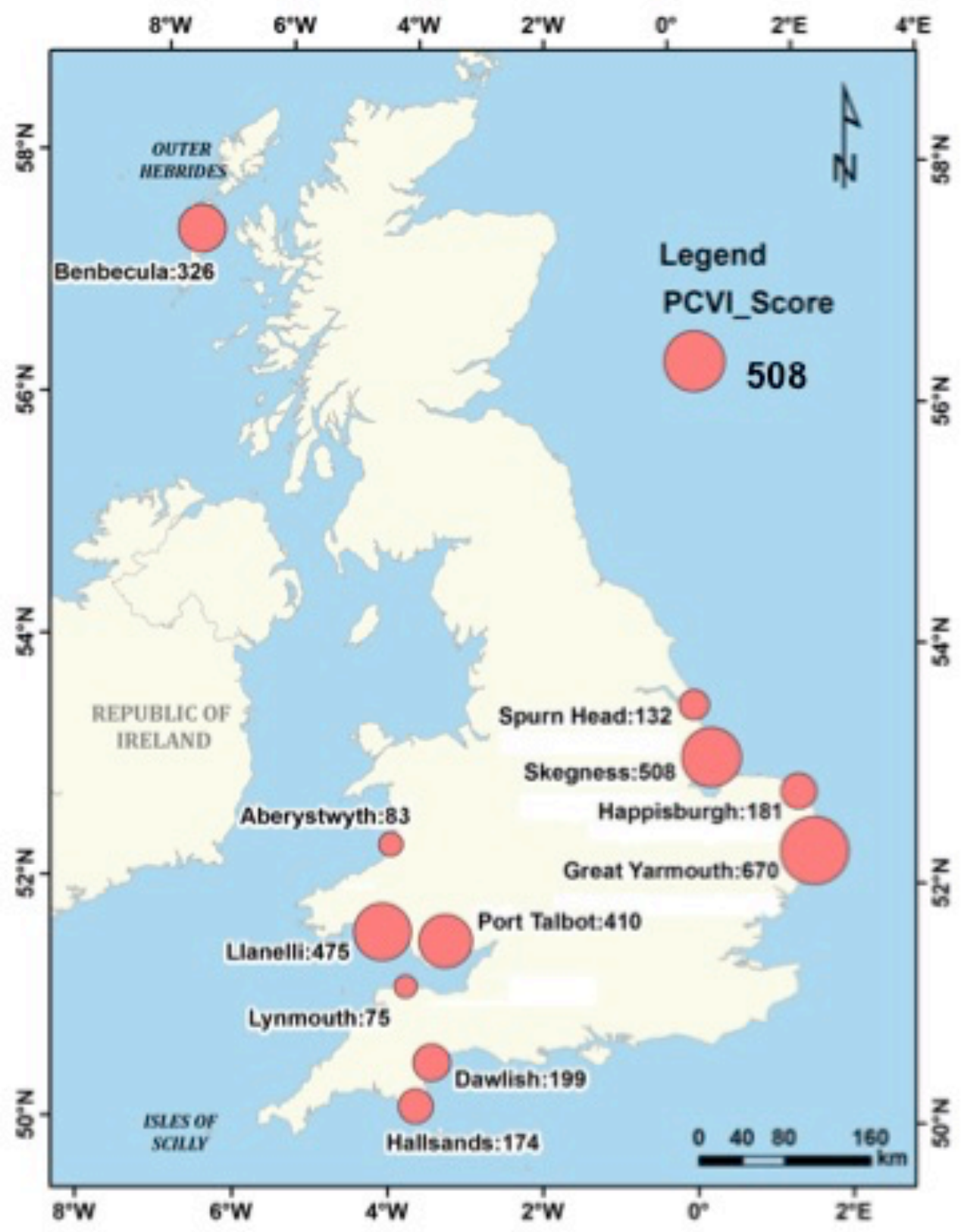

Figure 7.16: PCVI map 


\subsection{Summary}

This chapter has focused on the CVI analysis and development of seven individual physical parameters for the eleven selected sites. From this point, it is now necessary to consider the economic coastal vulnerability index for these study sites using and applying the six economic parameters (Section 5.6). 


\section{CHAPTER 8 - ECVI}




\section{Economic Coastal Vulnerability Index (ECVI) 8.1 Introduction}

Following completion of the physical coastal vulnerability index (PCVI) analyses in Chapter 7, this Chapter will start focusing on the development of the Economic Coastal Vulnerability Index (ECVI) and its consequences. Analysis of the six economic parameters, justified for identifying economic vulnerability (Section 4.5, Table 4.2, Section 5.5), will enable a simple numerical model to be developed to rank coastline sections in terms of their change potential. Therefore, the resulting ECVI will support managers in the development of sound economic coastal management policies and procedures designed to improve resilience under various scenarios of climate change and sea level rise, by focusing on areas with relatively high economic vulnerability.

\subsection{Population and properties}

As presented in Section 4.4, chosen coastal locations were each subdivided into $1 \mathrm{~km}$ cells along the shoreline frontage. In total 80 cells along $80 \mathrm{~km}$ of coastline were identified (Table 8.1). Three locations in Wales representing circa $26 \mathrm{~km}$ of coastline (26 cells), seven in England representing $49 \mathrm{~km}$ (49 cells) and one area in Scotland circa $5 \mathrm{~km}$ (5 cells) were chosen alongside the physical CVI. Figures 8.1 - 8.11 show yellow lines that represent the cells from which measurements were taken, red horizontal lines indicate the approximate shore alignment and red vertical arrows represent boundaries of each $1 \mathrm{~km}$ coastal cell. While the boundaries of the $1 \mathrm{~km}$ coastal cells were determined according to geographical area and economic importance. 
Table 8.1: Total transect line and $1 \mathrm{~km}$ coastal cells

\begin{tabular}{|l|c|c|c|c|c|}
\hline \multicolumn{1}{|c|}{ Site } & $\begin{array}{c}\text { Shoreline } \\
\text { length } \\
(\mathbf{k m})\end{array}$ & $\begin{array}{c}\text { No. of } \\
\mathbf{1} \mathbf{~ k m} \\
\mathbf{C e l l s}\end{array}$ & $\begin{array}{c}\text { Population } \\
\text { (No) }\end{array}$ & $\begin{array}{c}\text { Commercial } \\
\text { Properties } \\
\text { (No) }\end{array}$ & $\begin{array}{c}\text { Residential } \\
\text { properties } \\
\text { (No) }\end{array}$ \\
\hline Spurn Head & 2 & 2 & 50 & $7+2$ & 57 \\
\hline Hallsands & 4 & 4 & $>50$ & 6 & 179 \\
\hline Lynmouth & 2 & 2 & 490 & 106 & 423 \\
\hline Happisburgh & 4 & 4 & 1372 & 64 & 7899 \\
\hline Dawlish & 6 & 6 & 13161 & 680 & 42079 \\
\hline Great Yarmouth & 13 & 13 & 97277 & 6169 & 7342 \\
\hline Skegness & 18 & 18 & 19579 & 973 & 647 \\
\hline Benbecula & 5 & 5 & 861 & 132 & 6591 \\
\hline Aberystwyth & 2 & 2 & 15139 & 758 & 1829 \\
\hline Port Talbot & 12 & 12 & 37276 & 25833 & 7253 \\
\hline Llanelli & 12 & 12 & 35000 & 1672 & \\
\hline
\end{tabular}

Spurn Head forms part of an extensive spit $>5 \mathrm{~km}$ long and as such, this rural environment only has 9 properties (commercial and residential) and just 50 inhabitants (Table 8.1). As a consequence, the studied section of coastline was $2.5 \mathrm{~km}$ long and therefore, 2 No. $1 \mathrm{~km}$ cells were chosen as representative of where commercial and residential properties were located, from which measurements were collected (Figure 8.1). Hallsands, a village located on the Devon coastline has 57 residential and 6 commercial properties. Most private dwellings can be described as holiday homes rather than permanent residencies. For safety reasons the local authority closed the village to tourists, leaving just a limited access footpath. Properties and valuable agricultural landed is threatened by coastal erosion and floods. The shoreline frontage is $4.5 \mathrm{~km}$ long and therefore, 4 cells were used for taking measurements (Figure 8.2). Lynmouth has a population of 490 with 179 residential and 106 commercial properties. The shoreline frontage is $2.3 \mathrm{~km}$ and 2 representative $1 \mathrm{~km}$ cells were used to take measurements (Figure 8.3). Happisburgh has 1372 habitants, 423 households and 64 commercial properties. Four $1 \mathrm{~km}$ cells represented the shoreline frontage of $4.5 \mathrm{~km}$ were used for data acquisition (Figure 8.4). 


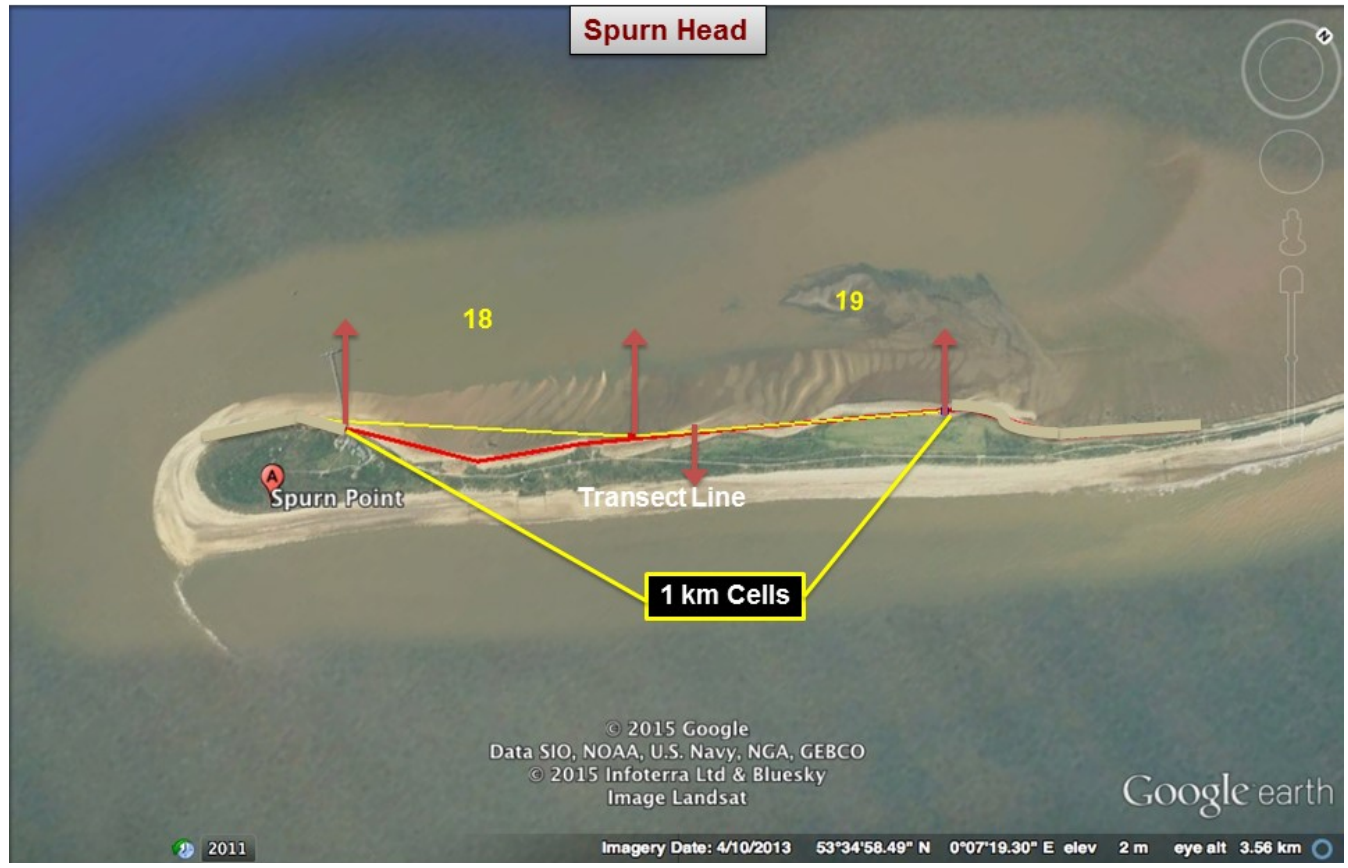

Figure 8.1: Transect line showing $1 \mathrm{~km}$ coastal cells: Spurn Head

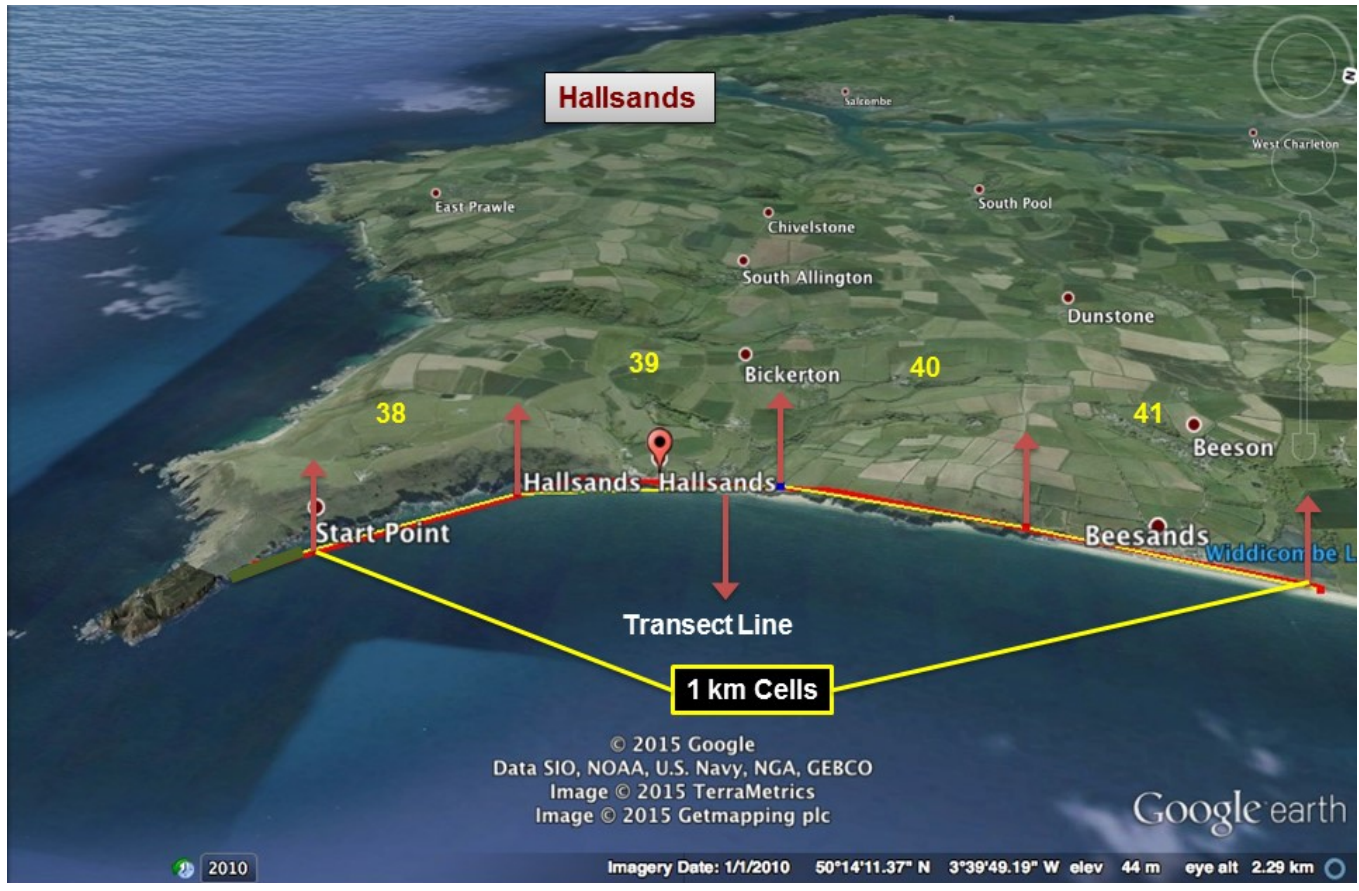

Figure 8.2: Transect Line showing $1 \mathrm{~km}$ coastal cells: Hallsands 


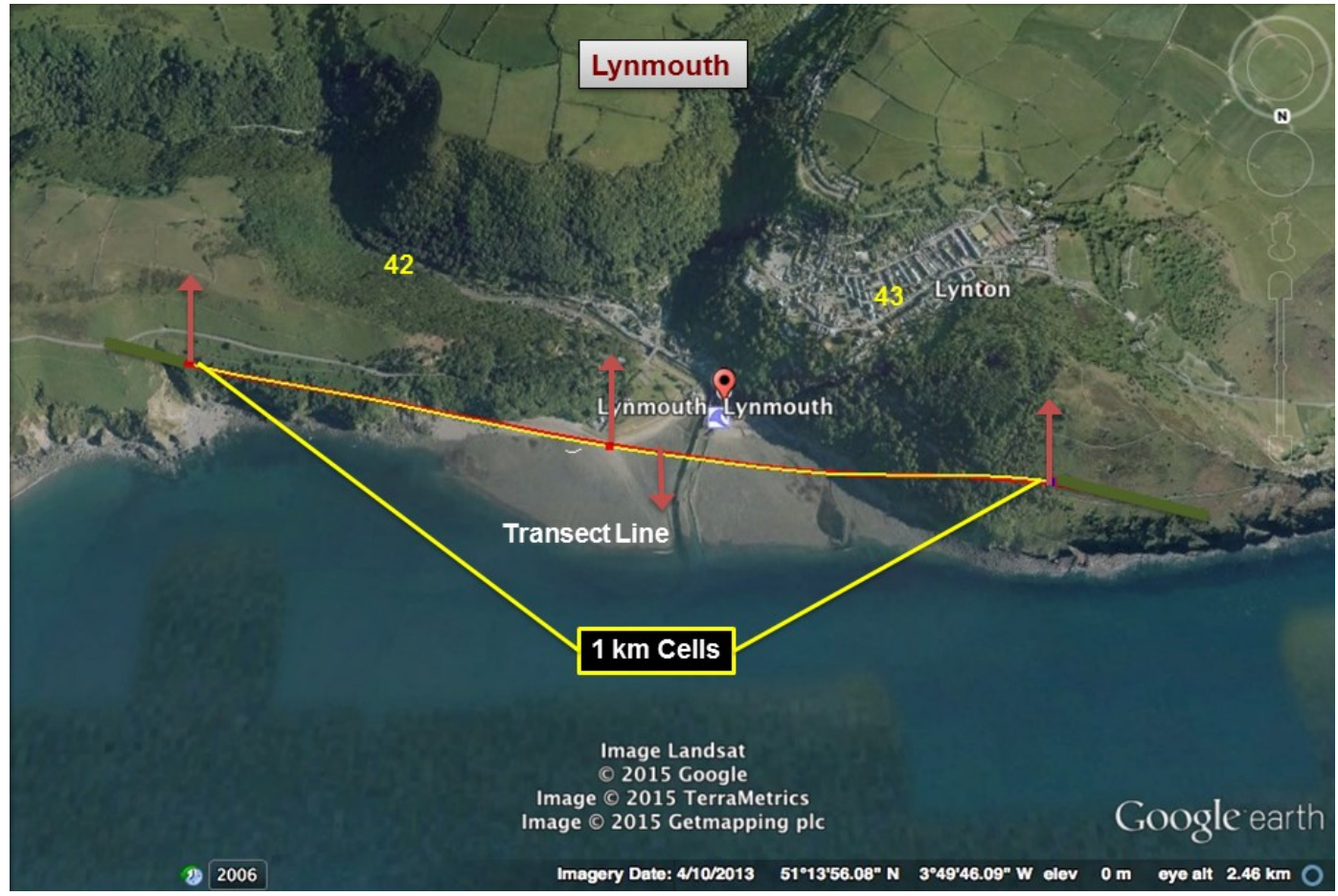

Figure 8.3: Transect line showing $1 \mathrm{~km}$ coastal cells: Lynmouth

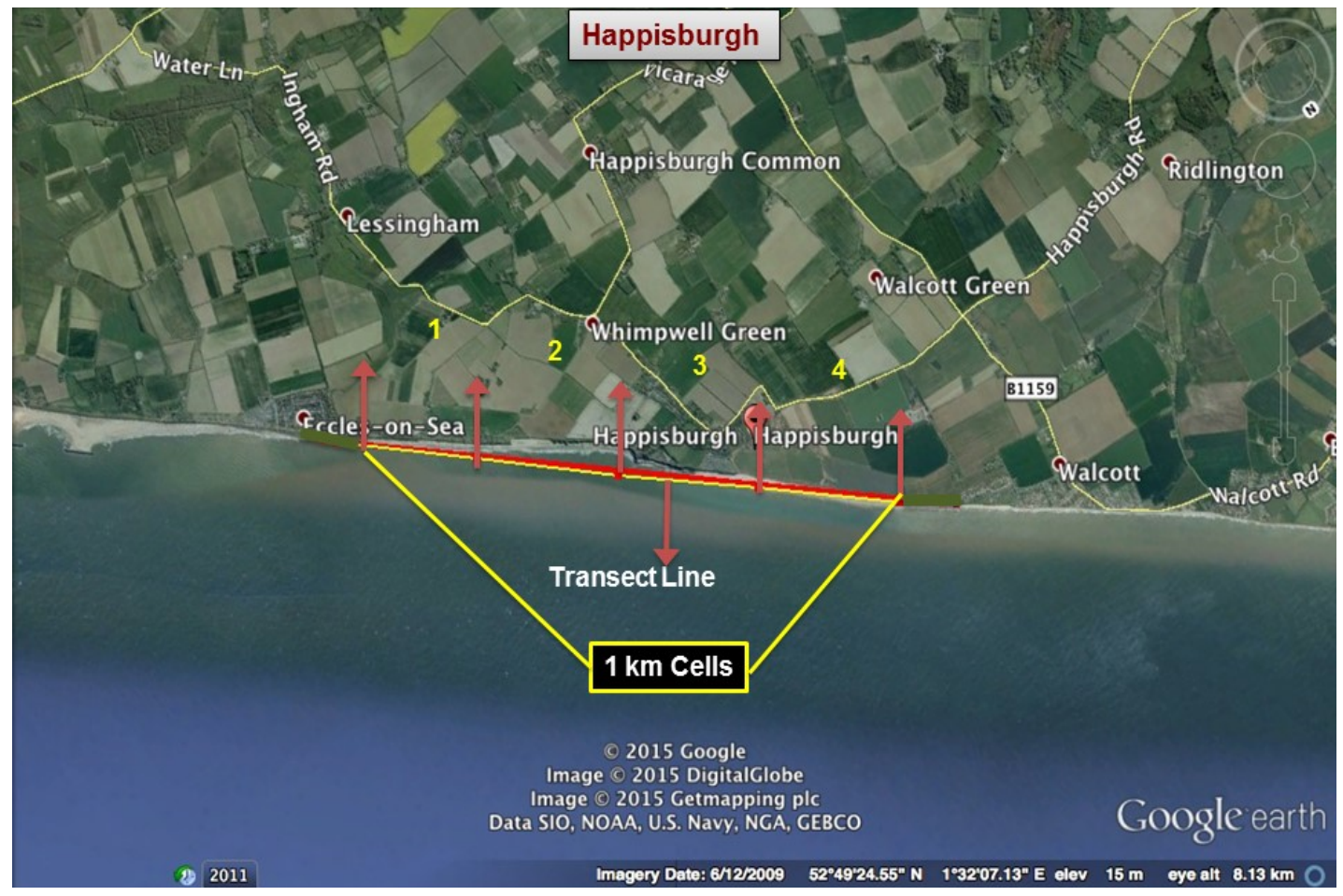

Figure 8.4: Transect line showing $1 \mathrm{~km}$ coastal cells: Happisburgh

Dawlish has a population of 13161 with 7889 residential and 680 commercial properties. The shoreline frontage is circa $6 \mathrm{~km}$ and contains 6 cells from which measurements were taken (Figure 8.5). Great Yarmouth is situated at the mouth of the River Yare with a 
population exceeding 97000 along $>20 \mathrm{~km}$ of coastline. The regional economic prosperity relies on the port, light industry and tourism. There are 42079 residential and 6169 commercial properties along a shoreline frontage of approximately $15 \mathrm{~km}$ from which 13 cells were chosen for measurement (Figure 8.6). Skegness is predominantly a tourism destination, contributing significantly to the local, as well as national economy. There are currently > 19000 inhabitants, 973 commercial and 7342 residential properties. The shoreline frontage of $20 \mathrm{~km}$ was split into 19 cells from which measurements were taken (Figure 8.7). Benbecula, a low-lying island with a population is 861 has 647 homes and 132commercial properties located along a shoreline frontage of circa $7.5 \mathrm{~km}$. Five representative $1 \mathrm{~km}$ cells were chosen from which measurements were taken (Figure 8.8).

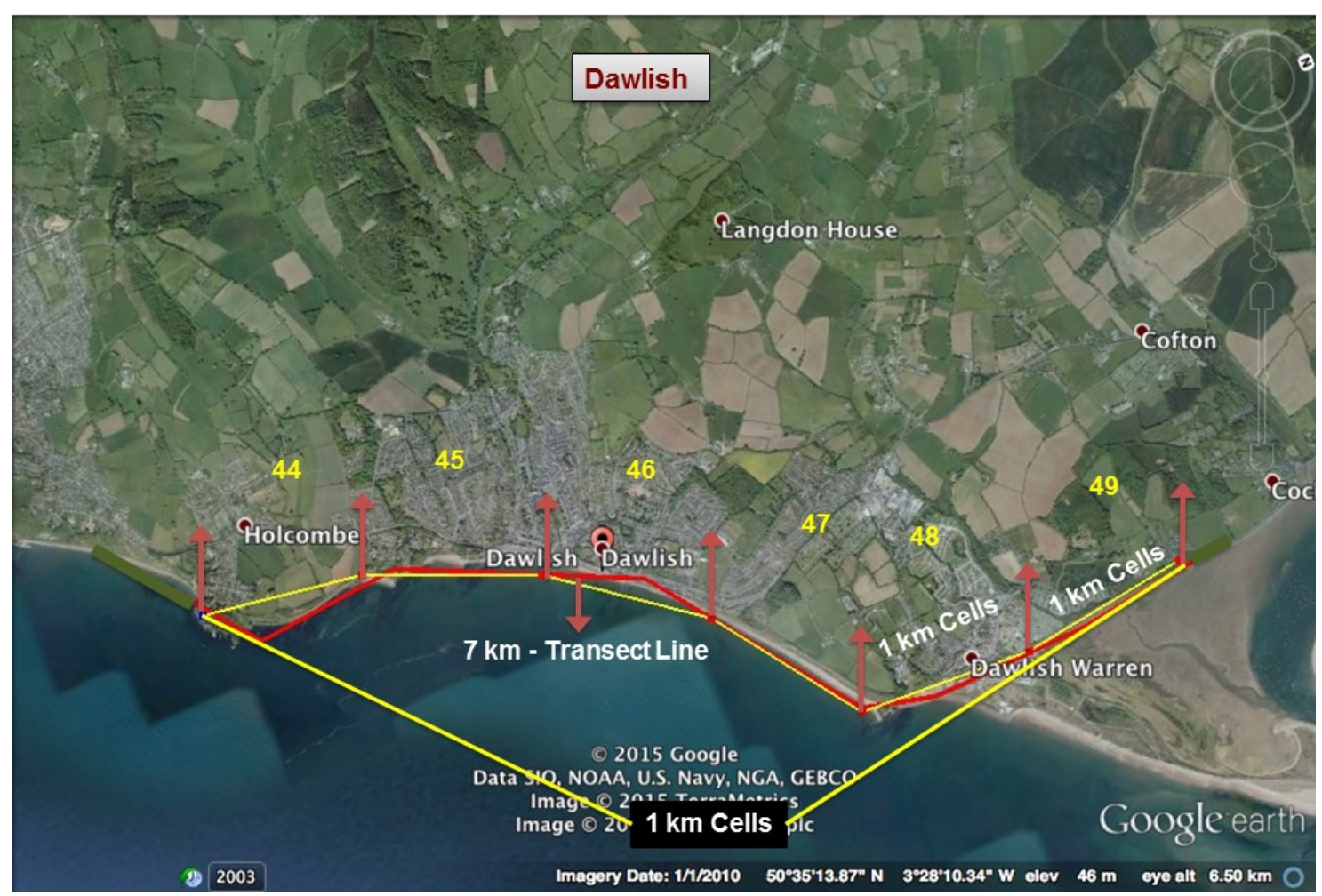

Figure 8.5: Transect line showing $1 \mathrm{~km}$ coastal cells: Dawlish 


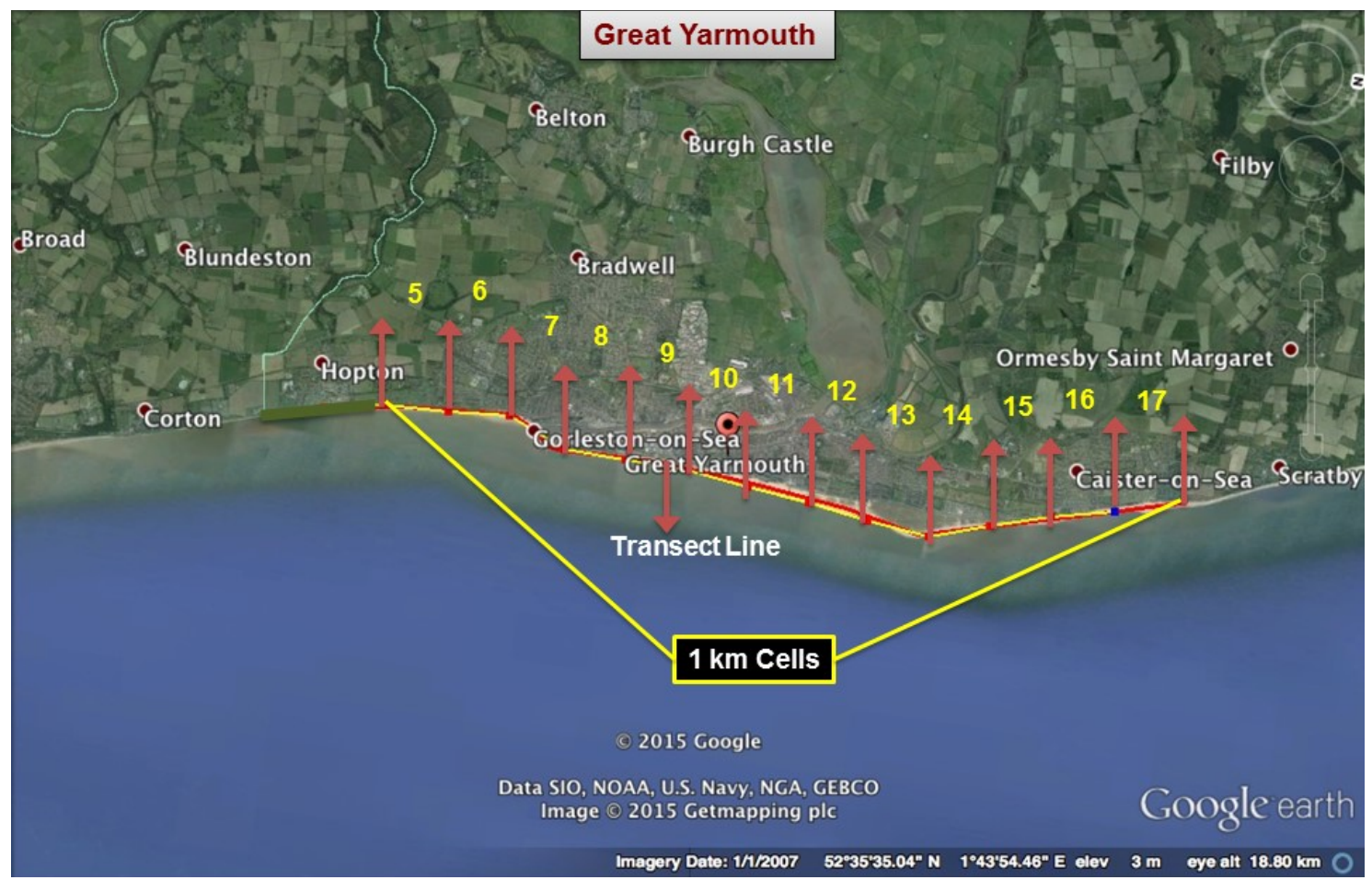

Figure 8.6: Transect line showing $1 \mathrm{~km}$ coastal cells: Great Yarmouth

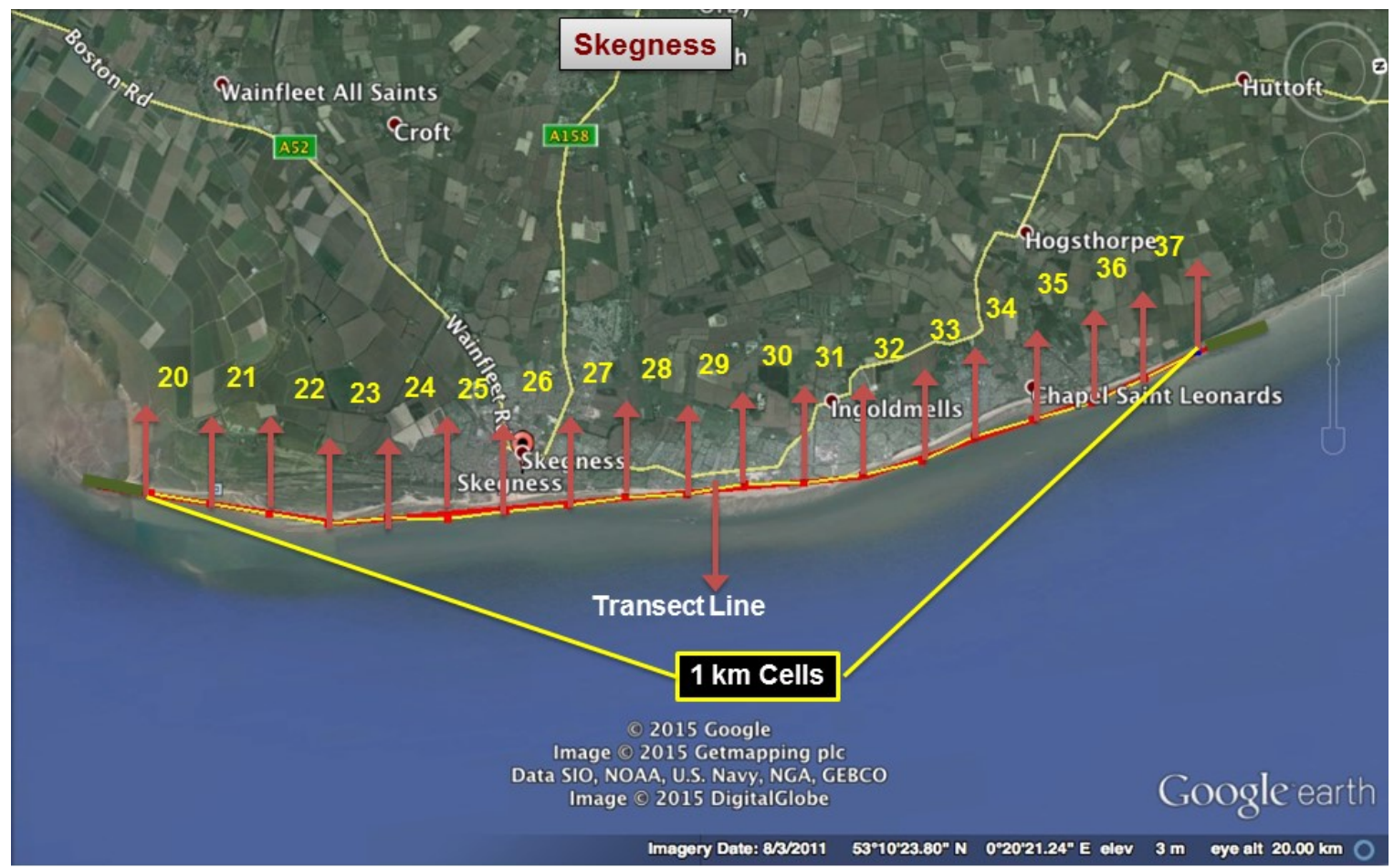

Figure 8.7: Transect line showing $1 \mathrm{~km}$ coastal cells: Skegness 


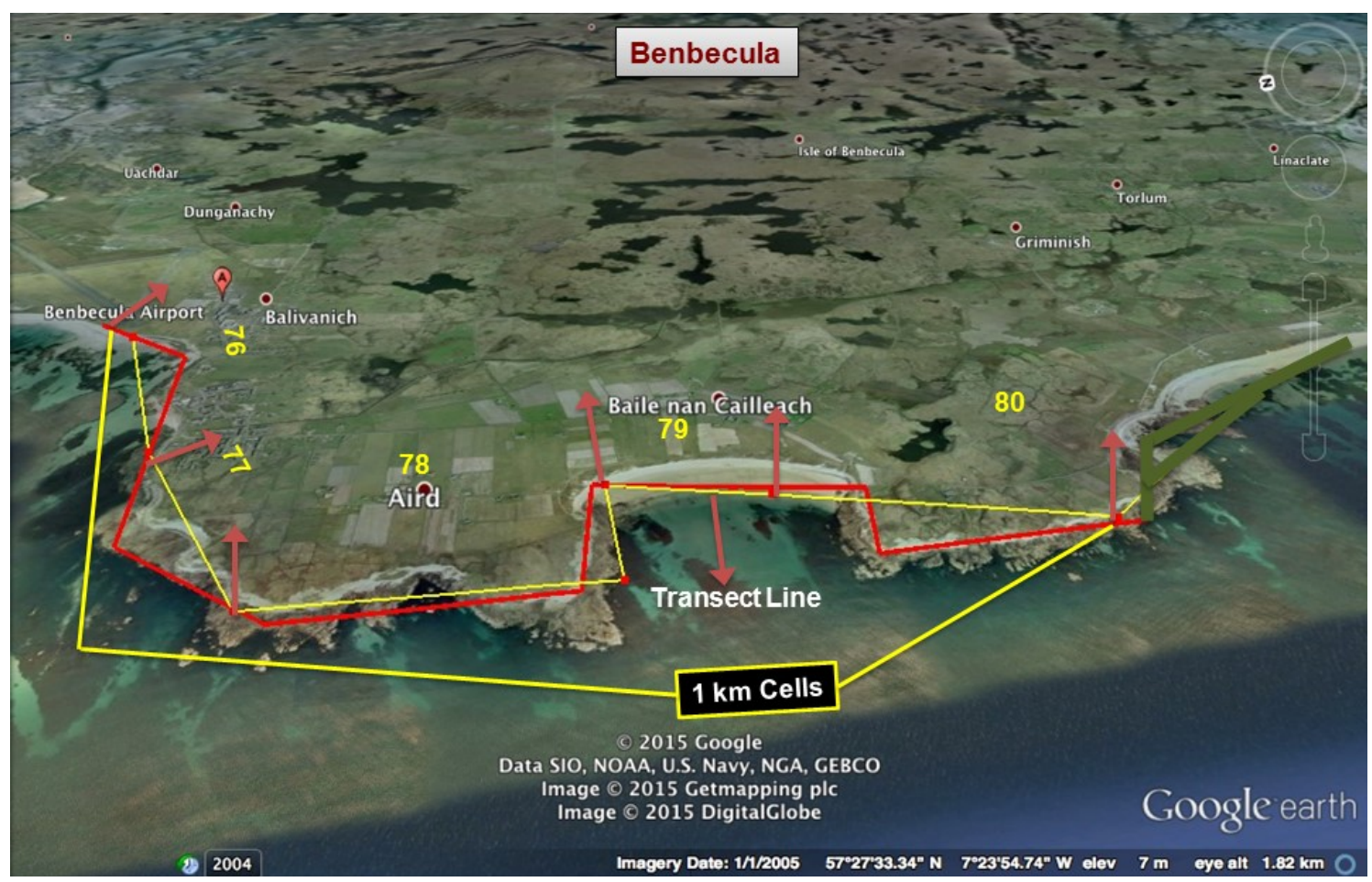

Figure 8.8: Transect line showing $1 \mathrm{~km}$ coastal cells: Benbecula

Aberystwyth has a population of 15139 with 758 commercial and 6591 residential properties. Two cells were used for data acquisition, as representative of a shoreline frontage of approximately $2.2 \mathrm{~km}$ (Figure 8.9). Port Talbot has a shoreline frontage of circa $13 \mathrm{~km}$ and a population of 37276 and 12 cells were used to collect data. This includes $>25000$ residential and $>1800$ commercial properties (Figure 8.10). There are 7253 residential and 1672 commercial properties in Llanelli with a 35000 population. The shoreline frontage of approximately $15 \mathrm{~km}$ included 12 cells from which measurements were taken (Figure 8.11). 


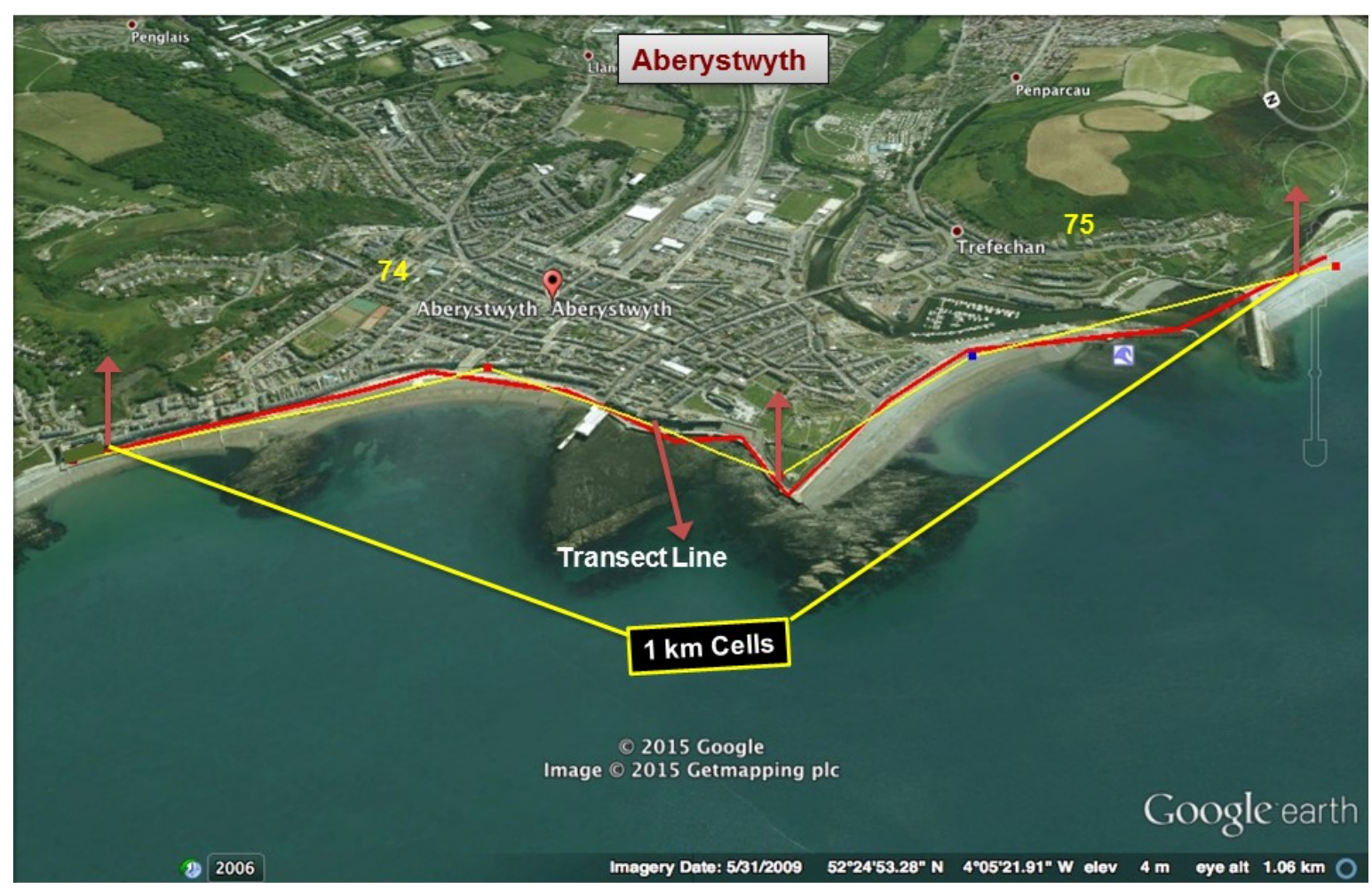

Figure 8.9: Transect line showing $1 \mathrm{~km}$ coastal cells: Aberystwyth

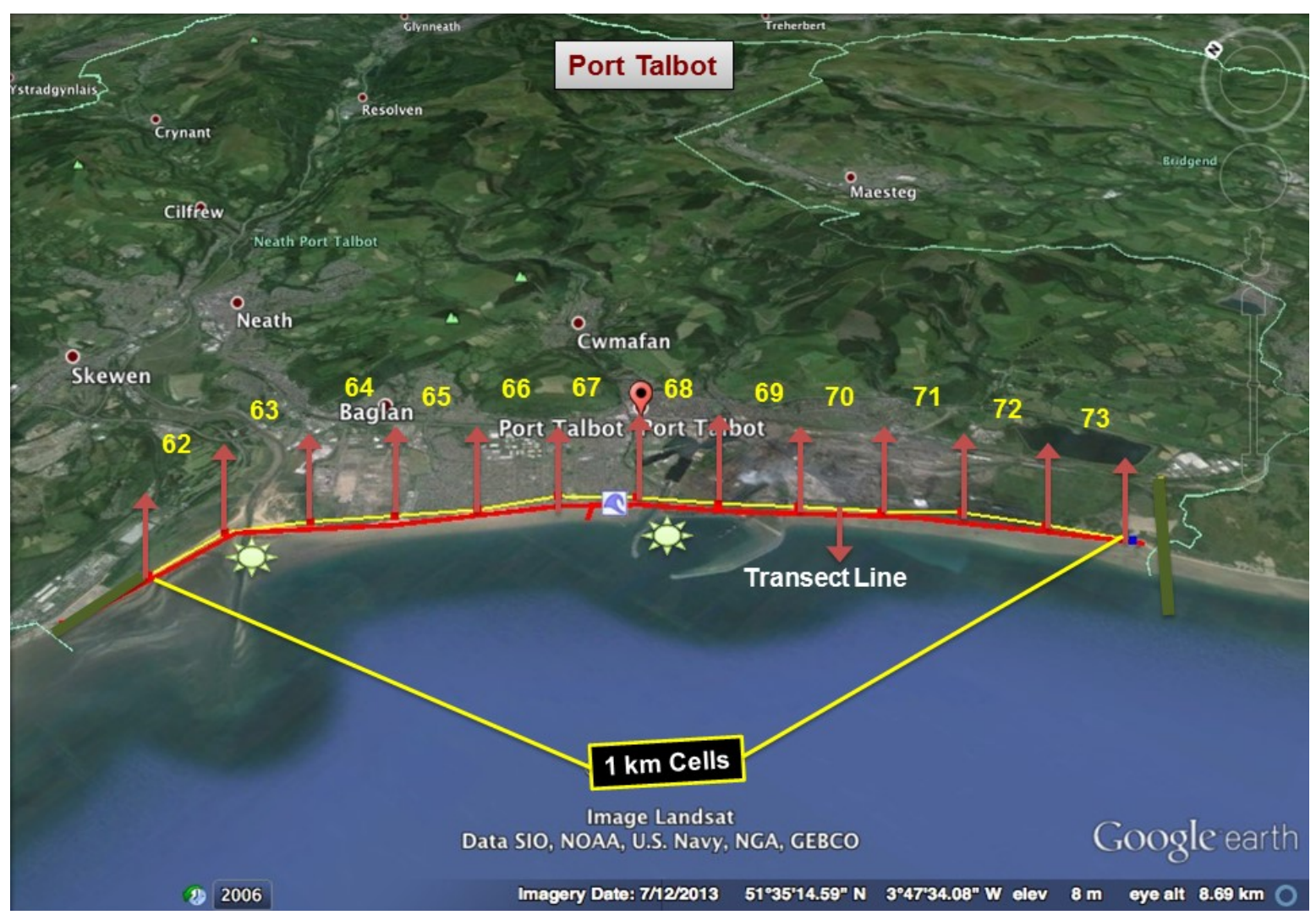

Figure 8.10: Transect line showing $1 \mathrm{~km}$ coastal cells: Port Talbot 


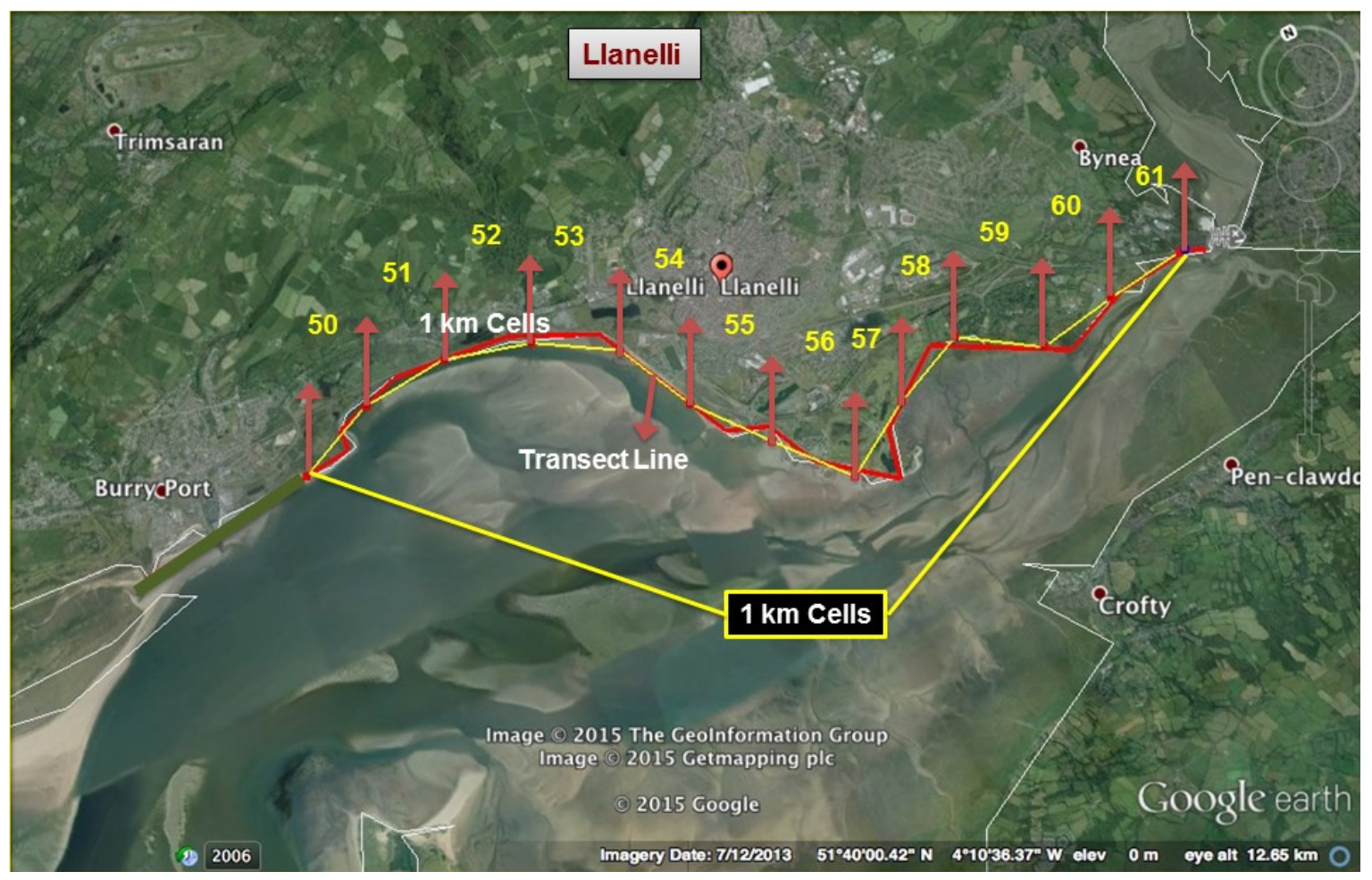

Figure 8.11: Transect line showing $1 \mathrm{~km}$ coastal cells: Llanelli

\subsection{Economic analysis}

\subsubsection{Commercial properties}

Economic data was obtained from various government and insurance sources, as discussed in Section 4.5, with six representative parameters chosen (Table 4.2), and this was applied to information acquired from analysis of the $1 \mathrm{~km}$ coastal cells. Consequently, an average commercial property value was derived from the range of facilities surveyed with a maximum of $£ 105 \mathrm{M}$ recorded in cell 8 at Great Yarmouth (Figure 8.6), to a minimum of $£ 0.02 \mathrm{M}$ in cell 73 at Port Talbot (Figure 8.10). An average commercial value of $£ 15.5 \mathrm{M}$ was determined and $27 \%$ of cells had higher than the average value, meaning $70 \%$ of cells were lower with two cells (38 and 80) not having commercial properties (Figure 8.12 and Table 8.2). 


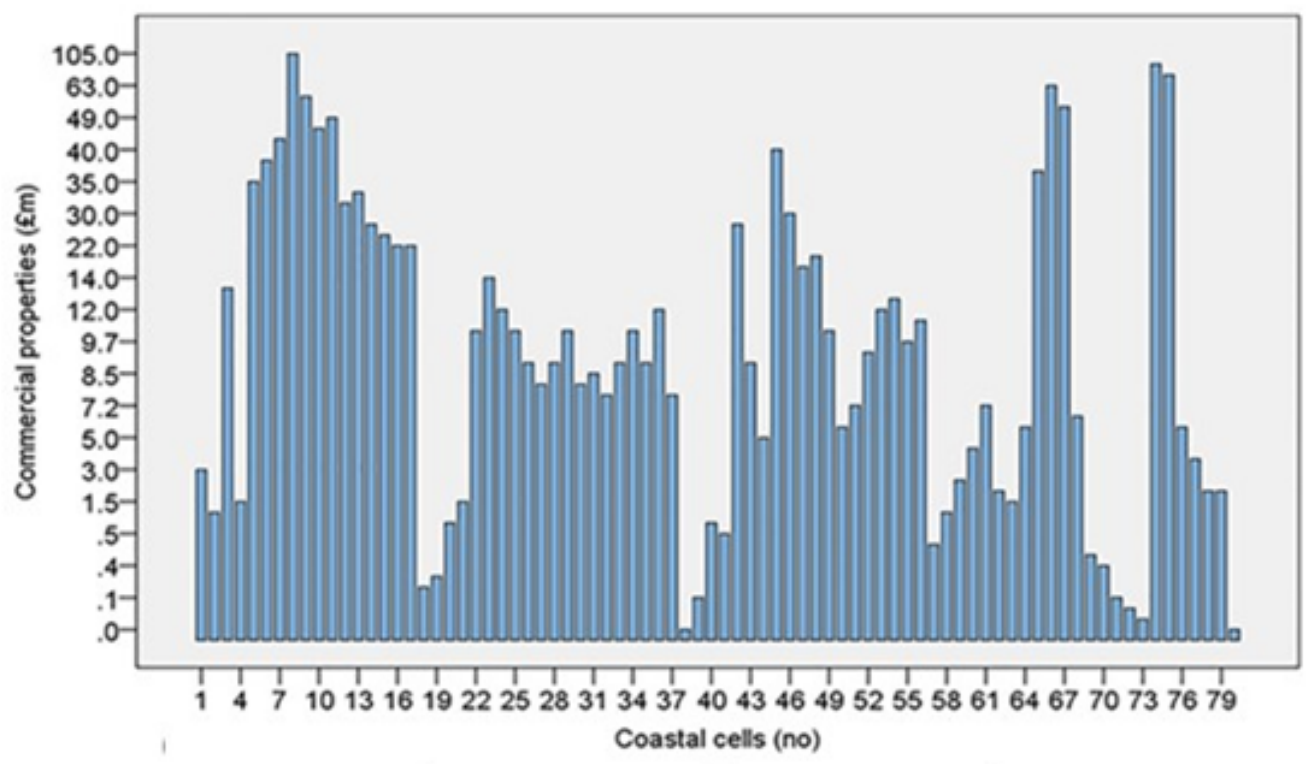

\begin{tabular}{|c|c|c|c|}
\hline 1-4 - Happisburgh & 5-17 - Great Yarmouth & 18-19 - Spurn Head & 20-37-Skegness \\
\hline 38-41 - Hallsands & 42 -43 - Lynmouth & 44-49- Dawlish & 50-61 - Llanelli \\
\hline 62-73 - Port Talbot & 74-75 - Aberystwyth & $76-80$ - Benbecula & \\
\hline
\end{tabular}

Figure 8.12: Commercial properties (£M-£B) 
Table 8.2: Economic Value: Commercial Properties

\begin{tabular}{|c|c|c|c|c|c|}
\hline $\begin{array}{c}\text { Coastal } \\
\text { Cell }\end{array}$ & Coastal Area & $\begin{array}{c}\text { Commercial } \\
\text { Properties } \\
\text { (£ Million) }\end{array}$ & $\begin{array}{c}\text { Coastal } \\
\text { Cell }\end{array}$ & Coastal Area & $\begin{array}{c}\text { Commercial } \\
\text { Properties } \\
\text { (£Million) }\end{array}$ \\
\hline 1 & Happisburgh & 3 & 41 & Hallsands & 0.5 \\
\hline 2 & Happisburgh & 1.2 & 42 & Lynmouth & 28 \\
\hline 3 & Happisburgh & 13.5 & 43 & Lynmouth & 9 \\
\hline 4 & Happisburgh & 1.5 & 44 & Dawlish & 5 \\
\hline 5 & Great Yarmouth & 35 & 45 & Dawlish & 40 \\
\hline 6 & Great Yarmouth & 38 & 46 & Dawlish & 30 \\
\hline 7 & Great Yarmouth & 42 & 47 & Dawlish & 16 \\
\hline 8 & Great Yarmouth & 105 & 48 & Dawlish & 18 \\
\hline 9 & Great Yarmouth & 55 & 49 & Dawlish & 10 \\
\hline 10 & Great Yarmouth & 45 & 50 & Llanelli & 6 \\
\hline 11 & Great Yarmouth & 49 & 51 & Llanelli & 7.2 \\
\hline 12 & Great Yarmouth & 31 & 52 & Llanelli & 9.6 \\
\hline 13 & Great Yarmouth & 33 & 53 & Llanelli & 12 \\
\hline 14 & Great Yarmouth & 28 & 54 & Llanelli & 13.2 \\
\hline 15 & Great Yarmouth & 26 & 55 & Llanelli & 9.7 \\
\hline 16 & Great Yarmouth & 22 & 56 & Llanelli & 10.8 \\
\hline 17 & Great Yarmouth & 22 & 57 & Llanelli & 0.48 \\
\hline 18 & Spurn Head & 0.2 & 58 & Llanelli & 1.2 \\
\hline 19 & Spurn Head & 0.25 & 59 & Llanelli & 2.4 \\
\hline 20 & Skegness & 1 & 60 & Llanelli & 4.8 \\
\hline 21 & Skegness & 1.5 & 61 & Llanelli & 7.2 \\
\hline 22 & Skegness & 10 & 62 & Port Talbot & 2 \\
\hline 23 & Skegness & 14 & 63 & Port Talbot & 1.5 \\
\hline 24 & Skegness & 12 & 64 & Port Talbot & 6 \\
\hline 25 & Skegness & 10 & 65 & Port Talbot & 36 \\
\hline 26 & Skegness & 9 & 66 & Port Talbot & 63 \\
\hline 27 & Skegness & 8 & 67 & Port Talbot & 51 \\
\hline 28 & Skegness & 9 & 68 & Port Talbot & 7 \\
\hline 29 & Skegness & 10 & 69 & Port Talbot & 0.4 \\
\hline 30 & Skegness & 8 & 70 & Port Talbot & 0.35 \\
\hline 31 & Skegness & 8.5 & 71 & Port Talbot & 0.1 \\
\hline 32 & Skegness & 7.5 & 72 & Port Talbot & 0.04 \\
\hline 33 & Skegness & 9 & 73 & Port Talbot & 0.02 \\
\hline 34 & Skegness & 10 & 74 & Aberystwyth & 66 \\
\hline 35 & Skegness & 9 & 75 & Aberystwyth & 42 \\
\hline 36 & Skegness & 12 & 76 & Benbecula & 6 \\
\hline 37 & Skegness & 7.5 & 77 & Benbecula & 4 \\
\hline 38 & Hallsands & 0.0 & 78 & Benbecula & 2 \\
\hline 39 & Hallsands & 0.1 & 79 & Benbecula & 2 \\
\hline 40 & Hallsands & 1 & 80 & Benbecula & 0 \\
\hline
\end{tabular}




\subsubsection{Residential properties}

The average value of residential properties within the 80 cells is $£ 135 \mathrm{M}$, with a maximum of $£ 780 \mathrm{M}$ in cell 66 (Port Talbot) and a minimum of $£ 0.02 \mathrm{M}$ in cells 18 and 19 (Spurn Head; Figure 8.13 and Table 8.3 ). Twenty-six percent and $67 \%$ of cells recorded higher and lower values than the average respectively, while three cells (71-73 inclusive) did not include residential properties (Figure 8.13 and Table 8.3).

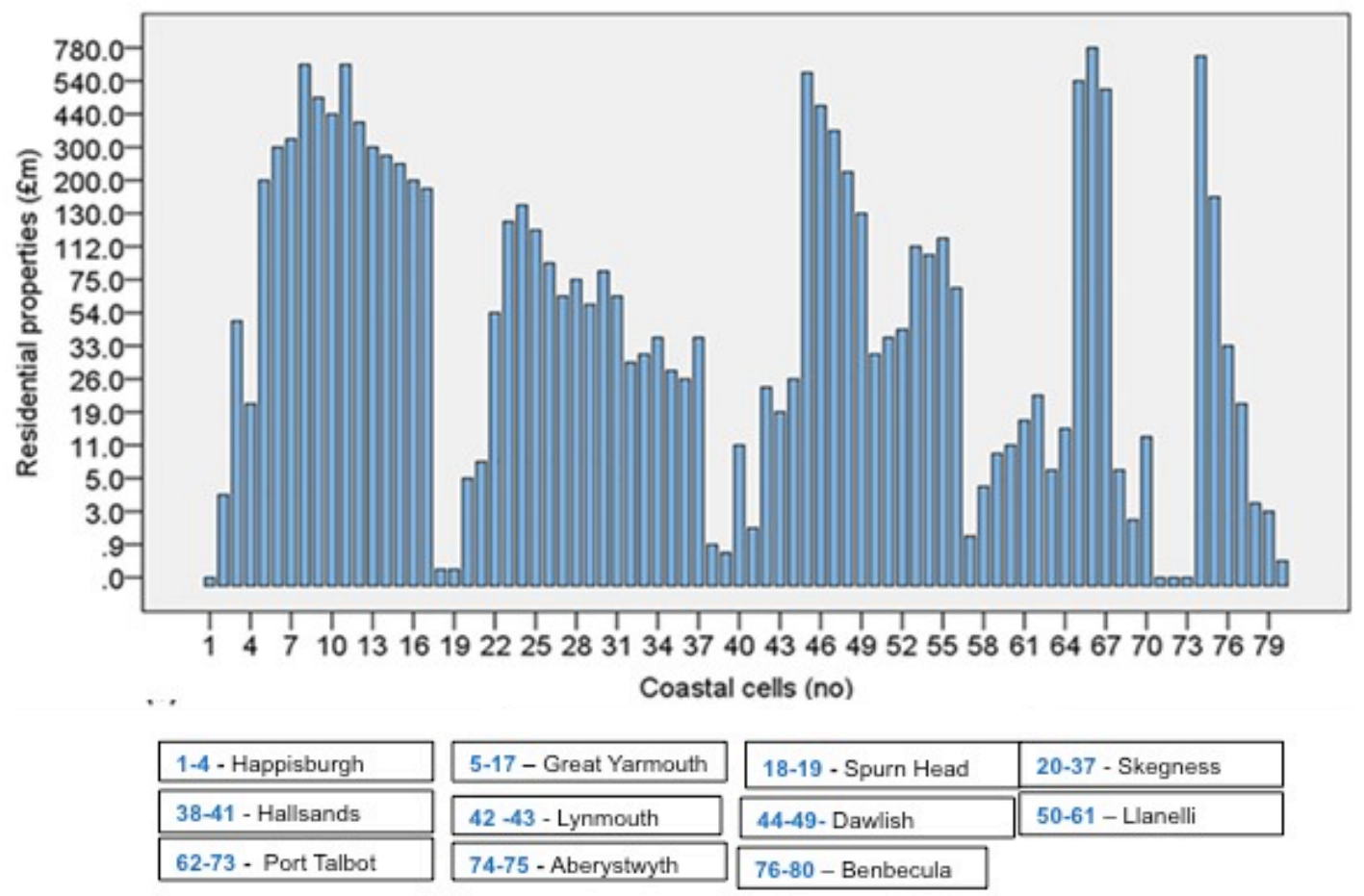

Figure 8.13: Residential properties (£M-£B) 
Table 8.3 Economic Value: Residential Properties

\begin{tabular}{|c|c|c|c|c|c|}
\hline $\begin{array}{c}\text { Coastal } \\
\text { Cell }\end{array}$ & Site Area & $\begin{array}{c}\text { Residential } \\
\text { Properties } \\
\text { (in £Million) }\end{array}$ & $\begin{array}{c}\text { Coastal } \\
\text { Cell }\end{array}$ & $\begin{array}{c}\text { Site } \\
\text { Area }\end{array}$ & $\begin{array}{c}\text { Residential } \\
\text { Properties } \\
\text { (in } \\
\text { £Million) }\end{array}$ \\
\hline 1 & Happisburgh & 8 & 41 & Hallsands & 2 \\
\hline 2 & Happisburgh & 4 & 42 & Lynmouth & 25 \\
\hline 3 & Happisburgh & 50 & 43 & Lynmouth & 19 \\
\hline 4 & Happisburgh & 20 & 44 & Dawlish & 26 \\
\hline 5 & Great Yarmouth & 200 & 45 & Dawlish & 598 \\
\hline 6 & Great Yarmouth & 300 & 46 & Dawlish & 468 \\
\hline 7 & Great Yarmouth & 320 & 47 & Dawlish & 390 \\
\hline 8 & Great Yarmouth & 600 & 48 & Dawlish & 208 \\
\hline 9 & Great Yarmouth & 500 & 49 & Dawlish & 130 \\
\hline 10 & Great Yarmouth & 440 & 50 & Llanelli & 32 \\
\hline 11 & Great Yarmouth & 600 & 51 & Llanelli & 40 \\
\hline 12 & Great Yarmouth & 400 & 52 & Llanelli & 48 \\
\hline 13 & Great Yarmouth & 300 & 53 & Llanelli & 112 \\
\hline 14 & Great Yarmouth & 240 & 54 & Llanelli & 104 \\
\hline 15 & Great Yarmouth & 220 & 55 & Llanelli & 113 \\
\hline 16 & Great Yarmouth & 200 & 56 & Llanelli & 72 \\
\hline 17 & Great Yarmouth & 190 & 57 & Llanelli & 1.6 \\
\hline 18 & Spurn Head & 0.2 & 58 & Llanelli & 4.8 \\
\hline 19 & Spurn Head & 0.2 & 59 & Llanelli & 9.6 \\
\hline 20 & Skegness & 5 & 60 & Llanelli & 11 \\
\hline 21 & Skegness & 8 & 61 & Llanelli & 12.7 \\
\hline 22 & Skegness & 54 & 62 & Port Talbot & 24 \\
\hline 23 & Skegness & 121 & 63 & Port Talbot & 6 \\
\hline 24 & Skegness & 135 & 64 & Port Talbot & 12 \\
\hline 25 & Skegness & 120 & 65 & Port Talbot & 540 \\
\hline 26 & Skegness & 94 & 66 & Port Talbot & 780 \\
\hline 27 & Skegness & 67 & 67 & Port Talbot & 504 \\
\hline 28 & Skegness & 75 & 68 & Port Talbot & 6 \\
\hline 29 & Skegness & 63 & 69 & Port Talbot & 2.4 \\
\hline 30 & Skegness & 81 & 70 & Port Talbot & 11.5 \\
\hline 31 & Skegness & 67 & 71 & Port Talbot & 0 \\
\hline 32 & Skegness & 27 & 72 & Port Talbot & 0 \\
\hline 33 & Skegness & 32 & 73 & Port Talbot & 0 \\
\hline 34 & Skegness & 40 & 74 & Aberystwyth & 594 \\
\hline 35 & Skegness & 26.6 & 75 & Aberystwyth & 167 \\
\hline 36 & Skegness & 26 & 76 & Benbecula & 33 \\
\hline 37 & Skegness & 40 & 77 & Benbecula & 20 \\
\hline 38 & Hallsands & 0.9 & 78 & Benbecula & 3.1 \\
\hline 39 & Hallsands & 0.6 & 79 & Benbecula & 3 \\
\hline 40 & Hallsands & 11 & 80 & Benbecula & 0.4 \\
\hline
\end{tabular}




\subsubsection{Economic value of site}

The average economic value of all sites is approximately $£ 103 \mathrm{M}$ from a total value of approximately $£ 8.3 \mathrm{~B}$ (Table 8.4). Assessments showed maximum site values of $£ 1000 \mathrm{M}$ (£1B) occurred in cells 70 and 71 (Port Talbot) and a minimum value of $£ 2 \mathrm{M}$ in cell 18 (Spurn Head) and therefore, it can be seen that approximately $30 \%$ and $70 \%$ of cells had higher and lower values than the mean respectively (Figure 8.14 and Table 8.4).

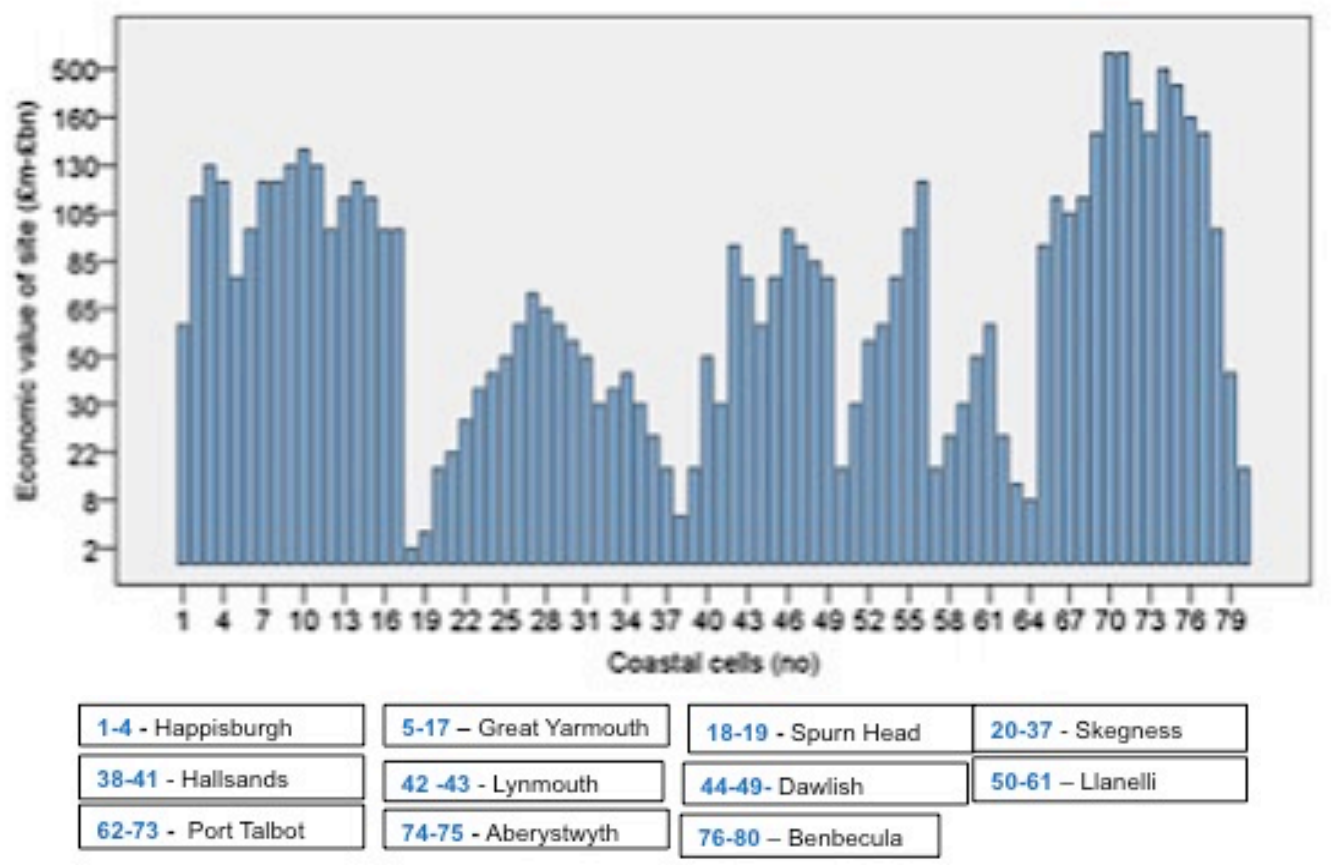

Figure 8.14: Economic value of site $(£ M-£ B)$ 
Table 8.4: Economic Value of Site

\begin{tabular}{|c|c|c|c|c|c|}
\hline $\begin{array}{c}\text { Coastal } \\
\text { Cell }\end{array}$ & Coastal Site & $\begin{array}{c}\text { Economic } \\
\text { Value of } \\
\text { Place } \\
\text { (£Million) }\end{array}$ & $\begin{array}{c}\text { Coastal } \\
\text { Cell }\end{array}$ & Coastal Site & $\begin{array}{c}\text { Economic } \\
\text { Value of Place } \\
\text { (£Million) }\end{array}$ \\
\hline 1 & Happisburgh & 60 & 41 & Hallsands & 30 \\
\hline 2 & Happisburgh & 110 & 42 & Lynmouth & 90 \\
\hline 3 & Happisburgh & 130 & 43 & Lynmouth & 80 \\
\hline 4 & Happisburgh & 120 & 44 & Dawlish & 60 \\
\hline 5 & Great Yarmouth & 80 & 45 & Dawlish & 80 \\
\hline 6 & Great Yarmouth & 100 & 46 & Dawlish & 100 \\
\hline 7 & Great Yarmouth & 120 & 47 & Dawlish & 90 \\
\hline 8 & Great Yarmouth & 120 & 48 & Dawlish & 85 \\
\hline 9 & Great Yarmouth & 130 & 49 & Dawlish & 80 \\
\hline 10 & Great Yarmouth & 135 & 50 & Llanelli & 20 \\
\hline 11 & Great Yarmouth & 130 & 51 & Llanelli & 30 \\
\hline 12 & Great Yarmouth & 100 & 52 & Llanelli & 55 \\
\hline 13 & Great Yarmouth & 110 & 53 & Llanelli & 60 \\
\hline 14 & Great Yarmouth & 120 & 54 & Llanelli & 80 \\
\hline 15 & Great Yarmouth & 110 & 55 & Llanelli & 100 \\
\hline 16 & Great Yarmouth & 100 & 56 & Llanelli & 120 \\
\hline 17 & Great Yarmouth & 100 & 57 & Llanelli & 20 \\
\hline 18 & Spurn Head & 2 & 58 & Llanelli & 25 \\
\hline 19 & Spurn Head & 3 & 59 & Llanelli & 30 \\
\hline 20 & Skegness & 20 & 60 & Llanelli & 50 \\
\hline 21 & Skegness & 22 & 61 & Llanelli & 60 \\
\hline 22 & Skegness & 28 & 62 & Port Talbot & 25 \\
\hline 23 & Skegness & 35 & 63 & Port Talbot & 15 \\
\hline 24 & Skegness & 40 & 64 & Port Talbot & 8 \\
\hline 25 & Skegness & 50 & 65 & Port Talbot & 90 \\
\hline 26 & Skegness & 60 & 66 & Port Talbot & 110 \\
\hline 27 & Skegness & 68 & 67 & Port Talbot & 105 \\
\hline 28 & Skegness & 65 & 68 & Port Talbot & 110 \\
\hline 29 & Skegness & 60 & 69 & Port Talbot & 150 \\
\hline 30 & Skegness & 55 & 70 & Port Talbot & 1000 \\
\hline 31 & Skegness & 50 & 71 & Port Talbot & 1000 \\
\hline 32 & Skegness & 30 & 72 & Port Talbot & 200 \\
\hline 33 & Skegness & 35 & 73 & Port Talbot & 150 \\
\hline 34 & Skegness & 40 & 74 & Aberystwyth & 500 \\
\hline 35 & Skegness & 30 & 75 & Aberystwyth & 300 \\
\hline 36 & Skegness & 25 & 76 & Benbecula & 160 \\
\hline 37 & Skegness & 20 & 77 & Benbecula & 150 \\
\hline 38 & Hallsands & 5 & 78 & Benbecula & 100 \\
\hline 39 & Hallsands & 20 & 79 & Benbecula & 40 \\
\hline 40 & Hallsands & 50 & 80 & Benbecula & 20 \\
\hline
\end{tabular}




\subsubsection{Population}

The average population in all cells was found to be approximately 1480 with a maximum of 10000 in cell 66 (Port Talbot) and minimum of 1 in cell 38 (Hallsands; Table 8.5). Sixtyseven percent of cells had lower than the average populations, while $30 \%$ recorded higher than average figures (Figure 8.15 and Table 8.5).

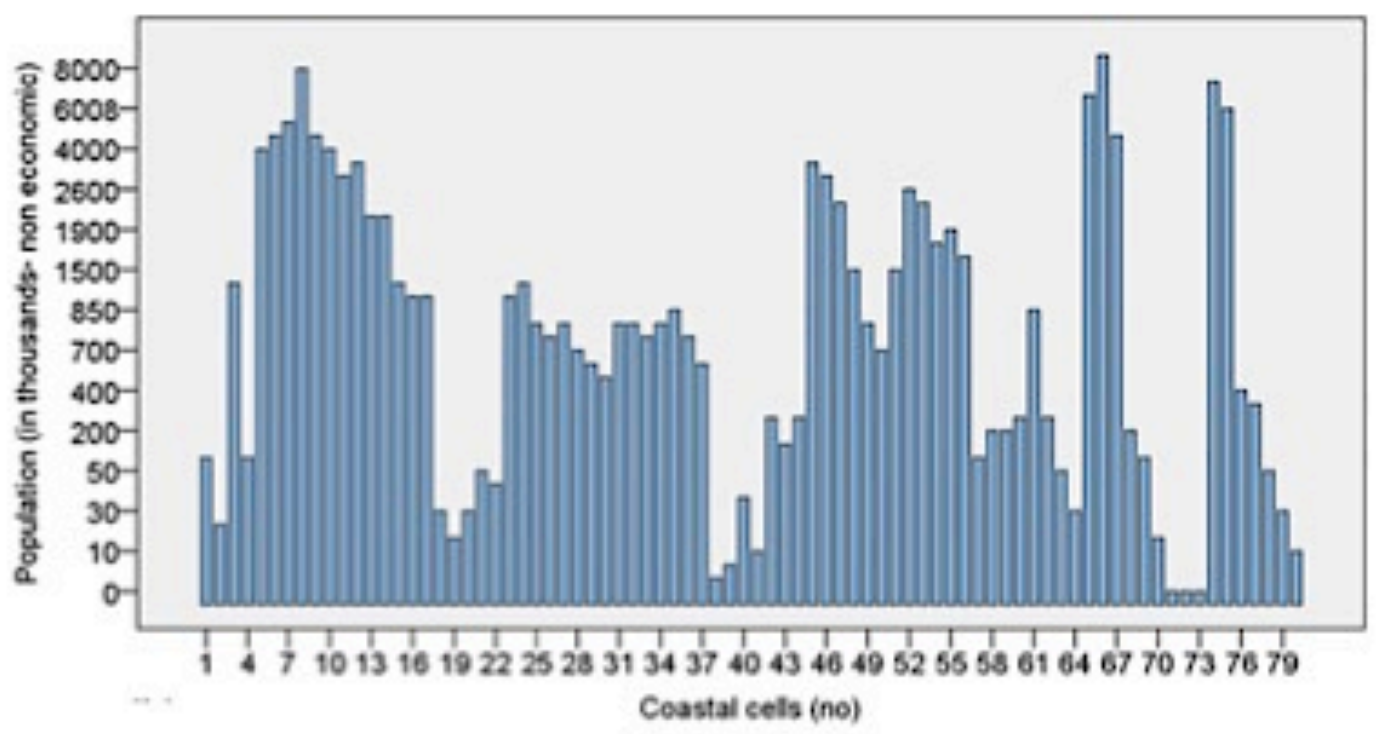

\begin{tabular}{|l|}
\hline 1-4 - Happisburgh \\
\hline 38-41 - Hallsands \\
\hline \hline $62-73$ - Port Talbot \\
\hline
\end{tabular}

\begin{tabular}{|l|}
\hline 5-17 - Great Yarmouth \\
\hline $42-43$ - Lynmouth \\
\hline 74-75 - Aberystwyth \\
\hline
\end{tabular}

\begin{tabular}{|l|l|}
\hline 18-19 - Spurn Head & $20-37$ - Skegness \\
\hline 44-49- Dawlish & $50-61$ - Llanelli \\
\hline 76-80 - Benbecula \\
\hline
\end{tabular}

Figure 8.15: Population per coastal cell 
Table 8.5: Population

\begin{tabular}{|c|c|c|c|c|c|}
\hline $\begin{array}{c}\text { Coastal } \\
\text { Cell }\end{array}$ & Coastal Site & $\begin{array}{c}\text { Population } \\
\text { Numbers }\end{array}$ & $\begin{array}{c}\text { Coastal } \\
\text { Cell }\end{array}$ & Coastal Site & $\begin{array}{c}\text { Population } \\
\text { Numbers }\end{array}$ \\
\hline 1 & Happisburgh & 100 & 41 & Hallsands & 10 \\
\hline 2 & Happisburgh & 27 & 42 & Lynmouth & 300 \\
\hline 3 & Happisburgh & 1100 & 43 & Lynmouth & 190 \\
\hline 4 & Happisburgh & 100 & 44 & Dawlish & 300 \\
\hline 5 & Great Yarmouth & 4000 & 45 & Dawlish & 3500 \\
\hline 6 & Great Yarmouth & 5000 & 46 & Dawlish & 3000 \\
\hline 7 & Great Yarmouth & 6000 & 47 & Dawlish & 2200 \\
\hline 8 & Great Yarmouth & 8000 & 48 & Dawlish & 1500 \\
\hline 9 & Great Yarmouth & 5000 & 49 & Dawlish & 800 \\
\hline 10 & Great Yarmouth & 4000 & 50 & Llanelli & 700 \\
\hline 11 & Great Yarmouth & 3000 & 51 & Llanelli & 1500 \\
\hline 12 & Great Yarmouth & 3500 & 52 & Llanelli & 2600 \\
\hline 13 & Great Yarmouth & 2000 & 53 & Llanelli & 2200 \\
\hline 14 & Great Yarmouth & 2000 & 54 & Llanelli & 1800 \\
\hline 15 & Great Yarmouth & 1100 & 55 & Llanelli & 1900 \\
\hline 16 & Great Yarmouth & 1000 & 56 & Llanelli & 1700 \\
\hline 17 & Great Yarmouth & 1000 & 57 & Llanelli & 100 \\
\hline 18 & Spurn Head & 30 & 58 & Llanelli & 200 \\
\hline 19 & Spurn Head & 20 & 59 & Llanelli & 200 \\
\hline 20 & Skegness & 30 & 60 & Llanelli & 300 \\
\hline 21 & Skegness & 50 & 61 & Llanelli & 850 \\
\hline 22 & Skegness & 40 & 62 & Port Talbot & 300 \\
\hline 23 & Skegness & 1000 & 63 & Port Talbot & 50 \\
\hline 24 & Skegness & 1100 & 64 & Port Talbot & 30 \\
\hline 25 & Skegness & 800 & 65 & Port Talbot & 6700 \\
\hline 26 & Skegness & 750 & 66 & Port Talbot & 10000 \\
\hline 27 & Skegness & 800 & 67 & Port Talbot & 5000 \\
\hline 28 & Skegness & 700 & 68 & Port Talbot & 200 \\
\hline 29 & Skegness & 600 & 69 & Port Talbot & 100 \\
\hline 30 & Skegness & 500 & 70 & Port Talbot & 20 \\
\hline 31 & Skegness & 800 & 71 & Port Talbot & 0 \\
\hline 32 & Skegness & 800 & 72 & Port Talbot & 0 \\
\hline 33 & Skegness & 750 & 73 & Port Talbot & 0 \\
\hline 34 & Skegness & 800 & 74 & Aberystwyth & 6600 \\
\hline 35 & Skegness & 850 & 75 & Aberystwyth & 4000 \\
\hline 36 & Skegness & 750 & 76 & Benbecula & 400 \\
\hline 37 & Skegness & 600 & 77 & Benbecula & 350 \\
\hline 38 & Hallsands & 1 & 78 & Benbecula & 50 \\
\hline 39 & Hallsands & 4 & 79 & Benbecula & 30 \\
\hline 40 & Hallsands & 36 & 80 & Benbecula & 10 \\
\hline
\end{tabular}




\subsubsection{Coastal erosion}

The average cost of coastal erosion was $£ 5.4 \mathrm{M}$ (Table 8.6) with a maximum of $£ 20 \mathrm{M}$ in cells 2, 46, and 68 (Happisburgh, Dawlish and Port Talbot respectively) and minimum of $0.3 \mathrm{M}$ in cell 20 (Skegness). It can be seen that $62 \%$ of cells had lower than average values, while $38 \%$ were higher (Figure 8.16 and Table 8.6), showing that coastal erosion would be an ongoing economic challenge.

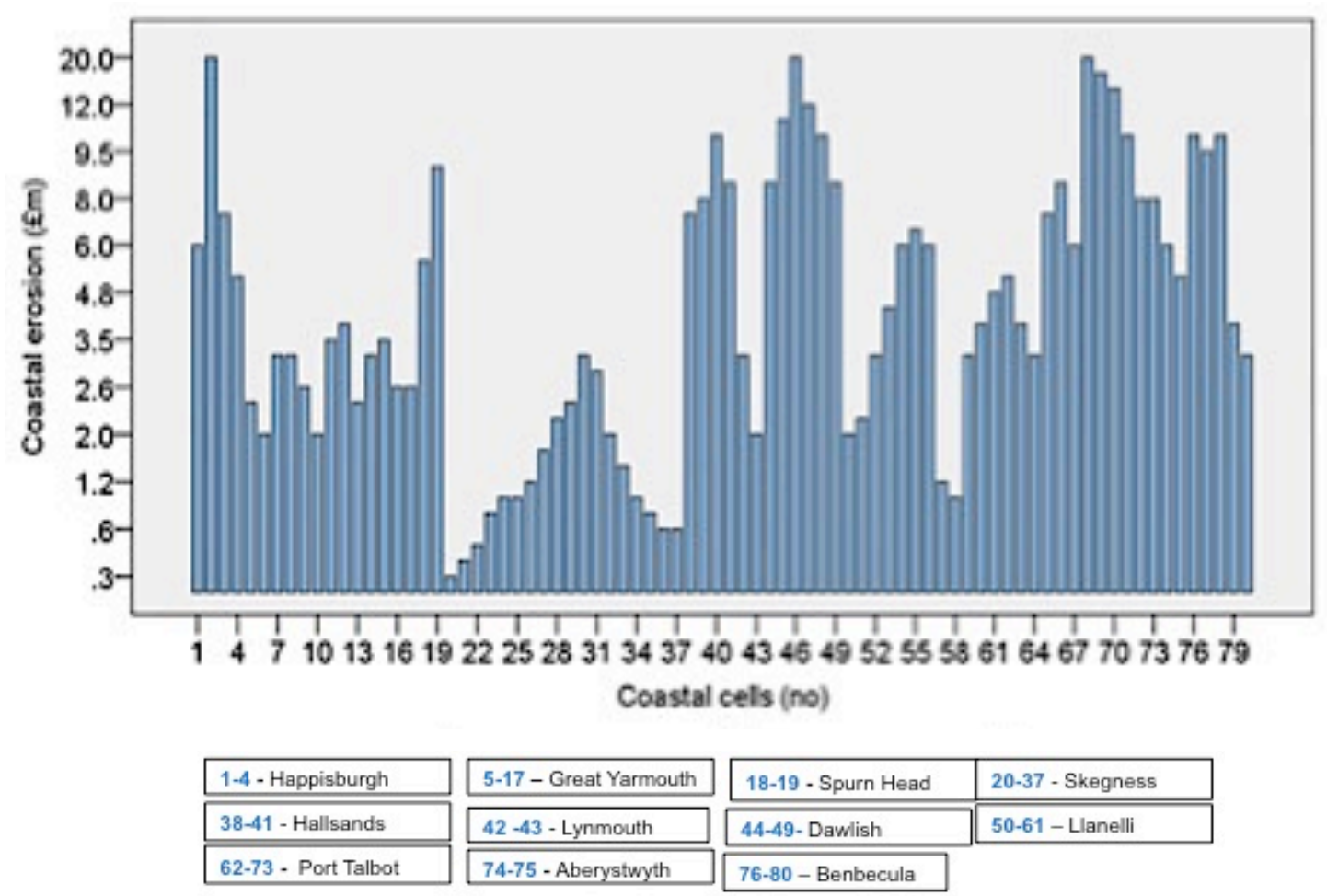

Figure 8.16: Coastal erosion (£M) 
Table 8.6: Coastal erosion: economic cost

\begin{tabular}{|c|c|c|c|c|c|}
\hline $\begin{array}{c}\text { Coastal } \\
\text { Cell }\end{array}$ & Coastal Site & $\begin{array}{c}\text { Coastal } \\
\text { Erosion } \\
(£ \text { Million) }\end{array}$ & $\begin{array}{c}\text { Coastal } \\
\text { Cell }\end{array}$ & Coastal Site & $\begin{array}{c}\text { Coastal } \\
\text { Erosion } \\
\text { (£Million) }\end{array}$ \\
\hline 1 & Happisburgh & 6 & 41 & Hallsands & 9 \\
\hline 2 & Happisburgh & 20 & 42 & Lynmouth & 3 \\
\hline 3 & Happisburgh & 7 & 43 & Lynmouth & 2 \\
\hline 4 & Happisburgh & 5 & 44 & Dawlish & 9 \\
\hline 5 & Great Yarmouth & 2.5 & 45 & Dawlish & 11 \\
\hline 6 & Great Yarmouth & 2 & 46 & Dawlish & 20 \\
\hline 7 & Great Yarmouth & 3 & 47 & Dawlish & 12 \\
\hline 8 & Great Yarmouth & 3 & 48 & Dawlish & 10 \\
\hline 9 & Great Yarmouth & 2.6 & 49 & Dawlish & 9 \\
\hline 10 & Great Yarmouth & 2 & 50 & Llanelli & 2 \\
\hline 11 & Great Yarmouth & 3.5 & 51 & Llanelli & 2.2 \\
\hline 12 & Great Yarmouth & 4 & 52 & Llanelli & 3 \\
\hline 13 & Great Yarmouth & 2.5 & 53 & Llanelli & 4.5 \\
\hline 14 & Great Yarmouth & 3 & 54 & Llanelli & 6 \\
\hline 15 & Great Yarmouth & 3.5 & 55 & Llanelli & 6.5 \\
\hline 16 & Great Yarmouth & 2.6 & 56 & Llanelli & 6 \\
\hline 17 & Great Yarmouth & 2.6 & 57 & Llanelli & 1.2 \\
\hline 18 & Spurn Head & 5.1 & 58 & Llanelli & 1 \\
\hline 19 & Spurn Head & 9.1 & 59 & Llanelli & 3 \\
\hline 20 & Skegness & 0.3 & 60 & Llanelli & 4 \\
\hline 21 & Skegness & 0.4 & 61 & Llanelli & 4.8 \\
\hline 22 & Skegness & 0.5 & 62 & Port Talbot & 5 \\
\hline 23 & Skegness & 0.8 & 63 & Port Talbot & 4 \\
\hline 24 & Skegness & 1 & 64 & Port Talbot & 3 \\
\hline 25 & Skegness & 1 & 65 & Port Talbot & 7 \\
\hline 26 & Skegness & 1.2 & 66 & Port Talbot & 9 \\
\hline 27 & Skegness & 1.8 & 67 & Port Talbot & 6 \\
\hline 28 & Skegness & 2.2 & 68 & Port Talbot & 20 \\
\hline 29 & Skegness & 2.5 & 69 & Port Talbot & 18 \\
\hline 30 & Skegness & 3 & 70 & Port Talbot & 15 \\
\hline 31 & Skegness & 2.8 & 71 & Port Talbot & 10 \\
\hline 32 & Skegness & 2 & 72 & Port Talbot & 8 \\
\hline 33 & Skegness & 1.5 & 73 & Port Talbot & 8 \\
\hline 34 & Skegness & 1 & 74 & Aberystwyth & 6 \\
\hline 35 & Skegness & 0.8 & 75 & Aberystwyth & 5 \\
\hline 36 & Skegness & 0.6 & 76 & Benbecula & 10 \\
\hline 37 & Skegness & 0.6 & 77 & Benbecula & 9.5 \\
\hline 38 & Hallsands & 7 & 78 & Benbecula & 10 \\
\hline 39 & Hallsands & 8 & 79 & Benbecula & 4 \\
\hline 40 & Hallsands & 10 & 80 & Benbecula & 3 \\
\hline
\end{tabular}




\subsubsection{Flood impact}

Flooding costs were determined as approximately $£ 1.6 \mathrm{~B}$ across all 80 cells (Table 8.7), with an average flood impact of $£ 20 \mathrm{M}$ ranging between a maximum of $£ 40 \mathrm{M}$ in cells 8 and 14 (Great Yarmouth) and a minimum of $£ 2 \mathrm{M}$ in cells 57, 64 and 80 (Llanelli, Port Talbot and Benbecula respectively). Therefore, $38 \%$ of cells recorded lower than the average and $62 \%$ more than the average flood impact values (Figure 8.17 and Table 8.7). Therefore, flooding can clearly be seen as an economic vulnerability.

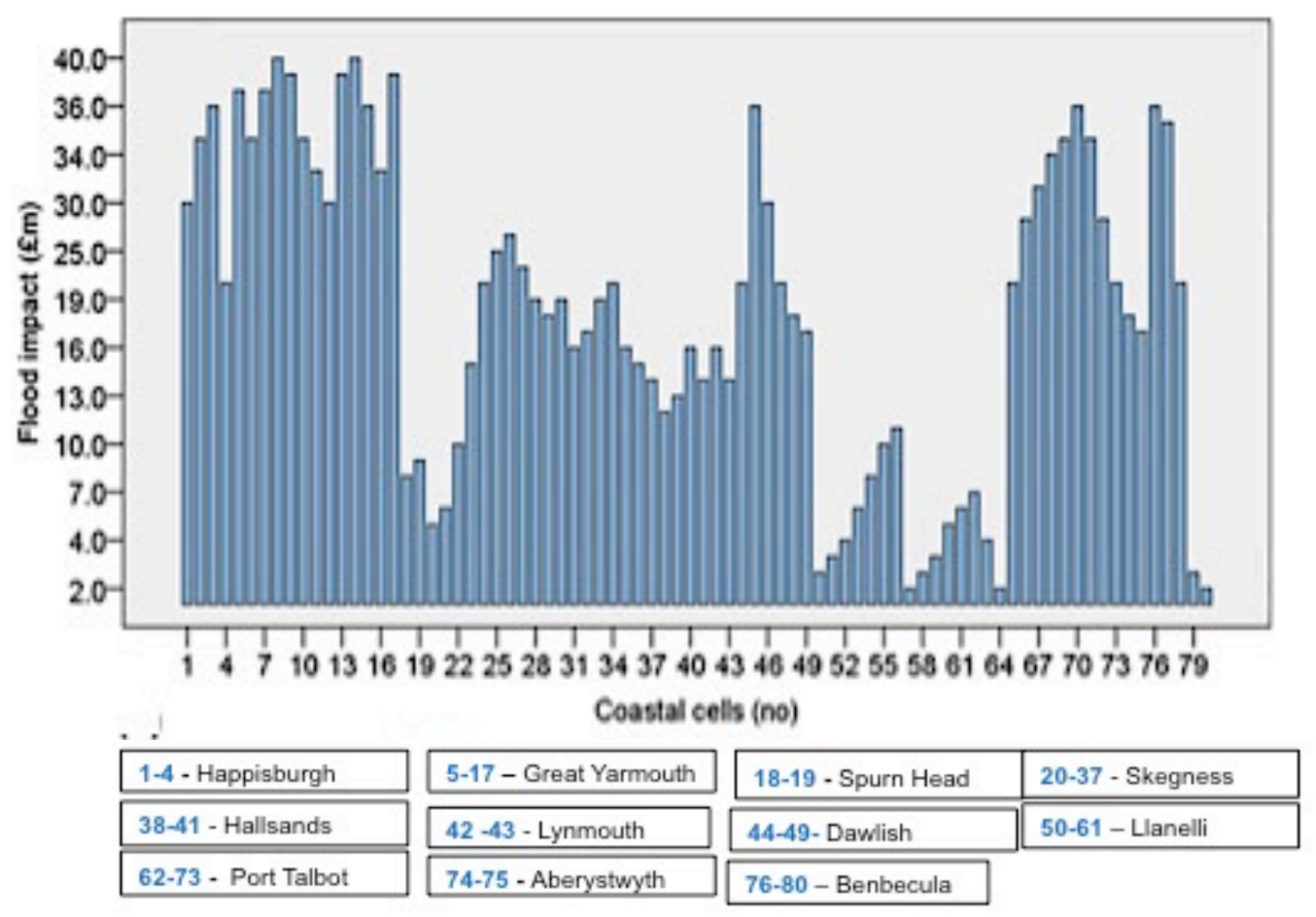

Figure 8.17: Flood Impact (£M- $£ B$ ) 
Table 8.7: Flood impact economic assessment

\begin{tabular}{|c|c|c|c|c|c|}
\hline $\begin{array}{c}\text { Coastal } \\
\text { Cell }\end{array}$ & Coastal Site & $\begin{array}{l}\text { Flood Impact } \\
\text { (£Million) }\end{array}$ & $\begin{array}{c}\text { Coastal } \\
\text { Cell }\end{array}$ & Coastal Site & $\begin{array}{c}\text { Flood } \\
\text { Impact } \\
\text { (£Million) }\end{array}$ \\
\hline 1 & Happisburgh & 30 & 41 & Hallsands & 14 \\
\hline 2 & Happisburgh & 35 & 42 & Lynmouth & 16 \\
\hline 3 & Happisburgh & 36 & 43 & Lynmouth & 14 \\
\hline 4 & Happisburgh & 20 & 44 & Dawlish & 20 \\
\hline 5 & Great Yarmouth & 37 & 45 & Dawlish & 36 \\
\hline 6 & Great Yarmouth & 35 & 46 & Dawlish & 30 \\
\hline 7 & Great Yarmouth & 37 & 47 & Dawlish & 20 \\
\hline 8 & Great Yarmouth & 40 & 48 & Dawlish & 18 \\
\hline 9 & Great Yarmouth & 38 & 49 & Dawlish & 17 \\
\hline 10 & Great Yarmouth & 35 & 50 & Llanelli & 3 \\
\hline 11 & Great Yarmouth & 32 & 51 & Llanelli & 3.2 \\
\hline 12 & Great Yarmouth & 30 & 52 & Llanelli & 4 \\
\hline 13 & Great Yarmouth & 38 & 53 & Llanelli & 6 \\
\hline 14 & Great Yarmouth & 40 & 54 & Llanelli & 9 \\
\hline 15 & Great Yarmouth & 36 & 55 & Llanelli & 10 \\
\hline 16 & Great Yarmouth & 32 & 56 & Llanelli & 10.5 \\
\hline 17 & Great Yarmouth & 38 & 57 & Llanelli & 2 \\
\hline 18 & Spurn Head & 9 & 58 & Llanelli & 3 \\
\hline 19 & Spurn Head & 9.5 & 59 & Llanelli & 3.2 \\
\hline 20 & Skegness & 5 & 60 & Llanelli & 5 \\
\hline 21 & Skegness & 6 & 61 & Llanelli & 6 \\
\hline 22 & Skegness & 10 & 62 & Port Talbot & 7 \\
\hline 23 & Skegness & 15 & 63 & Port Talbot & 4 \\
\hline 24 & Skegness & 20 & 64 & Port Talbot & 2 \\
\hline 25 & Skegness & 25 & 65 & Port Talbot & 20 \\
\hline 26 & Skegness & 26 & 66 & Port Talbot & 28 \\
\hline 27 & Skegness & 21 & 67 & Port Talbot & 31 \\
\hline 28 & Skegness & 19 & 68 & Port Talbot & 34 \\
\hline 29 & Skegness & 18 & 69 & Port Talbot & 35 \\
\hline 30 & Skegness & 19 & 70 & Port Talbot & 36 \\
\hline 31 & Skegness & 16 & 71 & Port Talbot & 35 \\
\hline 32 & Skegness & 17 & 72 & Port Talbot & 28 \\
\hline 33 & Skegness & 19 & 73 & Port Talbot & 20 \\
\hline 34 & Skegness & 20 & 74 & Aberystwyth & 18 \\
\hline 35 & Skegness & 16 & 75 & Aberystwyth & 17 \\
\hline 36 & Skegness & 15 & 76 & Benbecula & 36 \\
\hline 37 & Skegness & 14 & 77 & Benbecula & 35.5 \\
\hline 38 & Hallsands & 12 & 78 & Benbecula & 20 \\
\hline 39 & Hallsands & 13 & 79 & Benbecula & 3 \\
\hline 40 & Hallsands & 16 & 80 & Benbecula & 2 \\
\hline
\end{tabular}




\subsection{ECVI values}

Having evaluated the six economic parameters determined in Sections 4.5 and applying them to the 11 selected coastal areas, it is now necessary to assess these results and allocate vulnerability scores, and thereby develop an ECVI. From the descriptive analysis of the six parameters, vulnerability ranges and thresholds given in Table 4.3 will be applied.

\subsubsection{Commercial properties}

Integrating data from Section 8.3.1 with parameter ranges in Table 4.3, ECVI values were determined as shown in Table 8.8. There was significant variation between ECVI values, as the overall mean value for commercial properties was 2.3 , with only one cell at the maximum score of 5 (Great Yarmouth). Fourteen percent of cells exhibited high levels of vulnerability and were allocated scores of 4, and these were mainly concentrated in Great Yarmouth, Port Talbot and Aberystwyth. Most Great Yarmouth cells have high vulnerability scores for commercial properties, while unsurprisingly the lowest vulnerability was recorded at Spurn Head due to lack of commercial infrastructure. ECVI economic threshold parameter scores for commercial properties clearly indicate that both the England and Wales case study sites have high economic vulnerability (Figure 8.18 and Table 8.8).

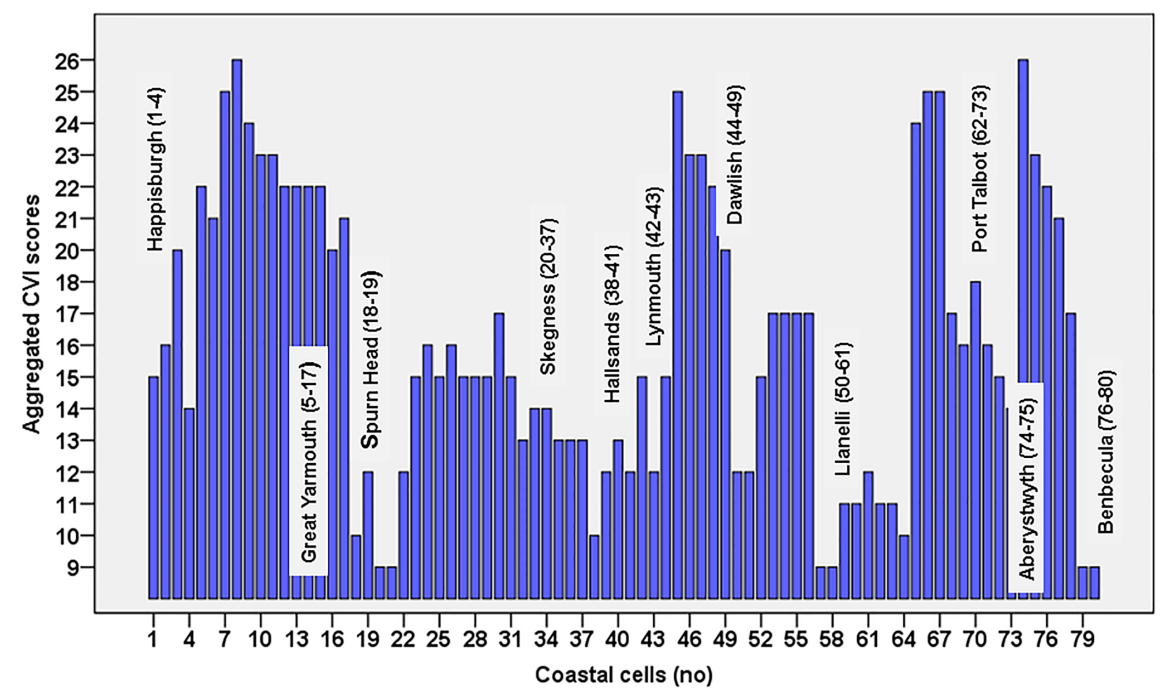

Figure 8.18: ECVI scores for commercial properties 
Table 8.8: ECVI scores for commercial properties

\begin{tabular}{|c|c|c|c|}
\hline Coastal Cell & $\begin{array}{c}\text { Commercial Properties } \\
\text { (£Million) }\end{array}$ & Coastal Cell & $\begin{array}{c}\text { Commercial Properties } \\
\text { (£Million) }\end{array}$ \\
\hline 1 & 2 & 41 & 1 \\
\hline 2 & 1 & 42 & 3 \\
\hline 3 & 3 & 43 & 2 \\
\hline 4 & 1 & 44 & 2 \\
\hline 5 & 4 & 45 & 4 \\
\hline 6 & 4 & 46 & 3 \\
\hline 7 & 4 & 47 & 3 \\
\hline 8 & 5 & 48 & 3 \\
\hline 9 & 4 & 49 & 2 \\
\hline 10 & 4 & 50 & 2 \\
\hline 11 & 4 & 51 & 2 \\
\hline 12 & 4 & 52 & 2 \\
\hline 13 & 4 & 53 & 3 \\
\hline 14 & 3 & 54 & 3 \\
\hline 15 & 3 & 55 & 2 \\
\hline 16 & 3 & 56 & 2 \\
\hline 17 & 3 & 57 & 1 \\
\hline 18 & 1 & 58 & 1 \\
\hline 19 & 1 & 59 & 2 \\
\hline 20 & 1 & 60 & 2 \\
\hline 21 & 1 & 61 & 2 \\
\hline 22 & 2 & 62 & 2 \\
\hline 23 & 3 & 63 & 2 \\
\hline 24 & 3 & 64 & 2 \\
\hline 25 & 2 & 65 & 4 \\
\hline 26 & 2 & 66 & 4 \\
\hline 27 & 2 & 67 & 4 \\
\hline 28 & 2 & 68 & 2 \\
\hline 29 & 2 & 69 & 1 \\
\hline 30 & 2 & 70 & 1 \\
\hline 31 & 2 & 71 & 1 \\
\hline 32 & 2 & 72 & 1 \\
\hline 33 & 2 & 73 & 1 \\
\hline 34 & 2 & 74 & 4 \\
\hline 35 & 2 & 75 & 4 \\
\hline 36 & 3 & 76 & 2 \\
\hline 37 & 2 & 77 & 2 \\
\hline 38 & 0 & 78 & 2 \\
\hline 39 & 1 & 79 & 1 \\
\hline 40 & 1 & 80 & 0 \\
\hline \multicolumn{2}{|c|}{ 1-4 - Happisburgh } & \begin{tabular}{|l|} 
18-19 - Spurn Head \\
\end{tabular} & 20-37-Skegness \\
\hline 38-41 - Hallsands & $42-43$ - Lynmouth & 44-49- Dawlish & 50-61 - Llanelli \\
\hline \multicolumn{2}{|r|}{ 74-75 - Aberystwyth } & $76-80$ - Benbecula & \\
\hline
\end{tabular}




\subsubsection{Residential properties}

As for commercial properties, ECVI values for residential properties varied between locations, with an average score of 2.6, and once again the highest score at Great Yarmouth. Twenty-nine percent of the cells are considered to be extremely vulnerable and were allocated scores of 5, mainly at Great Yarmouth and Dawlish. Conversely, Spurn Head was considered to have low economic vulnerability for residential properties, although overall, ECVI scores clearly indicate that sites in England have high economic vulnerability due to numbers of residential properties (Figure 8.19 and Table 8.9).

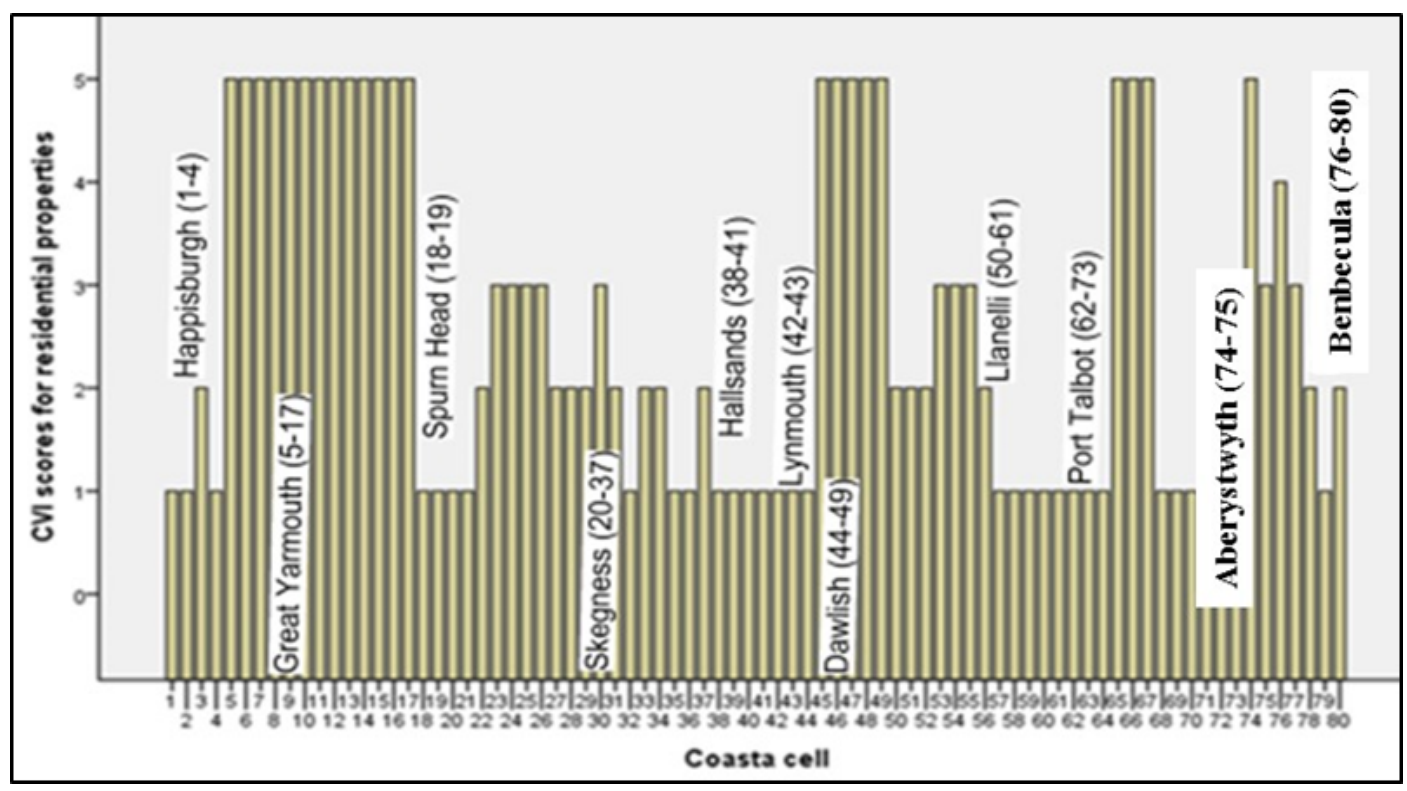

Figure 8.19: ECVI scores for residential properties 
Table 8.9: ECVI scores for residential properties

\begin{tabular}{|c|c|c|c|}
\hline Coastal Cell & $\begin{array}{l}\text { Residential Properties } \\
\text { (£Million) }\end{array}$ & Coastal Cell & $\begin{array}{c}\text { Residential Properties } \\
\text { (£Million) }\end{array}$ \\
\hline 1 & 1 & 41 & 1 \\
\hline 2 & 1 & 42 & 1 \\
\hline 3 & 2 & 43 & 1 \\
\hline 4 & 1 & 44 & 1 \\
\hline 5 & 5 & 45 & 5 \\
\hline 6 & 5 & 46 & 5 \\
\hline 7 & 5 & 47 & 5 \\
\hline 8 & 5 & 48 & 5 \\
\hline 9 & 5 & 49 & 5 \\
\hline 10 & 5 & $\mathbf{5 0}$ & 2 \\
\hline 11 & 5 & 51 & 2 \\
\hline 12 & 5 & 52 & 2 \\
\hline 13 & 5 & 53 & 3 \\
\hline 14 & 5 & 54 & 3 \\
\hline 15 & 5 & 55 & 3 \\
\hline 16 & 5 & 56 & 2 \\
\hline 17 & 5 & 57 & 1 \\
\hline 18 & 1 & 58 & 1 \\
\hline 19 & 1 & 59 & 1 \\
\hline 20 & 1 & 60 & 1 \\
\hline 21 & 1 & 61 & 1 \\
\hline 22 & 2 & 62 & 1 \\
\hline 23 & 3 & 63 & 1 \\
\hline 24 & 3 & 64 & 1 \\
\hline 25 & 3 & 65 & 5 \\
\hline 26 & 3 & 66 & 5 \\
\hline 27 & 2 & 67 & 5 \\
\hline 28 & 2 & 68 & 1 \\
\hline 29 & 2 & 69 & 1 \\
\hline 30 & 3 & 70 & 1 \\
\hline 31 & 2 & 71 & 0 \\
\hline 32 & 1 & 72 & 0 \\
\hline 33 & 2 & 73 & 0 \\
\hline 34 & 2 & 74 & 5 \\
\hline 35 & 1 & 75 & 3 \\
\hline 36 & 1 & 76 & 4 \\
\hline 37 & 2 & 77 & 3 \\
\hline 38 & 1 & 78 & 2 \\
\hline 39 & 1 & 79 & 1 \\
\hline 40 & 1 & 80 & 2 \\
\hline \begin{tabular}{|l|l}
$1-4-$ Happisb \\
\end{tabular} & 5-17 - Great Yarmouth & 18-19 - Spurn Hea & 20-37 - Skegness \\
\hline 38-41 - Hallss & $42-43$ - Lynmouth & 44-49- Dawlish & 50-61 - Llanelli \\
\hline 62-73 - Port & 74-75 - Aberystwyth & $76-80$ - Benbecula & \\
\hline
\end{tabular}




\subsubsection{Economic value of site}

The average parameter score for site economic value was 2.9, with the highest score of 5 was mostly being recorded at Aberystwyth and Port Talbot. Thirty percent of the cells had either high or extremely high vulnerability scores (4 and 5), with most being distributed in Great Yarmouth, Port Talbot, Aberystwyth and Benbecula. ECVI scores for site economic values showed that England, Wales and Scotland have a high economic vulnerability due to their natural environment (Figure 8.20 and Table 8.10).

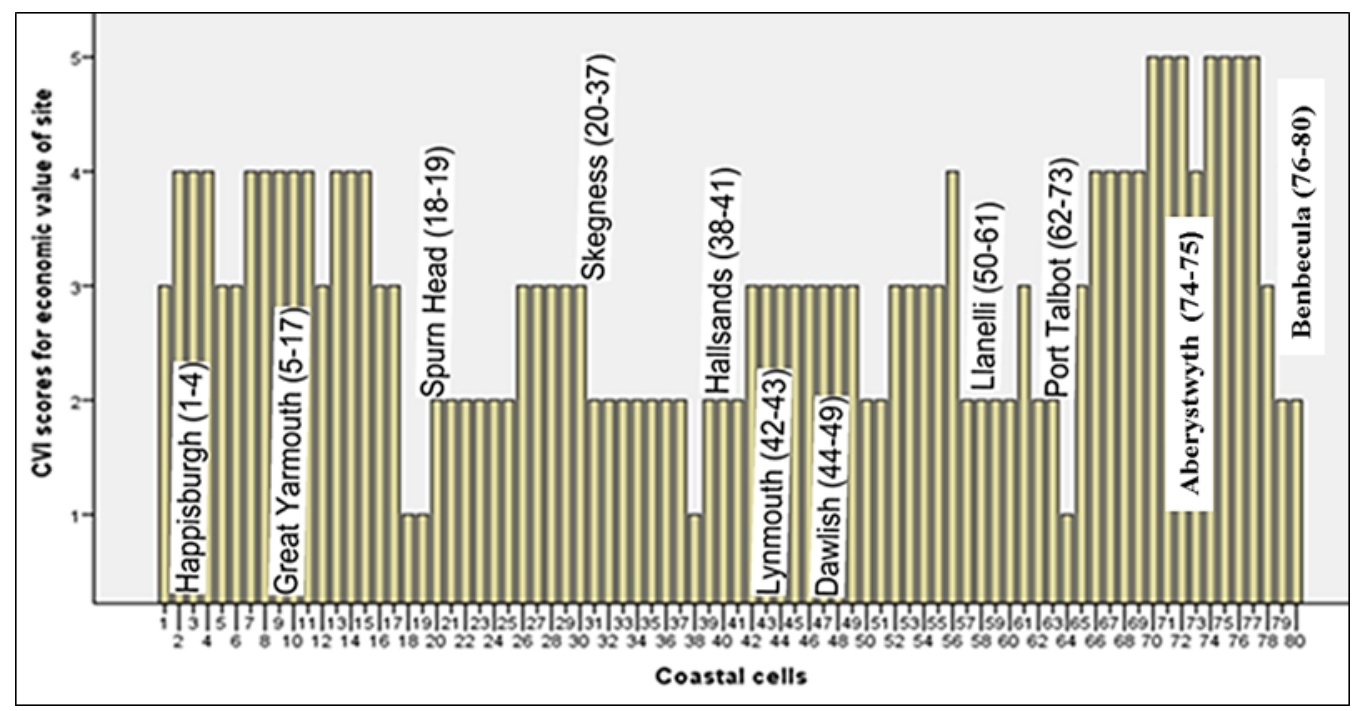

Figure 8.20: ECVI scores for economic value of site 
Table 8.10: ECVI scores for economic value of site

\begin{tabular}{|c|c|c|c|}
\hline Coastal Cell & $\begin{array}{c}\text { Economic Value of Place } \\
\text { (£Million) }\end{array}$ & Coastal Cell & $\begin{array}{c}\text { Economic Value of Place } \\
\text { (£Million) }\end{array}$ \\
\hline 1 & 3 & 41 & 2 \\
\hline 2 & 4 & 42 & 3 \\
\hline 3 & 4 & 43 & 3 \\
\hline 4 & 4 & 44 & 3 \\
\hline 5 & 3 & 45 & 3 \\
\hline 6 & 3 & 46 & 3 \\
\hline 7 & 4 & 47 & 3 \\
\hline 8 & 4 & 48 & 3 \\
\hline 9 & 4 & 49 & 3 \\
\hline 10 & 4 & 50 & 2 \\
\hline 11 & 4 & 51 & 2 \\
\hline 12 & 3 & 52 & 3 \\
\hline 13 & 4 & 53 & 3 \\
\hline 14 & 4 & 54 & 3 \\
\hline 15 & 4 & 55 & 3 \\
\hline 16 & 3 & 56 & 4 \\
\hline 17 & 3 & 57 & 2 \\
\hline 18 & 1 & 58 & 2 \\
\hline 19 & 1 & 59 & 2 \\
\hline 20 & 2 & 60 & 2 \\
\hline 21 & 2 & 61 & 3 \\
\hline 22 & 2 & 62 & 2 \\
\hline 23 & 2 & 63 & 2 \\
\hline 24 & 2 & 64 & 1 \\
\hline 25 & 2 & 65 & 3 \\
\hline 26 & 3 & 66 & 4 \\
\hline 27 & 3 & 67 & 4 \\
\hline 28 & 3 & 68 & 4 \\
\hline 29 & 3 & 69 & 4 \\
\hline 30 & 3 & 70 & 5 \\
\hline 31 & 2 & 71 & 5 \\
\hline 32 & 2 & 72 & 5 \\
\hline 33 & 2 & 73 & 4 \\
\hline 34 & 2 & 74 & 5 \\
\hline 35 & 2 & 75 & 5 \\
\hline 36 & 2 & 76 & 5 \\
\hline 37 & 2 & 77 & 5 \\
\hline 38 & 1 & 78 & 3 \\
\hline 39 & 2 & 79 & 2 \\
\hline 40 & 2 & 80 & 2 \\
\hline 1-4 - Happisburgh & 5-17 - Great Yarmouth & 18-19 - Spurn He: & 20-37-Skegness \\
\hline 38-41 - Hallsands & $42-43$ - Lynmouth & 44-49-Dawlish & 50-61 - Llanelli \\
\hline 62-73 - Port Talbot & 74-75 - Aberystwyth & $76-80$ - Benbecula & \\
\hline
\end{tabular}




\subsubsection{Population}

There was variance between parameter scores for population and an average score of 1.8 was determined (Table 8.11). The highest parameter score of 4 was recorded at Great Yarmouth Aberystwyth and Port Talbot with $42 \%$ of cells scoring 1, most of these being at Hallsands, Spurn Head and Benbecula (Figure 8.21 and Table 8.11).

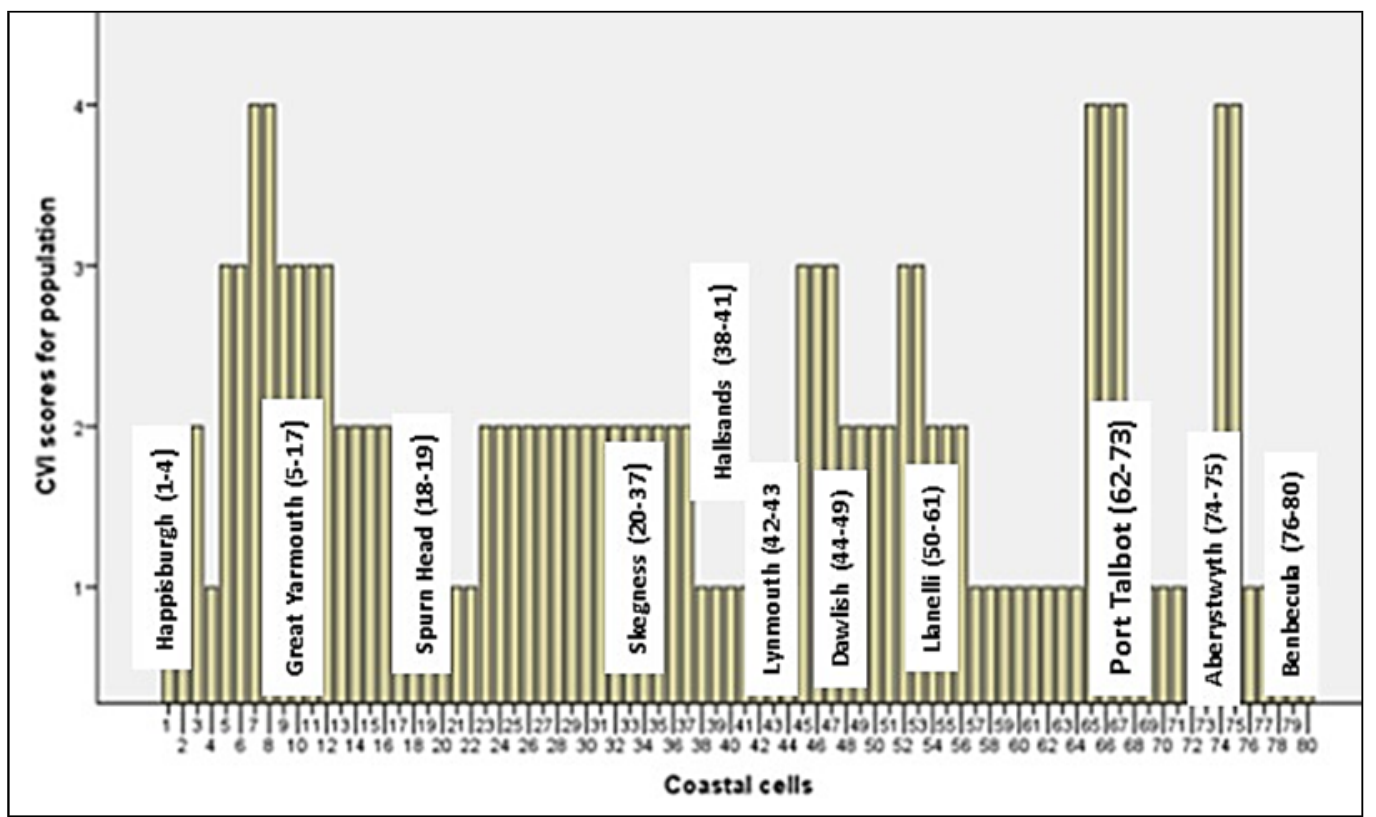

Figure 8.21: ECVI scores for population 
Table 8.11: ECVI scores for population

\begin{tabular}{|c|c|c|c|}
\hline Coastal Cell & $\begin{array}{c}\text { Population } \\
\text { (in Thousands) }\end{array}$ & Coastal Cell & $\begin{array}{c}\text { Population } \\
\text { (in Thousands) }\end{array}$ \\
\hline 1 & 1 & 41 & 1 \\
\hline 2 & 1 & 42 & 1 \\
\hline 3 & 2 & 43 & 1 \\
\hline 4 & 1 & 44 & 1 \\
\hline 5 & 3 & 45 & 3 \\
\hline 6 & 3 & 46 & 3 \\
\hline 7 & 4 & 47 & 3 \\
\hline 8 & 4 & 48 & 2 \\
\hline 9 & 3 & 49 & 2 \\
\hline 10 & 3 & 50 & 2 \\
\hline 11 & 3 & 51 & 2 \\
\hline 12 & 3 & 52 & 3 \\
\hline 13 & 2 & 53 & 3 \\
\hline 14 & 2 & 54 & 2 \\
\hline 15 & 2 & 55 & 2 \\
\hline 16 & 2 & 56 & 2 \\
\hline 17 & 2 & 57 & 1 \\
\hline 18 & 1 & 58 & 1 \\
\hline 19 & 1 & 59 & 1 \\
\hline 20 & 1 & 60 & 1 \\
\hline 21 & 1 & 61 & 1 \\
\hline 22 & 1 & 62 & 1 \\
\hline 23 & 2 & 63 & 1 \\
\hline 24 & 2 & 64 & 1 \\
\hline 25 & 2 & 65 & 4 \\
\hline 26 & 2 & 66 & 4 \\
\hline 27 & 2 & 67 & 4 \\
\hline 28 & 2 & 68 & 1 \\
\hline 29 & 2 & 69 & 1 \\
\hline 30 & 2 & 70 & 1 \\
\hline 31 & 2 & 71 & 1 \\
\hline 32 & 2 & 72 & 1 \\
\hline 33 & 2 & 73 & 1 \\
\hline 34 & 2 & 74 & 4 \\
\hline 35 & 2 & 75 & 4 \\
\hline 36 & 2 & 76 & 1 \\
\hline 37 & 2 & 77 & 1 \\
\hline 38 & 1 & 78 & 1 \\
\hline 39 & 1 & 79 & 1 \\
\hline 40 & 1 & 80 & 1 \\
\hline 1-4 - Happisburgh & 5-17 - Great Yarmouth & 18-19 - Spurn Head & 20-37-Skegness \\
\hline 38-41 - Hallsands & $42-43$ - Lynmouth & 44-49-Dawlish & 50-61 - Llanelli \\
\hline 62-73 - Port Talbot & 74-75 - Aberystwyth & $76-80$ - Benbecula & \\
\hline
\end{tabular}




\subsubsection{Coastal erosion}

The average parameter score for coastal erosion was 3.2 , with $>17 \%$ of the coastal cells assessed in the extremely high range (Table 8.12). Most of these sites were concentrated in Dawlish, Port Talbot, and Benbecula with $20 \%$ of the cells having high vulnerability and given scores of 4, mainly at Happisburgh, Hallsands, Llanelli, and Port Talbot. However, $31 \%$ of the cells were given scores of 2 , indicative of low vulnerability and these were mostly concentrated along the Skegness coastline (Figure 8.22 and Table 8.12).

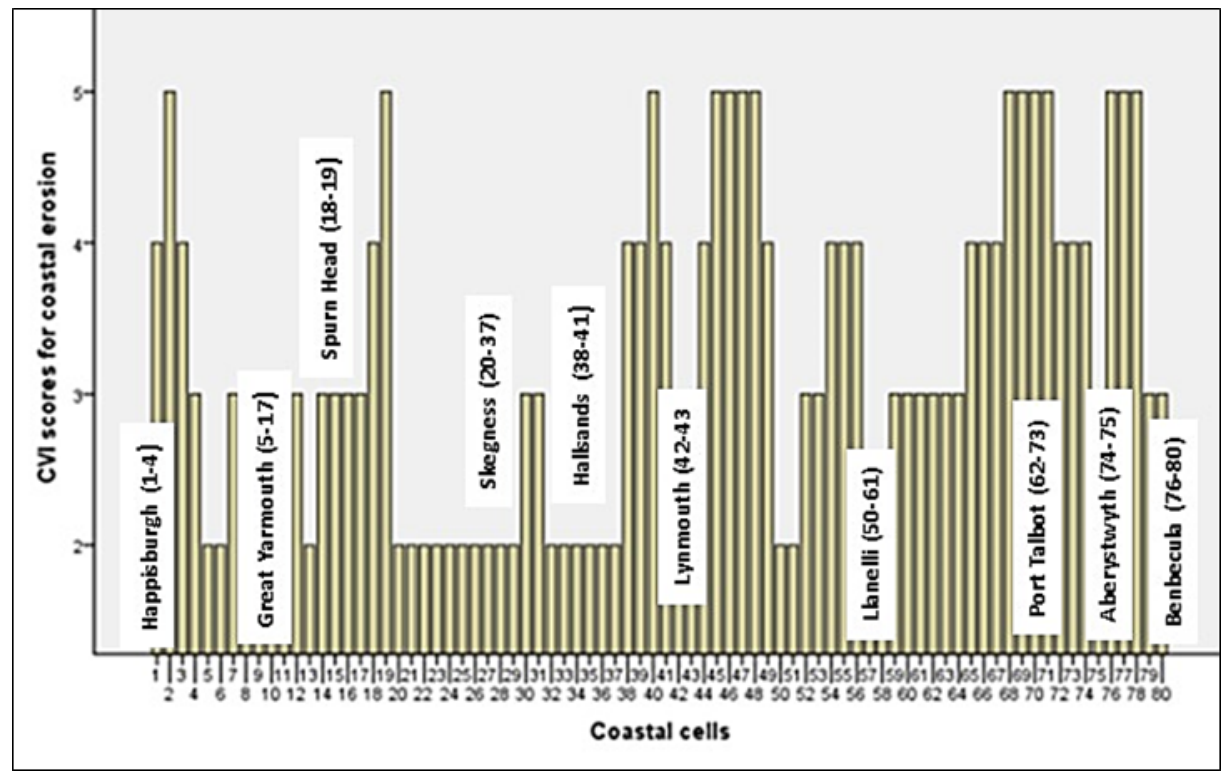

Figure 8.22: ECVI scores for coastal erosion 
Table 8.12: ECVI scores for coastal erosion

\begin{tabular}{|c|c|c|c|}
\hline Coastal Cell & $\begin{array}{l}\text { Coastal Erosion } \\
\text { (in £Millions) }\end{array}$ & Coastal Cell & $\begin{array}{l}\text { Coastal Erosion } \\
\text { (in £Millions) }\end{array}$ \\
\hline 1 & 4 & 41 & 4 \\
\hline 2 & 5 & 42 & 3 \\
\hline 3 & 4 & 43 & 2 \\
\hline 4 & 3 & 44 & 4 \\
\hline 5 & 2 & 45 & 5 \\
\hline 6 & 2 & 46 & 5 \\
\hline 7 & 3 & 47 & 5 \\
\hline 8 & 3 & 48 & 5 \\
\hline 9 & 3 & 49 & 4 \\
\hline 10 & 2 & 50 & 2 \\
\hline 11 & 3 & 51 & 2 \\
\hline 12 & 3 & 52 & 3 \\
\hline 13 & 2 & 53 & 3 \\
\hline 14 & 3 & 54 & 4 \\
\hline 15 & 3 & 55 & 4 \\
\hline 16 & 3 & 56 & 4 \\
\hline 17 & 3 & 57 & 2 \\
\hline 18 & 4 & 58 & 2 \\
\hline 19 & 5 & 59 & 3 \\
\hline 20 & 2 & 60 & 3 \\
\hline 21 & 2 & 61 & 3 \\
\hline 22 & 2 & 62 & 3 \\
\hline 23 & 2 & 63 & 3 \\
\hline 24 & 2 & 64 & 3 \\
\hline 25 & 2 & 65 & 4 \\
\hline 26 & 2 & 66 & 4 \\
\hline 27 & 2 & 67 & 4 \\
\hline 28 & 2 & 68 & 5 \\
\hline 29 & 2 & 69 & 5 \\
\hline 30 & 3 & 70 & 5 \\
\hline 31 & 3 & 71 & 5 \\
\hline 32 & 2 & 72 & 4 \\
\hline 33 & 2 & 73 & 4 \\
\hline 34 & 2 & 74 & 4 \\
\hline 35 & 2 & 75 & 3 \\
\hline 36 & 2 & 76 & 5 \\
\hline 37 & 2 & 77 & 5 \\
\hline 38 & 4 & 78 & 5 \\
\hline 39 & 4 & 79 & 3 \\
\hline 40 & 5 & 80 & 3 \\
\hline 1-4- Happisburgh & 5-17 - Great Yarmouth & 18-19 - Spurn Head & 20-37-Skegness \\
\hline 38-41 - Hallsands & $42-43$ - Lynmouth & 44-49-Dawlish & 50-61 - Llanelli \\
\hline 62-73 - Port Talbot & 74-75 - Aberystwyth & $76-80$ - Benbecula & \\
\hline
\end{tabular}




\subsubsection{Flood impact}

The average ECVI parameter score for flood impact was 3.5 (Table 8.13), indicative of $>$ $18 \%$ of the coastal cells, mostly concentrated in Great Yarmouth and Benbecula, having extremely high vulnerability. Forty-five percent of the cells were assessed as high vulnerability with scores of 4 and these were mainly concentrated in Happisburgh, Skegness, Dawlish, Port Talbot, and Aberystwyth. As well as having two sites scored as 5, the lowest score of 1 was also recorded at Benbecula. While, ECVI scores for the flood impact parameter indicate high economic vulnerability in a number of the English and Welsh case studies, Benbecula scores were due to it being a low lying island (Figure 8.23 and Table $8.13)$.

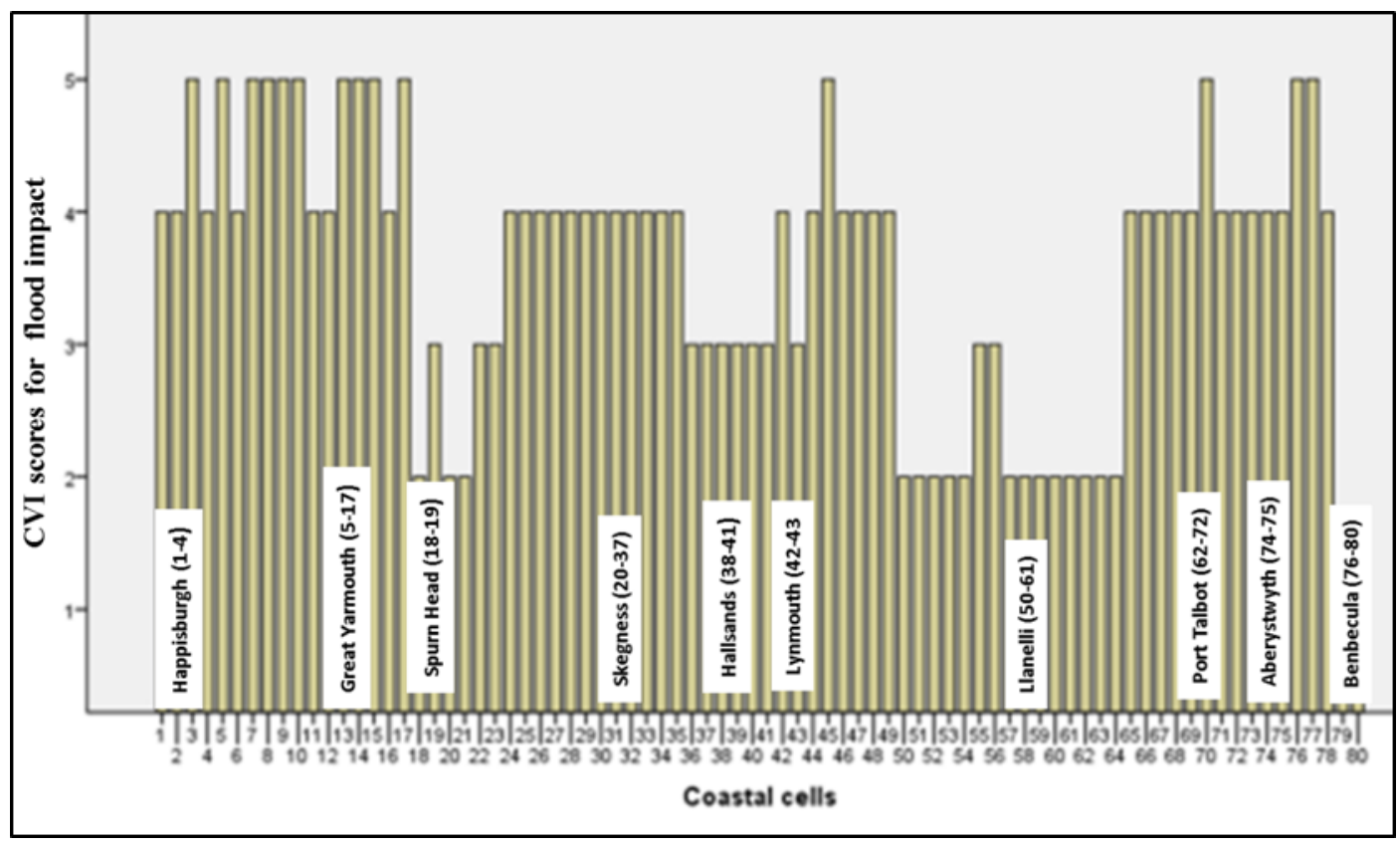

Figure 8.23: ECVI scores for flood impact 
Table 8.13: ECVI scores for flood impact

\begin{tabular}{|c|c|c|c|}
\hline Coastal Cell & $\begin{array}{l}\text { Flood Impact } \\
\text { (in £million) }\end{array}$ & Coastal Cell & $\begin{array}{l}\text { Flood Impact } \\
\text { (in £million) }\end{array}$ \\
\hline 1 & 4 & 41 & 3 \\
\hline 2 & 4 & 42 & 4 \\
\hline 3 & 5 & 43 & 3 \\
\hline 4 & 4 & 44 & 4 \\
\hline 5 & 5 & 45 & 5 \\
\hline 6 & 4 & 46 & 4 \\
\hline 7 & 5 & 47 & 4 \\
\hline 8 & 5 & 48 & 4 \\
\hline 9 & 5 & 49 & 4 \\
\hline 10 & 5 & 50 & 2 \\
\hline 11 & 4 & 51 & 2 \\
\hline 12 & 4 & 52 & 2 \\
\hline 13 & 5 & 53 & 2 \\
\hline 14 & 5 & 54 & 2 \\
\hline 15 & 5 & 55 & 3 \\
\hline 16 & 4 & 56 & 3 \\
\hline 17 & 5 & 57 & 2 \\
\hline 18 & 2 & 58 & 2 \\
\hline 19 & 3 & 59 & 2 \\
\hline 20 & 2 & 60 & 2 \\
\hline 21 & 2 & 61 & 2 \\
\hline 22 & 3 & 62 & 2 \\
\hline 23 & 3 & 63 & 2 \\
\hline 24 & 4 & 64 & 2 \\
\hline 25 & 4 & 65 & 4 \\
\hline 26 & 4 & 66 & 4 \\
\hline 27 & 4 & 67 & 4 \\
\hline 28 & 4 & 68 & 4 \\
\hline 29 & 4 & 69 & 4 \\
\hline 30 & 4 & 70 & 5 \\
\hline 31 & 4 & 71 & 4 \\
\hline 32 & 4 & 72 & 4 \\
\hline 33 & 4 & 73 & 4 \\
\hline 34 & 4 & 74 & 4 \\
\hline 35 & 4 & 75 & 4 \\
\hline 36 & 3 & 76 & 5 \\
\hline 37 & 3 & 77 & 5 \\
\hline 38 & 3 & 78 & 4 \\
\hline 39 & 3 & 79 & 1 \\
\hline 40 & 3 & 80 & 1 \\
\hline 1-4 - Happisburgh & 5-17 - Great Yarmouth & \begin{tabular}{|l} 
18-19 - Spurn Head \\
\end{tabular} & 20-37-Skegness \\
\hline 38-41 - Hallsands & $42-43$ - Lynmouth & 44-49-Dawlish & 50-61 - Llanelli \\
\hline 62-73- Port Talbot & 74-75 - Aberystwyth & $76-80$ - Benbecula & \\
\hline
\end{tabular}




\subsection{ECVI evaluation}

The economic analysis undertaken in Section 8.4 obtained a parameter score for each of the 80 coastal cells for commercial properties, residential properties, and economic value of site, coastal erosion and flood event impact. Consequently, parameter values were combined for each site as per the methodology of Phillips and House (2009) for a scenic parameters and Phillips et al. (2007) for physical and human use parameters in Function Analysis. Consequently, Table 8.14 shows the accumulated parameter scores taken from Tables 8.8, 8.9, 8.10, 8.12 and 8.13 for each coastal cell. Population was also considered (Table 8.11) but these parameters will be utilised later in the analysis. 
Table 8.14: Cumulative ECVI scores

\begin{tabular}{|c|c|c|c|}
\hline Coastal Cell & ECVI Score & Coastal Cell & ECVI Score \\
\hline 1 & 15 & 41 & 12 \\
\hline 2 & 15 & 42 & 15 \\
\hline 3 & 20 & 43 & 12 \\
\hline 4 & 14 & 44 & 15 \\
\hline 5 & 22 & 45 & 25 \\
\hline 6 & 21 & 46 & 23 \\
\hline 7 & 25 & 47 & 23 \\
\hline 8 & 26 & 48 & 22 \\
\hline 9 & 24 & 49 & 20 \\
\hline 10 & 23 & 50 & 12 \\
\hline 11 & 23 & 51 & 12 \\
\hline 12 & 22 & 52 & 16 \\
\hline 13 & 22 & 53 & 17 \\
\hline 14 & 22 & 54 & 17 \\
\hline 15 & 22 & 55 & 17 \\
\hline 16 & 20 & 56 & 17 \\
\hline 17 & 21 & 57 & 9 \\
\hline 18 & 10 & 58 & 9 \\
\hline 19 & 12 & 59 & 11 \\
\hline 20 & 9 & 60 & 11 \\
\hline 21 & 9 & 61 & 12 \\
\hline 22 & 12 & 62 & 11 \\
\hline 23 & 15 & 63 & 11 \\
\hline 24 & 16 & 64 & 10 \\
\hline 25 & 15 & 65 & 24 \\
\hline 26 & 16 & 66 & 25 \\
\hline 27 & 15 & 67 & 25 \\
\hline 28 & 15 & 68 & 17 \\
\hline 29 & 15 & 69 & 16 \\
\hline 30 & 17 & 70 & 18 \\
\hline 31 & 15 & 71 & 16 \\
\hline 32 & 13 & 72 & 15 \\
\hline 33 & 14 & 73 & 14 \\
\hline 34 & 14 & 74 & 26 \\
\hline 35 & 13 & 75 & 23 \\
\hline 36 & 13 & 76 & 22 \\
\hline 37 & 13 & 77 & 21 \\
\hline 38 & 10 & 78 & 17 \\
\hline 39 & 12 & 79 & 9 \\
\hline 40 & 13 & 80 & 9 \\
\hline 1-4 - Happisburgh & 5-17 - Great Yarmouth & 18-19 - Spurn Head & 20-37 - Skegness \\
\hline 38-41 - Hallsands & $42-43$ - Lynmouth & 44-49-Dawlish & 50-61 - Llanelli \\
\hline 62-73 - Port Talbot & 74-75 - Aberystwyth & $76-80$ - Benbecula & \\
\hline
\end{tabular}




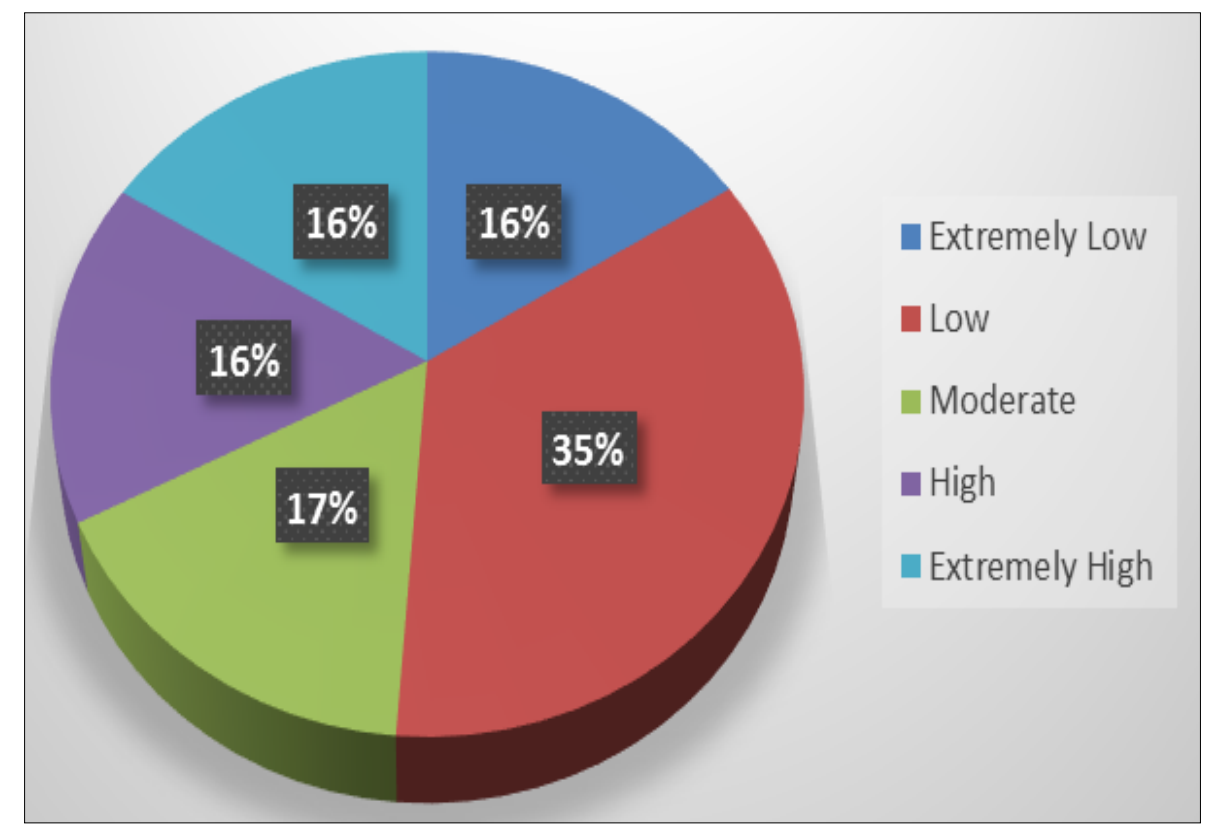

Figure 8.24: Percentage distribution of ECVI categories

A considerable variance exists between the coastal cells and cumulative ECVI parameter scores. The average ECVI score was 16.4, with the highest score of 26 recorded at Great Yarmouth and Aberystwyth coasts and the lowest being 9, recorded in six cells at Skegness, Llanelli and Benbecula (Table 8.14). However, more than $16 \%$ of cells fall into the extremely high category with a further $16 \%$ having high economic vulnerability. Thirty-five percent of cells fall into the lower category, with $16 \%$ belonging to extremely low categories. Figure 8.24 graphically shows the percentage distribution of ECVI categories defined in Table 4.4. This is important for helping decision-makers assess economic vulnerability against physical vulnerability; for example, coastal areas may have high physical vulnerability but low economic consequences regarding loss. The significance of this high/low vulnerability will be discussed later in Chapter 9.

Figure 8.25 represents the distribution of economic vulnerability by coastal cell and location and cumulative ECVI scores clearly show that Great Yarmouth is highly vulnerable in terms of economic risk and parts of the Llanelli and Benbecula coastlines have extremely low economic vulnerability (Figure 8.25 and Table 8.14). 


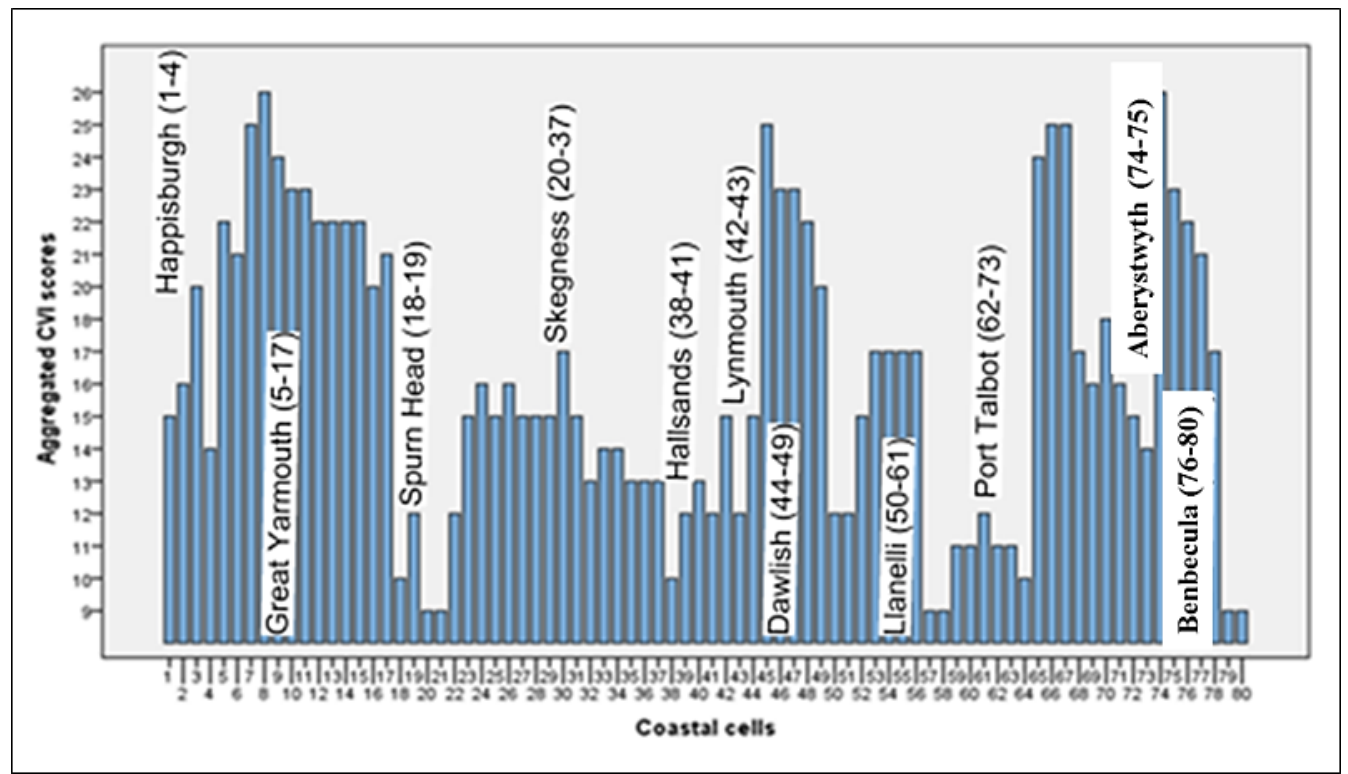

Figure 8.25: Coastal Cells and Cumulative ECVI

Although Table 8.14 indicates cumulative ECVI by coastal cell, and Figure 8.25 identifies location by coastal cells, the next stage requires a basis for comparison between coastal locations. Consequently, mean ECVI values were determined from Table 8.14 and Figure 8.25 for each coastal location. For example, Happisburgh is represented by coastal cells 1 to 4 (Table 8.14) and the ECVI for each km cell was added together i.e. $15+15+20+14=64$. This was then averaged to get a mean ECVI value for Happisburgh, i.e. $64 / 4=16$. Data was entered in Table 8.15 and the process replicated for all eleven coastal locations. Effectively, it could also be considered as a mean ECVI per $\mathrm{km}$ of coastline. 
Table 8.15: Cumulative and mean ECVI scores

\begin{tabular}{|c|c|c|c|c|c|}
\hline $\begin{array}{c}\text { Coastal } \\
\text { Cell }\end{array}$ & Coastal Site & $\begin{array}{l}\text { Number } \\
\text { of Sections }\end{array}$ & $\begin{array}{c}\text { Coastal } \\
\text { Cell }\end{array}$ & Coastal Site & $\begin{array}{c}\text { Number } \\
\text { Of Sections }\end{array}$ \\
\hline 1 & Happisburgh & \multirow{4}{*}{$\begin{array}{c}4 \text { coastal cells } \\
\qquad(1-4) \\
\text { Total ECVI score }= \\
64 \\
\text { Mean Happisburgh } \\
\text { ECVI }=64 / 4=16\end{array}$} & 41 & Hallsands & \\
\hline 2 & Happisburgh & & 42 & Lynmouth & \multirow[b]{2}{*}{$\begin{array}{c}2 \text { coastal cells } \\
(42-43) \\
\text { Total ECVI score }= \\
27 \\
\text { Mean Lynmouth } \\
\text { ECVI }=27 / 2=13.5\end{array}$} \\
\hline 3 & Happisburgh & & 43 & Lynmouth & \\
\hline 4 & Happisburgh & & 44 & Dawlish & \multirow{6}{*}{$\begin{array}{c}6 \text { coastal cells } \\
(44-49) \\
\text { Total ECVI score }= \\
128 \\
\text { Mean Dawlish } \\
\text { ECVI }=128 / 6= \\
21.3\end{array}$} \\
\hline 5 & Great Yarmouth & \multirow{6}{*}{$\begin{array}{l}13 \text { coastal cells } \\
(5-17) \\
\text { otal ECVI score = } \\
293\end{array}$} & 45 & Dawlish & \\
\hline 6 & Great Yarmouth & & 46 & Dawlish & \\
\hline 7 & Great Yarmouth & & 47 & Dawlish & \\
\hline 8 & Great Yarmouth & & 48 & Dawlish & \\
\hline 9 & Great Yarmouth & & 49 & Dawlish & \\
\hline 10 & Great Yarmouth & & 50 & Llanelli & \multirow{10}{*}{$\begin{array}{c}12 \text { coastal cells } \\
(50-61) \\
\text { Total ECVI score }= \\
160 \\
\text { Mean Llanelli } \\
\text { ECVI }=160 / 12= \\
13.3\end{array}$} \\
\hline 11 & Great Yarmouth & \multirow{7}{*}{$\begin{array}{c}\text { Mean Great } \\
\text { Yarmouth ECVI = } \\
293 / 13=22.5\end{array}$} & 51 & Llanelli & \\
\hline 12 & Great Yarmouth & & 52 & Llanelli & \\
\hline 13 & Great Yarmouth & & 53 & Llanelli & \\
\hline 14 & Great Yarmouth & & 54 & Llanelli & \\
\hline 15 & Great Yarmouth & & 55 & Llanelli & \\
\hline 16 & Great Yarmouth & & 56 & Llanelli & \\
\hline 17 & Great Yarmouth & & 57 & Llanelli & \\
\hline 18 & Spurn Head & \multirow[b]{2}{*}{$\begin{array}{c}2 \text { coastal cells } \\
(18-19) \\
\text { Total ECVI score }= \\
22 \\
\text { Mean Spurn Head } \\
\text { ECVI }=22 / 2=11\end{array}$} & 58 & Llanelli & \\
\hline 19 & Spurn Head & & 59 & Llanelli & \\
\hline 20 & Skegness & \multirow{9}{*}{$\begin{array}{c}18 \text { coastal cells } \\
(20-37)\end{array}$} & 60 & Llanelli & \\
\hline 21 & Skegness & & 61 & Llanelli & \\
\hline 22 & Skegness & & 62 & Port Talbot & \multirow{6}{*}{$\begin{array}{c}12 \text { coastal cells } \\
(62-73) \\
\text { Total ECVI score }= \\
202\end{array}$} \\
\hline 23 & Skegness & & 63 & Port Talbot & \\
\hline 24 & Skegness & & 64 & Port Talbot & \\
\hline 25 & Skegness & & 65 & Port Talbot & \\
\hline 26 & Skegness & & 66 & Port Talbot & \\
\hline 27 & Skegness & & 67 & Port Talbot & \\
\hline 28 & Skegness & & 68 & Port Talbot & \multirow{6}{*}{$\begin{array}{c}\text { Mean Port Talbot } \\
\text { ECVI }=202 / 12= \\
16.8\end{array}$} \\
\hline 29 & Skegness & \multirow{3}{*}{$\begin{array}{c}\text { Total ECVI score }= \\
249\end{array}$} & 69 & Port Talbot & \\
\hline 30 & Skegness & & 70 & Port Talbot & \\
\hline 31 & Skegness & & 71 & Port Talbot & \\
\hline 32 & Skegness & \multirow{6}{*}{$\begin{array}{l}\text { Mean Skegness ECVI } \\
\quad=249 / 18=13.8\end{array}$} & 72 & Port Talbot & \\
\hline 33 & Skegness & & 73 & Port Talbot & \\
\hline 34 & Skegness & & 74 & Aberystwyth & \multirow[b]{2}{*}{$\begin{array}{c}2 \text { coastal cells } \\
(74-75) \\
\text { Total ECVI score }= \\
49 \\
\text { Mean Aberystwyth } \\
\text { ECVI }=49 / 2=24.5\end{array}$} \\
\hline 35 & Skegness & & 75 & Aberystwyth & \\
\hline 36 & Skegness & & 76 & Benbecula & \multirow{4}{*}{$\begin{array}{l}5 \text { coastal cells } \\
(76-80)\end{array}$} \\
\hline 37 & Skegness & & 77 & Benbecula & \\
\hline 38 & Hallsands & \multirow{2}{*}{$\begin{array}{c}4 \text { coastal cells } \\
(38-41)\end{array}$} & 78 & Benbecula & \\
\hline & & & & & \\
\hline
\end{tabular}


[PHD THESIS]

April 2017

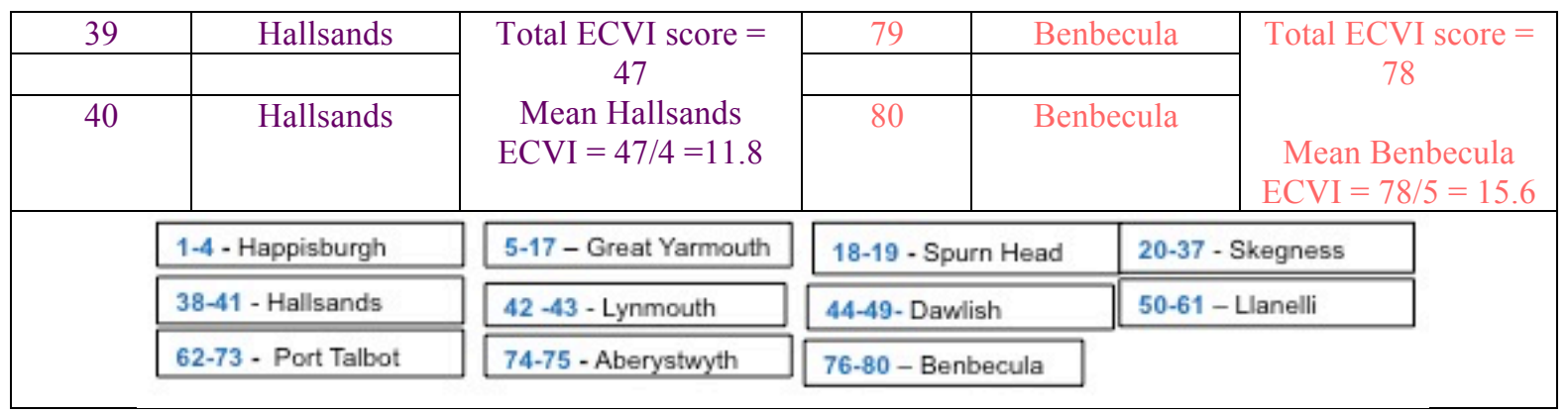




\subsection{Economic costs/values}

Tables 8.2, 8.3, 8.4, 8.6 and 8.7 identified the economic value/cost for each coastal cell according to commercial property, residential property, economic value of site, erosion and flood impact. These are summed for each coastal cell and results are shown in Table 8.16. The total value for all coastal locations $>£ 22 \mathrm{~B}$, which means the selected sites represent a vulnerability value/cost $>£ 22$ billion.

Table 8.16: Economic cost/value of coastal cells

\begin{tabular}{|c|c|c|c|c|c|c|}
\hline $\begin{array}{c}\text { Coastal } \\
\text { Cell }\end{array}$ & $\begin{array}{c}\text { Commercial } \\
\text { Property } \\
\mathfrak{£ M}\end{array}$ & $\begin{array}{c}\text { Residential } \\
\text { Property } \\
\text { fM }\end{array}$ & $\begin{array}{c}\text { Economic } \\
\text { Value of Site } \\
\mathfrak{£ M}\end{array}$ & $\begin{array}{c}\text { Erosion } \\
£ M\end{array}$ & $\begin{array}{c}\text { Flood Impact } \\
£ M\end{array}$ & $\begin{array}{c}\text { Value of } \\
\text { Coastal } \\
\text { Cell } \\
£ M \\
\end{array}$ \\
\hline 1 & 3 & 8 & 60 & 6 & 30 & 107 \\
\hline 2 & 1.2 & 4 & 110 & 20 & 35 & 170.2 \\
\hline 3 & 13.5 & 50 & 130 & 7 & 36 & 236.5 \\
\hline 4 & 1.5 & 20 & 120 & 5 & 20 & 166.5 \\
\hline 5 & 35 & 200 & 80 & 2.5 & 37 & 354.5 \\
\hline 6 & 38 & 300 & 100 & 2 & 35 & 475 \\
\hline 7 & 42 & 320 & 120 & 3 & 37 & 522 \\
\hline 8 & 105 & 600 & 120 & 3 & 40 & 868 \\
\hline 9 & 55 & 500 & 130 & 2.6 & 38 & 725.6 \\
\hline 10 & 45 & 440 & 135 & 2 & 35 & 657 \\
\hline 11 & 49 & 600 & 130 & 3.5 & 32 & 814.5 \\
\hline 12 & 31 & 400 & 100 & 4 & 30 & 565 \\
\hline 13 & 33 & 300 & 110 & 2.5 & 38 & 483.5 \\
\hline 14 & 28 & 240 & 120 & 3 & 40 & 431 \\
\hline 15 & 26 & 220 & 110 & 3.5 & 36 & 395.5 \\
\hline 16 & 22 & 200 & 100 & 2.6 & 32 & 356.6 \\
\hline 17 & 22 & 190 & 100 & 2.6 & 38 & 352.6 \\
\hline 18 & 0.2 & 0.2 & 2 & 5.1 & 9 & 16.5 \\
\hline 19 & 0.25 & 0.2 & 3 & 9.1 & 9.5 & 22.05 \\
\hline 20 & 1 & 5 & 20 & 0.3 & 5 & 31.3 \\
\hline 21 & 1.5 & 8 & 22 & 0.4 & 6 & 37.9 \\
\hline 22 & 10 & 54 & 28 & 0.5 & 10 & 102.5 \\
\hline 23 & 14 & 121 & 35 & 0.8 & 15 & 185.8 \\
\hline 24 & 12 & 135 & 40 & 1 & 20 & 208 \\
\hline 25 & 10 & 120 & 50 & 1 & 25 & 206 \\
\hline 26 & 9 & 94 & 60 & 1.2 & 26 & 190.2 \\
\hline 27 & 8 & 67 & 68 & 1.8 & 21 & 165.8 \\
\hline 28 & 9 & 75 & 65 & 2.2 & 19 & 170.2 \\
\hline 29 & 10 & 63 & 60 & 2.5 & 18 & 153.5 \\
\hline 30 & 8 & 81 & 55 & 3 & 19 & 166 \\
\hline 31 & 8.5 & 67 & 50 & 2.8 & 16 & 144.3 \\
\hline
\end{tabular}




\begin{tabular}{|c|c|c|c|c|c|c|}
\hline 32 & 7.5 & 27 & 30 & 2 & 17 & 83.5 \\
\hline 33 & 9 & 32 & 35 & 1.5 & 19 & 96.5 \\
\hline 34 & 10 & 40 & 40 & 1 & 20 & 111 \\
\hline 35 & 9 & 26.6 & 30 & 0.8 & 16 & 82.4 \\
\hline 36 & 12 & 26 & 25 & 0.6 & 15 & 78.6 \\
\hline 37 & 7.5 & 40 & 20 & 0.6 & 14 & 82.1 \\
\hline 38 & 0 & 0.9 & 5 & 7 & 12 & 24.9 \\
\hline 39 & 0.1 & 0.6 & 20 & 8 & 13 & 41.7 \\
\hline 40 & 1 & 11 & 50 & 10 & 16 & 88 \\
\hline 41 & 0.5 & 2 & 30 & 9 & 14 & 55.5 \\
\hline 42 & 28 & 25 & 90 & 3 & 16 & 162 \\
\hline 43 & 9 & 19 & 80 & 2 & 14 & 124 \\
\hline 44 & 5 & 26 & 60 & 9 & 20 & 120 \\
\hline 45 & 40 & 598 & 80 & 11 & 36 & 765 \\
\hline 46 & 30 & 468 & 100 & 20 & 30 & 648 \\
\hline 47 & 16 & 390 & 90 & 12 & 20 & 528 \\
\hline 48 & 18 & 208 & 85 & 10 & 18 & 339 \\
\hline 49 & 10 & 130 & 80 & 9 & 17 & 246 \\
\hline 50 & 6 & 32 & 20 & 2 & 3 & 63 \\
\hline 51 & 7.2 & 40 & 30 & 2.2 & 3.2 & 82.6 \\
\hline 52 & 9.6 & 48 & 55 & 3 & 4 & 119.6 \\
\hline 53 & 12 & 112 & 60 & 4.5 & 6 & 194.5 \\
\hline 54 & 13.2 & 104 & 80 & 6 & 9 & 212.2 \\
\hline 55 & 9.7 & 113 & 100 & 6.5 & 10 & 239.2 \\
\hline 56 & 10.8 & 72 & 120 & 6 & 10.5 & 219.3 \\
\hline 57 & 0.48 & 1.6 & 20 & 1.2 & 2 & 25.28 \\
\hline 58 & 1.2 & 4.8 & 25 & 1 & 3 & 35 \\
\hline 59 & 2.4 & 9.6 & 30 & 3 & 3.2 & 48.2 \\
\hline 60 & 4.8 & 11 & 50 & 4 & 5 & 74.8 \\
\hline 61 & 7.2 & 12.7 & 60 & 4.8 & 6 & 90.7 \\
\hline 62 & 2 & 24 & 25 & 5 & 7 & 63 \\
\hline 63 & 1.5 & 6 & 15 & 4 & 4 & 30.5 \\
\hline 64 & 6 & 12 & 8 & 3 & 2 & 31 \\
\hline 65 & 36 & 540 & 90 & 7 & 20 & 693 \\
\hline 66 & 63 & 780 & 110 & 9 & 28 & 990 \\
\hline 67 & 51 & 504 & 105 & 6 & 31 & 697 \\
\hline 68 & 7 & 6 & 110 & 20 & 34 & 177 \\
\hline 69 & 0.4 & 2.4 & 150 & 18 & 35 & 205.8 \\
\hline 70 & 0.35 & 11.5 & 1000 & 15 & 36 & 1062.85 \\
\hline 71 & 0.1 & 0 & 1000 & 10 & 35 & 1045.1 \\
\hline 72 & 0.04 & 0 & 200 & 8 & 28 & 236.04 \\
\hline 73 & 0.02 & 0 & 150 & 8 & 20 & 178.02 \\
\hline 74 & 66 & 594 & 500 & 6 & 18 & 1184 \\
\hline 75 & 42 & 167 & 300 & 5 & 17 & 531 \\
\hline
\end{tabular}




\begin{tabular}{|c|c|c|c|c|c|c|}
\hline 76 & 6 & 33 & 160 & 10 & 36 & 245 \\
\hline 77 & 4 & 20 & 150 & 9.5 & 35.5 & 219 \\
\hline 78 & 2 & 3.1 & 100 & 10 & 20 & 135.1 \\
\hline 79 & 2 & 3 & 40 & 4 & 3 & 52 \\
\hline 80 & 0 & 0.4 & 20 & 3 & 2 & 25.4 \\
\hline \multicolumn{6}{|c|}{ Economic vulnerability of all coastal cells } & 22362.44 \\
\hline \multicolumn{2}{|c|}{ 1-4 - Happisburgh } & 5-17 - Great Yarmouth & \multicolumn{2}{|c|}{ 18-19 - Spurn Head } & \multicolumn{2}{|l|}{ 20-37-Skegness } \\
\hline \multicolumn{2}{|c|}{ 38-41 - Hallsands } & $42-43$ - Lynmouth & \multicolumn{2}{|c|}{ 44-49- Dawlish } & 50-61 - Llanelli & \\
\hline \multicolumn{2}{|c|}{ 62-73 - Port Talbot } & 74-75 - Aberystwyth & \multicolumn{2}{|c|}{$76-80$ - Benbecula } & & \\
\hline
\end{tabular}

Similar to the determination of mean ECVI values; economic value per km length was calculated for each of the eleven coastal sites. For example, Happisburgh is represented by coastal cells 1 to 4 (Figure 8.25, Table 8.16) and the value of each coastal cell was added together to get a total value for Happisburgh, i.e. $107+170.2+236.5+166.5=£ 680.2 \mathrm{M}$. This was then averaged to obtain a mean value per km length for Happisburgh, i.e. $680.2 / 4=$ $£ 170.05 \mathrm{M} \mathrm{km}^{-1}$. This procedure was replicated for all 11 coastal sites and calculated data was included in Table 8.17. Mean ECVI values from Table 8.15 were also included in the order of most to least vulnerability, and finally, population data from Table 8.5 was transposed for each coastal site to obtain population per $\mathrm{km}\left(\mathrm{km}^{-1}\right)$.

Table 8.17: Site Ranking according to ECVI, including cost/value and population data

\begin{tabular}{|c|c|c|c|}
\hline Coastal Site & $\begin{array}{c}\text { Mean Cost/Value } \\
\left(£ \mathrm{~km}^{-1}\right)\end{array}$ & $\begin{array}{c}\text { Mean Population } \\
\left(\mathrm{No} . \mathrm{km}^{-1}\right)\end{array}$ & $\begin{array}{c}\text { ECVI } \\
\left(\mathrm{km}^{-1}\right)\end{array}$ \\
\hline Aberystwyth & 857.5 & 5300 & 24.5 \\
\hline Great Yarmouth & 538.5 & 3508 & 22.5 \\
\hline Dawlish & 441 & 1883 & 21.3 \\
\hline Port Talbot & 450.8 & 1867 & 16.8 \\
\hline Happisburgh & 170.1 & 332 & 16 \\
\hline Benbecula & 135.3 & 168 & 15.6 \\
\hline Skegness & 129.7 & 651 & 13.8 \\
\hline Lynmouth & 143 & 245 & 13.3 \\
\hline Llanelli & 117 & 1171 & 11.8 \\
\hline Hallsands & 52.5 & 13 & 11 \\
\hline Spurn Head & 19.3 & 25 & \\
\hline
\end{tabular}

The ECVI enabled the ranking of the eleven coastal sites in order of severity of economic vulnerability (Table 8.17 ), and relative site economic vulnerabilities according to ECVI are 
illustrated in Figure 8.26. The eleven sites represent a total economic risk of $£ 22.4 \mathrm{~B}$ under current scenarios (Table 8.16 ), which includes $>50,000$ residential properties $(0.2 \%$ of UK total) and $>6000$ commercial properties $(0.37 \%$ of UK total). Furthermore, approximately 118400 people $(0.2 \%$ of the UK population) are at risk of displacement from flooding, etc.

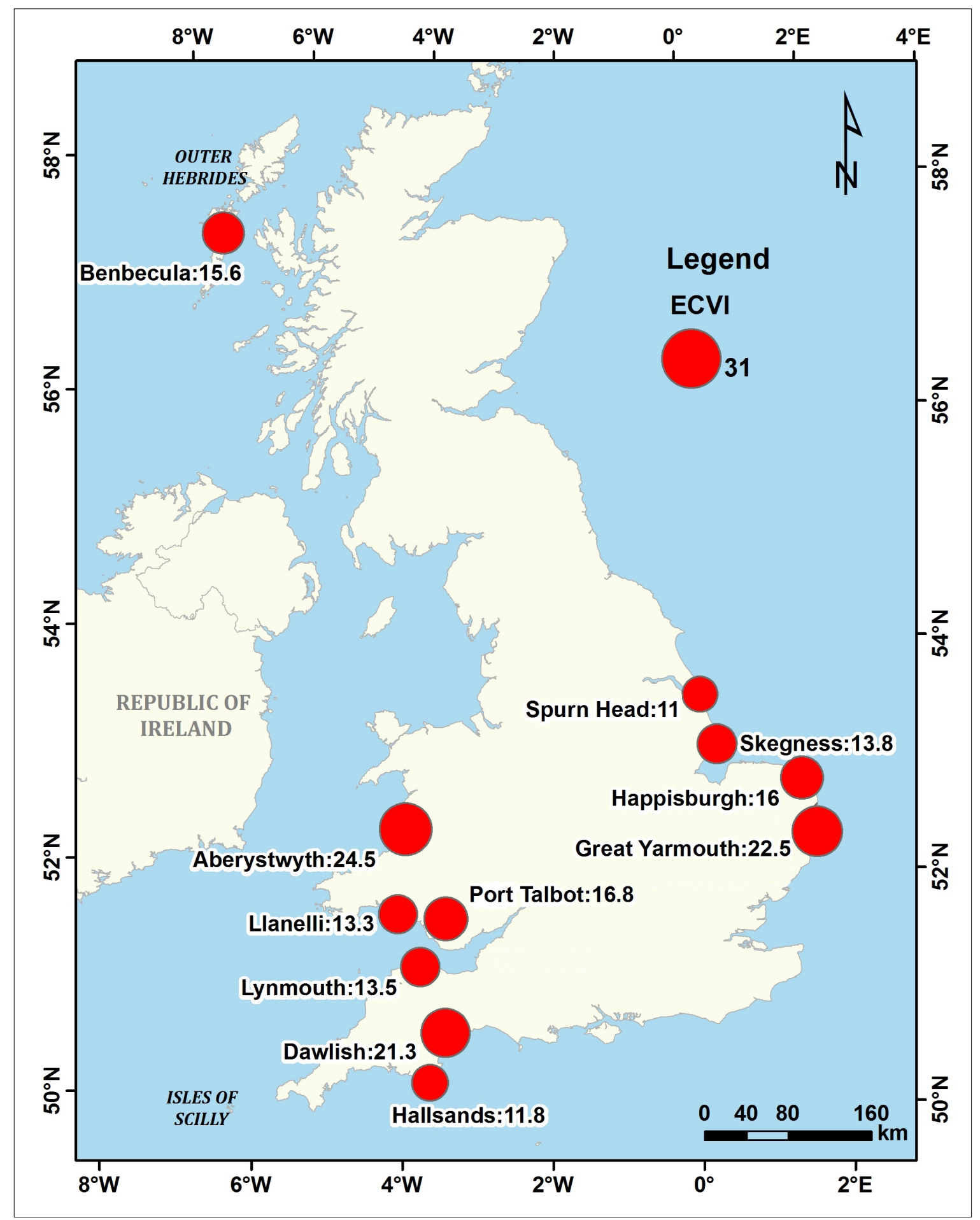

Figure 8.26: Average economic vulnerability according to ECVI 
Table 8.17 clearly shows that Aberystwyth has the highest ECVI, population $\mathrm{km}^{-1}$ and economic vulnerability, and sites with the three highest ECVI scores also have very high relative economic values and populations. Historically, Aberystwyth has been vulnerable to wave attacks and since the turn of the twenty-first century, it has been severely affected by a series of storms with high waves, tides and storm surges, i.e. 2008, 2010, 2013, and 2014. The tidal range is higher than at the other sites with the greatest incidence of waves coming from the southwest, which is also the direction of the most frequent storms. In 2014, a storm struck this area and caused $>£ 1.5 \mathrm{M}$ worth of damage (Ceredigion County Council, 2014) and Figure 8.27 shows storm damage and subsequent remedial works. There is an economic risk of $£ 857.5 \mathrm{M} \mathrm{km}^{-1}$ including 530 commercial properties and 4613 residential properties. There are 10597 inhabitants at risk of displacement from coastal flooding and an ECVI of 24.5 puts Aberystwyth in the 'extremely high vulnerability' range (Table 4.4).

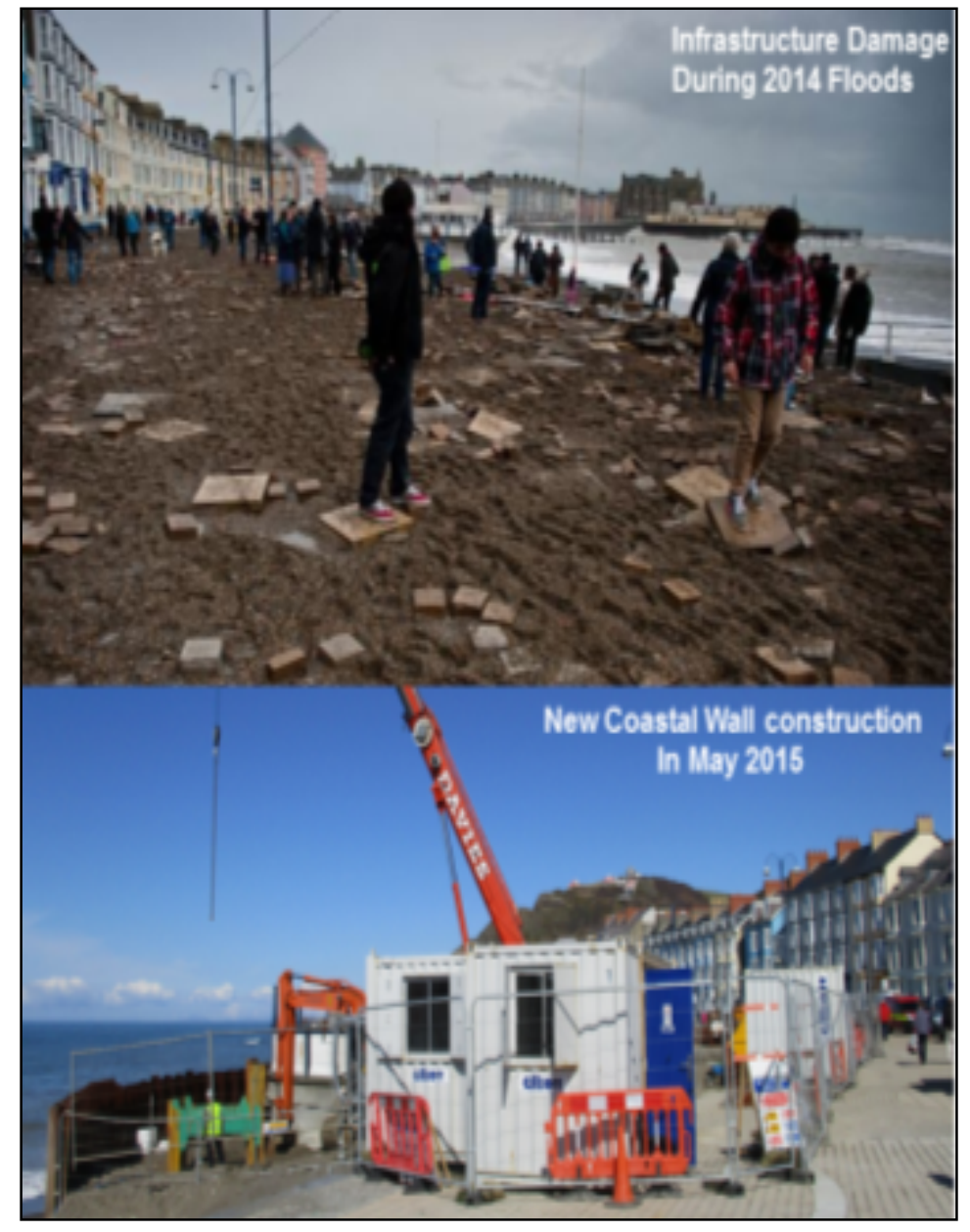

Figure 8.27: Aberystwyth: Coastal damage and consequent defence improvements 
Great Yarmouth is a medium-sized seaport and industrial corridor, as well as a major tourist attraction (Section 4.4). It was the longest frontage considered and results showed it was also in the 'extremely high vulnerability' range (Table 4.4) with an ECVI of 22.5 (Table 8.17). Its economic importance was assessed at $£ 538 \mathrm{M} \mathrm{km}^{-1}$ with a population of $3507 \mathrm{~km}^{-1}$ at risk of displacement from coastal flooding.

Dawlish is very likely to be at constant risk from sea level rise, storms, storm surges and resulting coastal erosion. Infrastructure at Dawlish is very close to the shoreline and therefore has high coastal vulnerability. Recent storm events in 2012, 2013 and 2014 caused billions of pounds worth of damage. The 2014 storm damage shown in Figure 8.28 caused a two month rail closure at a cost of $£ 1.2 \mathrm{~B}$ with resulting repairs costing $£ 35 \mathrm{M}$, making an overall total of $£ 1.235 B$ (Dawson et al., 2016). Dawlish’s ECVI is 21.3 (Table 8.17) giving it a high relative vulnerability score (Table 4.4). Currently, the economic risk includes residential and commercial properties, worth $£ 441 \mathrm{M} \mathrm{km} \mathrm{km}^{-1}$ with a population of approximately $1883 \mathrm{~km}^{-1}$ at risk (Table 8.17 ).

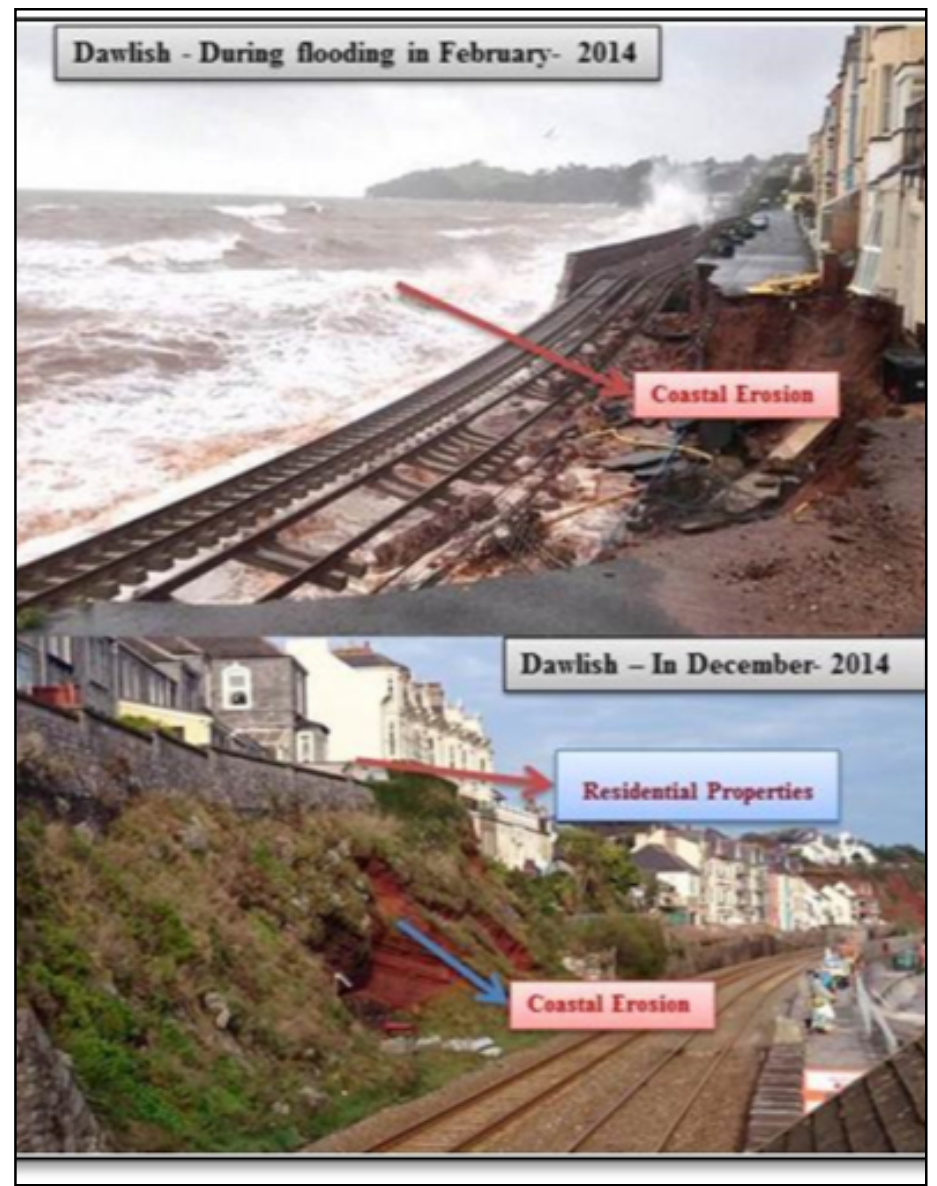

Figure 8.28: Infrastructure damage and flooding at Dawlish (2014) 
Port Talbot is highly industrialised and has significant economic value. Exposed to significant southwesterly storms the Steelworks is protected by revetments made from blast furnace slag. The area is considered to be one of the most economically vulnerable coastal locations although Port Talbot's ECVI of 16.8 (Table 8.17) puts it in the moderate category for its relative vulnerability (Table 4.4). With an approximate population of $1867 \mathrm{~km}^{-1}$ and an economic value of $£ 450.8 \mathrm{M} \mathrm{km}^{-1}$ it was fourth of the eleven sites in terms of economic vulnerability. Happisburgh has experienced severe coastal erosion over many years due to its geology, which provides little resistance to storms and surges. This had led to residential properties being at risk of falling into the sea and homeowners are unable to get insurance (Phillips, 2008). This vulnerability is likely to increase with predicted increases in storm severity meaning the rate of erosion will also increase. Assessment showed that Happisburgh ECVI is 16 (Table 8.17), which puts it in the moderate relative vulnerability category (Table 4.4 ), with a population of $332 \mathrm{~km}^{-1}$ and an economic value of $£ 170.1 \mathrm{M} \mathrm{km}^{-1}$. It is suggested that the ECVI is not higher because the actual number of properties at risk is small in comparison to the total number, i.e. 423 residential and 64 commercial properties.

Benbecula Island was severely affected by a 2005 storm event which caused $>£ 20 \mathrm{M}$ (converted to 2014 rates) worth of infrastructure damage (Dawson et al., 2007). Therefore, following storm events there is an extremely high risk of coastal erosion. Benbecula ECVI was determined as 15.6 (Table 8.17), which puts it on boundary of the moderate/low relative vulnerability categories (Table 4.4), having an economic value/cost of $£ 135.3 \mathrm{M} \mathrm{km}^{-1}$ and a population of $168 \mathrm{~km}^{-1}$. Once again, the relatively low number of residential and commercial properties influenced the site ECVI. The next site in the ranking was Skegness, a popular tourism destination which is considered as one of the best places for holidays, as well as being an ideal place to live for those who are retired (Butler, 2006). Accordingly, Skegness is considered as a highly valuable location from a socio-economic perspective. However, this is currently changing due to unprecedented flooding, rapid changes in weather patterns and rising incidence of storms even in the summer period (Zsamboky et al., 2011; Montreuil and Bullard, 2012). An ECVI score of 13.8 (Table 8.17) puts Skegness in the low vulnerability category (Table 4.4), having an economic value/cost of $£ 129.7 \mathrm{M} \mathrm{km}^{-1}$ and a population of $651 \mathrm{~km}^{-1}$. However, as Skegness is influenced by shoreline exposure, there will be a significant number of people at risk should current trends of flooding and storms continue. Due to current climatic fluctuations, Lynmouth experienced severe weather conditions, including storm surges and high winds during the 2012 and 2014 storms. These 
events highlighted the coastal vulnerability of this particular area and Figure 8.29 shows both cliff-face erosion and how precariously properties have been constructed on the cliff. Therefore, the ECVI for Lynmouth was determined as 13.5 (Table 8.17), which like Skegness puts it in the low vulnerability category (Table 4.4), and its economic value/cost was assessed at $£ 143 \mathrm{M} \mathrm{km}^{-1}$ with a population of $245 \mathrm{~km}^{-1}$ (Table 8.17).

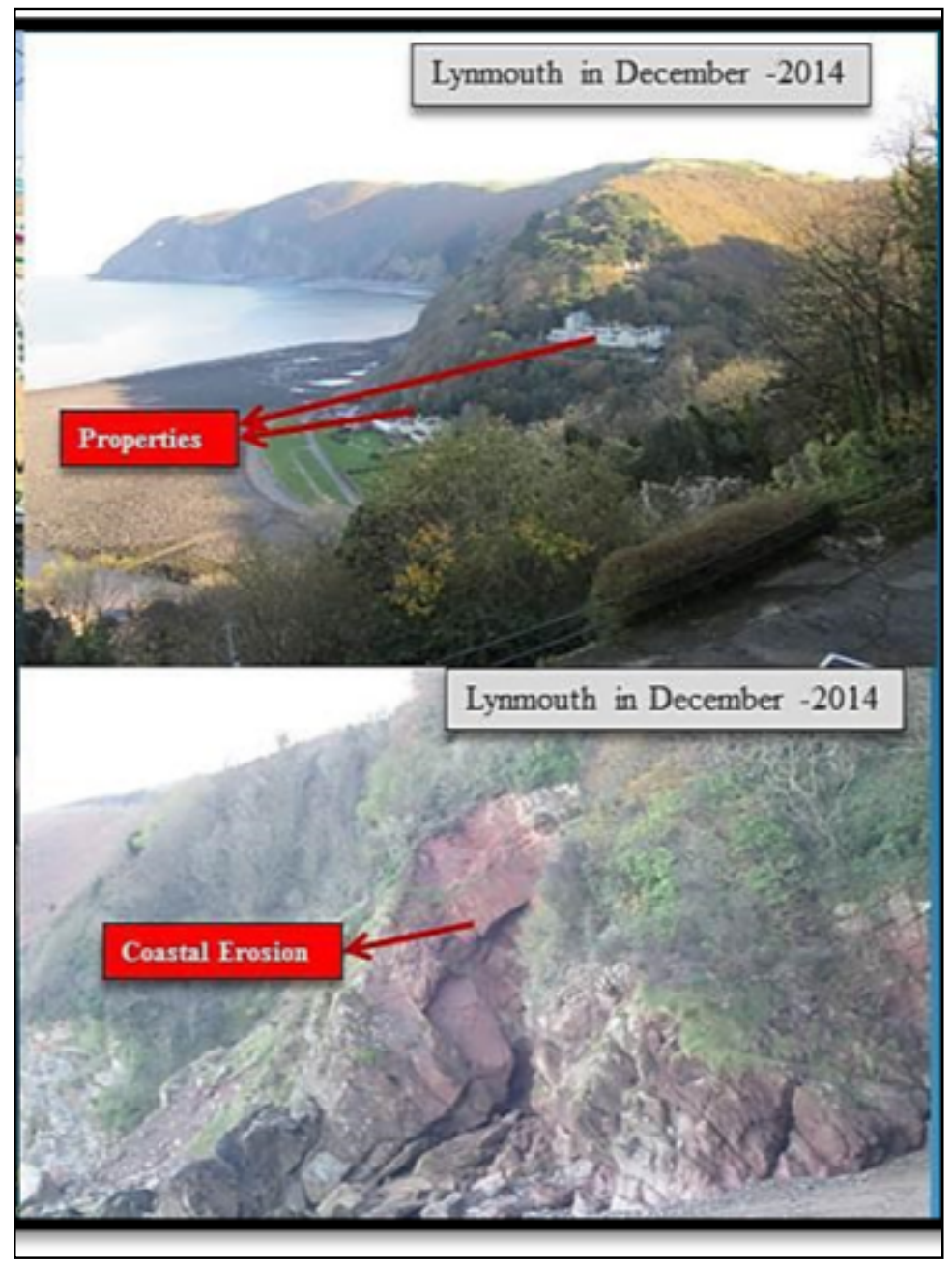

Figure 8.29: Coastal vulnerability: Lynmouth

Llanelli is at high risk from storm events, surges and coastal erosion. Recent storm events, particularly the 2010 storm, ravaged the $£ 27 \mathrm{~m}$ Millennium Coastal Path with high waves and tides, costing the Local Authorities $>£ 400,000$ in repairs (Phillips et al., 2009). Following analysis of the economic parameters, the ECVI for Llanelli was 13.3, in the low vulnerability category. With an economic value of $£ 117 \mathrm{M} \mathrm{km}^{-1}$ and population of $1171 \mathrm{~km}^{-}$ ${ }^{1}$ Llanelli's economic vulnerability is not equally distributed along its coastal frontage. During the storm of 1917, a major part of Hallsands vanished into the sea. Landslides are also a big concern here and the area is currently closed off due to coastal risk associated with 
coastal erosion. Most homeowners use their properties as holiday homes rather than permanent residences. Consequently, Hallsands has an economic risk of $£ 52.5 \mathrm{M} \mathrm{km}^{-1}$ and a population of $13 \mathrm{~km}^{-1}$ who are at risk of displacement, giving it an ECVI of 11.8, i.e. an extremely low relative economic vulnerability (Table 4.4). However, Hallsands properties are at risk from coastal flooding and erosion (Figure 8.30), which affects its PCVI and not ECVI score.

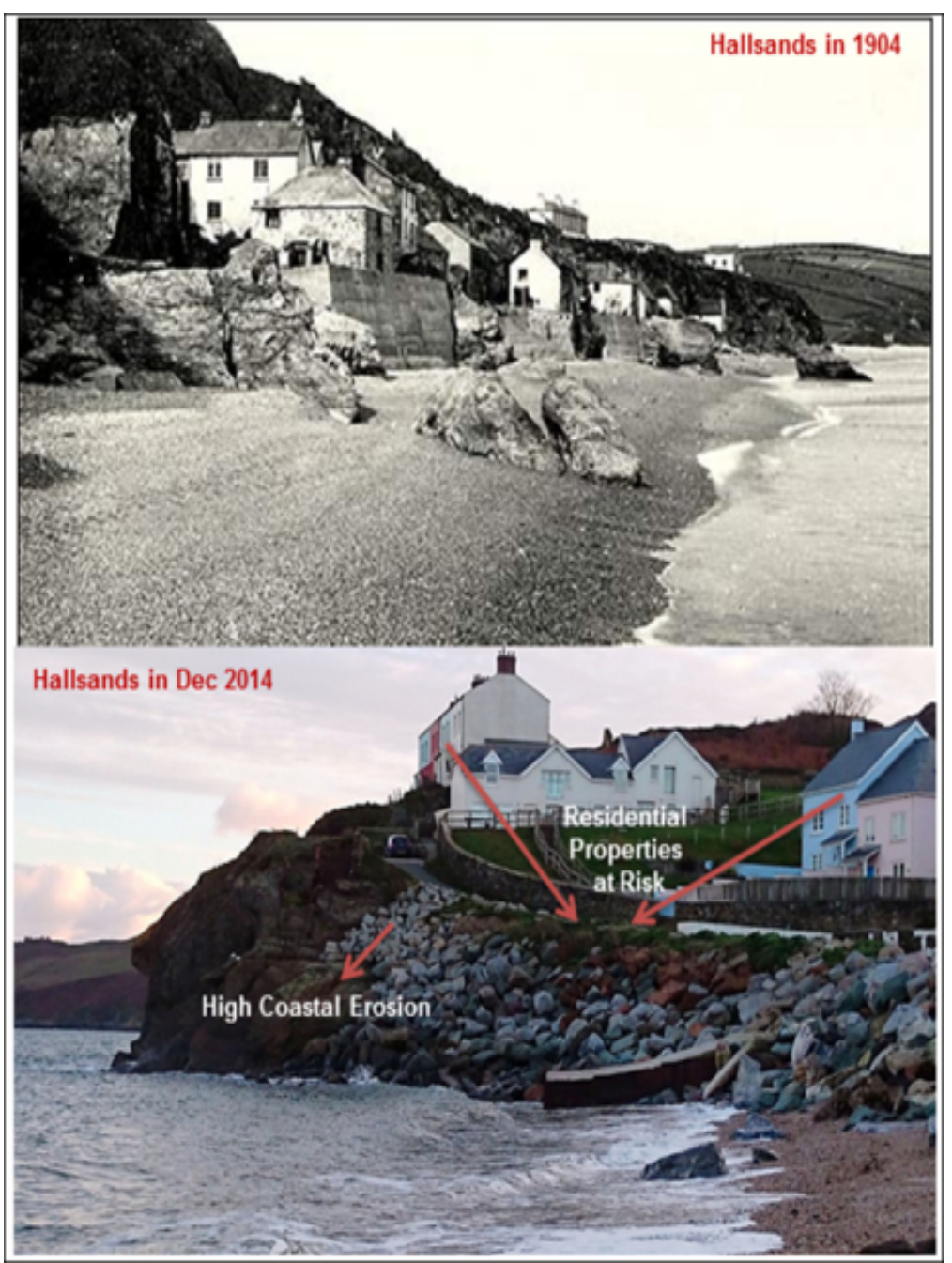

Figure 8.30: Coastal risk at Hallsands

Spurn Head is ecologically very important for bird migration and is considered to be one of the most vulnerable of the sites due to rapid erosion rates. However, its ECVI is 11 (Table 8.17) giving it an extremely low relative vulnerability score. However, erosion has greater impact on Spurn Head's PCVI score and in monetary terms, has an economic vulnerability of $£ 19.3 \mathrm{M} \mathrm{km}^{-1}$, comprised of its site value and 9 residential/commercial properties. With a population of only $25 \mathrm{~km}^{-1}$, displacement costs are also low, thereby justifying the lowest 
ECVI score of all sites. Therefore, even though Hallsands and Spurn Head have high decadal erosion rates, due to them having relatively few commercial and residential properties they have lowest ECVI values. 


\subsection{Summary}

This chapter started by defining the coastal cells and population numbers, which would be used to determine site ECVIs. Economic parameters justified in Table 4.3 were assessed, i.e. residential properties, commercial properties, economic value of site, population, coastal erosion and flood event/impact. These were subsequently quantified according to monetary value and also range in line with boundaries defined in Table 4.5 and 8.16. ECVI values for each parameter were then combined to produce a cumulative ECVI for each coastal location and then averaged according to the number of cells per coastal site. The total economic value for each cell was determined and an overall site value calculated which was also averaged to obtain a value per $\mathrm{km}$. Population numbers were similarly converted per $\mathrm{km}$. These were then compared and from analysis a Site Ranking according to ECVI was determined, which also included cost/value and population data per $\mathrm{km}$. Aberystwyth had the highest ECVI, population $\mathrm{km}^{-1}$ and relative economic vulnerability, a situation mirrored in the three sites with the highest ECVI scores. Chapter 8 concluded by analysing ECVI results for all eleven coastal locations, highlighting areas at risk and under threat, and categorising them according to range and relative vulnerability. The next Chapter will compare PCVI and ECVI results to get a better understanding of both magnitude of change and economic consequences; and subsequently develop a combined coastal vulnerability index (CCVI). 


\section{CHAPTER 9 - DISCUSSION}




\section{Discussion}

\subsection{Introduction}

The world's coastlines are under increasing physical, environmental and socio-economic pressures that is often at the forefront of discussions and of great concern for all stakeholders. Therefore, a better understanding of both the magnitude of change and economic consequences is vital and was the main rationale for this research. Assessment of physical vulnerability and PCVI (Chapters 5,6 and 7) followed by derivation of the economic coastal vulnerability and ECVI (Chapters 5 and 8 ) allows coastal areas to be evaluated according to physical environment constraints and socio-economic costs. Consequently, this Chapter will integrate PCVI and ECVI results to develop a combined coastal vulnerability index (CCVI) and subsequently evaluate implications of both for coastal managers and decision-makers.

\subsection{PCVI}

Several physical coastal vulnerability indices have been developed and many tools employed to assess the scale of coastal vulnerability around the world (e.g. Denner et al., 2015; Palmer et al., 2011; Pethick and Crooks, 2000). However, these have not been extensively applied in the UK, with the exception of small-scale studies such as Llanelli and Northern Ireland. The present PCVI was developed using physical parameters recognised to be significant in relation to vulnerability, which was then applied to eleven coastal zones. PCVI development was explained in Section 4.5 and results showed that physical vulnerability varies according to UK location, despite all eleven sites having suffered consequences of coastal storms and flooding. The site of greatest vulnerability was shown to be Great Yarmouth. Accordingly, coastal planners and developers can use this kind of PCVI analysis in conjunction with socioeconomic conditions without the need for in-depth knowledge of technical issues and coastal processes.

This research adapted the PCVI methodology of Denner et al. (2015) to evaluate physical coastal vulnerability based upon physical environment parameters. An important feature of this PCVI is its ease of application to any geographical area based on the availability of relevant data. Use of physical vulnerability data is also vital for communicating research results and enlightening a broader audience regarding coastal processes and physical consequences. Physical parameters can be adapted and social, economic and ecological factors can be considered alongside to categorise an area under definitive environmental conditions. 
The selection of physical parameters can be complicated, due to the number of driving forces within specific coastal environments. In the case of Llanelli, the movement of deep-water channels had an important influence upon erosion on the northern shore (Section 5.4), while dunes, rocky outcrops and sea defences played vital roles in shoreline protection, which delayed the consequences of erosion becoming evident (Phillips et al., 2009). However, in some places such as Benbecula (Scotland) and Aberystwyth (Wales) there are no dunes, and generally these are more vulnerable than areas that have dunes. Modifications to the methodology included sea defences, because physical interventions make the shoreline less vulnerable. Consequently, the highest PCVI score was allocated to dune width, coastal slope, rocky outcrop and sea defence. The highest overall PCVI was recorded at Great Yarmouth (27) and the lowest at Port Talbot and Aberystwyth (17), which reflected that all eleven sites are subject to damage from storms. PCVI scores suggest that Great Yarmouth and Happisburgh are areas of highest vulnerability, although sites where the majority of properties are located within $0.6 \mathrm{~km}$ of the coastline; Aberystwyth, Dawlish, Hallsands and Skegness, are also vulnerable. Flooding and erosion were the two major issues impacting the coastal areas (Section 3.8 and 3.9; Figure $3.7 \& 3.8$ ) and in locations such as Aberystwyth and Llanelli, the addition of new developments in these areas of high vulnerability will increase pressures, leading to even greater economic loss from flooding and storm damage (Denner et al., 2015; Kantamaneni, 2015).

Conversely, the use of the PCVI in determining the vulnerability of specific sites can identify shorelines that are less vulnerable and therefore, will inform future redevelopment decisions. It is recognised that the identification and assessment of socio-economic and ecological components and their association with zones of high vulnerability is also significant and needs consideration when assessing coastal zone vulnerability and management options. These aspects are subjects of on-going research but this method of estimating vulnerability will ultimately allow cost-benefit analysis. Coastal vulnerability assessments can also be employed to justify the economic feasibility and benefits of coastal defence enabling more effective targeting of increasingly limited public funding. This method makes it easier to generate data and quantify risk to fulfil the requirements delegated to local authorities in the National Strategy for Flood and Coastal Erosion Risk Management in the UK.

\subsection{ECVI}

The Literature Review (Chapter 2) identified that vulnerability classifications can be achieved in many ways, but most vulnerability methodologies do not predict economic 
consequences of coastal erosion, storms and flooding. While the work of Palmer et al. (2011) and Balica et al. (2012) included socio-economic variables under human use categories, e.g. fishing, etc., these were integrated on a regional and not site basis. The ECVI was determined from six economic parameters that were assessed on a site/coastal location basis. Consequently, this methodology can be used by coastal developers, decision and policy makers to evaluate financial risk, without needing to assess complex economic data, as the model provides an innovative way to evaluate economic vulnerability. Development of ECVI scores per cell (Chapter 8) showed that economic vulnerability varies both within and between sites. Great Yarmouth had the highest PCVI and second highest ECVI and generally urban areas were most vulnerable, having larger populations than rural communities. Understanding population numbers at risk is important for both physical and socioeconomic aspects of coastal research (Simone 2004). Assessments of population in monetary terms requires a cost to be allocated to a human life and based on 2011 US EPA (Environmental Protection Agency) estimates, it is $£ 6.9$ million adjusted for 2015 inflation rates (Appelbaum, 2011). However, coastal populations represent diverse age groups and communities with different economic status and an average figure of $£ 4 \mathrm{M}$ for a life could be argued (Kantamaneni, 2016a). Even though population numbers are available, it would be unrealistic to include population costs at $£ 4 \mathrm{M} \mathrm{head}^{-1}$ in the ECVI methodology because there are relatively few deaths recorded in the UK during severe storms. Therefore, this ECVI methodology, which includes population numbers, can be applied at regional and sub regional levels to determine levels of economic vulnerability.

Unrestricted and rapid settlement in coastal areas increases pressure (Section 5.3; Figure 5.2), both physically and economically, which leads to further vulnerability and risk (Nicholls, 2007). For example, Great Yarmouth and Skegness populations have increased year on year ultimately causing increased coastal vulnerability and as a consequence was considered as a significant site for this research. ECVI values for Aberystwyth, Great Yarmouth and Dawlish showed the majority of the coastal cells were highly vulnerable, not only with respect to site value and commercial and residential properties (Section 8.5), but also with population numbers. Spurn Head and Hallsands were identified as having the lowest economic vulnerability, as although Spurn Head has a high erosion rate, the lack of properties and population reduced its ECVI. The Llanelli coastline ECVI was variable according to cell location due to expensive developments alternating with rural locations, while Port Talbot's economic vulnerability was based on the value of its industries, including 
TATA Steel. However, its coastal risk is reduced due to a buffer zone between the sea and many of Port Talbot's properties.

The majority of residential and commercial properties are located within $0.6 \mathrm{~km}$ of the shoreline in all eleven sites. Therefore, predicted increases in storm occurrences and associated flooding events, winds and storm surges that often result in coastal erosion are major problems in these areas. Denner et al. (2015) stated that Llanelli poses a high risk of present and future flooding and results from this research confirm that this is indeed the case. Kantamaneni (2016a) revealed that Aberystwyth has the highest risk of storm surges, flooding and erosion and consequently, it received the highest ECVI score. Of the coastal defences built to protect several of the study sites, particularly Llanelli, the protection of new properties and infrastructure relies on circa $25 \%$ - 35\% having less than a 20 -year lifespan remaining (Denner et al., 2015). This highlights an on-going problem in that not enough money is available for coastal protection, whilst storms, sea level rise (Section 3.3; Figure 3.2) and inundation events are likely to become more frequent. The problem is compounded by there not being updated government reports on coastal defences and protection measures for the eleven sites, particularly Aberystwyth (Kantamaneni and Phillips, Kantamaneni, 2016a), and that where data is available, most is more than 5-10 years old and will not help accurate assessment. Accordingly, the capability of local authorities without sufficient resources to defend coastal infrastructure, especially for Llanelli and Aberystwyth, has been questioned (Phillips et al., 2009; Kantamaneni, 2016a).

Except when events make the television news, e.g. Aberystwyth, etc. in 2014, there is a general lack of public awareness of coastal issues from both economic and physical perspectives. Consequently, regeneration strategies have already led to further coastal erosion and flooding. New developments may get short-term monetary gain from improvements to coastal real estate and investment, but if there is a vulnerability to erosion and flooding, the investment is at risk. Meanwhile, there are no rigorous policies or procedures that can be immediately implemented to avert such situations, and it becomes more complex when developers call on Local Authorities to provide protection because they were encouraged to build on the coast as part of a regeneration strategy (Phillips et al., 2009). These situations represent failures of coastal management strategies instead of an economic gain. Therefore, using the ECVI to assess economic vulnerability will quantify the relative vulnerability of coastal areas to various hazards and consequently will be a useful tool for planning authorities to assess economic risk. 


\subsection{Comparison of ECVI and PCVI}

Comparison of PCVI and ECVI drivers (Figure 9.1; Table 9.1) allows for a better estimation of the overall vulnerability of any site. This is why both were developed using economic and physical parameters and applied to the eleven selected UK coastal sites: Spurn Head, Hallsands, Lynmouth, Happisburgh, Dawlish, Great Yarmouth and Skegness (England); Benbecula (Scotland); and Aberystwyth, Port Talbot and Llanelli (Wales).

Table 9.1 Physical and economic drivers

\begin{tabular}{|c|c|}
\hline Physical drivers & Economic Drivers \\
\hline - Beach width & - Commercial properties \\
\hline - Dune width & - Residential properties \\
\hline - Coastal erosion & - Economic value of the site \\
\hline $\begin{array}{l}\text { - Distance of vegetation behind the } \\
\text { back beach }\end{array}$ & - Population \\
\hline $\begin{array}{l}\text { - Distance of built structures behind } \\
\text { the back beach }\end{array}$ & - Coastal erosion \\
\hline - Rocky outcrop & - Flood impact \\
\hline - Sea defences & \\
\hline
\end{tabular}

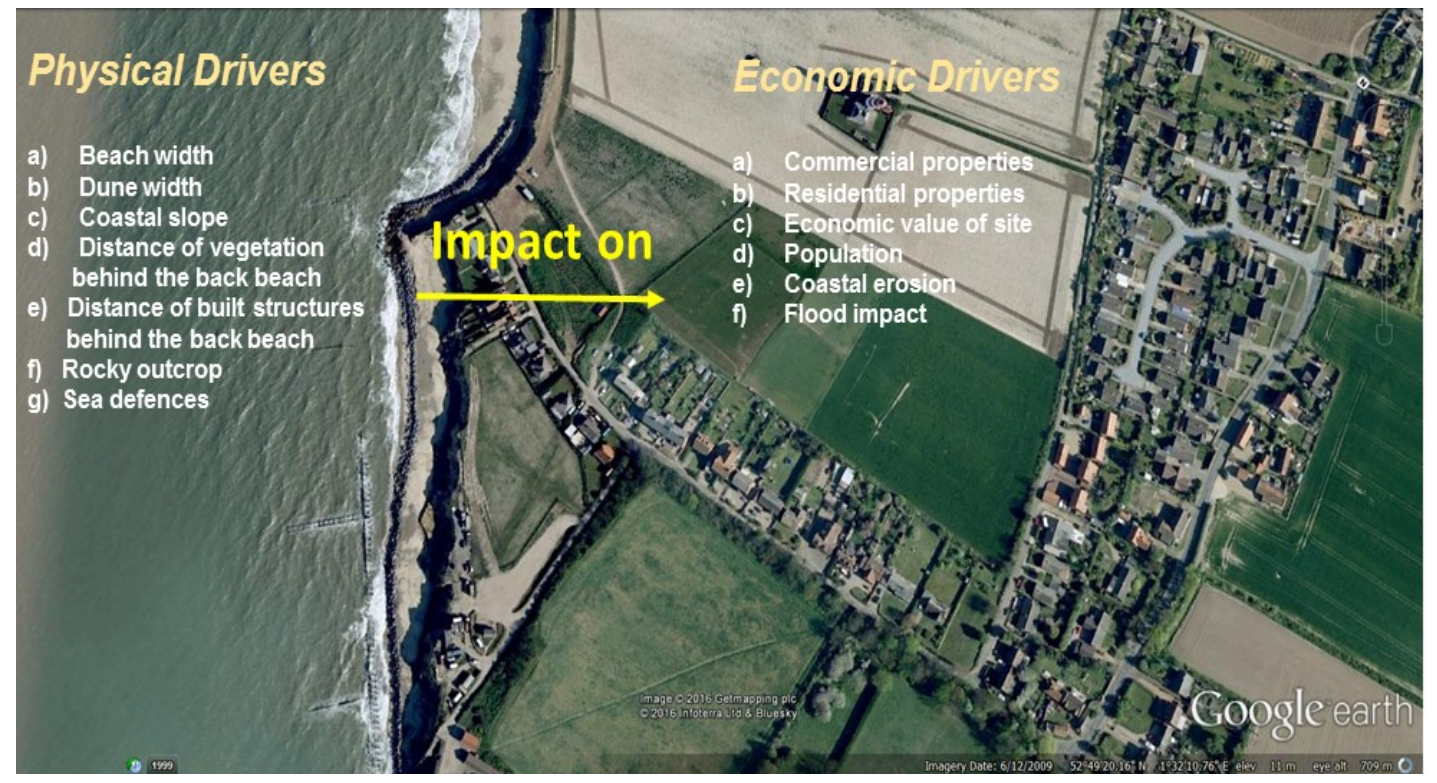

Figure 9.1: Interlinking physical and economic impacts

Both indices gave interesting results as shown in Table 9.2 and Figure 9.2. In Great Yarmouth, the PCVI (27) is higher than the ECVI (22.3), but Aberystwyth's ECVI (24.5) is higher than its PCVI (17). In Spurn Head, physical vulnerability is much higher (22) than its economic vulnerability (11), probably due to the lack of coastal defences and rocky outcrops, 
as well as having fewer commercial and residential properties per km. Port Talbot is an interesting site because it PCVI and ECVI are more or less the same, 17 and 16.8 respectively. For Hallsands, physical vulnerability is much higher indicated by a PCVI of 22 compared with economic vulnerability i.e. an ECVI of 11.7. Furthermore, Dawlish's economic vulnerability $(\mathrm{ECVI}=21.3)$ is more than its physical vulnerability $(\mathrm{PCVI}=18)$, and this can be explained by the number of expensive properties located near the shoreline.

To assess potential links between PCVI and ECVI and get a better understanding of both the magnitude of change and economic consequences Table 9.2 shows PCVI and ECVI values for each of the eleven areas, from which Figure 9.2 was produced.

Table 9.2: PCVI and PCVI average values

\begin{tabular}{lcc}
\hline Site & PCVI & ECVI \\
Great Yarmouth & 27 & 22.5 \\
Happisburgh & 23 & 16 \\
Spurn head & 22 & 11 \\
Hallsands & 22 & 11.7 \\
Lynmouth & 19 & 13.5 \\
Skegness & 22 & 13.8 \\
Benbecula & 22 & 15.6 \\
Dawlish & 18 & 21.3 \\
Llanelli & 18 & 13.3 \\
Aberystwyth & 17 & 24.5 \\
Port Talbot & 17 & 16.8 \\
\hline
\end{tabular}




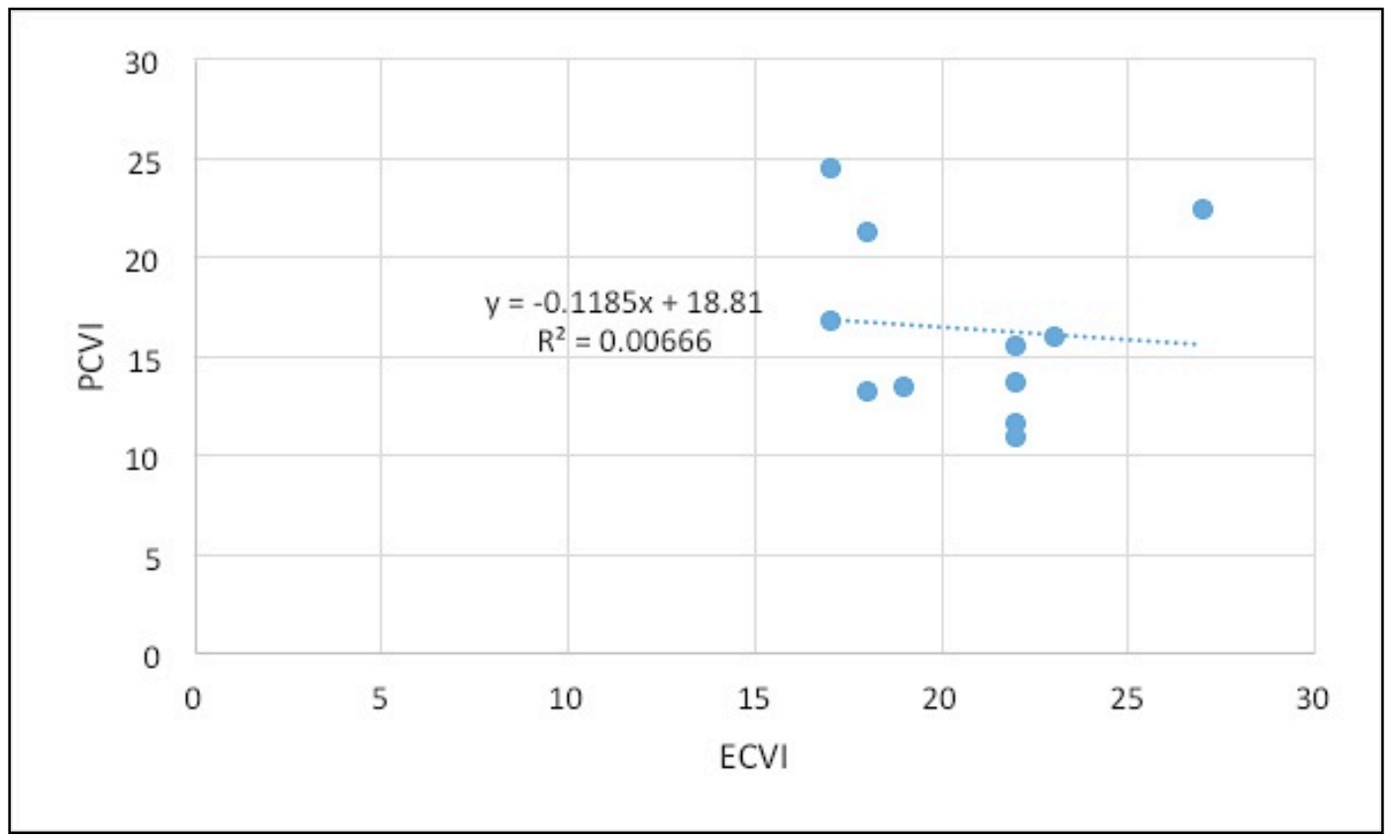

Figure 9.2: Variation of PCVI and ECVI

Figure 9.2 graphically illustrates the variation of PCVI with ECVI from which strengths of the inter-relationship and correlation were determined. It is clearly seen that there is little correlation between the variation of PCVI and ECVI, highlighted by a very low coefficient of determination $\left(\mathrm{R}^{2}=0.0067\right)$. The reason for this is that PCVI values are based on physical environment parameters, e.g. beach width, etc., while ECVI values are influenced by varying market prices, development and infrastructure, e.g. number of commercial properties, etc. Therefore, the greater the number of properties, the higher the economic value and this is independent of the physical environment.

Phillips et al. (2007) amongst others, graphically represented beach areas according to environmental and human use parameters. This approach has been adopted for site PCVI and ECVI values, as shown in Figure 9.3. 


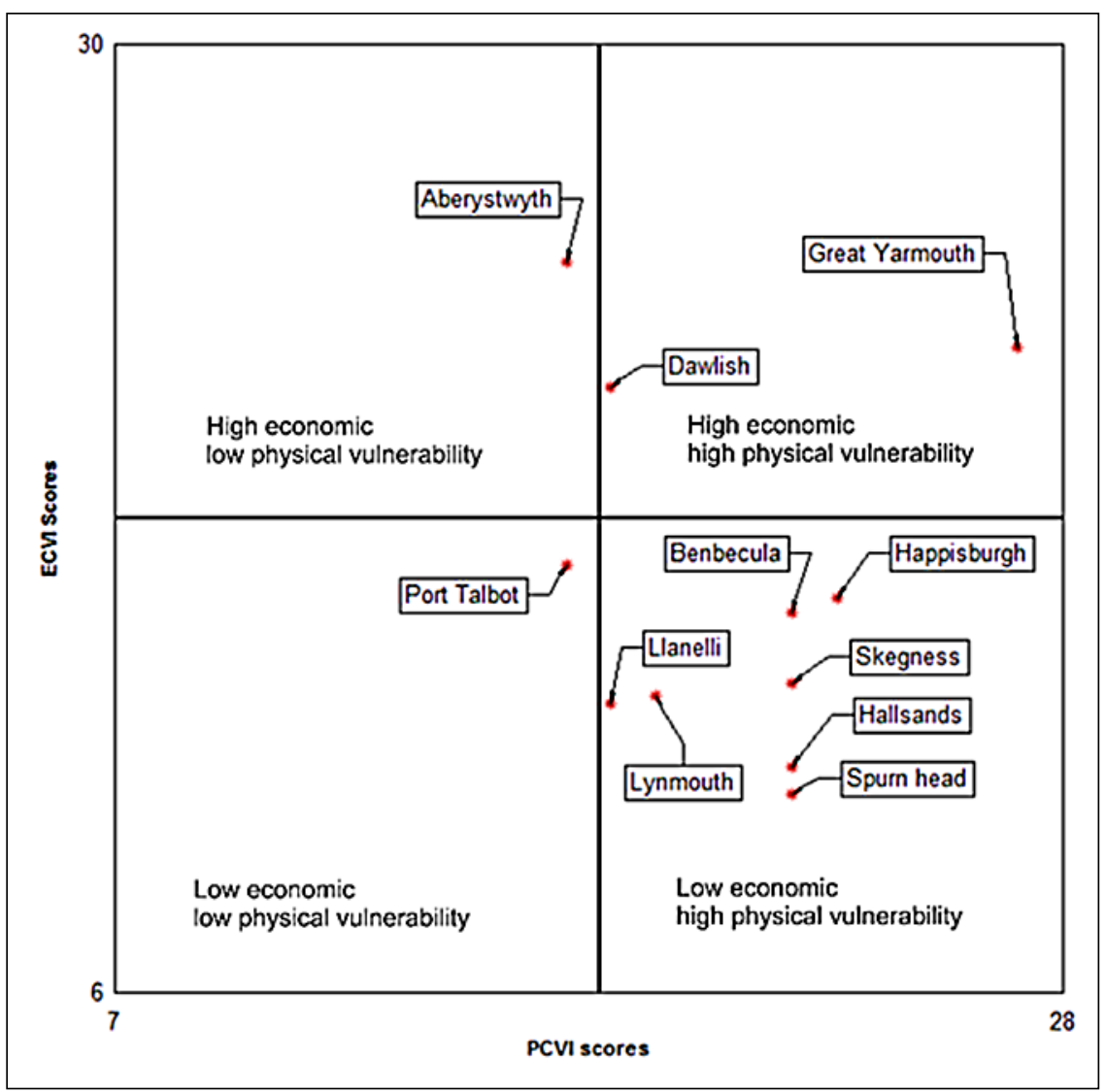

Figure 9.3: Graphical Representation of sites by PCVI and ECVI

The graphical quadrants represent sites according to low physical/low economic, low physical/high economic, high physical/low economic and high physical/high economic categories. Therefore, this graphical representation can be used at various resolutions to compare coastal areas, which in turn will help decision-makes prioritise limited funding to protect areas at most risk.

\subsection{Combined coastal vulnerability Index (CCVI)}

Further interpretation of PCVI and ECVI was undertaken via the formulation of a Combined Coastal Vulnerability Index (CCVI), as described in Chapter 4. Data from Table 9.2 was combined to form a CCVI for each site, as shown in Table 9.3. Results showed that Great Yarmouth has the highest overall vulnerability demonstrated by a CCVI of 25, followed by Aberystwyth (21), Happisburgh and Dawlish (20). Llanelli and Lynmouth have the joint lowest CCVI (16) with Spurn Head and Port Talbot just above with a CCVI of 17. 
Table 9.3: CCVI values and site ranking

\begin{tabular}{lcc} 
Site & CCVI & Rank \\
Great Yarmouth & 25 & 1 \\
Aberystwyth & 21 & 2 \\
Happisburgh & 20 & 3 \\
Dawlish & 20 & 3 \\
Benbecula & 19 & 5 \\
Skegness & 18 & 6 \\
Hallsands & 18 & 6 \\
Port Talbot & 17 & 8 \\
Spurn Head & 17 & 8 \\
Lynmouth & 16 & 10 \\
Llanelli & 16 & 10 \\
\hline
\end{tabular}

Table 9.3 indicates that overall, the English sites were generally the most vulnerable, although that is also a function of number of sites assessed. Therefore, to enable comparison of sites by PCVI, ECVI and CCVI, Figure 9.4 was produced. Unsurprisingly, Great Yarmouth has the highest physical and second highest economic rankings. While, the highest economic ranking at Aberystwyth is offset by the lowest recorded physical ranking, obviously, influenced by shoreline protection structures. Contrastingly, Spurn Head has a high physical ranking but low economic ranking, influenced by sand and shingle spit morphology that is not conducive to construction and population growth. Port Talbot and Llanelli areas are centred on industry and consequently, high numbers of residential and commercial properties. However, these areas are generally protected by sea defences, although the sustainability of these protection measures have been questioned by both Phillips et al. (2007) and Denner et al. (2015). In these cases the protection measures are a function of the industrial importance, resulting in similar physical and economic ranking. To enable easy reference the PVCI and ECVI and CCVI results are superimposed upon a map of the UK (Figures $9.5 \mathrm{a}$ and $9.5 \mathrm{~b}$ respectively). 


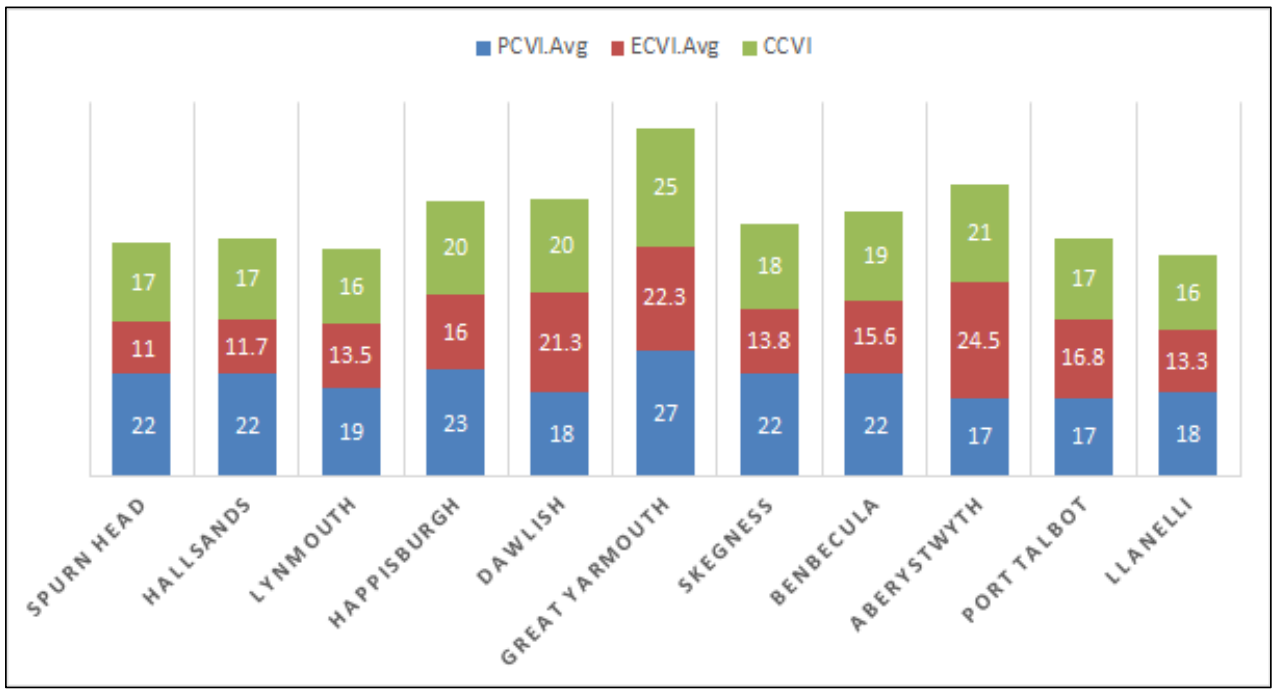

Figure 9.4: Representation of vulnerability indexes

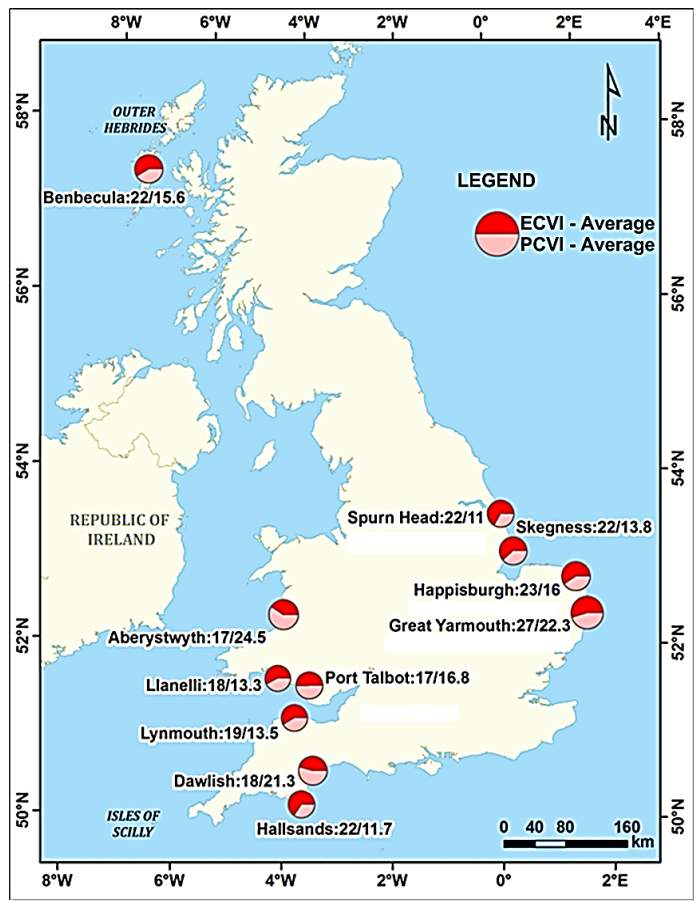

a)

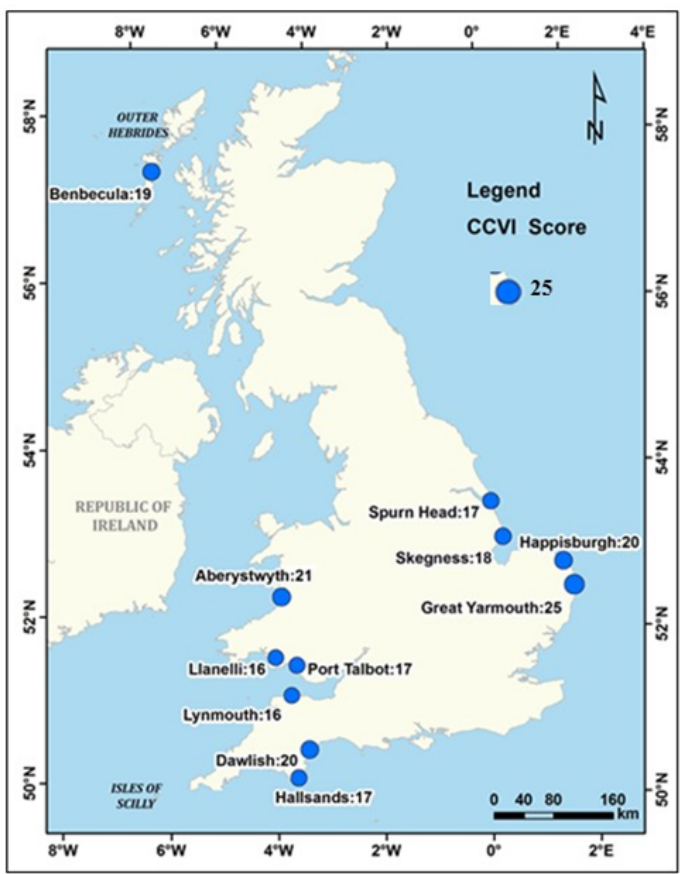

b)

Figure 9.5: Coastal vulnerability maps showing a) ECVI and PCVI average values and b) combined values (Key: red ECVI; amber PCVI; blue CCVI). 


\subsection{Summary}

This chapter completes the research project by presenting a PCVI, developed using parameters recognised to be significant in relation to physical vulnerability and an ECVI, designed to quantify relative economic vulnerability to various hazards. These were then applied to eleven coastal zones and the PCVIs and ECVIs were combined to form a CCVI which produced a useful tool for assessing physical and economic risk. Results of this research will improve understanding of both physical and economic consequences of changing environmental conditions, particularly in highly populated low-lying areas and can be used to inform effective planning of coastal management strategies in both physically and/or economically important areas. 


\section{CHAPTER 10 - CONCLUSIONS}




\section{Conclusions}

\subsection{Introduction}

Predicted future climate change, sea level rise and increasing storm intensities will result in increasing physical, environmental and socioeconomic pressures, particularly for communities living in low lying coastal areas around the world. Although this is affected by uncertainty due to environmental complexity, potential effects could be mitigate by a comprehensive understanding of both physical and economic vulnerability. Literature searches identified that some research has been conducted on physical and to a lesser extent on the socio-economic aspects of coastal vulnerability, and there is a lack of current research detailing economic coastal vulnerability. Therefore, this work that details both economic and physical vulnerability aspects of 11 case study areas with contrasting environmental and economic conditions, provides additional information to improve confidence and will inform coastal management strategies for locations most at risk.

\subsection{PCVI}

The selection of physical parameters used to develop a PVCI was complicated, due to the number of driving forces within specific coastal environments. Dunes, rocky outcrops and sea defences play a vital natural role in shoreline protection, by delaying the consequences of erosion becoming evident. However, in some places no dunes or rocky outcrops exist and generally these are more vulnerable than areas that have dunes. Modifications to the methodology included sea defences, because physical interventions make the shoreline less vulnerable. Consequently, the highest PCVI score was allocated to dune width, coastal slope, rocky outcrop and sea defence. The highest overall PCVI was recorded at Great Yarmouth (27) and the lowest at Port Talbot and Aberystwyth (17), which suggests that all eleven sites are subject to damage from storms. PCVI scores suggest that Great Yarmouth and Happisburgh area are areas of highest vulnerability centred on postglacial rebound, sea level rise and a relatively weak geomorphology. Also vulnerable are areas where the majority of properties are located close to coastline, for example, Aberystwyth, Dawlish, Hallsands and Skegness. This research recognised the importance of identification and assessment of socioeconomic and ecological components and their association with zones of high vulnerability and these aspects must be considered when assessing coastal zone vulnerability and management options. It was also recognised that these physical coastal vulnerability assessments can also be employed to justify the economic feasibility and benefits of defending the coast to enable more effective targeting of increasingly limited public funding. 
This method makes it easier to generate data and quantify risk to fulfil the requirements delegated to local authorities in the National Strategy for Flood and Coastal Erosion Risk Management in the UK.

\subsection{ECVI}

When applied to the eleven selected coastal areas, results showed that economic vulnerability varies both within and between sites. Great Yarmouth had the highest PCVI and second highest ECVI and generally urban areas were most vulnerable, having larger populations than rural communities. The study recognised the importance of understanding population numbers at risk for both physical and socio-economic aspects of coastal research. The study highlighted that unrestricted and rapid settlement in coastal areas increases pressure leading to vulnerability and risk. Great Yarmouth and Skegness populations have increased and are the cause augmented coastal vulnerability and as a consequence was considered as a significant site for this research. ECVI values for Aberystwyth, Great Yarmouth and Dawlish showed that most coastal cells were highly vulnerable, with respect to site value, commercial and residential properties and population numbers. It was no surprise that Spurn Head and Hallsands were identified as having the lowest economic vulnerability, as the lack of properties and population reduced its ECVI. Using an ECVI to assess economic vulnerability will quantify the relative vulnerability of coastal areas to various hazards and consequently will be a useful tool for planning. The ECVI was determined from six economic parameters to provide a useful coastal management tool assessed on a site/coastal location basis. It is argued that coastal developers and policy makers could apply this model to evaluate financial risk without needing complex economic data as the methodology provides an innovative way to evaluate economic vulnerability.

\subsection{Comparison of PCVI and ECVI/ Combined coastal vulnerability, CCVI}

Results from the two indices (PCVI and ECVI) were compared to estimate the relative severity of physical and economic vulnerability in the selected sites. Accordingly, Great Yarmouth and Aberystwyth have the highest combined vulnerability, both economically and physically with the highest scores. Lynmouth and Spurn Head were the least physically and economically vulnerable sites, with the lowest recorded scores. Furthermore, based on CCVI (combined coastal vulnerability index) values, Great Yarmouth is highly vulnerable with the 
highest average score (25) followed by Aberystwyth, Dawlish, and Happisburgh. Llanelli and Lynmouth are the least vulnerable sites with lowest recorded scores. To improve results from PCVI, ECVI and CCVI analysis, it is suggested that future work should include 'fuzzy logic' techniques to apply a weighting system to parameters.

\subsection{Justification of aims and objectives}

Section 1.3 identified the main aim of this research, i.e. to develop a combined physical and economic coastal vulnerability index. Accordingly, three indices were generated (PCVI, ECVI and CCVI) (Sections 4.1 to 4.3, 4.5, 4.6) and applied to eleven selected coastal areas (Section 4.4) which enabled the evaluation of physical and economic parameters. The methodological frameworks which were developed for this study, can easily be applied to any geographical area following similar data acquisition techniques. In summary, this research achieved all stated aims and objectives and future projects are in the process of being developed.

\subsection{Limitations of research}

Though the current research has achieved its aims and objectives, there are some limitations which will underpin recommendations for future work. Due to the lack of decadal or census data regarding the number of deaths caused by flooding events in coastal areas, this research was unable to consider economic consequences for local populations. It was not possible to allocate the same economic value to all coastal areas, e.g. Aberystwyth has a higher economic value than Port Talbot if the Welsh Government's Social Deprivation Index is considered. It was also not possible to determine actual economic value of populations in the eleven coastal areas due to time and data restrictions. Time and resource restrictions also meant it was not possible to fully assess implications of large infrastructure such as transportation and bridges for the ECVI. This study could not assess accurate flood damage information before 2007 because Met Office systematic information is unavailable for periods prior to this date. However, the use of population census data to augment data acquired from the Local Authority would have improved estimates.

\subsection{Data collection and challenges}

With these concerns in mind, factors such as GDP, local economy, and redevelopment strategies would need to be carefully assessed in any effort of simplification of findings. During the data collection process, many obstacles were faced. Some Local Authorities did not respond to requests for information, and while others offered to arrange meetings and 
interviews, sadly not all appointments were kept. To overcome these challenges, statistical information was requested via the Freedom of Information (FOI) Act, 2000. Access to information in some areas was prohibited (Dawlish) due to political and economic tensions as infrastructure (a railway) was being rebuilt. Despite these difficulties, most of the key statistical data were obtained during the data collection period. 


\subsection{Summary}

This section summarises how the research aims and objectives were achieved by developing and applying a combined coastal vulnerability index (physical and economic) along with the development of coastal vulnerability GIS maps at various scales. Future projects offer varied applications and with climate change impacts showing no sign of reducing in magnitude, such tools give authorities information needed for appropriate decision making. 


\section{References}

ABERYSTWYTH GUIDE. 2015. Sea Front. [Online]. Available:

https://www.aberystwyth.org.uk/attractions/ [Accessed 19/12/2015].

ABSON, D. J., DOUGILL, A. J. and STRINGER, L. C. 2012. Using principal component analysis for information-rich socio-ecological vulnerability mapping in Southern Africa. Applied Geography, 35, 515-524.

ABUODHA, P. A. and WOODROFFE, C. D. 2010. Assessing vulnerability to sea-level rise using a coastal sensitivity index: a case study from southeast Australia. Journal of Coastal Conservation, 14, 189-205.

ADGER, W. N. 1999. Social vulnerability to climate change and extremes in coastal Vietnam. World development, 27, 249-269.

ADGER, W. N., HUGHES, T. P., FOLKE, C., CARPENTER, S. R. and ROCKSTRÖM, J. 2005. Social-ecological resilience to coastal disasters. Science, 309, 1036-1039.

ADGER, W. N. 2006. Vulnerability. Global environmental change, 16, 268-281

AGNETIS, A., BASOSI, R., CABALLERO, K., CASINI, M., CHESI, G., CIASCHETTI, G., DETTI, P., FEDERICI, M., FOCARDI, S. and FRANCHI, E. 2006. Development of a Decision Support System for the management of Southern European lagoons. Center for Complex Systems Studies University of Siena, Siena, Italy. Disponível em http://www. dittyproject. org/Article/WP8_DSS_structure_final. $p d f$.

ALHARBI, O. A., WILliAMS, A. T., PHILliPS, M. R. \& THOMAS, T. 2016. Textural characteristics of sediments along the southern Red Sea coastal areas, Saudi Arabia. Arabian Journal of Geosciences, 9, 735.

ALEXANDER, L. and JONES, P. 2000. Updated precipitation series for the UK and discussion of recent extremes. Atmospheric science letters, 1, 142-150.

ALLAN, R., TETT, S. and ALEXANDER, L. 2009. Fluctuations in autumn-winter severe storms over the British Isles: 1920 to present. International Journal of Climatology, 29, 357-371.

ANTHOFF, D., NICHOLLS, R. J. and TOL, R. S. 2010. The economic impact of substantial sea-level rise. Mitigation and Adaptation Strategies for Global Change, 15, 321-335.

ANTHOFF, D. and TOL, R. S. 2010. On international equity weights and national decision making on climate change. Journal of Environmental Economics and Management, 60, 14-20. 
ANTUNES, C. and TABORDA, R. 2009. Sea level at Cascais tide gauge: data, analysis and results. Journal of Coastal Research, 218-222.

APPELBAUM, B. 2011. As US agencies put more value on a life, businesses fret. The New York Times, 16.

ATLAS, U. 2013. percent of us live in coastal areas, retrieved October 22, 2013.

BAGDANAVIČIŪTĖ, I., KELPŠAITĖ, L. and SOOMERE, T. 2015. Multi-criteria evaluation approach to coastal vulnerability index development in micro-tidal lowlying areas. Ocean and Coastal Management, 104, 124-135.

BAKER, J. L. 2012. Climate change, disaster risk, and the urban poor: cities building resilience for a changing world, World Bank Publications.

BALICA, S., WRIGHT, N. G. and VAN DER MEULEN, F. 2012. A flood vulnerability index for coastal cities and its use in assessing climate change impacts. Natural Hazards, 64, 73-105.

BALLINGER, R.C., 2002. An evaluation of integrated coastal management in the United Kingdom. Sustainable Coastal Management: A Transatlantic and EuroMediterranean Perspective .75-93. Springer Netherlands.

BBC (BRITISH BROADCASTING CORPORATION). 2003. [Online]. Available:http://www.bbc.co.uk/insideout/east/series4/great_storm.shtml [Accessed 14/03/2015]

BBC (BRITISH BROADCASTING CORPORATION). 2007. [Online]. Available: http://www.bbc.co.uk/bristol/content/articles/2007/01/30/flood_feature.shtml [Accessed 14/03/2014]

BBC (BRITISH BROADCASTING CORPORATION). 2013. Thousands hit by floods and power cuts at Christmas [Online]. Available: http://www.bbc.co.uk/news/uk25512391 [Accessed 14/03/2014]

BBC (BRITISH BROADCASTING CORPORATION). 2010. The 1952 Lynmouth flood disaster [Online]. Available: http://news.bbc.co.uk/local/devon/hi/people_and_places/history/newsid_8475000/8 475525.stm [Accessed 22/10/2012].

BENKER, S. C., LANGFORD, R. P. \& PAVLIS, T. L. 2011. Positional accuracy of the Google Earth terrain model derived from stratigraphic unconformities in the Big Bend region, Texas, USA. Geocarto International, 26, 291-303. 
BENSON, C. and CLAY, E. J. 2004. Understanding the economic and financial impacts of natural disasters, World Bank Publications.

BGS (BRITISH GEOLOGICAL SURVEY). 2014. Coastal erosion at Happisburgh, Norfolk. [Online]. Available: http://www.bgs.ac.uk/landslides/happisburgh.html [Accessed 10/11/2015].

BLAIKIE, P., CANNON, T., DAVIS, I. and WISNER, B. 2014. At risk: natural hazards, people's vulnerability and disasters, Routledge.

BORUFF, B. J., EMRICH, C. and CUTTER, S. L. 2005. Erosion hazard vulnerability of US coastal counties. Journal of Coastal Research, 932-942.

BOUWER, L. M. 2011. Have disaster losses increased due to anthropogenic climate change? Bulletin of the American Meteorological Society, 92, 39.

BOYKOFF, M. T. 2007. Flogging a dead norm? Newspaper coverage of anthropogenic climate change in the United States and United Kingdom from 2003 to 2006. Area, $39,470-481$.

BRIGUGLIO, L. 1995. Small island developing states and their economic vulnerabilities. World development, 23, 1615-1632.

BRIGUGLIO, L. and GALEA, W. 2003. Updating and augmenting the economic vulnerability index. Occasional Papers on Islands and Small States, 4, 2003.

BROOKS, N., ADGER, W. N. and KELLY, P. M. 2005. The determinants of vulnerability and adaptive capacity at the national level and the implications for adaptation. Global Environmental Change, 15, 151-163.

BROOKS, S. M. and SPENCER, T. 2012. Shoreline retreat and sediment release in response to accelerating sea level rise: measuring and modelling cliffline dynamics on the Suffolk Coast, UK. Global and Planetary Change, 80, 165-179.

CAMACHO, A., COHUET, S., GRANDESSO, F., LUQUERO, F., LYNCH, E., PASETTO, D., FINGER, F., BERTUZZO, E. \& RINALDO, A. 2016. Prediction of cholera dynamics in Haiti following the passage of Hurricane Matthew.

CANNEll, M., BROWN, T., SPARKS, T., MARSH, T., PARR, T., GEORGE, G., PALUTIKOF, J., LISTER, D., DOCKERTY, T. and LEAPER, R. 2004. Review of UK climate change indicators. Edinburgh: Centre for Ecology and Hydrology.

CAPOBIANCO, M., DEVRIEND, H. J., NICHOLLS, R. J. and STIVE, M. J. 1999. Coastal area impact and vulnerability assessment: the point of view of a morphodynamic modeller. Journal of Coastal Research, 701-716. 
CARAPUCO, M. M., TABORDA, R., SILVEIRA, T. M., PSUTY, N. P., ANDRADE, C. and FREITAS, M. C. 2016. Coastal geoindicators: Towards the establishment of a common framework for sandy coastal environments. Earth-Science Reviews.

CARTER, R. W. G. 2013. Coastal environments: an introduction to the physical, ecological, and cultural systems of coastlines, Elsevier.

CARTER, R. \& WOODROFFE, C. 1994. Coastal evolution: an introduction. Coastal Evolution: late Quaternary shoreline morphodynamics, 1-31.

CCC (Carmarthenshire County Council), 2007. Unitary development plan. The Carmarthenshire Local Development Plan Summary. [Online].Available : http://www.cartoplus.co.uk/carmarthenshire/ [Accessed on: 3.01.12.].

CEREDIGION COUNTY COUNCIL. 2006. Community Profile. [Online]. Available: http://www.ceredigion2020.org.uk/utilities/action/act_download.cfm?mediaid=774 5andlangtoken=eng [Accessed 22/08/2014].

CHEJARLA, V. R., MANDLA, V. R., PALANISAMY, G. and CHOUDHARY, M. 2016. Estimation of damage to agriculture biomass due to Hudhud cyclone and carbon stock assessment in cyclone affected areas using Landsat-8. Geocarto International, $1-14$.

CHURCH, J. A. and WHITE, N. J. 2011. Sea-level rise from the late 19th to the early $21 \mathrm{st}$ century. Surveys in Geophysics, 32, 585-602.

CICIN-SAIN, B. and BELFIORE, S. 2005. Linking marine protected areas to integrated coastal and ocean management: a review of theory and practice. Ocean and Coastal Management, 48, 847-868.

CIA. 2012. World Factbook- coastline [Online]. Available: https://www.cia.gov/library/publications/the-world-factbook/fields/2060.html [Accessed 06/05/2013].

CONRAD, R. 1996. Soil microorganisms as controllers of atmospheric trace gases (H2, CO, CH4, OCS, N2O, and NO). Microbiological reviews, 60, 609-640.

COOPER, J. and MCKENNA, J. 2008. Social justice in coastal erosion management: The temporal and spatial dimensions. Geoforum, 39, 294-306.

COOPER, J. and MCLAUGHLIN, S. 1998. Contemporary multidisciplinary approaches to coastal classification and environmental risk analysis. Journal of Coastal Research, 512-524. 
COX, P. M., BETTS, R. A., JONES, C. D., SPALL, S. A. and TOTTERDELL, I. J. 2000. Acceleration of global warming due to carbon-cycle feedbacks in a coupled climate model. Nature, 408, 184-187.

CREEL, L. 2003. Ripple effects: population and coastal regions, Population Reference Bureau Washington, DC. 1-7

CRUTZEN, P. J. 2006. The “anthropocene”, Berlin Heidelberg.Springer. 13-18

CUTTER, S. L., BORUFF, B. J. and SHIRLEY, W. L. 2003. Social vulnerability to environmental hazards*. Social science quarterly, 84, 242-261.

DALAL, R. C. and ALLEN, D. E. 2008. TURNER REVIEW No. 18. Greenhouse gas fluxes from natural ecosystems. Australian Journal of Botany, 56, 369-407.

DARA. 2012. Global Vulnerability Monitor [Online]. Available: http://daraint.org/climatevulnerability-monitor/climate-vulnerability-monitor-2012/ [Accessed 14/03/2014]

DAVENPORT, J. and DAVENPORT, J. L. 2006. The impact of tourism and personal leisure transport on coastal environments: a review. Estuarine, Coastal and Shelf Science, 67, 280-292.

DAVIS, J. C. 2005. Statistics and Data Analysis in Geology. JSTOR.

DAWSON, A. G., DAWSON, S. and RITCHIE, W. 2007. Historical climatology and coastal change associated with the 'Great Storm'of January 2005, South Uist and Benbecula, Scottish Outer Hebrides. Scottish Geographical Journal, 123, 135-149.

DAWSON, R. J., DICKSON, M. E., NICHOLLS, R. J., HALL, J. W., WALKDEN, M. J., STANSBY, P. K., MOKRECH, M., RICHARDS, J., ZHOU, J. and MILLIGAN, J. 2009. Integrated analysis of risks of coastal flooding and cliff erosion under scenarios of long term change. Climatic Change, 95, 249-288.

DAWSON, D., SHAW, J. and GEHRELS, W. R. 2016. Sea-level rise impacts on transport infrastructure: The notorious case of the coastal railway line at Dawlish, England. Journal of Transport Geography, 51, 97-109.

DE LEÓN, V. and CARLOS, J. 2006. Vulnerability: a conceptional and methodological review, UNU-EHS.

DENNER, K., PHILLIPS, M., JENKINS, R. and THOMAS, T. 2015. A coastal vulnerability and environmental risk assessment of Loughor Estuary, South Wales. Ocean and Coastal Management, 116, 478-490. 
DERHAM, W. 1704. A Letter for the Reverend Mr William Derham, FRS Containing His Observations concerning the Late Storm. Philosophical Transactions, 24, 15301534.

DESA. 2014. LDC (Least Developed Country Information) criteria [Online]. Available: http://www.un.org/en/development/desa/policy/cdp/ldc/ldc_criteria.shtml [Accessed 12/12/2015].

DEVON CITY COUNCIL. 2007. Dawlish -Devon Town Population Projections. [Online]. Available: http://www.devon.gov.uk/dawlish-projections.pdf [Accessed $18 / 10 / 2013]$

DOBBIE, C. H. \& WOLF, P. O. 1953. The Lynmouth flood of August 1952. Proceedings of the Institution of Civil Engineers, 2, 522-546.

DODMAN, D., HARDOY, J. and SATTERTHWAITE, D. 2009. Urban development and intensive and extensive risk. background paper for the ISDR Global Assessment Report on Disaster Risk Reduction.

DONAT, M. G., LECKEBUSCH, G. C., PINTO, J. G. and ULBRICH, U. 2010. Examination of wind storms over Central Europe with respect to circulation weather types and NAO phases. International Journal of Climatology, 30, 1289-1300.

DOODY, J. P. 2004a. 'Coastal squeeze' - an historical perspective. Journal of Coastal Conservation, 10, 129-138.

DOODY, J. P. 2004b. Living with Coastal Erosion in Europe: Sediment and Space for Sustainability: Results from the EUROSION Study, Office for Official Publications of the European Communities.

DOODY, J. P. 2013. Coastal squeeze and managed realignment in southeast England, does it tell us anything about the future? Ocean and Coastal Management, 79, 34-41.

DORLING, D. and THOMAS, B. 2004. People and places: A 2001 census atlas of the UK, Policy Press.

DOUBEN, K. J. 2006. Characteristics of river floods and flooding: a global overview, 19852003. Irrigation and drainage, 55- S9-S21.

DOUGLAS, B. C., CROWELL, M. \& LEATHERMAN, S. P. 1998. Considerations for shoreline position prediction. Journal of Coastal Research, 1025-1033.

DOUGLAS, B. C. 2001. Sea level change in the era of the recording tide gauge. Sea level rise: history and consequences, 75, 37-64. 
DOUGLAS, B. C. and CROWELL, M. 2000. Long-term shoreline position prediction and error propagation. Journal of Coastal Research, 145-152.

DOUKAKIS, E. 2005. Coastal vulnerability and risk parameters. European Water, 11, 3-7.

DUGDALE, R. and VERE, A. 1993. Saving Lincolnshire's beaches. East Midland Geographer, 16, 31-32.

DUTTA, D., HERATH, S. and MUSIAKE, K. 2003. A mathematical model for flood loss estimation. Journal of Hydrology, 277, 24-49.

EAKIN, H. and LUERS, A. L. 2006. Assessing the vulnerability of social-environmental systems. Annual Review of Environment and Resources, 31, 365.

EASTERLING, D. R., MEEHL, G. A., PARMESAN, C., CHANGNON, S. A., KARL, T. R. and MEARNS, L. O. 2000. Climate extremes: observations, modeling, and impacts. science, 289, 2068-2074.

ECONOMICS, O. 2013. The economic impact of the UK maritime services sector. Report for Maritime UK, Oxford Economics, Oxford.

EL RAEY, M. 2011. Mapping areas affected by sea-level rise due to climate change in the Nile delta until 2100. Coping with global environmental change, disasters and security. Springer.

EPA (Environemntal Protection Agency). 2015. Climate Change- Global Greenhouse Gas Emissions Data [Online]. Available: https://www3.epa.gov/climatechange/ghgemissions/global.html_ [Accessed $16 / 10 / 2015]$

EM-DAT. 2014. EM-DAT Database [Online]. Available: http://www.emdat.be/database [Accessed 15/12/2014].

ENVIRONMENT AGENCY. 2010. Flood and Coastal Erosion Risk Management appraisal guidance. [Online]. Avaliable:

https://www.gov.uk/government/uploads/system/uploads/attachment_data/file/4817 68/LIT_4909.pdf

ENVIRONMENT AGENCY. 2010. The costs of the summer 2007 floods in England [Online]. Available:

https://www.gov.uk/government/uploads/system/uploads/attachment_data/file/2911 90/scho1109brja-e-e.pdf [Accessed 12/12/2012].

ENVIRONMENT AGENCY. 2012. Managing flood risk. [Online]. Available: http://www.exmoor nationalpark.gov.uk/_data/assets/pdf_file/0006/754359/EB68- 
Environment-Agency-2012-North-Devon-Catchment-Flood-Management-PlanSummary-Report.pdf [Accessed 10/10/2015].

EUROSION. 2004. Living with Coastal Erosion in Europe: Sediment and Space for Sustainability_Part I-Major Findings and Policy. Recommendations of the EUROSION project. National Institute for Coastal and Marine Management (RIKZ); the EU Coastal Union (EUCC); IGN France International; Autonomous University of Barcelona (UAB); French Geological Survey (BRGM); French Institute of Environment (IFEN); EADS Systems \& Defence Electronics.

[Online]

Avaliable: http://www.eurosion.org/reports-online/part1.pdf.

FABER, B., THOMAS, V., THOMAS, M. and OLSENHOLLER, J. 1997. Enhancing stakeholder involvement in environmental decision making: Active Response Geographic Information System. National Association of Environmental Professionals, Washington, DC (United States).

FANKHAUSER, S. 2010. The costs of adaptation. Wiley Interdisciplinary Reviews: Climate Change, 1, 23-30.

FAUSOLD, C. J. and LILIEHOLM, R. J. 1999. The economic value of open space: A review and synthesis. Environmental Management, 23, 307-320.

FLANAGAN, B. E., GREGORY, E. W., HALLISEY, E. J., HEITGERD, J. L. \& LEWIS, B. 2011. A social vulnerability index for disaster management. Journal of Homeland Security and Emergency Management, 8.

FIELD, A. 2009. Discovering statistics using SPSS, Sage publications.

FOLKE, C., CARPENTER, S., ELMQVIST, T., GUNDERSON, L., HOLLING, C. S. and WALKER, B. 2002. Resilience and sustainable development: building adaptive capacity in a world of transformations. AMBIO: A journal of the human environment, 31, 437-440.

FRENCH, P. W. 2004. The changing nature of, and approaches to, UK coastal management at the start of the twenty- first century. The Geographical Journal, 170, 116-125.

FRENCH, J. R. 1993. Numerical simulation of vertical marsh growth and adjustment to accelerated sea-level rise, north Norfolk, UK. Earth Surface Processes and Landforms, 18, 63-81.

GALLOPIN, G. C. 1997. Indicators and their use: information for decision-making. SCOPESCIENTIFIC COMMITTEE ON PROBLEMS OF THE ENVIRONMENT INTERNATIONAL COUNCIL OF SCIENTIFIC UNIONS, 58, 13-27. 
GARTHE, S. and HÜPPOP, O. 2004. Scaling possible adverse effects of marine wind farms on seabirds: developing and applying a vulnerability index. Journal of applied Ecology, 41, 724-734.

GILBERT, J. and VELLINGA, P. 1990. Strategies for adaption to sea level rise. Report of the Coastal Zone Management Subgroup, Intergovernmental Panel on Climate Change. World Meteorological Organization and UN Environmental Programme: the Netherlands.[Links].

GILJUM, S. and POLZIN, C. 2009. Indicator-based evaluation of interlinkages between different sustainable development objectives (INDI-LINK). SERI for European Commission, DG Research.

GORMSEN, E. 1997. The impact of tourism on coastal areas. GeoJournal, 42, 39-54.

GORNITZ, V. 1990. Vulnerability of the East Coast, USA to future sea level rise. Journal of Coastal Research, 9, 201-237.

GORNITZ, V. 1991. Global coastal hazards from future sea level rise. Palaeogeography, Palaeoclimatology, Palaeoecology, 89, 379-398.

GORNITZ, V. 1993. Mean sea level changes in the recent past, Cambridge University Press, Cambridge.

GORNITZ, V. and KANCIRUK, P. 1989. Assessment of global coastal hazards from sea level rise. Oak Ridge National Lab., TN (USA). 1345-1359

GORNITZ, V., ROSENZWEIG, C. and HILLEL, D. 1997. Effects of anthropogenic intervention in the land hydrologic cycle on global sea level rise. Global and Planetary Change, 14, 147-161.

GORNITZ, V. M., DANIELS, R. C., WHITE, T. W. and BIRDWELL, K. R. 1994. The development of a coastal risk assessment database: vulnerability to sea-level rise in the US Southeast. Journal of Coastal Research, 327-338.

GOROKHOVICH, Y., LEISEROWITZ, A. and DUGAN, D. 2013. Integrating coastal vulnerability and community-based subsistence resource mapping in Northwest Alaska. Journal of Coastal Research, 30, 158-169.

GREAT YARMOUTH COUNCIL. 2014. Facts and Figures. [Online]. Available: http://www.great-yarmouth.gov.uk/CHttpHandler.ashx?id=988andp=0 [Accessed $12 / 10 / 2015]$. 
GRIMM, N. B., FAETH, S. H., GOLUBIEWSKI, N. E., REDMAN, C. L., WU, J., BAI, X. and BRIGGS, J. M. 2008. Global change and the ecology of cities. Science, 319, 756-760.

GUHA-SAPIR, D., HARGITT, D. and HOYOIS, P. 2004. Thirty years of natural disasters 1974-2003: The numbers, Presses univ. de Louvain.

GUILLAUMONT, P. 2009. An economic vulnerability index: its design and use for international development policy. Oxford Development Studies, 37, 193-228.

HAHN, M. B., RIEDERER, A. M. and FOSTER, S. O. 2009. The Livelihood Vulnerability Index: A pragmatic approach to assessing risks from climate variability and change-A case study in Mozambique. Global Environmental Change, 19, 74-88.

HANNA, E., HUYBRECHTS, P., STEFFEN, K., CAPPELEN, J., HUFF, R., SHUMAN, C., IRVINE-FYNN, T., WISE, S. and GRIFFITHS, M. 2008. Increased runoff from melt from the Greenland Ice Sheet: a response to global warming. Journal of Climate, $21,331-341$.

HANSEN, J., NAZARENKO, L., RUEDY, R., SATO, M., WILLIS, J., DEL GENIO, A., KOCH, D., LACIS, A., LO, K. and MENON, S. 2005. Earth's energy imbalance: Confirmation and implications. Science, 308, 1431-1435.

HARRISON, P. A., HOLMAN, I. P., COJOCARU, G., KOK, K., KONTOGIANNI, A., METZGER, M. J. and GRAMBERGER, M. 2013. Combining qualitative and quantitative understanding for exploring cross-sectoral climate change impacts, adaptation and vulnerability in Europe. Regional Environmental Change, 13, 761780.

HART, C. 1998. Doing a literature review: Releasing the social science research imagination, Sage.

HART, J. K. 1999. Glacial sedimentology: a case study from Happisburgh, Norfolk. The Description and Analysis of Quaternary Stratigraphic Field Sections. Technical Guide, 7, 209-234.

HARTMUTH, G. 1998. Ansätze und Konzepte eines umweltbezogenen gesellschaftlichen Monitoring. Ziele, Moeglichkeiten und Probleme eines gesellschaftlichen Monitorings, MAB-Mitteilungen, 42, 9-33.

HASLETT, S. 2008. Coastal systems, Routledge. London and New York. 240

LI, L., HEYMSFIELD, G., CARSWELL, J., SCHAUBERT, D. H., MCLINDEN, M. L., CRETICOS, J., PERRINE, M., COON, M., CERVANTES, J. I. \& VEGA, M. 2016. 
The NASA High-Altitude Imaging Wind and Rain Airborne Profiler. IEEE Transactions on Geoscience and Remote Sensing, 54, 298-310.

HINKEL, J. 2011. "Indicators of vulnerability and adaptive capacity": towards a clarification of the science-policy interface. Global Environmental Change, 21, 198208.

HINKEL, J. and KLEIN, R. J. 2009. Integrating knowledge to assess coastal vulnerability to sea-level rise: The development of the DIVA tool. Global Environmental Change, 19, 384-395.

HINKEL, J., LINCKE, D., VAFEIDIS, A. T., PERRETTE, M., NICHOLLS, R. J., TOL, R. S., MARZEION, B., FETTWEIS, X., IONESCU, C. and LEVERMANN, A. 2014. Coastal flood damage and adaptation costs under 21 st century sea-level rise. Proceedings of the National Academy of Sciences, 111, 3292-3297.

HINKEL, J., NICHOLLS, R. J., VAFEIDIS, A. T., TOL, R. S. and AVAGIANOU, T. 2010. Assessing risk of and adaptation to sea-level rise in the European Union: an application of DIVA. Mitigation and Adaptation Strategies for Global Change, 15, 703-719.

HITZ, S. and SMITH, J. 2004. Estimating global impacts from climate change. Global Environmental Change, 14, 201-218.

HOLMES, P., MOORE, H., FOX, H. and ELLIOTT, S. Millennium Coastal Park, LlanelliWales' largest coastal regeneration scheme. Land Reclamation: Extending the Boundaries. Proceedings of the 7th International Conference of the International Affiliation of Land Reclamationists, Runcorn, UK, 13-16 May 2003., 2003. AA Balkema Publishers, 19-23.

HOOZEMANS, F., MARCHAND, M. and PENNEKAMP, H. 1993. A global vulnerability analysis: vulnerability assessment for population, coastal wetlands and rice production on a global scale. Delft Hydraulics, Delft.

HORTON, R., HERWEIJER, C., ROSENZWEIG, C., LIU, J., GORNITZ, V. and RUANE, A. C. 2008. Sea level rise projections for current generation CGCMs based on the semi-empirical method. Geophysical Research Letters, 35.

HOUGHTON, J. 2009. Global warming: the complete briefing, Cambridge University Press. 
HOUGHTON, J. T., DING, Y., GRIGGS, D. J., NOGUER, M., VAN DER LINDEN, P. J., DAI, X., MASKELL, K. and JOHNSON, C. 2001. Climate Change 2001: the scientific basis. 473-512

HULME, M., JENKINS, G., LU, X., TURNPENNY, J., MITCHELL, T., JONES, R., LOWE, J., MURPHY, J., HASSELL, D. and BOORMAN, P. 2002. Climate change scenarios for the United Kingdom: the UKCIP02 scientific report, Tyndall Centre for Climate Change Research, School of Environmental Sciences, University of East Anglia Norwich.

HUNTINGFORD, C., MARSH, T., SCAIFE, A. A., KENDON, E. J., HANNAFORD, J., KAY, A. L., LOCKWOOD, M., PRUDHOMME, C., REYNARD, N. S. and PARRY, S. 2014. Potential influences on the United Kingdom's floods of winter 2013/14. Nature Climate Change, 4, 769-777.

HUQ, S., KOVATS, S., REID, H. and SATTERTHWAITE, D. 2007. Editorial: Reducing risks to cities from disasters and climate change. Environment and Urbanization, 19, 3-15.

HYNDMAN, D. and HYNDMAN, D. 2016. Natural hazards and disasters, Cengage Learning.

IPCC. 2007. Climate change 2007: the physical science basis. Agenda, 6, 333.

JENKINS, D. and NEWBOROUGH, M. 2007. An approach for estimating the carbon emissions associated with office lighting with a daylight contribution. Applied Energy, 84, 608-622.

JEVREJEVA, S., MOORE, J., GRINSTED, A. and WOODWORTH, P. 2008. Recent global sea level acceleration started over 200 years ago? Geophysical Research Letters, 35.

JEVREJEVA, S., MOORE, J. C. and GRINSTED, A. 2012. Sea level projections to AD2500 with a new generation of climate change scenarios. Global and Planetary Change, 80, $14-20$.

JIMÉNEZ, J. A., GUILLÉN, J. \& FALQUÉS, A. 2008. Comment on the article "Morphodynamic classification of sandy beaches in low energetic marine environment” by Gómez-Pujol, L., Orfila, A., Cañellas, B., Alvarez-Ellacuria, A., Méndez, FJ, Medina, R. and Tintoré, J. Marine Geology, 242, pp. 235-246, 2007. Marine Geology, 255, 96-101.

JOHNSON, A. C., ACREMAN, M. C., DUNBAR, M. J., FEIST, S. W., GIACOMELLO, A. M., GOZLAN, R. E., HINSLEY, S. A., IBBOtSON, A. T., JARVIE, H. P. and 
JONES, J. I. 2009. The British river of the future: how climate change and human activity might affect two contrasting river ecosystems in England. Science of the Total Environment, 407, 4787-4798.

JOHNSON, H., KOVATS, R., MCGREGOR, G., STEDMAN, J., GIBBS, M. and WALTON, H. 2005. The impact of the 2003 heat wave on daily mortality in England and Wales and the use of rapid weekly mortality estimates. Euro Surveill, 10, 168171.

JOHNSON, C., PENNING-ROWSELL, E. and PARKER, D. 2007. Natural and imposed injustices: the challenges in implementing fair flood risk management policy in England. The Geographical Journal, 173, 374-390.

JONGMAN, B., WINSEMIUS, H. C., AERTS, J. C., DE PEREZ, E. C., VAN AALST, M. K., KRON, W. and WARD, P. J. 2015. Declining vulnerability to river floods and the global benefits of adaptation. Proceedings of the National Academy of Sciences, 112, E2271-E2280.

KALY, U. L. and COMMISSION, S. P. A. G. 1999. Environmental Vulnerability Index (EVI) to summarise national environmental vulnerability profiles, South Pacific Applied Geoscience Commission Suva, Fiji. 73

KANTAMANENI, K. 2016a. Coastal infrastructure vulnerability: an integrated assessment model. Natural Hazards, 84, 139-154.

KANTAMANENI, K. 2016b. Counting the cost of coastal vulnerability. Ocean \& Coastal Management, 132, 155-169.

KANTAMANENI.K. 2015. Hurricanes and Climate Change: A Case of United Kingdom; European Space Agency [Online]. Available: $\mathrm{http}: / /$ seom.esa.int/atmos2015/page_session16.php\#8p [Accessed 08/08/2015]

KANTAMANENI, K., ALRASHED, I. and PHILLIPS, M. 2015. Cost vs. safety: A novel design for tornado proof homes. HBRC Journal.

KANTAMANENI, K. and PHILLIPS, M. 2013. Two Economic Front-Runners: Will Economies Suffer Due to Lack of Flood Resilience?

KANTAMANENI, K., PHILLIPS, M. 2016. Transformation of Climate: Will Floods and Coastal Erosion Crumble the UK Economy?. International Journal of Climate Change: Impacts and Responses, 8. 45-59. 
KASPERSON, R. E. and ARCHER, E. R. 2005. Vulnerable Peoples and Places. Ecosystems and Human Well-Being: Current State and Trends: Findings of the Condition and Trends Working Group, 1, 143.

KELLY, P. M. and ADGER, W. N. 2000. Theory and practice in assessing vulnerability to climate change andFacilitating adaptation. Climatic change, 47, 325-352.

KELMAN, I. 2003. storm surge deaths: UK. Version.

KEMP, A. C., HORTON, B. P., VANE, C. H., BERNHARDT, C. E., CORBETT, D. R., ENGELHART, S. E., ANISFELD, S. C., PARNELL, A. C. and CAHILL, N. 2013. Sea-level change during the last 2500 years in New Jersey, USA. Quaternary Science Reviews, 81, 90-104.

KENDON, M. and MCCARTHY, M. 2015. The UK's wet and stormy winter of 2013/2014. Weather, 70, 40-47.

KIRSHEN, P., WATSON, C., DOUGLAS, E., GONTZ, A., LEE, J. and TIAN, Y. 2008. Coastal flooding in the Northeastern United States due to climate change. Mitigation and Adaptation Strategies for Global Change, 13, 437-451.

KLEIN, R. J. and NICHOLLS, R. J. 1999. Assessment of coastal vulnerability to climate change. Ambio, 182-187.

KNUTSON, T. R., MCBRIDE, J. L., CHAN, J., EMANUEL, K., HOLLAND, G., LANDSEA, C., HELD, I., KOSSIN, J. P., SRIVASTAVA, A. and SUGI, M. 2010. Tropical cyclones and climate change. Nature Geoscience, 3, 157-163.

KOCHEL, R. C. and BAKER, V. R. 1982. Paleoflood hydrology. Science, 215, 353-361.

KOLEN, B., SLOMP, R., VAN BALEN, W., TERPSTRA, T., BOTTEMA, M. and NIEUWENHUIS, S. 2010. Learning from French experiences with storm Xynthia; damages after a flood. HKV.

KOTTEK, M., GRIESER, J., BECK, C., RUDOLF, B. and RUBEL, F. 2006. World map of the Köppen-Geiger climate classification updated. Meteorologische Zeitschrift, 15, 259-263.

KUMAR, T. S., MAHENDRA, R., NAYAK, S., RADHAKRISHNAN, K. \& SAHU, K. 2010. Coastal vulnerability assessment for Orissa State, east coast of India. Journal of Coastal Research, 523-534.

KUNTE, P. D., JAUHARI, N., MEHROTRA, U., KOTHA, M., HURSTHOUSE, A. S. and GAGNON, A. S. 2014. Multi-hazards coastal vulnerability assessment of Goa, India, using geospatial techniques. Ocean and Coastal Management, 95, 264-281. 
LAGMAY, A. M. F., AGATON, R. P., BAhAlA, M. A. C., BRiOnES, J. B. L. T., CABACABA, K. M. C., CARO, C. V. C., DASAllas, L. L., GONZALO, L. A. L., LADIERO, C. N. and LAPIDEZ, J. P. 2015. Devastating storm surges of Typhoon Haiyan. International journal of disaster risk reduction, 11, 1-12.

LAL, R. 2004. Soil carbon sequestration to mitigate climate change. Geoderma, 123, 1-22.

LANGSTON, C. 2008. Sustainable practices in the built environment, Routledge.

LEE, J. R., ROSE, J., HAMBLIN, R. J. and MOORLOCK, B. S. 2004. Dating the earliest lowland glaciation of eastern England: a pre-MIS 12 early Middle Pleistocene Happisburgh glaciation. Quaternary Science Reviews, 23, 1551-1566.

LEISEROWITZ, A. 2006. Climate change risk perception and policy preferences: The role of affect, imagery, and values. Climatic change, 77, 45-72.

LEWIS, H., MITTERMAIER, M., MYLNE, K., NORMAN, K., SCAIFE, A., NEAL, R., PIERCE, C., HARRISON, D., JEWELL, S. and KENDON, M. 2015. From months to minutes-exploring the value of high-resolution rainfall observation and prediction during the UK winter storms of 2013/2014. Meteorological Applications, 22, 90-104.

LILlESAND, T., KIEFER, R. W. and CHIPMAN, J. 2014. Remote sensing and image interpretation, John Wiley and Sons.

LIN, I. I., PUN, I. F. and LIEN, C. C. 2014. "Category-6” supertyphoon Haiyan in global warming hiatus: Contribution from subsurface ocean warming. Geophysical Research Letters, 41, 8547-8553.

LOÁICIGA, H. 2011. Challenges to phasing out fossil fuels as the major source of the world's energy. Energy and Environment, 22, 659-680.

LUM, T. and MARGESSON, R. 2014. TYPHOON HAIYAN (YOLANDA): US AND INTERNATIONAL RESPONSE TO PHILIPPINES DISASTER*. Current Politics and Economics of South, Southeastern, and Central Asia, 23, 209.

LUMSDAINE, R. L. and PRASAD, E. S. 2003. Identifying the Common Component of International Economic Fluctuations: A New Approach*. The Economic Journal, $113,101-127$.

MACKINDER, H. J. 1907. Britain and the British seas, Clarendon Press.

MACKLIN, M. G., BENITO, G., GREGORY, K., JOHNSTONE, E., LEWIN, J., MICHCZYŃSKA, D., SOJA, R., STARKEL, L. and THORNDYCRAFT, V. R. 2006. Past hydrological events reflected in the Holocene fluvial record of Europe. Catena, 66, 145-154. 
MAHLMAN, J. 1997. Uncertainties in projections of human-caused climate warming. Science, 278, 1416.

MAMAUAG, S. S., ALINO, P. M., MARTINEZ, R. J. S., MUALLIL, R. N., DOCTOR, M. V. A., DizON, E. C., GERONimO, R. C., PANGA, F. M. and CABrAL, R. B. 2013. A framework for vulnerability assessment of coastal fisheries ecosystems to climate change-Tool for understanding resilience of fisheries (VA-TURF). Fisheries Research, 147, 381-393.

MARINE INDUSTRIES LEADERSHIP COUNCIL. 2011. A strategy for growth for the UK Marine Industries [Online]. Available: https://www.gov.uk/government/uploads/system/uploads/attachment_data/file/3181 3/11-1310-strategy-for-growth-uk-marine-industries.pdf [Accessed 12/09/2012].

MARSH, T. and DALE, M. 2002. The UK floods of 2000-2001: a hydrometeorological appraisal. Water and Environment Journal, 16, 180-188.

MARTINEZ, M. L., GALLEGO-FERNANDEZ, J. B., GARCIA-FRANCO, J. G., MOCTEZUMA, C. and JIMENEZ, C. D. 2006. Assessment of coastal dune vulnerability to natural and anthropogenic disturbances along the Gulf of Mexico. Environmental Conservation, 33, 109-117.

MASSELINK, G. and RUSSELL, P. 2011. Coastal erosion in MCCIP annual report card 2010-11, MCCIP Science Review. 1-12

MASSELINK, G. \& RUSSELL, P. 2013. Impacts of climate change on coastal erosion. MCCIP Science Review, 2013, 71-86.

MASSELINK, G., SCOTT, T., CONLEY, D., DAVIDSON, M. \& RUSSELL, P. 2015. Regional variability in Atlantic storm response along the southwest coast of England. The Proceedings of the Coastal Sediments 2015. World Scientific

MAY, V. and HANSOM, J. D. 2003. Coastal Geomorphology of Great Britain, Joint Nature Conservation Committee. 1-30

MCCARTHY, J. J. 2001. Climate change 2001: impacts, adaptation, and vulnerability: contribution of Working Group II to the third assessment report of the Intergovernmental Panel on Climate Change, Cambridge University Press.

MCEWEN, L., HALL, T., HUNT, J., DEMPSEY, M. and HARRISON, M. 2002. Flood warning, warning response and planning control issues associated with caravan parks: the April 1998 floods on the lower Avon floodplain, Midlands region, UK. Applied Geography, 22, 271-305. 
MCGRANAHAN, G., BALK, D. and ANDERSON, B. 2007. The rising tide: assessing the risks of climate change and human settlements in low elevation coastal zones. Environment and urbanization, 19, 17-37.

MCLAUGHLIN, S. and COOPER, J. A. G. 2010. A multi-scale coastal vulnerability index: A tool for coastal managers? Environmental Hazards, 9, 233-248.

MCLAUGHLIN, S., MCKENNA, J. and COOPER, J. 2002. Socio-economic data in coastal vulnerability indices: constraints and opportunities. Journal of Coastal Research, 36, $487-497$

MCLEOD, E., POULTER, B., HINKEL, J., REYES, E. and SALM, R. 2010. Sea-level rise impact models and environmental conservation: A review of models and their applications. Ocean and Coastal Management, 53, 507-517.

MEEHL, G., COVEY, C., DELWORTH, T., LATIF, M., MCAVANEY, B., MITCHELL, J., STOUFFER, R. and TAYLOR, K. Coauthors, 2007: Global climate projections. Climate Change 2007: The Physical Science Basis, S. Solomon et al., Eds. Cambridge University Press.

MEINSHAUSEN, M., MEINSHAUSEN, N., HARE, W., RAPER, S. C., FRIELER, K., KNUTTI, R., FRAME, D. J. and ALLEN, M. R. 2009. Greenhouse-gas emission targets for limiting global warming to 2 C. Nature, 458, 1158-1162.

MENDOZA, E. T. and JIMÉNEZ, J. A. Vulnerability assessment to coastal storms at a regional scale. Proc. 31st Int. Conf. on Coastal Engineering, ASCE, Hamburg, 2008.1-14

MERZ, B., KREIBICH, H., SCHWARZE, R. and THIEKEN, A. 2010. Review article" Assessment of economic flood damage". Natural Hazards and Earth System Sciences, 10, 1697-1724.

MET OFFICE. 2014. Winter 2013/14 [Online]. Available: http://www.metoffice.gov.uk/climate/uk/summaries/2014/winter [Accessed 05/06/2015].

MET OFFICE. 2015. Tropical cyclone facts [Online]. Available: http://www.metoffice.gov.uk/weather/tropicalcyclone/facts [Accessed 08/10/2015].

MEYER, W. B. and TURNER, B. L. 1992. Human population growth and global landuse/cover change. Annual review of ecology and systematics, 23, 39-61.

MITCHELL, J. F., LOWE, J., WOOD, R. A. and VELLINGA, M. 2006. Extreme events due to human-induced climate change. Philosophical Transactions of the Royal 
Society of London A: Mathematical, Physical and Engineering Sciences, 364, $2117-$ 2133.

MOHAMMED, N. Z., GHAZI, A. \& MUSTAFA, H. E. 2013. Positional accuracy testing of Google Earth. International Journal of Multidisciplinary Sciences and Engineering, 4, 6-9.

MOORE, L. J. 2000. Shoreline mapping techniques. Journal of Coastal Research, 111-124. MONTREUIL, A.-L. \& BULLARD, J. E. 2012. A 150-year record of coastline dynamics within a sediment cell: Eastern England. Geomorphology, 179, 168-185.

MONTANARI, A., LONDEI, A. and STANISCIA, B. 2014. Can we interpret the evolution of coastal land use conflicts? Using Artificial Neural Networks to model the effects of alternative development policies. Ocean and Coastal Management, 101, 114-122. MOSS, R. H., EDMONDS, J. A., HIBBARD, K. A., MANNING, M. R., ROSE, S. K., VAN VUUREN, D. P., CARTER, T. R., EMORI, S., KAINUMA, M. and KRAM, T. 2010. The next generation of scenarios for climate change research and assessment. Nature, 463, 747-756.

MOTHA, R. P. and BAIER, W. 2005. Impacts of present and future climate change and climate variability on agriculture in the temperate regions: North America. Increasing Climate Variability and Change. Springer.

MUIR, D., DAWSON, A. G., GAGNON, A. S. \& O'MAHONY, C. Vulnerability and Adaptation to Extreme Coastal Flooding: An Example from the South Ford Area, Scottish Outer Hebrides. Coasts, Marine Structures and Breakwaters: From Sea to Shore e Meeting the Challenges of the Sea. ICE Publishing, Edinburgh, Scotland, UK, 2013.

NASA (National Aeronautics and Space Administration) . 2014. How do hurricanes form? [Online]. Available: http://spaceplace.nasa.gov/hurricanes/en/ [Accessed 08/12/2014]

NASA -EOSDIS (National Aeronautics and Space Administration- earth observing system data and information system). 2016. The next generation earth science discovery school [Online]. Available:

https://reverb.echo.nasa.gov/reverb/\#utf8= $\checkmark$ \&spatial_map=satellite\&spatial_type= rectangle [Accessed 05/10/2016]

NATIONAL OCEANOGRAPHY CENTRE. 2014. The National Tidal and Sea Level Facility [Online]. Available: https://www.ntslf.org/ [Accessed 12/07/2015]. 
NATIONAL OCEANOGRAPHY CENTRE. 2015. [Online]. Available: http://www.ntslf.org/data/uk-network-real-time [Accessed 12/10/2014].

NATURAL RESOURCES WALES. 2016. Flood Risk Map [Online]. Avaliable: https://naturalresources.wales/our-evidence-and-reports/maps/flood-riskmap/?lang=en [Accessed on 10/11/2016]

NEATH PORT TALBOT COUNTY BOROUGH COUNCIL. 2012. Local Flood Risk $\begin{array}{lll}\text { Management } & \text { Strategy. } & \text { Anline]. }\end{array}$ https://www.npt.gov.uk/pdf/LFRMS_NPT_Local_Flood_Risk_Management_Strate gy.pdf [Accessed 10/06/2014].

NEWTON, A., CARRUTHERS, T. J. B. and ICELY, J. 2012. The coastal syndromes and hotspots on the coast. Estuarine, Coastal and Shelf Science, 96, 39-47.

NICHOLLS, R. J. and CAZENAVE, A. 2010. Sea-level rise and its impact on coastal zones. science, 328, 1517-1520.

NICHOLLS, R. J. and KEBEDE, A. S. 2011. The implications on the UK of the impacts of climate change and sea-level rise on critical coastal infrastructure overseas, 2010 to 2100. London, GB, Foresight, Government Office for Science, 79

NICHOLLS, R. J. and SMALL, C. 2002. Improved estimates of coastal population and exposure to hazards released. Eos, Transactions American Geophysical Union, 83, 301-305.

NICHOLLS, R. J. and TOL, R. S. 2006. Impacts and responses to sea-level rise: a global analysis of the SRES scenarios over the twenty-first century. Philosophical Transactions of the Royal Society of London A: Mathematical, Physical and Engineering Sciences, 364, 1073-1095.

NICHOLLS, R. J., WONG, P. P., BURKETT, V., CODIGNOTTO, J., HAY, J., MCLEAN, R., RAGOONADEN, S., WOODROFFE, C. D., ABUODHA, P. and ARBLASTER, J. 2007. Coastal systems and low-lying areas. impacts, adaptation and vulnerability. In: Parry ML, Canziani OF, Palutikof JP, van der Linden PJ, Hanson CE (eds) Contribution of working group II to the fourth assessment report of the intergovernmental panel on climate change. Cambridge University Press, Cambridge,315-356

NOAA. 2016. Global Analysis - April 2016 [Online] Available: https://www.ncdc.noaa.gov/sotc/global/201604 [Accessed 02/04/2016] 
NORFOLK HERITAGE EXPLORER. 2015. Great Yarmouth: Geology and Environment

[Online]. Available: http://www.heritage.norfolk.gov.uk/record-details?TNF432Great-Yarmouth-Geology-and-Environment-(Urban-Summary)

[Accessed 19/11/2015].

ONS (Office of National Statistics) 2012. 2011 Census: Population and Household Estimates for Wales, $2011 . \quad$ [Online]. Available: http://www.ons.gov.uk/peoplepopulationandcommunity/populationandmigration/po pulationestimates/bulletins/2011censuspopulationandhouseholdestimatesforwales/2 012-07-16 [Accessed 12/09/2014].

ONS (Office of National Statistics 2014. Population Projections. [Online]. Available: https://www.ons.gov.uk/peoplepopulationandcommunity/populationandmigration/p opulationprojections [Accessed 12/12/2015].

O'RIORDAN, T. 1996. Politics of climate change: a European perspective, Psychology Press.

OLIVER-SMITH, A. 2009. Sea level rise and the vulnerability of coastal peoples: responding to the local challenges of global climate change in the 21st century, UNU-EHS.

OVERPECK, J., HUGHEN, K., HARDY, D., BRADLEY, R., CASE, R., DOUGLAS, M., FINNEY, B., GAJEWSKI, K., JACOBY, G. and JENNINGS, A. 1997. Arctic environmental change of the last four centuries. Science, 278, 1251-1256.

PACHAURI, R. K., ALLEN, M., BARROS, V., BROOME, J., CRAMER, W., CHRIST, R., CHURCH, J., CLARKE, L., DAHE, Q. and DASGUPTA, P. 2014. Climate Change 2014: Synthesis Report. Contribution of Working Groups I, II and III to the Fifth Assessment Report of the Intergovernmental Panel on Climate Change.

PAll, P., AINA, T., STONE, D. A., STOTT, P. A., NOZAWA, T., HilBERTS, A. G., LOHMANN, D. and ALLEN, M. R. 2011. Anthropogenic greenhouse gas contribution to flood risk in England and Wales in autumn 2000. Nature, 470, 382385.

PALMER, B., VAN DER ELST, R., MACKAY, F., MATHER, A., SMITH, A., BUNDY, S., THACKERAY, Z., LEUCI, R. and PARAK, O. 2011. Preliminary coastal vulnerability assessment for KwaZulu-Natal, South Africa. Journal of Coastal Research, 1390.

PARAHOO, K. 2006. Nursing research: principles, process and issues. Palgrave Macmillan 
PARMESAN, C. and YOHE, G. 2003. A globally coherent fingerprint of climate change impacts across natural systems. Nature, 421, 37-42.

PARSON, E. A. 2006. Reflections on air capture: The political economy of active intervention in the global environment. Climatic Change, 74, 5-15.

PENDLETON, E. A., THIELER, E. R. and WILLIAMS, S. J. 2010. Importance of coastal change variables in determining vulnerability to sea-and lake-level change. Journal of Coastal Research, 176-183.

PENNING-ROWSEll, E., PRIEST, S., PARKER, D., MORRIS, J., TUNSTALl, S., VIAVATTENE, C., CHATTERTON, J. and OWEN, D. 2014. Flood and coastal erosion risk management: a manual for economic appraisal, Routledge.London. 364-384

PETHICK, J. S. and CROOKS, S. 2000. Development of a coastal vulnerability index: a geomorphological perspective. Environmental Conservation, 27, 359-367.

PHILLIPS, M. and CRISP, S. 2010. Sea level trends and NAO influences: the Bristol Channel/Severn Estuary. Global and Planetary Change, 73, 211-218.

PHILLIPS, M., POWELL, V. and DUCK, R. 2009. Coastal regeneration at Llanelli, South Wales, UK: lessons not learned. Journal of Coastal Research, 1276-1280.

PHILLIPS, M., REES, E. and THOMAS, T. 2013. Winds, sea levels and North Atlantic Oscillation (NAO) influences: An evaluation. Global and Planetary Change, 100, 145-152.

PHILLIPS, M. R. and JONES, A. L. 2006. Erosion and tourism infrastructure in the coastal zone: Problems, consequences and management. Tourism Management, 27, 517524.

PHILLIPS, M.R. and HOUSE, C. 2009. An evaluation of priorities for beach tourism: case studies from South Wales, UK. Tourism Management. Vol 30(2): 176-183.

PHILLIPS, M.R., ABRAHAM, E. J., WILLIAMS, A. T. and HOUSE, C. 2007. Function analysis as a coastal management tool: the South Wales coastline UK. Journal of Coastal Conservation. Vol. 11(3): 159-170.

PHILLIPS M.R. 2008. Beach erosion and marine aggregate dredging: a question of evidence? The Geographical Journal. Vol 174(4): 332-343.

PILKEY, O. H. 1987. An analysis of coastal recession models: North Carolina coast, in Nummedal, D., Pilkey, O. H., and Howard, J. (eds.), Sea-level Fluctuations and 
Coastal Evolution, Society of Economic Paleontologists and Mineralogists Special Publication No. 41, 59-68.

PITT, M. 2008. Learning lessons from the 2007 floods. London : Cabinet Office.”1-505

POULTON, C. V., LEE, J., HOBBS, P., JONES, L. and HALL, M. 2006. Preliminary investigation into monitoring coastal erosion using terrestrial laser scanning: case study at Happisburgh, Norfolk. Bulletin of the Geological Society of Norfolk, 45-64.

POTERE, D., 2008. Horizontal positional accuracy of Google Earth's high-resolution imagery archive. Sensors, 7973-7981.

PRINCE, S. H. 1920. Catastrophe and social change, based upon a sociological study of the Halifax disaster, Columbia university.

PULIGHE, G., BAIOCCHI, V. \& LUPIA, F. 2016. Horizontal accuracy assessment of very high resolution Google Earth images in the city of Rome, Italy. International Journal of Digital Earth, 9, 342-362.

PYE, K. and BLOTT, S. J. 2006. Coastal processes and morphological change in the Dunwich-Sizewell area, Suffolk, UK. Journal of Coastal Research, 453-473.

QUINN, J., PHILIP, L. and MURPHY, W. 2009. Understanding the recession of the Holderness Coast, east Yorkshire, UK: a new presentation of temporal and spatial patterns. Quarterly Journal of Engineering Geology and Hydrogeology, 42, 165-178.

RAHMSTORF, S. 2010. A new view on sea level rise. Nature reports climate change, 4445.

RAHMSTORF, S., CAZENAVE, A., CHURCH, J. A., HANSEN, J. E., KEELING, R. F., PARKER, D. E. and SOMERVILLE, R. C. 2007. Recent climate observations compared to projections. Science, 316, 709-709.

RAMANATHAN, V. and CARMICHAEL, G. 2008. Global and regional climate changes due to black carbon. Nature Geoscience, 1, 221-227.

RAMIERI, E., HARTLEY, A., BARBANTI, A., SANTOS, F. D., GOMES, A., HILDEN, M., LAIHONEN, P., MARINOVA, N. and SANTINI, M. 2011. Methods for assessing coastal vulnerability to climate change. European Environment Agency, European topic centre on climate change impacts, vulnerability and adaptation.

RANGEl-BUitrago N. G., THOMAS, T., PhilliPS, M. R., ANFUSO, G. and WILliAMS, A. T. 2016. Wave Climate, Storminess, and Northern Hemisphere Teleconnection Patterns Influences: The Outer Bristol Channel, South Wales, UK. Journal of Coastal Research. 1262-1276. 
RE, M. 1997. Flooding and insurance. Munich Re, Munich, Germany, 78.

RE, M. 2000. Topics-annual Review of Natural Disasters 1999. Munich Reinsurance Group, Munich, Germany.

RE, M. 2007. Natural Catastrophes 2006: Analyses, Assessments. Positions. Munich Re Publications, Munich.

ROGERS, J., LORAN, F. \& ASTLE, G. National coastal erosion risk mapping the first national run. Coastal Engineering, Proceedings of the 31 st International Conference, Hamburg, Germany, 2008. World Scientific, 4237-4249.

ROMIEU, E., WELlE, T., SCHNEIDERBAUER, S., PELLING, M. \& VINCHON, C. 2010. Vulnerability assessment within climate change and natural hazard contexts: revealing gaps and synergies through coastal applications. Sustainability Science, 5, 159-170.

RUBEL, F. and KOTTEK, M. 2010. Observed and projected climate shifts 1901-2100 depicted by world maps of the Köppen-Geiger climate classification. Meteorologische Zeitschrift, 19, 135-141.

RYGEL, L., O'SULLIVAN, D. and YARNAL, B. 2006. A method for constructing a social vulnerability index: an application to hurricane storm surges in a developed country. Mitigation and Adaptation Strategies for Global Change, 11, 741-764.

SAVILLS WORLD RESEARCH. 2016. [Online]. Available: Around the world in dollors and cents. http://pdf.euro.savills.co.uk/global-research/around-the-world-in-dollarsand-cents-2016.pdf [Accessed 02/04/2016].

SCHELLNHUBER, H. J. 2006. Avoiding dangerous climate change, Cambridge University Press.

SCHRÖTER, D., CRAMER, W., LEEMANS, R., PRENTICE, I. C., ARAÚJO, M. B., ARNELL, N. W., BONDEAU, A., BUGMANN, H., CARTER, T. R. and GRACIA, C. A. 2005. Ecosystem service supply and vulnerability to global change in Europe. Science, 310, 1333-1337.

SCRASE, J. I. and SHEATE, W. R. 2005. Re-framing flood control in England and Wales. Environmental Values, 14, 113-137.

SEINFELD, J. H. and PANDIS, S. N. 2012. Atmospheric chemistry and physics: from air pollution to climate change, John Wiley and Sons.

SENEVIRATNE, S. I., NICHOLLS, N., EASTERLING, D., GOODESS, C. M., KANAE, S., KOSSIN, J., LUO, Y., MARENGO, J., MCINNES, K. and RAHIMI, M. 2012. 
Changes in climate extremes and their impacts on the natural physical environment. Managing the risks of extreme events and disasters to advance climate change adaptation, 109-230.

SHAW, J., TAYLOR, R. B., FORBES, D. L., RUZ, M. and SOLOMON, S. 1998. Sensitivity of the coasts of Canada to sea-level rise, Geological Survey of Canada Ottawa. Bulletin, 505

SHINE, K. P., FUGlestVedT, J. S., HAILEMARIAM, K. and STUBER, N. 2005. Alternatives to the global warming potential for comparing climate impacts of emissions of greenhouse gases. Climatic Change, 68, 281-302.

SIBLEY, A. 2010. Analysis of extreme rainfall and flooding in Cumbria 18-20 November 2009. Weather, 65, 287-292.

SINGH, A. 2006. Assessing coastal vulnerability: developing a global index for measuring risk, UNEP/Earthprint.

SISTERMANS, P. and NIEUWENHUIS, O. 2013. Holderness Coast (United Kingdom). Case Study. Amerstfoort: DHV Group, nd.

SLINGO, J., BELCHER, S., SCAIFE, A., MCCARTHY, M., SAULTER, A., MCBEATH, K., JENKINS, A., HUNTINGFORD, C., MARSH, T. and HANNAFORD, J. 2014. The recent storms and floods in the UK. Exeter, UK Met Office, 27pp. (UNSPECIFIED)

SMEETS, E., WETERINGS, R. and VOOR TOEGEPASTNATUURWETENSCHAPPELIJK, N. C. O. 1999. Environmental indicators: Typology and overview, European Environment Agency Copenhagen.

SMIT, B. and PILIFOSOVA, O. 2003. Adaptation to climate change in the context of sustainable development and equity. Sustainable Development, 8, 9.

SMITH, K. 2013. Environmental hazards: assessing risk and reducing disaster, Routledge. STERN, N. 2007. The economics of climate change: the Stern review, cambridge University press.

STERN, N. H., PETERS, S., BAKHSHI, V., BOWEN, A., CAMERON, C., CATOVSKY, S., CRANE, D., CRUICKSHANK, S., DIETZ, S. \& EDMONSON, N. 2006. Stern Review: The economics of climate change, Cambridge University Press Cambridge.

STEYNOR, A., GAWITH, M. \& STREET, R. 2012. Engaging users in the development and delivery of climate projections: the UKCIP experience of UKCP09. UKCIP. Oxford. 
STROBL, E. 2011. The economic growth impact of hurricanes: evidence from US coastal counties. Review of Economics and Statistics, 93, 575-589.

SULLIVAN, C. and MEIGH, J. 2005. Targeting attention on local vulnerabilities using an integrated index approach: the example of the climate vulnerability index. Water Science and Technology, 51, 69-78.

SUTTON-GRIER, A. E., WOWK, K. and BAMFORD, H. 2015. Future of our coasts: the potential for natural and hybrid infrastructure to enhance the resilience of our coastal communities, economies and ecosystems. Environmental Science and Policy, 51, 137-148.

TAN, Y. and CHADBOURNE, M. 2015. Spatially identifying vulnerable communities to climate change impact in South Australia. Local Environment, 20, 1265-1289.

THE CABINET OFFICE. 2012. Chapter 4 Local responder risk assessment duty-Revision to Emergency Preparedness-. Civil Contingencies Act Enhancement Programme [Online]. Available:

https://www.gov.uk/government/uploads/system/uploads/attachment_data/file/6102 7/Chapter-4-Local_20Responder-Risk-assessment-duty-revised-March.pdf. [Accessed 10/11/2016].

THE CANADIAN COUNCIL OF MINISTRIES OF THE ENVIRONMENT. 2013.

Climate, nature, people: indicators of Canada's climate change. [Online].

Available: www.ccme.ca [Accessed 28/09/2-15].

THE TIMES. 2015. Flood warnings as more rain arrives [Online]. Available: http://www.thetimes.co.uk/tto/multimedia/archive/00500/144566140_500385b.jpg [Accessed 05/06/2015]

THE TIMES. 2014. Landmarks that stood firm for centuries swept away by storm [Online]. Available: http://www.thetimes.co.uk/tto/weather/article3967743.ece [Accessed 03/04/2015]

THE WORLD BANK. 2015. GDP at market prices [Online]. Available: http://data.worldbank.org/indicator/NY.GDP.MKTP.CD [Accessed 06/12/2015].

THE WORLD BANK. 2016. UK GDP DATA [Online]. Available: http://data.worldbank.org/country/united-kingdom [Accessed 01/02/2016].

THIELER, E. R. \& HAMMAR-KLOSE, E. S. 1999. National assessment of coastal vulnerability to sea-level rise; US Atlantic Coast. 
THOMALLA, F. and VINCENT, C. 2003. Beach response to shore-parallel breakwaters at Sea Palling, Norfolk, UK. Estuarine, Coastal and Shelf Science, 56, 203-212.

THOMAS, T., PHILLIPS, M. and LOCK, G. 2015. An analysis of subaerial beach rotation and influences of environmental forcing adjacent to the proposed Swansea Bay Tidal Lagoon. Applied Geography, 62, 276-293.

THOMAS, T., PHILLIPS, M. \& WILLIAMS, A. 2010. Mesoscale evolution of a headland bay: Beach rotation processes. Geomorphology, 123, 129-141.

THOMAS, T., PHILLIPS, M., WILLIAMS, A. \& JENKINS, R. 2011. Medium timescale beach rotation; gale climate and offshore island influences. Geomorphology, 135, 97-107.

THOMAS, T., PHILliPS, M. R., WILliAMS, A. T. \& JENKINS, R. E. 2014. Links between wave forcing, offshore islands and a macro-tidal headland-bound bay beach. Earth Surface Processes and Landforms, 39, 143-155.

THORNE, C. R., EVANS, E. P. and PENNING-ROWSELL, E. C. 2007. Future flooding and coastal erosion risks, Thomas Telford.

TOL, R. S. 2002. Estimates of the damage costs of climate change. Part 1: Benchmark estimates. Environmental and Resource Economics, 21, 47-73.

TURNER, R. K., SUBAK, S. and ADGER, W. N. 1996. Pressures, trends, and impacts in coastal zones: interactions between socioeconomic and natural systems. Environmental Management, 20, 159-173.

UKCIP (UK CLIMATE IMPACTS PROGRAMME). 2010. UKCP09 sea level change estimates [Online]. Available: http://www.ukcip.org.uk/wordpress/wpcontent/PDFs/UKCIP_sea-level.pdf [Accessed 02/02/2013].

UNEP (UNITED NATIONS ENVIRONMENT PROGRAMME)a. 2013. Our Planet [Online]. Available: http://pm22100.net/pages/enercoop/01_dossiers/04-unepcoastal.htm [Accessed 06/03/2014]

UNEP (UNITED NATIONS ENVIRONMENT PROGRAMME)b. 2013. Vital Water Graphics- Coastal populations and shoreline degradation [Online]. Available: http://www.unep.org/dewa/vitalwater/article180.html [Accessed 08/05/2014]

VAN DER WAL, D. \& PYE, K. 2004. Patterns, rates and possible causes of saltmarsh erosion in the Greater Thames area (UK). Geomorphology, 61, 373-391.

VAZ, B., WILLIAMS, A. T., SILVA, C. P. D. and PHILLIPS, M. 2009. The importance of user's perception for beach management. Journal of Coastal Research, 1164-1168. 
VELlingA, P., KATSMAN, C., STERL, A., BEERSMA, J., HAZELEGER, W., CHURCH, J., KOPP, R., KROON, D., OPPENHEIMER, M. and PLAG, H. 2009. Exploring high-end climate change scenarios for flood protection of the Netherlands. KNMI. International scientific assessment carried out at request of the delta committee. Scientific Report WR-2009-05. KNMI/Alterra, The Netherlands

VINCENT, K. 2004. Creating an index of social vulnerability to climate change for Africa. Tyndall Center for Climate Change Research. Working Paper, 56, 41.

VITTAL HEGDE, A. and RADHAKRISHNAN REJU, V. 2007. Development of coastal vulnerability index for Mangalore coast, India. Journal of Coastal Research, 11061111.

WADEY, M. P., NICHOLLS, R. J. \& HAIGH, I. 2013. Understanding a coastal flood event: the 10th March 2008 storm surge event in the Solent, UK. Natural hazards, 67, 829854

WALTHER, G.-R., POST, E., CONVEY, P., MENZEL, A., PARMESAN, C., BEEBEE, T. J., FROMENTIN, J.-M., HOEGH-GULDBERG, O. and BAIRLEIN, F. 2002. Ecological responses to recent climate change. Nature, 416, 389-395.

WARWIC UNIVERSITY. 2010. UK Maritime Industry. [Online]. Available: http://www2.warwick.ac.uk/fac/soc/ier/ngrf/stem/basics/sources/stem_supplementuk_maritime_industry.pdf [Accessed 12/10/2014].

WHEATER, C. P. and COOK, P. A. 2000. Using statistics to understand the environment, Psychology Press.

WEISSE, R., BELlAFIORE, D., MENÉNDEZ, M., MÉNDEZ, F., NICHOLLS, R. J., UMGIESSER, G. and WILLEMS, P. 2014. Changing extreme sea levels along European coasts. Coastal Engineering, 87, 4-14.

WIEDMANN, T. and MINX, J. 2008. A definition of 'carbon footprint'. Ecological Economics Research Trends, 1, 1-11.

WILBY, R. L. and KEENAN, R. 2012. Adapting to flood risk under climate change. Progress in Physical Geography, 0309133312438908.

WOLF, J. and WOOLF, D. K. 2006. Waves and climate change in the north-east Atlantic. Geophysical Research Letters, 33.

WOOD, S. and COWIE, A. 2004. A review of greenhouse gas emission factors for fertiliser production. IEA Bioenergy Task, 2004. 1-20. 
WUEBBLES, D. J. and JAIN, A. K. 2001. Concerns about climate change and the role of fossil fuel use. Fuel Processing Technology, 71, 99-119.

ZANUTTIGH, B., SIMCIC, D., BAGLI, S., BOZZEDA, F., PIETRANTONI, L., ZAGONARI, F., HOGGART, S. and NICHOLLS, R. J. 2014. THESEUS decision support system for coastal risk management. Coastal Engineering, 87, 218-239.

ZSAMBOKY, M., FERNÁNDEZ-BILBAO, A., SMITH, D., KNIGHT, J. and ALLAN, J. 2011. Impacts of climate change on disadvantaged UK coastal communities. York, UK: Joseph Rowntree Foundation. 


\section{APPENDICES}

Please see the volume 2 


\section{Assessing coastal vulnerability: development of a combined physical and economic index}

\section{Komali Kantamaneni (B.Sc., M.Sc., M.B.A)}

Director of Studies: Professor Mike Phillips Second Supervisor: Professor Rhian Jenkins

Submitted to the University of Wales Trinity Saint David in partial fulfilment for the degree of Doctor of Philosophy

University of Wales Trinity Saint David Faculty of Architecture, Computing and Engineering April 2017

Volume 2 


\section{Declaration}

This work has not previously been accepted in substance for any degree and is not being concurrently submitted in candidature for any degree.

Signed

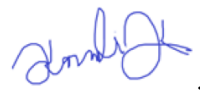

(candidate)

Date $.05 / 06 / 2017$

\section{STATEMENT 1}

This thesis is the result of my own investigations, except where otherwise stated. Where correction services have been used the extent and nature of the correction is clearly marked in a footnote(s). Other sources are acknowledged by footnotes giving explicit references. A bibliography is appended.

Signed

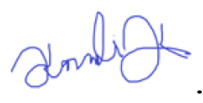
(candidate)

Date $. .05 / 06 / 2017$

\section{STATEMENT 2}

I hereby give consent for my thesis, if accepted, to be available for photocopying and for inter-library loan, and for the title and summary to be made available to outside organisations.

Signed

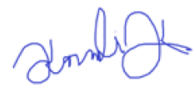
(candidate)

Date $.05 / 06 / 2017$

\section{STATEMENT 3}

I hereby give consent for my thesis, if accepted, to be available for deposit in the University's digital repository.

Signed<smiles></smiles>
(candidate)

Date $.05 / 06 / 2017$

NB: Candidates on whose behalf a bar on access has been approved by the University, should use the following version of Statement 2:

I hereby give consent for my thesis, if accepted, to be available for photocopying and for inter-library loans after expiry of a bar on access approved by the University of Wales on the special recommendation of the Member Institution concerned.

Signed

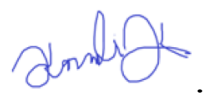
(candidate)

Date $.05 / 06 / 2017$ 


\section{Table of Contents}

DECLARATION 2

APPENDICES 4

1. APPENDIX - PCVI AND ECVI DATA 5

2. APPENDIX - PROFESSIONAL ACHIEVEMENTS AND AWARDS 34

EU -FUNDING PROJECT -PORTUGAL - 2017 35

INVITED GUEST RESEARCHER - BRITISH COUNCIL/NEWTON FUND 36

CONFERENCE CHAIR/PRESENTER -

IMPERIAL COLLEGE LONDON-2016

GRADUATE SCHOLAR AWARDS - (2014 -2016)

VISITING SCHOLAR AWARD - 2015

AS A CONFERENCE CHAIR - ICELAND, 2014

AS A PRINCIPAL INVESTIGATOR-CHINA, 2014

DURING Visit OF CHINESE ACADEMY OF SCIENCES

POSTER - EXETER UNIVERSITY, 2013

47

PRESENTATION AT TyNDALl CENTRE - CARdifF UnIVERSITY, 2013

48

Key Publications 


\section{APPENDICES}




\section{Appendix - PCVI and ECVI Data}

Table 1: Beach width (m)

\begin{tabular}{|c|c|c|c|c|c|c|c|}
\hline $\begin{array}{l}\text { Shoreline } \\
\text { Measurement } \\
\text { No }\end{array}$ & $\begin{array}{l}\text { Beach } \\
\text { Width } \\
\text { (m) }\end{array}$ & $\begin{array}{l}\text { Shoreline } \\
\text { Measurement } \\
\text { No }\end{array}$ & $\begin{array}{l}\text { Beach } \\
\text { Width (m) }\end{array}$ & $\begin{array}{l}\text { Shoreline } \\
\text { Measurement } \\
\text { No }\end{array}$ & $\begin{array}{l}\text { Beach } \\
\text { Width } \\
\text { (m) }\end{array}$ & $\begin{array}{l}\text { Shoreline } \\
\text { Measurement } \\
\text { No }\end{array}$ & $\begin{array}{l}\text { Beach } \\
\text { Width } \\
(\mathrm{m})\end{array}$ \\
\hline 1 & 630 & 41 & 28.3 & 81 & 129 & 121 & 123 \\
\hline 2 & 360 & 42 & 58.19 & 82 & 128 & 122 & 192 \\
\hline 3 & 364 & 43 & 42.22 & 83 & 139 & 123 & 100 \\
\hline 4 & 260 & 44 & 1.4 & 84 & 219 & 124 & 198 \\
\hline 5 & 109 & 45 & 1.4 & 85 & 159 & 125 & 339 \\
\hline 6 & 170 & 46 & 590 & 86 & 173 & 126 & 315 \\
\hline 7 & 76 & 47 & 565 & 87 & 220 & 127 & 323 \\
\hline 8 & 21 & 48 & 12 & 88 & 220 & 128 & 335 \\
\hline 9 & 20.71 & 49 & 13.75 & 89 & 255 & 129 & 302 \\
\hline 10 & 21.26 & 50 & 10.05 & 90 & 213 & 130 & 371 \\
\hline 11 & 26.3 & 51 & 11.61 & 91 & 50 & 131 & 366 \\
\hline 12 & 24 & 52 & 12.54 & 92 & 107 & 132 & 557 \\
\hline 13 & 25.6 & 53 & 14.72 & 93 & 121 & 133 & 590 \\
\hline 14 & 27.34 & 54 & 14.53 & 94 & 61 & 134 & 775 \\
\hline 15 & 125 & 55 & 10.16 & 95 & 107 & 135 & 500 \\
\hline 16 & 213 & 56 & 18.48 & 96 & 53 & 136 & 604 \\
\hline 17 & 378 & 57 & 17.35 & 97 & 82 & 137 & 820 \\
\hline 18 & 121 & 58 & 11 & 98 & 37 & 138 & 542 \\
\hline 19 & 11.39 & 59 & 10.39 & 99 & 111.35 & 139 & 400 \\
\hline 20 & 18.76 & 60 & 12.36 & 100 & 148 & 140 & 95 \\
\hline 21 & 48.13 & 61 & 17.26 & 101 & 60 & 141 & 1400 \\
\hline 22 & 34.7 & 62 & 16.68 & 102 & 113.7 & 142 & 1600 \\
\hline 23 & 49.57 & 63 & 19.29 & 103 & 67.99 & 143 & 1900 \\
\hline 24 & 41.64 & 64 & 6.72 & 104 & 72 & 144 & 1900 \\
\hline 25 & 41.25 & 65 & 7.4 & 105 & 83 & 145 & 898 \\
\hline 26 & 42.9 & 66 & 296 & 106 & 168 & 146 & 995 \\
\hline 27 & 35.1 & 67 & 246 & 107 & 67 & 147 & 550 \\
\hline 28 & 74.73 & 68 & 223 & 108 & 63 & 148 & 650 \\
\hline 29 & 42.23 & 69 & 143 & 109 & 179 & 149 & 760 \\
\hline 30 & 21.22 & 70 & 132 & 110 & & 150 & 696 \\
\hline 31 & 27.29 & 71 & 143.76 & 111 & & 151 & 470 \\
\hline 32 & 32.42 & 72 & 145.93 & 112 & 835 & 152 & 384 \\
\hline 33 & 37.63 & 73 & 309 & 113 & 530 & 153 & 362 \\
\hline 34 & 139 & 74 & 326 & 114 & 382 & 154 & 250 \\
\hline 35 & 135 & 75 & 296 & 115 & 351 & 155 & 120 \\
\hline 36 & 91.56 & 76 & 255 & 116 & 327 & 156 & 38 \\
\hline 37 & 107 & 77 & 263 & 117 & 373 & 157 & 18 \\
\hline 38 & 17.44 & 78 & 220 & 118 & 360 & 158 & 65 \\
\hline 39 & 17.34 & 79 & 214 & 119 & 364 & & \\
\hline 40 & 15.78 & 80 & 160 & 120 & 245 & & \\
\hline
\end{tabular}


Table 2: Dune width (m)

\begin{tabular}{|c|c|c|c|c|c|c|c|}
\hline $\begin{array}{l}\text { Shoreline } \\
\text { Measurement } \\
\text { No }\end{array}$ & $\begin{array}{l}\text { Dune } \\
\text { Width } \\
\text { (m) }\end{array}$ & $\begin{array}{l}\text { Shoreline } \\
\text { Measurement } \\
\text { No }\end{array}$ & $\begin{array}{l}\text { Dune } \\
\text { Width } \\
\text { (m) }\end{array}$ & $\begin{array}{l}\text { Shoreline } \\
\text { Measurement } \\
\text { No }\end{array}$ & $\begin{array}{l}\text { Dune } \\
\text { Width } \\
\text { (m) }\end{array}$ & $\begin{array}{l}\text { Shoreline } \\
\text { Measurement } \\
\text { No }\end{array}$ & $\begin{array}{l}\text { Dune } \\
\text { Width } \\
\text { (m) }\end{array}$ \\
\hline 1 & 17.49 & 41 & & 81 & & 121 & \\
\hline 2 & 18 & 42 & & 82 & & 122 & 49 \\
\hline 3 & & 43 & & 83 & & 123 & 110.68 \\
\hline 4 & 13 & 44 & & 84 & & 124 & \\
\hline 5 & 59 & 45 & & 85 & & 125 & \\
\hline 6 & 63 & 46 & & 86 & & 126 & \\
\hline 7 & & 47 & 16 & 87 & & 127 & \\
\hline 8 & & 48 & & 88 & & 128 & \\
\hline 9 & & 49 & & 89 & 184 & 129 & \\
\hline 10 & 10 & 50 & & 90 & & 130 & \\
\hline 11 & & 51 & & 91 & & 131 & 29 \\
\hline 12 & & 52 & & 92 & & 132 & 163 \\
\hline 13 & & 53 & & 93 & & 133 & \\
\hline 14 & & 54 & & 94 & & 134 & \\
\hline 15 & & 55 & 35 & 95 & & 135 & \\
\hline 16 & & 56 & 304 & 96 & & 136 & \\
\hline 17 & & 57 & 336 & 97 & & 137 & \\
\hline 18 & & 58 & 251 & 98 & & 138 & \\
\hline 19 & 21.44 & 59 & 60 & 99 & 58.91 & 139 & \\
\hline 20 & 33 & 60 & 33 & 100 & 49.81 & 140 & 95 \\
\hline 21 & & 61 & 115 & 101 & & 141 & \\
\hline 22 & & 62 & 60 & 102 & & 142 & \\
\hline 23 & & 63 & 71 & 103 & & 143 & \\
\hline 24 & & 64 & 47 & 104 & & 144 & \\
\hline 25 & & 65 & 17 & 105 & & 145 & \\
\hline 26 & & 66 & 91 & 106 & & 146 & \\
\hline 27 & & 67 & 34.32 & 107 & & 147 & \\
\hline 28 & & 68 & 157 & 108 & & 148 & \\
\hline 29 & & 69 & & 109 & 289 & 149 & \\
\hline 30 & & 70 & & 110 & 33.75 & 150 & \\
\hline 31 & & 71 & & 111 & 515 & 151 & \\
\hline 32 & & 72 & & 112 & 345 & 152 & \\
\hline 33 & & 73 & 55.17 & 113 & 66 & 153 & \\
\hline 34 & & 74 & 9.5 & 114 & 55 & 154 & \\
\hline 35 & 78.79 & 75 & & 115 & & 155 & \\
\hline 36 & 107.8 & 76 & & 116 & & 156 & \\
\hline 37 & 79 & 77 & 39.36 & 117 & & 157 & \\
\hline 38 & & 78 & 20 & 118 & & 158 & \\
\hline 39 & & 79 & & 119 & & & \\
\hline 40 & & 80 & & 120 & & & \\
\hline
\end{tabular}


Table 3: Coastal slope (\%)

\begin{tabular}{|c|c|c|c|c|c|c|c|}
\hline $\begin{array}{l}\text { Shoreline } \\
\text { Measurement } \\
\text { No }\end{array}$ & $\begin{array}{l}\text { Coastal } \\
\text { Slope }(\%)\end{array}$ & $\begin{array}{l}\text { Shoreline } \\
\text { Measurement No }\end{array}$ & $\begin{array}{l}\text { Coastal } \\
\text { Slope }(\%)\end{array}$ & $\begin{array}{l}\text { Shoreline } \\
\text { Measurement } \\
\text { No }\end{array}$ & $\begin{array}{l}\text { Coastal } \\
\text { Slope (\%) }\end{array}$ & $\begin{array}{l}\text { Shoreline } \\
\text { Measurement } \\
\text { No }\end{array}$ & $\begin{array}{l}\text { Coastal } \\
\text { Slope (\%) }\end{array}$ \\
\hline 1 & 2.5 & 41 & 4.1 & 81 & 1.2 & 121 & 4.2 \\
\hline 2 & & 42 & 3.6 & 82 & 1.3 & 122 & 2.3 \\
\hline 3 & & 43 & 2.2 & 83 & 2.2 & 123 & 1.2 \\
\hline 4 & & 44 & 1.7 & 84 & 1.3 & 124 & 15.6 \\
\hline 5 & & 45 & 0.9 & 85 & 0.9 & 125 & 10.9 \\
\hline 6 & & 46 & 3.1 & 86 & 3.9 & 126 & 3.9 \\
\hline 7 & 13.3 & 47 & 1.8 & 87 & 2.9 & 127 & 2.6 \\
\hline 8 & 17.8 & 48 & 2.3 & 88 & 2 & 128 & 2.7 \\
\hline 9 & 19.2 & 49 & 3.8 & 89 & 0.6 & 129 & 2.1 \\
\hline 10 & 6.8 & 50 & 1.7 & 90 & 1.9 & 130 & 3.8 \\
\hline 11 & 10.3 & 51 & 0.5 & 91 & 1.4 & 131 & 3 \\
\hline 12 & 19.8 & 52 & 1.8 & 92 & 0.7 & 132 & 3.1 \\
\hline 13 & 6 & 53 & 1.4 & 93 & 1.1 & 133 & 6.7 \\
\hline 14 & 2.4 & 54 & 1.7 & 94 & 1.2 & 134 & 1 \\
\hline 15 & 36 & 55 & 0.5 & 95 & 1.5 & 135 & 3 \\
\hline 16 & 21.3 & 56 & 1.5 & 96 & 0.9 & 136 & 4.1 \\
\hline 17 & 29.5 & 57 & 1.1 & 97 & 1.1 & 137 & 6.8 \\
\hline 18 & 48 & 58 & 0.9 & 98 & 1.1 & 138 & 11 \\
\hline 19 & 0.6 & 59 & 0.7 & 99 & 0.6 & 139 & 1.7 \\
\hline 20 & 1.1 & 60 & 0.6 & 100 & 1.2 & 140 & 3.6 \\
\hline 21 & 0.9 & 61 & 1 & 101 & 1.2 & 141 & 8.8 \\
\hline 22 & 1.3 & 62 & 0.7 & 102 & 1.3 & 142 & 3.6 \\
\hline 23 & 3.3 & 63 & 1.2 & 103 & 1.4 & 143 & 3.5 \\
\hline 24 & 3.9 & 64 & 0.8 & 104 & 10.6 & 144 & 2.2 \\
\hline 25 & 2.4 & 65 & 2 & 105 & 1.2 & 145 & 2.7 \\
\hline 26 & 1.4 & 66 & 0.4 & 106 & 4.3 & 146 & 3 \\
\hline 27 & 6 & 67 & 1.4 & 107 & 4.5 & 147 & 3.3 \\
\hline 28 & 11.2 & 68 & 1.3 & 108 & 14.7 & 148 & 0.9 \\
\hline 29 & 1.2 & 69 & 1.1 & 109 & 1.5 & 149 & 2.6 \\
\hline 30 & 8.2 & 70 & 1.2 & 110 & 1.9 & 150 & 2 \\
\hline 31 & 7.7 & 71 & 1.1 & 111 & 3.4 & 151 & 1.6 \\
\hline 32 & 5.3 & 72 & 1.8 & 112 & 2.1 & 152 & 1.5 \\
\hline 33 & 1.2 & 73 & 1 & 113 & 1.4 & 153 & 0.8 \\
\hline 34 & 1.9 & 74 & 2.4 & 114 & 2 & 154 & 4.6 \\
\hline 35 & 1.2 & 75 & 0.5 & 115 & 3.9 & 155 & 2 \\
\hline 36 & 1.6 & 76 & 2.9 & 116 & 2.6 & 156 & 0.9 \\
\hline 37 & 1.1 & 77 & 2.1 & 117 & 1.4 & 157 & 2.2 \\
\hline 38 & 3.4 & 78 & 3.4 & 118 & 1.3 & 158 & 2 \\
\hline 39 & 2 & 79 & 1.5 & 119 & 1.1 & & \\
\hline 40 & 3.4 & 80 & 1.7 & 120 & 2.8 & & \\
\hline
\end{tabular}


Table 4: Distance of vegetation behind the back beach (m)

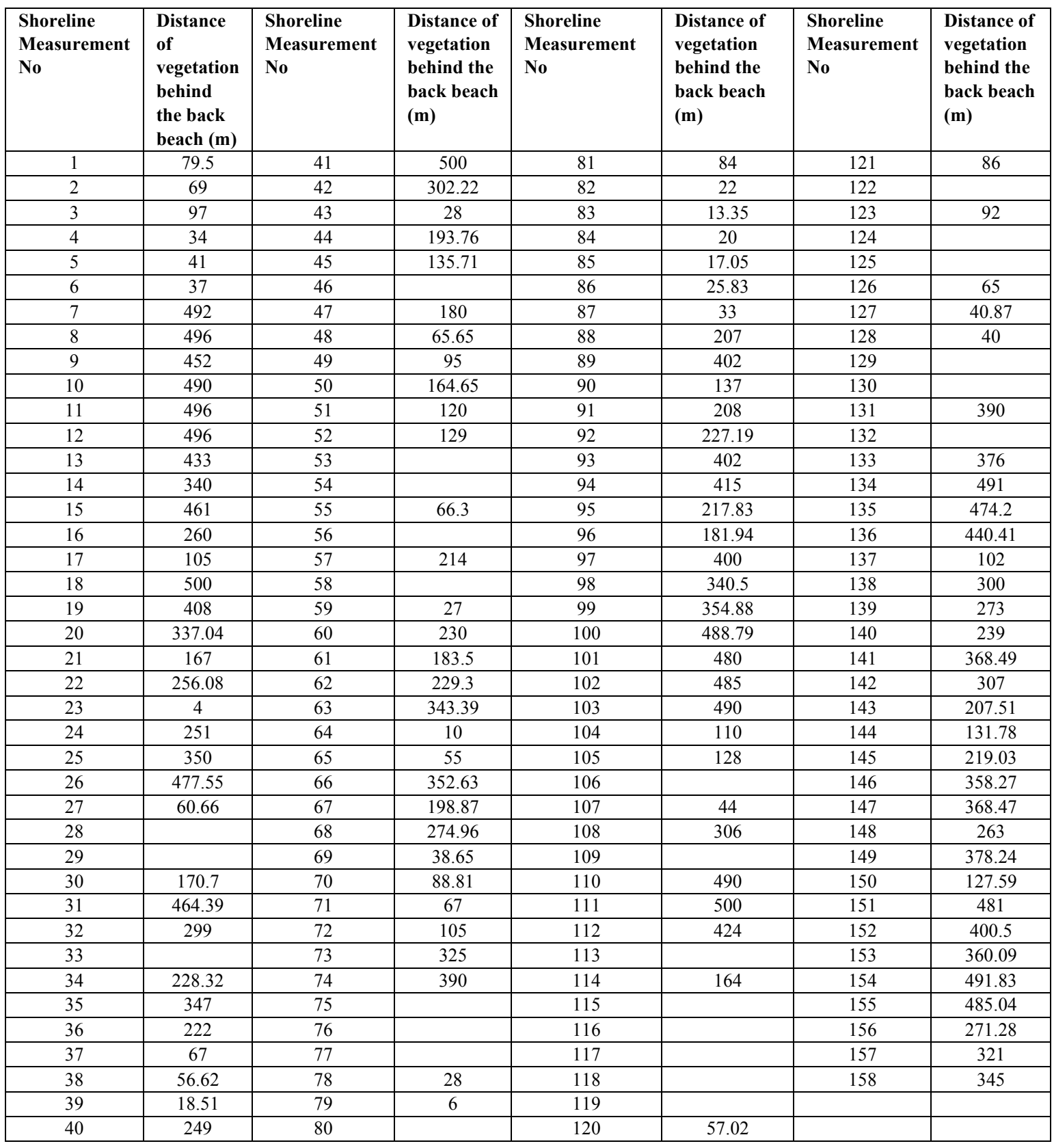


Table 5: Distance of built structures behind the back beach (m)

\begin{tabular}{|c|c|c|c|c|c|c|c|}
\hline $\begin{array}{l}\text { Shoreline } \\
\text { Measurement } \\
\text { No }\end{array}$ & $\begin{array}{l}\text { Distance } \\
\text { of Built } \\
\text { Structures } \\
\text { behind } \\
\text { the back } \\
\text { beach (m) }\end{array}$ & $\begin{array}{l}\text { Shoreline } \\
\text { Measurement } \\
\text { No }\end{array}$ & $\begin{array}{l}\text { Distance of } \\
\text { Built } \\
\text { Structures } \\
\text { behind the } \\
\text { back beach } \\
\text { (m) }\end{array}$ & $\begin{array}{l}\text { Shoreline } \\
\text { Measurement } \\
\text { No }\end{array}$ & $\begin{array}{l}\text { Distance of } \\
\text { Built } \\
\text { Structures } \\
\text { behind the } \\
\text { back beach } \\
\text { (m) }\end{array}$ & $\begin{array}{l}\text { Shoreline } \\
\text { Measurement } \\
\text { No }\end{array}$ & $\begin{array}{l}\text { Distance of } \\
\text { Built } \\
\text { Structures } \\
\text { behind the } \\
\text { back } \\
\text { beach (m) }\end{array}$ \\
\hline 1 & & 41 & & 81 & 394 & 121 & 380 \\
\hline 2 & 3 & 42 & 197.78 & 82 & 450 & 122 & 500 \\
\hline 3 & 3 & 43 & 482 & 83 & 449 & 123 & 395 \\
\hline 4 & 3.1 & 44 & 306.24 & 84 & 426 & 124 & 500 \\
\hline 5 & & 45 & 364.29 & 85 & 294 & 125 & 500 \\
\hline 6 & & 46 & 500 & 86 & 410 & 126 & 383 \\
\hline 7 & 8 & 47 & 82 & 87 & 415 & 127 & 311 \\
\hline 8 & 4 & 48 & 337.14 & 88 & 273 & 128 & 455 \\
\hline 9 & 48 & 49 & 316 & 89 & 98 & 129 & 500 \\
\hline 10 & & 50 & 335.35 & 90 & 363 & 130 & 500 \\
\hline 11 & 4 & 51 & 230 & 91 & 292 & 131 & 114 \\
\hline 12 & 4 & 52 & 359 & 92 & 272.81 & 132 & 300 \\
\hline 13 & 67 & 53 & 500 & 93 & 86 & 133 & 59.37 \\
\hline 14 & 160 & 54 & 500 & 94 & & 134 & 9 \\
\hline 15 & 39 & 55 & 433.7 & 95 & 282.17 & 135 & 25.8 \\
\hline 16 & 240 & 56 & 342 & 96 & 295.47 & 136 & 59 \\
\hline 17 & 295 & 57 & 80 & 97 & 75 & 137 & 343.9 \\
\hline 18 & & 58 & 198.73 & 98 & 32.87 & 138 & 146 \\
\hline 19 & 56.1 & 59 & 63.28 & 99 & 145.12 & 139 & 223 \\
\hline 20 & 162.96 & 60 & 35 & 100 & 11.21 & 140 & 260.44 \\
\hline 21 & 57.28 & 61 & 208 & 101 & 15 & 141 & 127 \\
\hline 22 & & 62 & 103 & 102 & 15 & 142 & 193 \\
\hline 23 & 477 & 63 & 133.38 & 103 & 10 & 143 & 171.56 \\
\hline 24 & 138.22 & 64 & 490 & 104 & 65 & 144 & 73.12 \\
\hline 25 & 105 & 65 & 5 & 105 & 29.45 & 145 & 97.65 \\
\hline 26 & & 66 & 30.18 & 106 & 455 & 146 & 141.82 \\
\hline 27 & 433.34 & 67 & 63 & 107 & 423 & 147 & 12.4 \\
\hline 28 & 500 & 68 & 145.21 & 108 & 36 & 148 & 46.79 \\
\hline 29 & 500 & 69 & 223.98 & 109 & 400 & 149 & 5.9 \\
\hline 30 & 322.3 & 70 & 261.16 & 110 & & 150 & 4.39 \\
\hline 31 & 35.61 & 71 & 367 & 111 & & 151 & 18.26 \\
\hline 32 & 201 & 72 & 338 & 112 & & 152 & 29.87 \\
\hline 33 & 500 & 73 & 100 & 113 & 30 & 153 & 139.91 \\
\hline 34 & & 74 & & 114 & 231 & 154 & 8.17 \\
\hline 35 & & 75 & 413 & 115 & 410 & 155 & 2.4 \\
\hline 36 & & 76 & 484 & 116 & 500 & 156 & 228.72 \\
\hline 37 & & 77 & 494 & 117 & 424 & 157 & 179 \\
\hline 38 & 443.58 & 78 & 366 & 118 & 428 & 158 & 55 \\
\hline 39 & 481.49 & 79 & 383 & 119 & 500 & & \\
\hline 40 & 251 & 80 & 470 & 120 & 419 & & \\
\hline
\end{tabular}


Table 6: Rocky outcrop (\%)

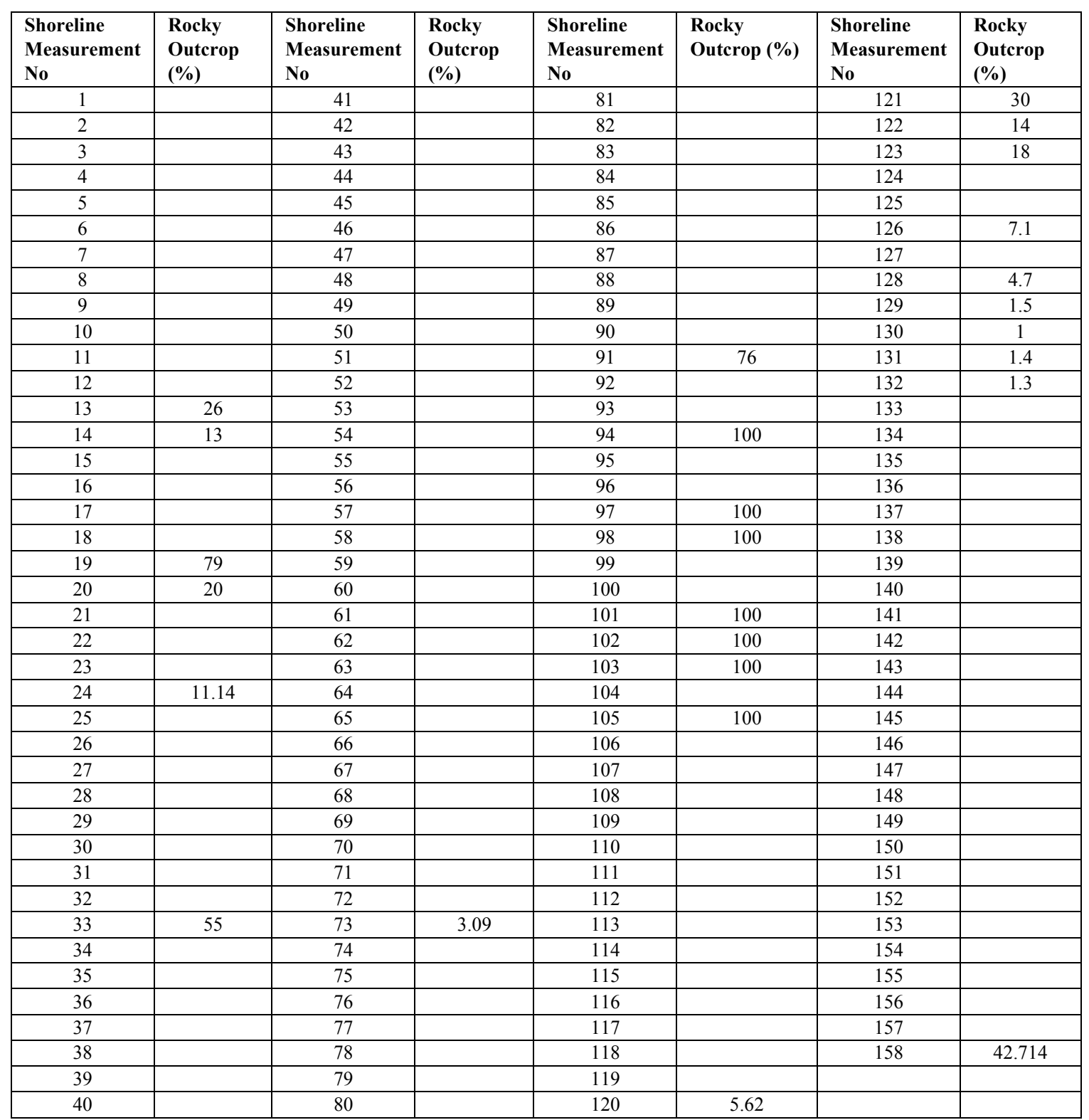


Table 7: Sea defences (\%)

\begin{tabular}{|c|c|c|c|c|c|c|c|}
\hline $\begin{array}{l}\text { Shoreline } \\
\text { Measurement } \\
\text { No }\end{array}$ & $\begin{array}{l}\text { Sea } \\
\text { Defences } \\
(\%)\end{array}$ & $\begin{array}{l}\text { Shoreline } \\
\text { Measurement } \\
\text { No }\end{array}$ & $\begin{array}{l}\text { Sea Defences } \\
(\%)\end{array}$ & $\begin{array}{l}\text { Shoreline } \\
\text { Measurement } \\
\text { No }\end{array}$ & $\begin{array}{l}\text { Sea } \\
\text { Defences } \\
(\%)\end{array}$ & $\begin{array}{l}\text { Shoreline } \\
\text { Measurement } \\
\text { No }\end{array}$ & $\begin{array}{l}\text { Sea } \\
\text { Defences } \\
(\%)\end{array}$ \\
\hline 1 & & 41 & & 81 & & 121 & 100 \\
\hline 2 & & 42 & & 82 & & 122 & \\
\hline 3 & & 43 & & 83 & & 123 & 100 \\
\hline 4 & & 44 & & 84 & & 124 & 73 \\
\hline 5 & & 45 & & 85 & & 125 & \\
\hline 6 & & 46 & & 86 & & 126 & 100 \\
\hline 7 & & 47 & & 87 & & 127 & 100 \\
\hline 8 & & 48 & & 88 & & 128 & 100 \\
\hline 9 & & 49 & & 89 & & 129 & 100 \\
\hline 10 & 25 & 50 & & 90 & & 130 & 100 \\
\hline 11 & & 51 & & 91 & & 131 & 100 \\
\hline 12 & & 52 & & 92 & & 132 & 100 \\
\hline 13 & 54 & 53 & & 93 & & 133 & 29 \\
\hline 14 & 100 & 54 & & 94 & & 134 & 54 \\
\hline 15 & & 55 & & 95 & & 135 & 67.8 \\
\hline 16 & & 56 & & 96 & & 136 & 100 \\
\hline 17 & & 57 & & 97 & & 137 & 100 \\
\hline 18 & & 58 & & 98 & & 138 & 100 \\
\hline 19 & 100 & 59 & & 99 & & 139 & 100 \\
\hline 20 & 60 & 60 & & 100 & & 140 & 100 \\
\hline 21 & & 61 & & 101 & & 141 & 14.4 \\
\hline 22 & & 62 & & 102 & & 142 & 11.4 \\
\hline 23 & 78 & 63 & & 103 & & 143 & 80 \\
\hline 24 & 24 & 64 & & 104 & 100 & 144 & 100 \\
\hline 25 & & 65 & & 105 & 100 & 145 & 32 \\
\hline 26 & & 66 & & 106 & 100 & 146 & 100 \\
\hline 27 & & 67 & & 107 & 100 & 147 & \\
\hline 28 & & 68 & & 108 & 100 & 148 & 96 \\
\hline 29 & 100 & 69 & & 109 & & 149 & 100 \\
\hline 30 & 100 & 70 & & 110 & & 150 & 100 \\
\hline 31 & 100 & 71 & & 111 & & 151 & 22.8 \\
\hline 32 & 100 & 72 & 35 & 112 & & 152 & 100 \\
\hline 33 & 100 & 73 & 100 & 113 & & 153 & 92 \\
\hline 34 & 100 & 74 & & 114 & & 154 & \\
\hline 35 & 100 & 75 & & 115 & & 155 & \\
\hline 36 & 100 & 76 & & 116 & & 156 & 22 \\
\hline 37 & 100 & 77 & & 117 & & 157 & 44 \\
\hline 38 & & 78 & & 118 & & 158 & 100 \\
\hline 39 & & 79 & & 119 & 2.2 & & \\
\hline 40 & & 80 & & 120 & 100 & & \\
\hline
\end{tabular}


Table 8: CVI scores for beach width

\begin{tabular}{|c|c|c|c|c|c|c|c|}
\hline $\begin{array}{l}\text { Shoreline } \\
\text { Measurement } \\
\text { No }\end{array}$ & $\begin{array}{l}\text { Beach } \\
\text { Width } \\
\text { CVI } \\
\text { Scores }\end{array}$ & $\begin{array}{l}\text { Shoreline } \\
\text { Measurement } \\
\text { No }\end{array}$ & $\begin{array}{l}\text { Beach Width } \\
\text { CVI Scores }\end{array}$ & $\begin{array}{l}\text { Shoreline } \\
\text { Measurement } \\
\text { No }\end{array}$ & $\begin{array}{l}\text { Beach Width } \\
\text { CVI Scores }\end{array}$ & $\begin{array}{l}\text { Shoreline } \\
\text { Measurement } \\
\text { No }\end{array}$ & $\begin{array}{l}\text { Beach Width } \\
\text { CVI Scores }\end{array}$ \\
\hline 1 & 3 & 41 & 1 & 81 & 4 & 121 & 4 \\
\hline 2 & 3 & 42 & 1 & 82 & 4 & 122 & 4 \\
\hline 3 & 1 & 43 & 1 & 83 & 3 & 123 & 4 \\
\hline 4 & 3 & 44 & 1 & 84 & 4 & 124 & 4 \\
\hline 5 & 3 & 45 & 1 & 85 & 4 & 125 & 4 \\
\hline 6 & 1 & 46 & 2 & 86 & 4 & 126 & 4 \\
\hline 7 & 1 & 47 & 1 & 87 & 4 & 127 & 4 \\
\hline 8 & 1 & 48 & 1 & 88 & 4 & 128 & 4 \\
\hline 9 & 1 & 49 & 1 & 89 & 2 & 129 & 4 \\
\hline 10 & 1 & 50 & 1 & 90 & 2 & 130 & 4 \\
\hline 11 & 1 & 51 & 1 & 91 & 3 & 131 & 4 \\
\hline 12 & 1 & 52 & 1 & 92 & 2 & 132 & 4 \\
\hline 13 & 3 & 53 & 1 & 93 & 1 & 133 & 4 \\
\hline 14 & 1 & 54 & 1 & 94 & 1 & 134 & 4 \\
\hline 15 & 1 & 55 & 1 & 95 & 3 & 135 & 4 \\
\hline 16 & 1 & 56 & 1 & 96 & 2 & 136 & 1 \\
\hline 17 & 1 & 57 & 1 & 97 & 2 & 137 & 1 \\
\hline 18 & 1 & 58 & 1 & 98 & 3 & 138 & 1 \\
\hline 19 & 1 & 59 & 1 & 99 & 2 & 139 & 2 \\
\hline 20 & 1 & 60 & 2 & 100 & 3 & 140 & 2 \\
\hline 21 & 1 & 61 & 2 & 101 & 3 & 141 & 2 \\
\hline 22 & 1 & 62 & 3 & 102 & 4 & 142 & 2 \\
\hline 23 & 1 & 63 & 4 & 103 & 2 & 143 & 1 \\
\hline 24 & 1 & 64 & 4 & 104 & 2 & 144 & 1 \\
\hline 25 & 1 & 65 & 4 & 105 & 3 & 145 & 1 \\
\hline 26 & 1 & 66 & 4 & 106 & 2 & 146 & 1 \\
\hline 27 & 1 & 67 & 4 & 107 & 3 & 147 & 1 \\
\hline 28 & 2 & 68 & 4 & 108 & 4 & 148 & 1 \\
\hline 29 & 4 & 69 & 4 & 109 & 4 & 149 & 1 \\
\hline 30 & 4 & 70 & 2 & 110 & 4 & 150 & 1 \\
\hline 31 & 3 & 71 & 1 & 111 & 4 & 151 & 2 \\
\hline 32 & 1 & 72 & 1 & 112 & 3 & 152 & 2 \\
\hline 33 & & 73 & 2 & 113 & 3 & 153 & 2 \\
\hline 34 & & 74 & 4 & 114 & 4 & 154 & 2 \\
\hline 35 & 1 & 75 & 4 & 115 & 4 & 155 & 2 \\
\hline 36 & 1 & 76 & 4 & 116 & 1 & 156 & 2 \\
\hline 37 & 1 & 77 & 4 & 117 & 1 & 157 & 2 \\
\hline 38 & 1 & 78 & 4 & 118 & 4 & 158 & 2 \\
\hline 39 & 1 & 79 & 4 & 119 & 4 & & \\
\hline 40 & 1 & 80 & 4 & 120 & 4 & & \\
\hline
\end{tabular}


Table 9: CVI scores for dune width

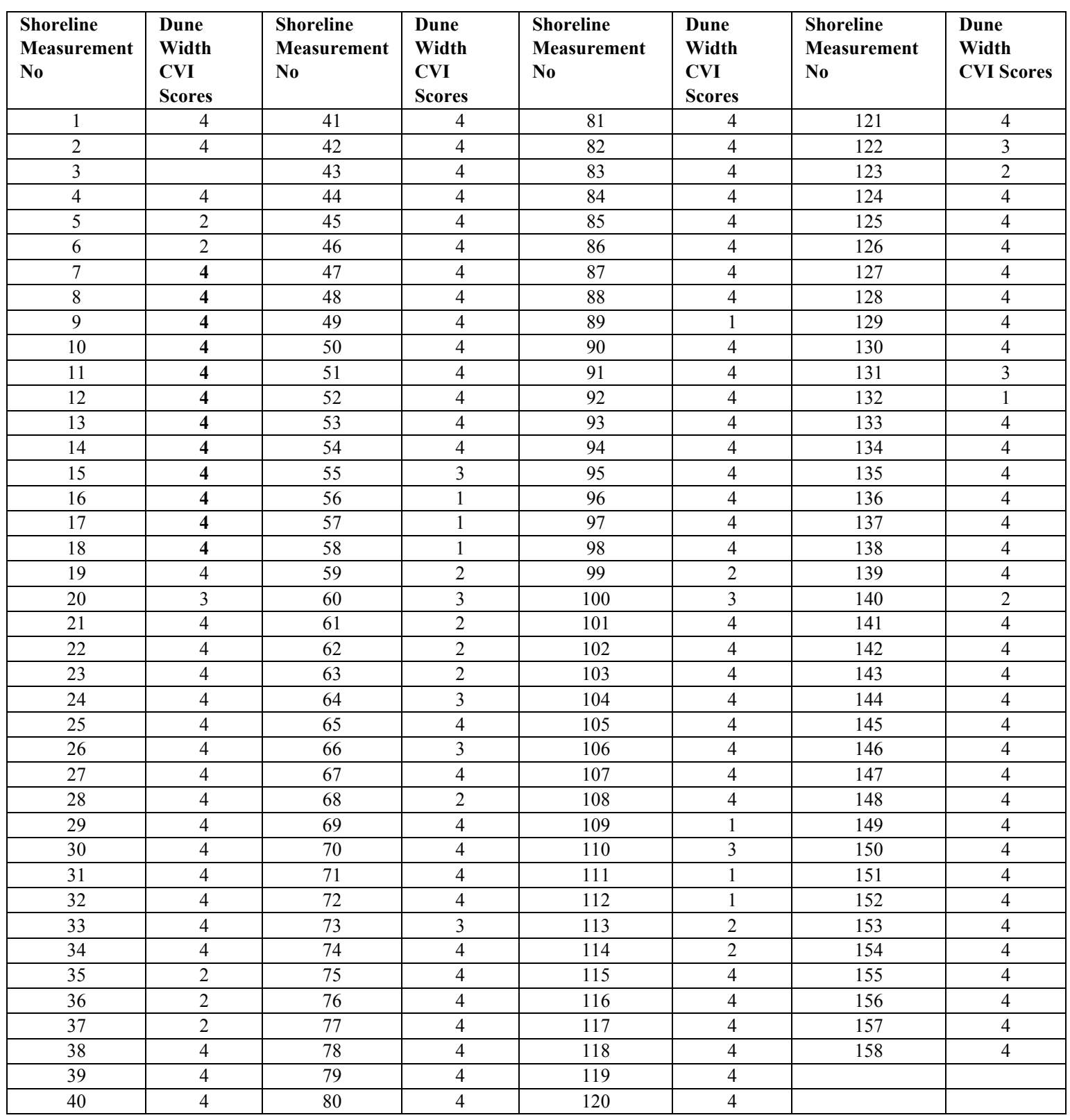


Table 10: CVI scores for coastal slope

\begin{tabular}{|c|c|c|c|c|c|c|c|}
\hline $\begin{array}{l}\text { Shoreline } \\
\text { Measurement } \\
\text { No }\end{array}$ & $\begin{array}{l}\text { Coastal } \\
\text { Slope } \\
\text { CVI Scores }\end{array}$ & $\begin{array}{l}\text { Shoreline } \\
\text { Measurement } \\
\text { No }\end{array}$ & $\begin{array}{l}\text { Coastal } \\
\text { Slope } \\
\text { CVI } \\
\text { Scores }\end{array}$ & $\begin{array}{l}\text { Shoreline } \\
\text { Measurement } \\
\text { No }\end{array}$ & $\begin{array}{l}\text { Coastal } \\
\text { Slope } \\
\text { CVI Scores }\end{array}$ & $\begin{array}{l}\text { Shoreline } \\
\text { Measurement } \\
\text { No }\end{array}$ & $\begin{array}{l}\text { Coastal } \\
\text { Slope } \\
\text { CVI Scores }\end{array}$ \\
\hline 1 & 2 & 41 & 4 & 81 & 4 & 121 & 4 \\
\hline 2 & 4 & 42 & 4 & 82 & 3 & 122 & 4 \\
\hline 3 & 3 & 43 & 4 & 83 & 2 & 123 & 4 \\
\hline 4 & 3 & 44 & 3 & 84 & 4 & 124 & 4 \\
\hline 5 & 1 & 45 & 4 & 85 & 2 & 125 & 4 \\
\hline 6 & 3 & 46 & 4 & 86 & 3 & 126 & 4 \\
\hline 7 & 4 & 47 & 3 & 87 & 3 & 127 & 4 \\
\hline 8 & 4 & 48 & 3 & 88 & 4 & 128 & 4 \\
\hline 9 & 3 & 49 & 4 & 89 & 4 & 129 & 4 \\
\hline 10 & 2 & 50 & 4 & 90 & 4 & 130 & 4 \\
\hline 11 & 4 & 51 & 4 & 91 & 4 & 131 & 4 \\
\hline 12 & 4 & 52 & 4 & 92 & 4 & 132 & 4 \\
\hline 13 & 4 & 53 & 4 & 93 & 4 & 133 & 4 \\
\hline 14 & 2 & 54 & 4 & 94 & 4 & 134 & 4 \\
\hline 15 & 4 & 55 & 4 & 95 & 4 & 135 & 4 \\
\hline 16 & 4 & 56 & 4 & 96 & 4 & 136 & 4 \\
\hline 17 & 4 & 57 & - & 97 & 4 & 137 & 4 \\
\hline 18 & 4 & 58 & $\ldots$ & 98 & 4 & 138 & 4 \\
\hline 19 & 4 & 59 & - & 99 & 4 & 139 & 4 \\
\hline 20 & 4 & 60 & - & 100 & 4 & 140 & 4 \\
\hline 21 & 4 & 61 & - & 101 & 4 & 141 & 4 \\
\hline 22 & 4 & 62 & 1 & 102 & 4 & 142 & 4 \\
\hline 23 & 4 & 63 & 1 & 103 & 4 & 143 & 4 \\
\hline 24 & 4 & 64 & 1 & 104 & 4 & 144 & 4 \\
\hline 25 & 4 & 65 & 3 & 105 & 4 & 145 & 4 \\
\hline 26 & 4 & 66 & 2 & 106 & 4 & 146 & 4 \\
\hline 27 & 3 & 67 & 1 & 107 & 4 & 147 & 4 \\
\hline 28 & 4 & 68 & 2 & 108 & 4 & 148 & 4 \\
\hline 29 & 4 & 69 & 4 & 109 & 4 & 149 & 4 \\
\hline 30 & 4 & 70 & 1 & 110 & 3 & 150 & 4 \\
\hline 31 & 4 & 71 & 1 & 111 & 4 & 151 & 4 \\
\hline 32 & 4 & 72 & 1 & 112 & 4 & 152 & 4 \\
\hline 33 & 4 & 73 & 1 & 113 & 4 & 153 & 4 \\
\hline 34 & 4 & 74 & 4 & 114 & 4 & 154 & 4 \\
\hline 35 & 4 & 75 & 4 & 115 & 4 & 155 & 4 \\
\hline 36 & 4 & 76 & 4 & 116 & 4 & 156 & 4 \\
\hline 37 & 4 & 77 & 4 & 117 & 4 & 157 & 4 \\
\hline 38 & 4 & 78 & 4 & 118 & 4 & 158 & 4 \\
\hline 39 & 4 & 79 & 4 & 119 & 4 & & \\
\hline 40 & 4 & 80 & 4 & 120 & 4 & & \\
\hline
\end{tabular}


Table 11: CVI scores for vegetation behind the back beach

\begin{tabular}{|c|c|c|c|c|c|c|c|}
\hline $\begin{array}{l}\text { Shoreline } \\
\text { Measurement } \\
\text { No }\end{array}$ & $\begin{array}{l}\text { Vegetation } \\
\text { Behind the } \\
\text { Back } \\
\text { Beach } \\
\text { CVI Scores }\end{array}$ & $\begin{array}{l}\text { Shoreline } \\
\text { Measurement } \\
\text { No }\end{array}$ & $\begin{array}{l}\text { Vegetation } \\
\text { Behind the } \\
\text { Back Beach } \\
\text { CVI Scores }\end{array}$ & $\begin{array}{l}\text { Shoreline } \\
\text { Measurement } \\
\text { No }\end{array}$ & $\begin{array}{l}\text { Vegetation } \\
\text { Behind the } \\
\text { Back } \\
\text { Beach } \\
\text { CVI Scores }\end{array}$ & $\begin{array}{l}\text { Shoreline } \\
\text { Measurement } \\
\text { No }\end{array}$ & $\begin{array}{l}\text { Vegetation } \\
\text { Behind the } \\
\text { Back Beach } \\
\text { CVI Scores }\end{array}$ \\
\hline 1 & 3 & 41 & $\ldots$ & 81 & 2 & 121 & 3 \\
\hline 2 & 3 & 42 & & 82 & 4 & 122 & 3 \\
\hline 5 & 2 & 45 & $\ldots$ & 85 & 3 & 125 & 4 \\
\hline 6 & 2 & 46 & 4 & 86 & 2 & 126 & \\
\hline 7 & 2 & 47 & $\ldots$ & 87 & 2 & 127 & 2 \\
\hline 8 & 2 & 48 & & 88 & & 128 & \\
\hline 9 & 2 & 49 & 4 & 89 & 2 & 129 & 4 \\
\hline 13 & 2 & 53 & & 93 & 2 & 133 & 2 \\
\hline 14 & 2 & 54 & 2 & 94 & 3 & 134 & 4 \\
\hline 15 & 2 & 55 & $\ldots$ & 95 & 2 & 135 & 4 \\
\hline 16 & 2 & 56 & 4 & 96 & 2 & 136 & 2 \\
\hline 17 & 3 & 57 & 4 & 97 & 2 & 137 & 3 \\
\hline 18 & 2 & 58 & 4 & 98 & 2 & 138 & 2 \\
\hline 19 & 2 & 59 & 4 & 99 & 2 & 139 & 4 \\
\hline 20 & 2 & 60 & 4 & 100 & 3 & 140 & 4 \\
\hline 21 & 2 & 61 & 4 & 101 & 2 & 141 & 4 \\
\hline 22 & 2 & 62 & 2 & 102 & 2 & 142 & 3 \\
\hline 30 & 2 & 70 & 2 & 110 & 2 & 150 & $\ldots$ \\
\hline 31 & 2 & 71 & 2 & 111 & 2 & 151 & 4 \\
\hline 32 & & 72 & 3 & 112 & 2 & 152 & 4 \\
\hline 33 & 2 & 73 & 2 & 113 & 4 & 153 & 4 \\
\hline 34 & 2 & 74 & 2 & 114 & 3 & 154 & 4 \\
\hline 35 & 2 & 75 & 2 & 115 & 3 & 155 & 4 \\
\hline 36 & - & 76 & 3 & 116 & - & 156 & 4 \\
\hline 37 & 3 & 77 & 2 & 117 & 3 & 157 & 4 \\
\hline 38 & - & 78 & 4 & 118 & 4 & 158 & 4 \\
\hline 39 & $=$ & 79 & 2 & 119 & 4 & & \\
\hline 40 & - & 80 & 2 & 120 & 3 & & \\
\hline
\end{tabular}


Table 12: CVI scores for built structures behind the back beach

\begin{tabular}{|c|c|c|c|c|c|c|c|}
\hline $\begin{array}{l}\text { Shoreline } \\
\text { Measurement } \\
\text { No }\end{array}$ & $\begin{array}{l}\text { Built } \\
\text { Structures } \\
\text { Behind the } \\
\text { Back Beach } \\
\text { CVI Scores }\end{array}$ & $\begin{array}{l}\text { Shoreline } \\
\text { Measurement } \\
\text { No }\end{array}$ & $\begin{array}{l}\text { Built } \\
\text { Structures } \\
\text { Behind the } \\
\text { Back Beach } \\
\text { CVI Scores }\end{array}$ & $\begin{array}{l}\text { Shoreline } \\
\text { Measurement } \\
\text { No }\end{array}$ & $\begin{array}{l}\text { Built } \\
\text { Structures } \\
\text { Behind the } \\
\text { Back Beach } \\
\text { CVI Scores }\end{array}$ & $\begin{array}{l}\text { Shoreline } \\
\text { Measurement } \\
\text { No }\end{array}$ & $\begin{array}{l}\text { Built } \\
\text { Structures } \\
\text { Behind the } \\
\text { Back } \\
\text { Beach } \\
\text { CVI } \\
\text { Scores } \\
\end{array}$ \\
\hline 1 & 4 & 41 & 2 & 81 & - & 121 & 2 \\
\hline 2 & 4 & 42 & 2 & 82 & 2 & 122 & 2 \\
\hline 3 & 2 & 43 & 2 & 83 & 2 & 123 & 2 \\
\hline 4 & 2 & 44 & 2 & 84 & 2 & 124 & 2 \\
\hline 5 & 4 & 45 & 2 & 85 & 2 & 125 & 2 \\
\hline 6 & 4 & 46 & 2 & 86 & 4 & 126 & 2 \\
\hline 7 & 4 & 47 & 2 & 87 & 3 & 127 & 4 \\
\hline 8 & 4 & 48 & 2 & 88 & 2 & 128 & 3 \\
\hline 9 & 4 & 49 & 2 & 89 & - & 129 & 4 \\
\hline 10 & 2 & 50 & 2 & 90 & 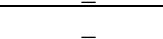 & 130 & 4 \\
\hline 11 & 3 & 51 & 2 & 91 & 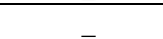 & 131 & 2 \\
\hline 12 & 2 & 52 & 2 & 92 & - & 132 & 3 \\
\hline 13 & 2 & 53 & 2 & 93 & 4 & 133 & 3 \\
\hline 14 & 3 & 54 & 3 & 94 & 2 & 134 & 2 \\
\hline 15 & 3 & 55 & 2 & 95 & 2 & 135 & 4 \\
\hline 16 & 3 & 56 & - & 96 & 2 & 136 & 4 \\
\hline 17 & 4 & 57 & 4 & 97 & 4 & 137 & 4 \\
\hline 18 & 4 & 58 & 4 & 98 & $\ldots$ & 138 & 3 \\
\hline 19 & 3 & 59 & 4 & 99 & 2 & 139 & 2 \\
\hline 20 & 4 & 60 & - & 100 & 2 & 140 & 2 \\
\hline 21 & 4 & 61 & - & 101 & 4 & 141 & 2 \\
\hline 22 & 4 & 62 & 4 & 102 & 4 & 142 & 2 \\
\hline 23 & 4 & 63 & 4 & 103 & 3 & 143 & 4 \\
\hline 24 & 4 & 64 & 4 & 104 & 4 & 144 & - \\
\hline 25 & 4 & 65 & $\ldots$ & 105 & 4 & 145 & 2 \\
\hline 26 & 3 & 66 & 4 & 106 & 4 & 146 & 2 \\
\hline 27 & 4 & 67 & 4 & 107 & 4 & 147 & 2 \\
\hline 28 & 4 & 68 & 4 & 108 & 2 & 148 & 2 \\
\hline 29 & 2 & 69 & 3 & 109 & 2 & 149 & 2 \\
\hline 30 & 3 & 70 & 4 & 110 & 2 & 150 & 2 \\
\hline 31 & 4 & 71 & 2 & 111 & & 151 & 2 \\
\hline 32 & 2 & 72 & 2 & 112 & 3 & 152 & 2 \\
\hline 33 & - & 73 & - & 113 & 2 & 153 & 2 \\
\hline 34 & - & 74 & 4 & 114 & 2 & 154 & 2 \\
\hline 35 & - & 75 & 3 & 115 & 2 & 155 & 2 \\
\hline 36 & 4 & 76 & 4 & 116 & 2 & 156 & 2 \\
\hline 37 & 2 & 77 & & 117 & 4 & 157 & 2 \\
\hline 38 & 2 & 78 & 2 & 118 & 2 & 158 & 2 \\
\hline 39 & 2 & 79 & 3 & 119 & 2 & & \\
\hline 40 & 2 & 80 & 3 & 120 & 2 & & \\
\hline
\end{tabular}


Table 13: CVI scores for rocky outcrop

\begin{tabular}{|c|c|c|c|c|c|c|c|}
\hline $\begin{array}{l}\text { Shoreline } \\
\text { Measurement } \\
\text { No }\end{array}$ & $\begin{array}{l}\text { Rocky } \\
\text { Outcrop } \\
\text { CVI Scores }\end{array}$ & $\begin{array}{l}\text { Shoreline } \\
\text { Measurement } \\
\text { No }\end{array}$ & $\begin{array}{l}\text { Rocky } \\
\text { Outcrop } \\
\text { CVI Scores }\end{array}$ & $\begin{array}{l}\text { Shoreline } \\
\text { Measurement } \\
\text { No }\end{array}$ & $\begin{array}{l}\text { Rocky } \\
\text { Outcrop } \\
\text { CVI Scores }\end{array}$ & $\begin{array}{l}\text { Shoreline } \\
\text { Measurement } \\
\text { No }\end{array}$ & $\begin{array}{l}\text { Rocky } \\
\text { Outcrop } \\
\text { CVI } \\
\text { Scores }\end{array}$ \\
\hline 1 & 4 & 41 & 4 & 81 & 4 & 121 & 2 \\
\hline 2 & 4 & 42 & 4 & 82 & 4 & 122 & \\
\hline 3 & 4 & 43 & 4 & 83 & 4 & 123 & 2 \\
\hline 4 & 4 & 44 & 4 & 84 & 4 & 124 & 4 \\
\hline 5 & 4 & 45 & 4 & 85 & 4 & 125 & \\
\hline 6 & 4 & 46 & 4 & 86 & 4 & 126 & 4 \\
\hline 7 & 4 & 47 & 4 & 87 & 4 & 127 & 4 \\
\hline 8 & 4 & 48 & 4 & 88 & 4 & 128 & 4 \\
\hline 9 & 4 & 49 & 4 & 89 & 4 & 129 & 4 \\
\hline 10 & 4 & 50 & 4 & 90 & 4 & 130 & 4 \\
\hline 11 & 4 & 51 & 4 & 91 & 1 & 131 & 4 \\
\hline 12 & 4 & 52 & 4 & 92 & 4 & 132 & 4 \\
\hline 13 & 2 & 53 & 4 & 93 & 4 & 133 & \\
\hline 14 & 3 & 54 & 4 & 94 & 1 & 134 & 4 \\
\hline 15 & 4 & 55 & 4 & 95 & 4 & 135 & 4 \\
\hline 16 & 4 & 56 & 4 & 96 & 4 & 136 & 4 \\
\hline 17 & 4 & 57 & 4 & 97 & 1 & 137 & 4 \\
\hline 18 & 4 & 58 & 4 & 98 & 1 & 138 & 4 \\
\hline 19 & 1 & 59 & 4 & 99 & 4 & 139 & 4 \\
\hline 20 & 3 & 60 & 4 & 100 & 4 & 140 & 3 \\
\hline 21 & 4 & 61 & 4 & 101 & 1 & 141 & 4 \\
\hline 22 & 4 & 62 & 4 & 102 & 1 & 142 & \\
\hline 23 & 4 & 63 & 4 & 103 & 1 & 143 & 4 \\
\hline 24 & 3 & 64 & 4 & 104 & 1 & 144 & 4 \\
\hline 25 & 4 & 65 & 4 & 105 & 1 & 145 & 4 \\
\hline 26 & 4 & 66 & 4 & 106 & 1 & 146 & 4 \\
\hline 27 & 4 & 67 & 4 & 107 & 1 & 147 & \\
\hline 28 & 4 & 68 & 4 & 108 & 1 & 148 & \\
\hline 29 & 4 & 69 & 4 & 109 & 4 & 149 & 4 \\
\hline 30 & 4 & 70 & 4 & 110 & 4 & 150 & 4 \\
\hline 31 & 4 & 71 & 4 & 111 & 4 & 151 & \\
\hline 32 & 4 & 72 & 4 & 112 & 4 & 152 & 4 \\
\hline 33 & 1 & 73 & 4 & 113 & 4 & 153 & \\
\hline 34 & 4 & 74 & 1 & 114 & 4 & 154 & \\
\hline 35 & 4 & 75 & 4 & 115 & 4 & 155 & \\
\hline 36 & 4 & 76 & 4 & 116 & 4 & 156 & \\
\hline 37 & 4 & 77 & 4 & 117 & 4 & 157 & \\
\hline 38 & 4 & 78 & 4 & 118 & 4 & 158 & 4 \\
\hline 39 & 4 & 79 & 4 & 119 & 4 & & \\
\hline 40 & 4 & 80 & 4 & 120 & 4 & & \\
\hline
\end{tabular}


Table 14: CVI scores for sea defences

\begin{tabular}{|c|c|c|c|c|c|c|c|}
\hline $\begin{array}{l}\text { Shoreline } \\
\text { Measurement } \\
\text { No }\end{array}$ & $\begin{array}{l}\text { Sea Defences } \\
\text { CVI } \\
\text { Scores }\end{array}$ & $\begin{array}{l}\text { Shoreline } \\
\text { Measurement } \\
\text { No }\end{array}$ & $\begin{array}{l}\text { CVI } \\
\text { Scores }\end{array}$ & $\begin{array}{l}\text { Shoreline } \\
\text { Measurement } \\
\text { No }\end{array}$ & $\begin{array}{l}\text { CVI } \\
\text { Scores }\end{array}$ & $\begin{array}{l}\text { Shoreline } \\
\text { Measurement } \\
\text { No }\end{array}$ & $\begin{array}{l}\text { CVI } \\
\text { Scores }\end{array}$ \\
\hline 1 & 4 & 41 & 4 & 81 & 4 & 121 & 1 \\
\hline 2 & 4 & 42 & 4 & 82 & 4 & 122 & \\
\hline 3 & 4 & 43 & 4 & 83 & 4 & 123 & 1 \\
\hline 4 & 4 & 44 & 4 & 84 & 4 & 124 & 1 \\
\hline 5 & 4 & 45 & 4 & 85 & 4 & 125 & \\
\hline 6 & 4 & 46 & 4 & 86 & 4 & 126 & 1 \\
\hline 7 & 4 & 47 & 4 & 87 & 4 & 127 & 1 \\
\hline 8 & 4 & 48 & 4 & 88 & 4 & 128 & 1 \\
\hline 9 & 4 & 49 & 4 & 89 & 4 & 129 & 1 \\
\hline 10 & 2 & 50 & 4 & 90 & 4 & 130 & 1 \\
\hline 11 & 4 & 51 & 4 & 91 & 4 & 131 & 1 \\
\hline 12 & 4 & 52 & 4 & 92 & 4 & 132 & 1 \\
\hline 13 & 1 & 53 & 4 & 93 & 4 & 133 & 2 \\
\hline 14 & 1 & 54 & 4 & 94 & 4 & 134 & 1 \\
\hline 15 & 4 & 55 & 4 & 95 & 4 & 135 & 1 \\
\hline 16 & 4 & 56 & 4 & 96 & 4 & 136 & 1 \\
\hline 17 & 4 & 57 & 4 & 97 & 4 & 137 & 1 \\
\hline 18 & 4 & 58 & 4 & 98 & 4 & 138 & 1 \\
\hline 19 & 1 & 59 & 4 & 99 & 4 & 139 & 1 \\
\hline 20 & 1 & 60 & 4 & 100 & 4 & 140 & 1 \\
\hline 21 & 4 & 61 & 4 & 101 & 4 & 141 & 3 \\
\hline 22 & 4 & 62 & 4 & 102 & 4 & 142 & 3 \\
\hline 23 & 1 & 63 & 4 & 103 & 4 & 143 & 1 \\
\hline 24 & 2 & 64 & 4 & 104 & 1 & 144 & 1 \\
\hline 25 & 4 & 65 & 4 & 105 & 1 & 145 & 2 \\
\hline 26 & 4 & 66 & 4 & 106 & 1 & 146 & 1 \\
\hline 27 & & 67 & 4 & 107 & 1 & 147 & \\
\hline 28 & & 68 & 4 & 108 & 1 & 148 & 1 \\
\hline 29 & 1 & 69 & 4 & 109 & 4 & 149 & 1 \\
\hline 30 & 1 & 70 & 4 & 110 & 4 & 150 & 1 \\
\hline 31 & 1 & 71 & 4 & 111 & 4 & 151 & 2 \\
\hline 32 & 1 & 72 & 4 & 112 & 4 & 152 & 1 \\
\hline 33 & 1 & 73 & 2 & 113 & 4 & 153 & 1 \\
\hline 34 & 1 & 74 & 1 & 114 & 4 & 154 & \\
\hline 35 & 1 & 75 & 4 & 115 & 4 & 155 & \\
\hline 36 & 1 & 76 & 4 & 116 & 4 & 156 & 2 \\
\hline 37 & 1 & 77 & 4 & 117 & 4 & 157 & 2 \\
\hline 38 & 4 & 78 & 4 & 118 & 4 & 158 & 1 \\
\hline 39 & 4 & 79 & 4 & 119 & 4 & & \\
\hline 40 & 4 & 80 & 4 & 120 & 1 & & \\
\hline
\end{tabular}


Table 15: Aggregated CVI scores for PCVI

\begin{tabular}{|c|c|c|c|c|c|c|c|}
\hline $\begin{array}{l}\text { Shoreline } \\
\text { Measurement } \\
\text { No }\end{array}$ & $\begin{array}{l}\text { CVI } \\
\text { Scores }\end{array}$ & $\begin{array}{l}\text { Shoreline } \\
\text { Measurement } \\
\text { No }\end{array}$ & CVI Scores & $\begin{array}{l}\text { Shoreline } \\
\text { Measurement } \\
\text { No }\end{array}$ & $\begin{array}{l}\text { CVI } \\
\text { Scores }\end{array}$ & $\begin{array}{l}\text { Shoreline } \\
\text { Measurement } \\
\text { No }\end{array}$ & $\begin{array}{l}\text { CVI } \\
\text { Scores }\end{array}$ \\
\hline 1 & 21 & 41 & 22 & 81 & 24 & 121 & 17 \\
\hline 2 & 21 & 42 & 24 & 82 & 24 & 122 & 10 \\
\hline 3 & 17 & 43 & 25 & 83 & 24 & 123 & 17 \\
\hline 4 & 21 & 44 & 25 & 84 & 24 & 124 & 15 \\
\hline 5 & 16 & 45 & 25 & 85 & 24 & 125 & 10 \\
\hline 6 & 16 & 46 & 19 & 86 & 24 & 126 & 20 \\
\hline 7 & 22 & 47 & 24 & 87 & 24 & 127 & 20 \\
\hline 8 & 23 & 48 & 26 & 88 & 24 & 128 & 20 \\
\hline 9 & 23 & 49 & 26 & 89 & 20 & 129 & 16 \\
\hline 10 & 19 & 50 & 25 & 90 & 22 & 130 & 16 \\
\hline 11 & 24 & 51 & 25 & 91 & 20 & 131 & 18 \\
\hline 12 & 23 & 52 & 25 & 92 & 22 & 132 & 13 \\
\hline 13 & 19 & 53 & 22 & 93 & 24 & 133 & 16 \\
\hline 14 & 21 & 54 & 22 & 94 & 18 & 134 & 20 \\
\hline 15 & 21 & 55 & 25 & 95 & 22 & 135 & 20 \\
\hline 16 & 18 & 56 & 19 & 96 & 24 & 136 & 19 \\
\hline 17 & 19 & 57 & 23 & 97 & 22 & 137 & 17 \\
\hline 18 & 17 & 58 & 20 & 98 & 23 & 138 & 19 \\
\hline 19 & 20 & 59 & 26 & 99 & 21 & 139 & 18 \\
\hline 20 & 20 & 60 & 25 & 100 & 23 & 140 & 17 \\
\hline 21 & 27 & 61 & 23 & 101 & 22 & 141 & 19 \\
\hline 22 & 22 & 62 & 23 & 102 & 21 & 142 & 17 \\
\hline 23 & 23 & 63 & 23 & 103 & 22 & 143 & 19 \\
\hline 24 & 22 & 64 & 25 & 104 & 16 & 144 & 21 \\
\hline 25 & 25 & 65 & 28 & 105 & 19 & 145 & 21 \\
\hline 26 & 22 & 66 & 22 & 106 & 12 & 146 & 19 \\
\hline 27 & 21 & 67 & 24 & 107 & 18 & 147 & 15 \\
\hline 28 & 15 & 68 & 20 & 108 & 18 & 148 & 16 \\
\hline 29 & 19 & 69 & 24 & 109 & 16 & 149 & 20 \\
\hline 30 & 20 & 70 & 24 & 110 & 17 & 150 & 21 \\
\hline 31 & 22 & 71 & 24 & 111 & 15 & 151 & 17 \\
\hline 32 & 21 & 72 & 23 & 112 & 16 & 152 & 20 \\
\hline 33 & 16 & 73 & 20 & 113 & 19 & 153 & 15 \\
\hline 34 & 17 & 74 & 13 & 114 & 20 & 154 & 14 \\
\hline 35 & 15 & 75 & 19 & 115 & 19 & 155 & 16 \\
\hline 36 & 16 & 76 & 19 & 116 & 19 & 156 & 18 \\
\hline 37 & 17 & 77 & 19 & 117 & 19 & 157 & 19 \\
\hline 38 & 26 & 78 & 23 & 118 & 19 & 158 & 22 \\
\hline 39 & 26 & 79 & 23 & 119 & 19 & & \\
\hline 40 & 23 & 80 & 19 & 120 & 20 & & \\
\hline
\end{tabular}


Table 16: PCVI measurements for seven physical parameters (overall)

\begin{tabular}{|c|c|c|c|c|c|c|c|c|}
\hline $\begin{array}{l}\text { Shoreline } \\
\text { No }\end{array}$ & $\begin{array}{l}\text { Beach } \\
\text { Width }\end{array}$ & $\begin{array}{l}\text { Dune } \\
\text { Width }\end{array}$ & $\begin{array}{l}\text { Coastal } \\
\text { Slope }\end{array}$ & $\begin{array}{l}\text { Dis } \\
\text { Vegetation }\end{array}$ & $\begin{array}{l}\text { Dist. Built } \\
\text { Structures }\end{array}$ & $\begin{array}{l}\text { Rocky } \\
\text { Outcrop }\end{array}$ & $\begin{array}{l}\text { Sea } \\
\text { Defences }\end{array}$ & Region \\
\hline 1 & 630 & 17.49 & 2.5 & 79.5 & & & & Spurn Head \\
\hline 2 & 360 & 18 & & 69 & 3 & & & Spurn Head \\
\hline 3 & 364 & & & 97 & 3 & & & Spurn Head \\
\hline 4 & 260 & 13 & & 34 & 3.1 & & & Spurn Head \\
\hline 5 & 109 & 59 & & 41 & & & & Spurn Head \\
\hline 6 & 170 & 63 & & 37 & & & & Spurn Head \\
\hline 7 & 76 & & 13.3 & 492 & 8 & & & Hallsands \\
\hline 8 & 21 & & 17.8 & 496 & 4 & & & Hallsands \\
\hline 9 & 20.71 & & 19.2 & 452 & 48 & & & Hallsands \\
\hline 10 & 21.26 & 10 & 6.8 & 490 & & & 25 & Hallsands \\
\hline 11 & 26.3 & & 10.3 & 496 & 4 & & & Hallsands \\
\hline 12 & 24 & & 19.8 & 496 & 4 & & & Hallsands \\
\hline 13 & 25.6 & & 6 & 433 & 67 & 26 & 54 & Hallsands \\
\hline 14 & 27.34 & & 2.4 & 340 & 160 & 13 & 100 & Hallsands \\
\hline 15 & 125 & & 36 & 461 & 39 & & & Lynmouth \\
\hline 16 & 213 & & 21.3 & 260 & 240 & & & Lynmouth \\
\hline 17 & 378 & & 29.5 & 105 & 295 & & & Lynmouth \\
\hline 18 & 121 & & 48 & 500 & & & & Lynmouth \\
\hline 19 & 11.39 & 21.44 & 0.6 & 408 & 56.1 & 79 & 100 & Happisburgh \\
\hline 20 & 18.76 & 33 & 1.1 & 337.04 & 162.96 & 20 & 60 & Happisburgh \\
\hline 21 & 54.13 & & 0.9 & 167 & 57.28 & & & Happisburgh \\
\hline 22 & 34.7 & & 1.3 & 256.08 & & & & Happisburgh \\
\hline 23 & 60.57 & & 3.3 & 4 & 477 & & 78 & Happisburgh \\
\hline 24 & 41.64 & & 3.9 & 251 & 138.22 & 11.14 & 24 & Happisburgh \\
\hline 25 & 41.25 & & 2.4 & 350 & 105 & & & Happisburgh \\
\hline 26 & 42.9 & & 1.4 & 477.55 & & & & Happisburgh \\
\hline 27 & 35.1 & & 6 & 60.66 & 433.34 & & & Dawlish \\
\hline 28 & 74.73 & & 11.2 & & 500 & & & Dawlish \\
\hline 29 & 42.23 & & 1.2 & & 500 & & 100 & Dawlish \\
\hline 30 & 21.22 & & 8.2 & 170.7 & 322.3 & & 100 & Dawlish \\
\hline 31 & 27.29 & & 7.7 & 464.39 & 35.61 & & 100 & Dawlish \\
\hline 32 & 32.42 & & 5.3 & 299 & 201 & & 100 & Dawlish \\
\hline 33 & 37.63 & & 1.2 & & 500 & 55 & 100 & Dawlish \\
\hline 34 & 139 & & 1.9 & 228.32 & & & 100 & Dawlish \\
\hline 35 & 135 & 78.79 & 1.2 & 347 & & & 100 & Dawlish \\
\hline 36 & 91.56 & 107.8 & 1.6 & 222 & & & 100 & Dawlish \\
\hline 37 & 107 & 79 & 1.1 & 67 & & & 100 & Dawlish \\
\hline 38 & 17.44 & & 3.4 & 56.62 & 443.58 & & & Great Yarmouth \\
\hline 39 & 17.34 & & 2 & 18.51 & 481.49 & & & Great Yarmouth \\
\hline 40 & 15.78 & & 3.4 & 249 & 251 & & & Great Yarmouth \\
\hline 41 & 28.3 & & 4.1 & 500 & & & & Great Yarmouth \\
\hline 42 & 58.19 & & 3.6 & 302.22 & 197.78 & & & Great Yarmouth \\
\hline
\end{tabular}




\begin{tabular}{|c|c|c|c|c|c|c|c|c|}
\hline 43 & 42.22 & & 2.2 & 28 & 482 & & & Great Yarmouth \\
\hline 44 & 1.4 & & 1.7 & 193.76 & 306.24 & & & Great Yarmouth \\
\hline 45 & 1.4 & & 0.9 & 135.71 & 364.29 & & & Great Yarmouth \\
\hline 46 & 590 & & 3.1 & & 500 & & & Great Yarmouth \\
\hline 47 & 565 & 16 & 1.8 & 180 & 82 & & & Great Yarmouth \\
\hline 48 & 12 & & 2.3 & 65.65 & 337.14 & & & Great Yarmouth \\
\hline 49 & 13.75 & & 3.8 & 95 & 316 & & & Great Yarmouth \\
\hline 50 & 10.05 & & 1.7 & 164.65 & 335.35 & & & Great Yarmouth \\
\hline 51 & 11.61 & & 0.5 & 120 & 230 & & & Great Yarmouth \\
\hline 52 & 12.54 & & 1.8 & 129 & 359 & & & Great Yarmouth \\
\hline 53 & 14.72 & & 1.4 & & 500 & & & Great Yarmouth \\
\hline 54 & 14.53 & & 1.7 & & 500 & & & Great Yarmouth \\
\hline 55 & 10.16 & 35 & 0.5 & 66.3 & 433.7 & & & Great Yarmouth \\
\hline 56 & 18.48 & 304 & 1.5 & & 342 & & & Great Yarmouth \\
\hline 57 & 17.35 & 336 & 1.1 & 214 & 80 & & & Great Yarmouth \\
\hline 58 & 11 & 251 & 0.9 & & 198.73 & & & Great Yarmouth \\
\hline 59 & 10.39 & 60 & 0.7 & 27 & 63.28 & & & Great Yarmouth \\
\hline 60 & 12.36 & 33 & 0.6 & 230 & 35 & & & Great Yarmouth \\
\hline 61 & 17.26 & 115 & 1 & 183.5 & 208 & & & Great Yarmouth \\
\hline 62 & 16.68 & 60 & 0.7 & 229.3 & 103 & & & Great Yarmouth \\
\hline 63 & 19.29 & 71 & 1.2 & 343.39 & 133.38 & & & Great Yarmouth \\
\hline 64 & 6.72 & 47 & 0.8 & 10 & 490 & & & Great Yarmouth \\
\hline 65 & 7.4 & 17 & 2 & 55 & 5 & & & Great Yarmouth \\
\hline 66 & 296 & 91 & 0.4 & 352.63 & 30.18 & & & Skegness \\
\hline 67 & 246 & 34.32 & 1.4 & 198.87 & 63 & & & Skegness \\
\hline 68 & 223 & 157 & 1.3 & 274.96 & 145.21 & & & Skegness \\
\hline 69 & 143 & & 1.1 & 38.65 & 223.98 & & & Skegness \\
\hline 70 & 132 & & 1.2 & 88.81 & 261.16 & & & Skegness \\
\hline 71 & 143.76 & & 1.1 & 67 & 367 & & & Skegness \\
\hline 72 & 145.93 & & 1.8 & 105 & 338 & & 35 & Skegness \\
\hline 73 & 309 & 55.17 & 1 & 325 & 100 & 3.09 & 100 & Skegness \\
\hline 74 & 326 & 9.5 & 2.4 & 390 & & & & Skegness \\
\hline 75 & 296 & & 0.5 & & 413 & & & Skegness \\
\hline 76 & 255 & & 2.9 & & 484 & & & Skegness \\
\hline 77 & 263 & 39.36 & 2.1 & & 494 & & & Skegness \\
\hline 78 & 220 & 20 & 3.4 & 28 & 366 & & & Skegness \\
\hline 79 & 214 & & 1.5 & 6 & 383 & & & Skegness \\
\hline 80 & 160 & & 1.7 & & 470 & & & Skegness \\
\hline 81 & 129 & & 1.2 & 84 & 394 & & & Skegness \\
\hline 82 & 128 & & 1.3 & 22 & 450 & & & Skegness \\
\hline 83 & 139 & & 2.2 & 13.35 & 449 & & & Skegness \\
\hline 84 & 219 & & 1.3 & 20 & 426 & & & Skegness \\
\hline 85 & 159 & & 0.9 & 17.05 & 294 & & & Skegness \\
\hline 86 & 173 & & 3.9 & 25.83 & 410 & & & Skegness \\
\hline
\end{tabular}




\begin{tabular}{|c|c|c|c|c|c|c|c|c|}
\hline 87 & 220 & & 2.9 & 33 & 415 & & & Skegness \\
\hline 88 & 220 & & 2 & 207 & 273 & & & Skegness \\
\hline 89 & 255 & 184 & 0.6 & 402 & 98 & & & Benbecula \\
\hline 90 & 213 & & 1.9 & 137 & 363 & & & Benbecula \\
\hline 91 & 50 & & 1.4 & 208 & 292 & 76 & & Benbecula \\
\hline 92 & 107 & & 0.7 & 227.19 & 272.81 & & & Benbecula \\
\hline 93 & 121 & & 1.1 & 402 & 86 & & & Benbecula \\
\hline 94 & 61 & & 1.2 & 415 & & 100 & & Benbecula \\
\hline 95 & 107 & & 1.5 & 217.83 & 282.17 & & & Benbecula \\
\hline 96 & 53 & & 0.9 & 181.94 & 295.47 & & & Benbecula \\
\hline 97 & 82 & & 1.1 & 400 & 75 & 100 & & Benbecula \\
\hline 98 & 37 & & 1.1 & 340.5 & 32.87 & 100 & & Benbecula \\
\hline 99 & 111.35 & 58.91 & 0.6 & 354.88 & 145.12 & & & Benbecula \\
\hline 100 & 148 & 49.81 & 1.2 & 488.79 & 11.21 & & & Benbecula \\
\hline 101 & 60 & & 1.2 & 480 & 15 & 100 & & Benbecula \\
\hline 102 & 113.7 & & 1.3 & 485 & 15 & 100 & & Benbecula \\
\hline 103 & 67.99 & & 1.4 & 490 & 10 & 100 & & Benbecula \\
\hline 104 & 72 & & 10.6 & 110 & 65 & & 100 & Aberystwyth \\
\hline 105 & 83 & & 1.2 & 128 & 29.45 & 100 & 100 & Aberystwyth \\
\hline 106 & 168 & & 4.3 & & 455 & & 100 & Aberystwyth \\
\hline 107 & 67 & & 4.5 & 44 & 423 & & 100 & Aberystwyth \\
\hline 108 & 63 & & 14.7 & 306 & 36 & & 100 & Aberystwyth \\
\hline 109 & 179 & 289 & 1.5 & & 400 & & & Port Talbot \\
\hline 110 & & 33.75 & 1.9 & 490 & & & & Port Talbot \\
\hline 111 & & 515 & 3.4 & 500 & & & & Port Talbot \\
\hline 112 & 835 & 345 & 2.1 & 424 & & & & Port Talbot \\
\hline 113 & 530 & 66 & 1.4 & & 30 & & & Port Talbot \\
\hline 114 & 382 & 55 & 2 & 164 & 231 & & & Port Talbot \\
\hline 115 & 351 & & 3.9 & & 410 & & & Port Talbot \\
\hline 116 & 327 & & 2.6 & & 500 & & & Port Talbot \\
\hline 117 & 373 & & 1.4 & & 424 & & & Port Talbot \\
\hline 118 & 360 & & 1.3 & & 428 & & & Port Talbot \\
\hline 119 & 364 & & 1.1 & & 500 & & 2.2 & Port Talbot \\
\hline 120 & 245 & & 2.8 & 57.02 & 419 & 5.62 & 100 & Port Talbot \\
\hline 121 & 123 & & 4.2 & 86 & 380 & 30 & 100 & Port Talbot \\
\hline 122 & 192 & 49 & 2.3 & & 500 & 14 & & Port Talbot \\
\hline 123 & 100 & 110.68 & 1.2 & 92 & 395 & 18 & 100 & Port Talbot \\
\hline 124 & 198 & & 15.6 & & 500 & & 73 & Port Talbot \\
\hline 125 & 339 & & 10.9 & & 500 & & & Port Talbot \\
\hline 126 & 315 & & 3.9 & 65 & 383 & 7.1 & 100 & Port Talbot \\
\hline 127 & 323 & & 2.6 & 40.87 & 311 & & 100 & Port Talbot \\
\hline 128 & 335 & & 2.7 & 40 & 455 & 4.7 & 100 & Port Talbot \\
\hline 129 & 302 & & 2.1 & & 500 & 1.5 & 100 & Port Talbot \\
\hline 130 & 371 & & 3.8 & & 500 & 1 & 100 & Port Talbot \\
\hline
\end{tabular}


[PHD THESIS]

April 2017

\begin{tabular}{|c|c|c|c|c|c|c|c|c|}
\hline 131 & 366 & 29 & 3 & 390 & 114 & 1.4 & 100 & Port Talbot \\
\hline 132 & 557 & 163 & 3.1 & & 300 & 1.3 & 100 & Port Talbot \\
\hline 133 & 590 & & 6.7 & 376 & 59.37 & & 29 & Llanelli \\
\hline 134 & 775 & & 1 & 491 & 9 & 1 & 54 & Llanelli \\
\hline 135 & 500 & & 3 & 474.2 & 25.8 & 5.3 & 67.8 & Llanelli \\
\hline 136 & 604 & & 4.1 & 440.41 & 59 & 5.22 & 100 & Llanelli \\
\hline 137 & 820 & & 6.8 & 102 & 343.9 & 2.77 & 100 & Llanelli \\
\hline 138 & 542 & & 11 & 300 & 146 & 3.7 & 100 & Llanelli \\
\hline 139 & 400 & & 1.7 & 273 & 223 & 5.5 & 100 & Llanelli \\
\hline 140 & 95 & 95 & 3.6 & 239 & 260.44 & 17 & 100 & Llanelli \\
\hline 141 & 1400 & & 8.8 & 368.49 & 127 & 0.94 & 14.4 & Llanelli \\
\hline 142 & 1600 & & 3.6 & 307 & 193 & & 11.4 & Llanelli \\
\hline 143 & 1900 & & 3.5 & 207.51 & 171.56 & 2.38 & 80 & Llanelli \\
\hline 144 & 1900 & & 2.2 & 131.78 & 73.12 & 1.03 & 100 & Llanelli \\
\hline 145 & 898 & & 2.7 & 219.03 & 97.65 & 0.87 & 32 & Llanelli \\
\hline 146 & 995 & & 3 & 358.27 & 141.82 & 0.8 & 100 & Llanelli \\
\hline 147 & 550 & & 3.3 & 368.47 & 12.4 & & & Llanelli \\
\hline 148 & 650 & & 0.9 & 263 & 46.79 & & 96 & Llanelli \\
\hline 149 & 760 & & 2.6 & 378.24 & 5.9 & 5.53 & 100 & Llanelli \\
\hline 150 & 696 & & 2 & 127.59 & 4.39 & 1.97 & 100 & Llanelli \\
\hline 151 & 470 & & 1.6 & 481 & 18.26 & & 22.8 & Llanelli \\
\hline 152 & 384 & & 1.5 & 400.5 & 29.87 & 1.3 & 100 & Llanelli \\
\hline 153 & 362 & & 0.8 & 360.09 & 139.91 & & 92 & Llanelli \\
\hline 154 & 250 & & 4.6 & 491.83 & 8.17 & & & Llanelli \\
\hline 155 & 120 & & 2 & 485.04 & 2.4 & & & Llanelli \\
\hline 156 & 38 & & 0.9 & 271.28 & 228.72 & & 22 & Llanelli \\
\hline 157 & 18 & & 2.2 & 321 & 179 & 12.9 & 44 & Llanelli \\
\hline 158 & 65 & & 2 & 345 & 55 & 6.47 & 100 & Llanelli \\
\hline
\end{tabular}


Table 17: CVI scores for physical analysis

\begin{tabular}{|c|c|c|c|c|c|c|c|c|c|}
\hline $\begin{array}{l}\text { Shoreline } \\
\text { No }\end{array}$ & $\begin{array}{l}\text { Beach } \\
\text { Width }\end{array}$ & $\begin{array}{l}\text { Dune } \\
\text { Width }\end{array}$ & $\begin{array}{l}\text { Coastal } \\
\text { Slope }\end{array}$ & $\begin{array}{l}\text { Dist. } \\
\text { Vegetation }\end{array}$ & $\begin{array}{l}\text { Dist. } \\
\text { Built Str }\end{array}$ & $\begin{array}{l}\text { Rocky } \\
\text { Outcrop }\end{array}$ & $\begin{array}{l}\text { Sea } \\
\text { Defences }\end{array}$ & $\begin{array}{l}\text { Aggregated } \\
\text { CVI }\end{array}$ & Region \\
\hline 1 & 1 & 4 & 4 & 4 & & 4 & 4 & 21 & Spurn Head \\
\hline 2 & 1 & 4 & 4 & 4 & 4 & 4 & 4 & 25 & Spurn Head \\
\hline 3 & 1 & & 4 & 4 & 4 & 4 & 4 & 21 & Spurn Head \\
\hline 4 & 1 & 4 & 4 & 4 & 4 & 4 & 4 & 25 & Spurn Head \\
\hline 5 & 2 & 2 & 4 & 4 & & 4 & 4 & 20 & Spurn Head \\
\hline 6 & 2 & 2 & 4 & 4 & & 4 & 4 & 20 & Spurn Head \\
\hline 7 & 3 & 4 & 1 & 2 & 4 & 4 & 4 & 22 & Hallsands \\
\hline 8 & 4 & 4 & 1 & 2 & 4 & 4 & 4 & 23 & Hallsands \\
\hline 9 & 4 & 4 & 1 & 2 & 4 & 4 & 4 & 23 & Hallsands \\
\hline 10 & 4 & 4 & 3 & 2 & & 4 & 2 & 19 & Hallsands \\
\hline 11 & 4 & 4 & 2 & 2 & 4 & 4 & 4 & 24 & Hallsands \\
\hline 12 & 4 & 4 & 1 & 2 & 4 & 4 & 4 & 23 & Hallsands \\
\hline 13 & 4 & 4 & 2 & 2 & 4 & 2 & 1 & 19 & Hallsands \\
\hline 14 & 4 & 4 & 4 & 2 & 3 & 3 & 1 & 21 & Hallsands \\
\hline 15 & 2 & 4 & 1 & 2 & 4 & 4 & 4 & 21 & Lynmouth \\
\hline 16 & 1 & 4 & 1 & 2 & 2 & 4 & 4 & 18 & Lynmouth \\
\hline 17 & 1 & 4 & 1 & 3 & 2 & 4 & 4 & 19 & Lynmouth \\
\hline 18 & 2 & 4 & 1 & 2 & & 4 & 4 & 17 & Lynmouth \\
\hline 19 & 4 & 4 & 4 & 2 & 4 & 1 & 1 & 20 & Happisburgh \\
\hline 20 & 4 & 3 & 4 & 2 & 3 & 3 & 1 & 20 & Happisburgh \\
\hline 21 & 4 & 4 & 4 & 3 & 4 & 4 & 4 & 27 & Happisburgh \\
\hline 22 & 4 & 4 & 4 & 2 & & 4 & 4 & 22 & Happisburgh \\
\hline 23 & 4 & 4 & 4 & 4 & 2 & 4 & 1 & 23 & Happisburgh \\
\hline 24 & 4 & 4 & 4 & 2 & 3 & 3 & 2 & 22 & Happisburgh \\
\hline 25 & 4 & 4 & 4 & 2 & 3 & 4 & 4 & 25 & Happisburgh \\
\hline 26 & 4 & 4 & 4 & 2 & & 4 & 4 & 22 & Happisburgh \\
\hline 27 & 4 & 4 & 3 & 4 & 2 & 4 & & 21 & Dawlish \\
\hline 28 & 3 & 4 & 2 & & 2 & 4 & & 15 & Dawlish \\
\hline 29 & 4 & 4 & 4 & & 2 & 4 & 1 & 19 & Dawlish \\
\hline 30 & 4 & 4 & 2 & 3 & 2 & 4 & 1 & 20 & Dawlish \\
\hline 31 & 4 & 4 & 3 & 2 & 4 & 4 & 1 & 22 & Dawlish \\
\hline 32 & 4 & 4 & 3 & 2 & 3 & 4 & 1 & 21 & Dawlish \\
\hline 33 & 4 & 4 & 4 & & 2 & 1 & 1 & 16 & Dawlish \\
\hline 34 & 2 & 4 & 4 & 2 & & 4 & 1 & 17 & Dawlish \\
\hline 35 & 2 & 2 & 4 & 2 & & 4 & 1 & 15 & Dawlish \\
\hline 36 & 3 & 2 & 4 & 2 & & 4 & 1 & 16 & Dawlish \\
\hline 37 & 2 & 2 & 4 & 4 & & 4 & 1 & 17 & Dawlish \\
\hline
\end{tabular}




\begin{tabular}{|c|c|c|c|c|c|c|c|c|c|}
\hline 38 & 4 & 4 & 4 & 4 & 2 & 4 & 4 & 26 & Great Yarmouth \\
\hline 39 & 4 & 4 & 4 & 4 & 2 & 4 & 4 & 26 & Great Yarmouth \\
\hline 40 & 4 & 4 & 3 & 2 & 2 & 4 & 4 & 23 & Great Yarmouth \\
\hline 41 & 4 & 4 & 4 & 2 & & 4 & 4 & 22 & Great Yarmouth \\
\hline 42 & 3 & 4 & 4 & 2 & 3 & 4 & 4 & 24 & Great Yarmouth \\
\hline 43 & 3 & 4 & 4 & 4 & 2 & 4 & 4 & 25 & Great Yarmouth \\
\hline 44 & 4 & 4 & 4 & 3 & 2 & 4 & 4 & 25 & Great Yarmouth \\
\hline 45 & 4 & 4 & 4 & 3 & 2 & 4 & 4 & 25 & Great Yarmouth \\
\hline 46 & 1 & 4 & 4 & & 2 & 4 & 4 & 19 & Great Yarmouth \\
\hline 47 & 1 & 4 & 4 & 3 & 4 & 4 & 4 & 24 & Great Yarmouth \\
\hline 48 & 4 & 4 & 4 & 4 & 2 & 4 & 4 & 26 & Great Yarmouth \\
\hline 49 & 4 & 4 & 4 & 4 & 2 & 4 & 4 & 26 & Great Yarmouth \\
\hline 50 & 4 & 4 & 4 & 3 & 2 & 4 & 4 & 25 & Great Yarmouth \\
\hline 51 & 4 & 4 & 4 & 3 & 2 & 4 & 4 & 25 & Great Yarmouth \\
\hline 52 & 4 & 4 & 4 & 3 & 2 & 4 & 4 & 25 & Great Yarmouth \\
\hline 53 & 4 & 4 & 4 & & 2 & 4 & 4 & 22 & Great Yarmouth \\
\hline 54 & 4 & 4 & 4 & & 2 & 4 & 4 & 22 & Great Yarmouth \\
\hline 55 & 4 & 3 & 4 & 4 & 2 & 4 & 4 & 25 & Great Yarmouth \\
\hline 56 & 4 & 1 & 4 & & 2 & 4 & 4 & 19 & Great Yarmouth \\
\hline 57 & 4 & 1 & 4 & 2 & 4 & 4 & 4 & 23 & Great Yarmouth \\
\hline 58 & 4 & 1 & 4 & & 3 & 4 & 4 & 20 & Great Yarmouth \\
\hline 59 & 4 & 2 & 4 & 4 & 4 & 4 & 4 & 26 & Great Yarmouth \\
\hline 60 & 4 & 3 & 4 & 2 & 4 & 4 & 4 & 25 & Great Yarmouth \\
\hline 61 & 4 & 2 & 4 & 3 & 2 & 4 & 4 & 23 & Great Yarmouth \\
\hline 62 & 4 & 2 & 4 & 2 & 3 & 4 & 4 & 23 & Great Yarmouth \\
\hline 63 & 4 & 2 & 4 & 2 & 3 & 4 & 4 & 23 & Great Yarmouth \\
\hline 64 & 4 & 3 & 4 & 4 & 2 & 4 & 4 & 25 & Great Yarmouth \\
\hline 65 & 4 & 4 & 4 & 4 & 4 & 4 & 4 & 28 & Great Yarmouth \\
\hline 66 & 1 & 3 & 4 & 2 & 4 & 4 & 4 & 22 & Skegness \\
\hline 67 & 1 & 4 & 4 & 3 & 4 & 4 & 4 & 24 & Skegness \\
\hline 68 & 1 & 2 & 4 & 2 & 3 & 4 & 4 & 20 & Skegness \\
\hline 69 & 2 & 4 & 4 & 4 & 2 & 4 & 4 & 24 & Skegness \\
\hline 70 & 2 & 4 & 4 & 4 & 2 & 4 & 4 & 24 & Skegness \\
\hline 71 & 2 & 4 & 4 & 4 & 2 & 4 & 4 & 24 & Skegness \\
\hline 72 & 2 & 4 & 4 & 3 & 2 & 4 & 4 & 23 & Skegness \\
\hline 73 & 1 & 3 & 4 & 2 & 4 & 4 & 2 & 20 & Skegness \\
\hline 74 & 1 & 4 & 4 & 2 & & 1 & 1 & 13 & Skegness \\
\hline 75 & 1 & 4 & 4 & & 2 & 4 & 4 & 19 & Skegness \\
\hline 76 & 1 & 4 & 4 & & 2 & 4 & 4 & 19 & Skegness \\
\hline 77 & 1 & 4 & 4 & & 2 & 4 & 4 & 19 & Skegness \\
\hline 78 & 1 & 4 & 4 & 4 & 2 & 4 & 4 & 23 & Skegness \\
\hline 79 & 1 & 4 & 4 & 4 & 2 & 4 & 4 & 23 & Skegness \\
\hline 80 & 1 & 4 & 4 & & 2 & 4 & 4 & 19 & Skegness \\
\hline 81 & 2 & 4 & 4 & 4 & 2 & 4 & 4 & 24 & Skegness \\
\hline
\end{tabular}




\begin{tabular}{|c|c|c|c|c|c|c|c|c|c|}
\hline 82 & 2 & 4 & 4 & 4 & 2 & 4 & 4 & 24 & Skegness \\
\hline 83 & 2 & 4 & 4 & 4 & 2 & 4 & 4 & 24 & Skegness \\
\hline 84 & 2 & 4 & 4 & 4 & 2 & 4 & 4 & 24 & Skegness \\
\hline 85 & 2 & 4 & 4 & 4 & 2 & 4 & 4 & 24 & Skegness \\
\hline 86 & 2 & 4 & 4 & 4 & 2 & 4 & 4 & 24 & Skegness \\
\hline 87 & 2 & 4 & 4 & 4 & 2 & 4 & 4 & 24 & Skegness \\
\hline 88 & 2 & 4 & 4 & 4 & 2 & 4 & 4 & 24 & Skegness \\
\hline 89 & 1 & 1 & 4 & 2 & 4 & 4 & 4 & 20 & Benbecula \\
\hline 90 & 1 & 4 & 4 & 3 & 2 & 4 & 4 & 22 & Benbecula \\
\hline 91 & 3 & 4 & 4 & 2 & 2 & 1 & 4 & 20 & Benbecula \\
\hline 92 & 2 & 4 & 4 & 2 & 2 & 4 & 4 & 22 & Benbecula \\
\hline 93 & 2 & 4 & 4 & 2 & 4 & 4 & 4 & 24 & Benbecula \\
\hline 94 & 3 & 4 & 4 & 2 & & 1 & 4 & 18 & Benbecula \\
\hline 95 & 2 & 4 & 4 & 2 & 2 & 4 & 4 & 22 & Benbecula \\
\hline 96 & 3 & 4 & 4 & 3 & 2 & 4 & 4 & 24 & Benbecula \\
\hline 97 & 3 & 4 & 4 & 2 & 4 & 1 & 4 & 22 & Benbecula \\
\hline 98 & 4 & 4 & 4 & 2 & 4 & 1 & 4 & 23 & Benbecula \\
\hline 99 & 2 & 2 & 4 & 2 & 3 & 4 & 4 & 21 & Benbecula \\
\hline 100 & 2 & 3 & 4 & 2 & 4 & 4 & 4 & 23 & Benbecula \\
\hline 101 & 3 & 4 & 4 & 2 & 4 & 1 & 4 & 22 & Benbecula \\
\hline 102 & 2 & 4 & 4 & 2 & 4 & 1 & 4 & 21 & Benbecula \\
\hline 103 & 3 & 4 & 4 & 2 & 4 & 1 & 4 & 22 & Benbecula \\
\hline 104 & 3 & 4 & 2 & 3 & 4 & 1 & 1 & 18 & Aberystwyth \\
\hline 105 & 3 & 4 & 4 & 3 & 4 & 1 & 1 & 20 & Aberystwyth \\
\hline 106 & 1 & 4 & 3 & & 2 & 1 & 1 & 12 & Aberystwyth \\
\hline 107 & 3 & 4 & 3 & 4 & 2 & 1 & 1 & 18 & Aberystwyth \\
\hline 108 & 3 & 4 & 1 & 2 & 4 & 1 & 1 & 16 & Aberystwyth \\
\hline 109 & 1 & 1 & 4 & & 2 & 4 & 4 & 16 & Port Talbot \\
\hline 110 & & 3 & 4 & 2 & & 4 & 4 & 17 & Port Talbot \\
\hline 111 & & 1 & 4 & 2 & & 4 & 4 & 15 & Port Talbot \\
\hline 112 & 1 & 1 & 4 & 2 & & 4 & 4 & 16 & Port Talbot \\
\hline 113 & 1 & 2 & 4 & & 4 & 4 & 4 & 19 & Port Talbot \\
\hline 114 & 1 & 2 & 4 & 3 & 2 & 4 & 4 & 20 & Port Talbot \\
\hline 115 & 1 & 4 & 4 & & 2 & 4 & 4 & 19 & Port Talbot \\
\hline 116 & 1 & 4 & 4 & & 2 & 4 & 4 & 19 & Port Talbot \\
\hline 117 & 1 & 4 & 4 & & 2 & 4 & 4 & 19 & Port Talbot \\
\hline 118 & 1 & 4 & 4 & & 2 & 4 & 4 & 19 & Port Talbot \\
\hline 119 & 1 & 4 & 4 & & 2 & 4 & 4 & 19 & Port Talbot \\
\hline 120 & 1 & 4 & 4 & 4 & 2 & 4 & 1 & 20 & Port Talbot \\
\hline 121 & 1 & 4 & 3 & 4 & 2 & 2 & 1 & 17 & Port Talbot \\
\hline 122 & 1 & 3 & 4 & & 2 & & & 10 & Port Talbot \\
\hline 123 & 2 & 2 & 4 & 4 & 2 & 2 & 1 & 17 & Port Talbot \\
\hline 124 & 1 & 4 & 3 & & 2 & 4 & 1 & 15 & Port Talbot \\
\hline 125 & 1 & 4 & 3 & & 2 & & & 10 & Port Talbot \\
\hline
\end{tabular}




\begin{tabular}{|c|c|c|c|c|c|c|c|c|c|}
\hline 126 & 1 & 4 & 4 & 4 & 2 & 4 & 1 & 20 & Port Talbot \\
\hline 127 & 1 & 4 & 4 & 4 & 2 & 4 & 1 & 20 & Port Talbot \\
\hline 128 & 1 & 4 & 4 & 4 & 2 & 4 & 1 & 20 & Port Talbot \\
\hline 129 & 1 & 4 & 4 & & 2 & 4 & 1 & 16 & Port Talbot \\
\hline 130 & 1 & 4 & 4 & & 2 & 4 & 1 & 16 & Port Talbot \\
\hline 131 & 1 & 3 & 4 & 2 & 3 & 4 & 1 & 18 & Port Talbot \\
\hline 132 & 1 & 1 & 4 & & 2 & 4 & 1 & 13 & Port Talbot \\
\hline 133 & 1 & 4 & 3 & 2 & 4 & & 2 & 16 & Llanelli \\
\hline 134 & 1 & 4 & 4 & 2 & 4 & 4 & 1 & 20 & Llanelli \\
\hline 135 & 1 & 4 & 4 & 2 & 4 & 4 & 1 & 20 & Llanelli \\
\hline 136 & 1 & 4 & 3 & 2 & 4 & 4 & 1 & 19 & Llanelli \\
\hline 137 & 1 & 4 & 2 & 3 & 2 & 4 & 1 & 17 & Llanelli \\
\hline 138 & 1 & 4 & 4 & 2 & 3 & 4 & 1 & 19 & Llanelli \\
\hline 139 & 1 & 4 & 4 & 2 & 2 & 4 & 1 & 18 & Llanelli \\
\hline 140 & 3 & 2 & 4 & 2 & 2 & 3 & 1 & 17 & Llanelli \\
\hline 141 & 1 & 4 & 2 & 2 & 3 & 4 & 3 & 19 & Llanelli \\
\hline 142 & 1 & 4 & 4 & 2 & 3 & & 3 & 17 & Llanelli \\
\hline 143 & 1 & 4 & 4 & 2 & 3 & 4 & 1 & 19 & Llanelli \\
\hline 144 & 1 & 4 & 4 & 3 & 4 & 4 & 1 & 21 & Llanelli \\
\hline 145 & 1 & 4 & 4 & 2 & 4 & 4 & 2 & 21 & Llanelli \\
\hline 146 & 1 & 4 & 4 & 2 & 3 & 4 & 1 & 19 & Llanelli \\
\hline 147 & 1 & 4 & 4 & 2 & 4 & & & 15 & Llanelli \\
\hline 148 & 1 & 4 & 4 & 2 & 4 & & 1 & 16 & Llanelli \\
\hline 149 & 1 & 4 & 4 & 2 & 4 & 4 & 1 & 20 & Llanelli \\
\hline 150 & 1 & 4 & 4 & 3 & 4 & 4 & 1 & 21 & Llanelli \\
\hline 151 & 1 & 4 & 4 & 2 & 4 & & 2 & 17 & Llanelli \\
\hline 152 & 1 & 4 & 4 & 2 & 4 & 4 & 1 & 20 & Llanelli \\
\hline 153 & 1 & 4 & 4 & 2 & 3 & & 1 & 15 & Llanelli \\
\hline 154 & 1 & 4 & 3 & 2 & 4 & & & 14 & Llanelli \\
\hline 155 & 2 & 4 & 4 & 2 & 4 & & & 16 & Llanelli \\
\hline 156 & 4 & 4 & 4 & 2 & 2 & & 2 & 18 & Llanelli \\
\hline 157 & 4 & 4 & 4 & 2 & 3 & & 2 & 19 & Llanelli \\
\hline 158 & 3 & 4 & 4 & 2 & 4 & 4 & 1 & 22 & Llanelli \\
\hline
\end{tabular}


Table 18: Economic parameters and selection process

\begin{tabular}{|c|c|}
\hline Parameters & Description \\
\hline $\begin{array}{l}\text { Population in Coastal } \\
\text { Vulnerability Zones }\end{array}$ & $\begin{array}{l}\text { More than } 50 \% \text { of population is living near to the UK coastlines and } 139 \text { coastal } \\
\text { regions across the UK (Eurostat, 2013) }\end{array}$ \\
\hline \multirow{2}{*}{$\begin{array}{l}\text { Infrastructures } \\
\text { (Properties, roads, } \\
\text { etc.) }\end{array}$} & $\begin{array}{l}\text { More than } 6 \text { million properties are at coastal risk ( } 5.3 \mathrm{~m} \text { in England and }>170,000 \\
\text { in Scotland) }\end{array}$ \\
\hline & $\begin{array}{l}\text { Very valuable infrastructure located in the coastal zones (E.g.: Dawlish, } \\
\text { Aberystwyth, Great Yarmouth, etc.) (Hooper and Chapman, 2012; Turner et al., } \\
\text { 1997) }\end{array}$ \\
\hline Land Use & $\begin{array}{l}\text { Around } 60 \text { per cent of the best agricultural land is } 5 \mathrm{~m} \text { or less above sea level } \\
\text { (Zsamboky et al., 2011) }\end{array}$ \\
\hline Rain Fall & $\begin{array}{l}\text { Heavy rain fall trends/ events across the UK in recent decades (Osborn et al., 2002; } \\
\text { Maraun et al., 2008) }\end{array}$ \\
\hline Erosion & $\begin{array}{l}\text { High coastal erosion at some places of the UK; E.g.; Happisburgh; Spurn Head; } \\
\text { Hallsands, etc. (Poulton et al., 2006; Saye et al., 2005; } \\
\text { Macfarlane, 2013) }\end{array}$ \\
\hline $\begin{array}{l}\text { Unpopulated coastal } \\
\text { Zones }\end{array}$ & $\begin{array}{l}\text { In some areas population is very less (Benbecula } 9 \text { people per sq. (Richards et al., } \\
2007 \text {; ) }\end{array}$ \\
\hline Coastal Discharges & $\begin{array}{l}\text { Coastal discharges are not even across the UK and some regions are in high } \\
\text { amounts (Morris et al., 2000; Turner et al., 1998; Walling and Webb, 1985; }\end{array}$ \\
\hline Urbanised Area & Urbanised zones with huge population and risks (Small, 2003) \\
\hline Frequency of Floods & $\begin{array}{l}\text { Increased trends in frequency of floods (Hannaford and Marsh, 2008; Robson, } \\
\text { 2002; Pall et al., 2011; Watts et al., 2015) }\end{array}$ \\
\hline Damage Costs & Great upsurge in disaster damage and coastal damage (Nicholas, 2007) \\
\hline Flood/storm impact & $\begin{array}{l}\text { Increased the severity of flood/storm impact in recent periods (Schwierz et al., } \\
\text { 2010; Kron et al., 2012 ) }\end{array}$ \\
\hline $\begin{array}{l}\text { Economic value of } \\
\text { place }\end{array}$ & $\begin{array}{l}\text { Economic value of the place plays vital role in economic studies as well as disaster } \\
\text { management studies (Porter, 2000; Hall, 2000; North, 1955; Kusumasari et al., } \\
\text { 2010) }\end{array}$ \\
\hline $\begin{array}{l}\text { Return period of } \\
\text { storms }\end{array}$ & $\begin{array}{l}\text { Return period of storm are highly changed in recent years (Prudhomme et al., 2003; } \\
\text { Wheater, 2006) }\end{array}$ \\
\hline Coastal defences & $\begin{array}{l}\text { Coastal defences advantages and disadvantages (Garbutt et al., 2006; Airoldi et al., } \\
\text { 2005; Phillips et al., 2009) } \\
\text { (Successful and unsuccessful coastal defences) }\end{array}$ \\
\hline $\begin{array}{l}\text { High growth of } \\
\text { civilisation alongside } \\
\text { the coasts }\end{array}$ & $\begin{array}{l}\text { Fast growth of civilisation alongside of coasts (Turner et al., 1998; Walton, 2000; } \\
\text { Cave et al., } 2003 \text { ) } \\
\text { (Eg: Skegness, Great Yarmouth, etc.) }\end{array}$ \\
\hline $\begin{array}{l}\text { Marine Industry } \\
\text { Growth } \\
\text { (Ports business, } \\
\text { warships, artificial } \\
\text { constructions on the } \\
\text { sea's and rivers, etc.) }\end{array}$ & $\begin{array}{l}\text { Marine Industry Growth } \\
\text { (Ports business, warships, artificial constructions on the sea's and rivers, etc.) } \\
90 \% \text { of trade is commuting through the seaports (Warwick University, 2010). } \\
\text { Maritime industries and the service sector annually contribute }>£ 17 \text { billion to the } \\
\text { UK economy and it will be } £ 25 \text { billion by } 2020 \text { (Marine Industries Leadership }\end{array}$ \\
\hline
\end{tabular}




\begin{tabular}{|c|c|}
\hline & Council, 2011) \\
\hline Drainage System & $\begin{array}{l}\text { Poor Drainage system cause to the severe problems particularly during flooding } \\
\text { strikes (Mark et al., 2004; Tunstall et al., 2004) }\end{array}$ \\
\hline $\begin{array}{l}\text { Awareness } \\
\text { Preparedness }\end{array}$ & $\begin{array}{l}\text { Public awareness and preparedness is very impartment during storm strikes } \\
\text { (Bingunath Ingirige and Kaluarachchi, 2013; Kohn et al., 2012 ) }\end{array}$ \\
\hline Storm Insurance & $\begin{array}{l}\text { Storm Insurance face a big factor in damage estimation studies (Pielke Jr et al., } \\
\text { 2008; Huber, 2004; Lamond et al., 2009) in particular in developed countries }\end{array}$ \\
\hline Urban Growth & $\begin{array}{l}\text { Rapid urban growth in coastal zones increase the vulnerability (McGranahan et al., } \\
\text { 2007; Nicholls et al., 2007) }\end{array}$ \\
\hline Warning System & $\begin{array}{l}\text { How much UK has the robust warning system about natural disasters } \\
\text { (Egg: nor waning system during tornado strikes (Kantamaneni, 2015) }\end{array}$ \\
\hline Topography & $\begin{array}{l}\text { UK consists different land scape structures and this also plays a role in coastal } \\
\text { vulnerability (Sutherland et al., 2006; Johnson and Priest, 2008) }\end{array}$ \\
\hline Transportation & $\begin{array}{l}\text { Roads and railways are plays very important role in the economic evaluation } \\
\text { studies particularly in the economic disaster management studies. } \\
\text { A number of storm events significantly damaged transportation infrastructure in } \\
\text { last two decades ((Bosher et al., 2007; Dawson et al., 2016) }\end{array}$ \\
\hline $\begin{array}{l}\text { Penetration of } \\
\text { warning /awareness }\end{array}$ & $\begin{array}{l}\text { Sometimes disaster warning systems are not reaching to the people particularly to } \\
\text { the remote areas (Bankoff et al., 2004; Kantamaneni et al., 2015) }\end{array}$ \\
\hline $\begin{array}{l}\text { Coastal Communities } \\
\text { and age }\end{array}$ & $\begin{array}{l}>274 \text { coastal communities in England and Wales most of the coastal communities } \\
\text { are over }>60 \text { (Atterton, 2006) }\end{array}$ \\
\hline Politics and Polices & $\begin{array}{l}\text { Changing political situation also plays a vital role in assessment of coastal } \\
\text { vulnerability (Berry et al., 2006; Bogardi et al., 2006) } \\
\text { (Eg: } 2008 \text { - Less budgets for coastal defences, huge budget in 2012); strict policy } \\
\text { implementation in since } 2012\end{array}$ \\
\hline
\end{tabular}


Table 19: Economic parameters analysis

\begin{tabular}{|c|c|c|c|c|c|c|c|}
\hline $\begin{array}{c}\text { Coastal } \\
\text { Cell }\end{array}$ & $\begin{array}{c}\text { Commercial } \\
\text { Properties }\end{array}$ & $\begin{array}{c}\text { Residential } \\
\text { Properties }\end{array}$ & $\begin{array}{c}\text { Economic } \\
\text { Value of Site }\end{array}$ & Population & $\begin{array}{l}\text { Coastal } \\
\text { Erosion }\end{array}$ & $\begin{array}{l}\text { Flood Event } \\
\text { Impact }\end{array}$ & Region \\
\hline 1 & 3 & 8 & 60 & 100 & 6 & 30 & Happisburgh \\
\hline 2 & 1.2 & 4 & 110 & 27 & 20 & 35 & Happisburgh \\
\hline 3 & 13.5 & 50 & 130 & 1100 & 7 & 36 & Happisburgh \\
\hline 4 & 1.5 & 20 & 120 & 100 & 5 & 20 & Happisburgh \\
\hline 5 & 35 & 200 & 80 & 4000 & 2.5 & 37 & Great Yarmouth \\
\hline 6 & 38 & 300 & 100 & 5000 & 2 & 35 & Great Yarmouth \\
\hline 7 & 42 & 320 & 120 & 6000 & 3 & 37 & Great Yarmouth \\
\hline 8 & 105 & 600 & 120 & 8000 & 3 & 40 & Great Yarmouth \\
\hline 9 & 55 & 500 & 130 & 5000 & 2.6 & 38 & Great Yarmouth \\
\hline 10 & 45 & 440 & 135 & 4000 & 2 & 35 & Great Yarmouth \\
\hline 11 & 49 & 600 & 130 & 3000 & 3.5 & 32 & Great Yarmouth \\
\hline 12 & 31 & 400 & 100 & 3500 & 4 & 30 & Great Yarmouth \\
\hline 13 & 33 & 300 & 110 & 2000 & 2.5 & 38 & Great Yarmouth \\
\hline 14 & 28 & 240 & 120 & 2000 & 3 & 40 & Great Yarmouth \\
\hline 15 & 26 & 220 & 110 & 1100 & 3.5 & 36 & Great Yarmouth \\
\hline 16 & 22 & 200 & 100 & 1000 & 2.6 & 32 & Great Yarmouth \\
\hline 17 & 22 & 190 & 100 & 1000 & 2.6 & 38 & Great Yarmouth \\
\hline 18 & 0.2 & 0.2 & 2 & 30 & 5.1 & 9 & Spurn Head \\
\hline 19 & 0.25 & 0.2 & 3 & 20 & 9.1 & 9.5 & Spurn Head \\
\hline 20 & 1 & 5 & 20 & 30 & 0.3 & 5 & Skegness \\
\hline 21 & 1.5 & 8 & 22 & 50 & 0.4 & 6 & Skegness \\
\hline 22 & 10 & 54 & 28 & 40 & 0.5 & 10 & Skegness \\
\hline 23 & 14 & 121 & 35 & 1000 & 0.8 & 15 & Skegness \\
\hline 24 & 12 & 135 & 40 & 1100 & 1 & 20 & Skegness \\
\hline 25 & 10 & 120 & 50 & 800 & 1 & 25 & Skegness \\
\hline 26 & 9 & 94 & 60 & 750 & 1.2 & 26 & Skegness \\
\hline 27 & 8 & 67 & 68 & 800 & 1.8 & 21 & Skegness \\
\hline 28 & 9 & 75 & 65 & 700 & 2.2 & 19 & Skegness \\
\hline 29 & 10 & 63 & 60 & 600 & 2.5 & 18 & Skegness \\
\hline 30 & 8 & 81 & 55 & 500 & 3 & 19 & Skegness \\
\hline 31 & 8.5 & 67 & 50 & 800 & 2.8 & 16 & Skegness \\
\hline 32 & 7.5 & 27 & 30 & 800 & 2 & 17 & Skegness \\
\hline 33 & 9 & 32 & 35 & 750 & 1.5 & 19 & Skegness \\
\hline 34 & 10 & 40 & 40 & 800 & 1 & 20 & Skegness \\
\hline 35 & 9 & 26.6 & 30 & 850 & 0.8 & 16 & Skegness \\
\hline 36 & 12 & 26 & 25 & 750 & 0.6 & 15 & Skegness \\
\hline 37 & 7.5 & 40 & 20 & 600 & 0.6 & 14 & Skegness \\
\hline 38 & 0 & 0.9 & 5 & 1 & 7 & 12 & Hallsands \\
\hline 39 & 0.1 & 0.6 & 20 & 4 & 8 & 13 & Hallsands \\
\hline 40 & 1 & 11 & 50 & 36 & 10 & 16 & Hallsands \\
\hline 41 & 0.5 & 2 & 30 & 10 & 9 & 14 & Hallsands \\
\hline 42 & 28 & 25 & 90 & 300 & 3 & 16 & Lynmouth \\
\hline 43 & 9 & 19 & 80 & 190 & 2 & 14 & Lynmouth \\
\hline 44 & 5 & 26 & 60 & 300 & 9 & 20 & Dawlish \\
\hline 45 & 40 & 598 & 80 & 3500 & 11 & 36 & Dawlish \\
\hline 46 & 30 & 468 & 100 & 3000 & 20 & 30 & Dawlish \\
\hline 47 & 16 & 390 & 90 & 2200 & 12 & 20 & Dawlish \\
\hline 48 & 18 & 208 & 85 & 1500 & 10 & 18 & Dawlish \\
\hline
\end{tabular}


[PHD THESIS]

April 2017

\begin{tabular}{|c|c|c|c|c|c|c|c|}
\hline 49 & 10 & 130 & 80 & 800 & 9 & 17 & Dawlish \\
\hline 50 & 6 & 32 & 20 & 700 & 2 & 3 & Llanelli \\
\hline 51 & 7.2 & 40 & 30 & 1500 & 2.2 & 3.2 & Llanelli \\
\hline 52 & 9.6 & 48 & 55 & 2600 & 3 & 4 & Llanelli \\
\hline 53 & 12 & 112 & 60 & 2200 & 4.5 & 6 & Llanelli \\
\hline 54 & 13.2 & 104 & 80 & 1800 & 6 & 9 & Llanelli \\
\hline 55 & 9.7 & 113 & 100 & 1900 & 6.5 & 10 & Llanelli \\
\hline 56 & 10.8 & 72 & 120 & 1700 & 6 & 10.5 & Llanelli \\
\hline 57 & 0.48 & 1.6 & 20 & 100 & 1.2 & 2 & Llanelli \\
\hline 58 & 1.2 & 4.8 & 25 & 200 & 1 & 3 & Llanelli \\
\hline 59 & 2.4 & 9.6 & 30 & 200 & 3 & 3.2 & Llanelli \\
\hline 60 & 4.8 & 11 & 50 & 300 & 4 & 5 & Llanelli \\
\hline 61 & 7.2 & 12.7 & 60 & 850 & 4.8 & 6 & Llanelli \\
\hline 62 & 2 & 24 & 25 & 300 & 5 & 7 & Port Talbot \\
\hline 63 & 1.5 & 6 & 15 & 50 & 4 & 4 & Port Talbot \\
\hline 64 & 6 & 12 & 8 & 30 & 3 & 2 & Port Talbot \\
\hline 65 & 36 & 540 & 90 & 6700 & 7 & 20 & Port Talbot \\
\hline 66 & 63 & 780 & 110 & 10000 & 9 & 28 & Port Talbot \\
\hline 67 & 51 & 504 & 105 & 5000 & 6 & 31 & Port Talbot \\
\hline 68 & 7 & 6 & 110 & 200 & 20 & 34 & Port Talbot \\
\hline 69 & 0.4 & 2.4 & 150 & 100 & 18 & 35 & Port Talbot \\
\hline 70 & 0.35 & 11.5 & 1000 & 20 & 15 & 36 & Port Talbot \\
\hline 71 & 0.1 & 0 & 1000 & 0 & 10 & 35 & Port Talbot \\
\hline 72 & 0.04 & 0 & 200 & 0 & 8 & 28 & Port Talbot \\
\hline 73 & 0.02 & 0 & 150 & 0 & 8 & 20 & Port Talbot \\
\hline 74 & 66 & 594 & 500 & 6600 & 6 & 18 & Aberystwyth \\
\hline 75 & 42 & 167 & 300 & 4000 & 5 & 17 & Aberystwyth \\
\hline 76 & 6 & 33 & 160 & 400 & 10 & 36 & Benbecula \\
\hline 77 & 4 & 20 & 150 & 350 & 9.5 & 35.5 & Benbecula \\
\hline 78 & 2 & 3.1 & 100 & 50 & 10 & 20 & Benbecula \\
\hline 79 & 2 & 3 & 40 & 30 & 4 & 3 & Benbecula \\
\hline 80 & 0 & 0.4 & 20 & 10 & 3 & 2 & Benbecula \\
\hline
\end{tabular}


Table 20. CVI scores for economic analysis

\begin{tabular}{|c|c|c|c|c|c|c|c|c|}
\hline $\begin{array}{c}\text { Coastal } \\
\text { Cell }\end{array}$ & $\begin{array}{c}\text { Commercial } \\
\text { Properties }\end{array}$ & $\begin{array}{l}\text { Residential } \\
\text { Properties }\end{array}$ & $\begin{array}{l}\text { Economic } \\
\text { Value of } \\
\text { Site }\end{array}$ & Population & $\begin{array}{l}\text { Coastal } \\
\text { Erosion }\end{array}$ & $\begin{array}{c}\text { Flood } \\
\text { Event } \\
\text { Impact }\end{array}$ & $\begin{array}{c}\text { Aggregated } \\
\text { CVI }\end{array}$ & Region \\
\hline 1 & 2 & 1 & 3 & 1 & 4 & 4 & 15 & Happisburgh \\
\hline 2 & 1 & 1 & 4 & 1 & 5 & 4 & 16 & Happisburgh \\
\hline 3 & 3 & 2 & 4 & 2 & 4 & 5 & 20 & Happisburgh \\
\hline 4 & 1 & 1 & 4 & 1 & 3 & 4 & 14 & Happisburgh \\
\hline 5 & 4 & 5 & 3 & 3 & 2 & 5 & 22 & Great Yarmouth \\
\hline 6 & 4 & 5 & 3 & 3 & 2 & 4 & 21 & Great Yarmouth \\
\hline 7 & 4 & 5 & 4 & 4 & 3 & 5 & 25 & Great Yarmouth \\
\hline 8 & 5 & 5 & 4 & 4 & 3 & 5 & 26 & Great Yarmouth \\
\hline 9 & 4 & 5 & 4 & 3 & 3 & 5 & 24 & Great Yarmouth \\
\hline 10 & 4 & 5 & 4 & 3 & 2 & 5 & 23 & Great Yarmouth \\
\hline 11 & 4 & 5 & 4 & 3 & 3 & 4 & 23 & Great Yarmouth \\
\hline 12 & 4 & 5 & 3 & 3 & 3 & 4 & 22 & Great Yarmouth \\
\hline 13 & 4 & 5 & 4 & 2 & 2 & 5 & 22 & Great Yarmouth \\
\hline 14 & 3 & 5 & 4 & 2 & 3 & 5 & 22 & Great Yarmouth \\
\hline 15 & 3 & 5 & 4 & 2 & 3 & 5 & 22 & Great Yarmouth \\
\hline 16 & 3 & 5 & 3 & 2 & 3 & 4 & 20 & Great Yarmouth \\
\hline 17 & 3 & 5 & 3 & 2 & 3 & 5 & 21 & Great Yarmouth \\
\hline 18 & 1 & 1 & 1 & 1 & 4 & 2 & 10 & Spurn Head \\
\hline 19 & 1 & 1 & 1 & 1 & 5 & 3 & 12 & Spurn Head \\
\hline 20 & 1 & 1 & 2 & 1 & 2 & 2 & 9 & Skegness \\
\hline 21 & 1 & 1 & 2 & 1 & 2 & 2 & 9 & Skegness \\
\hline 22 & 2 & 2 & 2 & 1 & 2 & 3 & 12 & Skegness \\
\hline 23 & 3 & 3 & 2 & 2 & 2 & 3 & 15 & Skegness \\
\hline 24 & 3 & 3 & 2 & 2 & 2 & 4 & 16 & Skegness \\
\hline 25 & 2 & 3 & 2 & 2 & 2 & 4 & 15 & Skegness \\
\hline 26 & 2 & 3 & 3 & 2 & 2 & 4 & 16 & Skegness \\
\hline 27 & 2 & 2 & 3 & 2 & 2 & 4 & 15 & Skegness \\
\hline 28 & 2 & 2 & 3 & 2 & 2 & 4 & 15 & Skegness \\
\hline 29 & 2 & 2 & 3 & 2 & 2 & 4 & 15 & Skegness \\
\hline 30 & 2 & 3 & 3 & 2 & 3 & 4 & 17 & Skegness \\
\hline 31 & 2 & 2 & 2 & 2 & 3 & 4 & 15 & Skegness \\
\hline 32 & 2 & 1 & 2 & 2 & 2 & 4 & 13 & Skegness \\
\hline 33 & 2 & 2 & 2 & 2 & 2 & 4 & 14 & Skegness \\
\hline 34 & 2 & 2 & 2 & 2 & 2 & 4 & 14 & Skegness \\
\hline 35 & 2 & 1 & 2 & 2 & 2 & 4 & 13 & Skegness \\
\hline 36 & 3 & 1 & 2 & 2 & 2 & 3 & 13 & Skegness \\
\hline 37 & 2 & 2 & 2 & 2 & 2 & 3 & 13 & Skegness \\
\hline 38 & 0 & 1 & 1 & 1 & 4 & 3 & 10 & Hallsands \\
\hline 39 & 1 & 1 & 2 & 1 & 4 & 3 & 12 & Hallsands \\
\hline 40 & 1 & 1 & 2 & 1 & 5 & 3 & 13 & Hallsands \\
\hline 41 & 1 & 1 & 2 & 1 & 4 & 3 & 12 & Hallsands \\
\hline 42 & 3 & 1 & 3 & 1 & 3 & 4 & 15 & Lynmouth \\
\hline 43 & 2 & 1 & 3 & 1 & 2 & 3 & 12 & Lynmouth \\
\hline 44 & 2 & 1 & 3 & 1 & 4 & 4 & 15 & Dawlish \\
\hline 45 & 4 & 5 & 3 & 3 & 5 & 5 & 25 & Dawlish \\
\hline 46 & 3 & 5 & 3 & 3 & 5 & 4 & 23 & Dawlish \\
\hline 47 & 3 & 5 & 3 & 3 & 5 & 4 & 23 & Dawlish \\
\hline 48 & 3 & 5 & 3 & 2 & 5 & 4 & 22 & Dawlish \\
\hline
\end{tabular}


[PHD THESIS]

April 2017

\begin{tabular}{|c|c|c|c|c|c|c|c|c|}
\hline 49 & 2 & 5 & 3 & 2 & 4 & 4 & 20 & Dawlish \\
\hline 50 & 2 & 2 & 2 & 2 & 2 & 2 & 12 & Llanelli \\
\hline 51 & 2 & 2 & 2 & 2 & 2 & 2 & 12 & Llanelli \\
\hline 52 & 2 & 2 & 3 & 3 & 3 & 2 & 15 & Llanelli \\
\hline 53 & 3 & 3 & 3 & 3 & 3 & 2 & 17 & Llanelli \\
\hline 54 & 3 & 3 & 3 & 2 & 4 & 2 & 17 & Llanelli \\
\hline 55 & 2 & 3 & 3 & 2 & 4 & 3 & 17 & Llanelli \\
\hline 56 & 2 & 2 & 4 & 2 & 4 & 3 & 17 & Llanelli \\
\hline 57 & 1 & 1 & 2 & 1 & 2 & 2 & 9 & Llanelli \\
\hline 58 & 1 & 1 & 2 & 1 & 2 & 2 & 9 & Llanelli \\
\hline 59 & 2 & 1 & 2 & 1 & 3 & 2 & 11 & Llanelli \\
\hline 60 & 2 & 1 & 2 & 1 & 3 & 2 & 11 & Llanelli \\
\hline 61 & 2 & 1 & 3 & 1 & 3 & 2 & 12 & Llanelli \\
\hline 62 & 2 & 1 & 2 & 1 & 3 & 2 & 11 & Port Talbot \\
\hline 63 & 2 & 1 & 2 & 1 & 3 & 2 & 11 & Port Talbot \\
\hline 64 & 2 & 1 & 1 & 1 & 3 & 2 & 10 & Port Talbot \\
\hline 65 & 4 & 5 & 3 & 4 & 4 & 4 & 24 & Port Talbot \\
\hline 66 & 4 & 5 & 4 & 4 & 4 & 4 & 25 & Port Talbot \\
\hline 67 & 4 & 5 & 4 & 4 & 4 & 4 & 25 & Port Talbot \\
\hline 68 & 2 & 1 & 4 & 1 & 5 & 4 & 17 & Port Talbot \\
\hline 69 & 1 & 1 & 4 & 1 & 5 & 4 & 16 & Port Talbot \\
\hline 70 & 1 & 1 & 5 & 1 & 5 & 5 & 18 & Port Talbot \\
\hline 71 & 1 & 0 & 5 & 1 & 5 & 4 & 16 & Port Talbot \\
\hline 72 & 1 & 0 & 5 & 1 & 4 & 4 & 15 & Port Talbot \\
\hline 73 & 1 & 0 & 4 & 1 & 4 & 4 & 14 & Port Talbot \\
\hline 74 & 4 & 5 & 5 & 4 & 4 & 4 & 26 & Aberystwyth \\
\hline 75 & 4 & 3 & 5 & 4 & 3 & 4 & 23 & Aberystwyth \\
\hline 76 & 2 & 4 & 5 & 1 & 5 & 5 & 22 & Benbecula \\
\hline 77 & 2 & 3 & 5 & 1 & 5 & 5 & 21 & Benbecula \\
\hline 78 & 2 & 2 & 3 & 1 & 5 & 4 & 17 & Benbecula \\
\hline 79 & 1 & 1 & 2 & 1 & 3 & 1 & 9 & Benbecula \\
\hline 80 & 0 & 2 & 2 & 1 & 3 & 1 & 9 & Benbecula \\
\hline
\end{tabular}




\section{Appendix - Professional Achievements and Awards}

I. RISC-KIT: Resilience-Increasing Strategies for Coasts - toolkit EU -Funding Project - Portugal - 2017 (Won partial funding)

II. Invited Guest Researcher-British Council/Newton Fund - London -2016

III. Conference Chair/Presenter - Imperial College, London- 2016

IV. Graduate Scholar Award - 2016 (Imperial College, London)

V. Graduate Scholar Award - 2015 (University of British Colombia, Canada)

VI. Graduate Scholar Award - 2014 (Iceland)

VII. Visiting Scholar- IISc - Indian Institute of Science - Bengaluru, India (June 2nd to 2nd July 2015)

VIII. Summer Institute for Disaster and Risk Research (SIDRR) Scholarship - Beijing, China 2014

IX. Financial Support for Conference Attendance - Delhi University, 2014

X. Financial Support for Conference Attendance - Exeter University 2013 


\section{EU -Funding Project -Portugal - 2017}

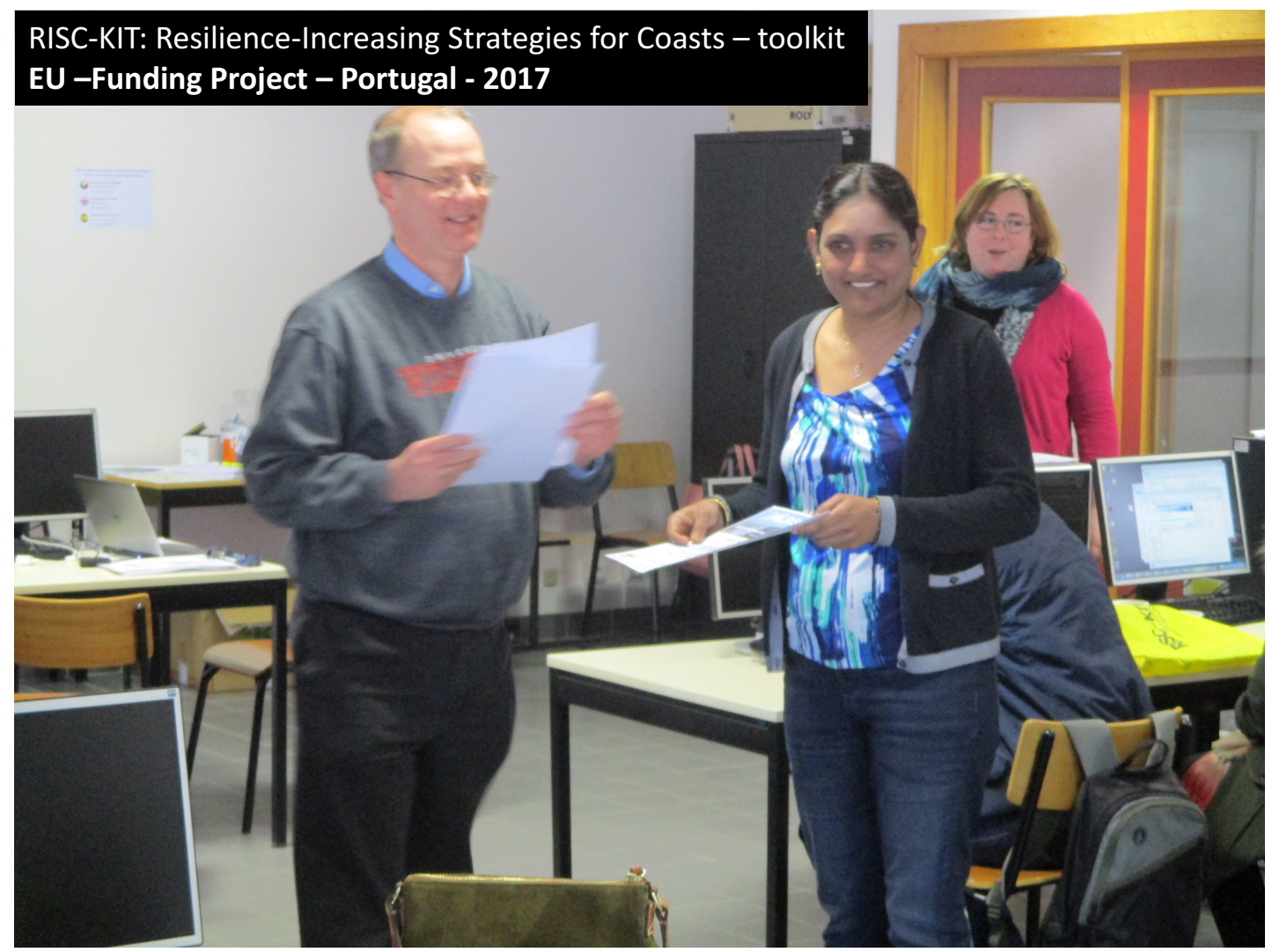




\section{Invited Guest Researcher - British Council/Newton}

Fund

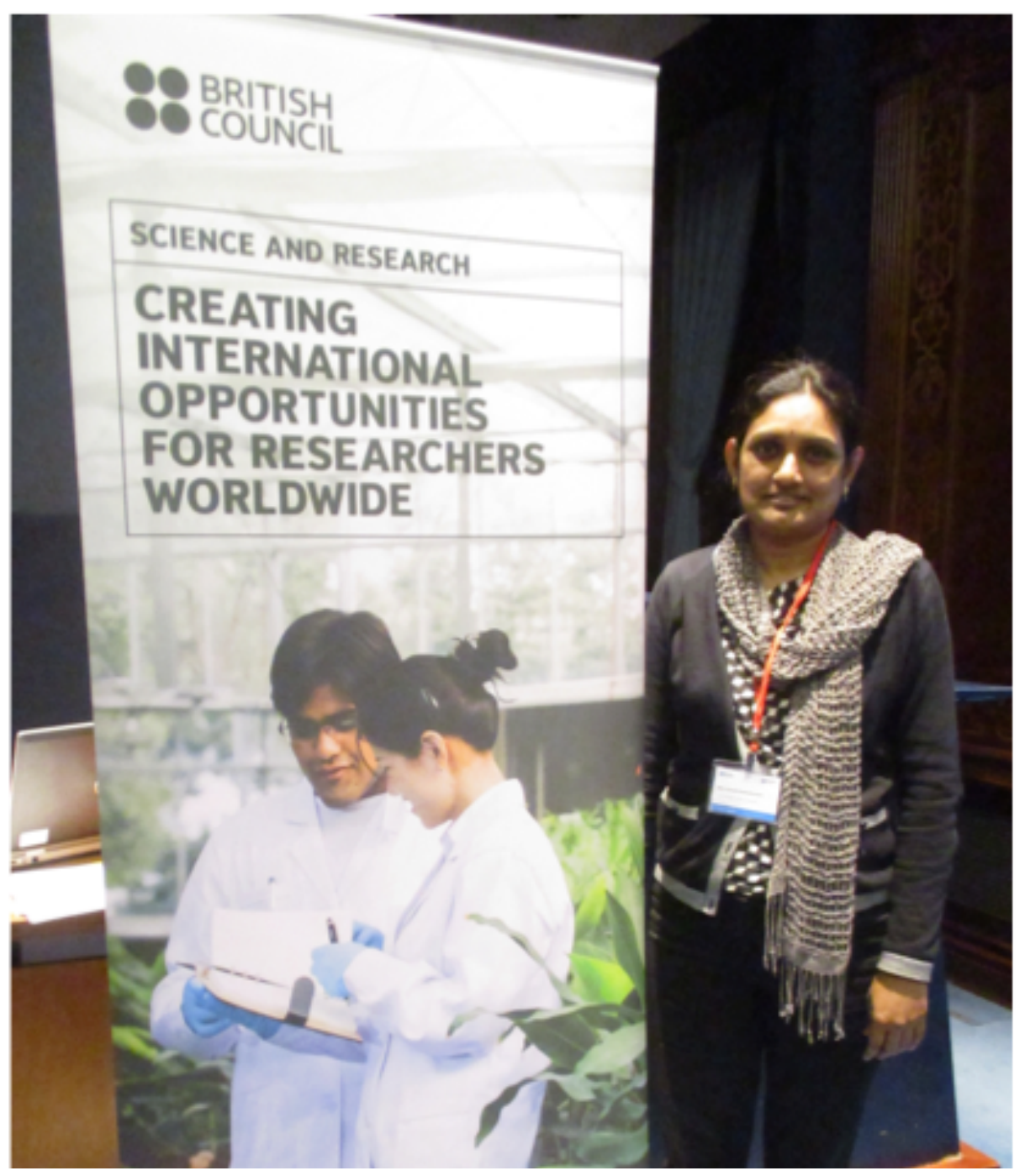




\section{Conference Chair/Presenter -}

\section{Imperial College London-2016}

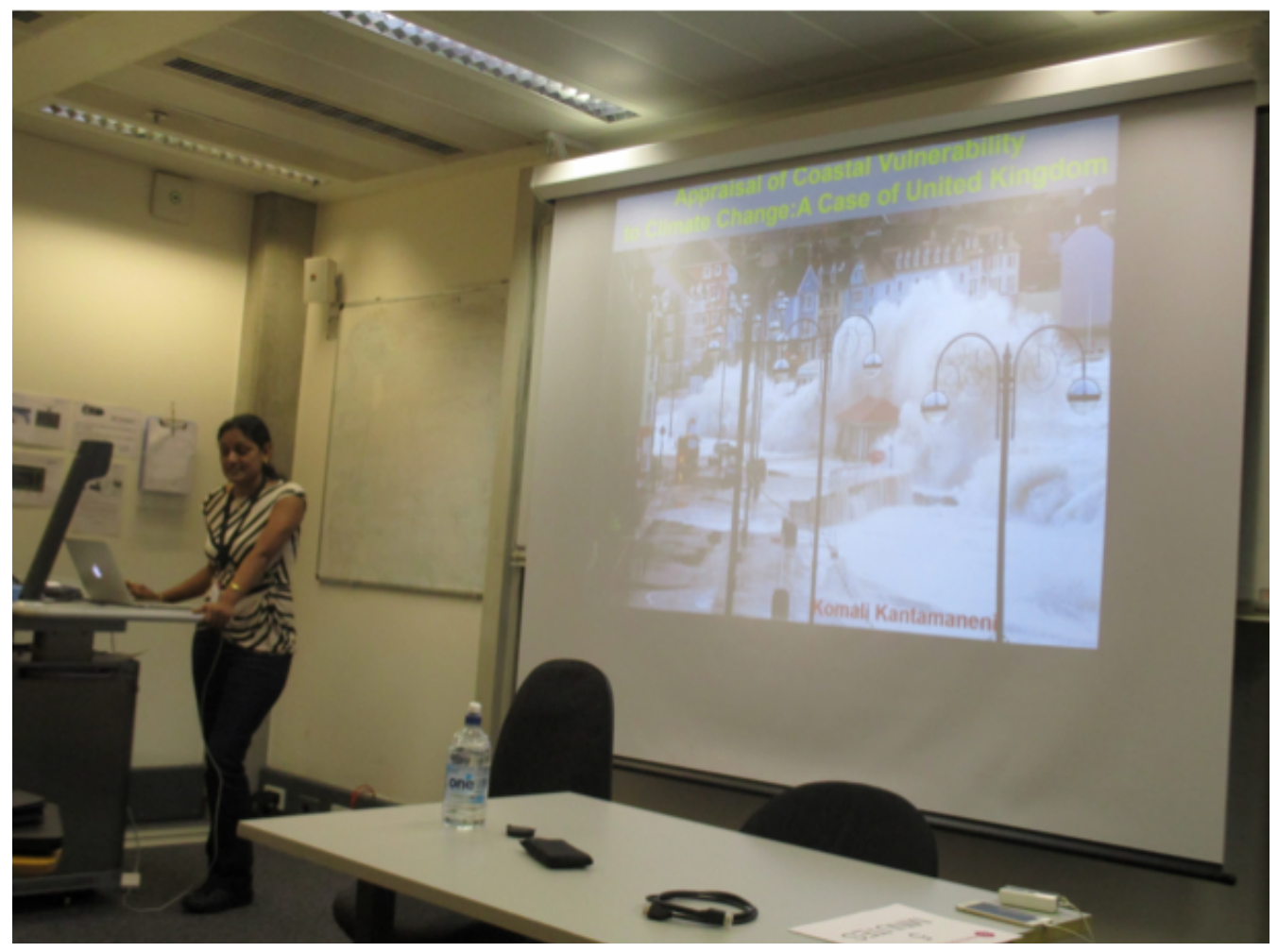




\section{Graduate Scholar Awards - (2014 -2016)}


2016 Recipients

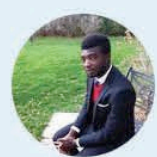

Brock University, St Catraines, Canads

Antwi Boasiako is completing his major research paper for his Master's degree in Political Science at Brock University in Canada. He will be receiving the prestigious Board of Trustees. Spint of Brock medal, for his outstanding leadership, courage, and community involvement, at the 2016 Spring Convocation to be held by the University. He holds several admission offers for further graduate studies from the London School of Economics. McMaster University, Dalhousie University, and Concordia University.

In September 2016, he will begin his Political Science doctoral study at Concordia University where, among other fellowships and

assistantships, he has received the Concordia University Dean's Award, International Tuition Award of Excellence, the Concordia Merit

Scholarship, and a Mentorship Award from the

Faculty of Arts and Sciences in the University.

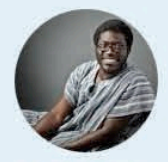

Kojo Dampte

Foval Roads univeraity. Victoria, BC. Canada

Kojo Damptey is an interdisciplinary educator and facilitator; his area of interest is social justice with a focus on leadership theory, race, racialization, postcolonial studies. He approaches these disciplines from an anti-oppressive framework with a foundation in Afro-centric indigenous traditions and culture. He also uses performing arts, specifically music, to address world phenomena discourses relating to human rights, marginalization and neo-colonialism.

As a Pan Africanist and a Freirean, his work involves participatory community organizing along side activist initlatives to tead to communal change in his temporary home Hamilton, Canada or his permanent home Accra, Ghana.

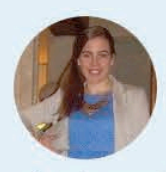

Lucía Lomba Portela

Lucia Lomba Portela is a PhD researcher in the Doctoral program of Education, Sport, and Health at the University of Vigo in Galicia, Spain, She has a degree in Education and she has a Master's degree in quality and improvement of education from the Autonomous University of Madrid She has also participated in courses on new methodologies in education organized by the University of Vigo. Currently she is researching about the difficulties to implement innovative educational projects that are based in an analysis of healthy and educational cities and the influence

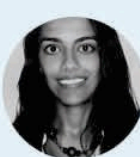

Louise Cardoso de metto

Universidad Pablo de Olavide, Sevilte, Spain

Louise is a Brazilian historian and anthropologist: She holds an MA with distinction in Indigenous Aistory of Latin Amenca fiom the Universidad specraizes in Amazonan Studies where she speciaizes in Amazonian studies as a Pho student Finjoint supervision with the Universidade Federal Fiuminense, in filo de Janeiro, Brazil. Previous Ustitutions she has collaborated with include the Université de Provence, in france, CHAMV in Lisoon, La saplenza, in italy. FuNDHAM in Brazil, the Universidad de San carlos de Guatemala, the Universidad de Oriente, In Mexico and the Universidad Amazonica de Madre de Dios, in Peru. she has further recently concluded an academic stay in the Division of Archaeology at the University of Cambridge.

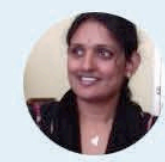

Komali Kantamanen

Komali Kantamaneni has accepted a Research Fellow position at the Southampton Solent University (England) which is to follow soon after her Pho. Cuntently she is a PhD cancidate at the University of Wales: Trinity Saint David, United kingaom. Her research is intorisk analysis of coastal communities due to climate change mpacts (such as increased flooding and storms) and development of corresponding mathematical systems that can holistically measure coastal vulnerability in fiscal terms. Currently, the geographical remit is the United Kingdom and United States of America, which she soon will be expanding to global levels. She holds an MBA in Business Studies from Cardiff Metropoiltan University (UK): an MSc in Environmental Sciences and a BSc in Biology from Nagariuna University, ndia. She has published several papers in refereed international journals as well as presented her research in various internationai conferences.

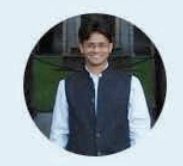

Aditya Mohanty

Aditya Mohanty is an Assistant Professor of Development Studies at the Central University of South Bihar, India. He is currently on a three year Pho study leave (2016-18) at the centre for Citizenship, civil Society and Rule of Law University of Aberdeen, UK and his thesis looks into the politics of local governance in Delhi-A sociologist by training, Aditya's key areas of esearch include questions of political ecology. Urban space and post colonialism. He was also a Visiting Research Scholar at the UrbanLab. University College London, UK (2011-12) under the

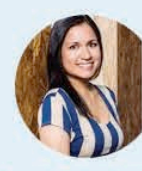

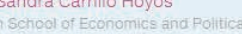

Sandra Carrillo Hoyos is an expert in socioenvironmental conflict prevention and sustainability management. She has wide experience in the implementation of sustainable projects working with public institutions; international cooperation agencies and leading extractive companies. Sandra has been engaged an academic career for the last 7 years as a
professor and researcher with papers presented at international congresses, such as the 2 nd international conference on Public Policy (Milan 2015), the Biennial Conference on the Business and Economics of Peace (Washington, DC, 2015) and the 2 nd International Conference on Sustainable Development Practice (New York 2014). Currently, she is a MSc Environment and 2014). Currently, she is a MSC Environment and
Development Candidate at The London School of Economics and Political Science (LSE).

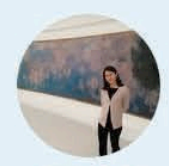

jongmi L

Jongmi Lee is currently pursuing a Master's degree in social policy at Seoul National University. Her primary academic interest is the compatibility of intemational migration and modern welfare states She has recently completed research on the public opinion towards immigrants in East Asia, and also had the opportunity to engage in a project to advise the European migration policy in an intergovernmental organization. Recently, her other interests reach into the relationship between renewable energy and human well-being in environmentally-vulnerable regions, she hopes to gain insight into this topic and is looking forward to collaborating with such an inspiring group of people.

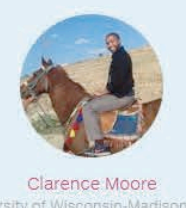

Clarence Moore is a doctoral candidate in political science at the University of Wisconsin-Madison. Clarence's dissertation analyzes the conditions under which civilaans support violent organizations-including the state-in Syria and iraq. To that end, he currently lives in Jordan as a Fulbright scholar and interviews Syrians and Iraqis to learn more about how armed groups behaved and how people responded to them. Upon finishing in Jordan, Clarence will move to Berlin. Germany in order to conduct more interviews. Clarence's general interests include identity 


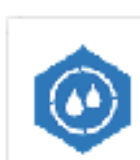

Climate Change:

Impacts \& Responses sign Up for Our Nowelottor | Log in to CaPutilaher

More Knowiedge Commentiles

\begin{tabular}{|l|l|l|l|l|l|l} 
About the Community & Our Focus & The Conference & Publications & Submitting Your Work & The Latest News & Contact Us
\end{tabular}

CALL FOR PAPERS

SUEMIT YOUR PROPOSAL

REOISTRATION

Frequenty Ashed Q-eastions

Payment Oprons and Torms

COMMUNITY MENBERSHP

TYPES OF CONFERENCE

SEssions

Onste Presentations

Orine Pwentations

PAOGRAM ANDEVENTS

De Owen Schemat Erming

Lecture

soloavio of Sossions

Pwency Speatiens

The Pocine insthno for Cimate

solutions

Achwes 8 Events

2015 special Foows

List of Acospeted Proposests

veNe

Acoemmodusons

Carben Orsetiling

Air Travel

Ths for Taveling Abroed

Delegato Pack

GRADUATE SCHOLAR

AMNRD

SUPPCFTERS

PAST CONFERENCES

FREQUENTIY ASKED

QUESTIONS

The Conference Graduate Scholar Awards

Tmeot

\begin{tabular}{l|l} 
GRADUATE 9CHOLAR AWARDS & 2016 RECIPIENTS
\end{tabular}

\section{Mukesh Dev Bhattaral}

Mukesh Dev Bhattaral is a doctoral candldate under Embronmental Resource and Pollcy Program a Southem Illinols Untversty Cartandale, USA (SIUC). His dissertation focuses an the roles of key ingredlenta of agriculure in agoravating andlor millgating Impacts of climate change and identilicatton of possible polcy instruments to address the impacts of clmste change. For his research, he is conducting

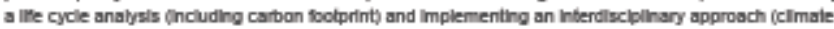
sclence, modelng, economics, mansgement and human behavior) bo understonding the real-worti

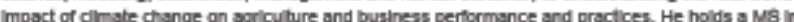
Envict of cimstectsange an soriculure and business performance and practices. He hoids a MS in Envirenmental Sclence and Tectinology from Internstonal Insthite for Hydrsulk and Envronmental Filneerng and

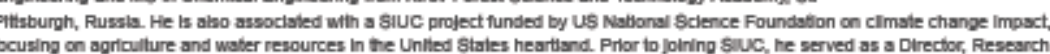
and Planning Department of Aalian Productivity Orpanization in Japan.

\section{Sabrina Dekcker}

Sabrina Dekker is currentify undertaking her PhD at Untversity Colege Dublh, where she is researching how Clles are addressing the impscts of climate change on human heath. Recently, she was a vilting PhD Researcher w th the internationsl Centre for CImate Governance (FEEM) in Venice, italk, where she contrituse to their work on climste change and hesth. Pribr to commencing her PhD, Sabring worked with Sustaingtie

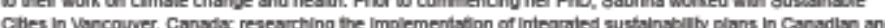
Cbes in Vencouver, Canstas, researding the implementibon of Mente double Master's degree in Pubic. Aftalrs from Sclences Po (Parls, France) and Pubic Poilicy from the Lee Kus Yew School of Public Polcy (UKY) at the Nastansi Universty of Singapore (SIngapore). She specialized in clences $\mathrm{Po}$, and In Public and Global Heath Pollcy, and Urban Develapment Pollcy at LKY. During her studles she was imvolved in the evaluation of Red

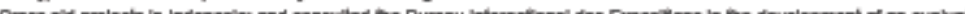
Sor EXPO host clles.

\section{Adekunle Dosumu}

Adekunite Dosumu is a PhD candidate at School of Blbloglcal Sclences, Untrersity of Essex, Colchester, UK. He completed a BSc (Hons.) in Zoology and MSC in Ecology' Emytronmental Blology at Untrersty of libsdan, He completed a Bsc (Hons.) in Zoology and MSc in Ecology' Emironmental Blology at Untversty of lisadin. dominsted sport. Adekunit is cumentify an Instructor Service Operator and sn Environmentsi Champlon with dominated sport. Adekunie is currently an Instructor Service Operator and sn Environmental Champlon wi Transport for Londan (ThL), He la a member of Insthite of Environmental Manspement and Assesament

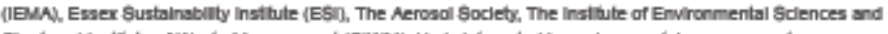
Chartered Insthute of Waste Manapement (CIWM). He is interested in emwironmental mansoement, envirormental sustainstilly, warkplace ssitety and pubilc health. He is very passionste about presenting the nabural emwronment. Hils istest pubication is on Greerhouse Gas Emissians: Contritubitans Made by Footbal Cubs in England.

\section{Hamed Hakim}

Hsmed Hakim is a PMD. student at the University of Florita and is worting as a graduste research sasistant at Powell Center tor Construction s Emironment Paralel to his Pho in Construction Mansoement, Hamed is following a Master of Sclence in Flnance at Warmington College of Business Administration. He recelved his Sollowing a Master of Sclence in Finsnce at Wasingtan College of Business Adminlatration. He recelved his 6.8c. In CMA Englneering with an emphass on Water Resources from istahan Untversity of Technology and his MSc. In Canstruction Engineerng Manapement from University of Flarida. Since 2012, he has devobed his tist to study and conduct research on green buldings and the sustalnabie bult envionment. Hamed has written case-studles and paper publications on the status of Net-Zero Energy Schools and la developing this topic over the course of hls Ph. D. Hamed has over three years of working experlence as a project engineer in commerctid bulliling projects, as well as experience in the heswy chil construction.

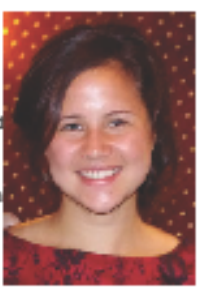

Komall Kantamanen! 
Komali Kantamaneni is a PhD research student based at the University of Wales: Trinity Saint David, United Kingdom. Her research area primarily focuses on the United Kingdom and United States of America, examining the fiscal costs incurred by coastal communities who face increasing vulnerability to coastal storm and sea level rise because of climate change. She holds a MBA in Business studies from Cardiff Metropolitan University, United Kingdom as well as a MSc degree in Environmental Sciences and a BSc in Biology from Nagarjuna University, India. To date, she has successfully published 10 papers and in addition to that, further 13 conference papers accepted for poster and oral presentations.

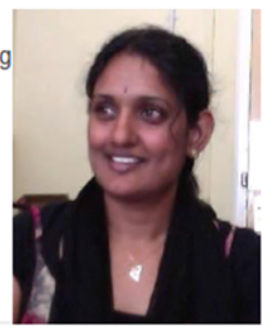

\section{Lindsay Luke}

Lindsay Luke has worked in resource management and environmental assessment throughout British Columbia and in the Northwest Territories. She is an alumna from Camosun College and Royal Roads University in BC She is currently a graduate student at the University of Saskatchewan.

\section{Miriam Matejova}

Miriam Matejova is a PhD student of Political Science, a Vanier Scholar, a Killam Laureate and a Liu Scholar at the University of British Columbia in Vancouver. Her research interests are international security and global environmental politics. She has written and co-authored papers on international peacebuilding, Canada's foreign intelligence, and environmental security. Prior to coming to UBC, Miriam worked as an analyst at the Canadian International Development Agency and as an economist at Environment Canada where she specialized in federal environmental impact assessment and protection of species at risk. Miriam holds a BA (Hons) in International Studies from the University of Northern British

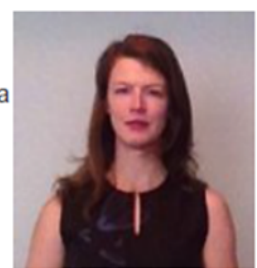
Columbia and an MA in International Affairs from Carleton University's Norman Paterson School of International Affairs.

\section{Kelly Stevens}

Kelly Stevens grew up in Rochester, New York before moving to Tallahassee, Florida in pursuit of a master's in meteorology at Florida State University, and later a master's in public administration from the same institution. While in Florida, she also worked as a meteorologist at the Florida Department of Environmental Protection's Division of Air Resource Management in the Office of Policy Analysis and Program Management for over five years. During her time in Florida, she worked on Florida's electric utility greenhouse gas cap-and-trade rule development, co-authoring a study on offset protocols that was later published in the International Journal of Climate Change Strategies and Management. Currently, she is a $\mathrm{PhD}$ candidate in public administration and international affairs at the Maxwell School at Syracuse University. She works with Peter Wilcoxen and David Popp in the Center for Policy Research on energy, 
Graduate Scholar Awards | The Conference | Climate Change: Impacts and Responses

Sign Up for Our Newsletter

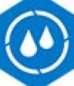

Climate Change:

Impacts \& Responses

More Knowledge Communities

About the Community

Our Focus

The Conference

Publications

Submitting Your Work

The Latest News

CALL FOR PAPERS

SUBMIT YOUR PROPOSAL

REGISTRATION

Frequently Asked Questions Payment Options and Terms COMMUNITY MEMBERSHIP TYPES OF CONFERENCE SESSIONS

On-site Presentation

Online Presentations

PROGRAM AND EVENTS Schedule of Sessions

Plenary Speakers

Tours

Reception

List of Accepted Proposals

VENUE

Accommodations

Tips for Traveling Abroad

Delegate Pack

Airport Transfers

GRADUATE SCHOLAR AWARDS

SUPPORTERS

PAST CONFERENCES

FREQUENTLY ASKED QUESTIONS

THE CONFERENCE - 2015
A The Conference Graduate Scholar Awards

Tweet

GRADUATE SCHOLAR AWARD

2014 GRADUATE SCHOLARS

KRISTINE BELESOVA

Kristine Belesova is a doctoral student of Public Health at the London School of Hygiene and Tropical Medicine. Her research interests include Climate change impacts and responses, vulherability reduction, hum security, and sustainability science. In her Ph.D. research she uses mixed methods to identify risk factors explaining child undernutrition and its health consequences in Burkina Faso. Previously, she worked on research projects at the United Nations Institute for Environment and Human Security in Germany and at the Dalla Lana School of Public Health, University of Toronto, in Canada. She also worked in finance for sustainability at the Latvian Environmental Investment Fund. She holds a BSc(Hons) in Sustainable Development from the University of St Andrews.

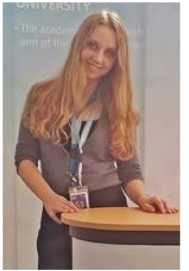

\section{BRIAN BULLA}

Brian Bulla is a doctoral candidate in the Department of Forestry and Environmental Resources at North Carolina State University in Raleigh, North Carolina. He is a policy scientist, interested in how people problematize and research vulnerability to climate change. More specifically, he is interested in the environmental and social justice implications of the policy responses that emerge from differen conceptualizations of vulnerability to climale change. He is working on a case study about public participation and water resource management in Kuger National Park, Soulh Africa, and a community-based participatory research project utilizing photovoice with small-scale farmers in central North Carolina. Prior to beginning his PhD studies, he completed a Master of Public Administration and a Master in International Studies at North Carolina State University

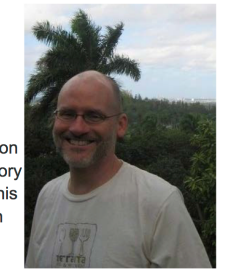

\section{ADEKUNLE DOSUMU}

Adekunle Dosumu is a PhD candidate at School of Biological Sciences, University of Essex; Colchester, UK. He completed a BSc (Hons.) in Zoology and MSc in Ecology/ Environmental Biology at University of Ibadan, Nigeria. His PhD research is on the impacts of sport on the environment. He is currently an Instructor Service Operator and an Environmental Champion with London Underground. He is a member of both Essex Sustainability Institute (ESI) and Chartered Institute of Waste Management (CIWM). He is also an affiliate member of Institute of Environmental Management and Assessment (IEMA).His undertaking research work on climate change, envirente He is very passionate about preserving the natural environment.

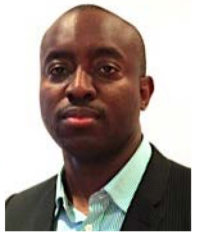

\section{GEORGE FREDUAH}

George Freduah is a PhD researcher at the Sustainability Research Center (SRC), University of the Sunshine Coast (USC), Australia. He has completed a BA in Geography and Resource Development at the University of Ghana and an MPhil in Development Geography at the University of Bergen, Norway. His research interests include climate change adaptations, livelihoods and natural resource management. His $\mathrm{PhD}$ research seeks to assess adaptive capacity of small-scale coastal fisheries for current and future stressors in light of climate change by using Ghana as a case study. Prior to enrolling at USC, he had worked with the Institute of Local Government Studies in Ghana as

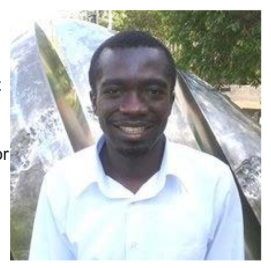

\section{KOMALI KANTAMANENI}

Komali Kantamaneni is a PhD research student based at the University of Wales: Trinity Saint David, United Kingdom. Her research area primarily focuses on the United Kingdom and United States of America, examining the economic costs incurred by coastal communities who face increasing vulnerability to coastal storm and sea level rise because of climate change. She holds a MBA in Business studies from Cardiff Metropolitan University, UK as well as a MSc degree in Environmental Studies and a BSC in Biogy from Nagariuna University, India. To date, she has successfully published 4 papers and in addition to that; further 10 conference papers accepted for poster and oral presentations.

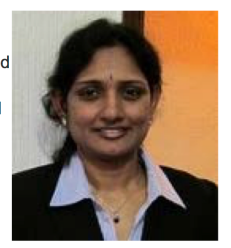




\section{Visiting Scholar Award - 2015}

\begin{tabular}{ll} 
Department of Civil Engineering \\
INDIAN INSTITUTE OF SCIENCE \\
BANGALORE - 560 012, India \\
\hline Dr. D. NAGESH KUMAR \\
Professor \& \\
Chairman, Centre for Earth Sciences
\end{tabular}

\section{Certificate}

This is to certify that Ms. Komali Kantamaneni has worked with me as visiting scholar during the period June 03, 2015 to July 03, 2015 in our Department of Civil Engineering, IISc, Bangalore. During this period she has worked broadly on climate change with in physical and fiscal perspectives with a focus on storm damage costs in developed and developing countries. She has shown keen interest to leam GIS and its applications for map projections and information extraction approaches. During this period she has attended several seminars organized in our department on related topics. She has also worked on her thesis related work and publications during this period. I wish to place on record my appreciation for her sincere efforts and hard work in learning new things and applying them in her research domain during this one month period.

$$
\text { (D. Nagesh Kumar) }
$$




\section{As a Conference Chair - Iceland, 2014}

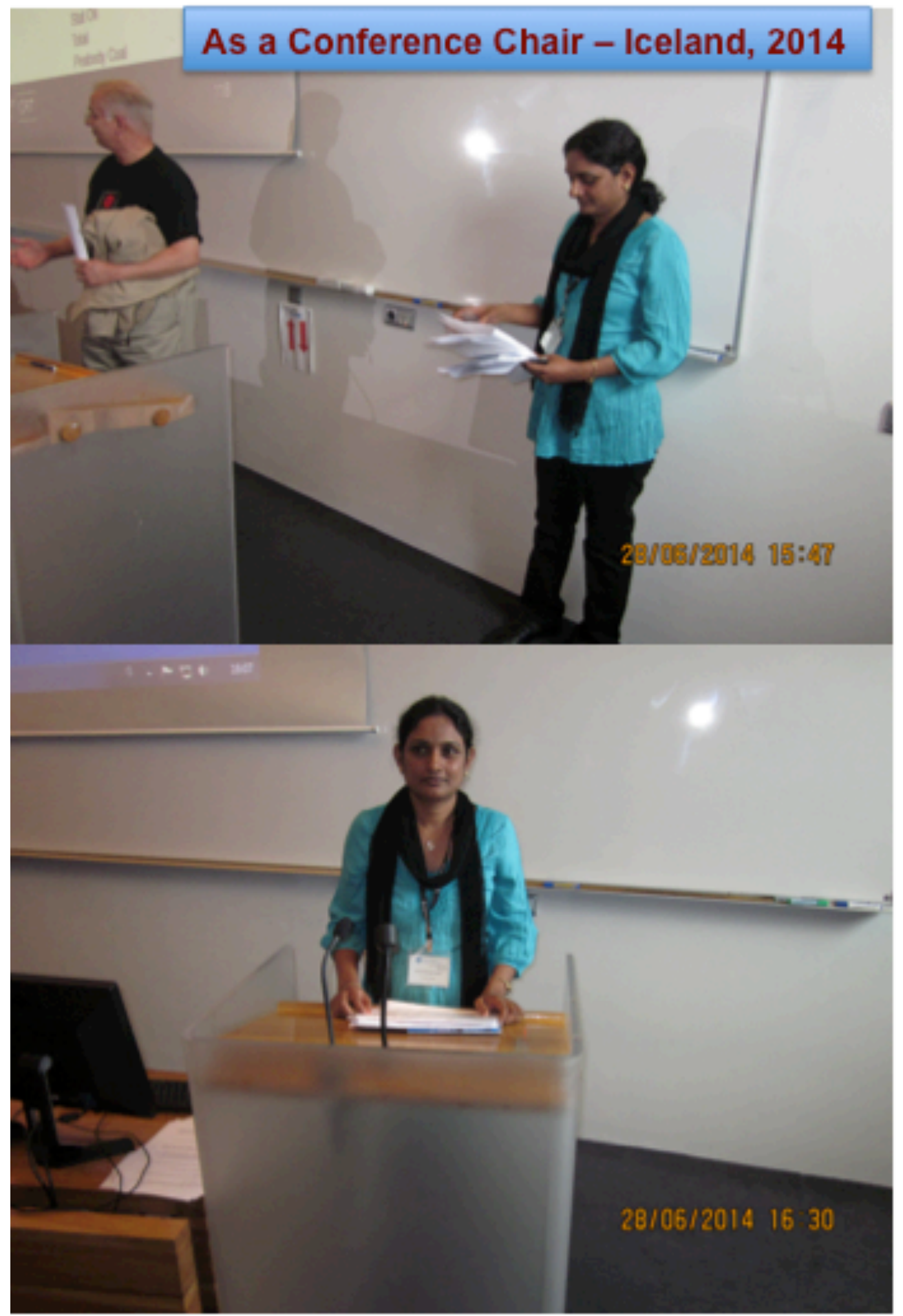




\section{As a Principal Investigator -China, 2014 (Republic of China's Funded Project)}

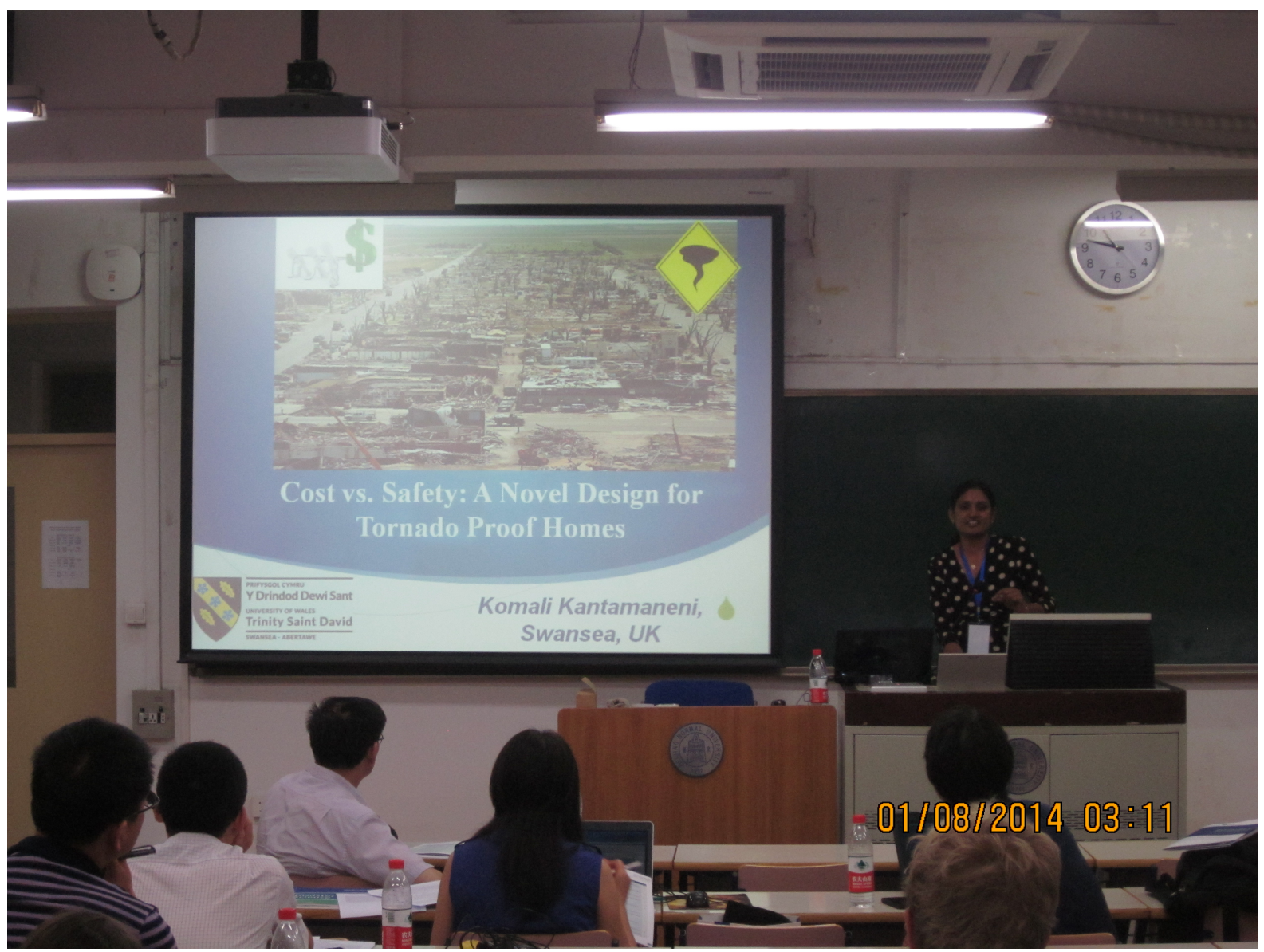




\section{During Visit of Chinese Academy of Sciences (CAS) \\ Beijing, China - 2014}

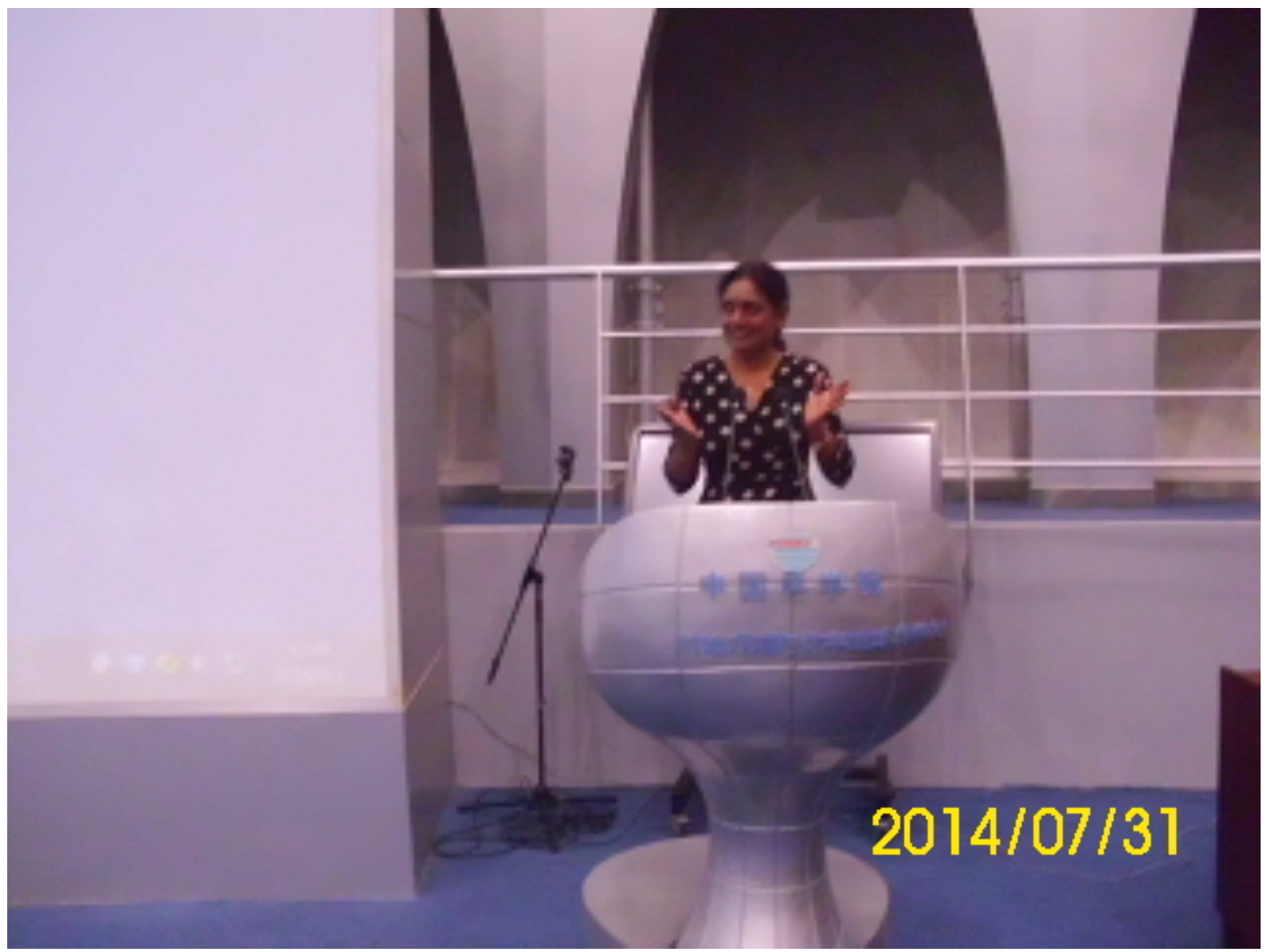




\section{Poster - Exeter University, 2013}

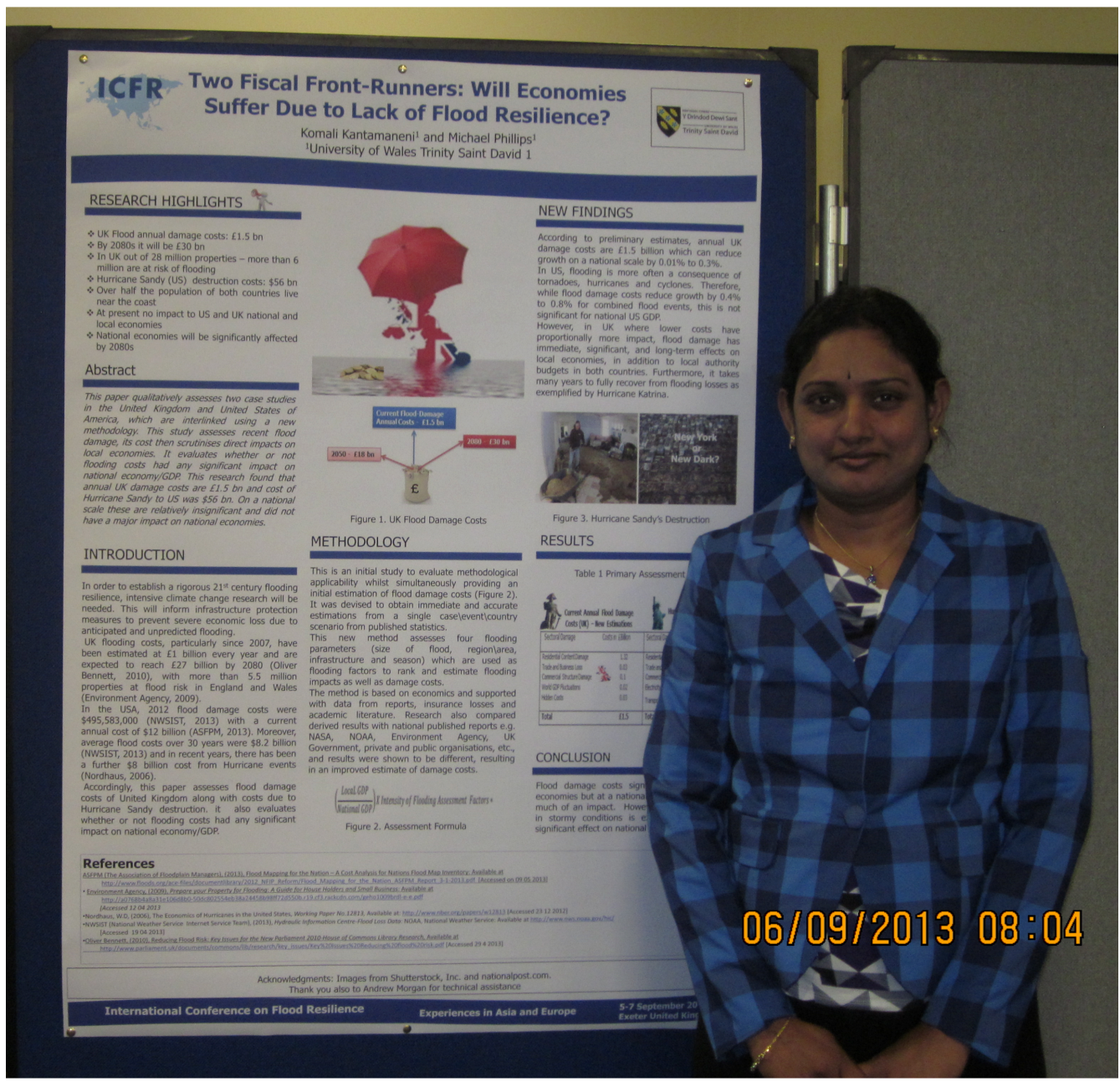




\section{Presentation at Tyndall Centre - Cardiff University, 2013}

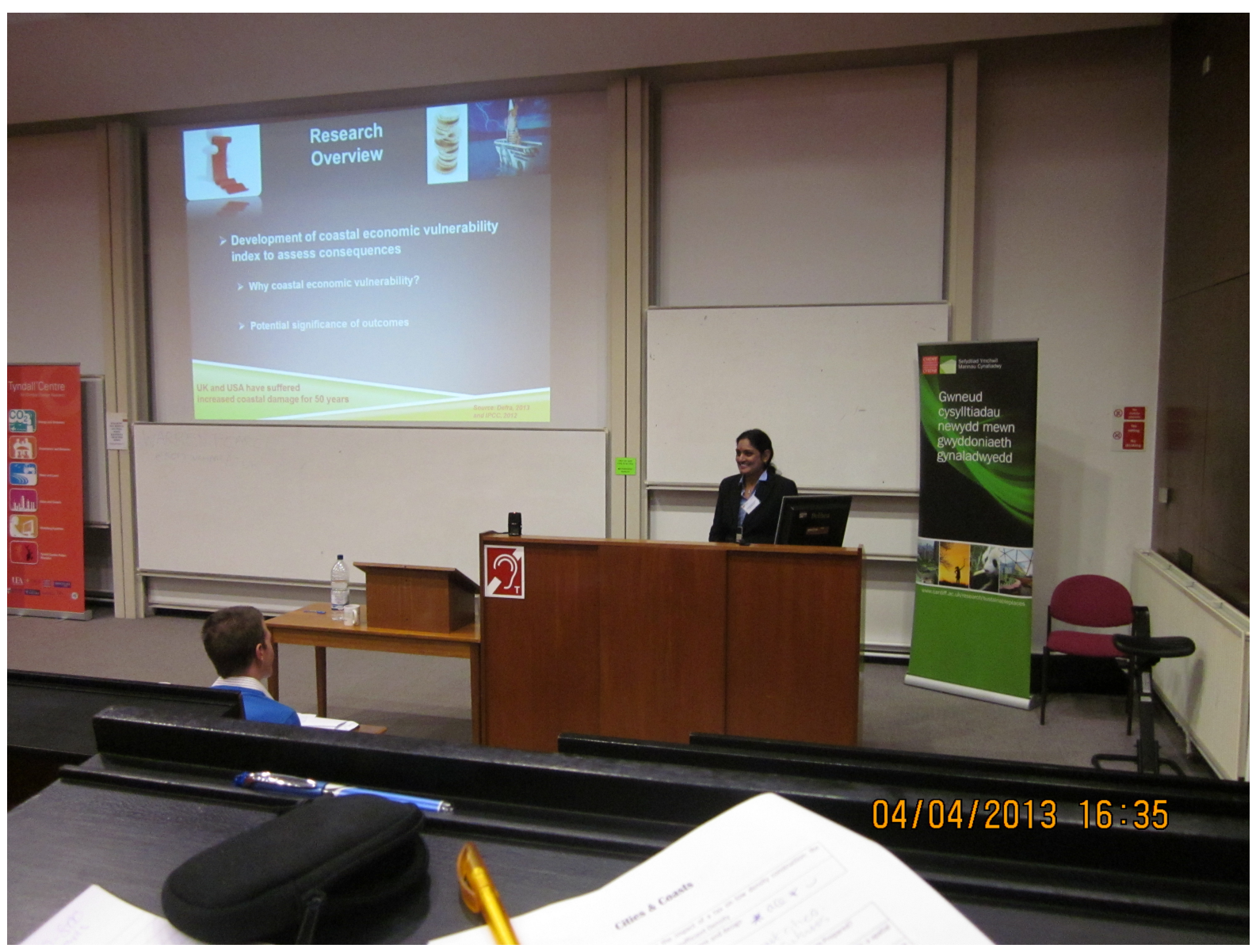




\section{Key Publications}




\title{
Counting the cost of coastal vulnerability
}

\author{
Komali Kantamaneni ${ }^{\text {a, b }}$ \\ ${ }^{\text {a }}$ Faculty of Architecture, Computing and Engineering, University of Wales, Trinity Saint David, Mount Pleasant, Swansea, SA1 6ED, United Kingdom \\ ${ }^{\mathrm{b}}$ School of Maritime and Engineering, Southampton Solent University, E Park Terrace, Southampton, Hampshire, SO14 OYN, United Kingdom
}

\section{A R T I C L E I N F O}

Article history:

Received 3 February 2016

Received in revised form

13 August 2016

Accepted 22 August 2016

Available online 13 September 2016

\section{Keywords:}

New model

Fiscal coastal vulnerability index (FCVI)

Costs

2 Path analysis

Coastal vulnerability sites

United Kingdom

\begin{abstract}
A B S T R A C T
Significant coastal vulnerability (CV) in the United Kingdom (UK) endangers the population and the infrastructure and distorts the national economy, yet present and proposed literature only quotes previous circumstances that failed to deliver factual fiscal assessment. The current estimate models for coastal vulnerability are useful for decision-making in some magnitudes, but coastal vulnerability models need to be extended to comprise a wider choice of economic effects. These are real problems that need to be addressed for an estimation of fiscal coastal vulnerability with novel models of science and economics to limit destruction costs or spend with greater resilience. To address the current research gap, this study appraised coastal vulnerability by establishing an innovative model: a Fiscal Coastal Vulnerability Index (FCVI) with fiscal parameters by 2 Path analysis (2 PA). It identifies the coastal vulnerability hotspots in Path One (P1) and develops an FCVI and GIS maps in Path Two (P2). Primary results revealed that 11 sites across the UK (seven in England, three in Wales, and one in Scotland) were identified as fiscally vulnerable coastal areas. Identified sites currently contain $£ 22.36$ billion worth of coastal vulnerability, and $>100,000$ people are at high risk of flooding, erosion, storm surge, and high winds. The Fiscal Coastal Vulnerability Index can be adapted depending on kind of coastal environment and used as a planning tool to establish economic susceptibility. This work explains that the methodological framework can be adjusted for any suitable coastal sites at global or regional scales, and can be used to vindicate in-depth studies for coastal defences and budget.
\end{abstract}

() 2016 Elsevier Ltd. All rights reserved.

\section{Introduction}

Coasts are greatly vulnerable to extreme weather events, such as storms, which impose significant costs on coastal civilisations. Historical information shows an extensive and fundamental association between coastal zones and anthropological settlements (Smit and Pilifosova, 2003; Singh, 2006; Smith, 2013). Coastal settlement increased dramatically during the 20th century, while a growing number of people and assets on the coasts are subject to additional stresses due to land use and hydrological changes in catchments (Jongman et al., 2012). More than 44\% of the world's population lives within $150 \mathrm{~km}$ of the coast and eight of the ten largest cities in the world are near the shoreline (Atlas, 2012). Several recent extreme storm events across the globe have triggered devastating human and fiscal losses in catchment areas, such as Hurricane Sandy (United States of America-2012), Typhoon Haiyan (Philippines-2013), Cyclone Hudhud (India and Nepal-2014) and Cyclone Pam (Vanuatu, Tuvalu and New Zealand-2015).

E-mail address: Komali.kantamaneni@uwtsd.ac.uk.
According to Nicholls et al. (2007), in excess of 120 million people are exposed to cyclone hazards every year, and 250,000 fatalities were caused by flooding between 1980 and 2000. Globally, floods affect 46 million people every year, and may rise to as many as 60 million a year by 2100 as a consequence of predicted climate change and associated sea level rise (Hoozemans et al., 1993). Increased flood events are greatly affecting socio-economic costs particularly in coastal regions (Hinkel et al., 2010). Populated estuaries, low-lying coastal urban areas, and islands are important communal hotspots of coastal vulnerability (De Sherbinin et al., 2007; Nicholls et al., 2007). The impact of regional and global climate change, sea level rise and rapid weather fluctuations, together with terrestrial processes, are a huge threat to coastal communities (Oliver-Smith, 2009; Zsamboky et al., 2011).

The coastline diverges significantly in terms of morphology and human usage. There are several segments of the UK coast, which are renowned for their natural beauty while others are distinguished by their distinctive and subtle environments such as Mumbles and Aberystwyth coasts. In some areas, there has been intensive tourism growth, while other parts have suffered from intensive industrial expansion. Suffolk and north Norfolk face 
extensive coastal erosion with property and vital natural territories under threat (Doody, 2001; Cooper and McKenna, 2008), all of which indicates that coastal vulnerability greatly impact the UK economy in near future. Recent storm activity as evidenced in 2007, 2012, 2013 and 2014 has exacerbated the vulnerability of various coastal regions. England and Wales are highly affected by these severe storms (Kantamaneni et al., 2015b); therefore, UK coastal vulnerability needs evaluation to a greater degree to ameliorate current problems and to prevent further decline.

Vulnerability evaluations are performed to appraise the amount of loss that could result from a hazardous incident of a given severity, comprising destruction to infrastructure, interruption of monetary activities, and the effect on livelihoods. The four main methods to evaluate coastal vulnerability are: index based (1), indicator based (2), GIS based decision support systems (3), and dynamic computer models (Ramieri et al., 2011). Several researchers across the globe: Gornitz (1990), Pethick and Crooks (2000), Martinez et al. (2006), Vittal Hegde and Radhakrishnan Reju (2007), Abuodha and Woodroffe (2010), Palmer et al. (2011), Balica et al. (2012), Addo (2013), Gorokhovich et al. (2013), Kunte et al. (2014) evaluated coastal vulnerability in geomorphological and physical perspectives but not from an economic point of view. Some studies added very few socio-economic variables (Population, cultural heritage, roads and railways, residential and commercial density, etc.) (Cutter et al., 2003; Vincent, 2004; Schröter et al., 2005; Rygel et al., 2006; Hahn et al., 2009; Mazumdar and Paul, 2016). Some other researchers (Wolters and Kuenzer, 2015; Rani et al., 2015; Nguyen et al., 2016) analysed the recent trends and methodological frameworks for assessing coastal vulnerability. Very few studies conducted research on the coastal vulnerability of the UK (McLaughlin et al., 2002; McLaughlin and Cooper, 2010; Denner et al., 2015; Kantamaneni, 2016). Despite research being conducted on individual locations, there is no CVI for the entire UK coast. In these particular conditions, there is a real need to develop CVIs that evaluate vulnerability within economic and geomorphological perspectives. Consequently, this study attempted to develop an FCVI via 2 Path analysis to fill the vital research gap in the field of coastal studies.

\section{Description of study area}

The United Kingdom is an island nation located in Western Europe, between latitudes $49^{\circ} \mathrm{N}$ and $59^{\circ} \mathrm{N}$ and longitudes $8^{\circ} \mathrm{W}$ to $2^{\circ} \mathrm{E}$. It consists of four governed regions: England, Wales, Scotland and Northern Ireland and bounded by four bodies of water, Celtic

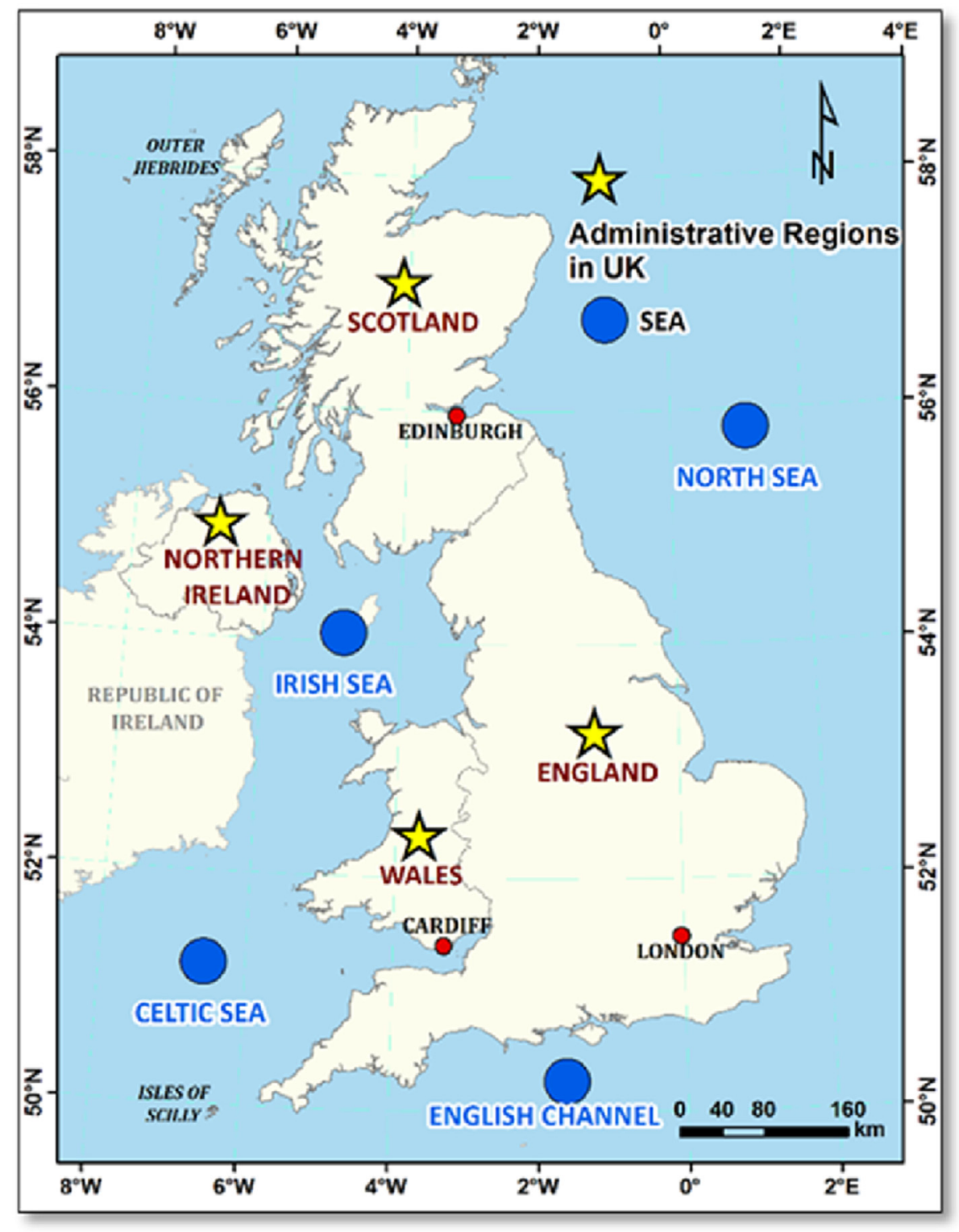

Fig. 1. Map of the study area. 


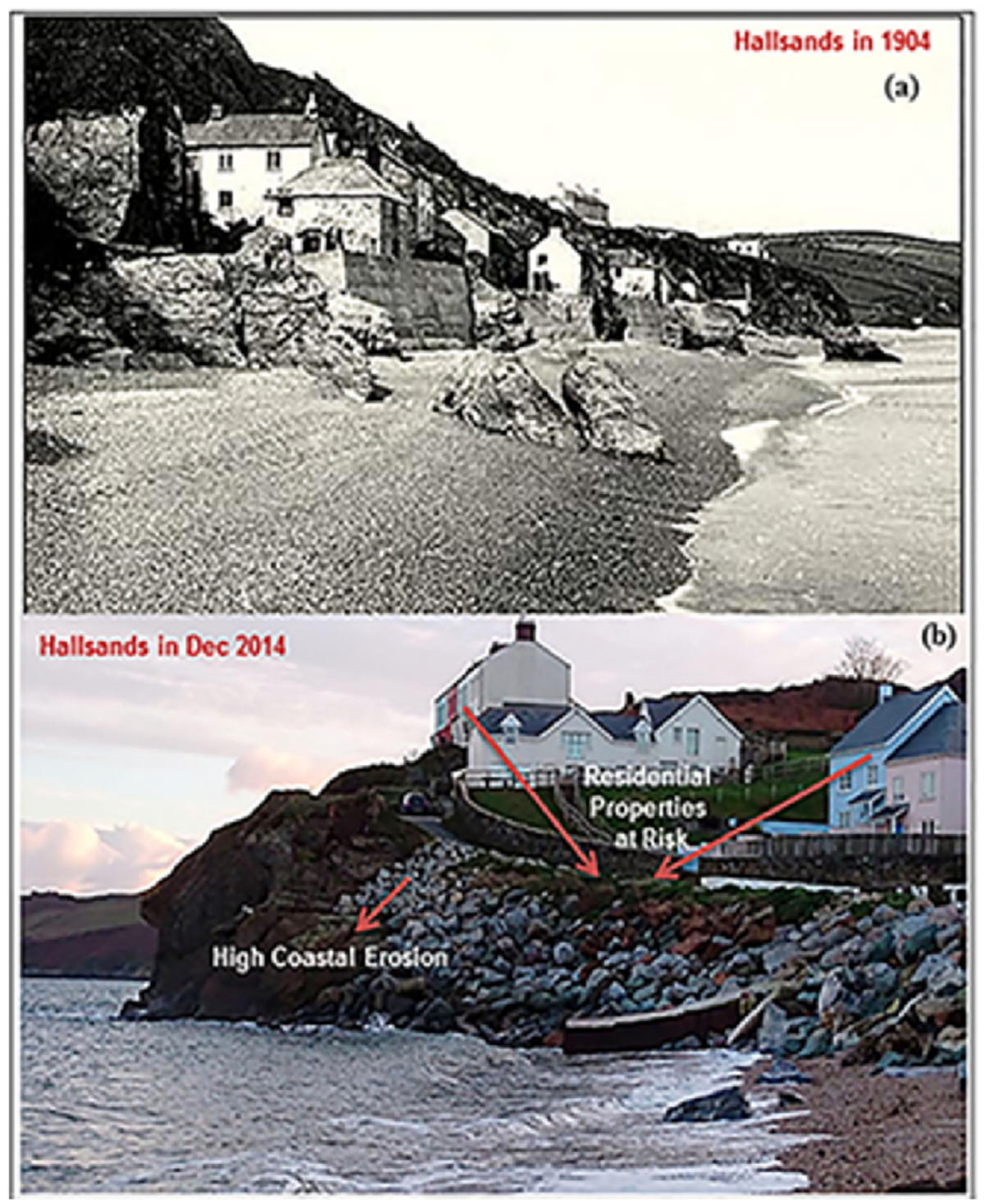

Fig. 2. (a \&b). Decadal coastal erosion in Hallsands, England.

Source: Fig. 2a - BBC (2014); Fig. 2b - Kantamaneni (2016).

Sea, North Sea, Irish Sea, and the English Channel (Fig. 1) (Ordnance Survey, 2013). It has a circa $17,381 \mathrm{~km}$ long coastline and over $60 \%$ of it situated in offshore islands and Scotland (Masselink and Russell, 2007). Coastal zones of the UK are rich in significant natural habitats, tourism, heritage sites, recreational opportunities, and other business: nearly half of the population is living near to the coast (Jones and Phillips, 2009; Atlas, 2012). Approximately 40\% of manufacturing industry and $60 \%$ of the fertile agricultural land is very near to the coast (Zsamboky et al., 2011), while $90 \%$ of trade is commuting by sea (Warwick University, 2010). Maritime industries and the service sector annually contribute $>£ 17$ billion to the UK economy and it will be $£ 25$ billion by 2020 (Marine Industries Leadership Council, 2011).

The maritime service sector made a $£ 13.8$ billion (direct valueadded) contribution to national GDP ( $0.9 \%$ of total) and $£ 2.7$ billion of tax revenue to the economy in 2011 (Economics, 2013). Although tourism and coastal recreation activities are important contributors to national, local and sub-local economies, continuous occupation, rapid population growth and other substantial business activities have recently intensified the current risk of coastal flooding and erosion. Coastlines are always subject to change through erosion and other natural processes: more than $17 \%$ of the UK coastline is suffering from erosion (Fig. 2(a \& b) and coastal erosion costs are over $£ 15$ million per year, and it could be $£ 126$ million by 2080 (in worst case scenarios) (Masselink and Russell, 2013).

\subsection{Vulnerability associated with the UK coast}

Coastal vulnerability can be allied with diverse hazards such as: natural (sea level rise, various storm events, coastal inundation and storm surges, etc.), socio-economic (population and economic recovery, etc.) and human-made hazards (nuclear waste) (Fletcher III et al., 2002; Papathoma and Dominey-Howes, 2003); these hazards cause more severe destruction in both fiscal and causalities. There have been substantial changes during the last two decades in the UK coastal zones due to distinctive storm events and powerful winds that were considered as extreme events (Phillips and Jones, 2006). However, storm occurrences were not only the reasons that were making the coast vulnerable, but also other significant factors like sea level rise, shoreline erosion, tides and currents. At present, sea level rise (SLR) and anthropogenic activities like an upsurge in coastal population and disruption of 
Table 1

Coastal hazards of the United Kingdom.

\begin{tabular}{|c|c|c|}
\hline Principal coastal regions & Coastal hazards & Impacts \\
\hline North Sea & $\begin{array}{l}\text { - Coastal flooding } \\
\text { - Various storm events } \\
\text { - Coastal erosion } \\
\text { - Storm surge } \\
\text { - High waves and tides } \\
\text { - High winds with tornado strikes }\end{array}$ & $\begin{array}{l}\text { - Infrastructure damage } \\
\text { - Community loss } \\
\text { - Land degradation } \\
\text { - Changes to the coastline } \\
\text { - Loss of marine habitats }\end{array}$ \\
\hline Celtic Sea & $\begin{array}{l}\text { - Coastal flooding } \\
\text { - Various storm events } \\
\text { - Coastal erosion } \\
\text { - Storm surge } \\
\text { - High waves and tides } \\
\text { - High winds with tornado strikes }\end{array}$ & $\begin{array}{l}\text { - Infrastructure damage } \\
\text { - Community loss } \\
\text { - Land degradation } \\
\text { - Damage to the coastline } \\
\text { - Landslides and cliffs erosion }\end{array}$ \\
\hline Irish Sea & $\begin{array}{l}\text { - Coastal flooding } \\
\text { - Various storm events } \\
\text { - Coastal erosion } \\
\text { - Storm surge } \\
\text { - High waves }\end{array}$ & $\begin{array}{l}\text { - Infrastructure damage } \\
\text { - Community loss } \\
\text { - Land degradation } \\
\text { - Mudslides and landslides } \\
\text { - Infrastructure damage }\end{array}$ \\
\hline English Channel & $\begin{array}{l}\text { - High waves } \\
\text { - Coastal flooding } \\
\text { - Coastal erosion }\end{array}$ & $\begin{array}{l}\text { - Community loss } \\
\text { - Land degradation } \\
\text { - Loss of marine habitats } \\
\text { - Loss of marine ecosystem and biodiversity }\end{array}$ \\
\hline
\end{tabular}

Source: Adapted from Ramieri et al. (2011).

hydrological cycles over the construction of properties along the coastline are making the actual natural system more vulnerable (Moser et al., 2012). However, following hazards (Table 1) are the main reason for the vulnerability of the UK at several coastal zones.

\section{Materials and methods}

\subsection{Materials (data)}

Statistical data regarding population, commercial and residential properties were obtained from the Office for National Statistics (ONS), together with county and district councils of England, Wales and Scotland. Property data related to the identified sites i.e. Llanelli, Happisburgh, Skegness and Benbecula was obtained from the UK government under the freedom of information Act. Flood data was obtained from Meteorological Office, Environment Agencies and local councils. Coastal erosion data was collected from British Geological Survey and United Kingdom Climate Impact Predictions. Estimated values of both commercial and residential properties and land values were obtained from Her Majesties Revenue Office for England, Wales and Scotland, Association of British Insurers (ABI) and the Agricultural Mortgage Corporation (AMC). In addition to the aforementioned, this study also utilised the data, obtained from multiple observations of the various coastal locations in the United Kingdom between 2013 and 2015. This work used the data of rateable properties but did not take into consideration heritage properties such as Churches and Museums together with large construction structures, such as, Bridges. In addition, statistical package for social sciences (SPSS) (21st version) was used for analysis and exploration of FCVI values and further construction of FCVI. Geographical information system (ArcGIS - 10.3 version) was used in the development of coastal vulnerability maps in various resolutions.

\subsection{Methods}

There are many methodological frameworks (mentioned in literature review) for estimating coastal vulnerability at global and regional levels in relation to climate change particularly within physical and geomorphological perspectives. There are no rigorous and precise methodologies (collective method) for an evaluation and estimating coastal vulnerability within fiscal perspectives in a standardised format. Accordingly, a coherent and concise framework

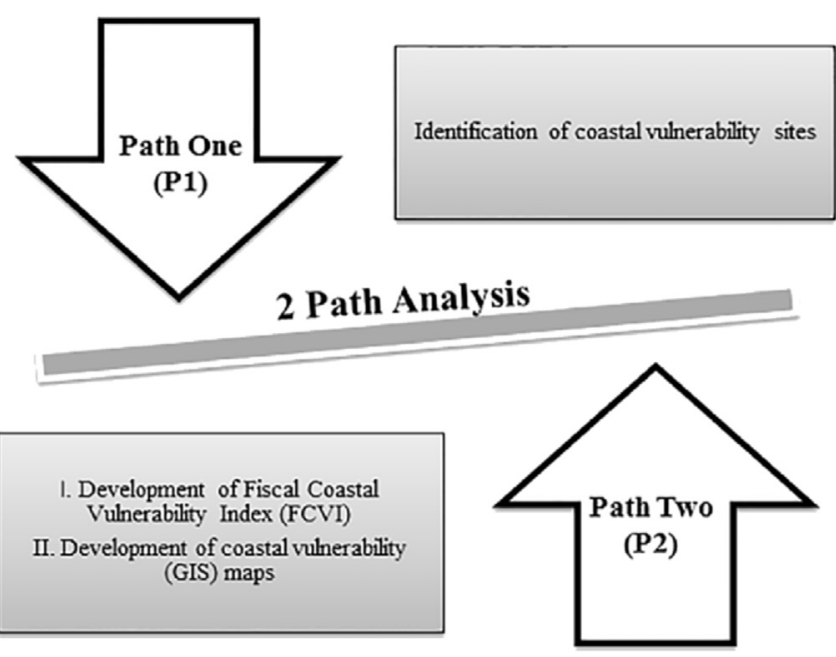

Fig. 3. 2 Path analysis (2 PA).

Source: Modified from Kantamaneni et al. (2015).

has been adapted based upon the work of Kantamaneni et al. (2015a) i.e., 2 PA (Two Path Analysis)(Fig. 3). This methodology comprises two vital paths as follows:

\subsection{Path One (P1)}

Identification of coastal vulnerability sites across the UK based

Table 2

Fiscal parameters.

\begin{tabular}{|c|c|c|c|}
\hline \multicolumn{2}{|c|}{ No. Parameter } & \multirow{2}{*}{$\begin{array}{l}\text { Designated symbol for } \\
\text { FCVI } \\
\mathrm{a}\end{array}$} & \multirow{2}{*}{$\begin{array}{l}\text { Measurable units } \\
\text { In £millions (economic) }\end{array}$} \\
\hline 1 & $\begin{array}{l}\text { Commercial } \\
\text { properties }\end{array}$ & & \\
\hline 2 & $\begin{array}{l}\text { Residential } \\
\text { properties }\end{array}$ & $\mathrm{b}$ & In £millions (economic) \\
\hline 3 & $\begin{array}{l}\text { Economic value of } \\
\text { site }\end{array}$ & c & $\begin{array}{l}\text { In £millions to fbillion } \\
\text { (economic) }\end{array}$ \\
\hline 4 & Population & d & In thousands (non-economic) \\
\hline 5 & Coastal erosion & e & In £millions (economic) \\
\hline 6 & $\begin{array}{l}\text { Flood (event) } \\
\text { impact }\end{array}$ & f & In £millions (economic) \\
\hline
\end{tabular}


on collected data and multiple site (coastal) observations. Sea level rise, precipitation and population trends were analysed to identify the fiscal vulnerability hotspots. In addition, recent climatic events were also used to find the most vulnerable sites all with varying physical and economic characteristics.

\subsection{Path Two (P2)}

Development of an FCVI as well as coastal vulnerability GIS maps: in order to achieve these aims, a part of Kantamaneni's (2016) basic concept of coastal vulnerability assessment method has been adapted for an establishment of FCVI and accordingly, a coastal vulnerability index (CVI) methodology and selection of fiscal parameters concepts were adapted for this research.

\subsection{Selection of fiscal parameters}

For coastal vulnerability assessment parameters are vital elements, and they could have diverse levels of response depending on impact magnitude (Palmer et al., 2011). Aligning with Kantamaneni's (2016) work on the Welsh coast, six fiscal parameters (Table 2) were used to estimate economic vulnerability. However, this study did not measure the population in monetary terms because it is unusual to offer the economic consequences to the communities (with the exception of Kantamaneni (2016) work) particularly in the UK. All of the chosen parameters were assigned equal weightage even though they have different fiscal values. Each parameter has been classified with 1 to 5 ranking representing a range from extremely low to extremely high. .

\subsection{Technical description and calculation of FCVI}

Using the 2014 aerial photograph, a transect baseline was drawn across the frontage (i.e. parallel to the coast) on each of the identified coastal vulnerability sites and $1 \mathrm{~km}$ grid square (or cell) was drawn inland from the baseline (Fig. 4). Subsequently, detailed measurements based upon each parameter are recorded within each identified cell.

Data was collected from the various organisations (mentioned in earlier paragraphs) regarding number of properties and cost,
Table 3

Rating fiscal coastal vulnerability parameters (£m-millions).

\begin{tabular}{|c|c|c|c|c|c|}
\hline \multirow[t]{2}{*}{ Fiscal Parameter } & \multicolumn{5}{|c|}{ Fiscal threshold } \\
\hline & $\begin{array}{l}\text { Extremely } \\
\text { low (1) }\end{array}$ & Low (2) & $\begin{array}{l}\text { Moderate } \\
\text { (3) }\end{array}$ & $\operatorname{High}(4)$ & $\begin{array}{l}\text { Extremely } \\
\text { high (5) }\end{array}$ \\
\hline $\begin{array}{l}\text { Commercial } \\
\text { Properties }\end{array}$ & $<2 \mathrm{~m}$ & $\begin{array}{l}2 \\
-10 \mathrm{~m}\end{array}$ & $\begin{array}{l}>10 \\
-30 \mathrm{~m}\end{array}$ & $>30-70 \mathrm{~m}$ & $>70 \mathrm{~m}$ \\
\hline $\begin{array}{l}\text { Residential } \\
\text { Properties }\end{array}$ & $<30 \mathrm{~m}$ & $\begin{array}{l}30 \\
-80 \mathrm{~m}\end{array}$ & $\begin{array}{l}>80 \\
-130 \mathrm{~m}\end{array}$ & $\begin{array}{l}>130 \\
-180 \mathrm{~m}\end{array}$ & $>180 \mathrm{~m}$ \\
\hline $\begin{array}{l}\text { Economic Value } \\
\text { of Site }\end{array}$ & $<10 \mathrm{~m}$ & $\begin{array}{l}10 \\
-50 \mathrm{~m}\end{array}$ & $\begin{array}{l}>50 \\
-100 \mathrm{~m}\end{array}$ & $\begin{array}{l}>100 \\
-150 \mathrm{~m}\end{array}$ & $>150 \mathrm{~m}$ \\
\hline Population & $<500$ & $\begin{array}{l}500- \\
2000\end{array}$ & $\begin{array}{l}>2000 \\
-5000\end{array}$ & $\begin{array}{l}>5000 \\
-10,000\end{array}$ & $>10,000$ \\
\hline Coastal Erosion & $<0.3 \mathrm{~m}$ & $\begin{array}{l}0.3 \\
-2.5 \mathrm{~m}\end{array}$ & $2.6-5 \mathrm{~m}$ & $>5-9 \mathrm{~m}$ & $>9 \mathrm{~m}$ \\
\hline $\begin{array}{l}\text { Flood (event) } \\
\text { Impact }\end{array}$ & $<3 \mathrm{~m}$ & 3- $9 \mathrm{~m}$ & $>9-15 \mathrm{~m}$ & $>15-35 \mathrm{~m}$ & $>35 \mathrm{~m}$ \\
\hline
\end{tabular}

Table 4

FCVI relative scores.

\begin{tabular}{ll}
$\mathrm{a}=$ Commercial properties & $5(\max )$ \\
$\mathrm{b}=$ Residential properties & $5(\max )$ \\
$\mathrm{c}=$ Economic value of site & $5(\max )$ \\
$\mathrm{d}=$ Population & $5(\max )$ \\
$\mathrm{e}=$ Coastal erosion & $5(\max )$ \\
$\mathrm{f}=$ Flood (event) impact & $5(\max )$ \\
Maximum FCVI value & $\mathbf{3 0}$ \\
Minimum FCVI Value & $\mathbf{0 6}$ \\
\hline
\end{tabular}

Table 5

FCVI relative ranking (Vulnerability level ratings grouped by total relative vulnerability score).

\begin{tabular}{ll}
\hline Total relative vulnerability score & Range of vulnerability \\
\hline$<12$ & Extremely Low \\
$12-15$ & Low \\
$16-18$ & Moderate \\
$19-22$ & High \\
$23-30$ & Extremely high \\
\hline
\end{tabular}

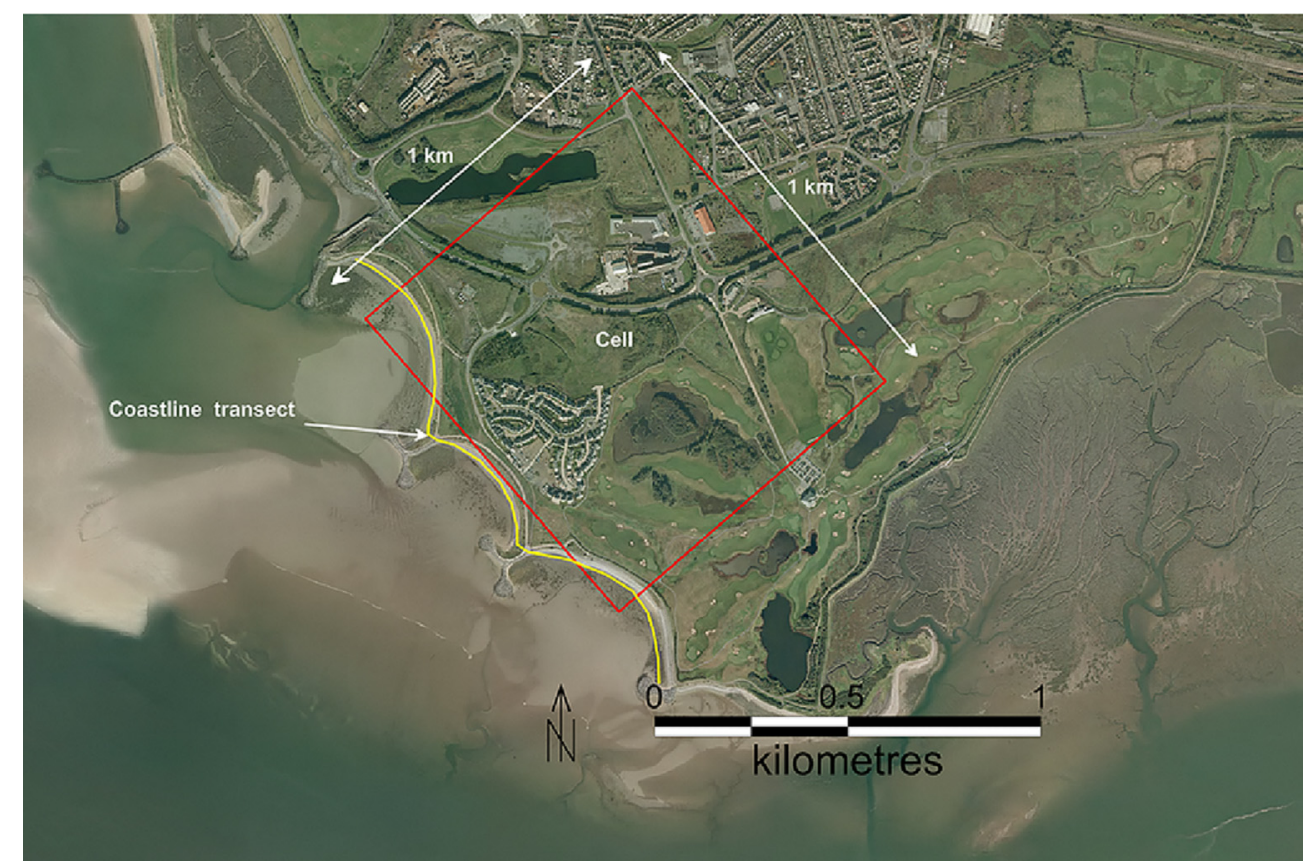

Fig. 4. $1 \mathrm{~km}$ Coastal section/cell on transect line. 
economic value of the site, population, and flood impact. These economic values were then used to construct Table 3 detailing economic thresholds for each parameter and assign a ranking score between 1 and 5 . The individual cell measurements were then compared and contrasted with Table 4 and assigned a ranking score between extremely low (1), low (2), moderate (3) high (4) and extremely high (5) to assess vulnerability quantitatively. With rankings applied, these values were then summed for each location to provide a relative CVI score using Comparative FCVI (equation (1)). The FCVI value would range between a minimum value of 6 and a maximum of 30 (Table 4). These scores were utilised (Table 5) to categorise the level of relative economic vulnerability for each location.

Relative FCVI $=\mathrm{a}+\mathrm{b}+\mathrm{c}+\mathrm{d}+\mathrm{e}+\mathrm{f}$

\section{Results}

4.1. Path One (P1) - identification of coastal vulnerability sites

Based on collected data and multiple site observations, this
Table 6

Identified fiscal coastal vulnerability sites.

\begin{tabular}{lll}
\hline England & Wales & Scotland \\
\hline Spurn Head & Port Talbot & Benbecula \\
Skegness & Llanelli & \\
Happisburgh & Aberystwyth & \\
Great Yarmouth & & \\
Hallsands & & \\
Dawlish & & \\
Lynmouth & & \\
\hline
\end{tabular}

study identified eleven coastal vulnerability sites across the UK (see Table 6 below).

Of the 11 identified there are seven in England, three in Wales and one in Scotland (Fig. 5). There is no significant vulnerability to the coastline of Northern Ireland at current scenarios.

\subsection{Path Two (P2) - FCVI development and assessment}

A total of $94.1 \mathrm{~km}$ of transect line was drawn on the 11 identified coastal vulnerability sites across the UK, and accordingly 80 cells (I $\mathrm{km}$ square cells) were identified (Table 7 ). Based on different

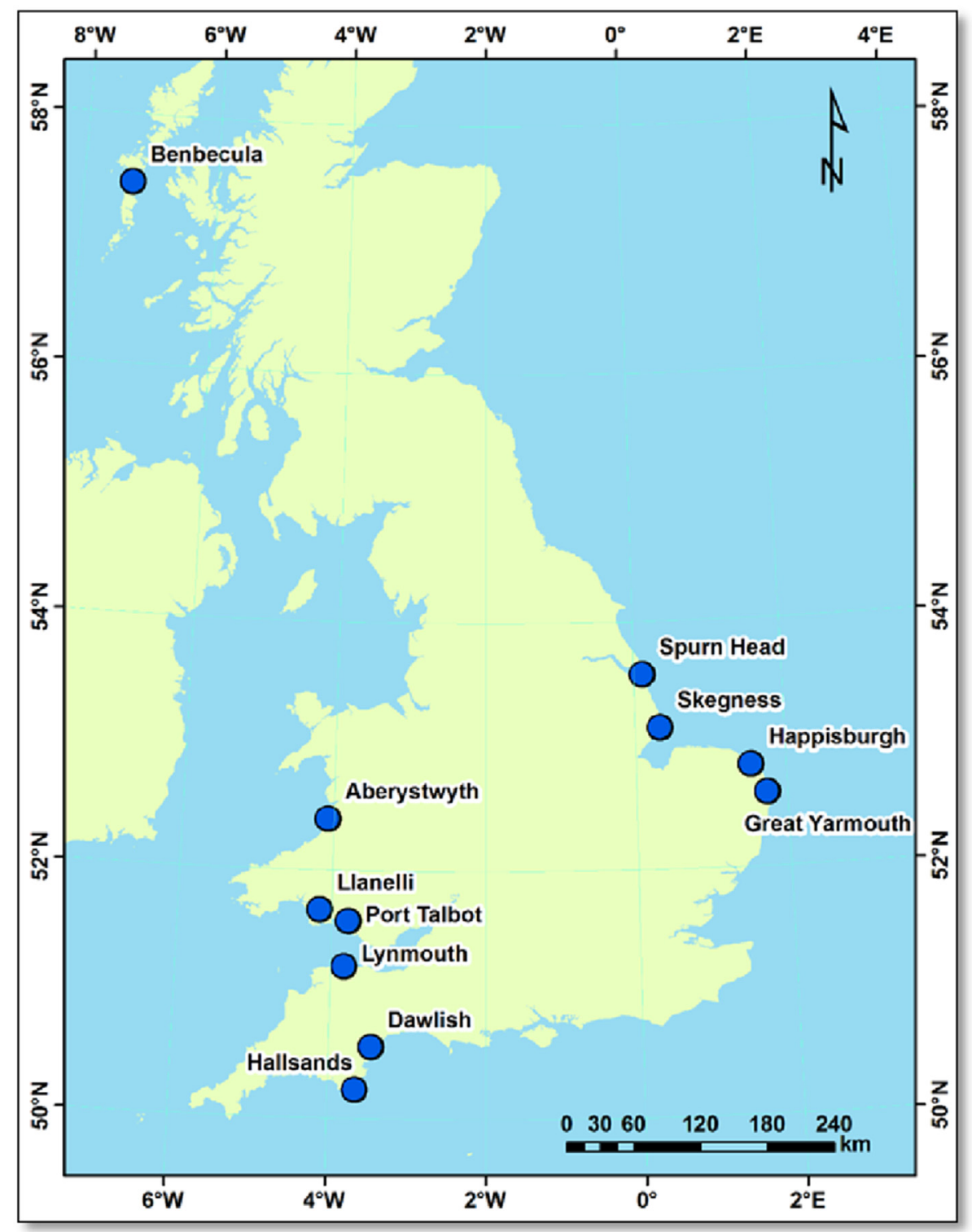

Fig. 5. Coastal vulnerability sites. 
Table 7

Coastal vulnerability sites with $1 \mathrm{~km}$ cells.

\begin{tabular}{llll}
\hline Number & Coastal vulnerability sites & Transect line in $\mathrm{km}$ & $1 \mathrm{~km}$ cells \\
\hline 1 & Happisburgh & 4.5 & 4 \\
2 & Great Yarmouth & 15.0 & 13 \\
3 & Spurn Head & 3.0 & 2 \\
4 & Skegness & 20.0 & 18 \\
5 & Hallsands & 4.5 & 4 \\
6 & Lynmouth & 2.3 & 2 \\
7 & Dawlish & 7.0 & 6 \\
8 & Llanelli & 15.0 & 12 \\
9 & Port Talbot & 13.0 & 12 \\
10 & Aberystwyth & 2.3 & 2 \\
11 & Benbecula & 7.5 & 5 \\
& & $\mathbf{9 4 . 1}$ (total) & $\mathbf{8 0}$ (total) \\
\hline
\end{tabular}

lengths of coastline, some coastal sites consists several number of coastal cells and some have fewer number of coastal cells.

\subsubsection{Appraisal of fiscal parameters}

Economic data was obtained from various government and insurance sources, as discussed in Section 3 with six representative parameters chosen (Table 2), and this was applied to information acquired from analysis of the $1 \mathrm{~km}$ coastal cells. Consequently, an average commercial property value was derived from the range of facilities surveyed with a maximum of $£ 105 \mathrm{~m}$ recorded in cell 8 at Great Yarmouth (Fig. 6a), to a minimum of $£ 0.02 \mathrm{~m}$ in cell 73 at Port Talbot (Fig. 6a). An average commercial value of $£ 15.5 \mathrm{~m}$ was determined and $27 \%$ of cells had higher than the average value, meaning $70 \%$ of cells were lower with two cells (38 and 80 ) not having commercial properties (Fig. 6b). The average value of residential properties within the 80 cells is $£ 135 \mathrm{~m}$, with a maximum of $£ 780 \mathrm{~m}$ in cell 66 (Port Talbot) and a minimum of $£ 0.02 \mathrm{~m}$ in cells 18 and 19 (Spurn Head; Fig. 6b). Twenty-six percent and 67\% of cells recorded higher and lower values than the average respectively, while three cells (71-73 inclusive) did not include residential properties.

The average economic value of all sites is approximately $£ 103 \mathrm{~m}$ from a total value of approximately $£ 8.3 \mathrm{bn}$. Assessments showed maximum site values of $£ 1000 \mathrm{~m}$ ( $£ 1 \mathrm{bn}$ ) occurred in cells 70 and 71 (Port Talbot) and a minimum value of $£ 2 \mathrm{~m}$ in cell 18 (Spurn Head) and therefore, it can be seen that approximately $30 \%$ and $70 \%$ of cells had higher and lower values than the mean respectively (Fig. 7a). The average population in all cells was found to be approximately 1480 with a maximum of 10,000 in cell 66 (Port Talbot) and minimum of 1 in cell 38 (Hallsands). Sixty-seven percent of cells had lower than the average populations, while $30 \%$ recorded higher than average figures (Fig. $7 \mathrm{~b}$ ).

The average cost of coastal erosion was $£ 5.4 \mathrm{~m}$ with a maximum
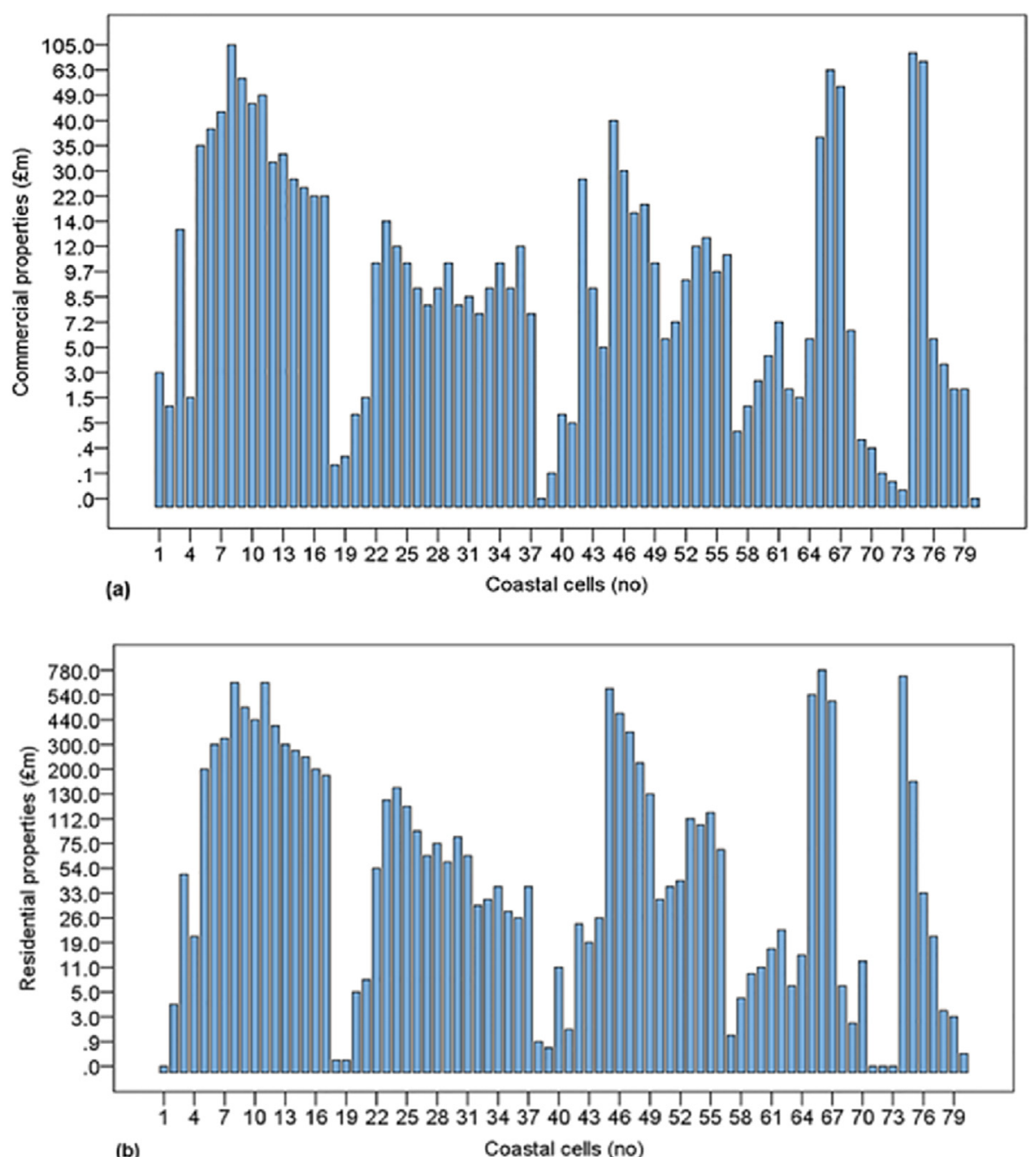

Fig. 6. Fiscal parameters assessment a) commercial properties and b) residential properties. 

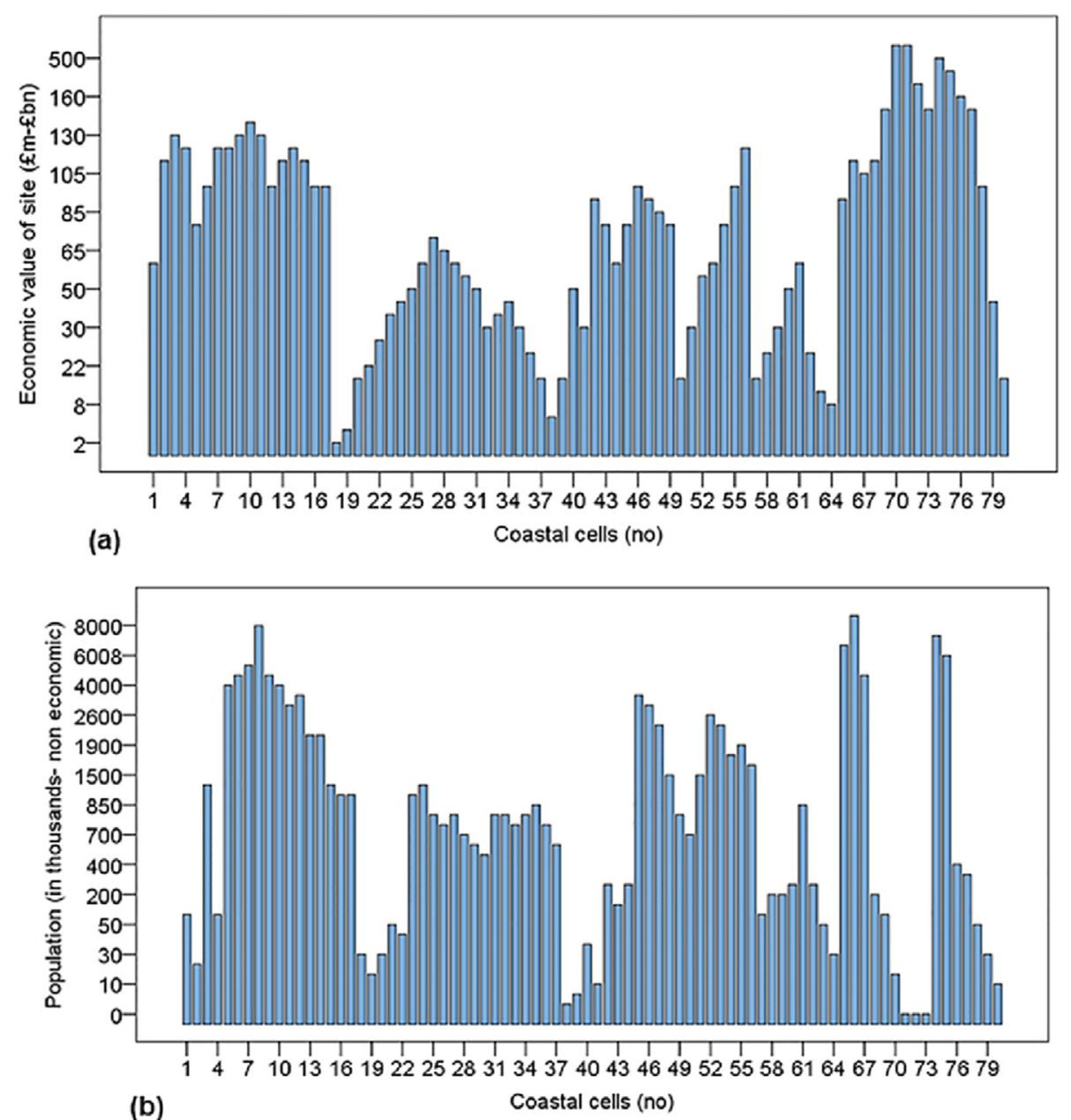

Fig. 7. Fiscal parameters assessment a) economic value of site and b) population.

of $£ 20 \mathrm{~m}$ in cells 2, 46, and 68 (Happisburgh, Dawlish and Port Talbot respectively) and minimum of $0.3 \mathrm{~m}$ in cell 20 (Skegness). It can be seen that $62 \%$ of cells had lower than average values, while $38 \%$ were higher (Fig. 8a), showing that coastal erosion would be an on-going economic challenge. Flooding costs were determined as approximately $£ 1.6 \mathrm{bn}$ across all 80 cells, with an average flood impact of $£ 20 \mathrm{~m}$ ranging between a maximum of $£ 40 \mathrm{~m}$ in cells 8 and 14 (Great Yarmouth) and a minimum of $£ 2 \mathrm{~m}$ in cells 57, 64 and 80 (Llanelli, Port Talbot and Benbecula respectively). Therefore, 38\% of cells recorded lower than the average and $62 \%$ more than the average flood impact values (Fig. 8b). Therefore, flooding can clearly be seen as an economic vulnerability.

The fiscal value was calculated for each of the eleven coastal sites. For example, Happisburgh is represented by coastal cells 1 to 4 and the value of each coastal cell was added together to get a total value for Happisburgh, i.e. $107+170.2+236.5+166.5=£ 680.2 \mathrm{~m}$. This procedure was replicated for all 11 coastal sites, and calculated data was included in the order of most to least vulnerability, and finally, population data from was transposed for each coastal site to obtain population per cell.

\subsubsection{Establishment of fiscal coastal vulnerability index}

The fiscal analysis obtained a parameter score for each of the 80 coastal cells for commercial properties, residential properties, the economic value of site, coastal erosion and flood event impact. Consequently, parameter values were combined for each site as per the methodology. Results showed that considerable variance exists between the coastal cells and FCVI parameter scores. The average FCVI score was 16.4, with the highest score of 26 recorded at Great Yarmouth and the lowest being 9, recorded in six cells at Skegness, Llanelli and Benbecula. However, more than $16 \%$ of cells fall into the extremely high category with a further $16 \%$ having high economic vulnerability. Thirty-five percent of cells fall into the lower category, with $16 \%$ belonging to extremely low categories. Fig. 9 graphically shows the percentage distribution of FCVI categories.

\subsubsection{Ranking of sites based on FCVI cumulative scores}

FCVI values were determined for each coastal location by aggregating CVI scores. For example, Happisburgh is represented by coastal cells 1 to 4 , and for each km cell was added together i.e. $15+15+20+14=64$. The process replicated for all eleven coastal locations and accordingly scores were allocated to 11 coastal sites (Table 7). This kind of summing approach offer more accurate results and helps to recognise the intensity of fiscal vulnerability of particular site. Fig. 10 represents the distribution of fiscal vulnerability by coastal cell and location: cumulative FCVI scores clearly show that Great Yarmouth is highly vulnerable in terms of fiscal risk and parts of the Llanelli and Benbecula coastlines have extremely low economic vulnerability.

The FCVI enabled the ranking of the eleven coastal sites in order of severity of the economic vulnerability, and site fiscal vulnerabilities according to FCVI scores were shown and illustrated in 

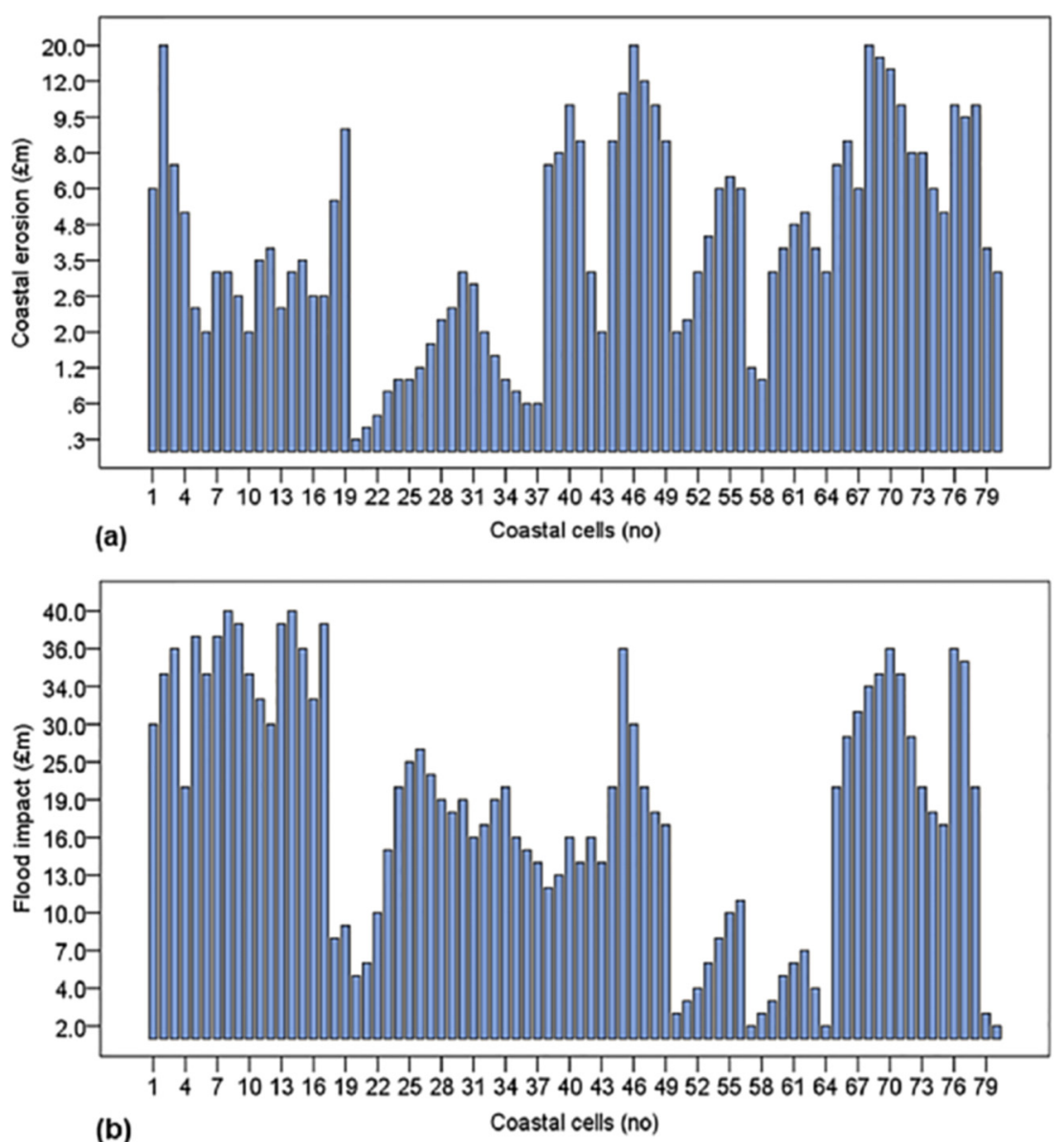

Fig. 8. Fiscal parameters assessment a) coastal erosion and b) flood impact.

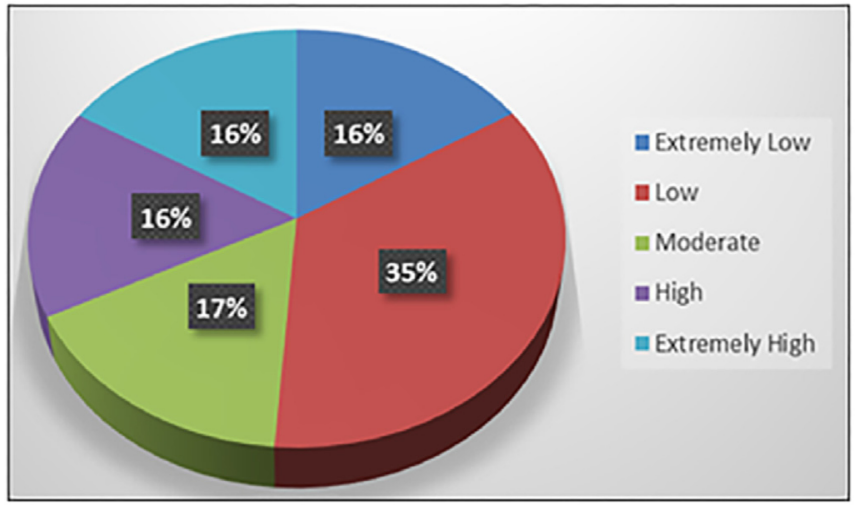

Fig. 9. Percentage distribution of FCVI categories.

Table 8

Ranking of coastal vulnerability sites based on FCVI cumulative scores.

\begin{tabular}{lll}
\hline Site name & FCVI score & Site ranking \\
\hline Great Yarmouth & 293 & 1 \\
Skegness & 249 & 2 \\
Port Talbot & 202 & 3 \\
Llanelli & 160 & 4 \\
Dawlish & 128 & 5 \\
Benbecula & 78 & 6 \\
Happisburgh & 64 & 7 \\
Aberystwyth & 49 & 8 \\
Hallsands & 47 & 8 \\
Lynmouth & 27 & 10 \\
Spurn Head & 22 & 11 \\
\hline
\end{tabular}

Table 8 and Fig. 11. The eleven sites represent a total economic risk of $£ 22.3$ bn under current scenarios, which includes $>50,000$ residential properties $(0.2 \%$ of UK total) and $>6000$ commercial properties $(0.37 \%$ of UK total). Furthermore, approximately 118,400 people $(0.2 \%$ of the UK population) are at risk of displacement from flooding, etc.

\subsubsection{Fiscal coastal vulnerability assessment for identified sites}

Great Yarmouth is a medium-sized seaport and industrial corridor, as well as a major tourist attraction. It was the longest frontage considered and results showed that it has high vulnerability with an FCVI of 293. Its economic importance was assessed which was $£ 7 \mathrm{bn}$ with a population of 45,00 people at risk of displacement from coastal flooding. Skegness, a popular tourism destination which is considered as one of the best places for holidays, as well as being an ideal place to live for those who are retired (Butler, 2006). Accordingly, Skegness is considered as a highly valuable location from a socio-economic perspective. However, this is currently changing due to unprecedented flooding, rapid changes in weather patterns and rising incidence of storms even in the summer period (Zsamboky et al., 2011). An FCVI score of 249 makes Skegness as second vulnerable site after Great Yarmouth, having an economic value/cost of $£ 2.29$ bn and a population of $>10,000$. However, as Skegness is influenced by shoreline exposure, there will be a significant number of people at risk should current trends of flooding and storms. Port Talbot is highly industrialised (Fig. 12) and has significant economic value. Exposed to significant southwesterly storms, the TATA steelworks is protected by revetments made from blast furnace slag. The region is considered to be one of 


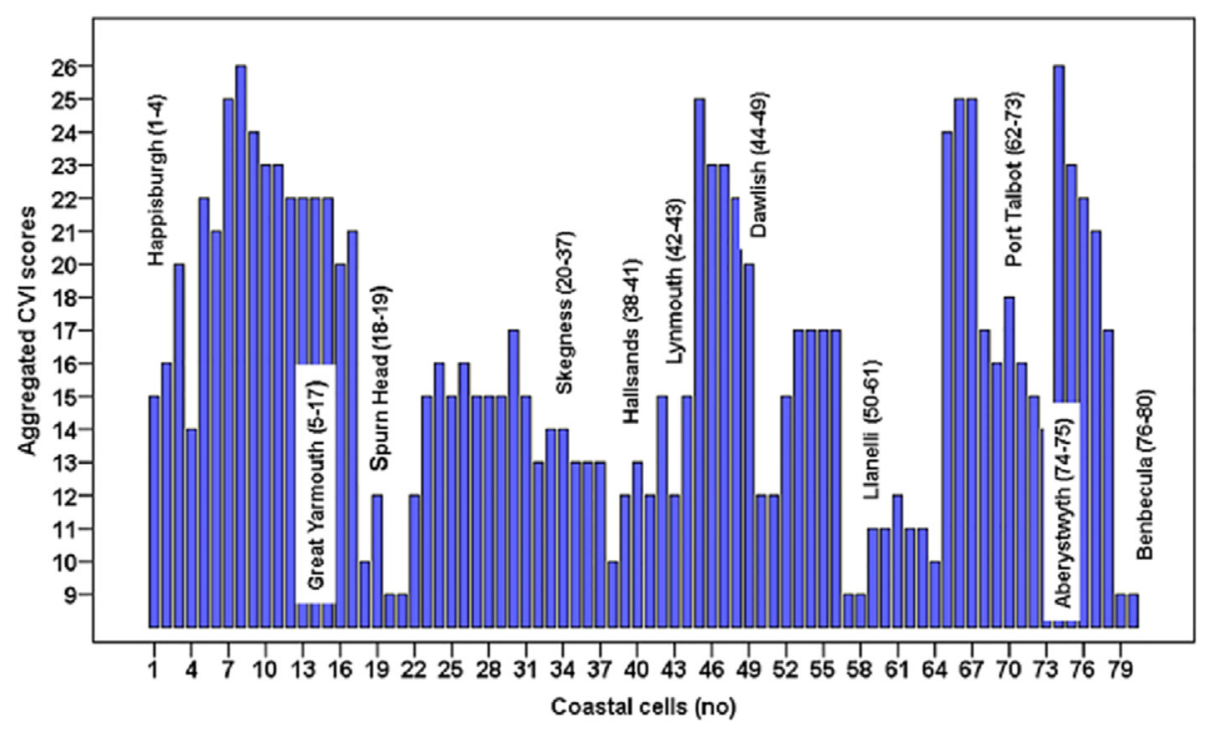

Fig. 10. Coastal cells and cumulative FCVI.

the most economically vulnerable coastal locations with FCVI of 202. With an approximate population of 1867 and an economic value of $£ 5.4 \mathrm{bn}$ and it was third of the eleven sites in terms of fiscal vulnerability. Llanelli is at high risk from storm events, surges and coastal erosion. Recent storm events, particularly the 2010 storm, ravaged the $£ 27 \mathrm{~m}$ Millennium Coastal Path with high waves and tides, costing the local council $>£ 400,000$ in repairs (Phillips et al., 2009). Following analysis of the economic parameters, the FCVI for Llanelli was 160 with an economic value of $£ 1.4 \mathrm{bn}$ and population 15,750 Llanelli's economic vulnerability is not equally distributed along its coastal frontage and accordingly, it was fourth of the eleven sites in the terms of economic vulnerability.

Dawlish is very likely to be at constant risk from sea level rise, storms, storm surges and resulting coastal erosion. Infrastructure at Dawlish is very close to the shoreline (Fig. 13) and therefore has a high coastal vulnerability. Recent storm events in 2012, 2013 and 2014 caused billions ( $£$ ) worth of damage. The 2014 storm damage caused a two month rail closure at a cost of $£ 1.2 \mathrm{bn}$ with resulting repairs costing $£ 35 \mathrm{~m}$, making an overall total of $£ 1.235 \mathrm{bn}$ (Dawson et al., 2016). Dawlish's FCVI was 128 giving it a high vulnerability with the economic risk includes residential and commercial properties, worth $£ 2.6 \mathrm{bn}$ with a population of $>12,000$ at risk.

Benbecula Island was severely affected by a 2005 storm event which caused $>£ 20 \mathrm{~m}$ (converted to 2014 rates) worth of infrastructure damage (Dawson et al., 2007). Therefore, following storm events there is an extremely high risk of coastal erosion. Benbecula FCVI was determined as 78, which puts it on boundary of the moderatevulnerability, having an economic value/cost of $>£ 676 \mathrm{~m}$ and a population of 861 . The relatively low number of residential and commercial properties influenced the site FCVI. Happisburgh has experienced severe coastal erosion over many years due to its geology, which provides little resistance to storms and surges. This had led to residential properties being at risk of falling into the sea and homeowners are unable to get insurance. This vulnerability is likely to increase with predicted increases in storm severity meaning the rate of erosion will also increase. Assessment showed that Happisburgh FCVI was 64 with a population of 1372 and an economic value of $£ 680 \mathrm{~m}$. It is suggested that the FCVI is not higher because the actual number of properties at risk is small in comparison to the total number, i.e. 423 residential and 64 commercial properties. Aberystwyth has 49 FCVI. Historically, Aberystwyth has been vulnerable to wave attacks and since the turn of the twenty- first century; it has been severely affected by a series of storms with high waves, tides and storm surges, i.e. 2008, 2010, 2013, and 2014. The tidal range is higher than at the other sites with the greatest incidence of waves coming from the southwest, which is also the direction of the most frequent storms. In 2014, a storm struck this region and caused $£ 1.5 \mathrm{~m}$ worth of damage (Ceredigion County Council, 2014). There is an economic risk of $£ 1.7 \mathrm{bn}$ including 530 commercial properties and 4613 residential properties (Fig. 14). There are 10,597 inhabitants at risk of displacement from coastal flooding.

During the storm of 1917, a major part of Hallsands vanished into the sea. Landslides are also a big concern here and the area is currently closed off due to coastal risk associated with coastal erosion. Most homeowners use their properties as holiday homes rather than permanent residences. Consequently, Hallsands has an economic risk of $£ 210 \mathrm{~m}$ with FCVI of 47 . Hallsands properties are at risk from coastal flooding and erosion. Due to current climatic fluctuations, Lynmouth experienced severe weather conditions, including storm surges and high winds during the 2012 and 2014 storms. These events highlighted the coastal vulnerability of this particular region and Fig. 15 shows both cliff-face erosion and how precariously properties have been constructed on the cliff. Therefore, the FCVI for Lynmouth was determined as 27 which put it in the low vulnerability (Fig. 15), and its economic value/cost was assessed at $>£ 286 \mathrm{~m}$ with a population of 250 . Spurn Head is ecologically very important for bird migration. However, its FCVI is 22 giving it an extremely low vulnerability score. Erosion has greater impact on Spurn Head's FCVI score and has an economic vulnerability of $£ 38.5 \mathrm{~m}$ comprised of its site value and 9 residential/commercial properties. With a population of only $>50$, displacement costs are also low, thereby justifying the lowest FCVI score of all sites. Therefore, even though Hallsands and Spurn Head have high decadal erosion rates, due to them having relatively few commercial and residential properties they have lowest FCVI values.

\section{Discussion}

This research adapted a part of recently established coastal vulnerability assessment methodology of Kantamaneni (2016) by aggregating cumulative FCVI scores to rank the identified coastal vulnerability sites in the UK. However, the process of identification 


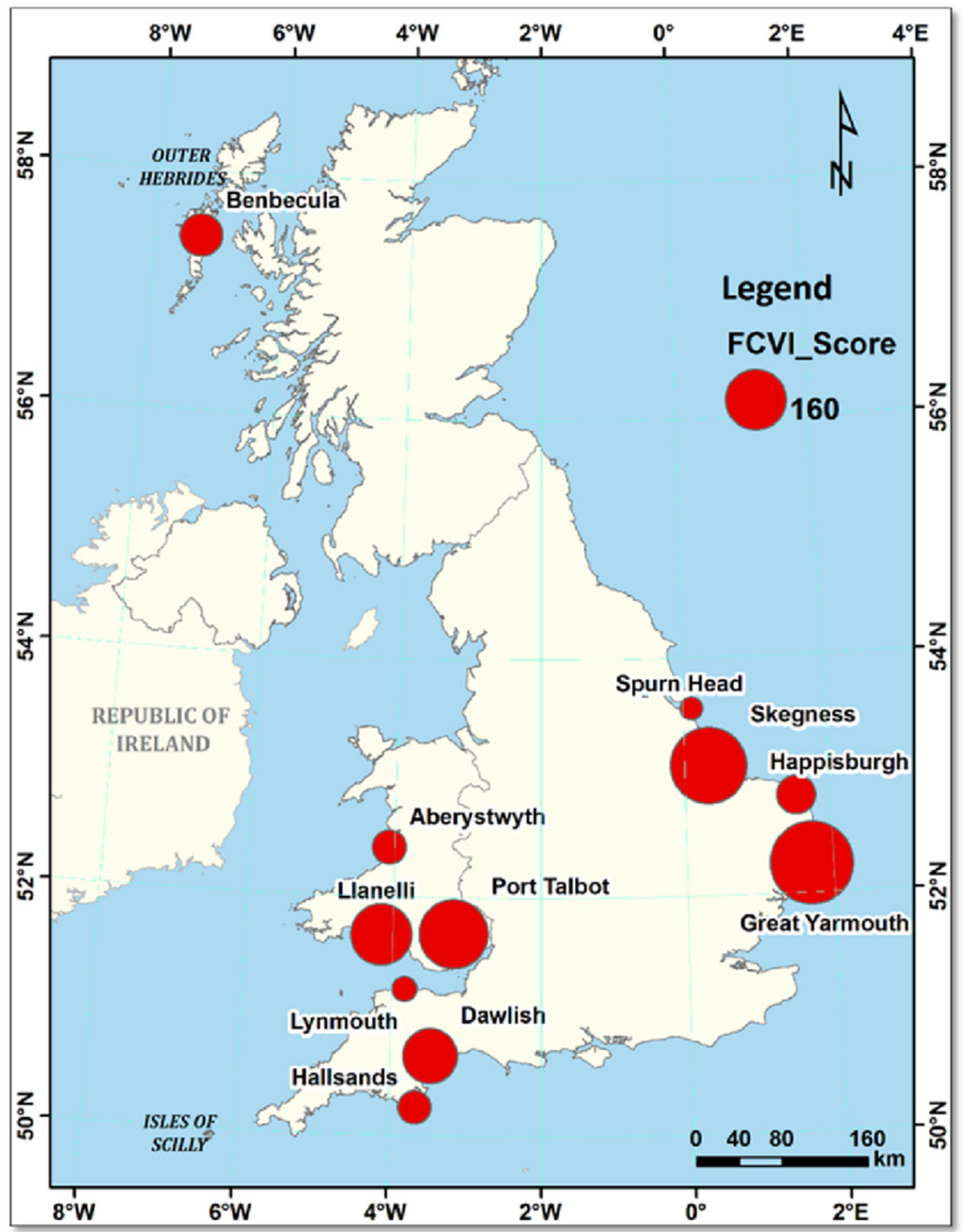

Fig. 11. Fiscal coastal vulnerability of the UK.

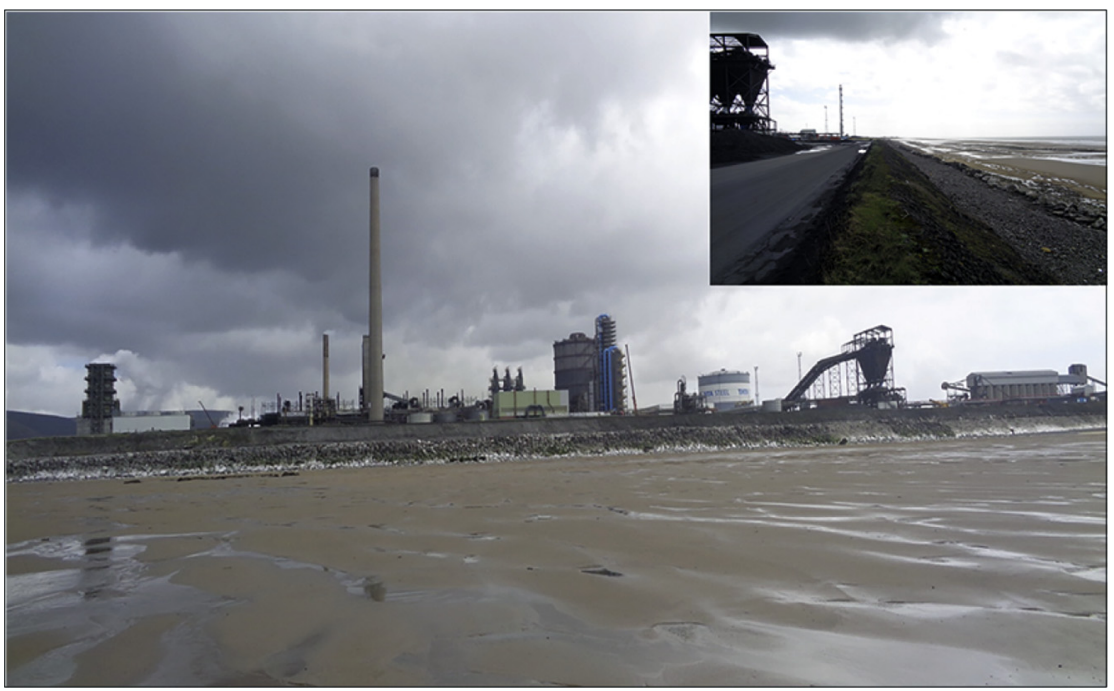

Fig. 12. TATA steel industry at Port Talbot coast. 


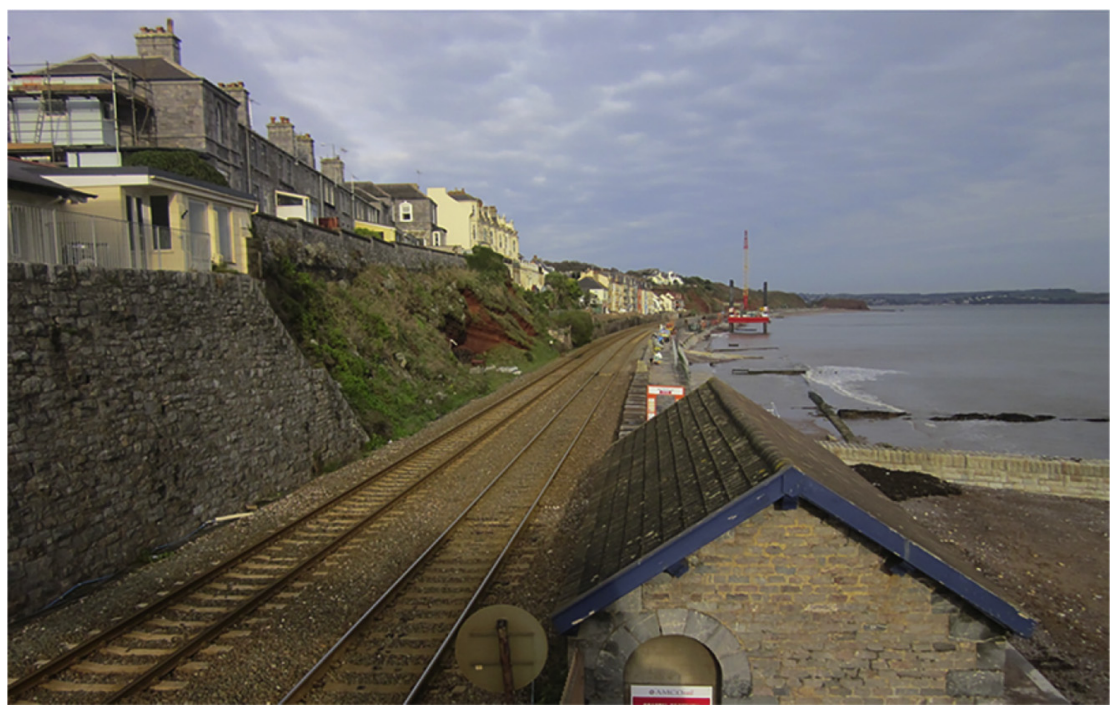

Fig. 13. Dawlish coastal properties.

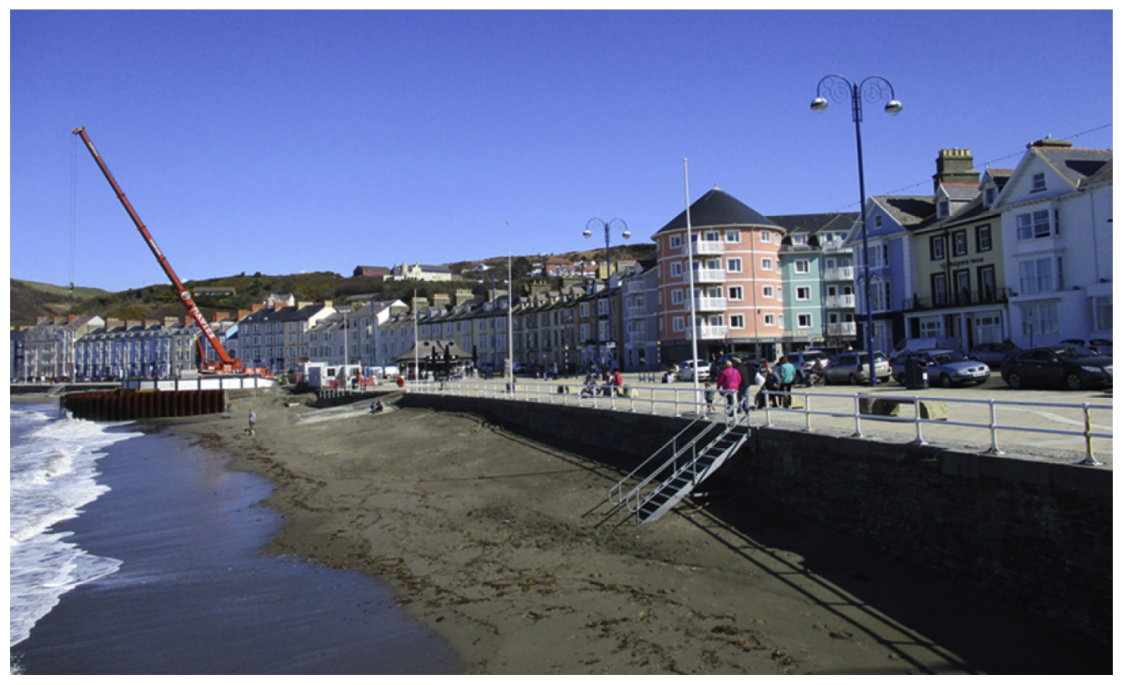

Fig. 14. Coastal properties and construction of the new coastal wall at Aberystwyth.

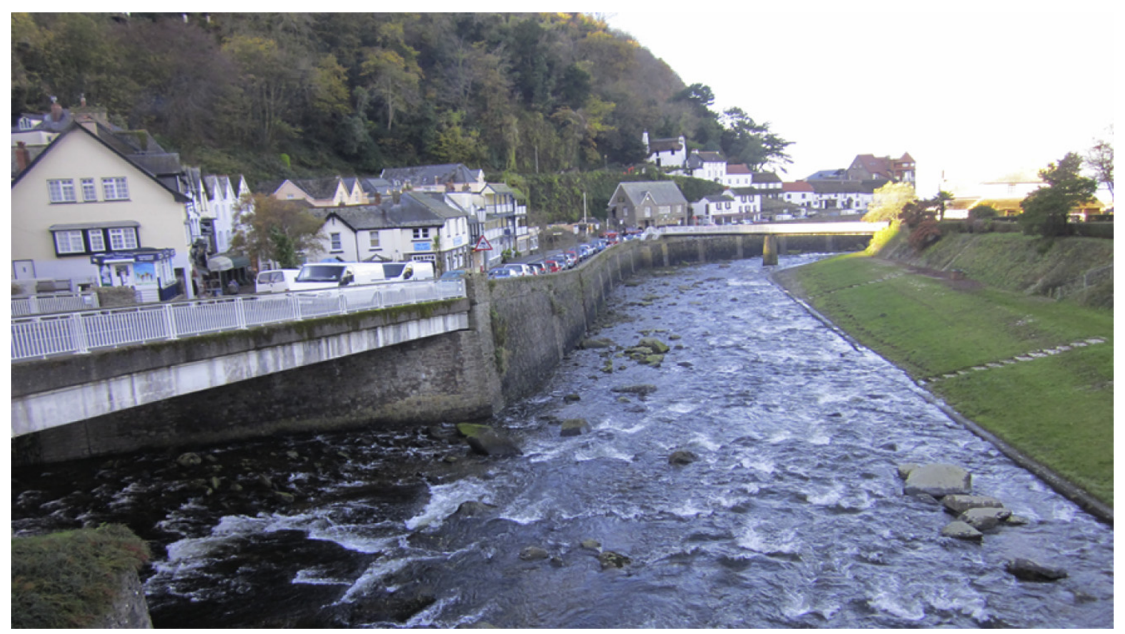

Fig. 15. Lynmouth properties. 
of coastal vulnerability sites across the UK and summing of cumulative coastal vulnerability index scores reflect the particular site economic situation and these things made this specific study unique. The FCVI was determined from six fiscal parameters that were assessed on a site/coastal location basis. Development of FCVI scores per cell showed that fiscal vulnerability varies between sites. Great Yarmouth had the highest FCVI and generally urban areas were most vulnerable, having larger populations than rural communities. Understanding population numbers at risk is important for both physical and socio-economic aspects of coastal research. Assessments of population in monetary terms requires a cost to be allocated to a human life and based on 2011 US EPA estimates, it is $£ 6.9$ million adjusted for 2015 inflation rates (Appelbaum, 2011). However, coastal populations represent diverse age groups and communities with different economic status and an average figure of $£ 4 \mathrm{~m}$ for a life could be argued (Kantamaneni, 2016). Even though population numbers are available, it would be unrealistic to include population costs at $£ 4 \mathrm{~m} \mathrm{head}^{-1}$ in the FCVI methodology because of presence of diverse physical and economic conditions at 11 identified sites. Therefore, this FCVI methodology, which includes population numbers, can be applied at local, regional and strategic to determine levels of economic vulnerability.

Unrestricted and rapid settlement in coastal regions increases pressure, both physically and economically, which leads to further vulnerability and risk (Nicholls et al., 2007). For example, Great Yarmouth and Skegness populations have increased year on year ultimately causing increased coastal vulnerability and as a consequence was considered as a significant site for this research. FCVI values for Great Yarmouth and Skegness showed the majority of the coastal cells were highly vulnerable, not only with respect to sites value and commercial and residential properties, but also with population numbers. Spurn Head and Hallsands were identified as having the lowest economic vulnerability, as although Spurn Head has a high erosion rate, the lack of properties and population reduced its FCVI. The Llanelli coastline FCVI was variable according to cell location due to expensive developments alternating with rural locations, while Port Talbot's economic vulnerability was based on the value of its industries, including TATA Steel.

The majority of residential and commercial properties are located within $0.6 \mathrm{~km}$ of the shoreline in all eleven sites. Therefore, predicted increases in storm occurrences and associated flooding events, winds and storm surges that often result in coastal erosion are major problems in these areas. Denner et al. (2015) stated that Llanelli poses a high risk of present and future flooding and results from this research confirm that this is indeed the case. Kantamaneni (2016) revealed that Aberystwyth has the highest risk of storm surges, flooding. Of the coastal defences built to protect several of the study sites, particularly Llanelli, the protection of new properties and infrastructure relies on circa $25 \%-35 \%$ having less than a 20-year lifespan remaining (Denner et al., 2015). This highlights an on-going problem in that not enough money is available for coastal protection, whilst storms, sea level rise and inundation events are likely to become more frequent. The problem is compounded by there not being updated government reports on coastal defences and protection measures for the eleven sites, particularly Aberystwyth (Kantamaneni and Phillips, 2016; Kantamaneni, 2016), and that where data is available, most is more than 5-10 years old and will not help accurate assessment. Accordingly, the capability of local authorities without sufficient resources to defend coastal infrastructure, especially for Llanelli and Aberystwyth, has been questioned (Phillips et al., 2009; Kantamaneni, 2016).

Except when events make the television news, e.g. Aberystwyth, etc. in 2014; there is a general lack of public awareness of coastal issues from both economic and physical perspectives.
Consequently, regeneration strategies have already led to further coastal erosion and flooding. New developments may get shortterm monetary gain from improvements to coastal real estate and investment, but if there is a vulnerability to erosion and flooding, the investment is at risk. Meanwhile, there are no rigorous policies or procedures that can be immediately implemented to avert such situations, and it becomes more complex when developers call on Local Authorities to provide protection because they were encouraged to build on the coast as a part of regeneration strategy (Phillips et al., 2009). These situations represent failures of coastal management strategies instead of an economic gain. Therefore, using the FCVI to assess fiscal vulnerability will quantify the relative vulnerability of coastal areas to various hazards and consequently will be a useful tool for planning authorities to assess economic risk.

\section{Conclusion}

Assessing the fiscal coastal vulnerability of a particular site is crucial for imminent spatial planning in accordance with environmental development principles. This study categorically demonstrates the coastal vulnerability of the UK by identification and mapping of coastal vulnerability sites in conjunction with the establishment of an FCVI via 2 Path Analysis (2 PA). The FCVI was determined from six fiscal parameters that were assessed on a site/ coastal location basis, and it is suggested that coastal developers and decision and policy makers could use this methodology to evaluate financial risk without needing to assess complex economic data as the model provides an innovative way to evaluate economic vulnerability. When applied to the eleven-identified coastal regions, results showed that economic vulnerability varies between sites. Current UK coastal vulnerability is $£ 22.3$ bn and is comparatively uneven across the country. The study highlighted that unrestricted and rapid settlement in coastal regions increases pressure leading to vulnerability and risk. Great Yarmouth and Skegness populations have increased and are the cause augmented coastal vulnerability and as a consequence was considered as significant sites for this research. FCVI values for Great Yarmouth and Skegness showed that most of the coastal cells were highly vulnerable. It was no surprise that Spurn Head and Hallsands were identified as having the lowest economic vulnerability, as the lack of properties and population reduced its FCVI. Using an FCVI to assess economic vulnerability will quantify the relative vulnerability of coastal areas to various hazards. This is a numerical approach to demonstrate the magnitude of fiscal coastal vulnerability at eleven identified sites. This method enables the production of economic data and quantification of various quantities of vulnerability to fulfil standards substitute to national and regional authorities in the nationalised policy for control of climate change and its related coastal hazards in the UK. This technique of assessing vulnerability can drive as an initial susceptibility assessment from which a map of probable intensities of susceptibility can be made to allow cost-benefit analysis. The FCVI can also be employed to define economic feasibility of coastal defence structures and the allocation of coastal budget. This tool can be modified depending on kind of geographical area and used as a framework for fiscal vulnerability evaluation.

\section{Recommendations}

Coastal vulnerability costs are major concerns in the UK at current scenarios. These issues affect the national GDP, local GDP, infrastructure, communities, etc. in several ways. As discussed in previous sections this research recommends for pro-active actions to avoid considerable damage costs as follows: 
$\triangleright$ Allocate an appropriate budget to coastal defence based on the severity of assessed coastal vulnerability and susceptibility to storm damage;

$>$ Inform government policy and procedures for insurance aspects of coastal management;

$>$ Economic coastal vulnerability assessments should be undertaken by statutory authorities every five years;

$>$ Met Office, Environment Agency (EA) and Office of National Statistics (ONS) should maintain records and statistics of various weather events, GDP (past, present, and future) and storm damage costs;

$>$ Information on coastal statistics and physical environment data such as wind, wave and directional components should be made easily available to researchers.

It is proposed that implementing the above-mentioned recommendations would help to create sustainable coastal management strategies for future generations. These should form the economic basis of shoreline management plans and consequently, inform the efficacy of the construction of new coastal defence structures and also ensure appropriate planning of infrastructure projects. This would ensure continued protection of vulnerable coastal communities, particularly in areas prone to severe flooding, erosion and other coastal related hazards.

\section{Conflict of interest}

This manuscript has not been previously published and is not under consideration in the same or substantially similar form in any other peer-reviewed media. To the best of my knowledge, no conflict of interest, financial or other, exists.

\section{Acknowledgements}

I would like to give special thanks for the comments of three anonymous reviewers on an earlier version, which contributed significantly to the improvement of the manuscript. I am also very grateful to the staff of local Councils and ONS for providing updated statistics of population, commercial and residential properties and to Welsh Assembly Government, Aerial Photographs Unit, Cardiff, Wales, for the aerial photographs used in the study.

\section{References}

Abuodha, P.A., Woodroffe, C.D., 2010. Assessing vulnerability to sea-level rise using a coastal sensitivity index: a case study from southeast Australia. J. Coast. Conserv. 14, 189-205.

Addo, K.A., 2013. Assessing coastal vulnerability index to climate change: the case of Accra-Ghana. J. Coast Res. 1892-1897. Special Issue No. 65.

Appelbaum, B., 2011. As US Agencies Put More Value on a Life, Businesses Fret. The New York Times, p. 16 [Online]. Available: http://www.nytimes.com/2011/02/ 17/business/economy/17regulation.html?_r=0 [Accessed 10/03/2014].

Atlas, U., 2012. Percent of Us Live in Coastal Areas, Retrieved October 22, 2013.

Balica, S., Wright, N.G., van der Meulen, F., 2012. A flood vulnerability index for coastal cities and its use in assessing climate change impacts. Nat. Hazards 64 73-105.

BBC, 2014. Hallsands - Archive Photos. http://www.bbc.co.uk/devon/content/ image_galleries/hallsands_archive_gallery.shtml?5.

Butler, R.W., 2006. The origins of the tourism area life cycle. Tour. Area Life Cycle 1, $13-26$.

Cooper, J., McKenna, J., 2008. Social justice in coastal erosion management: the temporal and spatial dimensions. Geoforum 39, 294-306.

Ceredigion County Council, 2014. 2014 storm Damage and Repair Costs [Online]. Available: http://www.ceredigion.gov.uk/English/Your-Council/Pages/default. aspx [Accessed 13/08/2015].

Cutter, S.L., Boruff, B.J., Shirley, W.L., 2003. Social vulnerability to environmental hazards*. Soc. Sci. Quart. 84, 242-261.

Dawson, A.G., Dawson, S., Ritchie, W., 2007. Historical climatology and coastal change associated with the 'Great Storm'of january 2005, south uist and Benbecula. Scott. Outer Hebrides. Scott. Geogr. J. 123, 135-149.

Dawson, D., Shaw, J., Gehrels, W.R., 2016. Sea-level rise impacts on transport infrastructure: the notorious case of the coastal railway line at Dawlish, England. J. Transp. Geogr. 51, 97-109.

De Sherbinin, A., Schiller, A., Pulsipher, A., 2007. The vulnerability of global cities to climate hazards. Environ. Urban 19, 39-64.

Denner, K., Phillips, M., Jenkins, R., Thomas, T., 2015. A coastal vulnerability and environmental risk assessment of Loughor Estuary, South Wales. Ocean. Coast. Manage 116, 478-490.

Doody, J.P., 2001. Coastal Conservation and Management. Springer Science \& Business Media.

Economics, O., 2013. The Economic Impact of the UK Maritime Services Sector. Oxford Economic Ltd, Oxford.

Fletcher III, C.H., Grossman, E.E., Richmond, B.M., Gibbs, A.E., 2002. Atlas of Natural Hazards in the Hawaiian Coastal Zone.

Gornitz, V., 1990. Vulnerability of the East Coast, USA to future sea level rise. J. Coast. Res. 9, 201-237.

Gorokhovich, Y., Leiserowitz, A., Dugan, D., 2013. Integrating coastal vulnerability and community-based subsistence resource mapping in Northwest Alaska. Coast. Res. 30, 158-169.

Hahn, M.B., Riederer, A.M., Foster, S.O., 2009. The Livelihood Vulnerability Index: a pragmatic approach to assessing risks from climate variability and change-A case study in Mozambique. Glob. Environ. Chang. 19, 74-88.

Hinkel, J. Nicholls, R.J. Vafeidis, A.T. Tol, R.S., Avagianou, T., 2010. Assessing risk of and adaptation to sea-level rise in the European Union: an application of DIVA Mitig. Adapt. Strategies Glob. Change 15, 703-719.

Hoozemans, F., Marchand, M., Pennekamp, H., 1993. Sea Level Rise: a Global Vulnerability Assessment for Population, Coastal Wetlands and Rice Production on a Global Scale. Deltares (WL).

Jones, A.L., Phillips, M.R., 2009. Disappearing Destinations: Climate Change and Future Challenges for Coastal Tourism. CABI.

Jongman, B., Ward, P.J., Aerts, J.C., 2012. Global exposure to river and coasta flooding: long term trends and changes. Glob. Environ. Chang. 22, 823-835.

Kantamaneni, K., Alrashed, I., Phillips, M., 2015a. Cost vs. safety: a novel design for tornado proof homes. HBRC J. 1-10. http://dx.doi.org/10.1016/ j.hbrcj.2015.05.004.

Kantamaneni, K., Phillips, M., Jenkins, R., Alharbi, O., Alrashed, I., 2015b. Monetary assessment of damage to residential and commercial properties during flooding in the United Kingdom. Res. J. Recent Sci. 4, 71-76.

Kantamaneni, K., Phillips, M., 2016. Transformation of climate: will floods and coastal erosion crumble the UK economy? Int. J. Clim. Change Impacts Responses 8 (Issue 3), 45-59.

Kantamaneni, K., 2016. Coastal infrastructure vulnerability: an integrated assessment model. Nat. Hazards 1-16. http://dx.doi.org/10.1007/s11069-016-2413-y.

Kunte, P.D., Jauhari, N., Mehrotra, U., Kotha, M., Hursthouse, A.S., Gagnon, A.S., 2014 Multi-hazards coastal vulnerability assessment of Goa, India, using geospatial techniques. Ocean. Coast. Manage 95, 264-281.

Marine Industries Leadership Council, 2011. A Strategy for Growth for the UK Marine Industries [Online]. Available: https://www.gov.uk/government/uploads system/uploads/attachment_data/file/31813/11-1310-strategy-for-growth-ukmarine-industries.pdf [Accessed 12/09/2012].

Martinez, M.L., Gallego-Fernandez, J.B., Garcia-Franco, J.G., Moctezuma, C., Jimenez, C.D., 2006. Assessment of coastal dune vulnerability to natural and anthropogenic disturbances along the Gulf of Mexico. Environ. Conserv. 33, anthropogen-117.

Masselink, G., Russell, P., 2007. Coastal Erosion and Coastal Geomorphology. MCCIP Marine Climate Group Impacts Partnership. Annual Report Card 2008.

Masselink, G. Russell, P. 2013. Impacts of Climate Change on Coastal Erosion. Marine Climate Change Impacts Partnership. http://www.mccip.org.uk/media/ 13234/2013arc_backingpapers_9_ce.pdf.

McLaughlin, S., McKenna, J., Cooper, J., 2002. Socio-economic data in coastal vulnerability indices: constraints and opportunities. J. Coast. Res. 36, 487-497.

McLaughlin, S., Cooper, J.A.G., 2010. A multi-scale coastal vulnerability index: a tool for coastal managers? Environ. Hazards 9, 233-248.

Moser, S.C., Jeffress Williams, S., Boesch, D.F., 2012. Wicked challenges at land's end: managing coastal vulnerability under climate change. Annu. Rev. Environ. Resour. 37, 51-78.

Mazumdar, J., Paul, S.K., 2016. Socioeconomic and infrastructural vulnerability indices for cyclones in the eastern coastal states of India. Nat. Hazards 82 , $1621-1643$.

Nicholls, R.J., Wong, P.P., Burkett, V.R., Codignotto, J.O., Hay, J.E., McLean, R.F. Ragoonaden, S., Woodroffe, C.D., 2007. Coastal systems and low- lying areas. In: Parry, M.L., Canziani, O.F., Palutikof, J.P., van der Linden, P.J., Hanson, C.E. (Eds.), Climate Change 2007: Impacts, Adaptation and Vulnerability. Contribution of Working Group II to the Fourth Assessment Report of the Intergovernmental Panel on Climate Change. Cambridge University Press, Cambridge, UK, pp. 315-356.

Nguyen, T.T., Bonetti, J., Rogers, K., Woodroffe, C.D., 2016. Indicator-based assessment of climate-change impacts on coasts: a review of concepts, methodological approaches and vulnerability indices. Ocean. Coast. Manage 123, 18-43.

Ordnance Survey, 2013. Boundary-LineTM [Online]. Available : http://data.gov.uk/ dataset/boundary-line [Accessed 10/11/2015].

Oliver-Smith, A., 2009. Sea Level Rise and the Vulnerability of Coastal Peoples: Responding to the Local Challenges of Global Climate Change in the 21st Century. UNU-EHS.

Palmer, B., Van der Elst, R., Mackay, F., Mather, A., Smith, A., Bundy, S., Thackeray, Z. Leuci, R., Parak, O., 2011. Preliminary coastal vulnerability assessment for 
KwaZulu-Natal, South Africa. J. Coast. Res. 64, 1390-1395.

Papathoma, M., Dominey-Howes, D., 2003. Tsunami vulnerability assessment and its implications for coastal hazard analysis and disaster management planning, Gulf of Corinth, Greece. Nat. Hazards Earth Syst. Sci. 3, 733-747.

Pethick, J.S., Crooks, S., 2000. Development of a coastal vulnerability index: a geomorphological perspective. Environ. Conserv. 27, 359-367.

Phillips, M.R., Jones, A.L., 2006. Erosion and tourism infrastructure in the coastal zone: problems, consequences and management. Tour. Manag. 27, 517-524.

Phillips, M., Powell, V., Duck, R., 2009. Coastal regeneration at Llanelli, South Wales, UK: lessons not learned. J. Coast. Res. 1276-1280.

Ramieri, E., Hartley, A., Barbanti, A., Santos, F.D., Gomes, A., Hilden, M., Laihonen, P., Marinova, N., Santini, M., 2011. Methods for Assessing Coastal Vulnerability to Climate Change. In: European Topic Centre on Climate Change Impacts, Vulnerability and Adaptation. European Environment Agency.

Rani, N.S., Satyanarayana, A., Bhaskaran, P.K., 2015. Coastal vulnerability assessment studies over India: a review. Nat. Hazards 77, 405-428.

Rygel, L. O'sullivan, D. Yarnal, B. 2006. A method for constructing a social vulnerability index: an application to hurricane storm surges in a developed country. Mitig. Adapt. Strategies Glob. Change 11, 741-764.

Schröter, D., Cramer, W., Leemans, R., Prentice, I.C., Araújo, M.B., Arnell, N.W.,
Bondeau, A., Bugmann, H., Carter, T.R., Gracia, C.A., 2005. Ecosystem service supply and vulnerability to global change in Europe. Science 310, 1333-1337.

Singh, A., 2006. Assessing Coastal Vulnerability: Developing a Global Index for Measuring Risk. UNEP/Earthprint.

Smit, B., Pilifosova, O., 2003. Adaptation to climate change in the context of sustainable development and equity. Sustain. Dev. 8, 9.

Smith, K., 2013. Environmental Hazards: Assessing Risk and Reducing Disaster. Routledge.

Vincent, K., 2004. Creating an index of social vulnerability to climate change for Africa. Tyndall center for climate change research. Work. Pap. 56, 41.

Vittal Hegde, A., Radhakrishnan Reju, V., 2007. Development of coastal vulnerability index for Mangalore coast, India. J. Coast. Res. 1106-1111.

Warwick University, 2010. UK Maritime Industry. Available from. http://www2. warwick.ac.uk/fac/soc/ier/ngrf/stem/basics/sources/stem_supplement-uk_ maritime_industry.pdf.

Wolters, M.L., Kuenzer, C., 2015. Vulnerability assessments of coastal river deltascategorization and review. J. Coast. Conserv, 19, 345-368.

Zsamboky, M., Fernández-Bilbao, A., Smith, D., Knight, J., Allan, J., 2011. Impacts of Climate Change on Disadvantaged UK Coastal Communities. Joseph Rowntree Foundation, York, UK. 


\title{
Coastal infrastructure vulnerability: an integrated assessment model
}

\author{
Komali Kantamaneni ${ }^{1,2}$
}

Received: 12 February 2016/ Accepted: 2 June 2016/Published online: 12 July 2016

(C) The Author(s) 2016. This article is published with open access at Springerlink.com

\begin{abstract}
The significance of coastal regions to the infrastructure and the need to protect such assets are crucial to the economy of countries. Therefore, there is a real need to enhance the understanding of coastal infrastructure susceptibility as well as to develop methodologies to estimate vulnerability. A review of the literature regarding coastal vulnerability reveals that the focus has been on geomorphological and physical parameters but not infrastructure and the associated fiscal factors. In order to address this knowledge gap, an innovative model is developed, i.e., the Coastal Infrastructure Vulnerability Index (CIVI). Then the model is applied to the case of the Aberystwyth coast demonstrating how the model estimates the vulnerability of the coastal infrastructure (comprising population, commercial and residential properties). Subsequently, the CIVI scores were used to rank coastal sections into five classes, ranging from extremely low to extremely high, based on the relative magnitude of the vulnerability. The rankings for each parameter were combined, and then an index value was calculated. Results revealed that Aberystwyth contains more than $£ 40$ billion of coastal infrastructure vulnerability and more than 10,000 inhabitants are at the high coastal risk posed by flooding, erosion, storm surges, and strong winds.
\end{abstract}

Keywords Integrated model · Coastal infrastructure vulnerability index (CIVI) · Aberystwyth · Costs

Komali Kantamaneni

Komali.kantamaneni@uwtsd.ac.uk

1 Faculty of Architecture, Computing and Engineering, University of Wales, Trinity Saint David, Mount Pleasant, Swansea SA1 6ED, UK

2 School of Maritime and Engineering, Southampton Solent University, E Park Terrace, Southampton, Hampshire SO14 0YN, UK 


\section{Introduction}

Several coastal regions across the world are endangered to both natural and anthropogenic hazards, which are expected to increase in the near future (Nicholls et al. 2007; Kron 2008; Weisse et al. 2012). The construction of a variety of infrastructures such as properties (commercial and residential), roads, ports, and breakwaters completely dominates the natural habitats and leads to further rapid coastal damage. Humans have changed coastal regions by introducing artificial constructions in 2580 BCE on the Red Sea shores in the Egypt (Tallet and Marouard 2014), and these structures affect geomorphology and coastal systems (Bulleri and Chapman 2010) in a negative way; however, this impact severity depends on the particular geographical area. Climate change induced elements such as sealevel rise, coastal flooding, erosion, and storm surge are the main reasons for coastal infrastructure damage as well as vulnerability (Dolan and Walker 2006; Phillips and Jones 2006; Bosello and De Cian 2014). Increased weather events also affect the socio-economic circumstances of coastal regions significantly (Hinkel et al. 2010). Therefore, coastal infrastructure vulnerability needs assessment to a greater degree to ameliorate existing problems and to prevent further decline.

\subsection{Coastal vulnerability appraisal methods}

Since three decades several works have been made to establish strategies and procedures for evaluating coastal vulnerability to climate change and other related aspects, accompanied with economics (Cutter et al. 2003; Lewsey et al. 2004; Vincent 2004; Rygel et al. 2006; Phillips and Jones 2006; Hinkel et al. 2009; Torresan et al. 2012; Addo 2013; Tang et al. 2013; Wolters and Kuenzer 2015; Denner et al. 2015; Wu et al. 2016). A summary of several methodologies established and applied globally is provided here. The four primary methods (Ramieri et al. 2011) to evaluate coastal vulnerability to climate change are as follows:

1. Index-based methodology

2. Indicator-based methodology

3. GIS (geographical information systems) based decision support systems

4. Dynamic computer models

\subsubsection{Index-based methodology}

Index-based methods evaluate coastal vulnerability by a single magnitude and are normally unit less. This method measures by the quantitative or semi-quantitative assessment as well as an amalgamation of diverse variables. These methods are not directly transparent since the final index does not allow for the understanding of the expectations and combinations that led to its measurement. The CVI outcomes can be shown on vulnerability maps at various scales to identify regions where the elements that add to coastal changes make greatest contributions to coastline retreat (Harvey and Woodroffe 2008; Pendleton et al. 2010). First coastal vulnerability index was developed by Gornitz (1990) followed by several researchers developing diverse CVI indices across the globe (McLaughlin and Cooper 2010; Palmer et al. 2011; Yin et al. 2012; Denner et al. 2015). 


\subsubsection{Indicator-based methodology}

An indicator-based index is a popular tool for measuring the intensity of exposure of communities to hazards and coastal vulnerability. The index comprises several indicators, which are interlinked with the specific formula. In recent decades, some researchers have established several vulnerability indicators within the socio-economic and ecological system context (King and MacGregor 2000; Brooks et al. 2005; Barnett et al. 2008; Torresan et al. 2008; Abson et al. 2012; Balica et al. 2012).

\subsubsection{GIS-based decision support systems (GIS-DSS)}

GIS-based methodologies are useful for evaluating the physical condition of a particular system and the development of risk maps. It is useful to acquire further information about the physical geography of particular region through computerisation to transmute vast databases into thematic maps. The GIS-DSS is two types; development of an information technology tool for the management of Southern European lagoons under the influence of river-basin runoff (DITTY-DSS) (Agnetis et al. 2006; Mocenni et al. 2009; Casini et al. 2015) and decision support system for coastal climate change impact assessment (DESYCO-DSS) (Santoro et al. 2013; Zanuttigh et al. 2014).

\subsubsection{Dynamic computer models}

Dynamic computer simulations are useful for analysing and mapping susceptibility and risks of coastal systems (Cowell et al. 1995; Brown et al. 2006). Available methods for this procedure can be divided into two parts; sector models and integrated assessment models. Sector models focus on the examination of coastal vulnerability linked to a specific coastal system, and integrated assessment models appraise the coastal vulnerability systems to multiple climate change impacts (Mcleod et al. 2010).

\subsection{Common framework for evaluation of coastal vulnerability}

In 1990, IPCC published a standard methodology for assessing the vulnerability of coastal areas to sea-level rise; it contains seven systematic stages (seven indicators) (Table 1) that permit for the identification of population, natural and physical resources at risk and costs and possibility of potential responses to adverse impacts (Nicholls 1995).

Though several other methods have been developed for coastal vulnerability assessment, most of the researchers focused their interest on the index- and indicator-based methods. However, there is no standard evaluation method on town/city scale to estimate the current infrastructure vulnerability of the Aberystwyth at current scenarios. Therefore, this study developed an integrated CIVI and subsequently analysed the infrastructure vulnerability of the population, commercial and residential properties of Aberystwyth, UK.

\section{Description of study area}

Aberystwyth $\left(52^{\circ} 25^{\prime} \mathrm{N} 4^{\circ} 05^{\prime} \mathrm{W}\right)$ is a small sea-side (Irish Sea) town in the county of Ceredigion in the Wales, UK (Aberystwyth Guide 2014) (Fig. 1), located towards the centre of the falcate of Cardigan Bay and also positioned between three hills. Aberystwyth 
Table 1 Indicators of the Coastal vulnerability_IPCC common approach (Gilbert and Vellinga 1990)

\begin{tabular}{|c|c|}
\hline Indicator & Explanation \\
\hline $\begin{array}{l}\text { Affected } \\
\text { Population }\end{array}$ & Number of people living in the hazard region affected by sea-level rise \\
\hline Population at risk & The average annual number of people inundated by storm surge \\
\hline $\begin{array}{l}\text { Investment value at } \\
\text { loss }\end{array}$ & Current market value of infrastructure which could be lost due to sea-level rise \\
\hline Land at loss & Size of land that would be lost due to rise of sea-level rise \\
\hline Wetland at loss & Size of area of wetland that would be lost due to sea-level rise \\
\hline Adaptation costs & Adaptation costs to sea-level rise, with an overwhelming importance on defence \\
\hline Population at risk & $\begin{array}{l}\text { The average number of people flooded by storm surge per year, supposing the cost of } \\
\text { adaptation to be in residence }\end{array}$ \\
\hline
\end{tabular}

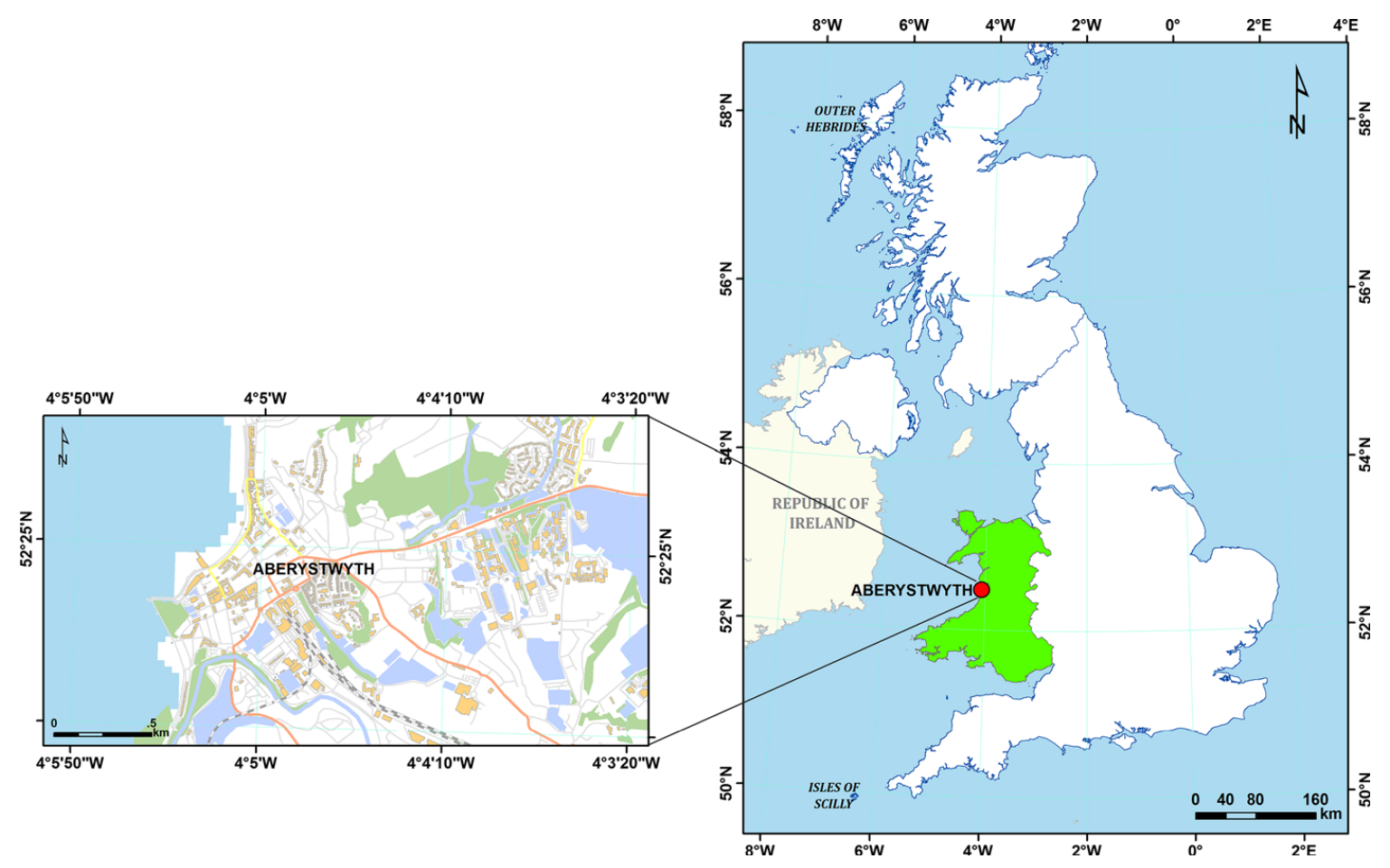

Fig. 1 Map of the study area

is the main touristic spot and administrative region of the west coast of Wales; though it has a small coastline ( $>2 \mathrm{~km}$ ) (Aberystwyth Guide 2014), it has a high socio-economic value because the town's economy is based mainly on tourism, education, and retail sectors.

\subsection{Coastal infrastructure damage}

Frequent storm strikes in Aberystwyth are not unusual phenomena. Starting several decades ago, repeated storms ravaged this region and damaged several £million to £billion worth of infrastructure (Fig. 2a-d as evidenced in 1927, 2008, 2013 and 2014 (major events). In particular, the 2014 massive tides ( $>20$ feet) damaged $>2 \mathrm{~km}$ of railway track 


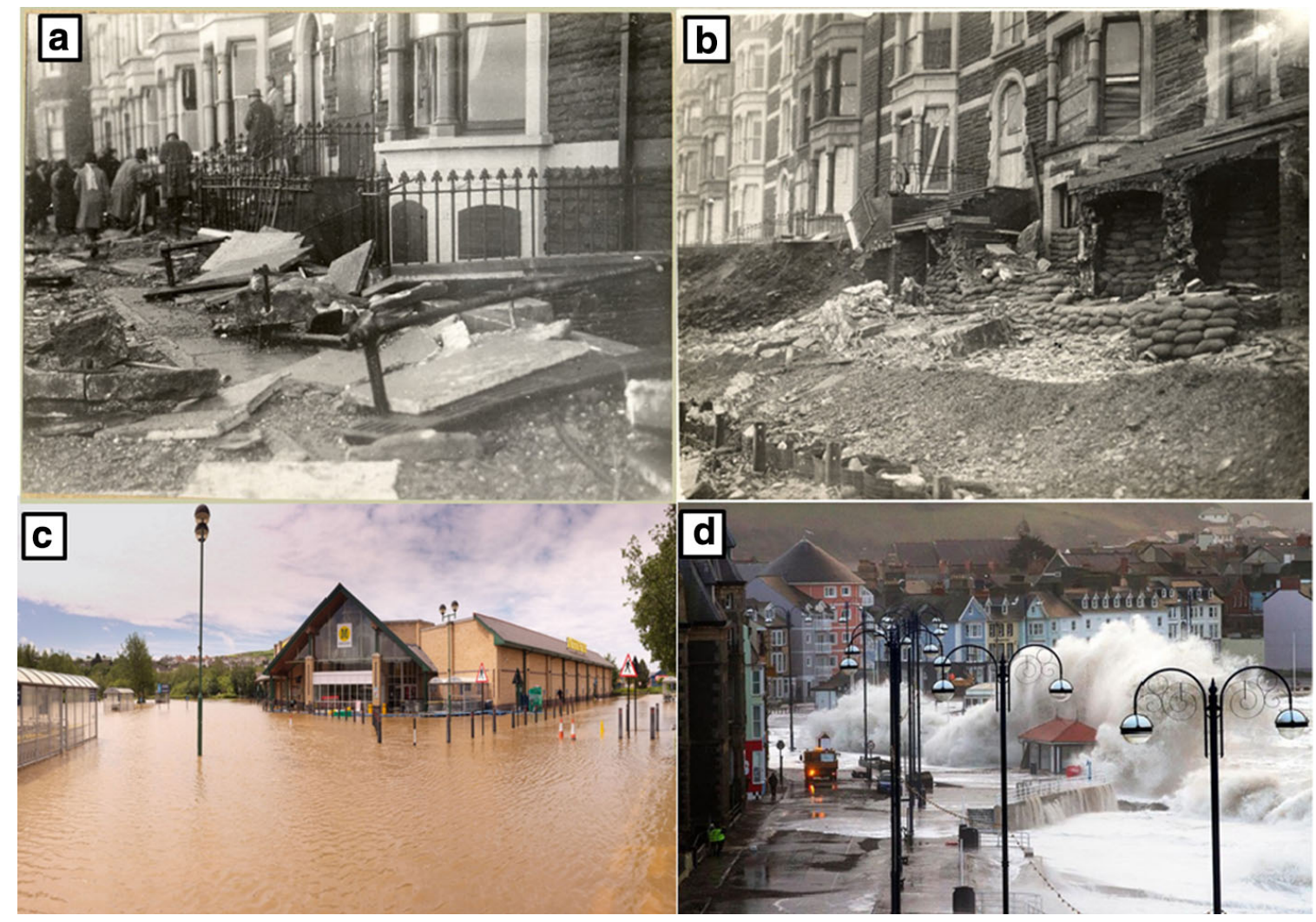

Fig. 2 Decadal Infrastructure Damage in Aberystwyth. a Residential property damage in 1927 (British Geological Survey 2014), b residential property damage in 1938 (British Geological Survey 2014), c commercial property damage in 2012 (Morris 2012), d commercial and residential property damage in 2014 (The Times 2014)

between Aberystwyth and Machynlleth severely, and nearly 2 weeks were needed for repairs. In addition, the widespread destruction of the seawall and walking path and the flooding of more than ten houses occurred (Welsh Government 2014). Future climatic conditions and levels of damage due to various coastal hazards (Table 2) will worsen the situation if strict adaptation and coastal defence procedures are not implemented in the near future (Slingo et al. 2014).

\section{Data}

Population, commercial and residential properties data were obtained from ONS (Office for National Statistics), local and sub-local Councils of Wales and Aberystwyth; fiscal data of commercial and residential properties obtained from HM Revenue and Customs (HMRC) offices of Wales and the Agricultural Mortgage Corporation (AMC). Along with the information as mentioned above, this study also utilised the data obtained by multiple observations of the coastal site of the Aberystwyth over 3 years (2012-2015) period. Parameter's statistics of each coastal cell (at $0.5 \mathrm{~km}$ resolution) was determined by using orthophotographs of Ordnance Survey, Welsh Assembly Government-Aerial Photographs and Google Earth maps. However, current study only used the data of rateable properties and did not take into consideration some heritage properties such as church and museums or massive structures like bridges and other constructions. While SPSS (statistical package for social sciences) (21st version) was used for analysis and exploration of 
Table 2 Coastal hazards of the Aberystwyth (Adopted from Ramieri et al. 2011)

\begin{tabular}{lll}
\hline $\begin{array}{l}\text { Principal } \\
\text { Marine regions }\end{array}$ & Coastal hazards & Vulnerability/impacts \\
\hline Celtic Sea & $\begin{array}{l}\text { Coastal flooding } \\
\text { Various storm events }\end{array}$ & $\begin{array}{l}\text { Infrastructure damage } \\
\text { Community loss }\end{array}$ \\
& Coastal erosion & Land degradation \\
& Storm surge & Damage to the coastline \\
& High waves, tides and winds & Damage to infrastructure \\
Coastal flooding & Infrastructure damage \\
& Various storm events & Community loss \\
& Coastal erosion & Land degradation \\
& Storm surge & Damage to infrastructure \\
& High waves & Damage to coastal wall and infrastructure
\end{tabular}

CIVI values and furtherer construction of CIVI. ArcGIS (10.3 version) and Welsh Assembly Government Arial and Google (Open Street) maps were used in the development of coastal vulnerability maps in various scales.

\section{Methodology}

\subsection{Development of an integrated model}

There is a real need to evaluate and compare the intensity of vulnerability of different sites, zones, and nations across the globe. The familiarity of coastal vulnerability will allow the researchers, policy, as well as decision makers to predict and perform on the adverse scenarios of existing and upcoming vicissitudes ensuing from global and regional sea-level rise and other impacts of climate change. A generalised and simple framework is required to illuminate explicit communication regarding coastal vulnerability and expressive comparison among susceptibility appraisals. Several kinds of technical, natural and social methods have already been employed (mentioned in the introduction section), but the process of applying the framework regionally and globally (from a fiscal perspective) is still in the embryonic stage. A definite procedure is then required to categorise the vulnerability of the coastal infrastructure; accordingly, a novel integrated model has been developed for the evaluation of coastal infrastructure vulnerability of the Aberystwyth coast, i.e., CIVI.

Two coastal vulnerability index (CVI) approaches were adopted for this study, based on an adaptation of the work of Balica et al. (2012) and Palmer et al. (2011). Accordingly, an integrated model (Fig. 3) was established to evaluate the vulnerability of the Aberystwyth coast by amalgamating indicator and index-based methods. The fiscal parameters were selected using the indicator-based method of Balica et al. (2012), and the concept of development of CIVI was taken from the index-based approach of Palmer et al. (2011). The fiscal values threshold for parameters was inspired by Aberystwyth fiscal consequences.

\subsection{Fiscal parameters selection}

Current study scrutinised various events in relation to a coastal vulnerability in the UK, such as population, commercial and residential properties, storm conditions, rainfall trends, 


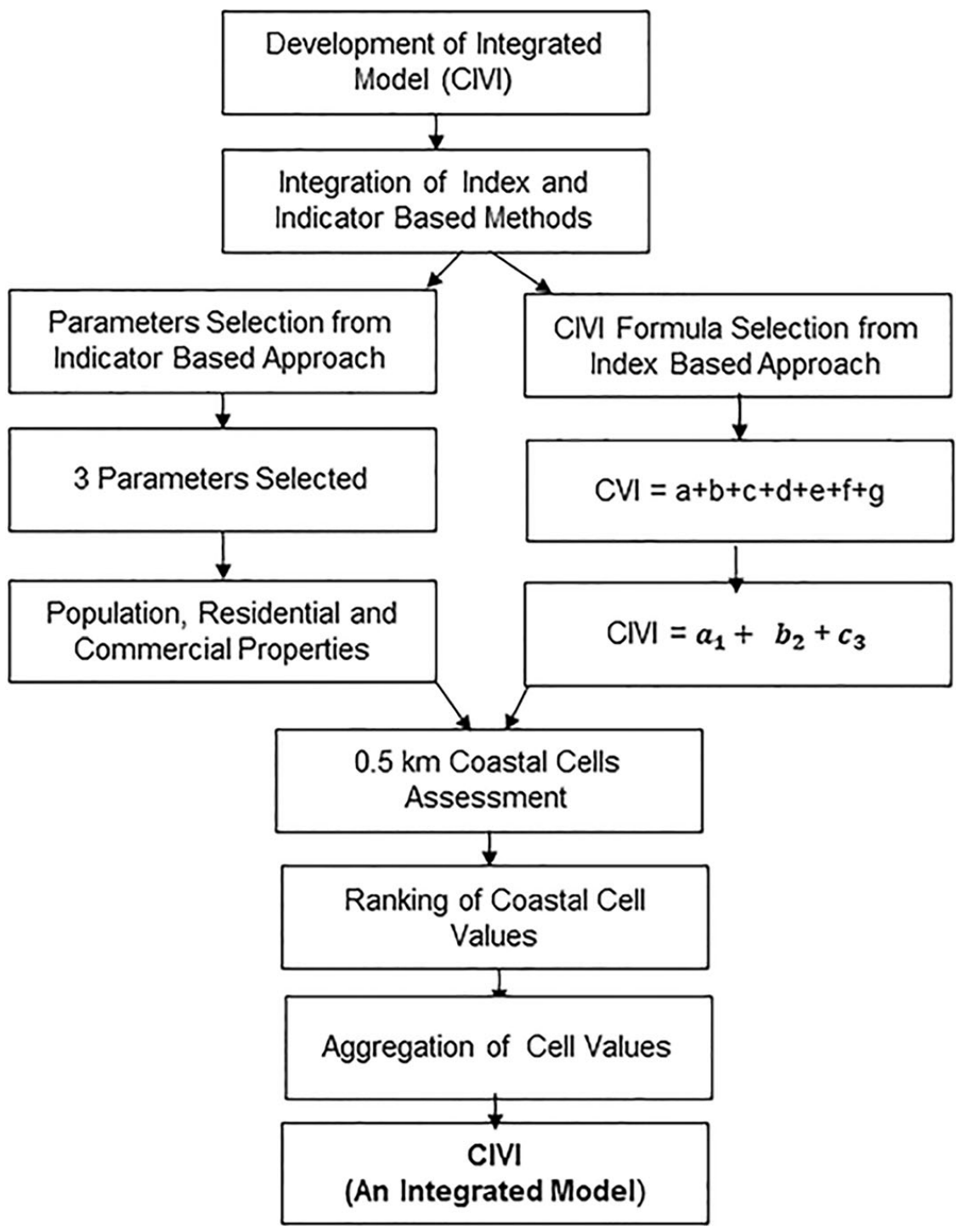

Fig. 3 Flow chart of development of integrated model

coastal erosion, etc. Based on the analysis of various conditions, which are presented in Table 3, twelve parameters were selected, taking into account the UK coastal regions and their susceptibility and exposure to the coastal vulnerability events.

\subsubsection{Reduction of parameters}

Reduction of parameters for an evaluation of fiscal coastal vulnerability at city or town scale is necessary. A large number of parameters (12) does not offer factual results in this particular scenario, so to simplify the methodological process, they are reduced and restricted to 3, based on the potentiality of the parameters (Table 4). Parameter reduction is not a new procedure in coastal vulnerability assessment studies, and several researchers have already implemented this technique successfully. Balica et al. (2012) initially considered 71 indicators and then reduced their number to 12, and the Canadian Council of Ministries of Environment (2003) selected nearly 100 indicators, which were reduced to 12 as well. 
Table 3 Parameters selection procedure

\begin{tabular}{|c|c|c|}
\hline Number & Parameter & Selection process and reason \\
\hline 1 & $\begin{array}{l}\text { Population in coastal } \\
\text { vulnerability zones }\end{array}$ & $\begin{array}{l}\text { More than } 50 \% \text { of population is living near the coastline (Small } \\
\text { and Nicholls 2003) }\end{array}$ \\
\hline 2 & $\begin{array}{l}\text { Infrastructure (properties, } \\
\text { roads, etc.) }\end{array}$ & $\begin{array}{l}\text { Nearly } 6 \text { million properties (one in six) are at risk of coastal } \\
\text { flooding and erosion (Ramsbottom et al. 2012) }\end{array}$ \\
\hline 3 & Land use & $\begin{array}{l}\text { Around } 60 \% \text { of the best agricultural land is } 5 \mathrm{~m} \text { or less above sea } \\
\text { level (Zsamboky et al. 2011) }\end{array}$ \\
\hline 4 & Rainfall & $\begin{array}{l}\text { Heavy rainfall trends across the country in recent decades (Osborn } \\
\text { and Hulme 2002; Maraun et al. 2008) }\end{array}$ \\
\hline 5 & Flood/storm impact & $\begin{array}{l}\text { Increased severity of flood/storm impact in recent periods } \\
\text { (Reynard et al. 2001; Woodworth et al. 2007; Stevens et al. 2014) }\end{array}$ \\
\hline 6 & Fiscal value of the place & $\begin{array}{l}\text { The economic value of the area plays a vital role in fiscal studies, } \\
\text { as well as disaster management studies (Swarbrooke 1999; Haigh } \\
\text { and Amaratunga 2010) }\end{array}$ \\
\hline 7 & Coastal erosion & $\begin{array}{l}\text { High coastal erosion at some regions of the UK (Phillips and Jones } \\
\text { 2006; Kantamaneni and Phillips 2016) }\end{array}$ \\
\hline 8 & $\begin{array}{l}\text { High growth of population } \\
\text { alongside coasts }\end{array}$ & $\begin{array}{l}\text { High growth of population expected alongside coasts (Small and } \\
\text { Nicholls 2003). }\end{array}$ \\
\hline 9 & Drainage system & $\begin{array}{l}\text { A poor drainage system causes severe problems particularly when } \\
\text { flooding strikes (Coulthard and Frostick 2010; Butler and Davies } \\
\text { 2004) }\end{array}$ \\
\hline 10 & Warning system & $\begin{array}{l}\text { The robustness of the UK's warning system for natural disasters, } \\
\text { e.g. no warning system during tornado strikes (Kantamaneni } \\
\text { et al. 2015) }\end{array}$ \\
\hline 11 & Marine Industry Growth & $\begin{array}{l}\text { Maritime industries and the service sector annually contributes } \\
>£ 17 \text { billion to the UK economy and it will be } £ 25 \text { billion by } \\
2020 \text { (Marine Industries Leadership Council 2011) }\end{array}$ \\
\hline 12 & Politics and Policies & $\begin{array}{l}\text { Changing the political situation also plays a vital role in the } \\
\text { assessment of coastal vulnerability (White and Howe 2002; Patt } \\
\text { et al. 2009) }\end{array}$ \\
\hline
\end{tabular}

Table 4 Fiscal (coastal infrastructure vulnerability) parameters

\begin{tabular}{llll}
\hline No. & Parameter & Designated symbol for CIVI & Measurable units (£) \\
\hline 1 & Population & $a 1$ & Million-billion (economic) \\
2 & Residential property & $b 2$ & Million-billion (economic) \\
3 & Commercial property & $c 3$ & Million-billion (economic) \\
\hline
\end{tabular}

\subsubsection{Parameters description}

The population is widely accepted imperative parameter in both physical and socio-economic sections of coastal research, and it also considers as one of the vital infrastructures (Simone 2004). Current study measures the population in monetary terms and sets a cost to the human life based on US-2011-Environment Protection Agency estimations, i.e., $£ 6.9$ million (adjusted for 2015 inflation £rates) (Appelbaum 2011). However, Aberystwyth population has diverse age groups and communities with different economic status; 
therefore, this study offers on average $£ 4 \mathrm{~m}$ to the life of the UK (Aberystwyth) people at current scenarios. ${ }^{1}$

Residential and commercial properties are also important parameters in the coastal vulnerability studies. Using these structures as parameters in coastal vulnerability studies is not new; several researchers used in their studies to evaluate vulnerability in both physical and socio-economic studies throughout the world (Klein et al. 2003; Jacob et al. 2007; Kubal et al. 2009; Thatcher et al. 2013; Arkema et al. 2013; Wu et al. 2016; Mazumdar and Paul 2016). The Economic threshold was offered by identifying a number of properties in $0.5 \mathrm{~km}$ cells and then estimated the commercial value of those properties and then provided the range of values from extremely low to extremely high.

\subsection{Technical description and calculation of CIVI}

A certain length of transect line was drawn on the Aberystwyth coastline, and then a $0.5 \mathrm{~km}$ square measurement was placed on the transect line from the coast point to outside of coast, i.e., towards the civilisation/communities (Fig. 4) to appraise coastal infrastructure vulnerability within the economic perspective, while, as shown in Fig. 4, second and third cells are overlapped. Therefore, these overlapped properties did not take into consideration for an evaluation. However, uncovered properties which are located in-between the cells of first and second as well as third and fourth are taken into account for an assessment. This consideration helps to attain factual fiscal figures.

Besides that, fiscal parameter ranking was (Table 5) used to measure the coastal vulnerability and subsequently each cell was assigned a CIVI score and then all the cells of the parameters were calculated.

This study categorised the CIVI scores into five categories: extremely low (1), low (2), moderate (3), high (4) and extremely high (5). The scores of all cells of three parameters aggregated to rank the coastal infrastructure vulnerability. With rankings applied these values were then put into a simple equation (Eq. 1) to analyse CIVI score for each coastal section. Simple summation of individual rankings provided a total relative vulnerability score. The minimum possible score was 3 , and the maximum was 15 .

$$
\begin{aligned}
& \text { Relative CIVI }=a_{1}+b_{2}+c_{3} \\
& a_{1} \text {-Population } \quad 5(\max ) \\
& b_{2} \text {-Residential property } 5(\max ) \\
& c_{3} \text {-Commercial Property } 5 \text { (max) } \\
& \text { Maximum CIVI score } 15 \\
& \text { Minimum CIVI score } 3
\end{aligned}
$$

\footnotetext{
1 It is not possible to give same fiscal consequences to all age groups of population of Aberystwyth and, accordingly this study offer the costs on average $£ 4 \mathrm{~m}$ to the life of the human.
} 


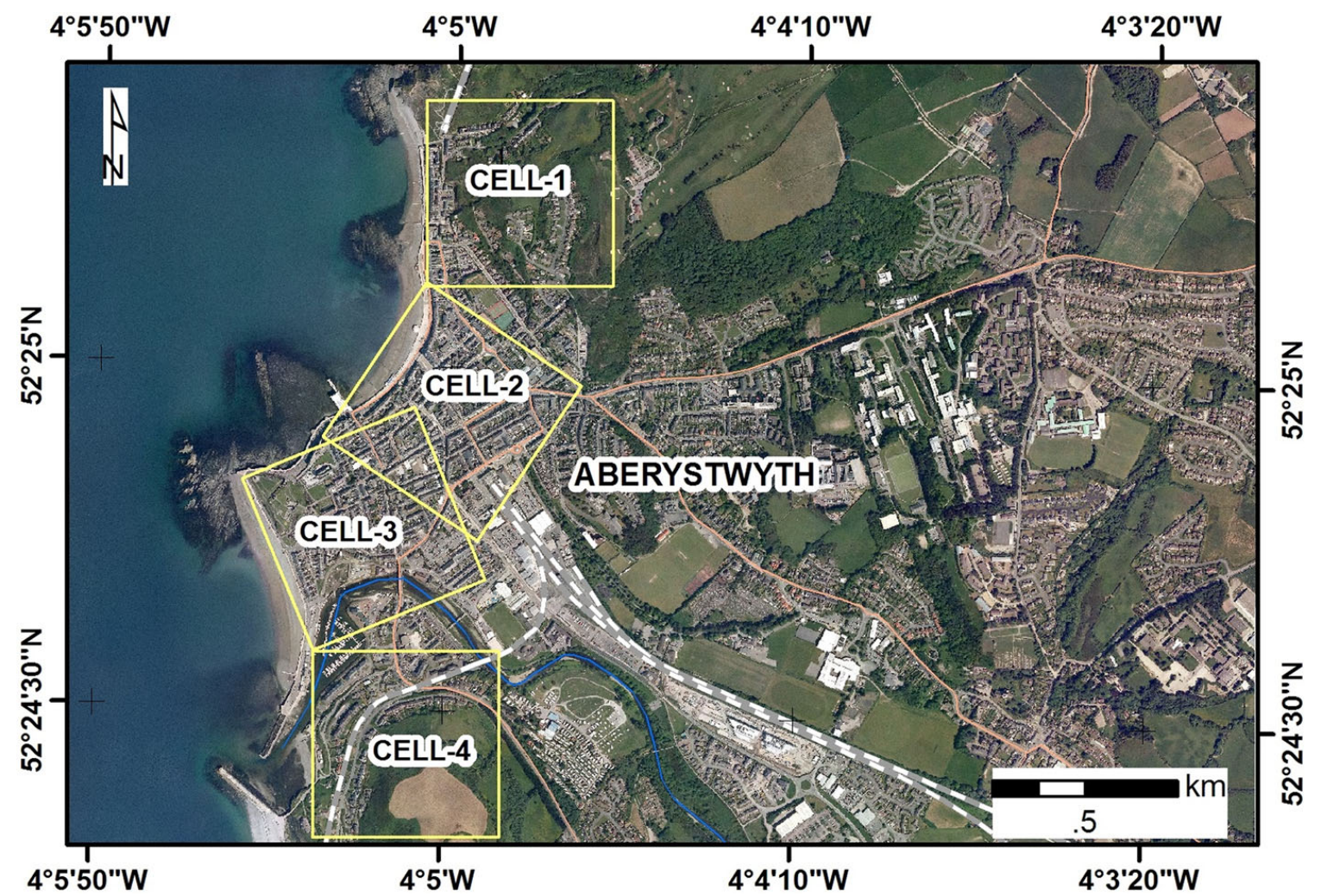

Fig. 4 Coastal cell $(0.5 \mathrm{~km})$ on transect line

Table 5 CIVI Parameter Ranking

\begin{tabular}{llllll}
\hline Fiscal & 1 & 2 & 3 & 4 & 5 \\
Parameter & $\begin{array}{l}\text { Extremely Low } \\
£\end{array}$ & $\begin{array}{l}\text { Low } \\
£\end{array}$ & $\begin{array}{l}\text { Moderate } \\
£\end{array}$ & $\begin{array}{l}\text { High } \\
£\end{array}$ & $\begin{array}{l}\text { Extremely High } \\
£\end{array}$ \\
\hline Population & $<1 \mathrm{bn}$ & $1 \mathrm{bn}-6 \mathrm{bn}$ & $>6 \mathrm{bn}-12 \mathrm{bn}$ & $>12 \mathrm{bn}-20 \mathrm{bn}$ & $>20 \mathrm{bn}-28 \mathrm{bn}$ \\
Residential property & $<30 \mathrm{~m}$ & $30 \mathrm{~m}-80 \mathrm{~m}$ & $>80 \mathrm{n}-30 \mathrm{~m}$ & $>130 \mathrm{~m}-180 \mathrm{~m}$ & $>180 \mathrm{~m}-1 \mathrm{bn}$ \\
Commercial property & $<2 \mathrm{~m}$ & $2 \mathrm{~m}-10 \mathrm{~m}$ & $>10 \mathrm{~m}-30 \mathrm{~m}$ & $>30 \mathrm{~m}-70 \mathrm{~m}$ & $>70-300 \mathrm{~m}$
\end{tabular}

( $m$ million, $b n$ billion)

Coastal sections scoring within the mid-range (7-9) were ranked as moderate vulnerability, and coastal sections scoring in between 13 and 15 were categorised as an extremely high vulnerability. However, the ranking system as follows (Table 6);

\section{Results and discussion}

More than two $\mathrm{km}$ transect line was drawn on Aberystwyth coast and accordingly, four $0.5 \mathrm{~km}$ cells placed and then measured. Currently, this town has thousands of coastal population and very expensive properties (commercial and residential) (Table 7).

Moreover, Aberystwyth is critically vulnerable to wave attacks and high tides (Fig. 5). For several decades, it has been affected severely by a series of storms with high waves, tides, and storm surges, particularly in 2008, 2010, 2013, and 2014. Specifically, 2014 storm ravaged this region and caused an astonishing $>£ 1.5 \mathrm{~m}$ worth of damage to the 
Table 6 Vulnerability level ratings classified by total relative vulnerability score

\begin{tabular}{lc}
\hline Relative vulnerability score & Rating of vulnerability \\
\hline Extremely high vulnerability & $13-15$ \\
High vulnerability & $10-12$ \\
Moderate vulnerability & $7-9$ \\
Low vulnerability & $4-6$ \\
Extremely low vulnerability & $1-3$
\end{tabular}

\begin{tabular}{ll}
\hline Infrastructure name & Number \\
\hline Commercial properties & 758 \\
Residential properties & 6591 \\
Population & 15,139 \\
\hline
\end{tabular}

Table 7 Infrastructure details of Aberystwyth

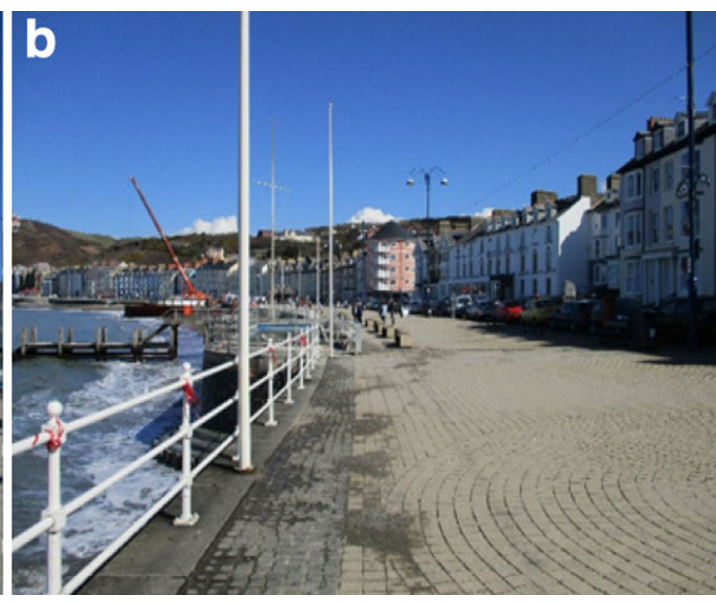

Fig. 5 a Construction of new coastal wall (during 2014 flood strike, coastal wall was severally damaged), b commercial and residential properties near the coastline in Aberystwyth (photographs were taken by author-2015)

infrastructure (Ceredigion County Council 2014). The tidal range in the area is always greater than on other sites, with the largest increase of waves coming from the south-west, which is also the direction of the most frequent storms.

Though Aberystwyth has a shorter coastline, it has a high coastal infrastructure vulnerability and comparatively uneven across the coast. Some coastal cells are extremely high, and some are high to moderate vulnerability. Extremely high CIVI scores were recorded at the second and third cells, high at the fourth cell, and moderate at the first cell (Fig. 6). Currently, Aberystwyth has $>40$ bn worth of CIV (Fig. 7) with 4613 residential properties, 530 commercial properties, and $>10,017$ people are at high coastal risk.

\section{Limitations}

Due to the lack of recent literature (most of the research information is more than 10 years old) on Aberystwyth coastal vulnerability in both physical and fiscal aspects, there is not much scope to compare with other similar existing studies, especially at regional and 


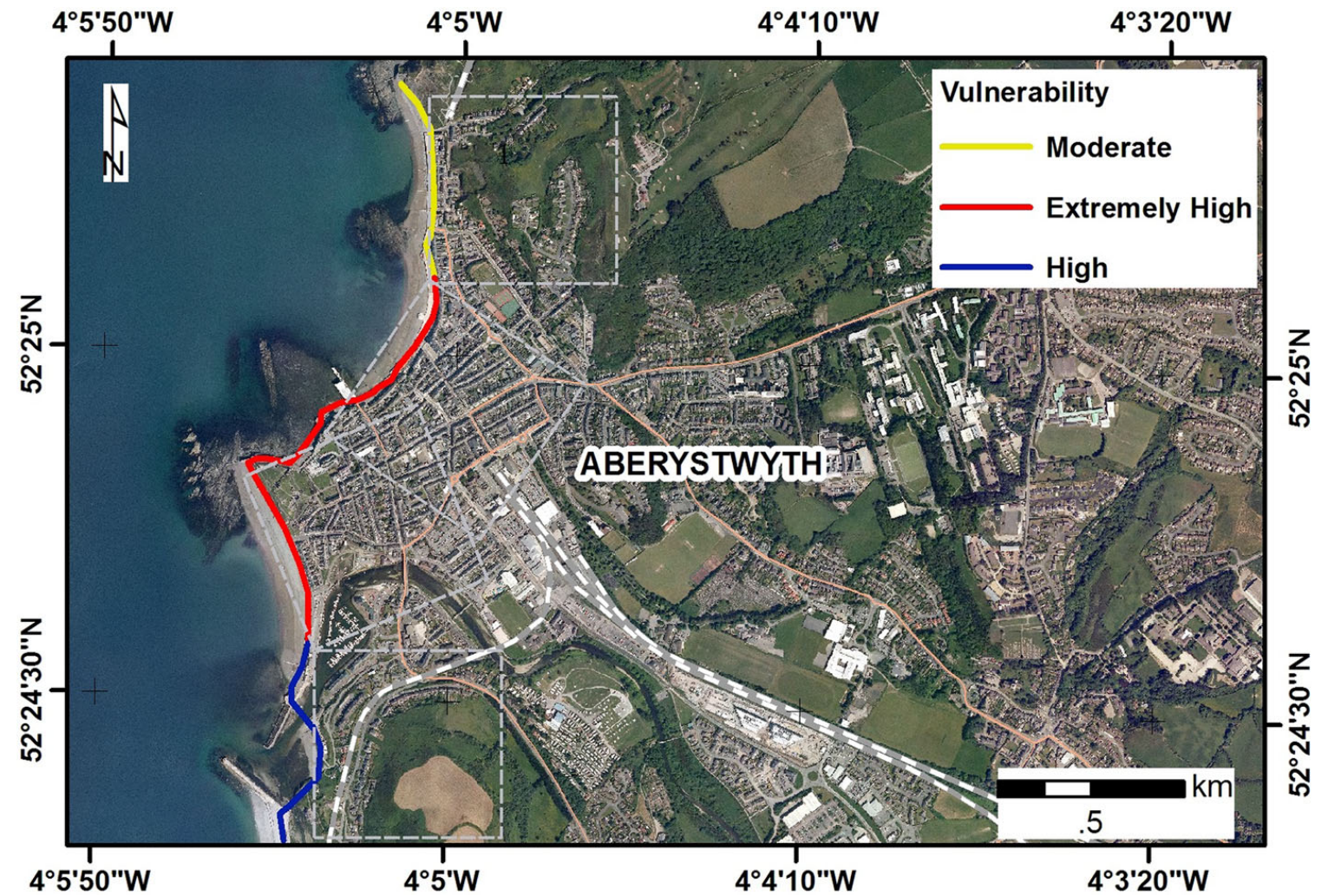

Fig. 6 Coastline vulnerability rates superimposed upon the aerial photograph

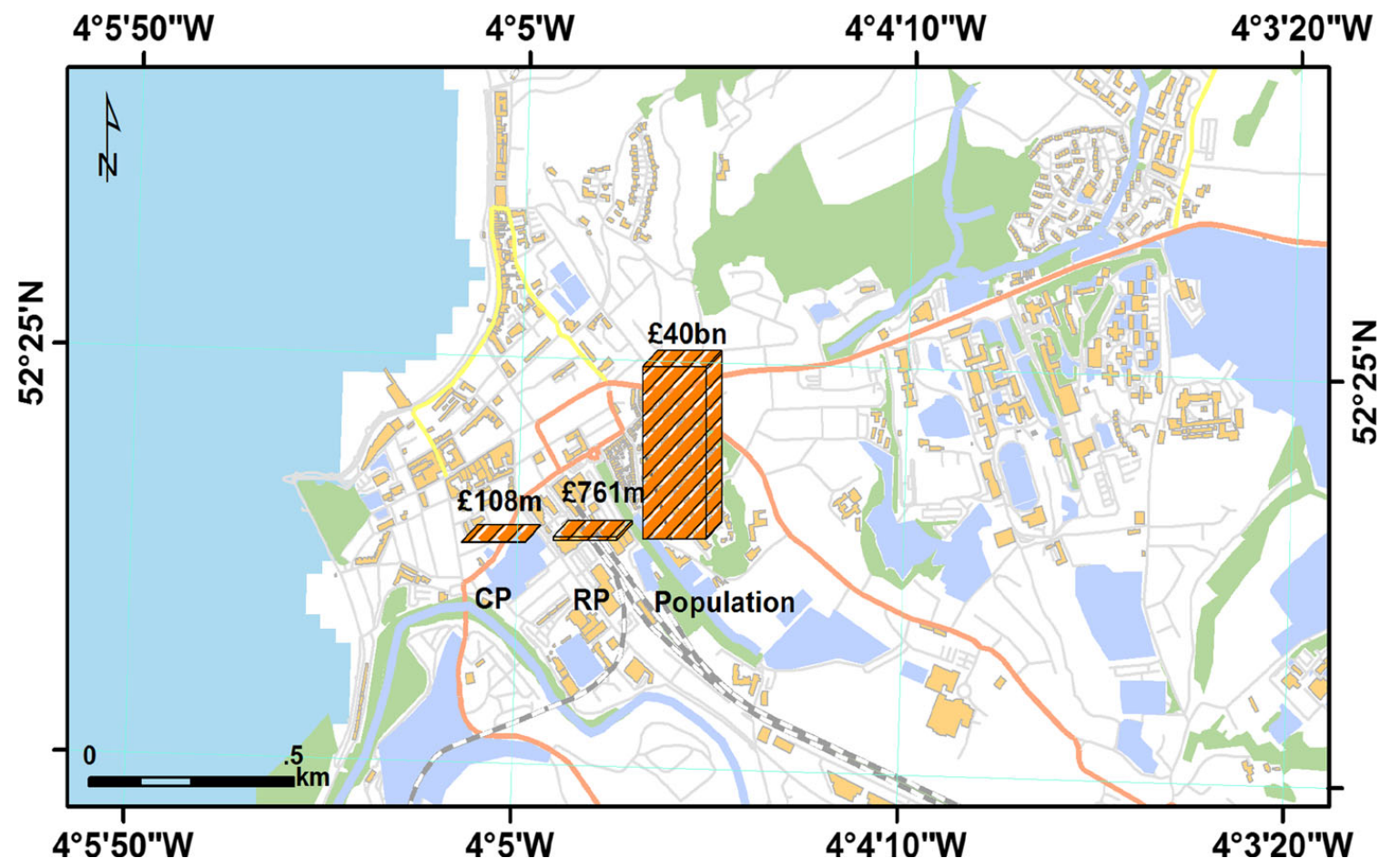

Fig. 7 Fiscal coastal vulnerability map of Aberystwyth (CP-commercial properties; RP-residential properties)

city/town scales. With these concerns in mind, the subsequent vital subjects in any effort of simplification of the findings would need to be certified carefully, such as GDP, local economy, and redevelopment procedures. 


\section{Conclusion}

This study revealed the coastal infrastructure vulnerability of the Aberystwyth by the establishment of a novel integrated model, i.e., CIVI. Fiscal parameters that considered the existing economic conditions of the population, commercial and residential properties were used to appraise the relative economic coastal infrastructure vulnerability. Results showed that Aberystwyth consists of $>£ 40$ billion worth of CIV. Efficient and factual results for CIVI computation are intensely reliant on the quality and varied type of data used, which influence the vulnerability of a particular coastal stretch. This is a statistical and objective approach to illustrate the intensity of coastal infrastructure vulnerability at Aberystwyth coast. This integrated method enables the production of statistics and quantification of different levels of vulnerability to fulfil standards substitute to regional, local and sub-local authorities in the nationalised policy for control of climate change related coastal hazards in North Wales, UK. This technique of assessing infrastructure vulnerability can purpose as a primary susceptibility appraisal from which a map of probable intensities of vulnerability can be generated to allow cost-benefit scrutinise. The use of an appraisal of coastal infrastructure vulnerability can also be employed to define fiscal viability of coastal defence and the distribution of compelled funding. This model will be very useful to coastal economists, engineers and planning managers for better planning to reduce the coastal vulnerability.

Acknowledgments I would like to thank Professor Mike Phillips, Dr. Rhian Jenkins (University of Wales Trinity Saint David, UK) and Professor Nagesh Kumar (Indian Institute of Science, Bengaluru, India) for much valuable discussion, who supported my work with vital insights from their vast experience. A particular acknowledgement is made to my work associates Dr. Talib Butt and Dr. Tony Thomas for their valuable comments on the conceptual framework. I wish to give special thanks for the comments of anonymous reviewers on an earlier version, which contributed significantly to the improvement of the manuscript. I am also very grateful to the staff of Aberystwyth Council for providing updated statistics of population, commercial and residential properties and to Welsh Assembly Government, Aerial Photographs Unit, Cardiff, Wales, for the aerial photographs used in the study.

\section{Compliance with ethical standards}

Conflict of interest This manuscript has not been previously published and is not under consideration in the same or substantially similar form in any other peer-reviewed media. To the best of my knowledge, no conflict of interest, financial or other, exists.

Open Access This article is distributed under the terms of the Creative Commons Attribution 4.0 International License (http://creativecommons.org/licenses/by/4.0/), which permits unrestricted use, distribution, and reproduction in any medium, provided you give appropriate credit to the original author(s) and the source, provide a link to the Creative Commons license, and indicate if changes were made.

\section{References}

Aberystwyth Guide (2014) Introduction. http://www.aberystwythguide.org.uk/aberpix.shtml. Accessed 13 Jan 2016

Abson DJ, Dougill AJ, Stringer LC (2012) Using principal component analysis for information-rich socioecological vulnerability mapping in Southern Africa. Appl Geogr 35:515-524

Addo KA (2013) Assessing coastal vulnerability index to climate change: the case of Accra-Ghana. J Coastal Res 2:1892

Agnetis A, et al (2006) Development of a decision support system for the management of Southern European lagoons Center for Complex Systems Studies University of Siena, Siena, Italy Disponível em. http://www.dittyproject.org/Article/WP8_DSS_structure_final.pdf 
Appelbaum B (2011) As US agencies put more value on a life, businesses fret. The New York Times, 16. http://www.nytimes.com/2011/02/17/business/economy/17regulation.html?_r=0. Accessed 10 Mar 2014

Arkema KK et al (2013) Coastal habitats shield people and property from sea-level rise and storms. Nat Climate Change 3:913-918

Balica S, Wright NG, van der Meulen F (2012) A flood vulnerability index for coastal cities and its use in assessing climate change impacts. Nat Hazards 64:73-105

Barnett J, Lambert S, Fry I (2008) The hazards of indicators: insights from the environmental vulnerability index. Ann As Am Geogr 98:102-119

Bosello F, De Cian E (2014) Climate change, sea level rise, and coastal disasters. A review of modeling practices. Energy Econ 46:593-605. doi:10.1016/j.eneco.2013.09.002

British Geological Survey (2014) BGS Geo-heritage-images from the collections http://britgeoheritage. blogspot.co.uk/2013/06/storm-damage-in-aberystwyth-october.html. Accessed 25 July 2015

Brooks N, Adger WN, Kelly PM (2005) The determinants of vulnerability and adaptive capacity at the national level and the implications for adaptation. Global Environ Change 15:151-163

Brown I, Jude S, Koukoulas S, Nicholls R, Dickson M, Walkden M (2006) Dynamic simulation and visualisation of coastal erosion. Comput Environ Urban Syst 30:840-860

Bulleri F, Chapman MG (2010) The introduction of coastal infrastructure as a driver of change in marine environments. J Appl Ecol 47:26-35

Butler D, Davies J (2004) Urban drainage. CRC Press, Boca Raton

Canadian Council of Ministries of the Environment (2003) Climate, nature, people: indicators of Canada's climate change. www.ccme.ca. Accessed 28 June 2013

Casini M, Mocenni C, Paoletti S, Pranzo M (2015) Decision support system development for integrated management of European coastal lagoons. Environ Model Softw 64:47-57

Ceredigion County Council (2014) 2014 storm damage and repair costs. http://www.ceredigion.gov.uk/ English/Your-Council/Pages/default.aspx. Accessed 22 June 2015

Coulthard T, Frostick L (2010) The Hull floods of 2007: implications for the governance and management of urban drainage systems. J Flood Risk Manag 3:223-231

Cowell P, Roy P, Jones R (1995) Simulation of large-scale coastal change using a morphological behaviour model. Mar Geol 126:45-61

Cutter SL, Boruff BJ, Shirley WL (2003) Social vulnerability to environmental hazards*. Soc Sci Q 84:242-261

Denner K, Phillips M, Jenkins R, Thomas T (2015) A coastal vulnerability and environmental risk assessment of Loughor Estuary, South Wales. Ocean Coast Manag 116:478-490

Dolan AH, Walker I (2006) Understanding vulnerability of coastal communities to climate change related risks. J Coastal Res 3:1316-1323

Gilbert J, Vellinga P (1990) Strategies for adaption to sea level rise. Report of the Coastal Zone Management Subgroup, Intergovernmental Panel on Climate Change World Meteorological Organization and UN Environmental Programme: the Netherlands

Gornitz V (1990) Vulnerability of the East Coast, USA to future sea level rise. J Coastal Res 9:201-237

Haigh R, Amaratunga D (2010) An integrative review of the built environment discipline's role in the development of society's resilience to disasters. Int J Disaster Resilience Built Environ 1:11-24

Harvey N, Woodroffe CD (2008) Australian approaches to coastal vulnerability assessment. Sustain Sci 3:67-87

Hinkel J, Klein RJ (2009) Integrating knowledge to assess coastal vulnerability to sea-level rise: the development of the DIVA tool. Global Environ Change 19:384-395

Hinkel J, Nicholls RJ, Vafeidis AT, Tol RS, Avagianou T (2010) Assessing risk of and adaptation to sealevel rise in the European Union: an application of DIVA. Mitig Adapt Strat Global Change 15:703-719

Jacob KH, Gornitz V, Rosenzweig C (2007) Vulnerability of the New York City metropolitan area to coastal hazards, including sea-level rise: inferences for urban coastal risk management and adaptation policies. Manag Coastal Vulnerability: Global Reg Local Elsevier Publ 141-158

Kantamaneni K, Phillips M (2016) Transformation of climate: will floods and coastal erosion crumble the UK economy? Int J Climate Ch Impacts Responses 8:45-59

Kantamaneni K, Phillips M, Jenkins R, Oakley J, Ibeabuchi KO (2015) Could the UK economy be impacted by an increase in Tornado occurrence?: a consequence of climate change in the 21 st century. Int $\mathrm{J}$ Climate Ch Impacts Responses 7:29-39

King D, MacGregor C (2000) Using social indicators to measure community vulnerability to natural hazards. Aust J Emerg Manag The 15:52 
Klein RJ, Nicholls RJ, Thomalla F (2003) Resilience to natural hazards: how useful is this concept? Global environmental change. Part B Environ Hazards 5:35-45

Kron W (2008) Coasts-The riskiest places on Earth. In: Proceedings of the 31 st international conference on coastal engineering (ICCE), World Scientific. Hamburg, Germany, pp 3-21

Kubal C, Haase D, Meyer V, Scheuer S (2009) Integrated urban flood risk assessment-adapting a multicriteria approach to a city. Nat Hazards Earth Syst Sci 9:1881-1895

Lewsey C, Cid G, Kruse E (2004) Assessing climate change impacts on coastal infrastructure in the Eastern Caribbean. Mar Policy 28:393-409

Maraun D, Osborn T, Gillett N (2008) United Kingdom daily precipitation intensity: improved early data, error estimates and an update from 2000 to 2006. Int Climatol 28:833-842

Marine Industries Leadership Council (2011) A strategy for growth for the UK marine industries. https:// www.gov.uk/government/uploads/system/uploads/attachment_data/file/31813/11-1310-strategy-forgrowth-uk-marine-industries.pdf. Accessed 12 Aug 2014

Mazumdar J, Paul SK (2016) Socioeconomic and infrastructural vulnerability indices for cyclones in the eastern coastal states of India. Nat Hazards 1-23

McLaughlin S, Cooper JAG (2010) A multi-scale coastal vulnerability index: a tool for coastal managers. Environ Hazards 9:233-248

Mcleod E, Poulter B, Hinkel J, Reyes E, Salm R (2010) Sea-level rise impact models and environmental conservation: a review of models and their applications. Ocean Coast Manag 53:507-517

Mocenni C, Casini M, Paoletti S, Giordani G, Viaroli P, Comenges J-MZ (2009) A decision support system for the management of the Sacca di Goro (Italy). In: Marcomini A, Suter GW, Critto A (eds) Decision support systems for risk-based management of contaminated sites. Springer, pp 1-24

Morris K (2012) Summer 2012 Part 1: The Great Flood of June 9th 2012: off the scale. http://www. geologywales.co.uk/storms/summer12a.htm. Accessed 15 Mar 2014

Nicholls RJ, Leatherman SP, Dennis K, Volonte C (1995) Impacts and responses to sea-level rise: qualitative and quantitative assessments. J Coast Res 1:26-43

Nicholls RJ, Wong PP, Burkett VR, Codignotto JO, Hay JE, McLean RF, Ragoonaden S, Woodroffe CD (2007) Coastal systems and low-lying areas. In: Parry ML, Canziani OF, Palutikof JP, van der Linden PJ, Hanson CE (eds) Climate change 2007: impacts, adaptation and vulnerability. Contribution of working group II to the fourth assessment report of the intergovernmental panel on climate change. Cambridge University Press, Cambridge, pp 315-356

Osborn TJ, Hulme M (2002) Evidence for trends in heavy rainfall events over the UK. Philos Trans R Soc Lond A Math Phys Eng Sci 360:1313-1325

Palmer B, et al (2011) Preliminary coastal vulnerability assessment for KwaZulu-Natal, South Africa. J Coastal Res 1390

Patt AG, Schroter D, Vega-Leinert ACDL et al (2009) Vulnerability research and assessment to support adaptation and mitigation: common themes from the diversity of approaches. In: Patt AG, Schroter D, Klein RJT, Vega-Leinert ACDL (eds) Assessing vulnerability to global environmental change: making research useful for adaptation, decision making and policy. Earthscan, London

Pendleton EA, Thieler ER, Williams SJ (2010) Importance of coastal change variables in determining vulnerability to sea-and lake-level change. J Coastal Res 176-183

Phillips MR, Jones AL (2006) Erosion and tourism infrastructure in the coastal zone: problems, consequences and management. Tour Manag 27:517-524

Ramieri E et al (2011) Methods for assessing coastal vulnerability to climate change European environment agency, European topic centre on climate change impacts, vulnerability and adaptation. pp 1-91. https://www.researchgate.net/profile/Andrea_Barbanti/publication/301296277_Methods_for_assessing _ coastal_vulnerability_to_climate_change/links/5710bd7008ae68dc790a2421.pdf. Accessed 15 June 2014

Ramsbottom D, Sayers P, Panzeri M (2012) Climate change risk assessment for the floods and coastal erosion sector Defra project code GA0204 report to Defra, London, UK

Reynard NS, Prudhomme C, Crooks SM (2001) The flood characteristics of large UK rivers: potential effects of changing climate and land use. Climat Change 48:343-359

Rygel L, O'sullivan D, Yarnal B (2006) A method for constructing a social vulnerability index: an application to hurricane storm surges in a developed country. Mitig Adapt Strat Global Change 11:741-764

Santoro F, Tonino M, Torresan S, Critto A, Marcomini A (2013) Involve to improve: a participatory approach for a decision support system for coastal climate change impacts assessment. The North Adriatic case. Ocean Coast Manag 78:101-111

Simone AM (2004) People as infrastructure: intersecting fragments in Johannesburg Public culture $16: 407-429$ 
Slingo J et al (2014) The recent storms and floods in the UK. UK Met. Office and Centre for Ecology and Hydrology. http://www.metoffice.gov.uk/research/news/2014/uk-storms-and-floods. Accessed 10 Mar 2015

Small C, Nicholls RJ (2003) A global analysis of human settlement in coastal zones. J Coast Res 584-599

Stevens AJ, Clarke D, Nicholls RJ (2014) Trends in reported flooding in the UK. Hydrol Sci J 61:1884-2013

Swarbrooke J (1999) Sustainable tourism management. CABI 1-61

Tallet P, Marouard G (2014) The harbor of Khufu on the Red Sea Coast at Wadi al-Jarf. Egypt Near East Archaeol (NEA) 77:4-14

Tang HS et al (2013) Vulnerability of population and transportation infrastructure at the east bank of Delaware Bay due to coastal flooding in sea-level rise conditions. Nat Hazards 69:141-163

Thatcher CA, Brock JC, Pendleton EA (2013) Economic vulnerability to sea-level rise along the northern US Gulf Coast. J Coast Res 63:234-243

The Times (2014) Flood warnings as more rain arrives. http://www.thetimes.co.uk/tto/weather/ article3965949.ece. Accessed 21 Mar 2015

Torresan S, Critto A, Dalla Valle M, Harvey N, Marcomini A (2008) Assessing coastal vulnerability to climate change: comparing segmentation at global and regional scales. Sustain Sci 3:45-65

Torresan S, Gallina V, Giannini V, Rizzi J, Zabeo A, Critto A, Marcomini A (2012) DESYCO: a decision support system to provide climate services for coastal stakeholders dealing with climate change impacts Sea 8:10

Vincent K (2004) Creating an index of social vulnerability to climate change for Africa Tyndall Center for Climate Change Research Working Paper 56:41

Weisse R, von Storch H, Niemeyer HD, Knaack H (2012) Changing North Sea storm surge climate: an increasing hazard. Ocean Coast Manag 68:58-68

Welsh Government (2014) Written statement-coastal flooding-January 2014. http://gov.wales/about/ cabinet/cabinetstatements/2014/coastalflooding/?lang=en. Accessed 12 Apr 2015

White I, Howe J (2002) Flooding and the role of planning in England and Wales: a critical review. J Environ Plan Manag 45:735-745

Wolters ML, Kuenzer C (2015) Vulnerability assessments of coastal river deltas-categorization and review. J Coast Conservat 19:345-368

Woodworth P, Flather R, Williams J, Wakelin S, Jevrejeva S (2007) The dependence of UK extreme sea levels and storm surges on the North Atlantic Oscillation. Cont Shelf Res 27:935-946

Wu T, Hou X, Chen Q (2016) Coastal economic vulnerability to sea level rise of Bohai Rim in China. Nat Hazards 80:1231-1241

Yin J, Yin Z, Wang J, Xu S (2012) National assessment of coastal vulnerability to sea-level rise for the Chinese coast. J Coast Conserv 16:123-133

Zanuttigh B et al (2014) The Seus decision support system for coastal risk management. Coast Eng $87: 218-239$

Zsamboky M, Fernández-Bilbao A, Smith D, Knight J, Allan J (2011) Impacts of climate change on disadvantaged UK coastal communities York. Joseph Rowntree Found, UK 
The International Journal of

Climate Change:

Impacts and Responses

Could the UK Economy Be Impacted by an Increase in Tornado Occurrence?

A Consequence of Climate Change in the 21 st Century 
THE INTERNATIONAL JOURNAL OF CLIMATE CHANGE: IMPACTS AND RESPONSES www.on-climate.com

First published in 2015 in Champaign, Illinois, USA

by Common Ground Publishing LLC

www.commongroundpublishing.com

\section{ISSN: 1835-7156}

(C) 2015 (individual papers), the author(s)

(C) 2015 (selection and editorial matter) Common Ground

All rights reserved. Apart from fair dealing for the purposes of study, research, criticism or review as permitted under the applicable copyright legislation, no part of this work may be reproduced by any process without written permission from the publisher. For permissions and other inquiries, please contact cg-support@commongroundpublishing.com.

The International Journal of Climate Change: Impacts and Responses is peer-reviewed, supported by rigorous processes of criterionreferenced article ranking and qualitative commentary, ensuring that only intellectual work of the greatest substance and highest significance is published. 


\title{
Could the UK Economy Be Impacted by an Increase in Tornado Occurrence?: A Consequence of Climate Change in the 21st Century
}

\author{
Komali Kantamaneni, University of Wales: Trinity Saint David, United Kingdom \\ Mike Phillips, University of Wales: Trinity Saint David, United Kingdom \\ Rhian Jenkins, University of Wales: Trinity Saint David, United Kingdom \\ Judith Oakley, University of Wales: Trinity Saint David, United Kingdom \\ Kelechi Obinna Ibeabuchi, University of Wales: Trinity Saint David, United Kingdom
}

\begin{abstract}
Violent tornadoes are uncommon in the United Kingdom when compared with the US tornado alleys where significant storms occur frequently. However, the UK does occasionally suffer moderate to strong tornadoes, as evidenced in Birmingham (2005), London (2006), and Essex (2013), all of which caused damage that cost approximately $£ 68.5$ million and a number of fatalities. These events inevitability lead to increased interest in UK tornado research in the 21st century. Consequently, this qualitative study primarily analyses the UK tornado damage costs in recent periods by incorporating an innovative methodology: the Three Path Analysis (3PA). Chronological records of destruction costs from tornadoes in the United Kingdom are taken and adjusted to current inflation and market rates. These amendments offer a more reliable comparative process, evaluating losses over time against a framework of significant social and economic change. Between 1050 and 2013, the most extensive and violent tornado (T8) occurred on 23rd October 1091 in London. However, the costliest tornado on record occurred in Birmingham on 28th July 2005. This tornado (T5) had a $£ 51$ million damage cost (adjusted to 2013 inflation rates). Rapid climate change scenarios suggest that weather patterns will favour tornado generation, and if strong to violent tornadoes travel through some of the world's trading centres such as London, Birmingham, or Manchester, damage costs would likely amount to more than £1billion, negatively affecting national GDP during the 21st century. Therefore, this research provides an important contribution to extremely sparse literature with respect to the economic impact of UK tornadoes.
\end{abstract}

Keywords: Tornadoes, UK Economy, Destruction Costs

\section{Introduction}

$\mathrm{T}$

The expected increase in the occurrence and intensity of severe climate events is probably the most important consequence of the continuous global temperature rise. Whilst temperature increases will possibly exceed the $2{ }^{\circ} \mathrm{C}$ threshold by Dangerous Anthropogenic Interferences (DAI) (Ramanathan and Feng 2008), certain failures to establish a rigorous framework for securing degrees of emissions to pre-industrial levels and consequences could cause $6^{\circ} \mathrm{C}$ temperature increases by the end of the $21^{\text {st }}$ century (Le Quéré et al. 2009).

It is debated in the academic press that climate change has caused the severe UK weather events in recent periods, such as storms (floods, hurricane winds and tornadoes), heat waves, prolonged winters, and water scarcity (Beniston et al. 2007). Among the different natural disasters, a series of flooding events caused the major damages during the past seven years. While, 2007 summer floods in England turned into a nationwide catastrophe and established as one of the costliest flooding event on the records, which left $£ 4$ billion worth damage costs (Chatterton et al. 2010). In addition, more than 2000 additional deaths were recorded in England and Wales during the August 2003 heat wave (Johnson et al. 2005). The Environment Agency (2012) revealed a temperature increase of approximately $1^{\circ} \mathrm{C}$ in England since 1970, with 2006 being declared as warmest year in the 348 year record. Meanwhile, in the last 30 years sea surface temperatures have increased by approximately $0.7^{\circ} \mathrm{C}$. Cumulatively, these weather patterns are stimulating very favourable conditions for tornado formation across the UK. However, research data on the nexus of UK tornadoes and climate change with an economical

The International Journal of Climate Change: Impacts and Responses Volume 7, Issue 2, 2015, www.on-climate.com, ISSN 1835-7156 (C) Common Ground, Komali Kantamaneni, Mike Phillips, Rhian Jenkins, Judith Oakley, Kelechi Obinna Ibeabuchi. All Rights Reserved

Permissions: cg-support@commongroundpublishing.com 
perspective is very limited. Therefore, this paper evaluates recent UK tornado occurrences and fiscal costs by applying novel methodology to fill the research gap.

\section{Theory}

Violent tornadoes are rare in the United Kingdom when compared with the US tornado alleys where violent storms occur frequently. However, the US leads the way, experiencing $75 \%$ of all tornadoes while Canada is in the second position with 5\% and followed by Bangladesh (NOAA 2013). While, the UK tornado frequency per unit area is higher than other countries and experiences more than 30 tornadoes on average per year (Bolton 2003). But, the mean intensity of tornado magnitude is very low compared with many other areas of the globe such as US (Clark 2009): among those, nearly two thirds of UK tornadoes occur in early periods of winter as well as in the autumn seasons (January to September) (Reynolds 1999). Furthermore, there are two methods existed to measure the tornado intensity across the globe; Enhanced Fajita scale (EF1 to EF5) and TORRO scale (T1 -T10- open ended) (Table 1). EF is using all over the world (Doswell et al. 2009) except Europe and TORRO scale is widely using in Europe (including UK) and this scale was originally developed by Terence Meaden, based on wind speed (TORRO 2014).

Table 1: TORRO Scale

\begin{tabular}{|c|c|c|}
\hline $\begin{array}{l}\text { Tornado } \\
\text { Intensity }\end{array}$ & $\begin{array}{l}\text { Description Of Tornado } \\
\text { \& Wind speeds }\end{array}$ & \multirow{5}{*}{$\begin{array}{l}\text { Weak Tornadoes } \\
\qquad \begin{aligned}> & \mathrm{T} 0 \\
> & \mathrm{T} 1 \\
> & \mathrm{T} 2 \\
> & \mathrm{T} 3\end{aligned} \\
\text { Strong Tornadoes }\end{array}$} \\
\hline T0 & $\begin{array}{c}\text { Light Tornado } \\
17-24 \mathrm{~m} \mathrm{~s}^{-}-(39-54 \mathrm{mi} \mathrm{h}-1)\end{array}$ & \\
\hline T1 & $\begin{array}{c}\text { Mild Tornado } \\
25-32 \mathrm{~m} \mathrm{~s}^{1}{ }^{--}(55-72 \mathrm{mi} \mathrm{h}-1) \\
\end{array}$ & \\
\hline T2 & $\begin{array}{c}\text { Moderate Tornado } \\
33-41 \mathrm{~m} \mathrm{~s}^{-}--(73-92 \mathrm{mi} \mathrm{h}-1)\end{array}$ & \\
\hline T3 & $\begin{array}{c}\text { Strong Tornado } \\
42-51 \mathrm{~m} \mathrm{~s}^{-1}--(93-114 \mathrm{mi} \mathrm{h}-1)\end{array}$ & \\
\hline T4 & $\begin{array}{c}\text { Severe Tornado } \\
52-61 \mathrm{~m} \mathrm{~s}^{-}{ }^{---}(115-136 \mathrm{mi} \mathrm{h}-1) \\
\end{array}$ & $\begin{array}{l}>\mathrm{T} 4 \\
>\mathrm{T} 5\end{array}$ \\
\hline T5 & $\begin{array}{c}\text { Intense Tornado } \\
62-72 \mathrm{~m} \mathrm{~s}^{1} \quad(137-160 \mathrm{mi} \mathrm{h}-1) \\
\end{array}$ & $\begin{array}{l}>\mathrm{T} 6 \\
>\mathrm{T} 7\end{array}$ \\
\hline T6 & $\begin{array}{l}\text { Moderately-Destructive Tornado } \\
73-83 \mathrm{~m} \mathrm{~s}^{-1}-(161-186 \mathrm{mi} \mathrm{h}-1)\end{array}$ & Violent Tornadoes \\
\hline $\mathbf{T 7}$ & $\begin{array}{c}\text { Strongly-Destructive Tornado } \\
84-95 \mathrm{~m} \mathrm{~s}^{-1}---(187-212 \mathrm{mi} \mathrm{h}-1)\end{array}$ & $\begin{array}{l}>\mathrm{T} 8 \\
>\quad \mathrm{T} 9\end{array}$ \\
\hline T8 & $\begin{array}{c}\text { Severely-Destructive Tornado } \\
96-107 \mathrm{~m} \mathrm{~s}-1--(213-240 \mathrm{mi} \mathrm{h}-1)\end{array}$ & $>\mathrm{T} 10$ \\
\hline T9 & $\begin{array}{l}\text { Extremely-Destructive Tornado } \\
108-120 \mathrm{~m} \mathrm{~s}^{-1}---\left(241-269 \mathrm{mi} \mathrm{h}^{-1}\right)\end{array}$ & TORRO Scale is Open \\
\hline T10 & $\begin{array}{c}\text { Super Tornado } \\
121-134 \mathrm{~m} \mathrm{~s}^{-}-\left(270-299 \mathrm{mi} \mathrm{h}^{-}{ }^{1}\right)\end{array}$ & \\
\hline
\end{tabular}




\section{Tornado Generation}

Due to the lack of much research data on tornado formation, it is still continuing an incomplete sub-sector in the field of tornadoes. However, NOAA (2013) suggested that tornadoes originate from super cell thunderstorms. An increase in ground temperatures causes moist air to warm and rise, and when this meets cool dry air, it immediately ruptures the above layer and creates favourable circumstances for the generation of super cell thunderstorm (BBC 2008). A strong vertical wind shear, which is present inside the thunderstorm, causes a horizontally spinning cylinder of air (Figure 1a). Rapid moment of air in both upward and downward directions push the rotating cylinder inside the super cell (Figure 1b). This tightens and becoming stretched, swirling faster and faster, creating a tornado (Figure 1c) (NOAA 2013). Due to climate change causing favourable weather conditions, there is likely to be an increase of UK tornadoes in near future (Holden and Wright 2004).

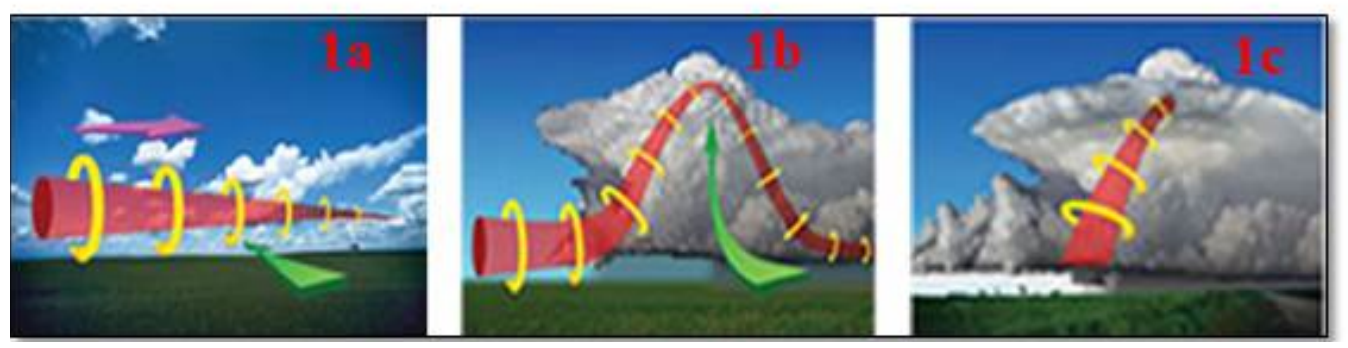

Figure 1(a, b \& c): Tornado Formation Source: NOAA 2013.

\section{Fiscal Consequences of Tornadoes}

The damage of tornado strikes mainly depends on gust speed. This force generally destroys the construction and properties within seconds. Normally, tornado events last for 1 minute to 10 hours based on category. However, destruction depends on intensity of tornado category rather than time (NOAA 2014). Violent tornadoes are usually long-lived and cause severe destruction to properties (residential and commercial) and infrastructure. It is well known that damage costs of tornadoes are huge in US, more than any other country, and this is generally the reason there are no data on global tornado damage costs, except from the US.

However, most UK tornadoes well documented (TORRO 2013; Holden and Wright 2004) (Table 2) in a systematic manner: based on the historical information, that first UK tornado (T8) was recorded on $23^{\text {rd }}$ October (1091) at London, longest tornado (T5-T6) on $21^{\text {st }}$ May (1950) at Buckinghamshire and widest tornado (T2) on 4th July (1946) at East Sussex. Historical evidence shows that only two violent (T8) tornadoes ravaged the UK since the 10th century, one in 1091 and another in 1810. However, 70\% of UK tornadoes are T2 tornadoes (TORRO 2013). 
Table 2: Tornado Occurrence across the UK (1995-1999)

\begin{tabular}{|l|c|}
\hline \multicolumn{1}{|c|}{ Region } & Tornado Occurrence in \% \\
\hline South-East England & 31 \\
\hline Central England & 29 \\
\hline North England & 16 \\
\hline South-West England & 15 \\
\hline Wales & 6 \\
\hline Scotland & 3 \\
\hline Northern Ireland & No historical information \\
\hline
\end{tabular}

Source: (Holden and Wright 2004)

Generally, tornado damage mainly comes from two vital segments: residential and commercial sectors. The devastation of residential and commercial properties owing to tornadoes is not a fresh problem. Every year thousands of homes are damaged permanently or partially across the globe by violent tornadoes. While, recent tornado events across the United Kingdom damaged residential properties (Figure 2), particularly terraced and individual houses with garages.

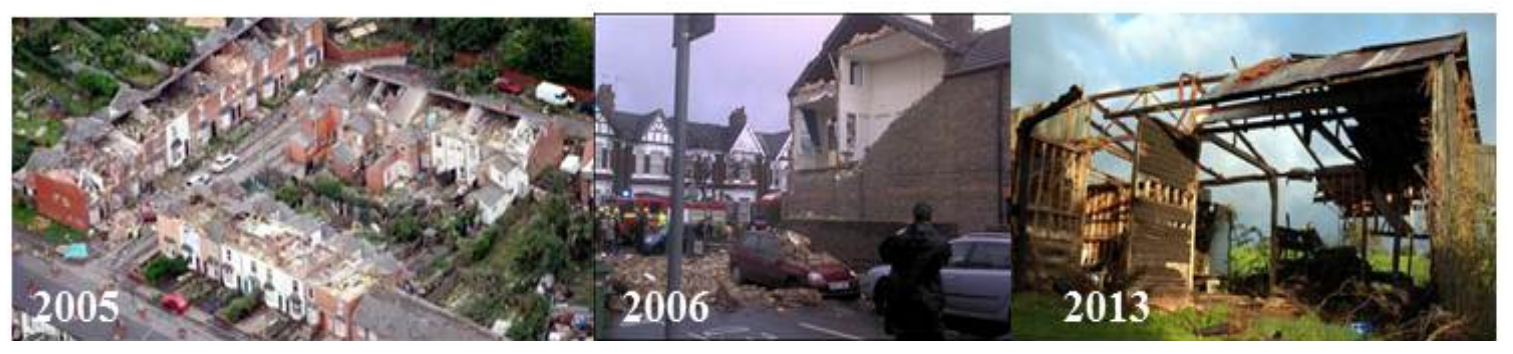

Figure 2: Birmingham (2005), London (2006) and Essex (2013) Tornadoes Source: Pearman 2005; BBC 2006; The Telegraph 2013

Consequently, cumulative damage from these incidents was estimated at $£ 55$ million (Table 3). However, destruction was not serious except Birmingham tornado, because of them being low category tornado strikes.

Table 3: Recent Tornadoes and Fiscal Costs in the United Kingdom

\begin{tabular}{|c|c|c|c|}
\hline Year & Place & $\begin{array}{c}\text { Damage Costs } \\
\text { in £Millions }\end{array}$ & Tornado Intensity \\
\hline $\mathbf{2 0 0 5}$ & Birmingham & 40 & T4-T5 \\
\hline $\mathbf{2 0 0 6}$ & London & 10 & T4 \\
\hline $\mathbf{2 0 1 3}$ & Essex & 5 & No official information \\
\hline \multicolumn{4}{|c|}{ Cumulative Damage Costs } \\
\hline
\end{tabular}

Source: ABI 2013; Spilsbury and Spilsbury 2008, 28.

Data and statistical information on tornado economics (UK) is very limited and no research papers produced in last five years particularly with in economic perspective. Consequently, there is no opportunity to examine the accuracy of long-term tornado fiscal destruction data. Accordingly, this study uses that limited data obtained from the TORRO centre, ABI (Association of British Insurers) and academic literature, for analysis of recent UK tornado damage costs. On the other hand, this study also qualitatively assessed the Birmingham, London 
and Essex events to compare fiscal information with existed (official) statistics. Then, estimates and results compared with previous estimations \& ABI (Association of British Insurers) data. Differences are identified and new assessments of tornado damage costs are derived.

\section{Methodology}

Collection of statistics for tornado events is very difficult and it is a "method of madness"; however, it is strictly associated with scientific passion (Lott and Ross 2006). Meanwhile, there is no specific single government organisation to evaluate fiscal tornado data in the United Kingdom even in technical era. In addition, Met office has not been forecasting tornado events due to the lack of advanced Doppler radar technology. Because of these objects, there is a lot of ambiguity on damage costs as well as number of fatalities. However, UK-Tornado statistics are usually recorded by independent organisations, based on the path of event, place, intensity and date. It is very hard to offer factual damage costs for these events with in short period, and some times it takes from months to years (in worst case scenarios).

Meanwhile, there are no rigorous and precise methodologies for estimating tornado impacts in the United Kingdom particularly for monetary evaluation. Accordingly, a coherent and concise framework has been developed to assess tornado damage costs i.e. 3 Path analysis (Figure 3), based on three important phases: surveying (1), fiscal (financial) estimation (2) and mapping (3), to achieve research aims.

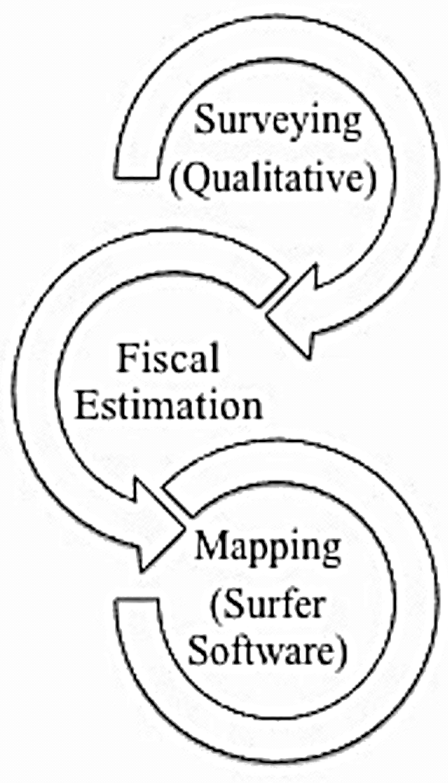

Figure 3: Three-Path Analysis

\section{Surveying - Phase 1}

A qualitative survey was undertaken in various parts of the UK in a 3 vs. 3 method, i.e. survey restricted to only 3 questions (Table -4 ) with 3 possible answer choices. This questionnaire was distributed to participants in London, Birmingham, Essex, Manchester and Cardiff. Fifty-three respondents formed the pilot study group to assess both methodology and results. These fiftythree questionnaires were analysed to obtain tornado damage costs. 
Table 4: Qualitative Survey Questions with Three Answer Choices

\begin{tabular}{|c|c|c|}
\hline Number & Questions & $\begin{array}{c}\text { Possible } \\
\text { Answers Choices }\end{array}$ \\
\hline 1. & $\begin{array}{l}\text { Are you getting sufficient tornado information and } \\
\text { warnings from national and local governments? }\end{array}$ & \\
\hline 2. & $\begin{array}{l}\text { Do you think that climate change is the main } \\
\text { reason for the formation of tornadoes in the UK? }\end{array}$ & 2. No ( Disagree) \\
\hline 3. & $\begin{array}{l}\text { Do you think there is adequate support from } \\
\text { national and local governments to repair tornado } \\
\text { damage? }\end{array}$ & 3. Not Known \\
\hline
\end{tabular}

\section{Fiscal Damage Cost Estimation - Phase 2}

New estimates are determined for previous and future UK tornado damage costs; meanwhile, damage costs adjusted to 2013 UK inflation rates except Essex (2013) tornado.

\section{Mapping - Phase 3}

Surfer software $\left(9^{\text {th }}\right.$ version$)$ was used to map probable paths of tornado events in the United Kingdom, particularly in England because of relatively high number of past tornado strikes than Wales, Scotland and Northern Ireland.

\section{Results and Discussion}

\section{Surveying - Phase 1}

Qualitative survey results reflected the views of fifty-three responses of selected communities, who were participated from London (20), Birmingham (10), Manchester (15), Swansea (4) and Cardiff (4). These results were analysed (Figures 4, 5 and 6) and used as supporting data to evaluate the UK'S tornado damage costs.

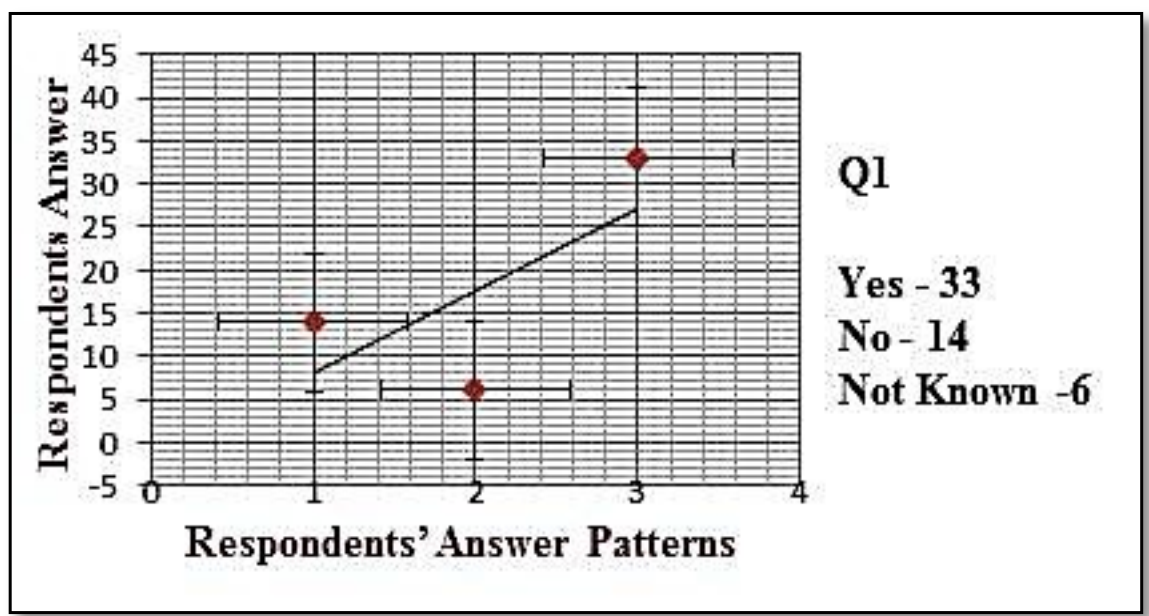

Figure 4: Qualitative Survey (Question - 1), Respondent Answer Patterns 


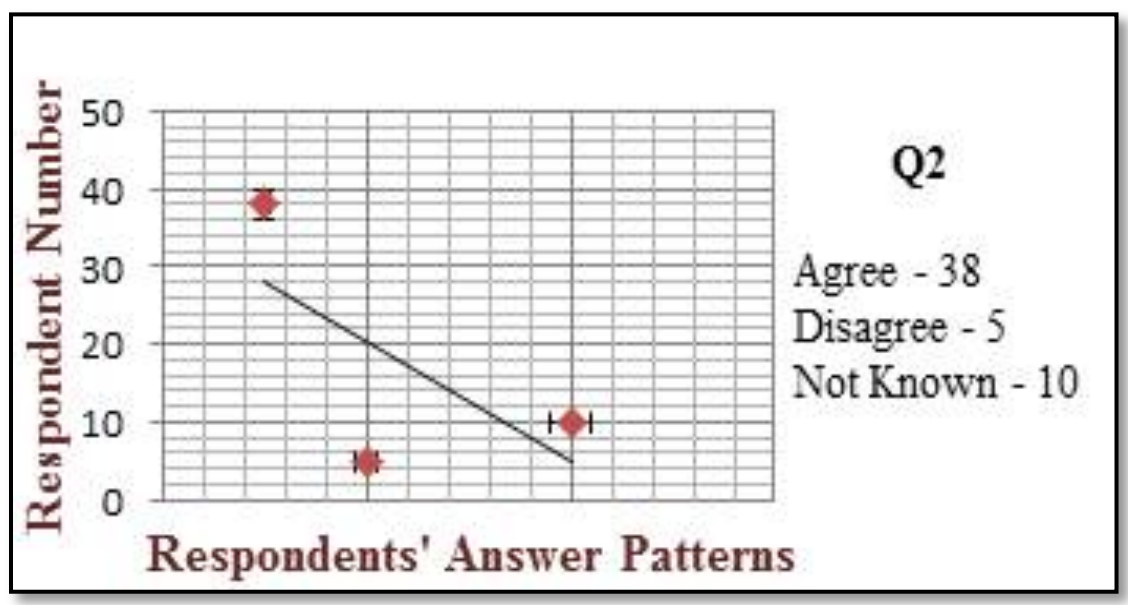

Figure 5: Qualitative survey (Question -2) Respondent answer Patterns

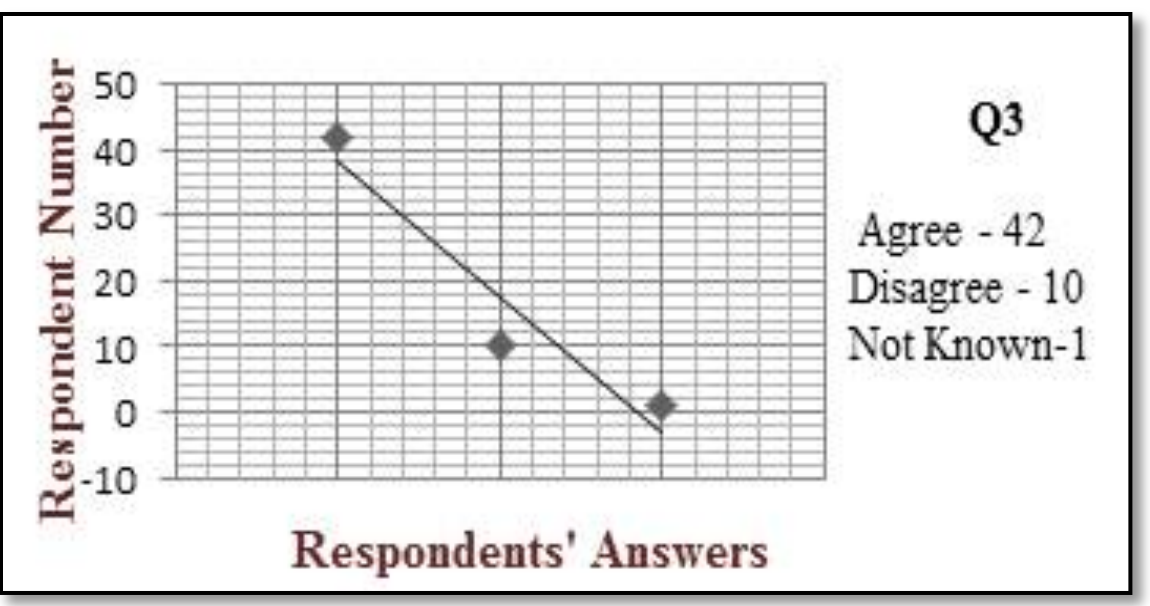

Figure 6: Qualitative survey (Question -3), Respondent answer Patterns

\section{Fiscal Estimation - Phase 2}

UK tornado damage costs (Table 5), are based on the analysis of qualitative-survey results, ABI (official) estimates and academic literature. Meanwhile, Birmingham (2005) tornado damaged circa 5000 houses, 600 businesses, and uprooted nearly 1000 trees. Cumulatively, these incidents caused $£ 51$ million of damage. On the other hand, the London tornado in 2006 , caused $£ 12.5$ million damage by destroying 100 houses and 180 businesses. Moreover, the Essex tornado in 2013 damaged approximately 40 houses and 60 businesses and caused $£ 5+$ million in damages. However, this study did not offer the economical consequences of fatalities as well as environmental degradation caused by tornadoes. 
Table 5: Recent Tornadoes and Novel Fiscal Costs in the United Kingdom

\begin{tabular}{|l|l|c|c|}
\hline \multicolumn{1}{|c|}{ Year } & \multicolumn{1}{|c|}{ Region } & $\begin{array}{c}\text { Damage Costs } \\
\text { in } \mathbf{\text { MMillions }}\end{array}$ & Tornado Intensity \\
\hline $\mathbf{2 0 0 5}$ & Birmingham & 51 & $\mathrm{~T} 4-\mathrm{T} 5$ \\
\hline $\mathbf{2 0 0 7}$ & London & 12.5 & $\mathrm{~T} 4$ \\
\hline $\mathbf{2 0 1 3}$ & Essex & $5+$ & $\mathrm{T} 2-\mathrm{T} 3$ \\
\hline \multicolumn{4}{|c|}{ Cumulative Damage Costs ---- >\$68.5 } \\
\hline
\end{tabular}

Table 5 results revealed that, recent UK tornado events cost $£ 68.5$ million. Furthermore, this work also offers projected damage costs for future tornadoes and accordingly, a new tornado travel path was constructed. If tornadoes travel (T6 - T8) via international trade hubs, i.e. London, Birmingham and Manchester (Table 6), destruction costs will be $>£ 1$ Billion by 2080 . During this fiscal assessment, some vital factors such as changing climate conditions, population growth and commercialization were considered.

Table 6: Novel Fiscal Costs for Future Tornadoes in the United Kingdom

\begin{tabular}{|l|c|c|}
\hline \multicolumn{1}{|c|}{ Place } & $\begin{array}{c}\text { Damage Costs } \\
\text { in } \mathbf{f} \text { Millions }\end{array}$ & Tornado Intensity \\
\hline Birmingham & 300 & $\mathrm{~T} 4-\mathrm{T} 8$ \\
\hline London & 650 & $\mathrm{~T} 4-\mathrm{T} 8$ \\
\hline Manchester & 150 & $\mathrm{~T} 4-\mathrm{T} 8$ \\
\hline \multicolumn{2}{|c|}{ Future Tornado Damage Costs -- >£1 Billion } \\
\hline
\end{tabular}

\section{Mapping - Phase 3}

By the using surfer software $\left(9^{\text {th }}\right.$ version), a clear path was drawn for future tornadoes. This track illustrated prospective tornado damage costs in London ( $£ 650$ million), Birmingham ( $£ 300$ million) and Manchester (150 million), which were assessed in separate sub-maps (Figure 7). 


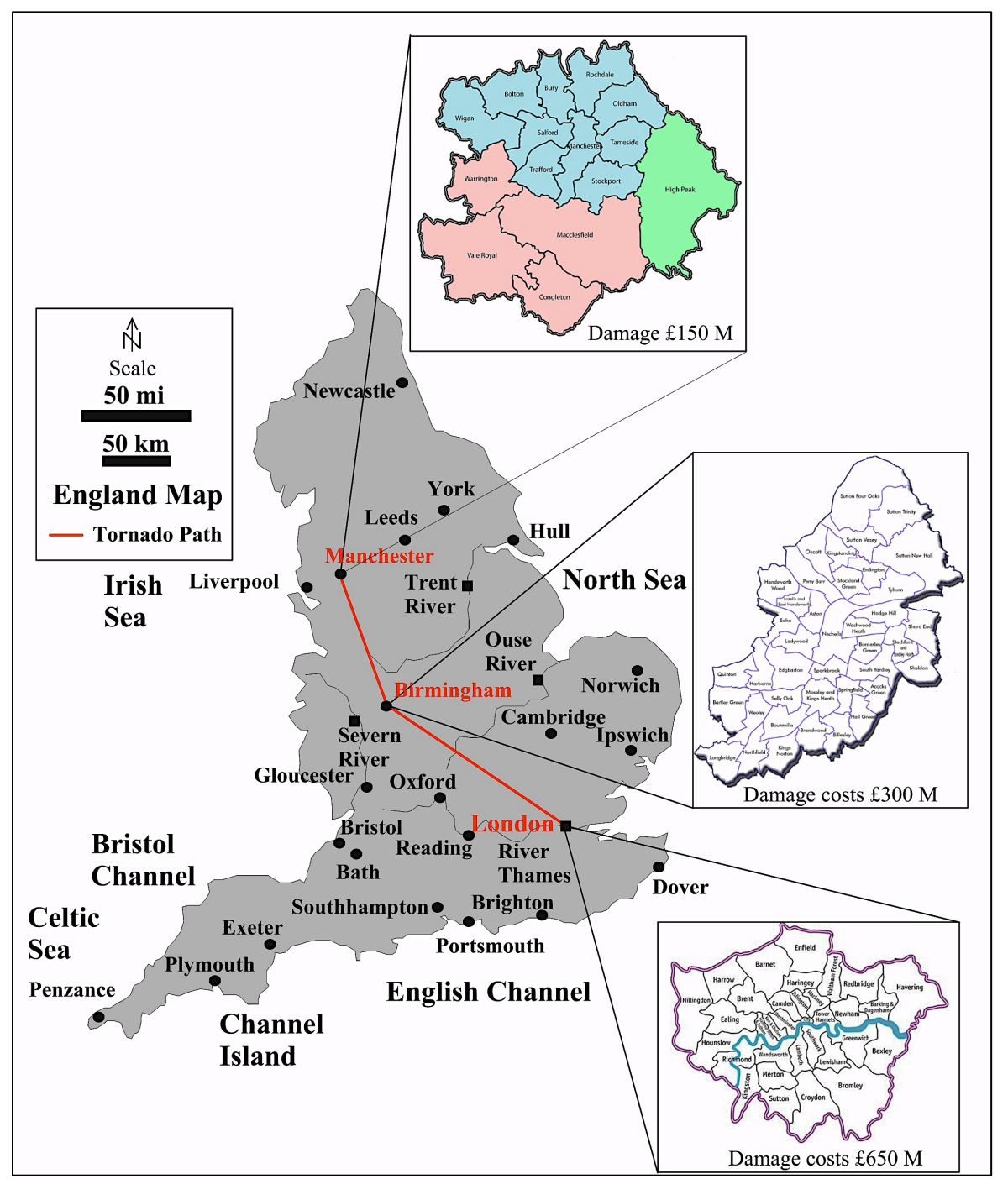

Figure 7: Tornado Travelling Path via London, Birmingham, Manchester

Source: Redeveloped (maps only) from (Maps of World 2013; London Council 2012; Birmingham City Council 2013; Highways Forecasting and Analytical Services 2012)

\section{Conclusion}

This study provided a comprehensive fiscal scaffold of recent tornado disasters in the United Kingdom along with innovative methodology (3 path analysis) for collecting and analysing statistical data for these events. This novel methodology was constructed in three vital phases: qualitative surveying, fiscal evaluation, and mapping. Results suggested that previous estimates are not significant and precise, while weather centres (Met Office) do not provide in-depth and accurate tornado information to the communities (path and future cost estimates). This research established a systematic framework to address these deficiencies and achieved a more realistic estimation of tornado damage costs. Recent tornado event (2005, 2006, and 2013) damages exceed $£ 68.5$ million and it will be $>£ 1$ billion, if future tornadoes travel through international trade centres like London, Birmingham, and Manchester in the future (by 2080). These costs would significantly affect national and local economics, and therefore, the United Kingdom must adopt rigorous climate change adaptations to protect future generations from human induced natural disasters such as tornadoes. 


\section{Acknowledgements}

The authors would like to acknowledge the TORRO Centre staff for allowing access to updated data on recent tornado events. Authors are also grateful to respondents for their valuable contribution to tornado damage costs during qualitative surveys.

\section{REFERENCES}

ABI. 2013. "Storm Damage." Accessed March 3, 2014. www.abi.org.uk/Searchresults?q=storm+damage.

BBC.2008. "Animated guide: Tornadoes.” Accessed November 5, 2013. news.bbc.co.uk/1/hi/sci/ tech/7533941.stm

BBC. 2006. "In pictures: Tornado hits London.” Accessed February 13, 2013. news.bbc.co.uk/ 1/hi/in_pictures/6217898.stm

Beniston, Martin, David B Stephenson, Ole B Christensen, Christopher AT Ferro, Christoph Frei, Stéphane Goyette, Kirsten Halsnaes, Tom Holt, Kirsti Jylhä, and Brigitte Koffi. 2007. "Future extreme events in European climate: an exploration of regional climate model projections." Climatic Change 81 (1): 71-95.

Birmingham City Council. 2013. Birmingham Districts. Accessed Decemebr 13, 2013. www.birmingham.gov.uk/districts

Bolton, Nigel, Derek M Elsom, and G Terence Meaden. 2003. "Forecasting tornadoes in the United Kingdom." Atmospheric research 67: 53-72.

Chatterton, John, Christophe Viviattene, Joe Morris, Edmund C Penning-Rowsell, and Sue M Tapsell. 2010. "The costs of the summer 2007 floods in England."

Clark, Matthew R. 2009. "The southern England tornadoes of 30 December 2006: Case study of a tornadic storm in a low CAPE, high shear environment." Atmospheric Research 93 (1): 50-65.

Doswell III, Charles A, Harold E Brooks, and Nikolai Dotzek. 2009. "On the implementation of the enhanced Fujita scale in the USA." Atmospheric Research 93 (1): 554-63

Environment Agency. 2012. UK Climate Change Risk Assessment: Government Report. Accessed March 5, 2013. www.gov.uk/government/organisations/environment-agency

Highways Forecasting and Analytical Services. 2012. The authorities of Greater Manchester. Accessed September 12, 2013. www.gmtu.gov.uk/about.html

Holden, J, and A Wright. 2004. "UK tornado climatology and the development of simple prediction tools." Quarterly Journal of the Royal Meteorological Society 130 (598): 1009-21.

Johnson, Howard, RS Kovats, G McGregor, J Stedman, M Gibbs, and H Walton. 2005. "The impact of the 2003 heat wave on daily mortality in England and Wales and the use of rapid weekly mortality estimates." Euro Surveill 10 (7): 168-71.

Le Quéré, Corinne, Michael R Raupach, Josep G Canadell, and Gregg Marland. 2009. "Trends in the sources and sinks of carbon dioxide." Nature Geoscience 2 (12): 831-6.

London Council. 2012. London boroughs map and profiles. Accessed December 13. http://www.londoncouncils.gov.uk/londonfacts/londonlocalgovernment/ londonmapandlinks.

Lott, Neal, and Tom Ross. 2006. "1.2 Tracking and Evaluating US Billion Dollar Weather Disasters, 1980-2005."

Maps of World. 2013. England Map. Accessed August 9, 2013. www.mapsofworld.com/england/ 
NOAA. 2013. Education Resources. Accessed December 18, 2013. www.education.noaa.gov/ Weather_and_Atmosphere/Tornadoes.html

NOAA. 2013. U.S. Tornado Climatology. Accessed October 12, 2013. www.ncdc.noaa.gov/ climate-information/extreme-events/us-tornado- climatology

NOAA. 2014. The Online Tornado FAQ. Accessed February 18, 2014. www.spc.noaa.gov/ faq/tornado.

Pearman, Adrian. 2005. Tornado wreaks havoc in suburbs of Birmingham. Accessed October 14, 2012. www.theguardian.com/environment/2005/jul/29/weather.climatechange.

Ramanathan, Veerabhadran, and Yan Feng. 2008. "On avoiding dangerous anthropogenic interference with the climate system: Formidable challenges ahead." Proceedings of the National Academy of Sciences 105 (38): 14245-50.

Reynolds, DJ. 1999. "A revised tornado climatology of the UK, 1960-1989." Journal of Meteorology-Trowbridge then Bradford on Avon-24: 290-321.

Spilsbury, Louise, and Richard Spilsbury. 2008. Hurricanes and Tornadoes in Action. New York: The Rosen Publishing Group.

The Telegraph. 2013. Tornado hits Britain. Accessed December 2, 2013. http://www.telegraph.co.uk/news/picturegalleries/9229126/Tornado-hits- Britain.html

TORRO. 2013. British \& European Tornado Extremes. Accessed November 12, 2013. www.torro.org.uk/site/whirlwind_info.php

TORRO. 2014. The International Tornado Intensity Scale. Accessed March 2, 2014. www.torro.org.uk/site/tscale.php

\section{ABOUT THE AUTHORS}

Komali Kantamaneni: Research Student, Faculty of Applied Design and Engineering, School of Build and Natural Environment, University of Wales: Trinity Saint David, Swansea, Glamorgan, UK.

Prof. Mike Phillips: Professor and Pro-Vice Chancellor, University of Wales: Trinity Saint David, Swansea, Glamorgan, UK.

Dr. Rhian Jenkins: Lecturer, School of the Built and Natural Environment, University of Wales: Trinity Saint David, Swansea, Glamorgan, UK.

Judith Oakley: Research Associate, School of the Built and Natural Environment, University of Wales: Trinity Saint David, Swansea, Glamorgan, UK.

Kelechi Obinna Ibeabuchi: PhD Research Student, University of Wales: Trinity Saint David, Swansea, Glamorgan, UK. 
The International Journal of Climate Change:

Impacts and Responses seeks to create an

interdisciplinary forum for discussion of evidence of climate change, its causes, its ecosystemic impacts, and its human impacts. The journal also explores technological, policy, strategic, and social responses to climate change.

The International Journal of Climate Change: Impacts and Responses is a peer-reviewed scholarly journal.

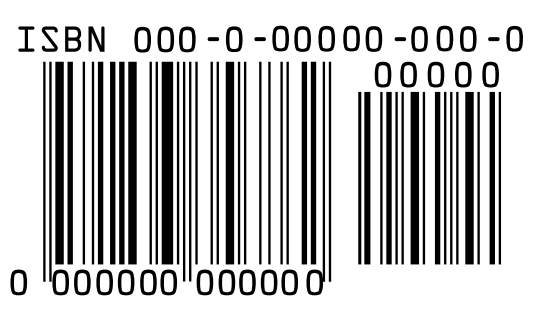


The International Journal of

Climate Change:

Impacts and Responses

Transformation of Climate

Will Floods and Coastal Erosion Crumble the UK

Economy?

KOMALI KANTAMANENI AND MIKE PHILLIPS

(1) $C O M M O N$

J $G R O U N D$ 


\section{The International Journal of Climate Change: Impacts and Responses}

www.on-climate.com

ISSN 1835-7156 (Print)

doi:10.18848/1835-7156/CGP (Journal)

First published in 2016 in Champaign, Illinois, USA by Common Ground Publishing

www.commongroundpublishing.com

The International Journal of Climate Change: Impacts and Responses is a peer-reviewed, scholarly journal.

\section{Editor}

Candice Howarth, Anglia Ruskin University, UK

\section{Community Editor}

Amanda Sabo, Common Ground Publishing

\section{Advisory Board}

Alison Anderson, University of Plymouth, UK Tapan Chakrabarti, National Environmental Engineering Research Institute (NEERI), India

Gowtam Raj Chintaram, ANPRAS/Earth-Mauritius, Mauritius

Candice Howarth, Anglia Ruskin University, UK Thomas Krafft, Geomed Research Corporation, Germany Mordechai Shechter, University of Haifa, Israel Gordon Wilson, The Open University, UK Zhihua Zhang, Beijing Normal University, China

\section{Associate Editors}

Articles published in The International Journal of Climate Change: Impacts and Responses are peer reviewed by scholars who are active participants of the Climate Change: Impacts \& Responses Knowledge Community or a thematically related Knowledge Community. This engagement with the Knowledge Community, as well as Common Ground Publishing's criterion-referenced evaluation system, distinguishes our peer-review process. In recognition of the valuable feedback and publication recommendations that they provide, reviewers are acknowledged as Associate Editors in the volume that includes the article(s) they have reviewed. The Associate Editors listed in the following link have contributed significantly to the overall editorial quality and content of the journal: www.on-climate.com/journal/editors.

\section{Article Submission}

The International Journal of Climate Change: Impacts and Responses publishes quarterly (March, June, September, December). Please visit www.on-climate.com/journal/call-for-articles to find out more about the submission process.

\section{Abstracting and Indexing}

Please visit www.on-climate.com/journal to view a full list of databases in which this journal is indexed.

\section{Knowledge Community Membership}

Authors in The International Journal of Climate Change: Impacts and Responses are members of the Climate Change: Impacts \& Responses Knowledge Community or a thematically related Knowledge Community. Members receive access to journal content. Please visit www.on-climate.com/about/become-amember to find out more about community membership.

\section{Our Model}

We are working to change the way in which knowledge is valued. Rather than focusing solely on acceptance rates and citation counts-standards that are seriously fraught-we measure quality by a criterion-based peerreview process, assessing the intellectual excellence and accessibility of the work against clearly articulated disciplinary standards. Please visit

www.on-climate.com/journal/model to find out more.

\section{Subscriptions}

The International Journal of Climate Change: Impacts and Responses is available in electronic and print formats. Subscribe to gain access to content from the current year and the entire backlist. Contact us at cg-support@commongroundpublishing.com.

\section{Ordering}

Single articles and issues are available from the journal bookstore at www.ijc.cgpublisher.com.

\section{Hybrid Open Access}

By publishing in The International Journal of Climate Change: Impacts and Responses, authors have made their articles available to a large number of scholars who have individual subscriptions or whose institutions subscribe. The International Journal of Climate Change: Impacts and Responses is Hybrid Open Access, meaning authors can also choose to make their articles open access. This allows their work to reach an even wider audience, broadening the dissemination of their research and potentially increasing the incidence of other scholars citing their work. Please visit

www.on-climate.com/journal/hybrid-open-access to find out more about our Open Access option.

\section{Disclaimer}

The authors, editors, and publisher will not accept any legal responsibility for any errors or omissions that may have been made in this publication. The publisher makes no warranty, express or implied, with respect to the material contained herein.

\section{Copyright and Copying}

(C) 2016 (individual papers), the author(s) (C) 2016 (selection and editorial matter) Common Ground Publishing

All rights reserved. Apart from fair dealing for the purposes of study, research, criticism, or review, as permitted under the applicable copyright legislation, no part of this work may be reproduced by any process without written permission from the publisher. For permissions and other inquiries, please contact cg-support@commongroundpublishing.com.

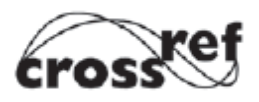

Common Ground Publishing is a member of crossRef. 


\title{
Transformation of Climate: Will Floods and Coastal Erosion Crumble the UK Economy?
}

\author{
Komali Kantamaneni, University of Wales Trinity Saint David, UK \\ Mike Phillips, University of Wales Trinity Saint David, UK
}

\begin{abstract}
Recent flooding events in the United Kingdom have raised concerns that climate change is increasing flood frequency and intensity. England and Wales were significantly affected by these extreme weather incidents. Rapid coastal erosion is becoming a major concern, particularly in England (Hallsands, Dawlish, and Lynmouth), South Wales (Llanelli), and Scotland (Balivanich) with circa $3008 \mathrm{~km}$ of coastline being lost to the sea. These situations result in significant losses of infrastructure mainly in coastal zones across the UK. Consequently, this qualitative study primarily analyses the UK flood damage costs for commercial and residential properties along with coastal erosion costs by using a methodology: 2PA (Two Path Analysis). Applications of the methodology provide more factual damage costs, which highlight potential climate change impacts on present and future generations. Primary results revealed that the UK flooding costs for properties and coastal erosion costs are to be $£ 1.3$ billion per year with more than 6 million properties at flood risk. These costs represent only $0.08 \%$ of national GDP, showing it to be small on a national scale. Predictions denote that socio-economic costs will negatively affect national GDP if flood resilience is not improved.
\end{abstract}

Keywords: Two Path Analysis, Climate Change, Flood Cost Assessment Tool, Coastal Erosion, National Economy

\section{Introduction}

$\mathrm{R}$ esearch on the nexus of climate change and storm intensity has widely been debated in the academic press, particularly regarding the rapid rise in the frequency and intensity of storms owing to either normal climatic variability or anthropogenic global warming (Knutson et al. 2010; Houghton et al. 2001; Easterling et al. 2000; Walsh et al. 2007; Doney et al. 2012). Already significant emissions commit the earth to certain levels of future warming and will possibly exceed the $20^{\circ} \mathrm{C}$ verge by dangerous anthropogenic interference (Ramanathan and Feng 2008). Greenhouse gases, in particular $\mathrm{CO} 2$ emissions, are the primary reason for rapid and recent climate change scenarios (Thomas et al. 2004; Meinshausen et al. 2009; Solomon et al. 2009). Approximately $40 \%$ of CO2 emissions, which are produced mainly from burning fossil fuels, increased for the period of 1990 to 2008. Since last century, the earth warmed by about $0.7^{\circ} \mathrm{C}$ and average UK temperature increased by $1^{\circ} \mathrm{C}$ from mid of the $1970 \mathrm{~s}$ (Hulme et al. 2002). Due to these regional and global climatic changes, the UK is facing significant risks like sea level rise, severe storms, storm surge, and rapid coastal erosion (Bray, Hooke, and Carter 1997; Pye and Blott 2006; de Alegria-Arzaburu and Masselink 2010). Coastal communities are especially vulnerable to these problems and, unfortunately, these regions are hugely populated (Nicholls and Cazenave 2010; Boruff, Emrich, and Cutter 2005; McGranahan, Balk, and Anderson 2007). Consequently, this qualitative study evaluates the UK floods and coastal erosion costs by using a methodology, i.e., Two Path Analysis (2PA), while also scrutinising the impacts of damage costs on the national economy.

\section{Description of Study Area}

The UK is an island nation located in Western Europe, and the mainland lie between latitudes $49^{\circ} \mathrm{N}$ and $59^{\circ} \mathrm{N}$ and longitudes $8^{\circ} \mathrm{W}$ to $2^{\circ} \mathrm{E}$. It is positioned between the North Atlantic Ocean and the North Sea. It is also made up of four administrative regions: England, Wales, Scotland, and Northern Ireland (Figure 1) (European Union 2013). The total area is $243,610 \mathrm{~km}^{2}$ (CIA 2013) and coastline is $17,381 \mathrm{~km}$ (Ordnance Survey 2013) with approximately $60 \%$ of this

\footnotetext{
The International Journal of Climate Change: Impacts and Responses Volume 8, Issue 3, 2016, www.on-climate.com (C) Common Ground Publishing, Komali Kantamaneni and Mike Phillips All Rights Reserved, Permissions: cg-support@commongroundpublishing.com ISSN: $1835-7156$ (Print)
} 
coastline is in Scotland and the offshore islands (UK Coast Guide 2013). The population is 62.74 million (World Bank 2014) of which circa 30m are living in coastal areas (Zsamboky et al. 2011). The UK is the world's sixth largest economy with a $£ 1.6$ trillion GDP (World Bank 2014), and most of the GDP is generating through tourism (Phillips 2008). However, the UK is increasingly vulnerable to impacts of coastal erosion, flash and surface flooding, storm surges, and extremes in weather compared to recent memory. Nevertheless, the main climate change consequences are flooding and coastal erosion.

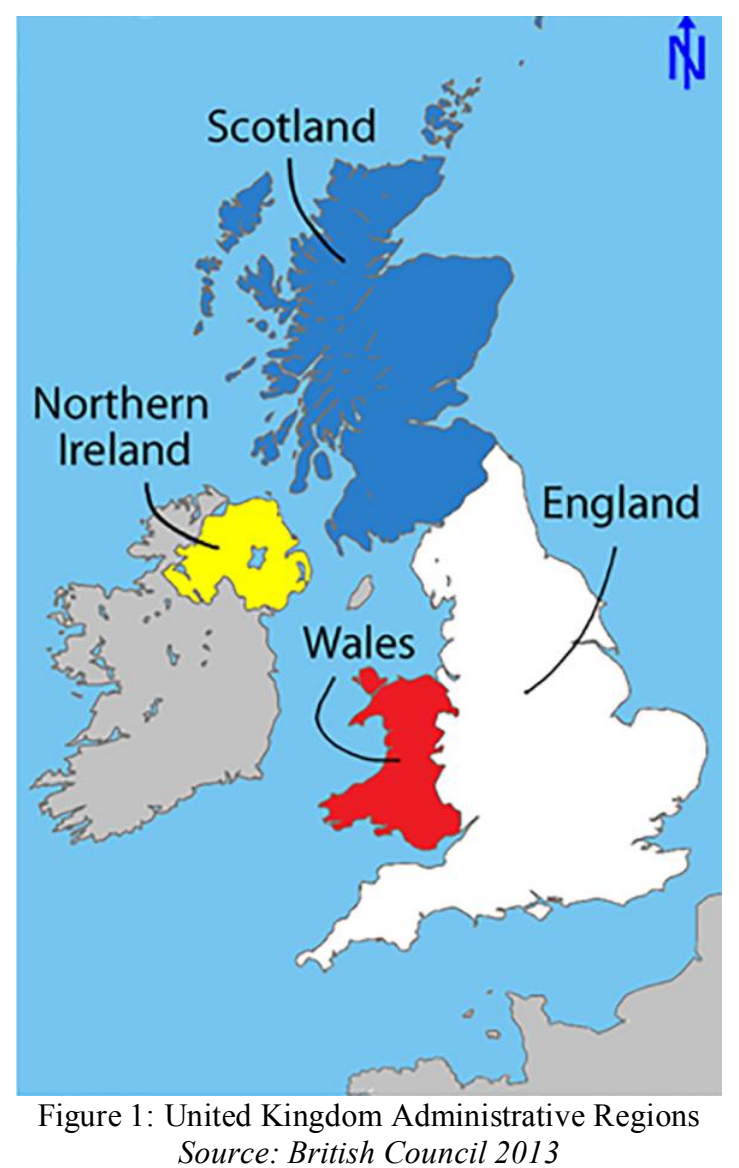

\section{Physical Geography}

\section{Flooding}

Prolonged time series data plays a vital role in understanding flood intensity in multiple dimensions (Kochel and Baker 1982; Ely et al. 1992). However, the majority of universal flood records are no longer than fifty years (Benito et al. 2004; Macklin Rumsby 2007). Meanwhile, there is no accurate statistical evidence in the UK regarding long-term flood damage costs as well as trends, but from 2007 onwards, the Environment Agency is providing detailed economic data in an agreed format. In 1952, a massive flood struck the coastal town of Lynmouth (Devon, England) and wrecked one hundred buildings and twenty-eight bridges (Figure 2a) (Dobbie and Wolf 1953; Marshall 1952). In 1953, North Sea floods struck England and Scotland and caused massive damage to $1,600 \mathrm{~km}$ of coastline (Pollard 1978). Moreover, in the autumn of 2000, major floods affected England and Wales and caused $£ 1$ billion of damage to $>10,000$ houses (Alexander and Jones 2000). Summer floods in 2007 caused $£ 4$ billion worth of damage, of which insured losses were approximately $£ 3$ billion (EA 2010) (Figure 2b). In 2012, 2013, and 2014, various flood events ravaged the United Kingdom with heavy rain and hurricane winds (Figure 2c) 


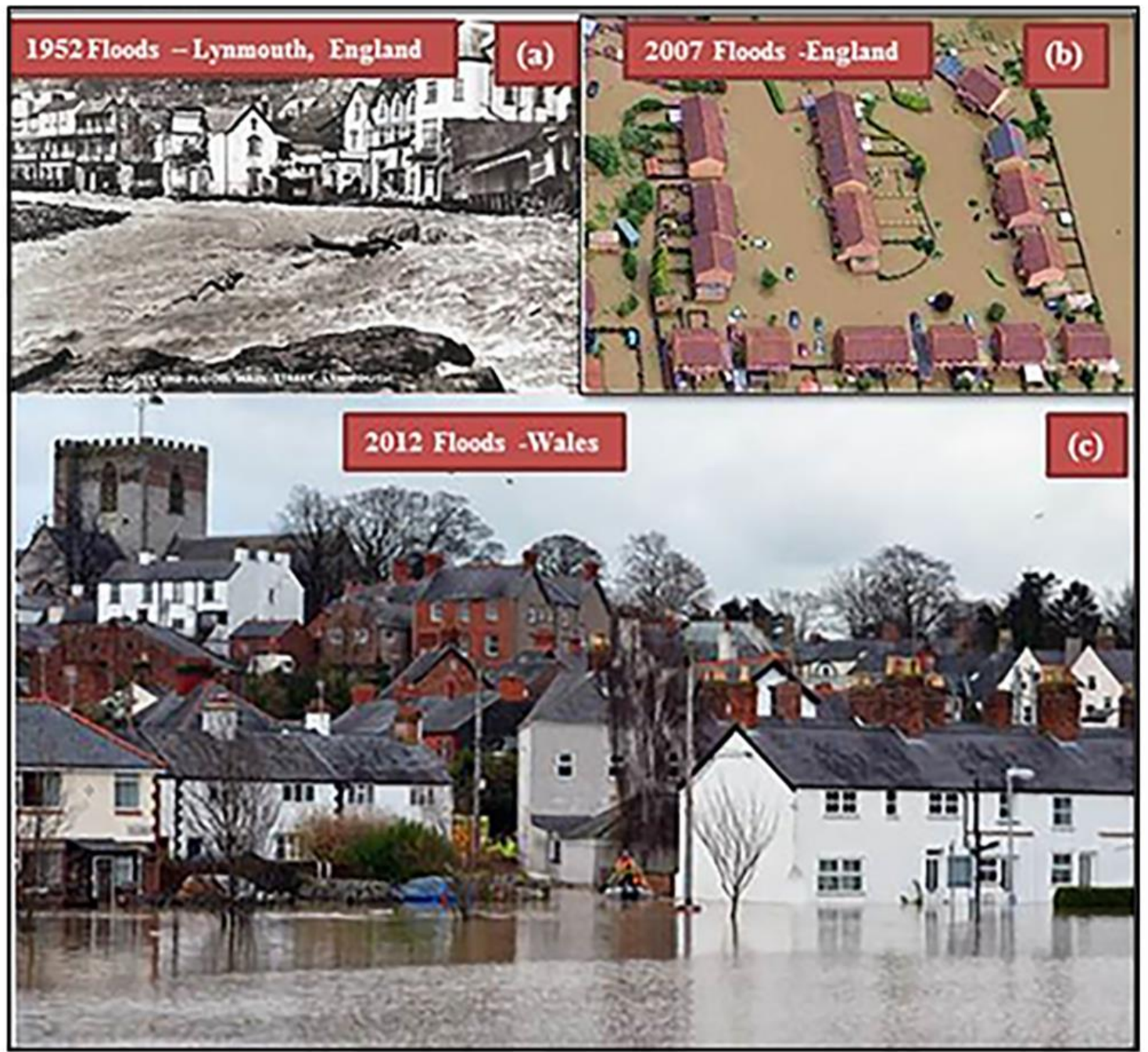

Figure 2(a, b, and c): Various Flood Events in the United Kingdom Source: (a) Joint 2008; (b) Reuters 2007; (c) Carrington 2012

\section{Coastal Erosion}

More than half of the global population, i.e., 3.2 billion people, lives within $200 \mathrm{~km}$ of the coastline (Hinrichsen 1999) and one-third of the UK population lives within $10 \mathrm{~km}$ of coastline (EA 1999). Coastlines are always subject to change through erosion and other natural processes. Continuous occupation and rapid population growth in UK coastal areas have aggravated current risks of coastal flooding and erosion (Dodman 2009); some of the UK coastline (3008 km) (Table 1) is currently undergoing erosion (Doody 2004).

Table 1: Coastal Erosion

\begin{tabular}{cccc}
\hline Region & Coast Length $(\mathrm{km})$ & $\begin{array}{c}\text { Eroding Coast } \\
\text { Length }(\mathrm{km})\end{array}$ & $\begin{array}{c}\text { Eroding Coastline } \\
(\%)\end{array}$ \\
\hline England & 4273 & 1275 & 29.8 \\
Wales & 1498 & 346 & 23.1 \\
Scotland & 11154 & 1298 & 11.6 \\
Northern Ireland & 456 & 89 & 19.5 \\
\hline Total & 17381 & 3008 & 17.3 \\
\hline
\end{tabular}

Source: Adapted from Masselink and Russell 2010 
Coastal erosion impacts can be clearly seen on tidal flats, cliffs, salt marshes, and beaches; the most significant risks from coastal erosion are flooding, rock falls, loss of land, and damage to commercial and residential properties (Figure 3). Coastal properties about 1,026,000 housing assets, 74,000 commercial assets, and some 432,000 hectares of farming land are potentially at risk from coastal flooding. Altogether this is equivalent to $>£ 10$ billion (Wallingford 2001).

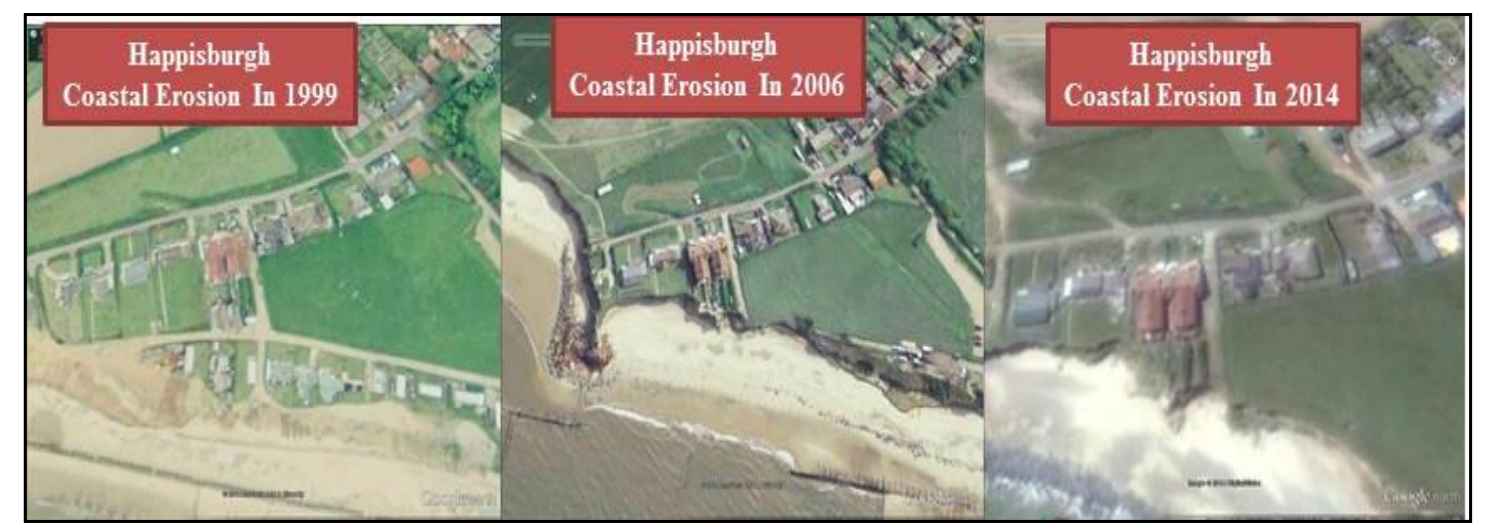

Figure 3: Coastal Erosion in Happisburgh, England

Source: Satellite Images (Google Earth Pro 2014)

\section{Data}

Data were obtained from the Environment Agency (England, Wales, and Scotland), British Geological Survey, Association of British Insurers, and Parliamentary reports for both flooding (commercial and residential properties) and coastal erosion, while ONS (Office for National Statistics) data were used for the evaluation of population trends and number of existed properties across the United Kingdom. Data regarding GDP was collected from World Bank. Moreover, the research team of this current study conducted multiple observations to appraise the changes in both the intensity and severity of flooding and coastal erosion at various places and then evaluated the costs. Based on this information, aerial maps are developed from the Ordnance Survey and-Google Earth Pro with live pictures and subsequently analysed. Derived results compared with published national reports to offer new damage estimations.

\section{Methodology}

There are many methodologies for estimating of flood damage and coastal erosion costs at global and regional levels in relation to climate change. Existing literature on flood and coastal erosion estimation methods developed by applying numerical approaches such as Smith (1981); Dutta, Herath, and Musiake (2003); Jonkman et al. (2008); Merz et al. (2004); Thorne, Evans, and Penning-Rowsell (2007); Turner et al. (2007); Roebeling, Coelho, and Reis (2011). However, research context and assessment criteria are different for this study and accordingly, a coherent and concise framework has been adopted based upon the work of Kantamaneni, Alrashed, and Phillips (2015), i.e., 2PA (Two Path Analysis) (Figure 4). This methodology comprises two vital paths:

Path One: Evaluation of flood damage costs for residential and commercial properties by applying Flood Cost Assessment Device.

Path Two: Identification and mapping of coastal eroding areas along with appraisal of coastal erosion costs. 


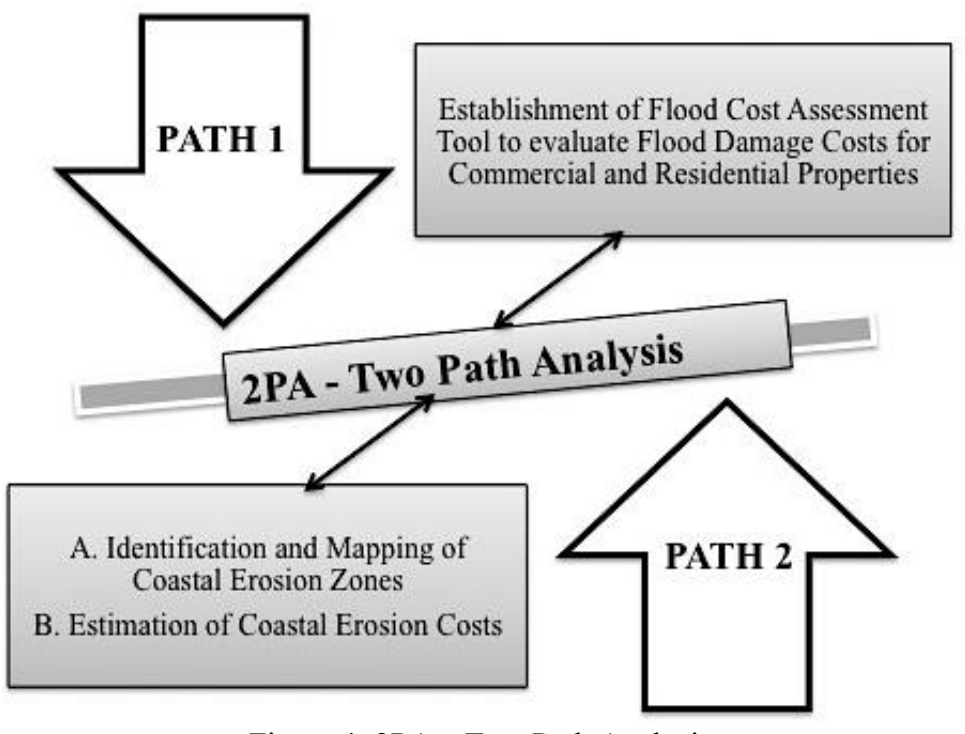

Figure 4: 2PA-Two Path Analysis

Source: Kantamaneni, Alrashed, and Phillips 2015

\section{Path One (P1): Flood Cost Assessment Device}

A Flood Cost Assessment Device (Figure 5) conceptual procedure was adopted for this research based upon an adaptation of the work of Kantamaneni et al. (2015) for evaluation of flood costs mainly for commercial and residential properties and, subsequently, applied to the UK scenarios.

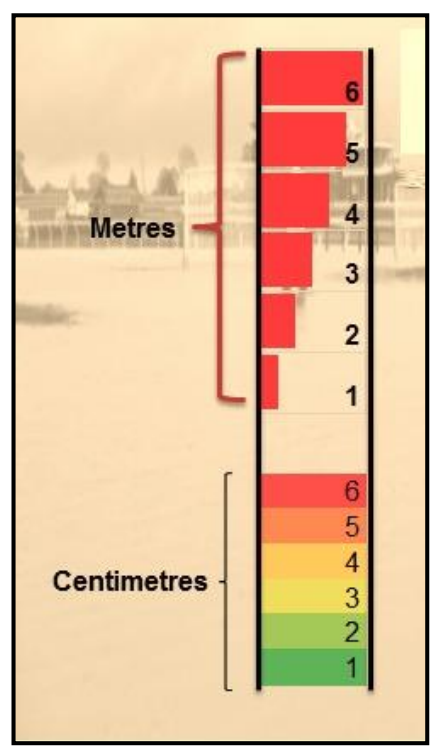

Figure 5: Flood Cost Assessment Device

Source: Kantamaneni et al. 2015

It has been established using a combination of $\mathrm{cm}$ and $m$ flooding levels, indicated by colour codes on a scale, to identify the intensity of flood water levels. If water level reaches between 2 and $5 \mathrm{~cm}$ into properties, there is not much damage, but if flood waters reach between 0.6 and 1.5 metres, it should cause significant damage to assets, including construction, structural fittings, furniture, and household equipment (Figure 6). Replacement costs for carpets, fridges, sofas, beds, electrical equipment, and decorations are generally higher than those assets lost. This assessment method critically analyses property damage costs especially for residential and commercial structures and then other and related expenses. 


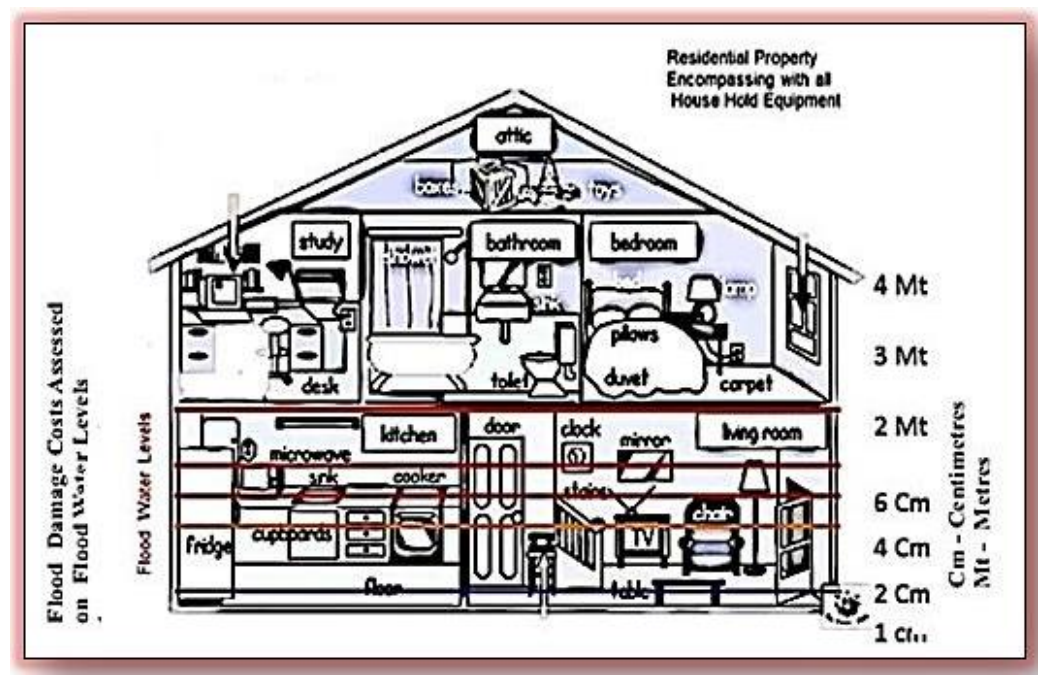

Figure 6: Applications of Flood Cost Assessment Device to Properties

This method used market values for each component and followed a systematic approach to obtain flood damage costs; the process being underpinned by a mathematical derivation as follows:

$\left(\frac{\text { Min. Property Damage Costs }+ \text { Max.Property Damage Costs }}{2}\right) \times$ No.of Properties at Risk

\section{Path Two (P2)}

Identification and mapping of coastal erosion sites and evaluation of coastal erosion cost based on collated data.

\section{Results and Discussion}

\section{Path One (P1): Flood Damage Costs for Commercial and Residential Properties}

The derived formula was considered alongside minimum and maximum costs for various items (commercial and residential) and scenarios as shown in Table 2.

Table 2 shows how diverse the costs are for residential and commercial properties. These values have been set from a minimum to maximum costs for a particular item, i.e., $£ 1,000$ (minimum) to $£ 22,000$ (Maximum). From Table 2, summing the total maximum (£41,500) and minimum values $(£ 18,500)$ enables the derivation of an average damage cost per property, which can be factored into the total number of properties at risk. This is currently estimated at 6 million, and flood damage costs for properties are compared with and are different from ABI (Association of British Insurers) results, which are between $£ 20,000$ and $£ 40,000$ for a single property. However, approximately (on average) 40,000 properties $(0.6 \%)$ are affected by (major $\backslash$ minor) floods every year, which means UK average flood damage costs for properties are $£ 1.2$ billion per annum.

$$
\left(\frac{£ 18,500+£ 41,500}{2}\right) X 40,000=£ 1.2 \text { billion }
$$


Table 2: Flood Damage Assessment for Commercial and Residential Properties

\begin{tabular}{cc}
\hline Flood Damage Cost per property & $\begin{array}{c}\text { Damage Costs for Residential\Commercial } \\
\text { properties (Minimum to Maximum) }\end{array}$ \\
\hline Carpet $\backslash$ Wooden Floor & $£ 1,000$ to $£ 3,000$ \\
Electrical Appliances & $£ 2,000$ to $£ 5,000$ \\
Doors \& Windows & $£ 1,500$ to $£ 3,000$ \\
Living $\backslash$ Dinning $\backslash$ Kitchen $\backslash$ Bed room & $£ 8,000$ to $£ 22,000$ \\
Furniture $\backslash$ Infrastructure & \\
Personal Items & $£ 1,000$ to $£ 1,500$ \\
Cleaning and Repairs & $£ 3,000$ to $£ 4,000$ \\
Others & $£ 2,000$ to $£ 3,000$ \\
\hline
\end{tabular}

\section{Newly Adopted Device: Feasibility and Rationalisation}

The newly adopted tool, i.e., Flood Cost Assessment Device, consists of innovative structures and this model is a significantly better model than existing methods, based on the following claims.

\section{Claim 1}

This model is not as complicated and contains only simple equations. This will be useful in evaluating the immediate aftermath of floods.

\section{Claim 2}

The Flood Cost Assessment tool is a combination of $\mathrm{cm}$ and $\mathrm{m}$ scales with defined colour bands representing codes for flood water level intensities. While being relatively simple in representation, the underlying methodology is mathematically based and refined.

\section{Claim 3}

The mechanism (described in Path Two) that is used in this device (useful for measuring flood water levels as well as for the assessment of flood damage costs) is completely innovative, fiscally effective, and a simple process. Based on the analysis, the current study concludes that the Flood Cost Assessment Tool is more consistent and cost-effective.

\section{Path Two (P2): Coastal Erosion}

This section evaluated the following two vital things: identified coastal erosion sites and developed maps and estimated coastal erosion costs.

\section{Identification of Coastal Erosion Sites and Mapping}

This study also identified highly rapid coastal erosion (vulnerable) sites (via multiple site visits as well as data collection) across the United Kingdom as follows: 
Table 3: Coastal Erosion (Vulnerable) Sites

\begin{tabular}{|c|c|c|c|}
\hline England & Wales & Scotland & Northern Ireland \\
\hline Devon & South Wales & & \\
\hline $\begin{array}{ll}\text { - } & \text { Hallsands } \\
\text { - } & \text { Dawlish } \\
\text { - } & \text { Lynmouth }\end{array}$ & - Llanelli & $\begin{array}{c}\text { Balivanich, } \\
\text { Benbecula } \\
\text { Island }\end{array}$ & $\begin{array}{c}\text { No Severe Coastal } \\
\text { Vulnerability } \\
\text { At present }\end{array}$ \\
\hline
\end{tabular}

Table 3 revealed the severe coastal erosion sites of the United Kingdom: three in England, one in South Wales, and one in Scotland. However, Northern Ireland is an exemption for severe coastal erosion.

\section{Coastal Erosion Sites and Maps}

I. Hallsands, England

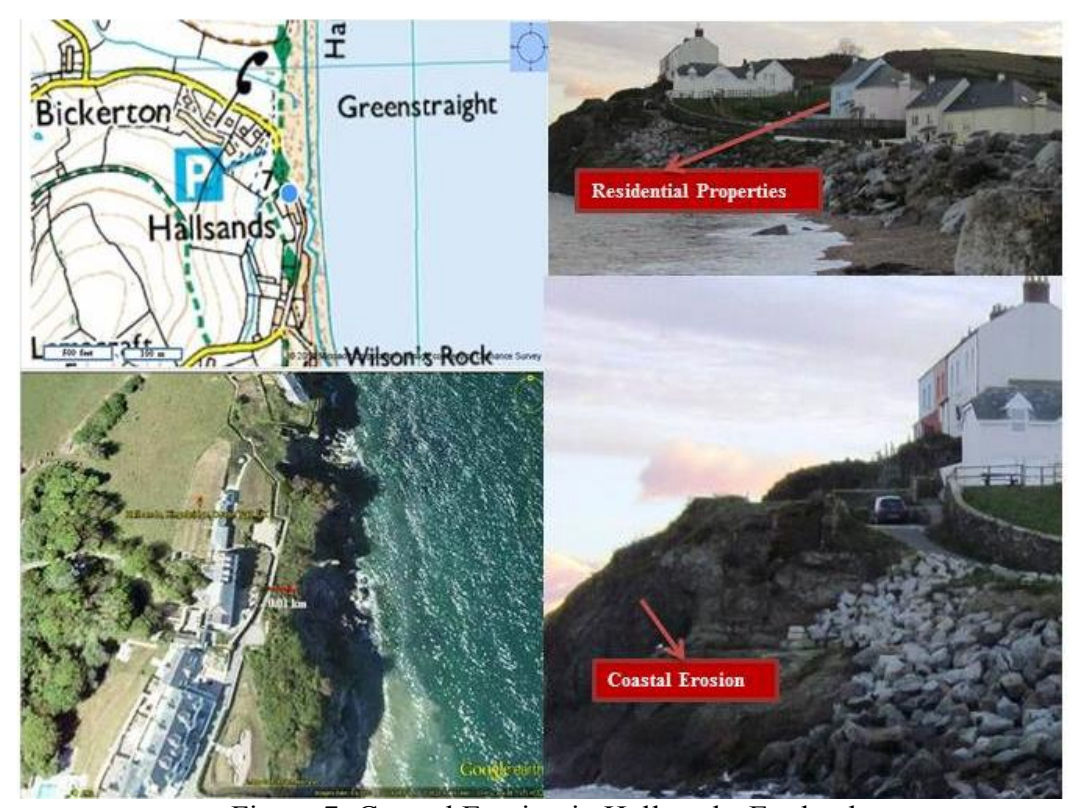

Figure 7: Coastal Erosion in Hallsands, England

Hallsands is one of the most rapidly eroding sites in the United Kingdom. Residential properties and agricultural land are at huge risk of erosion and flooding, as shown in Figure 7. The distance from residential properties to the coast is small, i.e., $0.01 \mathrm{~km}$.

II. Dawlish, England

Dawlish is a tourist location in Devon, England. It is at severe risk of flooding and coastal erosion as evidenced in December 2014 (Figure 8). Massive infrastructure was severely affected by this winter floods. 


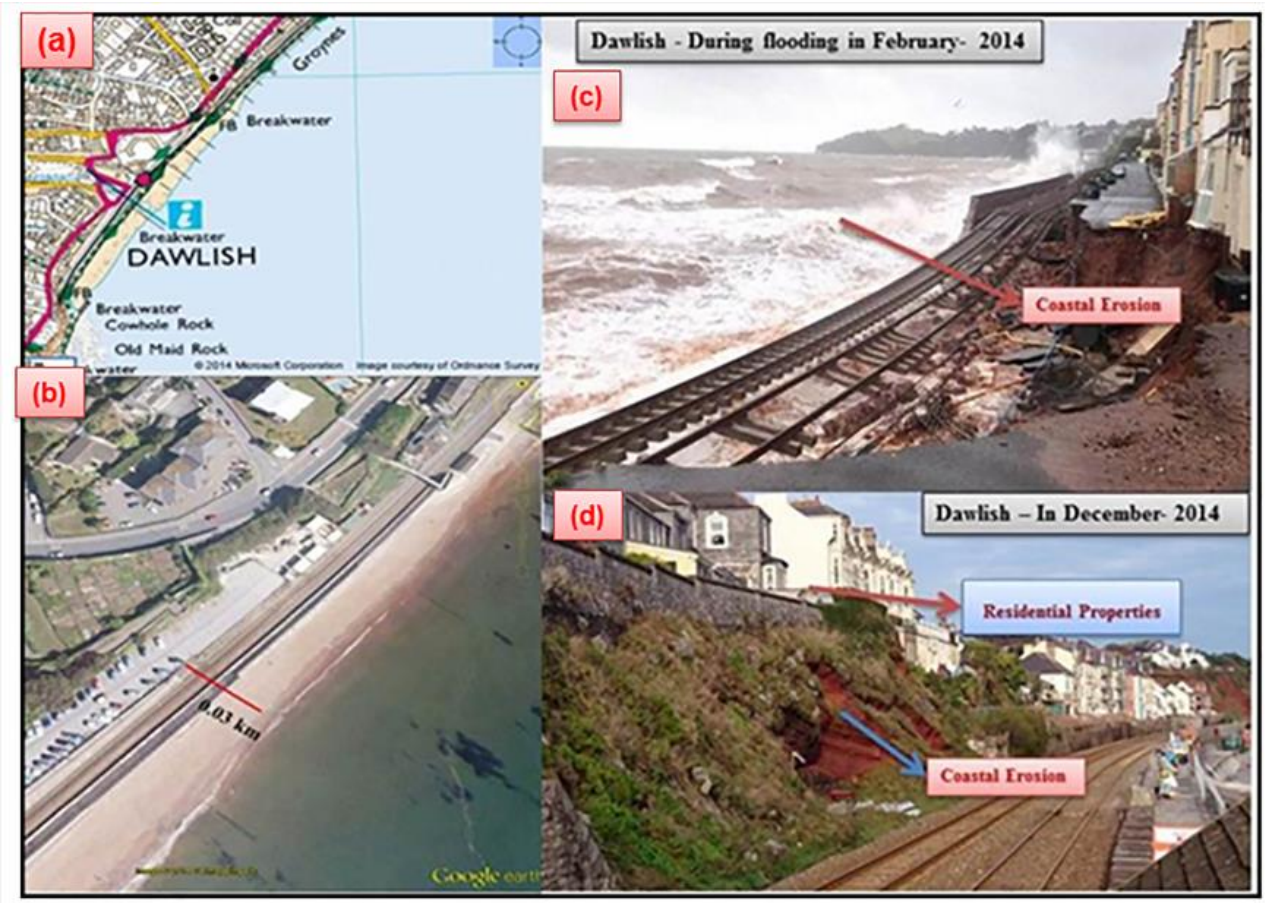

Figure 8: Dawlish during and after Flooding in 2014 Source: BBC 2014 (8c)

III. Lynmouth, England

Lynmouth is a coastal village located in England. Currently, it is at greater risk of coastal erosion and flooding as shown in Figure 9. This site has been severely affected by a series of flooding events since 1952 .

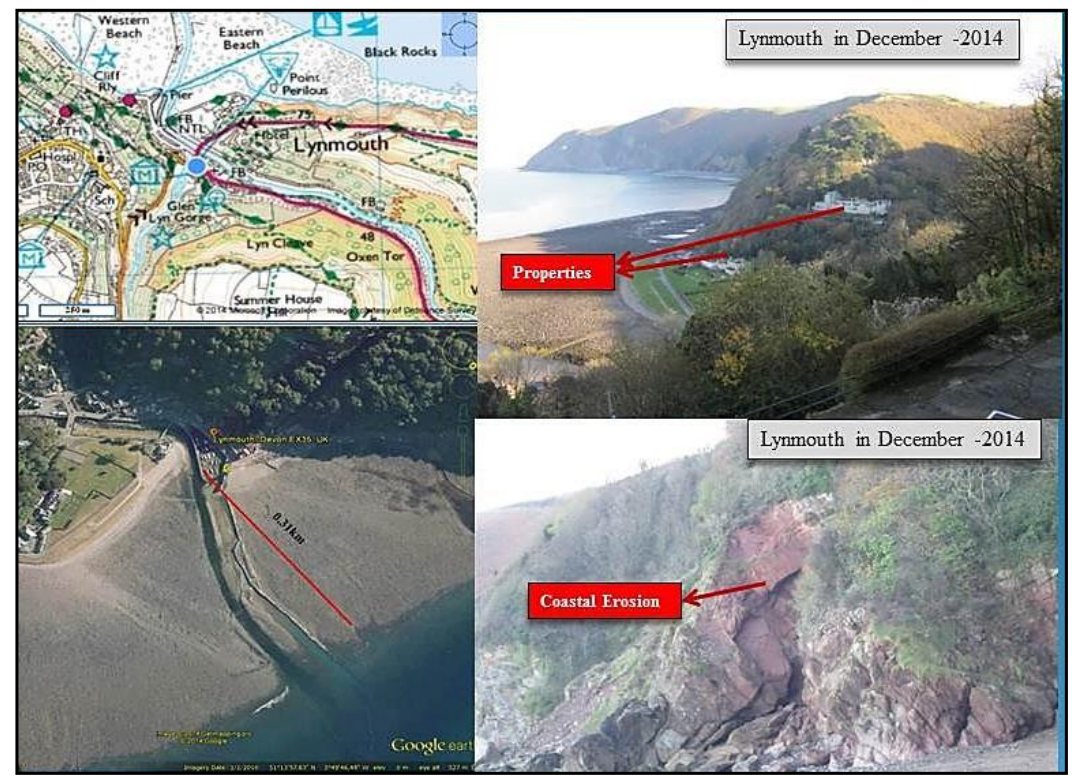

Figure 9: Coastal Erosion in Lynmouth in 2014

IV. Llanelli, South Wales

Llanelli is a Welsh town, and it is also at high risk of coastal erosion and flooding (Figure 10). The distance from the coast to properties is $>1 \mathrm{~km}$. Most of the commercial and residential properties are very near to the coast. 

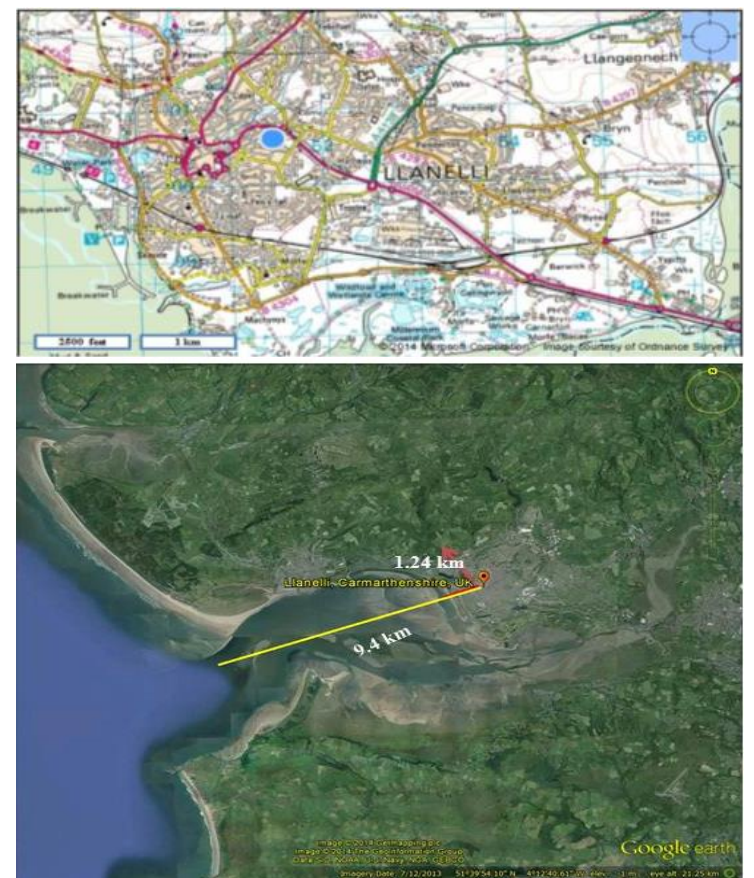

Figure 10: Coastal Erosion (Vulnerable) in Llanelli, South Wales

V. Balivanich, Benbecula Island, Scotland

Balivanich is a highly eroding site in Scotland due to the rapid disintegration of coastline into the sea (Figure 11). Most of the properties are at an enormous risk of coastal erosion. The distance from the coast to properties is $>0.8 \mathrm{~km}$.

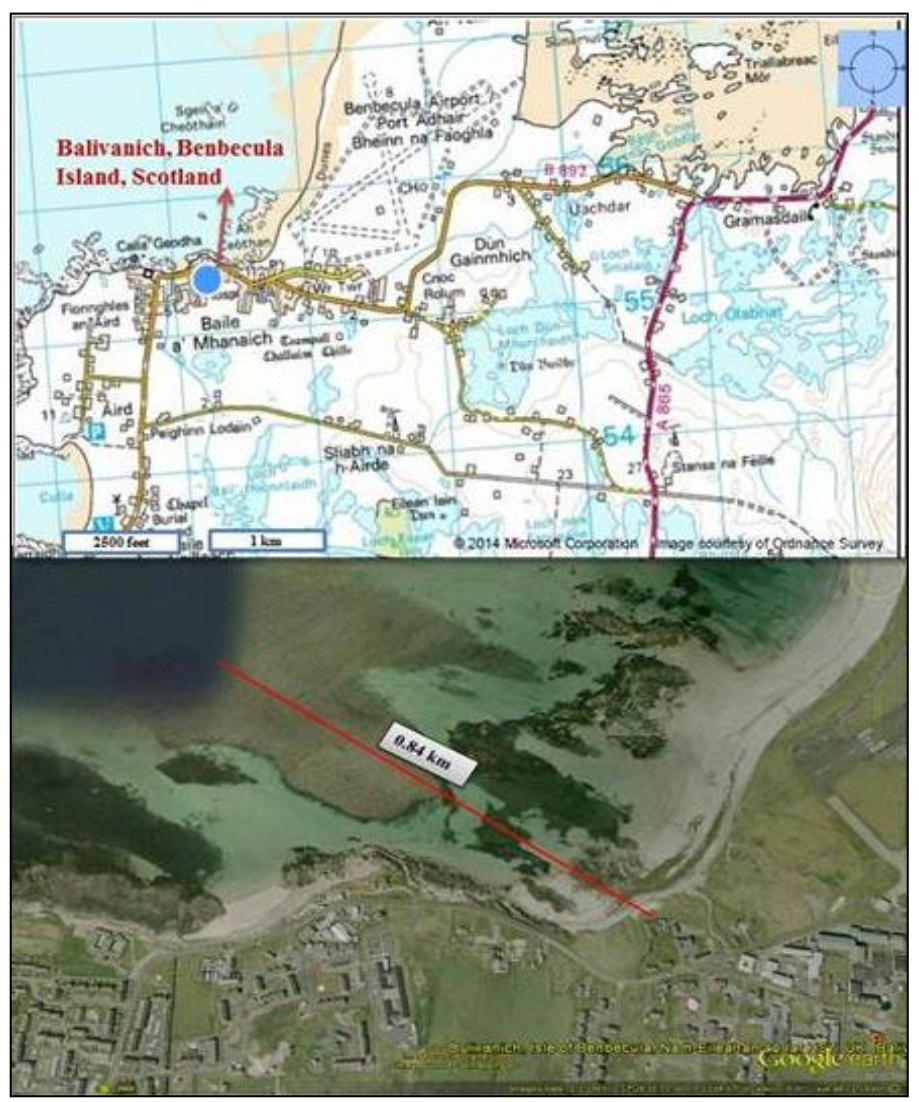

Figure 11: Coastal Erosion in Balivanich, Benbecula Island, Scotland 


\section{Evaluation of Coastal Erosion Costs}

Estimations of coastal erosion (Table 3) are made using the data from UK Government figures, which are currently $£ 15$ million as stated in the 2009 climate change projections and CCRA 2012 report. However, this study differed with these results and offered new estimations, i.e., $>16.5$ million per year. This study also found that the erosion rate is not the same throughout the UK; England is very vulnerable to erosion, Wales and Scotland are moderately vulnerable, and there is no risk to Northern Ireland. However, this study provided the cumulative of costs of coastal erosion rather than the sectoral assessment. In addition, during the estimation, this study considered the population trends, coastal zones, and yearly changes in the coastal areas, height of tides, and distance of properties from the coast.

Table 3: New estimations for Coastal Erosion

\begin{tabular}{|c|c|c|}
\hline \multicolumn{3}{|c|}{ Coastal Erosion Costs } \\
\hline $\begin{array}{l}\text { Foresight, } \\
\text { Estimati }\end{array}$ & $\begin{array}{l}\text { V.UK- } \\
\text { llions }\end{array}$ & New Estimations In £Millions \\
\hline $\begin{array}{c}\text { Current } \\
\text { Erosion costs }\end{array}$ & $15+$ & $>16.5$ \\
\hline
\end{tabular}

Analysis revealed that coastal depletion is growing faster than projected values, and it is likely to increase over the next fifty years. Climate change, particularly sea level rise and temperature fluctuations, are primary reasons for this. Each of these will cumulatively impact the UK coast. Consequently, England is the UK's most vulnerable zone for coastal erosion, but its fiscal impact is considerably less than the fiscal impact of coastal flooding. However, previous predictions were underestimated; accordingly this study has offered these new estimations.

\section{Flood Damage (Properties) and Erosion Costs Impact on National Economy}

Cumulative costs of flood damage (properties), as well as coastal erosion, are $>£ 1.3$ billion at current scenarios. This is a very fraction of the amount of national GDP, which is currently $£ 1.6$ trillion. These costs represent only $0.08 \%$ on a national scale (Figure 12) and do not have a significant current impact on the national economy. However, by 2080 it should be a more significant percentage. Therefore, if rigorous environmental protection and climate change policies and procedures are not followed, future generations will unquestionably be more frequently vulnerable to floods and coastal erosion.

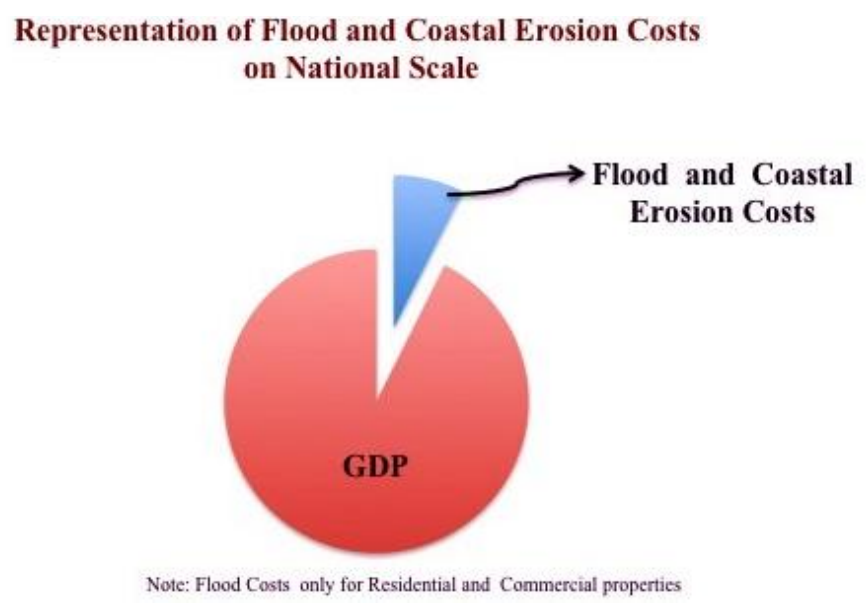

Figure 12: Flood and Coastal Erosion Costs on National Scale 


\section{Conclusion}

This paper adopted a methodology, i.e., 2P (Two Path Analysis). This approach analysed the flood damage costs for properties by using the Flood Cost Assessment Tool as in path one and then it identified the coastal erosion zones along with an evaluation of coastal erosion costs in path two. In addition, this study also scrutinised the impact of damage costs on national GDP. Accordingly, this study revealed that the current flood and coastal erosion costs ( $£ 1.3$ billion) insignificantly affects the national economy due to a fraction of the amount on the national scale. This study indicates that if flood risk planning and coastal protection measures are not improved, socio-economic costs will negatively affect national GDP in the future.

\section{REFERENCES}

Alexander, L. V., and P. D. Jones. 2000. "Updated Precipitation Series for the UK and Discussion of Recent Extremes." Atmospheric Science Letters 1 (2): 142-50.

BBC. 2014. "Dawlish Storm Damage Rail Closure 'to Cost Millions."” BBC News, February 6. http://www.bbc.co.uk/news/uk-england-26062712.

Benito, Gerardo, Michel Lang, Mariano Barriendos, M. Carmen Llasat, Felix Francés, Taha Ouarda, Varyl Thorndycraft, Yehouda Enzel, Andras Bardossy, and Denis Coeur. 2004. "Use of Systematic, Palaeoflood and Historical Data for the Improvement of Flood Risk Estimation. Review of Scientific Methods." Natural Hazards 31 (3): 623-43.

Boruff, Bryan J., Christopher Emrich, and Susan L. Cutter. 2005. "Erosion Hazard Vulnerability of US Coastal Counties." Journal of Coastal Research, 932-42.

Bray, Malcolm, Janet Hooke, and David Carter. 1997. "Planning for Sea-level Rise on the South Coast of England: Advising the Decision-makers." Transactions of the Institute of British Geographers, 13-30.

British Council. 2013. "Diversity of the UK." Accessed April 5. www.britishcouncil.org/tt-about -us-diversity-of-the-uk.htm.

Carrington, D. 2012. "David Cameron Forced into U-turn on Flood Defence Spending Cuts." The Guardian, November 30. www.theguardian.com/environment/2012/nov/30/flooding -120m-defence-spending.

Central Intelligence Agency (CIA). 2013. World Fact Book-United Kingdom. Accessed July. www.cia.gov/library/publications/the-world-factbook/geos/uk.html.

de Alegria-Arzaburu, Amaia Ruiz, and Gerhard Masselink. 2010. "Storm Response and Beach Rotation on a Gravel Beach, Slapton Sands, UK.” Marine Geology 278 (1): 77-99.

Dobbie, Charles Herbert, and Peter Otto Wolf. 1953. "The Lynmouth Flood of August 1952." ICE Proceedings: Engineering Divisions.

Dodman, David. 2009. "Urban Density and Climate Change." Analytical Review of the Interaction between Urban Growth Trends and Environmental Changes Paper 1.

Doney, Scott C., Mary Ruckelshaus, J. Emmett Duffy, James P. Barry, Francis Chan, Chad A. English, Heather M. Galindo, Jacqueline M. Grebmeier, Anne B. Hollowed, and Nancy Knowlton. 2012. "Climate Change Impacts on Marine Ecosystems." Marine Science 4.

Doody, J. Patrick. 2004. Living with Coastal Erosion in Europe: Sediment and Space for Sustainability: Results from the EUROSION Study. Schiedam: Office for Official Publications of the European Communities.

Dutta, Dushmanta, Srikantha Herath, and Katumi Musiake. 2003. "A Mathematical Model for Flood Loss Estimation.” Journal of Hydrology 277 (1): 24-49. 
Easterling, David R., Gerald A. Meehl, Camille Parmesan, Stanley A. Changnon, Thomas R. Karl, and Linda O. Mearns. 2000. "Climate Extremes: Observations, Modelling, and Impacts." Science 289 (5487): 2068-74.

Ely, Lisa L., Yehouda Enzel, Victor R. Baker, and Daniel R. Cayan. 1992. "A 5000-year Record of Extreme Floods and Climate Change in the Southwestern United States." Science 256: 1434 .

Environment Agency (EA). 1999. The State of the Environment in England and Wales: Coasts. London: TSO.

2010. Delivering Benefits through Evidence. Accessed December 13, 2013. http://nationalfloodforum.org.uk/wp-content/uploads/EA-Costs-of-Flooding.pdf.

European Union. 2013. "United Kingdom." European Union. Accessed July 7, 2013. http://europa.eu/about-eu/countries/member-countries/unitedkingdom/index_en.htm.

Google Earth Pro 2014. Happisburgh, UK. Digital Globe, Ariel View.

Hinrichsen, Don. 1999. "The Coastal Population Explosion." Trends and Future Challenges for US National Ocean and Coastal Policy. Proceedings of a Workshop.

Houghton, John Theodore, Y. D. J. G. Ding, David J. Griggs, Maria Noguer, Paul J. van der Linden, Xiaosu Dai, Kathy Maskell, and C. A. Johnson. 2001. Climate Change 2001: The Scientific Basis. UK: Cambridge University Press.

Hulme, Mike, G. J. Jenkins, X. Lu, J. R. Turnpenny, T. D. Mitchell, R. G. Jones, J. Lowe, J. M. Murphy, D. Hassell, and P. Boorman. 2002. Climate Change Scenarios for the United Kingdom: The UKCIP02 Scientific Report. Vol. 120. UK: Tyndall Centre for Climate Change Research, School of Environmental Sciences, University of East Anglia Norwich.

Joint, Lura. 2008. "Lynmouth Flood Disaster." $B B C$, January 25. www.bbc.co.uk/devon/news features/2002/lynmouth flood.shtml.

Jonkman, S. N., M. Bočkarjova, M. Kok, and P. Bernardini. 2008. "Integrated Hydrodynamic and Economic Modelling of Flood Damage in the Netherlands." Ecological Economics 66 (1): 77-90.

Kantamaneni, Komali, Ibrahim Alrashed, and Micheal Phillips. 2015. "Cost vs. Safety: A Novel Design for Tornado Proof Homes." HBRC Journal. doi:10.1016/j.hbrcj.2015.05.004.

Kantamaneni, Komali, Ibrahim Alrashed, Michael Phillips, and Rhian Jenkins. 2015. "Flood Crunch: A Fiscal Appraisal for Commercial and Residential Properties in England." Regional and Sectoral Economic Studies 15 (1): 17-26.

Knutson, Thomas R., John L. McBride, Johnny Chan, Kerry Emanuel, Greg Holland, Chris Landsea, Isaac Held, James P. Kossin, A. K. Srivastava, and Masato Sugi. 2010. "Tropical Cyclones and Climate Change." Nature Geoscience 3 (3): 157-63.

Kochel, R. Craig, and Victor R. Baker. 1982. "Paleoflood Hydrology." Science 215: 353-61.

Macklin, Mark G., and Barbara T. Rumsby. 2007. "Changing Climate and Extreme Floods in the British Uplands." Transactions of the Institute of British Geographers 32 (2): 168-86.

Marshall, W. A. L. 1952. "The Lynmouth Floods.” Weather 7 (11): 338-42.

Masselink, G., and P. Russell. 2010. "Coastal Erosion in MCCIP Annual Report Card 2010-11." MCCIP Science Review.

McGranahan, Gordon, Deborah Balk, and Bridget Anderson. 2007. "The Rising Tide: Assessing the Risks of Climate Change and Human Settlements in Low Elevation Coastal Zones." Environment and Urbanization 19 (1): 17-37.

Meinshausen, Malte, Nicolai Meinshausen, William Hare, Sarah C. B. Raper, Katja Frieler, Reto Knutti, David J. Frame, and Myles R. Allen. 2009. "Greenhouse-gas Emission Targets for Limiting Global Warming to 2 C.” Nature 458 (7242): 1158-62.

Merz, Bruno, Heidi Kreibich, A. Thieken, and Reinhard Schmidtke. 2004. "Estimation Uncertainty of Direct Monetary Flood Damage to Buildings." Natural Hazards and Earth System Science 4 (1):153-63. 
Nicholls, Robert J., and Anny Cazenave. 2010. "Sea-level Rise and Its Impact on Coastal Zones." Science 328 (5985): 1517-20.

Ordnance Survey. 2013. "Geography and Maps.” Ordnance Survey. Accessed December 2. www.ordnancesurvey.co.uk/oswebsite/support/geography-map-facts.html.

Phillips, M. R. 2008. "Beach Erosion and Marine Aggregate Dredging: a Question of Evidence?" The Geographical Journal 174 (4): 332-43.

Pollard, Michael. 1978. North Sea Surge: The Story of the East Coast Floods of 1953. UK: Terence Dalton.

Pye, Kenneth, and Simon J. Blott. 2006. "Coastal Processes and Morphological Change in the Dunwich-Sizewell Area, Suffolk, UK." Journal of Coastal Research, 453-73.

Ramanathan, Veerabhadran, and Yan Feng. 2008. "On Avoiding Dangerous Anthropogenic Interference with the Climate System: Formidable Challenges Ahead." Proceedings of the National Academy of Sciences 105 (38): 14245-50.

Reuters. 2007. "Thousands Powerless as UK Substation Floods." Reuters, June 26. www.reuters.com/article/2007/06/26/environment-britain-floods-power-cuts-dc -idUSL2672390420070626.

Roebeling, P. C., C. D. Coelho, and E. M. Reis. 2011. "Coastal Erosion and Coastal Defense Interventions: A Cost-benefit Analysis." Journal of Coastal Research 64: 1415-19.

Smith, David I. 1981. "Actual and Potential Flood Damage: A Case Study for Urban Lismore, NSW, Australia." Applied Geography 1 (1): 31-39.

Solomon, Susan, Gian-Kasper Plattner, Reto Knutti, and Pierre Friedlingstein. 2009. "Irreversible Climate Change Due to Carbon Dioxide Emissions." Proceedings of the National Academy of Sciences 106 (6): 1704-09.

Stern, Nicholas. 2007. The Economics of Climate Change: The Stern Review. Cambridge: Cambridge University Press.

Stratton, John M., Jack Houghton Brown, Ralph Whitlock, and Thomas Henry Baker. 1978. Agricultural Records AD 220-1977. USA: J. Baker.

Thomas, Chris D., Alison Cameron, Rhys E. Green, Michel Bakkenes, Linda J. Beaumont, Yvonne C. Collingham, Barend F. N. Erasmus, Marinez Ferreira De Siqueira, Alan Grainger, and Lee Hannah. 2004. "Extinction Risk from Climate Change." Nature 427 (6970): 145-48.

Thorne, Colin R., Edward P. Evans, and Edmund Charles Penning-Rowsell. 2007. Future Flooding and Coastal Erosion Risks. UK: Thomas Telford.

Turner, R, Kerry, Diane Burgess, David Hadley, Emma Coombes, and Nina Jackson. 2007. "A Cost-benefit Appraisal of Coastal Managed Realignment Policy." Global Environmental Change 17 (3): 397-407.

UK Coast Guide. 2013. "UK Coast Guide.” Accessed December 5. www.ukcoastguide.co.uk.

Wallingford, H. R. 2001. National Appraisal of Assets at Risk from Flooding and Coastal Erosion, Including the Potential Impact of Climate Change. Final Report. Department for Environment, Food and Rural Affairs.

Walsh, K. J. E., M. Fiorino, C. W. Landsea, and K. L. McInnes. 2007. “Objectively Determined Resolution-dependent Threshold Criteria for the Detection of Tropical Cyclones in Climate Models and Reanalyses." Journal of Climate 20 (10): 2307-14.

World Bank. 2014. "Data: United Kingdom." Accessed July 23. http://data.worldbank.org/country/united-kingdom.

Zsamboky, Mary, Amalia Fernández-Bilbao, David Smith, Jasper Knight, and James Allan. 2011. Impacts of Climate Change on Disadvantaged UK Coastal Communities. York, UK: Joseph Rowntree Foundation. 


\section{ABOUT THE AUTHORS}

Komali Kantamaneni: PhD student, University of Wales Trinity Saint David, Swansea, Wales, UK

Mike Phillips: Professor, Pro-Vice Chancellor, University of Wales Trinity Saint David, Swansea, Wales, UK 


\section{The International Journal of Climate Change:}

Impacts and Responses seeks to create an

interdisciplinary forum for discussion of evidence of

climate change, its causes, its ecosystemic impacts

and its human impacts. The journal also explores

technological, policy, strategic, and social responses to

climate change.

The International Journal of Climate Change: Impacts and Responses is a peer-reviewed, scholarly journal. 
FLOOD CRUNCH: A FISCAL APPRAISAL FOR COMMERCIAL AND

RESIDENTIAL PROPERTIES IN ENGLAND

Komali KANTAMANENI**,

Ibrahim ALRASHED,

Michael PHILLIPS

Rhian JENKINS

\section{Abstract}

This paper establishes and applies a coherent and concise empirical framework for evaluating damage costs for commercial and residential properties during flooding in England by incorporating a novel methodology i.e. Flood Cost Assessment Tool. This research also analyses whether these damage costs significantly impact on the national economy as well as local economies. This strategy differs from previous economic flood damage estimation models by focusing on different grades of properties and level of damage in various flood events across England. Results reveal that Environment Agency and British Insurers estimations are too optimistic and some vital aspects are often neglected. Indeed, the new estimates for England's flooding costs for commercial and residential properties were found to be $£ 1.6$ Billion per year. While current English property damage costs represent only $0.1 \%$ of national (UK) and country (England) GDP, showing it to be inconsequential at either scale, it has considerable fiscal impact on local economies (County Councils) in both short and long term scenarios

Keywords: New Methodology- Flood Cost Assessing Tool, Floods, Damage Costs, National and Local Economy

JEL CODE: Q540 - (Climate; Natural Disasters; Global Warming)

\section{Introduction}

The study of flood costs has attracted global interest in both environmental and pure economics. Flood damage varies significantly from year to year and predictions identify increasing trends over the last century (Pielke, 2000). Europe's current annual flood damage costs are $£ 5.2$ Billion and it is likely to rise rapidly in the future (Ciscar et al. 2011).

Subsequently, this study questions whether flood damage data shaped by the Environment Agency and Association of British Insurers (ABI) really fulfil owner estimations? Are predictions realistic? Although extensive research has been undertaken, the answers to aforementioned queries remain indistinct, mainly due to lack of digitization of flood economic data over decades, as well as robust research methodologies. These issues prompted the present study to develop a novel and simple conceptual framework to estimate true flood damage costs for residential and commercial

\footnotetext{
* Komali Kantamaneni, Ibrahim Alrashed, Michael Phillips and Rhian Jenkins, Faculty of Applied Design and Engineering, School of Built and Natural Environment, University of Wales Trinity Saint David, Swansea, United Kingdom.Email: Komali.kantamaneni@,sm.uwtsd.ac.uk Acknowledgements: The authors would like to acknowledge the Office of National Statistics, Environment Agency and British Insurers for allowing access to updated data on recent flooding events.
} 
properties by grading properties. It also assesses the impact of flood damage costs at UK, English and local level GDP.

\section{Study Area}

England was selected as a study area because of the frequency of flooding incidents. It is bounded by the English Channel (south), Celtic Sea (southwest) and North Sea (East) (Figure 1) (Maps of World, 2013): its coastline is more than 5581 miles (Darkes, 2008) and the population is 52 million (ONS, 2013). England is vulnerable to all types of floods, as evidenced in various locations in 2007, 2009 and 2012 (Zhou et al. 2011 \& Jha et.al. 2012). Consequently, this work estimates average annual flood damage costs of properties between 2007 and 2012.

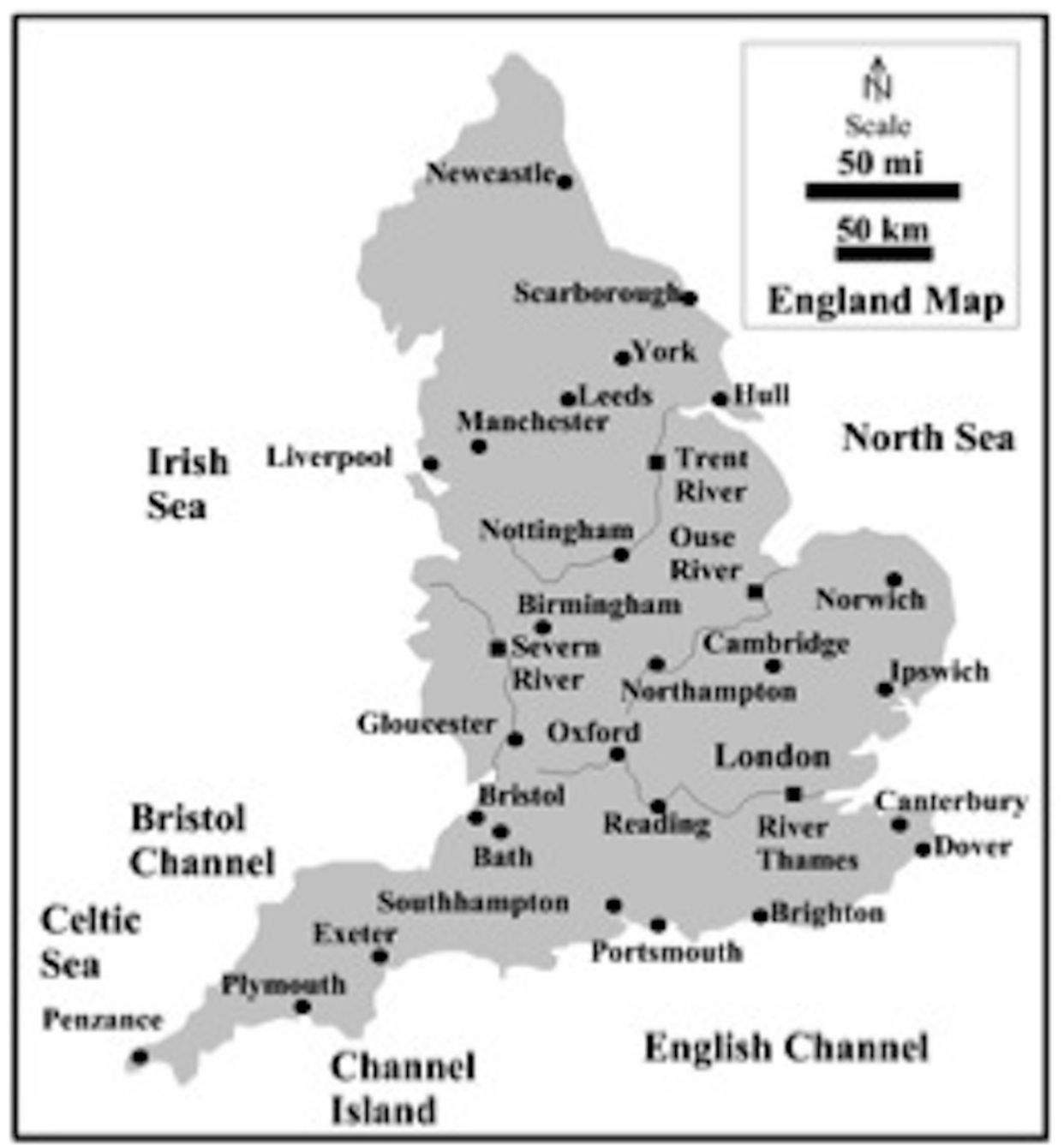

Fig.1. Location of study identified for Primary Flood Assessment Conceptual Framework Application. (Source: Maps of World, 2013) 


\section{Theory}

Approximately 5.2 million properties including 2 million commercial properties are at flood risk in England (Environment Agency, 2009). Summer floods (England) in 2007, turned into a nationwide catastrophe and caused $£ 3.5$ to $£ 4$ Billion worth of damage costs: of that amount, more than $£ 3$ Billion came from the housing sector (ABI, 2010, \& Environment Agency, 2014). Besides, 2009 flooding costs $£ 180$ million and 2012 floods costs more than $£ 600$ million, and these events hugely impacted the England's economy (ABI, 2010, \& Environment Agency, 2014)

\subsection{UK and England GDP}

The UK's economy is a paradox: while being the sixth largest economy in the world, with £1.6 trillion current (2012) GDP (World Bank, 2013) since 2007, its economic vigour has declined with a double credit crisis (The Economist, 2013). Consequently, for the last six to seven years, the economy has exhibited sluggish growth and flood costs have exacerbated the situation. Given the significance of these impacts, it is important to analyse residential and commercial property damage costs and impact of damage scenarios on national and local GDP.

\section{Methodology - Conceptual Framework}

This methodological approach contains two fundamental mechanisms. Primarily, it offers a conceptual framework for the precise evaluation of the flood water levels in properties. Secondly, implementing framework by establish three crude numerical equations to evaluate flood annual property damage costs as well as intensity of impact of damage costs on national and local economies. This approach was aggravated by FEMA's-USA (Federal Emergency Management Agency) flood cost tool. This crude numerical model relies on $\mathrm{cm}$ (centimetres) and $\mathrm{m}$ (metres) scales, indicated by various colour codes to categorise flood water levels (Figure 2).

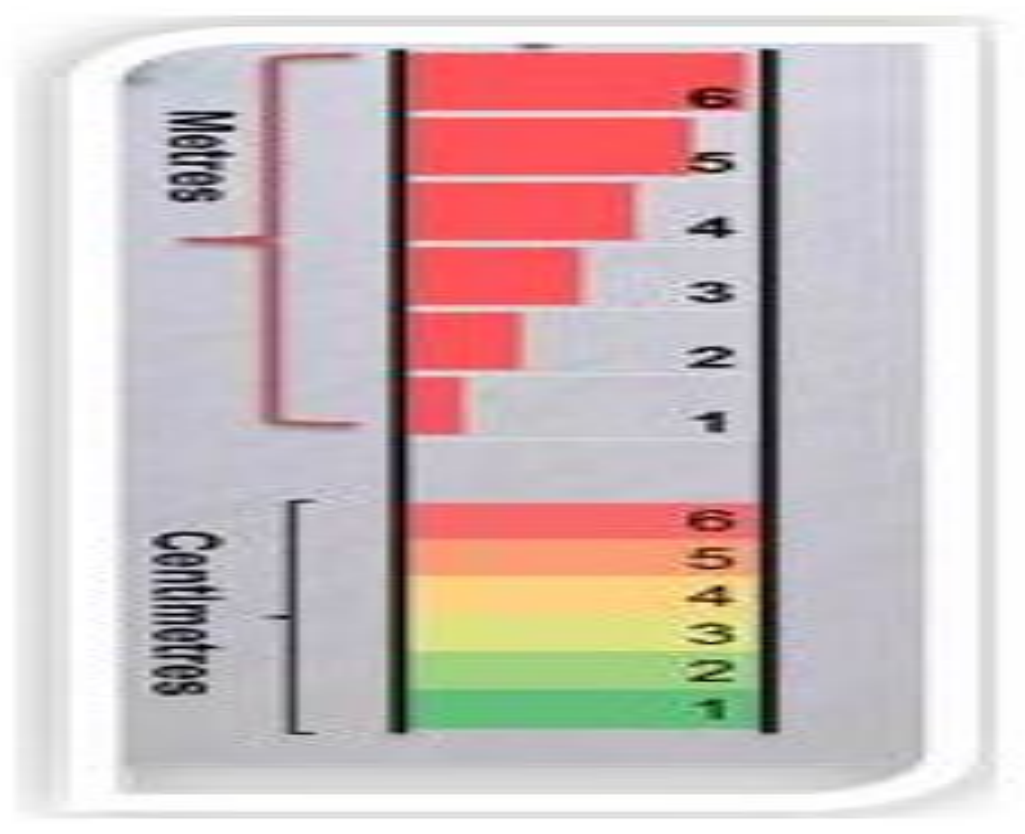

Fig. 2. Flooding Cost Assessment Tool 
Accordingly, this linear model empirically measures floodwater levels and assesses effects in various qualitative property grades based on household income: Grade 1 (Very High); Grade 2 (High); Grade 3 (Medium) and Grade 4 (Low), in England to show clearly flood damage severity. Inundation into properties of between $3 \mathrm{~cm}$ and $5 \mathrm{~cm}$ generally causes no serious damage, but there is potential damage to construction, equipment, carpeted and wooden floors, walls and other materials if the flood water level reaches $>5 \mathrm{~cm}$ (Figure 3(a) and 3(b)). Consequently, this distinct measurement tool enables analysis of the magnitudes of commercial and residential property damage costs during recent flooding events.

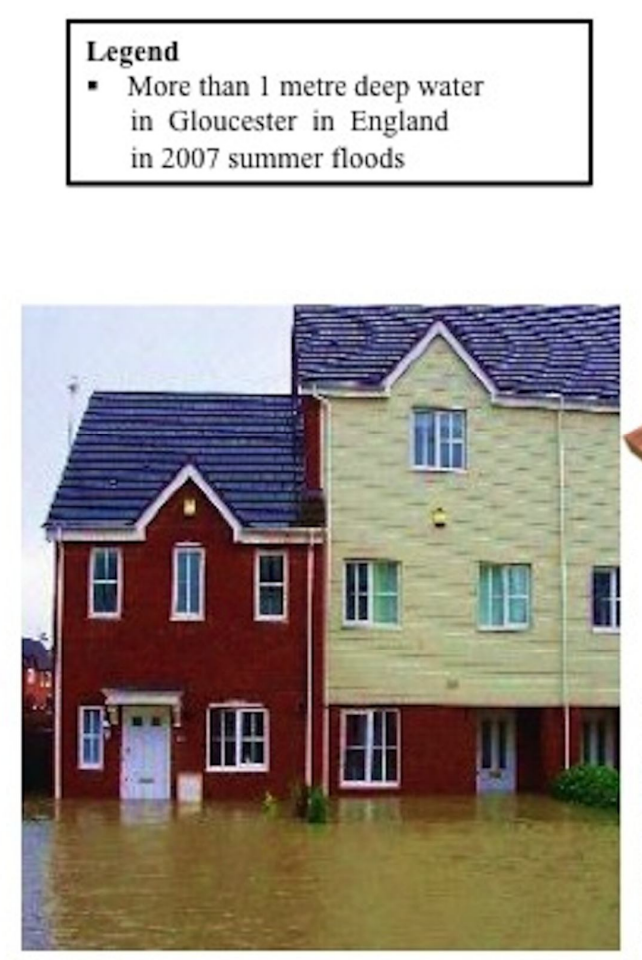

Figure 3(a)

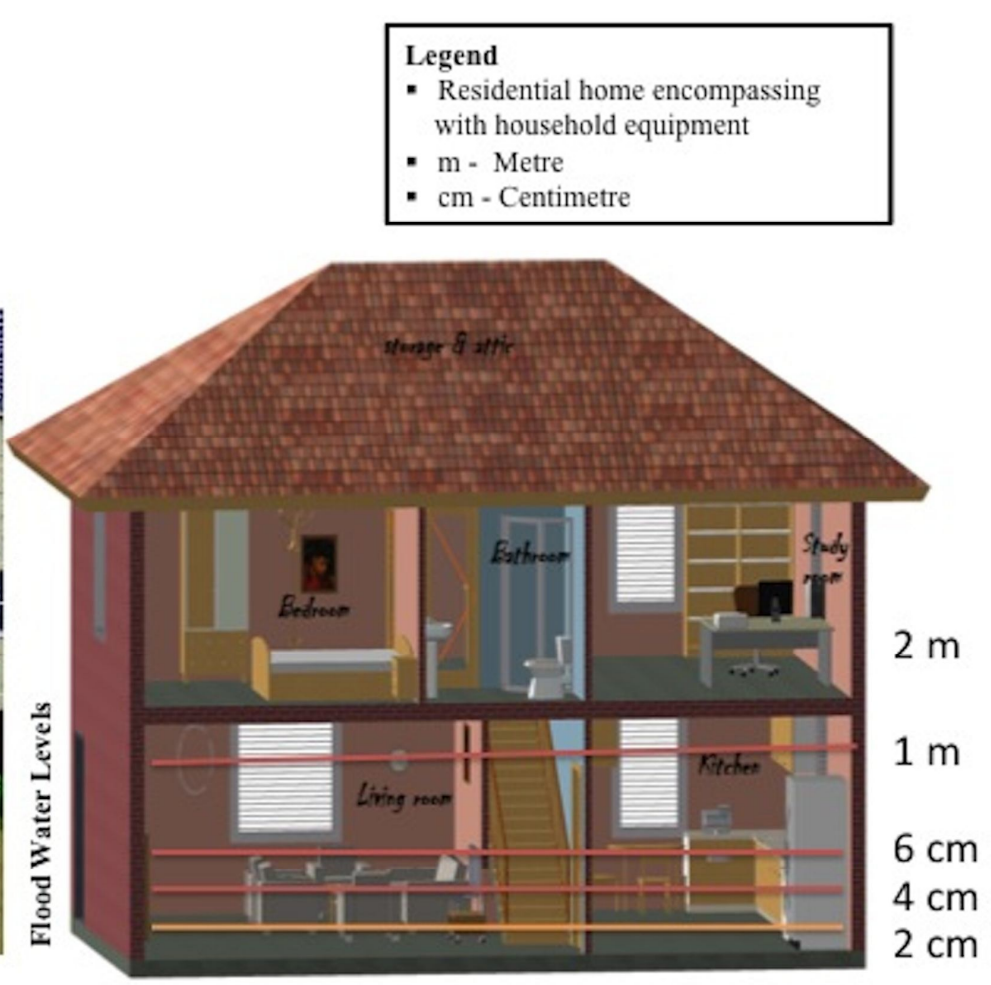

Figure 3(b)

Fig. 3 (a \& b): Applications of Flooding Cost Assessment Tool to Property (Source: (a)- BBC, 2009)

This framework also consists of three crude numerical formulas as support pillars to assess impact: \% of flood damage costs on local and national economies along with evolution of mean values of properties. These are,

\section{$\left(\frac{F D C C r}{N G D P}\right) X \%$}

Here, FDCcr denotes flood damage costs of commercial and residential properties and NGDP signifies national gross domestic product. 


$$
\left(\frac{F D C c r}{L E}\right) X \%
$$

From above equation, LE designates local economy.

$$
\left(\frac{M F D C+M A F D C}{2}\right) X N D P
$$

Where: MFDC is Minimum Flood Damage Costs

MAFD is Maximum Flood Damage Costs

NDP is Number of Damaged Properties

\section{Data}

This study uses data from British Insurers and the Environment Agency along with extensive academic literature. Data from these organisations were supplemented by information from UK Government Reports. While, this study divided properties into grades (G1 G2, G3 and G4 - Table 1) and also quotes the types of residential and commercial properties to evaluate fiscal damage with the novel flood cost assessment tool. Consequently, results were compared with statistics published by the British Insurers and Environment Agency and differences identified. Subsequently, new assessments of flood damage costs are derived.

Table 1

\begin{tabular}{|c|c|c|c|c|}
\hline \multicolumn{5}{|c|}{ Grading of Properties } \\
\hline $\begin{array}{l}\text { PROPERTY } \\
\text { TYPE }\end{array}$ & GRADE 1 & GRADE 2 & GRADE 3 & GRADE 4 \\
\hline Residential $^{\mathrm{i}}$ & Very high income & High income & Medium income & Low income \\
\hline Commercial ii & Very high value & High value & Medium value & Low value \\
\hline Heritage ${ }^{\text {iii }}$ & Very high value & High value & Medium value & Low value \\
\hline \multicolumn{5}{|c|}{ Property Description } \\
\hline \multicolumn{5}{|c|}{ ' ${ }^{i}$ Residential } \\
\hline \multicolumn{5}{|l|}{$\begin{array}{l}\text { ii Commercial } \\
\text { Academic. Indus }\end{array}$} \\
\hline \multicolumn{5}{|l|}{$\begin{array}{l}\text { iii Heritage } \\
\text { Museums, Art g }\end{array}$} \\
\hline
\end{tabular}

Grades of Property and Types of Residential and Commercial Properties 


\section{Results and Discussion}

Data analysis showed that England is a major contributor to UK GDP and in 2013 was estimated at $£ 1.35$ trillion: this was calculated on UK regional GVA (Gross Value Added) figures (ONS, 2013) S Subsequently, equation 3 was considered alongside minimum and maximum costs for various household items and flood scenarios as shown in Table 2.

Table 2. Flood Damage Assessment to Residential and Commercial properties

\begin{tabular}{|l|l|}
\hline Structural and property components & $\begin{array}{l}\text { Damage Costs for Residential and } \\
\text { Commercial properties } \\
\text { (Minimum to Maximum) }\end{array}$ \\
\hline Carpet $\backslash$ Wooden Floor & $£ 1,300$ to $£ 3,100$ \\
\hline Electrical Appliances & $£ 2,600$ to $£ 5,500$ \\
\hline Doors \& Windows & $£ 1,800$ to $£ 4,500$ \\
\hline $\begin{array}{l}\text { Living } \backslash \text { Dinning } \backslash \text { Kitchen } \backslash \\
\text { Bed room Furniture } \backslash \text { Infra structure }\end{array}$ & $£ 9,700$ to $£ 23,200$ \\
\hline Personal Items & $£ 2,800$ to $£ 4,400$ \\
\hline Cleaning and Repairs & $£ 4,900$ to $£ 8,280$ \\
\hline Hidden Costs & $£ 2,800$ to $£ 5,250$ \\
\hline
\end{tabular}

Table 2 demonstrates cost implications for commercial and residential properties and show a range between $£ 1,300$ and $£ 23,200$, depending on the item damaged/lost. Based on data from Table 2, cumulative damage costs might range from a minimum of $£ 25,900$ to a maximum of $£ 54,230$. However, according to the Environment Agency (2013) flood damage costs for property are $£ 1$ Billion, and the Association of British Insurers (ABI) (2010) estimates are between $£ 20,000$ (minimum) and $£ 40,000$ (maximum) for a single property. Subsequently, flood damage costs for commercial and residential properties were compared with aforementioned organisations evaluations and differed and offered new estimations.

However, flood events are not an every year phenomenon and their generation is highly uncertain. Typically, an average of 40,000 properties (estimated on previous flood events) are affected by very severe floods, which results in England's average annual destruction costs for commercial and residential properties being > £1.6 Billion, as follows:

$$
\left(\frac{£ 25,900+£ 54,230}{2}\right) \times 40,000=>£ 1.6 \text { Billion }
$$

It should be noted that indirect and secondary costs were not included in this assessment and the work does not distinguish between tangible and non-tangible aspects such as time lost from work, lives lost, emotional stress, etc. Consequently, the true costs could be much higher, but this is beyond the scope of this work. 


\section{Damage Cost Impacts on UK and English Economies}

It has been shown that commercial and residential property flood damage costs in England are $>£ 1.6$ Billion and therefore, the anticipated impact on GDP is assessed using equation 1:

\section{$\left(\frac{1602600000}{1600000000000}\right) X \%=0.10 \%$}

Therefore, £1.6 Billion represents $0.1 \%$ of UK GDP and consequently its effects at the macro scale is not significant. Moreover, analysis of impact of flood damage costs on local GDP and economies are determined accordingly:

\section{$\left(\frac{1602600000}{1300000000000}\right) X \%=0.12 \%$}

At the English scale flood damage costs represent $0.12 \%$ of GDP, and again is relatively insignificant. However, major infrastructure damage and environmental degradation are not included and these could have a more significant effect on national GDP. Future research will look into these scenarios.

\section{Conclusion}

Research on fiscal flood damage evaluation for properties in England has assessed two different approaches to cost assessment. Results suggest that the Environment Agency and British Insurers flood damage estimates are optimistic and secondly, a more considered in-depth evaluation for commercial and residential properties should be undertaken. This research established a systematic framework to address these deficiencies and achieved a more realistic estimate of flood damage costs. This new approach differentiated flood levels by using a measurement tool, which is colour, coded and represented at $\mathrm{cm}$ and $\mathrm{m}$ scales. English flood damage costs exceed £1.6 Billion, which was shown to be a fraction of UK and English GDPs $(0.1 \%)$. However, at a community level this remains a significant amount to local economies. Therefore, if flood adaptation processes are not enhanced, fiscal costs could ultimately negatively impact on future GDP.

\section{References}

ABI. (2010). Massive rise in Britain's flood damage bill highlights the need for more help for flood vulnerable communities says the ABI. https://www.abi.org.uk/News/News-releases/2010/11/Massive-rise-in-Britainsflood-damage-bill-highlights-the-need-for-more-help-for-flood-vulnerablecommunities-says-the-ABI 
BBC. (2009). Gloucestershire - Floods. 03 04, 2009.

http://www.bbc.co.uk/gloucestershire/content/image_galleries/july_floods_galler y.shtml?6

Ciscar, J. C., Iglesias, A., Feyen, L., Szabó, L., Van Regemorter, D., Amelung, B., ... \& Soria, A. (2011). Physical and economic consequences of climate change in Europe. Proceedings of the National Academy of Sciences, 108(7), 2678-2683. Darkes.G (2008). How long is the UK coastline. http://www.cartography.org.uk/default.asp?contentID=749

Environment Agency. (2009). Investing for the Future, Bristol: Environment Agency. Environment Agency (2014). 2012 floods cost UK economy nearly $£ 600$ million. 12 04, 2013. http://www.environment-agency.gov.uk/news/150900.aspx

Jha, A. K., Bloch, R., \& Lamond, J. (2012). Cities and flooding: a guide to integrated urban flood risk management for the 21st century. World Bank Publications.

Maps of World. (2013). England Map. http://www.mapsworld.com/england ONS. (2013) The countries of the UK. 02 12, 2013 http://www.ons.gov.uk/ons/guidemethod/geography/beginner-s-guide/administrative/the-countries-of-theuk/index.html

ONS. (2013).Regional GVA. 12,12,2013

http://www.ons.gov.uk/ons/taxonomy/index.html?nscl=Regional+GVA\#tab-data$\underline{\text { tables }}$

Pielke Jr, R. A., \& Downton, M. W. (2000). Precipitation and damaging floods: Trends in the United States, 1932-97. Journal of Climate, 13(20), 3625-3637.

The Economist. (2013). Britain's economy - Just better than nothing. 27042013 http://www.economist.com/news/britain/21576710-britain-has-escapedrecession-its-economy-remains-weak-house-building-industry-explains

World Bank. (2014).United Kingdom Data - GDP. 10 12, 2013

Available at: http://data.worldbank.org/country/united-kingdom

Zhou, Q., Mikkelsen, P. S., Halsnæs, K., \& Arnbjerg-Nielsen, K. (2012). Framework for economic pluvial flood risk assessment considering climate change effects and adaptation benefits. Journal of Hydrology, 414, 539-549.

Journal published by the EAAEDS: http://www.usc.es/economet/eaat.htm 


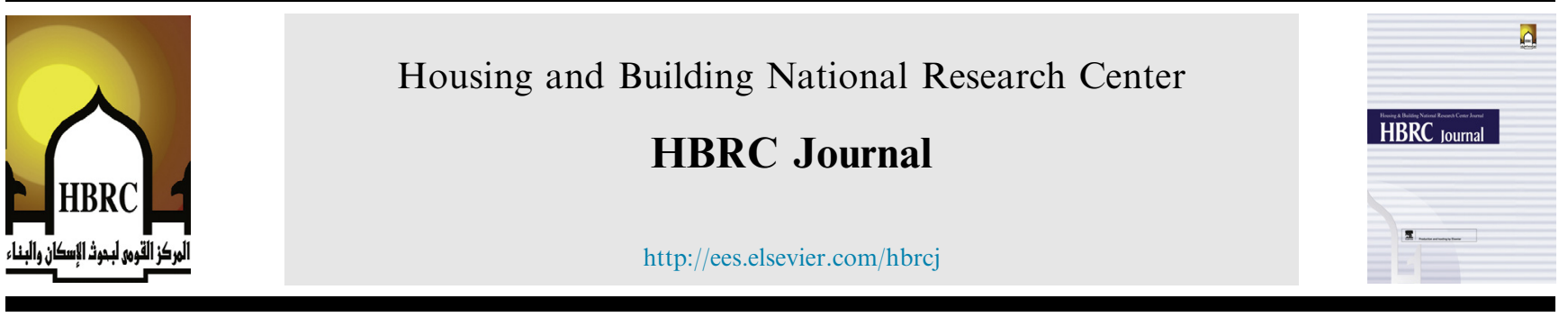

FULL LENGTH ARTICLE

\title{
Cost vs. safety: A novel design for tornado proof homes
}

\author{
Komali Kantamaneni *, Ibrahim Alrashed, Micheal Phillips
}

Faculty of Applied Design and Engineering, School of Built and Natural Environment, University of Wales Trinity Saint David, Swansea SA1 6ED, United Kingdom

Received 25 September 2014; revised 7 April 2015; accepted 24 May 2015

\author{
KEYWORDS \\ Novel design - 3D CAD \\ model; \\ Tornado proof home; \\ Missile steel and shield \\ technology; \\ Safety; \\ Construction costs
}

\begin{abstract}
Tornadoes are dangerous and destructive weather phenomena. The strongest category of tornadoes on the enhanced Fujita and TORRO scales is responsible for $75 \%$ of property destruction and deaths across the globe. These issues highlight the need for new design practices aimed at producing tornado proof homes in particular 3D CAD models in tornado prone zones at current climatic scenarios. Previous studies were entirely based on traditional slants and failed to offer a reliable tornado proof home, other than small rooms and trailers, while, none of the literature concentrated on multiple factors (cost, safety and high-wind proof). Therefore, a knowledge gap exists. In order to address the current research gap, this study attempts to develop an innovative 3D CAD model for tornado resistant homes by incorporating 2 PA (Two Path Analysis). Consequently, this study provides a new design using a 3D-CAD model for a tornado resistant home as in Path One and cost and safety scenarios in Path Two. However, this new design utilizes missile steel and shield technology. Preliminary results showed that, while this new design is safer and more technically sophisticated, it involves an increase of $25-30 \%$ in construction costs. However, this increased expense is low in comparison with rebuilding costs.

(c) 2015 The Authors. Production and hosting by Elsevier B.V. on behalf of Housing and Building National Research Center. This is an open access article under the CC BY-NC-ND license (http:// creativecommons.org/licenses/by-nc-nd/4.0/).
\end{abstract}

\section{Introduction}

Tornadoes cause moderate to serious infrastructure damage and fatalities. Specifically, recurrent strikes of tornadoes are high in the U.S.A. (75\%) followed by Canada $(5 \%)$ and Bangladesh (3\%) (Fig. 1) [1-7]. On average, > 1200 tornadoes occur annually at various locations in the U.S.A., and recent statistical data revealed that from 742 tornado incidents in 2013, there were 54 fatalities with damage costs of $\$ 3.6$ billion [8]. While, Structural damage costs at global and regional scales are $>\$ 8$ billion and $>\$ 1.5$ billion respectively, which comprises $60 \%$ of annual insurance loss [9].
E-mail address: Komali.kantamaneni@uwtsd.ac.uk (K. Kantamaneni). Peer review under responsibility of Housing and Building National Research Center.

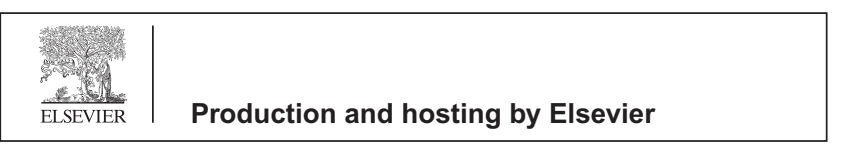




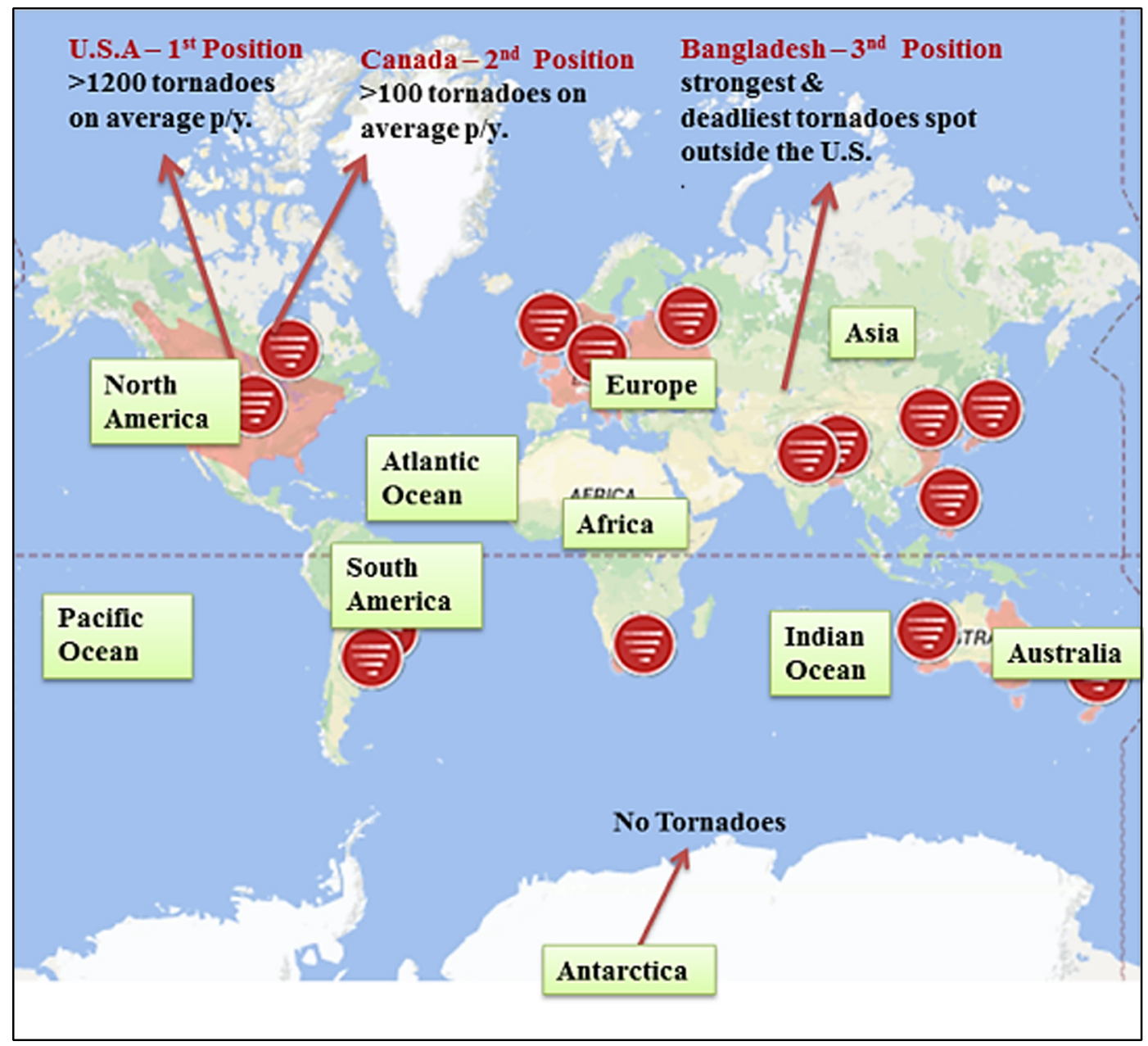

Fig. 1 Global incidences of tornadoes [12].

According to Brooks et al. [10], since the 16th century there have been more than 20,000 deaths in 3600 tornado strikes. Many tornadoes have relatively low wind speeds $(<180 \mathrm{~km} / \mathrm{h})$ and are between 40 and $100 \mathrm{~m}$ in diameter, potentially traveling many miles before dissipating. Some extremely violent tornadoes can reach speeds of $>450 \mathrm{~km} / \mathrm{h}$, and can expand to $>3 \mathrm{~km}$ in radius while traveling approximately $100 \mathrm{~km}[10,11]$.

Damage caused by tornadoes raises concerns regarding design methods and practices used for the construction of residential homes. However, the building of tornado resistant homes and the development of construction materials with steel components that are utilized to design residential structures against high winds are somewhat new. Consequently, this research paper will identify the importance of tornado proof homes, as well as financial consequences of loss. From a consideration of safety issues and utilizing a novel Three-Dimensional Computer Aided Design (3D CAD) model, a design for tornado proof houses will be developed. Subsequently, the novel designs will be analyzed and evaluated against construction cost and safety scenarios by incorporating 2PA -2 Path Analysis methodology.

\section{Background}

There has been a considerable amount of research on the designs and practices of tornado resistant homes, but this research is fairly limited. Martin [13] designed tornado escape capsules (Figs. 2 and 3) for the house trailer, which comprises a strongly constructed escape capsule with a lockable entrance. Silen [14] designed a model for a tornado protection building (Fig. 4), which has top and sidewalls. This is resistant to tornado windforces because, the metal sheet covering is reinforced by upright and straight beams bonded together in a structural framework. Both are feasible from a safety perspective but not from a cost viewpoint. Gopu and Levitan [9] proposed a low-cost lightwood frame construction for tornado resistant homes, while Green [15] suggested a portable pre-fabricated tornado shelter for use in tornado prone zones. Furthermore, Weber [16], Marroquin [17], Reed [18], Hillje [19] and Zubieta [20] suggested novel designs for tornado proof building/shelters. More recently, Zhou et al. [21] proposed a tornado safety room. While all models as mentioned above had diverse success rates from both cost and safety perspectives, it highlights that current design practices are not adequate to sufficiently resist tornado wind forces (400 mph). Consequently, this study focused on 


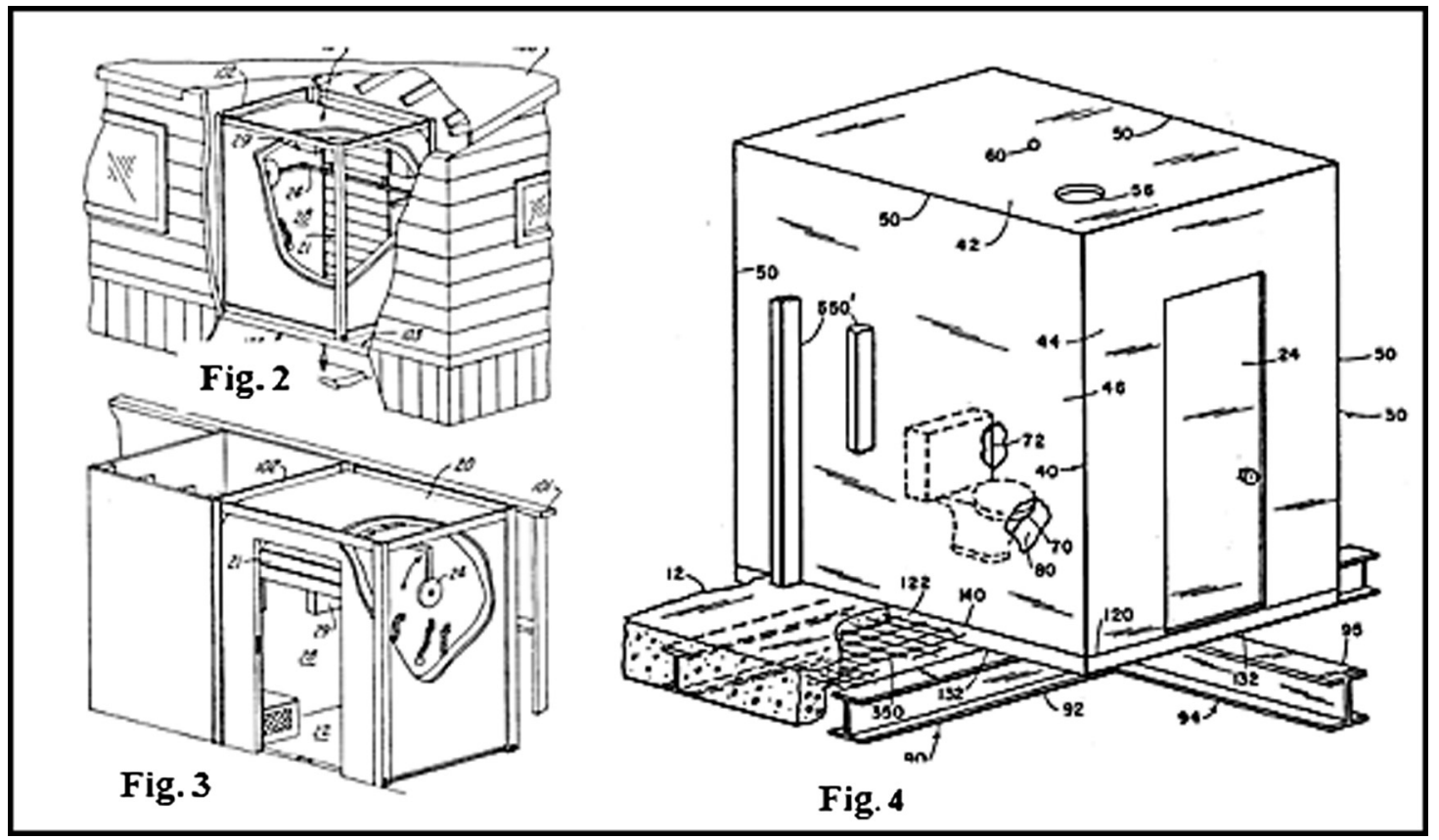

Figs. 2-4 (2 and 3) Tornado escape capsule [13]. (4) Tornado protection building [14].

construction designs for tornado resistant homes capable of resisting $400 \mathrm{mph}$ winds using missile shield and steel technology. The designs utilized a new 3D-CAD model and considered cost and safety consequences.

\section{Anatomy of tornado winds}

Measurement of tornado wind speed in severe weather conditions is a challenging task because of their occurrences at remote locations and short-lived nature. However, most of the tornadoes were not recorded by meteorological station networks across the globe due to the lack of sophisticated radar system such as Doppler on Wheels (DOW) [22]. Nonetheless, the damage of tornado strikes mainly depends on gust speed. This force destroys the construction and properties within seconds. Meanwhile, violent tornadoes are usually long-lived and cause severe destruction to structures (residential and commercial) and infrastructure $[23,24]$. Estimation of wind speed will usually acquired from post-tornado strikes. Nevertheless, wind intensity has often been categorized either using the Enhanced Fujita scale -EF (modified from E scale to EF scale in 2007) [25] or using the T-scale (TORRO Scale -Europe only) [26] or using both classifications (Table 1). However, they were initially devised as wind speed scales, but in practice, they are established and applied as explanatory scales that differentiate several levels (EF0-EF5) of destruction to structures (Figs. 5 and 6). Furthermore, highest wind speed in tornado history is $318 \mathrm{mph}$, which was recorded on 3rd May 1999 at Oklahoma [27], and more recently, above $200 \mathrm{mph}$ winds recorded at the same state in 2013 [28].

\section{Tornado losses (insurances) in the USA}

Based on insurances data for tornado damage in USA for the period of 1949-2006 explored that, more than 790 strong tornadoes caused $>\$ 6$ trillion losses [32]. Nevertheless, in 2011
Table 1 Wind measurement on Enhanced Fujita (EF) TORRO (T) scale [25].

\begin{tabular}{|c|c|c|}
\hline \multicolumn{3}{|l|}{$\mathrm{EF} / \mathrm{T}$ scale } \\
\hline $\begin{array}{l}\mathrm{EF} / \mathrm{T} \text { scale } \\
\text { rating }\end{array}$ & Gust (mph) speed $-3 \mathrm{sec}$ & $\begin{array}{l}\text { Distinctive } \\
\text { damage }\end{array}$ \\
\hline EF0 (T0\&T1) & $65-85$ & Light damage \\
\hline EF1 (T2\&T3) & $86-110$ & $\begin{array}{l}\text { Moderate } \\
\text { damage }\end{array}$ \\
\hline EF2 (T4\& T5) & $111-135$ & $\begin{array}{l}\text { Significant } \\
\text { damage }\end{array}$ \\
\hline EF3 (T6\&T7) & $136-165$ & Severe damage \\
\hline EF4 (T8\&T9) & $166-200$ & $\begin{array}{l}\text { Devastating } \\
\text { damage }\end{array}$ \\
\hline EF5 (T10\&T11) & Over 200 & $\begin{array}{l}\text { Incredible } \\
\text { damage }\end{array}$ \\
\hline $\begin{array}{l}\text { EF6 (T12 or } \\
\text { Open Ended) }\end{array}$ & $\begin{array}{l}300 \text { to } 400 \mathrm{mph} \text { (Under } \\
\text { Consideration of NOAA) }\end{array}$ & $\begin{array}{l}\text { Inconvenience } \\
\text { damage }\end{array}$ \\
\hline
\end{tabular}

thunderstorms and tornadoes together triggered the \$29 billion property damage [33]. Chronological statistics revealed that, 2013 and 2011 stand out as the most destructive years of the past 63 years period and deliver an indication that extreme damage levels have the possibility to upsurge and should social change lead to growing exposure of fortune and property. Catastrophic tornado strikes and losses are very common in Oklahoma, Texas and Kansas.

\section{Missile steel and shield technology ${ }^{1}$}

The maraging steel was developed in 1959 and then induced a great attention, particularly in the aerospace, nuclear and

\footnotetext{
${ }^{1}$ Authors contacted steel companies and missile construction engineers for the possibility of transforming maraging steel into proposed models and designs.
} 


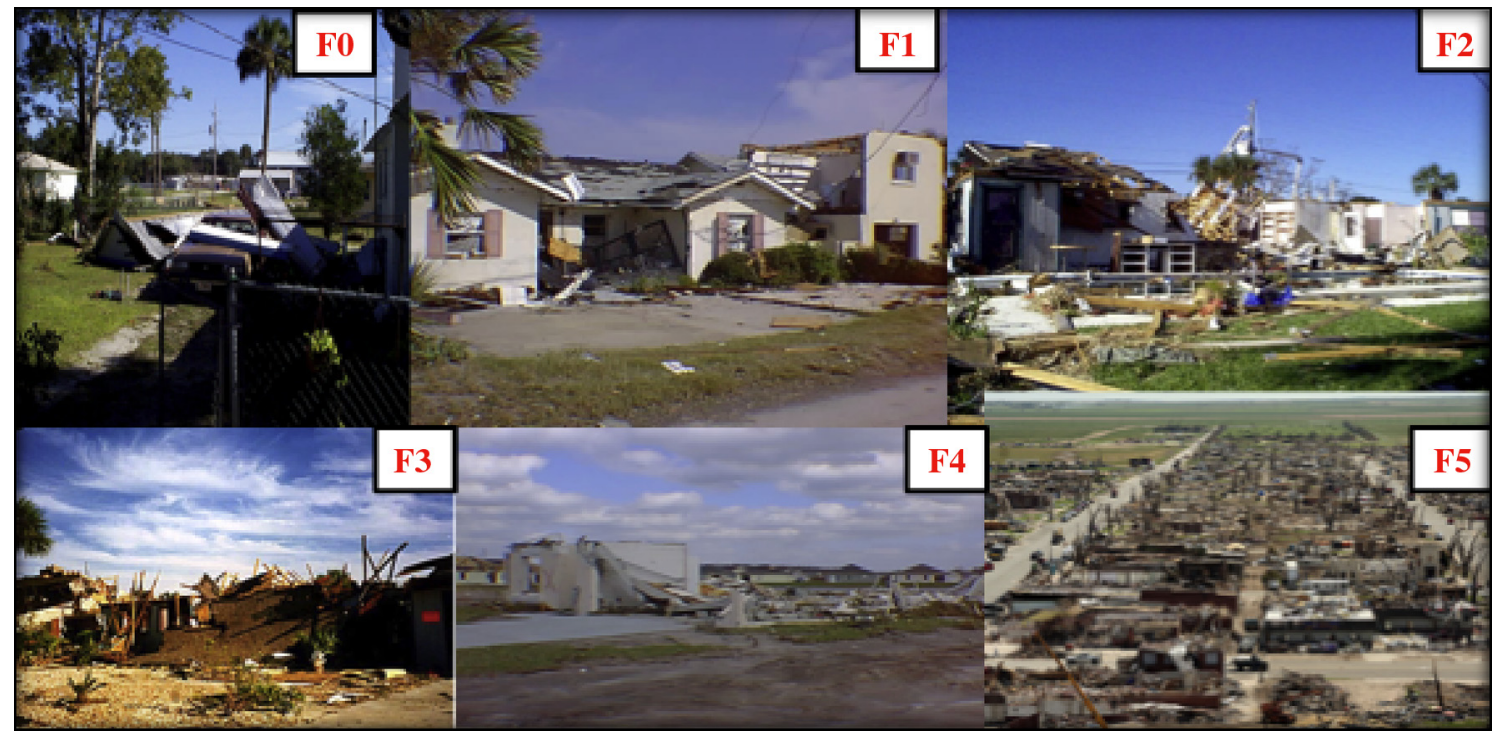

Fig. 5 F0 to F5 tornadoes' damage $[29,30]$.

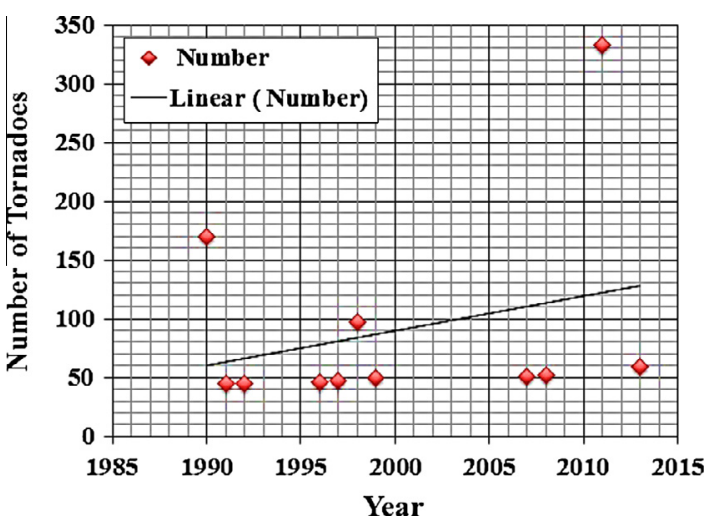

Fig. 6 F5 and EF5 tornados in the USA for the period of 1990-2013 [31].

military world because of its enormous mechanical properties. Maraging steel made up of high-nickel, extra-low-carbon, iron-base alloys held an inordinate promise of offering an amazing combination of structural strength and fracture robustness, while, these steels have high mechanical strength (1700-4000 MPa) and toughness, which means they can resist high winds and temperatures [34,35]. However, 0.0130 MPa are capable enough to resist the $>400 \mathrm{mph}$ winds [50,51,34]. Currently, some missiles are manufacturing alloys of one or two metals and composite materials [36-40]. Moreover, missile shield technology is a distinctive technology used in the formation of the body of the missile (Fig. 7). The steel is modified into a curved, arched, or sheet-like structure, based on the required properties and role of the missile; the steel is heated and then appropriately modified. Once formulated, it is then used to make the missile's outer casing [41-43]. This technology offers good results and high success rates and consequently, missile steel has been used for the construction of tornado proof homes. While, many modern houses are also constructed of steel and often have innovative designs (Figs. 8 and 9), TATA Steel that is one of the world's top 10 steel manufacturers offers many diverse steel structures and roofs (Fig. 10).

\section{Methodology}

There are no rigorous and precise methodologies (collective method) for designing and estimating the tornado proof homes within technical, fiscal and safety perspectives, while, most of the academic literature constructed on technical drawings [16,47,17-19,48,20,21]. Accordingly, a coherent and concise framework has been developed to design and assess tornado resistant homes and its costs by incorporating missile shield technology through - 2 Path Analysis (Fig. 11). This new methodology was constructed in two important paths:

Path One (P1): The practical applicability of providing new 3D-CAD designs for tornado-proof homes;

Path Two (P2): An initial estimate of construction costs and safety issues.

Consequently, this methodology utilizes 17 th version of Archi-CAD software to design an innovative tornado resistant home and subsequently assesses construction costs and safety issues based on collected data.

\section{Structural analysis of $3 D-C A D$ design}

This newly designed house consists of four vital structures (Fig. 12a and b) as follows:

1. A vertical reinforced concrete pillar is located in the middle of the house. It penetrates through the roof and extends $25 \%$ higher than roof height.

2. Secondly, a maraging steel sheet, is folded and located inside the pillar.

3. Thirdly, an electric engine which is fixed inside the bottom of the pillar is used for propelling the steel sheet prior to a tornado strike.

4. Fourthly, a tornado alarm is fixed to the pillar and located outside the roof. 


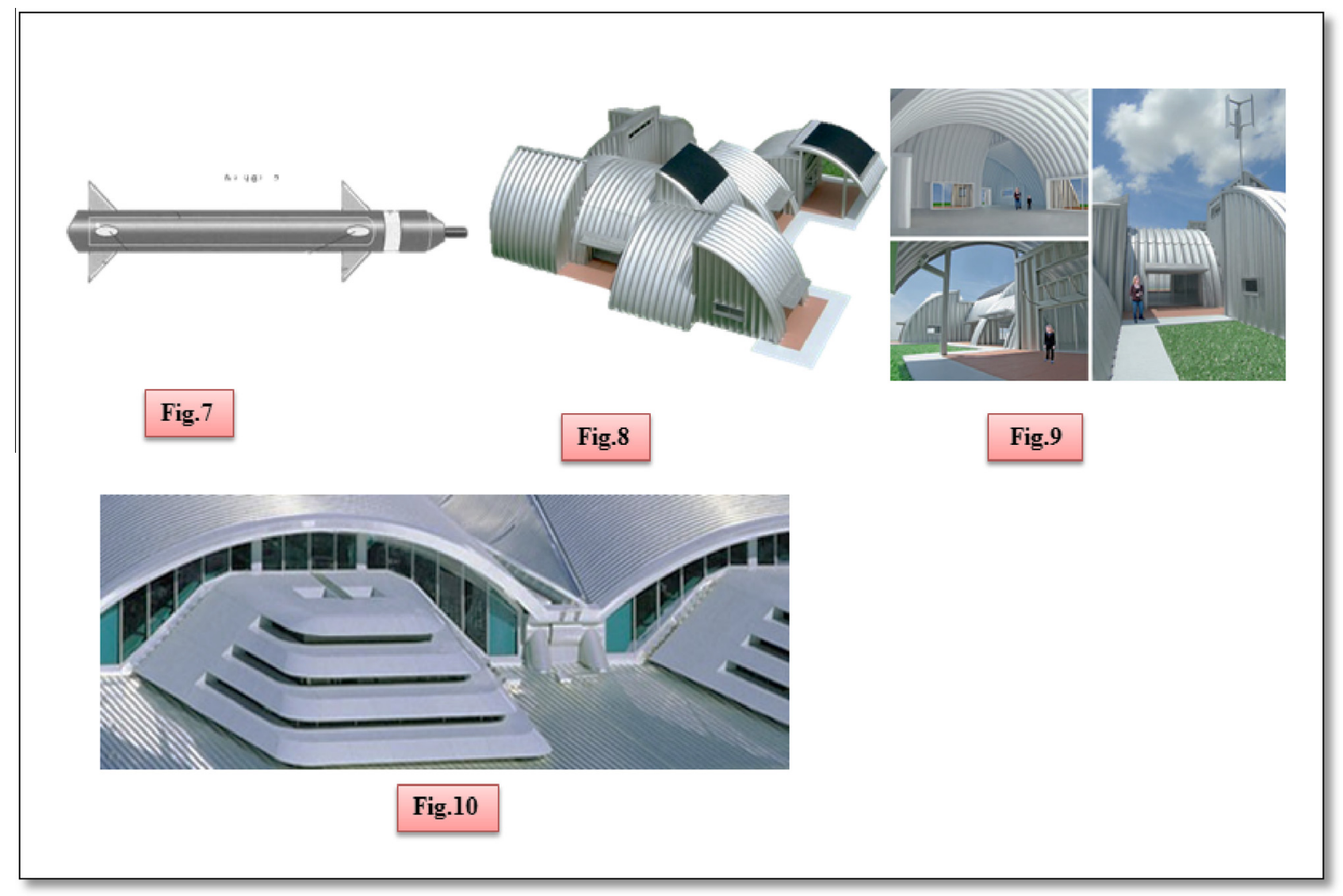

Figs. 7-10 (7) Missile body. (8) Steel home. (9) Inside the steel home. (10) TATA steel roof design for homes and commercial buildings [44-46].

Moreover, there is another special structure in this model that is an iron frame base, which stabilizes the maraging steel roof during a tornado strike.

\section{Evaluation of construction costs and safety scenarios}

The second phase of the methodology evaluates the cost of the missile steel roof. It also assesses how safe and technically feasible this model is compared with other designs.

\section{Data}

Tornado data were obtained from National Atmospheric Administration (NOAA), Storm Prediction Center (SPC) and TORRO databases. Besides, recent information regarding tornado proof homes and economic costs was obtained from the academic literature (Journals, Books, Conference papers), while, data relating to maraging steel and its costs were obtained from metal and steel companies as well as NASA website. In addition, global housing and construction statistics were obtained from legitimate construction databases across the world, such as U.S. Census Bureau, Office for National Statistics (ONS)-UK, and National Buildings Construction Corporation (NBCC)-India. Subsequently, these data were analyzed for factual results.

\section{Results and discussion}

Path One (P1)

Confronts in designing tornado proof homes

The design of the various components, materials and connections in a missile steel and shield construction to resist the anticipated level of wind loads is feasible. However, there are

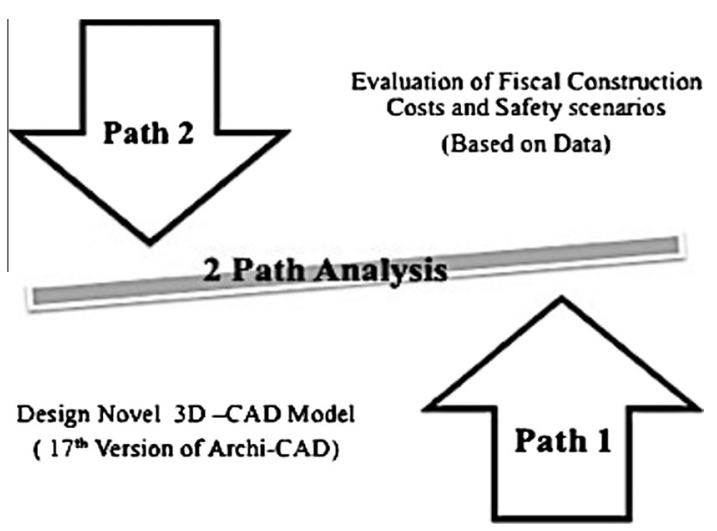

Fig. 11 Methodology - 2 Path Analysis. 


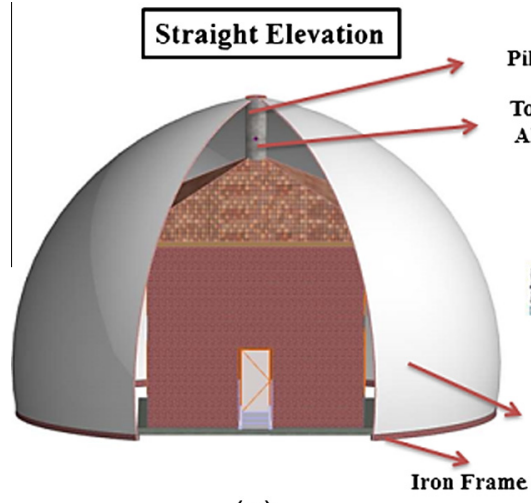

(a)

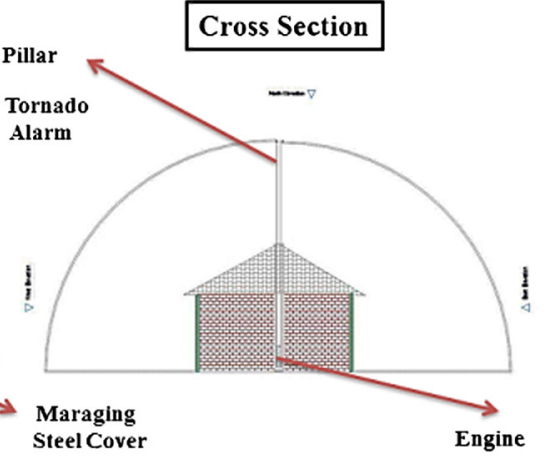

(b)

Fig. 12 3D CAD model - straight elevation of tornado proof home. (b) Cross section with missile steel and shield technology.

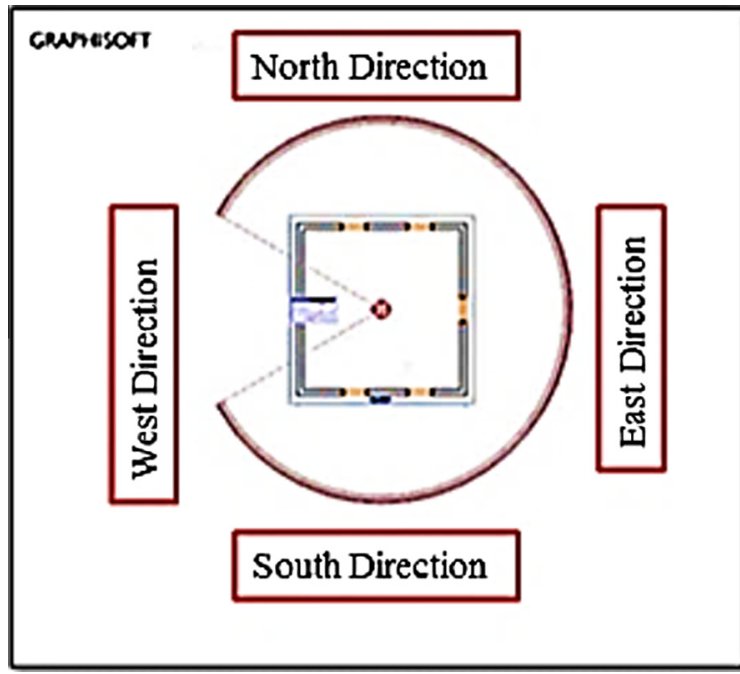

Fig. 13 Plan of tornado resistant home.

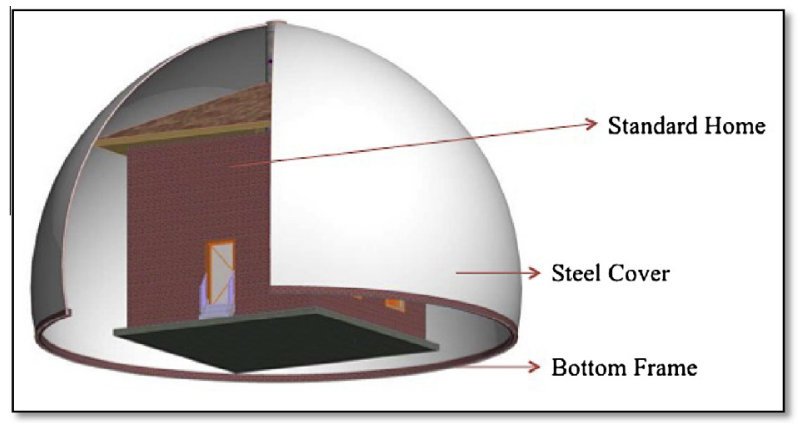

Fig. 14 3D-CAD model with steel cover with bottom frame.

some realistic confronts to developing these building models to be tornado resistant. In a tornado strike, the constructions are wedged by powerful winds $(250 \mathrm{~m} / \mathrm{h})$; therefore, protecting the home from these winds without casualties is a huge challenge. If resistance home to wind impact has to be attained, subsequently the construction cost would rise substantially - in surplus of $25-30 \%$, so raising the question regarding the cost of this extra investment. However, the current model is not an

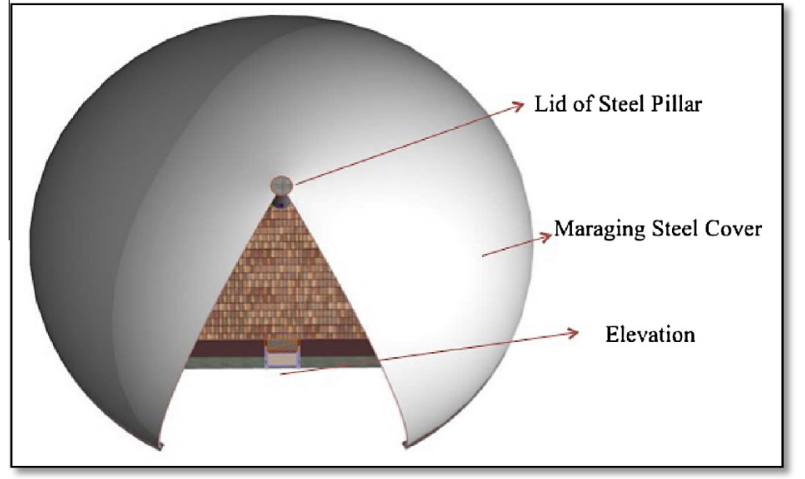

Fig. 15 Plan view of tornado resistant home.

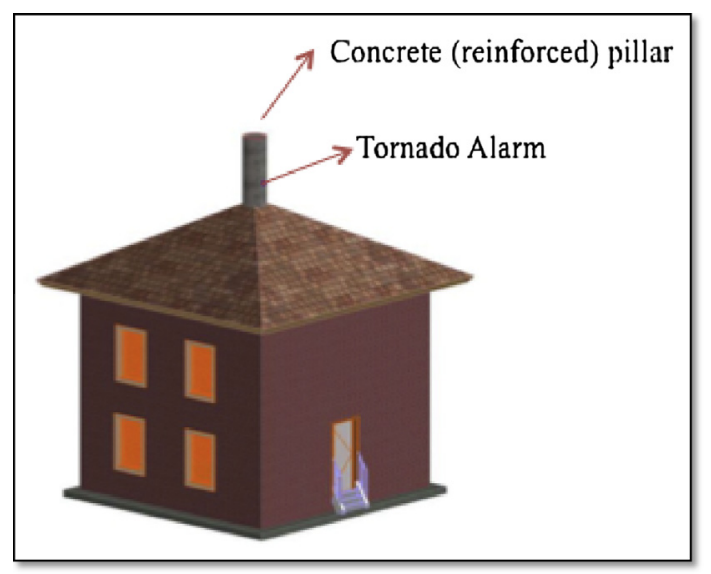

Fig. 16 Normal view of home, showing steel pillar.

exemption for those extra costs, but could be accepted by homeowners due to its special characteristics.

\section{Description of new invention}

Analysis of the deadliest and costliest tornadoes across the globe showed current strategies needed to be significantly improved by developing innovative tornado-proof homes. They are needed to protect people and property from severe tornadoes and accordingly, the proposed model would meet 


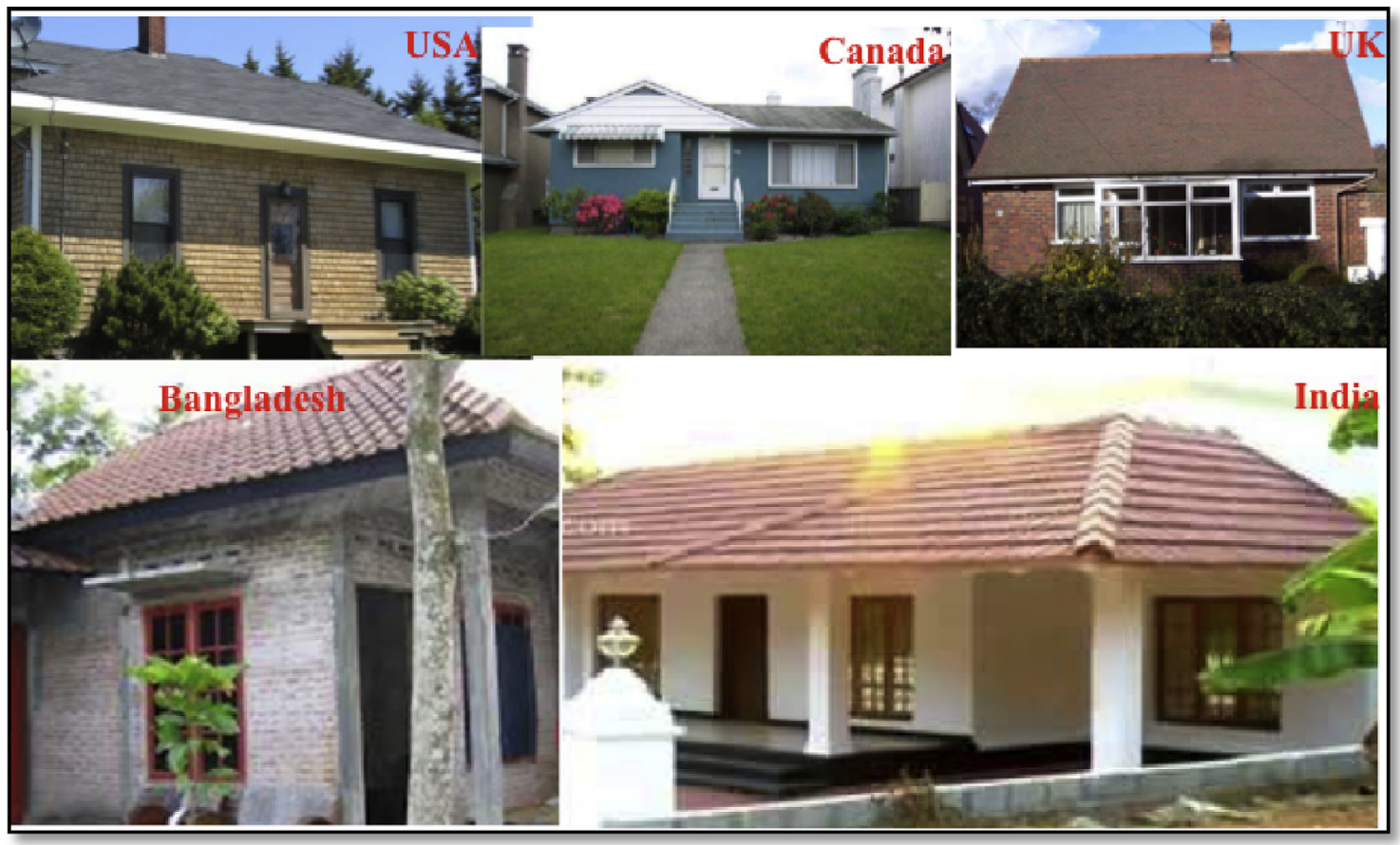

Fig. 17 House designs across the world (Asia, Europe, US and Canada) with different square foot (SF).

such objectives. Previous models failed to offer a reliable tornado proof home, other than small rooms and trailers. However, this innovative approach addresses all previous design disadvantages.

\section{Structural (technical) portrayals}

All figures (Figs. 13-16) showing the new design for the tornado resistant home were developed with 3D-CAD and Archi-CAD software.

\section{Mechanism}

As tornado alarms give (Fig. 12a) a warning approximately thirteen minutes before tornado strikes, there is time for the maraging steel sheet to be propelled to the top of the pillar by an electric engine fixed at the base. Subsequently, it opens like an umbrella, which covers the house on three sides, leaving one side open for access (Figs. 14 and 15), and its direction will depend on the country concerned. Strong winds generally approach from three directions with weak winds from the fourth and therefore, the new design covers three sides only. After the tornado event, the steel cover folds automatically, and the electric engine will then return close into the reinforced concrete pillar and the top. Electric engine (Fig. 12b) is a small and powerful device, and it is capable enough to impel any size of maraging steel sheet during tornado strike. Due to its super design, it is also very apt to pull back the maraging steel cover as in the form of folded manner after tornado event.

\section{Path Two (P2)}

Costs (\$)

The newly proposed tornado resistant house will cost more than previous models because of the use of maraging steel.
Table 2 Tornado proof home - components and costs (\$).

\begin{tabular}{ll}
\hline Components & Costs $(\$)-$ based on location and size \\
\hline Maraging steel & $\$ 15,000-\$ 55,000$ \\
Concrete reinforced pillar & $\$ 1800-\$ 10,000$ \\
Engine & $\$ 1000-\$ 5000$ \\
Tornado alarm & $\$ 100-\$ 300$ \\
Iron frame & $\$ 2000-\$ 8,000$ \\
Labor costs & $\$ 200-\$ 2000$ \\
Total costs & $\$ 20,100-\$ 80,300$ \\
\hline
\end{tabular}

Note: These are the extra costs for tornado proof homes along with normal construction costs.

Based on various maraging steel company data and quoted prices, costs are between $\$ 4000$ and $\$ 10,000$ per ton. The process of transformation from crude maraging steel to the highest quality steel roof is a complicated and costly process. However, it depends on various factors such as the area of the house, its location (e.g. Asia, America and Europe) (Fig. 17) and construction costs. Homes in many countries, e.g. US, Canada, UK, Bangladesh and India (Applicable to individual houses, bungalows and single story commercial buildings and not applicable to Chain houses, Flats, multistory commercial buildings and hurts) have a floor area of between 600 and $3000 \mathrm{SF}$, and accordingly construction costs for these houses range between $\$ 90,000$ and $\$ 300,000$, while, the proposed tornado resistant home incurs $25-30 \%$ higher construction costs (along with normal construction costs) (Table 2), with maraging steel being the most significant component. However, in the long-term it is suggested that these increased costs would be returned as it will save on rebuilding costs and importantly reduce the loss of life. 


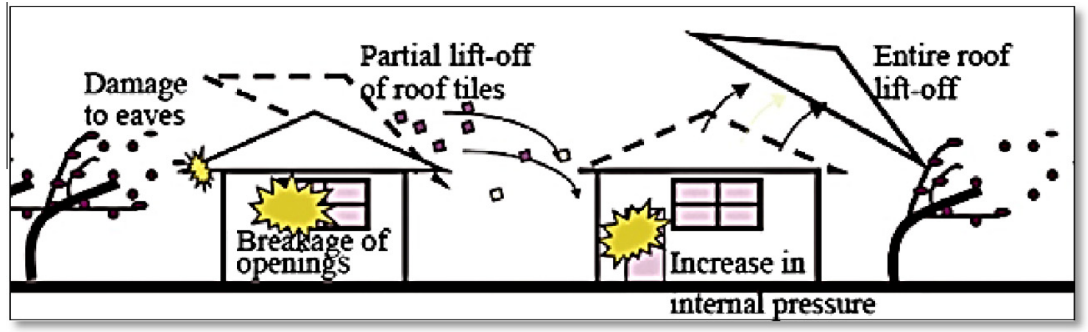

Fig. 18 Illustration of probable tornado wind and windborne debris damage to residential properties [49].

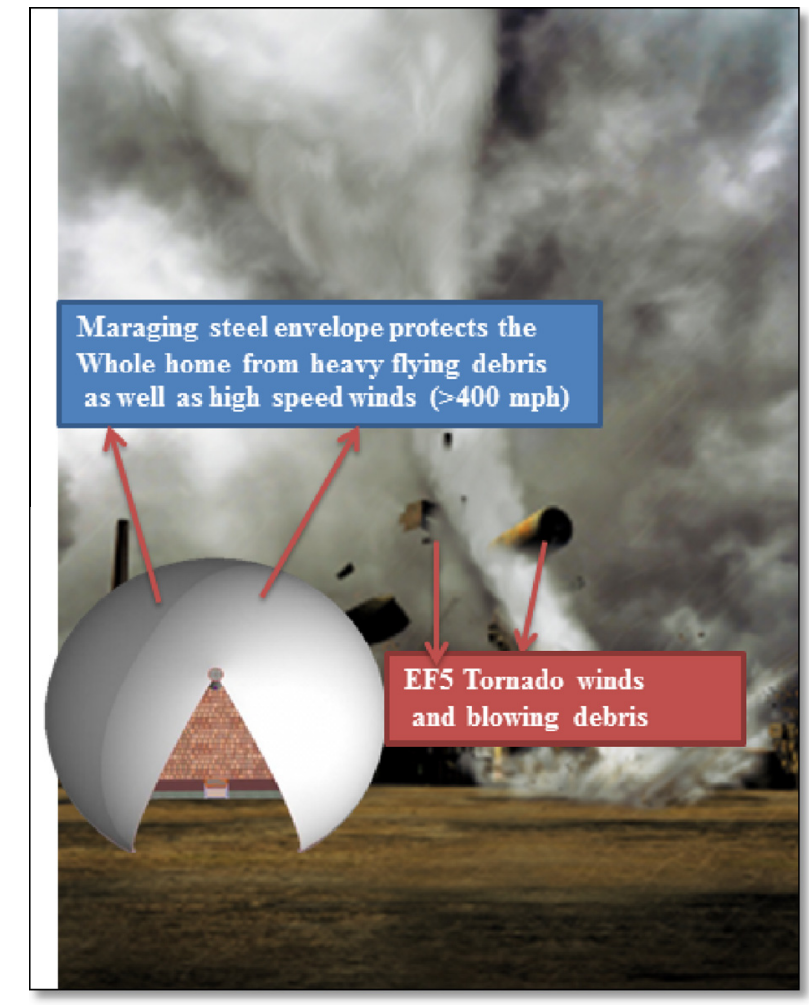

Fig. 19 3D-CAD model house during tornado strike.

\section{Safety}

As previously explained, from a safety perspective this proposed design is significantly safer than other models because of the maraging steel. Maraging steel has higher tensile strength, resistance and durability. Its use enables the building to withstand very severe atmospheric conditions and it will be capable of resisting unexpected changes in wind speed ( $>400 \mathrm{mph}$ ) and temperature, even under extreme circumstances. Material properties have made maraging steel a vital component of many missiles in use today, and based on this rationale, research has demonstrated its potential to produce a safe and resilient house.

\section{Novel 3D CAD model: feasibility and rationalization}

Four types of innovative structures and construction materials are introduced in the newly proposed 3D-CAD model, while, this model is significantly better model than existed models, based on flowing claims.
Table 3 Comparison of structural safety of the proposed design and existing models.

\begin{tabular}{|c|c|c|}
\hline Existing models & Protection & $\begin{array}{l}\text { Newly proposed } \\
\text { design }\end{array}$ \\
\hline $\begin{array}{l}\text { 1. Tornado } \\
\text { escape capsules }\end{array}$ & $\begin{array}{l}\text { Did not offer the } \\
\text { protection for whole } \\
\text { home }\end{array}$ & \\
\hline $\begin{array}{l}\text { 2. Low-cost } \\
\text { light-wood } \\
\text { frame } \\
\text { construction } \\
\text { model }\end{array}$ & $\begin{array}{l}\text { Not resistant } \\
\text { to }>400 \mathrm{mph} \text { winds }\end{array}$ & $\begin{array}{l}\text { Newly proposed } \\
\text { design protects the } \\
\text { whole building } \\
\text { through its specially } \\
\text { designed unique } \\
\text { mechanism and } \\
\text { components } \\
\text { (margining steel) from } \\
\text { air pressure and flying } \\
\text { debris caused by } \\
\text { tornado-force winds } \\
\text { (>400 mph) }\end{array}$ \\
\hline $\begin{array}{l}\text { 3. Portable } \\
\text { pre-fabricated } \\
\text { tornado shelter }\end{array}$ & $\begin{array}{l}\text { Failed to offer } \\
\text { protection for whole } \\
\text { home }\end{array}$ & \\
\hline $\begin{array}{l}\text { 4. Underground } \\
\text { structure }\end{array}$ & $\begin{array}{l}\text { Did not offer the } \\
\text { protection for whole } \\
\text { homes that are } \\
\text { constructed on the land }\end{array}$ & $\begin{array}{l}\text { Maraging Steel } \\
\text { comprises high } \\
\text { strength and can } \\
\text { withstand } \\
\text { in }>400 \mathrm{mph} \text { wind } \\
\text { environment }\end{array}$ \\
\hline
\end{tabular}

Note: Explanation and reference of existing models are provided in the Background Section.

\section{Claim 1}

Maraging steel envelope offers an ultimate protection from $>400$ winds as well as heavy flying objects (Figs. 18 and 19) for the whole home which were not provided by existing models (Table 3 ) due it its unique design and materials.

\section{Claim 2}

Maraging steel envelope also protects the human life from severe winds and flying objects, which also did not provide by previous designs, while there is no need to move to tornado shelters.

\section{Claim 3}

This model saves the repeated re-construction costs. 
Claim 4

The mechanism (described in section 3) used in this design to propel Maraging steel from the base, is completely innovative, fiscally effective and simple process.

Based on aforementioned issues, this research is concluding that, this model is more reliable, practicable, relatively safer and cost-effective than previous designs though it has high construction costs. (High construction costs are comparatively lower than repeated re-building costs).

\section{Conclusion}

This work described a novel 3D-CAD model incorporating missile steel and shield technology for tornado proof homes. It identified safety aspects for the construction and used Archi-3D-CAD software in the development of drawings. The newly designed model shows substantial advantages over most of the conventional resistant home designs or safe rooms via a vulnerability research study. Consequently, in this new design, a reinforced concrete pillar is located in the middle of the home, which extends a further $25 \%$ of its length above the roof. This supports a tornado alarm, while a maraging steel sheet folded within the pillar. Based on current advanced warnings of tornadoes, generally thirteen minutes before a tornado strike, alarms are sounded, and the steel sheet is released from the pillar, protecting three sides of the structure, while allowing access and egress. Following the event, the maraging steel sheet is returned into the pillar, and the top closed.

The newly designed model shows substantial advantages over most of the conventional resistant home designs or safe rooms via a vulnerability research study. Therefore, this new 3D-CAD model provides a safer and more responsive construction than previous models. However, while tornado proof buildings/homes with missile shield technology are feasible construction costs are $25-30 \%$ higher than for standard construction. Therefore, a house can become a home for many years to come, even when in the midst of tornadoes.

\section{Conflict of interest}

The authors declare that they have no conflict of interest.

\section{Acknowledgments}

This study is supported by 111 Project "Hazard and Risk Science Base at Beijing Normal University" under Grant B08008, Ministry of Education and State Administration of Foreign Experts Affairs, People's Republic of China. Authors are also immensely grateful to two anonymous reviewers for their useful comments that are helped to improve the quality of the manuscript.

\section{References}

[1] R. Peterson. Tornadoes of the former Soviet Union, in Preprints, 20th Conf. on Severe Local Storms, Orlando, FL, Amer. Meteor. Soc, vol. 138141, 2000.

[2] D. McCarthy, J. Schaefer. Tornado trends over the past thirty years, in: Preprints, 14th Conf. Applied Meteorology, Seattle, WA, Amer. Meteor. Soc, vol. 3, 2004.
[3] S.M. Verbout, H.E. Brooks, L.M. Leslie, D.M. Schultz, Evolution of the US tornado database: 1954-2003, Weather Forecast. 21 (2006) 86-93.

[4] M. Clark, The'Super Tuesday'Tornado Outbreak of 5-6 February 2008 over the Southern US, Int. J. Meteor. 33 (2008) 127.

[5] S.J. Hall, Editor's report: storm chasing holiday 10-30th may 2011 (Part 1) the Joplin Tornado, Missouri 22 may 2011: a report from a storm Chaser's perspective, Int. J. Meteoord. 36 (2011) 161.

[6] S. Banik, H. Hong, G.A. Kopp, Assessment of the wind hazard due to tornado outbreaks in southern Ontario, J. Wind. Eng. Ind. Aerod. 107 (2012) 28-35.

[7] NOAA. Monthly and Annual U.S. Tornado Summaries, 2014. $<$ http://www.spc.noaa.gov/climo/online/monthly/newm.html > (accessed 06.08.14)

[8] NOAA. Tornadoes - Annual, 2013. < http://www.ncdc. noaa.gov/sotc/tornadoes/2013/13> [accessed 10.05.14].

[9] V. Gopu, M. Levitan, Best design practices for wood frame construction in tornado prone areas, World 15 (2012) 19.

[10] H. Brooks, C.A. Doswell, Some aspects of the international climatology of tornadoes by damage classification, Atmos. Res. 56 (2001) 191-201.

[11] T.P. Grazulis, J.T. Schaefer, R.F. Abbey. Advances in tornado climatology, hazards, and risk assessment since tornado symposium II, The tornado: Its structure, dynamics, prediction, and hazards, 1993, pp. 409-426.

[12] C. Dolce, Tornado Strikes in the World, 2014. www. weather.com/news-tornado-around the world (accessed 02.06.14).

[13] F.A. Martin. Tornado escape capsule for trailer homes. Google Patents, 1999

[14] A. Silen. Tornado protection building. Google Patents, 1978.

[15] T.H. Green, Prefabricated portable tornado shelter, Google Patents, 2000.

[16] R.C. Weber, Underground structure for residential and business use, Google Patents, 1982.

[17] C. Marroquin. Tornado resistant house. Google Patents, 2008.

[18] R.S. Reed. Tornado resistant dome house. Google Patents, 2010.

[19] J. Hillje, Tornado storm shelter, Google Patents, 2012.

[20] S.D. Zubieta, Hurricane and tornado resistant structure, Google Patents, 2013.

[21] H. Zhou, K. Dhiradhamvit, T.L. Attard, Tornado-borne debris impact performance of an innovative storm safe room system protected by a carbon fiber reinforced hybrid polymeric-matrix composite, Eng. Struct. 59 (2014) 308-319.

[22] J. Wurman, P. Robinson, C. Alexander, Y. Richardson, Lowlevel winds in tornadoes and potential catastrophic tornado impacts in urban areas, Bull. Am. Meteor. Soc. 88 (2007) 31-46.

[23] J.H. Golden, J.T. Snow, Mitigation against extreme windstorms, Rev. Geophys. 29 (1991) 477-504.

[24] J. Wurman, D. Dowell, Y. Richardson, P. Markowski, E. Rasmussen, D. Burgess, L. Wicker, H.B. Bluestein, The second verification of the origins of rotation in tornadoes experiment: VORTEX2, Bull. Am. Meteor. Soc. 93 (2012) 1147-1170.

[25] C.A. Doswell, H.E. Brooks, N. Dotzek, On the implementation of the enhanced Fujita scale in the USA, Atmos. Res. 93 (2009) $554-563$.

[26] G. Meaden, Tornadoes in Britain: their intensities and distribution in space and time, J. Meteor. 1 (1976) 242-251.

[27] D.W. Burgess, M.A. Magsig, J. Wurman, D.C. Dowell, Y. Richardson, Radar observations of the 3 May 1999 Oklahoma City tornado, Weather Forecast. 17 (2002) 456-471.

[28] National Weather Service - Weather Forecast Office. Event Summary - May 19-20, 2013 Tornado Events, 2014. < http:// www.srh.noaa.gov/tsa/?n = weather-event_2013may19> (accessed 23.06.14). 
[29] National Weather Service - Weather Forecast Office. Tornado Strength in Florida, 2009. < http://www.srh.noaa.gov/mlb/?n= fscale $>$ (accessed 12.09.13).

[30] FEMA. Damaged Property in Greensburg, Kansa, 2007. < www. fema.gov/media-library/assets/images $/ 51340 ? \mathrm{id}==30066>$ (accessed 20 August 2013).

[31] SPC - Storm Prediction Center. F5 and EF5 Tornadoes in the US, 2014. <http://www.spc.noaa.gov./faq/tornado/fstorns. html $>$ (accessed 12.06.14).

[32] S.A. Changnon, Tornado losses in the United States, Natural Hazards Review 10 (2009) 145-150.

[33] K.M. Simmons, D. Sutter, R. Pielke, Normalized tornado damage in the United States: 1950-2011, Environ. Hazard. 12 (2013) 132-147.

[34] A.M. Hall, C. Slunder, The metallurgy, behavior, and application of the 18-percent nickel maraging steels, DTIC Document (1968).

[35] M. Ahmed, K. Hasnain, I. Nasim, H. Ayub, Magnetic properties of maraging steels in relation to nickel concentration, Metall. Mater. Trans. A 26 (1995) 1869-1876.

[36] W.S. Chang, Impact of solid missiles on concrete barriers, J. Struct. Div. 107 (1981) 257-271.

[37] D. Griffin, C.A. Field, Airborne missile launcher of modular construction, Google Patents, 1987.

[38] A. Shakesheff, G. Purdue, Designing metal matrix composites to meet their target: particulate reinforced aluminium alloys for missile applications, Mater. Sci. Technol. 14 (1998) 851-856.

[39] A.S. Smith, G.C. Hurst, J.L. Duerk, P.J. Diaz, MR of ballistic materials: imaging artifacts and potential hazards, Am. J. Neuroradiol. 12 (1991) 567-572.

[40] P. Mangalgiri, Composite materials for aerospace applications, Bull. Mater. Sci. 22 (1999) 657-664.

[41] J.A. Fant, B.E. Chitwood, M.S. Howeth, Composite structural beams and method, Google Patents, 1976
[42] T.L. Attard, High strength and high elasticity composite materials and methods of reinforcing substrates with the same, Google Patents, 2011.

[43] T.L. Attard, H. Zhou, Impact resistance of tornado shelters using a load bearing composite having a multi-phase hybrid polymeric interfacial cohesion mechanism, in: Proc ASCE Engineering Mechanics Institute Conf, Evaston, IL, 2013.

[44] Roberts A. Cortese. How Products are Made, 2006. < www.madehow.com/Volume-1/Laser-Guided-Missile.html > (accessed 15.04.13).

[45] Jantzen Michael. Steel House: Modular, Prefab, Off-the-Grid Green Design, 2014. < http://dornob.com/steel-house-modularprefab-off-the-grid-green-design/\#axzz38D9Di271> (accessed 25.04.14).

[46] TATA Steel. Roofs, 2014. < http://www.tatasteeleurope.com/ en/products_and_services/products/construction_products and_systems/roofs $>$ (accessed 12.03.14).

[47] J.E. Minor, Windborne debris and the building envelope, J. Wind Eng. Ind. Aerod. 53 (1994) 207-227.

[48] M. Grayson, W. Pang, S. Schiff, Three-dimensional probabilistic wind-borne debris trajectory model for building envelope impact risk assessment, J. Wind. Eng. Ind. Aerod. 102 (2012) 22-35.

[49] Y. Tamura, Wind induced damage to buildings and disaster risk reduction, in: Proceedings of the APCWE-VII, Taipei, Taiwan, 2009.

[50] A.C. Rodrigues, H.H. Bernardi, J. Otubo, Microstructural analysis of co-free maraging steel aged, J. Aerospace Technol. Man. 6 (2014) 389-394.

[51] A.T. Ferris, Force instrumentation for cryogenic wind tunnels using one-piece strain-gage balances, National Aeronautics and Space Administration Report. 1980, p. 1. 


\section{Two Fiscal Front-Runners: Will Economies Suffer Due to Lack of Flood Resilience?}

1 University of Wales Trinity Saint David, Swansea, United Kingdom 1

\section{RESEARCH HIGHLIGHTS}

* UK Flood annual damage costs: $£ 1.5$ bn

* By 2080s it will be $£ 30$ bn

- In UK out of 28 million properties - more than 6 million are at risk of flooding

* Hurricane Sandy (US) destruction costs: \$56 bn

* Over half the population of both countries live near the coast

* At present no impact to US and UK national economies

* National economies will be significantly affected by 2080 s

\section{Abstract}

This paper qualitatively assesses two case studies in the United Kingdom and United States of America, which are interlinked using a new methodology. This study assesses recent flood damage, its cost then scrutinises direct impacts on local economies. It evaluates whether or not flooding costs had any significant impact on national economy/GDP. This research found that annual UK damage costs are $£ 1.5$ bn and cost of Hurricane Sandy to US was $\$ 56 \mathrm{bn}$. On a national scale these are relatively insignificant and did not have a major impact on national economies.

\section{INTRODUCTION}

In order to establish a rigorous $21^{\text {st }}$ century flooding resilience, intensive climate change research will be needed. This will inform infrastructure protection measures to prevent severe economic loss due to anticipated and unpredicted flooding.

UK flooding costs, particularly since 2007, have been estimated at $£ 1$ billion every year and are expected to reach $£ 27$ billion by 2080 (Bennett, 2010), with more than 5.5 million properties at flood risk in England and Wales (Environment Agency, 2009).

In the USA, 2012 flood damage costs were $\$ 495,583,000$ (NWSIST, 2013) with a current annual cost of $\$ 12$ billion (ASFPM, 2013). Moreover, average flood costs over 30 years were $\$ 8.2$ billion (NWSIST, 2013) and in recent years, there has been a further $\$ 8$ billion cost from Hurricane events (Nordhaus, 2006).

Accordingly, this paper assesses flood damage costs of United Kingdom along with costs due to Hurricane Sandy destruction. it also evaluates whether or not flooding costs had any significant impact on national economy/GDP.
Komali Kantamaneni ${ }^{1}$ and Michael Phillips ${ }^{1}$

\section{References}

ASFPM (The Association of Floodplain Managers), (2013), Flood Mapping for the Nation - A Cost Analysis for Nations Flood Map Inventory: Available at http://www.floods.org/ace-files/documentlibrary/2012 NFIP Reform/Flood Mapping for the Nation ASFPM Report 3-1-2013.pdf [Accessed on 0905 2013] - Environment Agency, (2009), Prepare your Property for Flooding: A Guide for House Holders and Small Business: Available at http://a0768b4a8a31e106d8b0-50dc802554eb38a24458b98ff72d550b.r19.cf3.rackcdn.com/geho1009brdl-e-e.pdf [Accessed 12042013

-Nordhaus, W.D, (2006), The Economics of Hurricanes in the United States, Working Paper No.12813, Available at: http://www.nber.org/papers/w12813 [Accessed 2312 2012] -NWSIST (National Weather Service Internet Service Team), (2013), Hydraulic Information Centre-Flood Loss Data: NOAA, National Weather Service: Available at http://www.nws.noaa.gov/hic/ [Accessed 19042013

- Bennett, O. (2010), Reducing Flood Risk: Key Issues for the New Parliament 2010-House of Commons Library Research, Available at

http://www.parliament.uk/documents/commons/lib/research/key issues/Key\%20Issues\%20Reducing\%20flood\%20risk.pdf [Accessed 2942013 ] 